\title{
We are the noise between stations : a philosophical exploration of the work of David Byrne, at the crossroads of popular media, conceptual art, and performance theatre
}

Citation for published version (APA):

Steenstra, S. G. (2003). We are the noise between stations : a philosophical exploration of the work of David Byrne, at the crossroads of popular media, conceptual art, and performance theatre. [Doctoral Thesis, Maastricht University]. Mixed Media vof. https://doi.org/10.26481/dis.20030606ss

Document status and date:

Published: 01/01/2003

DOI:

$10.26481 /$ dis.20030606ss

Document Version:

Publisher's PDF, also known as Version of record

\section{Please check the document version of this publication:}

- A submitted manuscript is the version of the article upon submission and before peer-review. There can be important differences between the submitted version and the official published version of record. People interested in the research are advised to contact the author for the final version of the publication, or visit the DOI to the publisher's website.

- The final author version and the galley proof are versions of the publication after peer review.

- The final published version features the final layout of the paper including the volume, issue and page numbers.

Link to publication

\footnotetext{
General rights rights.

- You may freely distribute the URL identifying the publication in the public portal. please follow below link for the End User Agreement:

www.umlib.nl/taverne-license

Take down policy

If you believe that this document breaches copyright please contact us at:

repository@maastrichtuniversity.nl

providing details and we will investigate your claim.
}

Copyright and moral rights for the publications made accessible in the public portal are retained by the authors and/or other copyright owners and it is a condition of accessing publications that users recognise and abide by the legal requirements associated with these

- Users may download and print one copy of any publication from the public portal for the purpose of private study or research.

- You may not further distribute the material or use it for any profit-making activity or commercial gain

If the publication is distributed under the terms of Article $25 \mathrm{fa}$ of the Dutch Copyright Act, indicated by the "Taverne" license above, 


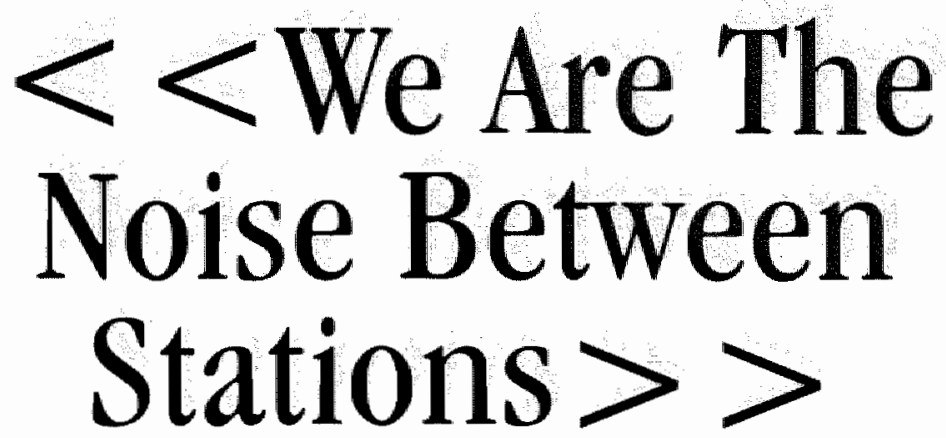

A philosophical exploration of the work of David Byrne, at the crossroads of popular media, conceptual art, and performance theatre

Sytze Steenstra 
ISBN: 90-9016874-5

Photos front cover (left to right): Australian News and Information Bureau Pamela Freese

Mark Lipson

Photos back cover (left to right): Press photo "Stop Making Sense" William Eggleston

Jean Baptiste Mondino

Book design: Josh Moll

Published by Mixed Media wof

Maastricht 2003 


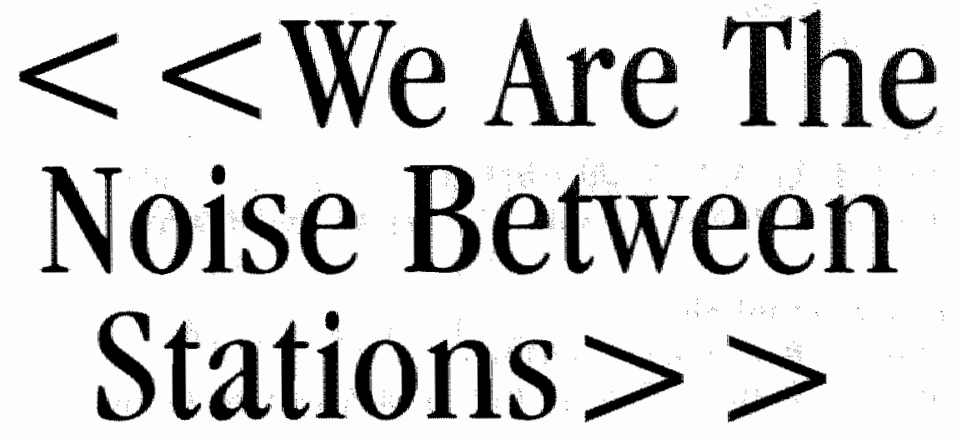

A philosophical exploration of the work of David Byrne, at the crossroads of popular media, conceptual art, and performance theatre

\section{PROEFSCHRIFT}

ter verkrijging van de graad van doctor aan de Universiteit Maastricht, op gezag van de Rector Magnificus, Prof. dr. A. C. Nieuwenhuijzen Kruseman volgens het besluit van het College van Decanen, in het openbaar te verdedigen op vrijdag 6 juni 2003 om 12:00 uur

door

Sytze Geert Steenstra 


\section{Promotores:}

Prof, dr. G. A. M. Widdershoven

Prof. dr. J, cle Mul (Erasmus Universiteit Rotterdam)

\section{Beoordelingscommissie:}

Prof. dr, R. de Wilde (voorzitter)

Prof. dr. R. W. Boomkens (Rijksuniversiteit Groningen)

Prof. dr. H. J. Pott

Met dank aan het Theory Department van de Jan van' Eyck Akademie te Maastricht voor de ondersteuning van het onderzoek, en aan de Capaciteitsgroep Wijsbegeerte van de faculteit Cultuurwetenschappen van de Universiteit Maastricht voor een bijdrage in de drukkosten van dit proefschrift. 
Yeah, we are the noise

The noise between stations

Yeah it's a kinda strange

Oh boy! a strange situation

David Byme: Rei Momo (1989)

Wherever we are, what we hear is mostly noise. When we ignore it, it disturbs us. When we listen to it, we find it fascinating. The sound of a truck at 50 miles per hour. Static between the stations. Rain.

John Cage: The Future of Music: Credo (1937)

The art of alienating in an agreeable manner, to make an object alien and yet familiar and attractive - that is the romantic poetics.

Novalis: Fragments and Studies (1799-1800) 


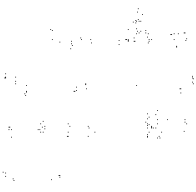




\section{Contents}

A conceptual landscape

An outline of David Byrne's work

Different approaches to interpretation

Conceptual resources in Byrne's work

A comparative approach to performance

A poetics of reflexivity

\section{CONCEPTUAL WORK IN THE MASS MEDIA}

2. MUSIC AS A MIMETIC ARENA

The mimetic potential of music

Artistic preparations: the rejection of mimesis 34

The Talking Heads' first two records $\quad 39$

Experiments with rhythms, textures and personae 46

The communal production of musical meaning $\quad 50$

Solitary voices embedded in communal rhythms

Anthropomorphic aspects of music 64

Archetypical conflicts: "We'te goin' boom boom boom" 70

Persona as mimetic texture: "Speaking In Tongues" 75

3 FILM AND PERFORMANCE THEATRE

A concert in the cinema: "Stop Making Sense" 83

A concert put in context: "Talking Heads vs. The Television" 87

"The Knee Plays", a score for Robert Wilson's performance theatre 90

"Little Creatures" and the video clip "Road to Nowhere" 96

"True Stories": Bytne's Gesamstexnstwerk. 100

Performance theatre on film: "Dead End Kids" 113

"The Forest": a music-theater piece 116 
Byme's version of "The Forest", a film that never got made

4. ANTHROPOLOGY AND MUSIC

Anthropology and the mass media

The Talking Heads' last record

"Ilé Aiyé": an ethnographic documentary on musical ritual

"Rei Momo": incorporating a foreign sensibility

Soundtracks for anthropological art documentaries

Luaka Bop: a record label against homogeneity

Byme's solo albums

Other projects and collaborations

Photography as a mimetic arena

Design and photography

"Strange Ritual": documents of sactalization

"Your Action World": profane motivations

"The New Sins": a catechism of chaos

"The Wedding Party"

The dance of politics, documented in press photography

\section{THEORIES OF PERFORMANCE}

6 EXPLORING THE FOUNDATIONS OF PERFORMANCE

Byme's theoretical orientation

The ubicquity of myth, according to Jung and Campbell

Evolutionary foundations of human culture

Richard Schechner's theory of performance

Robert Wilson: highlighting perceptual discontinuities

The Wooster Group: the historical reality of hallucinations 


\section{A POETICS OF REFLEXIVITY}

9 TOWARDS A PHILOSOPHY OF MIMESIS

Shortcomings of philosophical postmodernism

The role of mimesis

The reflexive potential of early Romanticism

10 THE MODEL OF EARLY ROMANTICISM

Reflexive aesthetics: the matter of subjectivity

Art as philosophy, philosophy as att

The early Romantic aesthetic and Byrne's work

11 BENJAMIN AND ADORNO ON MYTHS IN MODERNITY

Subjectivity between naturalism and symbolism

Imagination transformed by photography

The modern capital as a montage of mythical images

The industrial production of fun

The modernization of mimetic experience

The experimental functions of poiesis

Electronic extensions of the imagination $\quad 304$

Mimetic reflexivity

We are the noise between stations

NOTES

BIBJIOGRAPHY

INDEX

SAMENVATTING (SUMMARY IN DUTCH) 



\section{CHAPTER 1}

\section{Introduction}

\section{A CONCEPTUAL LANDSCAPE}

Fifty years ago, in 1952, John Cage wrote his Imaginary Landscape No. 4, a composition for twelve radios. During this four-minute piece, each radio was played by two musicians who executed a carefully detailed score, one turning the station selector, the other controlling the volume and tone knobs. These musicians were, as Cage said, "like fishermen catching sounds"." Every sound they picked up was acceptable: the radio stations' musical and other programmes as well as static noise or silence.

In musical experiments such as this, Cage was disturbingly indifferent to the actual sound of his music, but very much concerned with the perceptual relationship between composer, piece and audience. For him, music was never just sound, but an invitation to alter one's way of perceiving the world. Accordingly, it has not been through his music, but through his prose, where he could make explicit the "didactic element of my work," as he put it, that Cage has exerted his greatest influence.?

Through his writing, his innovative conceptual compositions, and his experimental collaborations with painter Robert Rauschenberg and choreographet Merce Cunningham, Cage has become a pioneer of an aesthetic that wishes to include the listener's situation before and after a concert, daily experience with its heterogeneous stimuli. This has made him the leader of a musical movement and a model for the next generation of artists in every artistic discipline. Cage has become an icon: his name stands for an aesthetic of heterogeneity, complexity and undecidability, for artistic collaboration without forced submission under a master 
plan, for a renewal of the Gesamiknsstwerk that champions an attitude that Cage has called "polyattentiveness".

It has been pointed out, in a comprehensive study on the American avantgarde since 1970, that David Byrne, together with composers like Philip Glass, Steve Reich, and Brian Eno, has made substantial contributions to the artistic movement that modeled itself after Cage's idea of a new Gesamtlewnstwerk. ${ }^{+}$And yet Byrne is first of all a rock star, singing songs that stand firmly within the tradition of rock, funk, or Latin music, songs designed to wrap concert audiences in the joys of recognition and of collective participation. Byrne was the songwriter, singer and main guitarist of the Talking Heads, a band that, from their recording debut in 1977 to their last album, released in 1988, was a popular success, met with admiration by most rock critics. Even though they never came close to the successes of, say, Michael Jackson, Madonna, or the Rolling Stones, the Talking Heads sold millions of albums and became a household name for most members of its generation. Many music stores still carry a few of their albums and Greatest Hits compilations. Whereas Cage insisted on conceptualized abstraction, Byrne's work appeals directly to the routines of mass media art, to the immediately recognized standards of pop songs, television and advertising. His work, both with and without the Talking Heads, may appear to be diametrically opposed to Cage's aesthetic.

The idea of this book is to unfold carefully, and in detail, what may appear at first glance to be a contradiction in Byme's work: its full participation in the most accessible forms of popular art does not impede its respect for the heterogeneity advocated by Cage. Indeed, Byrne's work as a whole has a didactic and prosaic element, since Byrne consistently accompanies his work with theoretical reflections. While it fully acknowledges the desire for focused attention that governs so much of daily life, the wish for easily recognized forms, clear meanings and concentrated enthusiasm, it also explicitly thematizes the perceptive distortions and delusions which this desire often produces, filtering out many of reality's less desirable aspects. Byme and the Talking Heads fully participated in the mythical stardom of rock and roll, yet managed for the greater part of their work not to succumb to this mythology, but to use it as a basis for a conceptual approach within the sphere of mass entertainment.

Guided by Byrne, the "Talking Heads succeeded in combining the routines of rock with the 'polyattentive' and reflexive attitude of art. This unlikely and difficult combination was made possible by the developments in New York's art scene around 1975. For one, there was a kinship between minimalism and structuralism in art and stripped-down and abstracted versions of rock and roll. ${ }^{5}$ Just as important was, that a new generation of performance artists began to explore the typical forms of mass media entertainment, Hollywood movies, TV soap opera"s and commercials, rock music and cabaret. This exploration produced cerebral and di- 
dactic works that looked beyond and beneath the attractive surface of entertainment, as well as works that sought to combine the heightened sensibility of performance with the excitement and accessibility of entertainment. ${ }^{6}$

Over the last twenty-five years, Byme has worked in several disciplines of mass media entertainment. Apart from making his mark in popular music, both with the Talking Heads and as a solo artist, he directed films and video clips; worked in theatre; showed photographs and objects in galleries and museums all over the world; hosted a weekly music show on television; founded his own distinctive record label; made scores for ballet, for feature films and for ethnographic documentaries; and published four books of photography. Moreover, in doing so, he has collaborated with many outstanding and innovative artists. In the field of performance theatre, a central influence on his work, Byrne has collaborated extensively with Robert Wilson, and also with Mabou Mines' JoAnne Akalaitis, with Spalding Gray (of the Wooster Group), and with Meredith Monk. In filmmaking, Byme has worked in different capacities, as producer, composer, advisor or director, with directors as different as Jonathan Demme, Jim Jarmusch, Bernardo Bertolucci, Philip Haas (who makes ethnographic documentaries) and experimental filmmaker Bruce Conner. In music, Byrne has worked with artists as different as Celia Cruz and Brian Eno, composer Philip Glass and funk keyboardist Bernie Worrell. His record label, Luaka Bop, presents bands from England and the U.S.A. next to singers and groups from Brazil, Cuba, Venezuela and Mexico as well as from Algeria, Angola, and South India. Even in graphic design, he has collaborated with a series of renowned mavericks, from Tibor Kalman to Stefan Sagmeister and David Carson. For good measure, one might add choreographers Twyla Tharp, Toni Basil, Suzushi Hanayagi and Wim Vandekeybus, ranging from theatrical ballet to street dance, Noh and surrealistic dance theatre. The variety of names, many of them stars in their own right, and of the associnted ways of making art, is bewildering: almost as if they had been chosen to escape any single common denominator.

Decisive for the point of view of this book is, that Byme has insisted throughout his career on clarifying the concepts that help to structure his work. He has collaborated with outstanding conceptual artists as different as Joseph Kosuth and Brian Eno, and has worked with academic specialists in the interdisciplinary field where ethnomusicology, cultural anthropology and art history meet and mingle. By gleaning the many conceptual references from Byrne's works, interviews and writings, it is possible to see his career, not just in the pragmatic terms of a successful artist who keeps broadening his range of activities, but as a process of ongoing artistic reflection. This makes it worthwhile to engage his work critically. This is done, first, by weaving its many theoretical references into a single tissue, an aesthetic of reflexive heterogeneity; and second, by comparing this new aes- 
thetic to some crucial older developments in the philosophy of the Gesamtketwstowerk.

\section{AN OUTLINE OF DAVID BYRNE'S WORK}

David Byme was born in Scotland in 1952. When he was two years old, his family emigrated to Canada, to resettle in the U.S.A., in Baltimore, when he was eight. After high school, he spent two years in art schools in Maryland and Rhose Island, where he experimented with conceptual art and performance art. Later, he moved to New York City, where he founded the Talking Heads with two friends from the Rhode Island School of Design, drummer Chris Frantz and bass piayer Tina Weymouth. They were soon joined by guitarist and keyboard player Jerry Harrison, an architecture student who had been in Jonathan Richman's band "The Modern Lovers".

With the Talking Heads, Byrne wanted to make music that was meaningful in terms of American culture in general as well as in terms of New York's art world: the Talking Heads set out to be a rock band, but combined this with a conceptual approach. Two concerts they gave in The Kitchen in 1976 are significant: The Kitchen, at that time based in New York's SoHo district, was dedicated to the alternative performing arts, to experimental music, dance, theater, video, and performance art. In The Kitchen's catalogue for 1976, the Talking Heads described themselves as:

a group of performing artists whose medium is rock-and-roll and the pursuant "band" onganization and visual presentation. The original music and lyrics are structured within the commercial accessibility of rock-and-roll sound and contempotary, popular language. Lead singer Byme relies on Chris Frantz and Tina Weymouth to complete their anti-individualist stance as a group concept 7

As a point of departure, this attitude is directly opposed to the exclusive emphasis on emotion, self-expression and authenticity that are the very stock in trade of popular music. In 1992, remembering the original intentions of the Talking Heads, Byrne commented:

"Throw away all the paintings and art becomes a manifestation of an idea So why nor just write down. the idea? A lot of pop music with its guitur and drum solos seemed to be supettluous to the idea of what the music was about. So why not strip it down and deal with the idea, which ofren seemed to be textural rather than natrative? A lot of pop music communicated by texture rather than by what the words were saying."

Byme sensed that there were certain assumptions that he shared with an important part of the New York art scene of those days. When the Talking Heads were playing at the downtown tock club CBGB's, 
I would be excited if some of the artists whose worll I knew at the time showed up; whether it was Vito Acconci, or Joseph Kosuth, or Dennis Oppenheimer, Andy Warhol, these people were in the audience... it was somehow exciting, but I often didn't get to meet them. They were interested in what we were doing musically, and I was interested in what they were doing in galleties and publica tions. "There was some kind of connection."

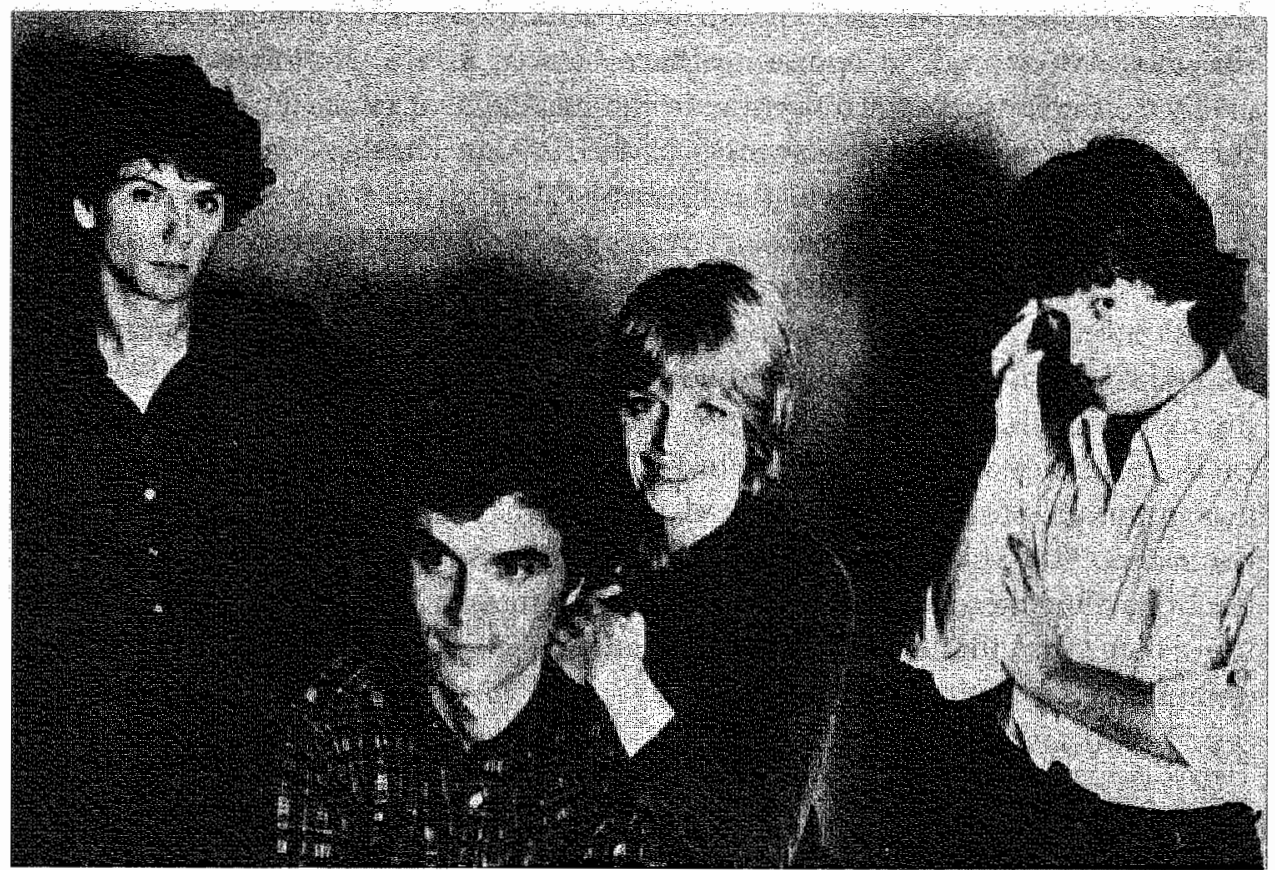

1 The Talking Heads, left to right: Jerry Harrison, David Byrne, Tina Weymouth, Chris Fiants. Photo by Mick Rock, from the inner sleeve of the "77" album.

With the benefit of hindsight, one might conclude that the Talking Heads set out to investigate the conceptual structure of popular music, that complex meeting ground of the individual fantasy and desire, collective tradition and innovation, and the mass media. Their first album, " 77 " (1977) contained songs that projected a sense of maladaptation, played in the conventional rock song chorus-and-verse format. The band sounded so austere, Byrne's singing so distinctive and quaint, that the Talking Heads were often associated with punk's ostentatious protest against commercial pop.

For their next three albums, the band was joined by Brian Eno, who acted as their producer. Eno, a conceptual artist in his own right, aimed to make the many possibilities of the electronic sound recording studio into his own artistic medium. He was instrumental in showing the band how the recording process could be used to provide each element of music with its own aural quality, so that the very 
texture of the music might exude meaningful suggestions. The albums "More Songs about Buildings and Food" (1978) and "Fear of Music" (79) demonstrated this heightened sensibility. When "Remain In Light" (80) was issued, Byrne and Eno added a small bibliography to the handout for the press, mentioning books that analyzed art-ranging from traditional African music, African sculpture and dance, to architecture in general-to the matrix of the surrounding society. From this moment onwards, it appears to have been at least as important to Byrne to explore different ways for reflecting on the meanings of music, as it was to him to further the growing popular success of the Talking Heads. Together with Brian Eno, he recorded "My Life in the Bush of Ghosts" (1981), adding music to recordings of yoices they "found" on American radio and on records. Byme also made a score for an evening-length ballet, "The Catherine Wheel" ("81). On this occasion he invited etnomusicologist John Chernoff, whose work on African music he had found highly inspiring, to join in the process of recording and composing music.

Because the songs of "Remain In Light" had been constructed in the strudio, it was impossible for the Talking Heads to play that music live on stage. To overcome that, they asked a number of funk musicians to join them. This expanded the original white rock quarter to a black and white, male and female funk band of more than twice that number. This worked out quite well, and Byrne explained his enthusiasm for this new band in interviews:

The feeling onstage is nothing at all like performing rock or pop songs, which relieves me greatly. I think some of the other musicians feel the same way. "Spiritual" is a sort of dangerous word to use because of the western definition of the word, but that is how I describe the music. A lot of spiritual music which has its roots in Africa is very exciting and people have a lot of fun dancing to it. It's casual, too... There"s just less of a feeling of a performer projecting his own ego to a crowd, which rock and roll seems to be about. For me, there's more of a feeling of community-a group of people working and playing together. The kind of thing we"re doing now deals with a different series of metaphors than pop music.. The nature of the music is to inspire a mystical communion among the musicians and the audience through repetitive thythms and so on. On a good night, it can become a transcendent experience that is mainly to do with a lot of people feeling that they"re locking togethet and titring together into one thing which is very different from the other music.

Byme's songs on the next Talking Heads' album, "Speaking In Tongues" (1983), explote these metaphors of mystical communion. When explaining these songs, Byrne referred to Carl Gustav Jung's concept of archetypal forms in a collective human unconscious, archetypes that may move people, and bring about a state of emotional transportation, resulting in a mythological experience of reality. To deepen his understanding of the ways in which popular music affect an audience, Byrne began to read books on comparative mythology, from Sir James Frazer and Jung to Joseph Campbell. In seven albums, and in as many years, he had not only become a rock star, but he had also gained a perspective on the meanings of mu- 
sic that could accommodate the technology of the modern recording studio as well as psychological archetypes and mythology, and that could accommodate the analytical bent of conceptual art next to insights from the field of cultural anthropology. This development is investigated more closely in chapter 2, "Music as a mimetic arena".

The next chapter, "Fillm and performance theatre",; documents a shift of focus. The success of Talking Heads, often considered America's greatest band in the eighties, made it feasible for Byme to explore the possibilities of film and video. More than records or concerts, film allowed him dramarize and document the cultural and spiritual functions of music; Byrne set out to apply ways of making art that had been developed in New York's performance theater. When he first came to New York, he was fascinated by this theater: Byrne has often mentioned Robert Wilson, Mabou Mines and the Wooster Group as decisive influences.

In this performance theater, music, dance and the architecture of the scene are as important as the narrative, the 'play' of traditional European theatre. When a dramatic performance succeeds in braiding these elements, thereby creating a ritual totality, its elements can stand in for one another: narrative can turn into dance, scenographic changes transform the meaning of music. In 1983, when director Jonathan Demme approached the expanded Talking Heads with a proposal to make a film out of their concerts, Byrne grasped the opportunity. He developed a show that combined the energy of live performance with a dramatic choreography, lighting, and background projections. He explained about this film, "Stop Making Sense":

I'd seen a lot of work that [director] JoAnne [Akalaitis] had done with Mabou Mines, and Lee Breuer, and other people and all those theatre people from late sixties and early seventies whose work was still very much happening in Nexw York, which was very exciting for me, it was a way of putring things on stage that seemed kind of vibrant and exciting and alive. So it was an inspiration in making that kind of show, the inspiration came more from that kind of theatre. From Japanese theatre, from Eastem ideas of theatre and ritual, as opposed to tock and roll shows."

Byrne also entered into collaborations with both Robert Willson and Mabou Mines. He contributed music and lyrics to Robert Wilson's theatrical production "The Knee Plays" (1985), a piece that was originally developed to connect the many acts of Wilson's grandiose production "the CIVIL warS". This twelve-hour play, comparable in scale to Wagnerian opera, combined mythical and historical motifs from all continents. It was conceived as an artistic companion piece to the 1984 Olympics in Los Angeles, but in the end proved to be impossible to finance. The financially less demanding "Knee Plays" finally toured as an independent theater production. For Mabou Mines, Byme provided a musical score for the film version of their play "Dead End Kids: A Story of Nuclear Power" (1986). 
In 86 , Byme directed the feature film "True Stonies", a Gesamtlewntwerk of his own design. Set in Texas, the film portrays a series of members of a smalltown community, partly through documenting the use these chatacters make of popular songs. The result is part musical, part documentary on contemporary American culture. "True Stories" also brings together several influences from performance theatre: the film opens with a choreography by Meredith Monk; one of its actors is the Wooster Group's core member Spalding Gray, and there are several references to the Judson Dance Theatre and to Robert Wilson.

In 1988, Byrue worked again with Wilson, now on a large-scale piece, "The Forest". Bytne's idea for this music theatre, commissioned by the city of West Berlin, was to describe the industrialization and the romanticism of nineteenth century Germany by using the wocabulary and Imagery of Gilgamesh, the world's oldest epic. The point was to demonstrate the presence of mythical forces in modern history. The plan was that Wilson would develop a theater vetsion of the project, with music by Bytne and text by Heiner Müller, while Byrne would later make his own film version. In the end, however, he could not find enough financial backing, and the film could not be made. Byrne also tried to develop a script for a film titled "Shango". This would be a dramatic love story about Santería, an Afro-American religion like Vodun, set in Haiti and San Francisco. Producer Ed Pressman described the problems with the screenplay: "We went with a couple of writers, but the script was never satisfactory to David. When a more conventional writer's approach was brought that made it as a script and Zoctrope Francis Ford Coppola's studio] liked it, David shied away. He kept trying to break the narrative." Unable to find the money to realize his ideas in the cinema, Byrne introduced the working methods of performance theatre in a number of videoclips fot Talking Heads songs. In the role of attistic advisor, Byrne also introduced his experimental approach to a television documentary about the Talking Heads, directed by British filmmaker Geoff Dunlop. Here, imagery from a Talking Heads concert is interlaced with ethnographic footage made in several cultures, showing "foreign" and "exotic" as well as contemporary American forms of ritual.

From 1988 onwards, Byme"s work shows an ethonographic and documentary interest. In that year, Byrne ditected an anthropological documentary, "Tlé Aiyé: "The House of Life". This documentary, made for television, portrays Candomblé, a Brazilian religion that combines African animist practices, brought over by the slave trade, with Catholic mythology, brought by colonizers; music and dancing are central to its ceremonics. In 1990, Byrne provided soundtracks for four short documentary films by Philip Haas: "A Young Man's Dream" and "A Woman's Secret" about traditional sculpting in Madagascar and painting in Papua New Guinea, and "The Giant Woman" and "The Lightning Man" about two traditions of Australian Aboriginal painting. These films were part of "Magiciens de la "lerre", an influential exhibition in Paris' Centre Georges Pompidou, presenting 
contemporary Westem artists next to traditionally working artists from cultures all over the world. Chapter 4, titled "Anthropology and Music", describes this in more detail.

In his songwriting, Byrne also entered a new phase. He recorded one more album with the Talking Heads, "Naked" ("88). According to ethnomusicologist Chernoff, on this album the band mastered the idioms of African pop music more truly than, for example, Paul Simon did on his "Graceland" album. ${ }^{13}$ Following that accomplishment, Byrne further investigated African-detived music by recording and touring with an orchestra of New York-based Latin musicians, playing standard Latin dance formats. The ensuing allbum, "Rei Momo", was among the first to appear on Byme's own record label, called Luaka Bop. This label mostly presents popular songs that have come from a different mould than that of American and English pop: it has released compilations and new albums by artists from Brazil, Cuba and other Latin-American countries, as well as from Angola, Algeria, Cape Verde, and from Japan and South India. These recordings document the many strands of cultural cross-fertilization that have shaped popular music all. over the world.

After "Rei Momo", Byme has recorded a series of solo albums: "Uh-Oh" (92); "David Byrne" (94); "Feelings" (97); and "Look Into the Eyeball" (2001). Recorded with many musicians and producers, and partaking freely of many different styles of popular music, these songs attempt to recreate specific individual moods without projecting a sense of ego. They are as sophisticated and hybrid as those of the Brazilian Tropicalismo songwriters Byrne admires and emulates: Caetano Veloso, Tom Zê, Gilberto Gil and others.

A chapter on photography and books completes the overview of Byme's artistic production. In 1987, he contributed photos and an introduction to an art book: "What The Songs Look Like: contemporary artists interpret Talking Heads songs" (" 87 ). This book presents work by established artists like Robert Rauschenberg, Nam June Paik and Edward Ruscha, along with stars of the eighties art world like Jenny Holzer, Barbara Kruger, Jean-Michel Basquiat and Keith Haring, and criti. cally acclaimed artists such as James Casebere, Anne Turyn and William W/egman $^{14}$ next to Byrne's lyrics, together with work by illustrators, photographers, and even Studio Dumbar, a Dutch design firm. As artists are often very particular about the places where they show their work, this mixture is remarkable in itself. ${ }^{15}$ Byrne also published a book to accompany his film "True Stories". In this book, also titled "True Stories" he combined work of other photographers with his own photos, newspaper photos and clippings (the true stories that inspired the film) plus film stills and the script.

In 1989, Byrne published six photographs in Artforum: "We Eat We Are Eaten. A project by David Byrne". The following year, he had an insert in the international art magazine "Parkett", and took part in a small but prestigious exhibi- 
tion that was curated by conceptual artist Joseph Kosuth, "Reproduced Authentic". These projects launched Byrne's career as an art photographer, exhibiting in galleries and museums all over the world.

Most interestingly, Byrne has produced books that combine photography with writing and graphic design. Compared to the forbidding cost of making feature films, such books are relatively cheap to produce; this form has allowed Byrne to pursue his interest in cross-cultural comparative mythology and in the Gesamtlewnstwerk. The first of his books, "Strange Ritual" ("95) clearly shows the didlactic element of Byrne's work. His photos are accompanied by musing remarks and theoretical outlines like these:

We spend our lives listening to ourselves, watching ourselves, seeing how we are reflected, how we are responded to by others, and then we fine tune ourselves in order to project accurately what it is we think we are.

Windows are mirrors through which we see ourselves reflected. Our view is coloured by our prejudices, history, and class. We see teflected our perceptions of the landscape, the skyline, the people on the street, the weather, and what they mean to us. Photographs are also mitrors. In them we see teflected our own internal biases, our own assumptions, our own presuppositions. Television is a mirror through which we see reflected our own internal culnure, our personal lusts and fears, desires and hatreds. We see our concepts of knowledge-what it is and is not-what emotion is made of, and what constitutes feeling and what constitutes fact-and where the difference lies. What we don't see is a reflection of our face, we see instead a reflection of our interiot. An X-tay mirtor. ${ }^{16}$

In "Your Action World" (1998) and "The New Sins" (2001), Byrne's theme is the process of sacralization and profanation in an environment that is full of stimuli from commercial sources like corporate reports and motivational pamphlets, the "non-literature" and "non-art" that makes up a great part of our daily experience. An exhibition titled "The Wedding Party" ("98), combined photography with "dressed objects" or sculptures, focusing on the projection of human qualities on to objects, a process Byme describes as beneficial:

We cannot be separated from the objects that surround us. They animate and imitate us just as much as we imitate objects and animate them. By breathing a soul into dead objects, we feel and understand that the world is truly allive, not just existing as an aggregate of dead objects and lifeless landscapes. ${ }^{317}$

And in 2001, Byme functioned as curator of a small New York exhibition of political news photographs, "Gesture, Posture, and Bad Attitude in Contemporary News Photography", in which he tried to show what he called "the choreography of politics", the quotidian representation of authotity and power through a repertoire of poses and gestures.

This overview of an unusually ambitious and effective body of work clearly documents a succession of conceptual influences. Throughout his career, Byrne 
has been influenced by a diversity of theorists, either in direct collaboration or, more often, by encountering theoretical concepts in the work of other artists. This rich theoretical material deserves a closer scrutiny. But before approaching these intellectual sources of Byrne's work, it is good to consider how that work has been interpreted by other authors: their work helps to provide a general orientation,

\section{DIFFERENT APPROACHES TO INTERPRETATION}

Generally speaking, Byme's work is an attempt to overcome the division between serious art and popular entertainment, and between the formal and the sensual, without neglecting the very real forces behind this division of the high and the low. In spite of this, a considerable part of the available literature on Byrne's work either deals just with the popular image of the Talking Heads, or interprets Byrne's work in terms of pre-arranged academic categories. However onesided such interpretations may be, there is much to be learned from them, as long as their limitations are seen clearly.

The Talking Heads have been the subject of several fan books. In 1981, [Barry] Miles published "Talking Heads", a quick compilation of interviews and photographs that has been described succinctly as "smarter than the norm, primarily" because of its subjects"18. In 1986, Jerome Davis (pseudonym for an anonymous author plus several additional writers) published "Talking Heads. A Biography". This book porttays the band members by threading together the recollections of a great many people who knew them; but as it faills to develop a perspective of its own, its many facts and anecdotes resemble an extended magazine article. ${ }^{19}$ And in 2001, journalist and novelist David Bowman published a 400-page biography of the band, titled (in Britain): "Fa fa fa fa fa fa. The Adventures of Talking Heads in the 20th Century" (for the USA edition, the title was changed to "This Must Be the Place"). A single sentence from this book's introduction characterizes the ambition of its author: "Just as the story of the Beatles can be reduced to a tale of the lowe/hate relationship between John and Yoko and Paul, the story of Talking Heads can be reduced to a similar equation between Tina [Weymouth, bass player of the Talking Heads] and David [Byrne]." ${ }^{20}$ Over the course of the book, this greedy interest in personal affairs eclipses every artistic consideration. In this kind of biography, the attention that is paid to personal relationships outweighs the much more interesting relationship between an artwork, its maker and its auclience.

Of course, a different approach is to be found in academic literature. There, Byme and/or the Talking Heads have repeatedly been categorized under the label 'postmodernism'. Examples of this can be found throughout the literature on cultural studies and the related philosophy: in the influential work of theorist Fredric Jameson"1, in a general survey of postmodemism, "The Postmodern 'Turn" by 
Steven Best and Douglas Kellner ${ }^{22}$, as well as in the pages of the American Joumal of Semiotics, where Byrne has been called "the preeminent deconstructive artist", "more so than Baudrillard"23. However, these judgments tend to use Byrne's work as just another example within an argument that has its sources elsewhere, in a very specific interweaving of theoretical texts. As will be argued in greater detail in chapter 9, because of this they mostly overlook the concepts and reflections that Byme himself finds relevant for his work. These postmodern theorists also neglect the practical circumstances in which art is made, as well as the ways in which it is received and used by its audience, ways that also go beyond the textual. Even Dick Hebdidgess lengthy interpretation of Byrne's vicleoclip "Road to Nowhere" (1984) as an exemplary postmodern work only partially escapes these limitations. The entire concluding chapter of Hebdidge's "Hiding in the Light" (1988: pp. 233-44) is dedicated to an analysis of this clip, which Hebdidge fuses with his own philosophical insights. Hebdidge calls Byrne "an organic intellectual of the airwaves"2, but neglects, without further explanation, Byrne's own theoretical understanding of pop music. Instead, Hebdidge refers to Barthes, Jameson and Bakhtin, familiar authors within the field of cultural studies.

The fan books mostly try to prolong the enjoyment of the Talking Heads' music by furnishing it with an anecdotic background, and do not question the authenticity of the terms on which mass entertainment may be enjoyed. A large part of the academic comment is just as one-sided, as it suggests that the work can be interpreted adequately without engaging the terms in which it is enjoyed by the majority of its audience. But there have also been some studies which do take Byme's work seriously on its own terms, and these books have much to offer. The most comprehensive is John Howell's "David Byme" (1992), which contains a biographical and critical essay, as well as the most extensive interview with Byrne that I have come across. Working in New York as an art critic, Howell is adept at placing Byrne in the artistic contexts from which his work draws its impulses, the art world of SoHo and the music scene of New York. Musicologist John Rockwell, who used to combine the position of classical music critic for the New York Times with that of its chief rock critic, has repeatedly written about Byrne's music, comparing it to other forms of composing. This broad perspective is exemplified in the chapter on Talking Heads in his "All American Music" (1983). Last but not least, art historian Henry M. Sayre's "The Object of Performance: The American Avant-Garde since 1970 " (1989) emphatically gives Byrne's work a place in the collective artistic project that he finds in performative art, where Cagean heterogeneity is combined with a preference for the vernacular and for collaboration. Sayre devotes the epilogue of his book to Byrne's feature film "True Stories" (1986), describing it as "a film about performance-performance in everyday life, a vernacular Gesantleunstwerke."25. 
In writing, I have also made use of a great number of interviews given by Byme throughout his career ${ }^{26}$, as well as his written statements in books, articles, and in the liner notes that accompany several albums. Many of Byrne's interviews may be considered to be a part of Byrne's artistic work. Of course, giving interviews is part of the job of a rock star, as much a way of communicating with an andience as making an album or performing live; but the fact that Byme at one time added a list of relevant bibliographical references to a press release, in the hope that this would enable journalists to ask more pertinent questions, shows his wish to use interviews as a mature medium. ${ }^{27}$ Byme has consistently used interviews to promote his own perspective on his work, often by emphasizing the importance of theoretical approaches. I have liberally combined these sources with information from the fan books, and with the insights of Sayre, Rockwell, and Howell. In the last part of this book, after giving a more detailed critique of the postmodern approach to Byrne's work, I propose an alternative approach, an attempt to do justice to its complicated poetics by giving equal attention to its mimetic and to its reflexive aspects, based on the conviction that these two are inseparable.

Susan Sontag's well-known essay "Against Interpretation" provides an excellent background against which to introduce this perspective on art. In her text, Sontag denounces those forms of interpretation that neglect the sensuous enjoyment of art, and explain the value and meaning of artworks only in terms of an external theoretical framework. She points out that "In some cultural contexts, interpretation is a liberating act. It is a means of revising, of transvaluing, of escaping the dead past. In other cultural contexts, it is reactionary, impertinent, cowardly, stifling... By reducing the work of art to its content and then interpreting that, one tames the work of art. Interpretation makes art manageable, comformable." 28 Her essay ends in a passionate plea: "Interpretation takes the sensory experience of the work of art for granted, and proceeds from there. This cannot be taken for granted, now. Ours is a culture based on excess, on overproduction; the result is the steady loss of sharpness in our sensory experience. What is important now is to recover our senses. We must learn to see more, to bear more, to feet more... In place of a hermeneutics we need an erotics of art." "Sontag argues in favor of an encompassing sensibility, as demonstrated in her "One Culture and the New Sensibility" 30 , and at the same time in favor of rigorous formal criticism, since the formal qualities of art are also its sensuous qualities. The kind of interpretation that she opposes is the conscious illustration of a certain code, following predetermined rules ${ }^{31}$ - which in fact summarizes much of the work that is done in today's cultural studies. ${ }^{32}$ Even while Sontag polemically opposes erotics to hermeneutics, in fact she combines the two.

A similar combination may result from emphasizing the importance of mimesis as much as that of reflexivity. Reflexivity is the term for formal criticism in a tradition that shall be traced, in the chapters on the poetics that underlies Byrne's 
work, from the speculative poets and aesthetic philosophers of early German Romanticism, through the pivotal work of Walter Benjamin and Theodor W. Adorno, to such contemporary masters of reflexive anthropology as Bruno Latour, Arjun Appadurai, and Pierre Bourdieu. Mimesis refers, in the same tradition, not to the passive imitation of a preconceived idea, as in Plato, but to the sensitive response to a work of att, to the sensual, both productive and receptive changes of mood and attitude that are inseparable from a formal understanding. Compare it to the experience of the first day in a new job, when one may ask of oneself not just: what can I make out of this opportunity, but also: who am I going to be in this new position? How will I be changed by this environment?

This is to say that I disagree with the following suggestion by Best and Kellner, who have connected Byrne to Sontag as follows:

The title of the film "Stop Making Sense" by David Byrne and the Talking Heads enunciates the tendency of this [ludic, knowingly superficial] Eorm of postmodern art, perhaps first arriculated by Susan Sontag $(1967)$, to seek pleasure in aesthetic forms and surfaces and to eschew systems of meaning, polysemic and multillayered complex artifacts that demand depth hemeneutics, and works that intend to make personal and political statements. ${ }^{3 .}$

Paying close attention to changing sensibilities as such may, contrary to this suggestion, be the only way to demonstrate how deeply relevant, both personal and political, a poetics can be. In this respect, David Bowman's journalistic ear for personal detail is to be preferred over Best and Kellner's academic schematizations: Bowman tells how; during a Talking Heads concert in 1982, Robert Wilson sat beside Susan Sontag, "intellectual prima donna of Manhattan", watching David Byrne. After the show, Sontag came to meet Byrne and introduced him to Wilson: "The theater director had never met anyone as instantly compatible as David." 34 This kind of stmalltalk is illuminating if one looks beyond the personal to the artistic affinities between Byrne and Wilson. Wilson's theater productions are studies in perception, which in their turn have been made the subject of several academic interpretations: as the next section will suggest, it is worth while to compare Byrne's working methods to those of Robert Wilson.

\section{CONGEPTUAL RESOURCES IN BYRNE'S WORK}

Byrne's work has been influenced by several strands of performance art, performance thearre, and conceptual art. In his art school years he showed an interest in the cutting edge of conceptual art: especially in the Art \& Language movement that had been founded in 1968, simultaneously in England and New York. Byrne was fascinated by this work, and "thought it was the ultimate in eliminating all the superfluous stuff in att and being left with nothing but the idea." 35 
The artists who formed 'Art \& Language' wete determined to oppose the ant' intellectualism and the focus on heroic artistic personalities that had been associated with painting and sculpture during the 1950's and '60's. According to them, the expressive and perceptual aspects, the "good looks" of art, were overvalued to the detriment of the more abstract presuppositions that could be embodied in artworks. They undertook a Marxist-based critique of the gallery system, with its marketing and exploitation of the artistic personality, and tried to establish forms of art production and distribution that would not fit the usual. gallery-andmuseum-system.

Art \& Language was especially opposed to the traditional division of art from criticism. Instead of 'illusionist' artworks, the group produced critical texts which combined a Maxist critique of society with a Wittgensteinian critique of language and representations. ${ }^{36}$ Accordingly, the critical analysis of the consumption of art and culture was seen as the crucial task of the artist. Art, in this view, says nothing whatsoever about the personality of the artist; this is a likely source for the "antiindividualist stance as a group concept" which the "Talking Heacls embraced in their statement for The Kitchen.

Most relevant for Byrne's work was Joseph Kosuth, who at first was closely associated with Art \& Language, but disengaged himself from the group by 1976 , when he felt that it deteriorated into an orthodox marxist-leninist collective. ${ }^{37}$ To distance himself from such straitlaced premises, Kosuth developed a wider theoretical perspective, as laid down in his essay "The Artist as Anthropologist"38. This text is a mosaic of quotations, derived from two sources. The first of these is Martin Jay's "The Dialectical Imagination" (1973), a historical account of the unotthodox and self-reflexive marxism of the so-called 'Frankfurt School' philosophers: Max Horkheimer, Herbert Marcuse, Theodor W. Adorno, and Walter Benjamin. His second source was an atticle by cultural anthropologist Bob Scholte: "Toward a Reflexive and Critical Anthropology" (1972). Scholte was part of a selfcritical movement within anthtopology that pointed to the many Western assumptions upon which anthropology has often been based, and stressed the need for a decolonization of anthropology 3 Kosuth turned to Scholte's article to argue that art cannot give itself a foundation in the logical analysis of what it means to make art: instead, artists have to "explicate, as part of our activities, the intentional process of constitutive reasoning which make both encounter and understanding possible", and thus to enter into a hermeneutic exploration.4"

Byme met another, second strand of conceptualism in the person of Brian Eno, who produced the 'Talking Heads' records from 1978 until '80. Eno had studied at Ipswich Art School, taking part in an unconventional and interdisciplinary programme that encouraged art students to focus on the nature of creative behaviour, rather than drawing or painting. Pursuing this course, Eno combined cybernetics (the mathematical science of organization and control) and biological 
theotics of evolution to explore creatuity. In doing so, he focused not on the result, but on the process of making art, conceiving of this process in terms of a system that has to come to terms with random mutations within a demanding environment, by basing itself on a limited set of instructions. As Eno wrote in an article on "Generating and Organizing Variety in the Arts":

As the wariety of the environment magnifies in both time and space, and as the structures that were thought to describe the operation of the world becone progressively mote unworkable, other concepts of organization nust become curtent. These concepts will base themselves on the assumprion of change rather than stasis, and on the assumption of probability rather than certainty. I believe that contemporary art is giving as the feel for this outlook. 11

In accordance with this credo, Eno does not consider himself a musician in the conventional meaning of the word. Instead, he has made the recording studio itself, as well as the decisions made during the recording process, into his instruments. An application of this approach can be found in Oblique Strategies, written by Eno together with painter Peter Schmidt. Oblique Strategies, subtitled 'Over one hundred worthwhile dilemmas', consists of a box of more than one hundred playing cards, each of which states a dilemma that may come up in the making of a work of art. An artist might pick a card at random, as Eno has suggested, "simply to bring the consciousness one has as a listener to one's consciousness as a composer-to deal with things in a much more situdied way." "2? Many of these statements encourage the artist to get rid of the narrow focus that often results from intense concentration under stressful circumstances (like working in an expensive recording studio), to trust in errors and unpredictable actions rather than to adhere strictly to a narrowly premeditated course of action. Some results of this approach can be heard on the first two albums of Roxy Music, the rock group of which Eno was a founding member, and on his later "Ambient" records, which present a music without emotional focus, open to drift and contemplation.

Eno likes to emphasize the human propensity to become accustomed to sounds, and to detect minute variations within monotonous repetitions. He compared the "listening brain" under such circumstances to the functioning of the eye of a frog: "The frog's eye, unlike ours, is absolutely static, so that its retina rapidly becomes saturated from looking at a static situation and ceases to distinguish detail. However, the most minute change (movement) in the environment is thus considerably highlighted. So the frog disregards the common (unvarying, continuous) information and becomes more and more intensely aware of any changing (new) information." 4.3

At the end of the 1970's, Eno had established himself as the prime theoretician of rock4-although it has been noted that ideas which look positively iconoclastic in the world of rock music were often common currency on the contemporary art 
scene, so that Eno's originality derives at least as much from the context in which he applied his ideas as from the ideas themselves. 45 His success as a record producer (for David Bowie, U2 and others) is based on his ability to apply conceptat insights to the continually evolwing technology of the recording studio. A typical example of his mannet of producing has been recounted by "Talking Heads" Tina Weymouth: "The last time we sing "Air" [from the album "Fear of Music"], we sing very breathy. Here's an instance where Brian Eno used a conventional piece of studio machinery to achieve an unconventional effect. Normally you recond without Dolby and then add it. He did the opposite. He recorded with Dolby and then took it off after it was recorded, so that it sounded even more natural. "46

New York's experimental performance theatre has been a third source of practical as well as theoretical insights for Byrne. The theoretical assumptions that feed into this theatre have been investigated by one of the most prominent scholats in this field: Richard Schechner, professor of performance studies at New Yotk University and former director of New York's "Performance Group". His work demonstrates a wide experience of traditional as well as experimental forms of both Western and non-Western theatre, together with insights in the performative aspects of such diverse social situations as rituals, ceremonies, theme parks and modern mass media. Central to his work is the notion that an actor playing a role is at the same time himself and not himself, " $T$ " and "not-I". There are many techniques to bring about this transformation from I to not-I, and many different cultural modes of dealing with the resulting mixture of "real" and "performed" iden tity. There are also many ways of training performers to achieve this transformation: this training can be predominantly physical (as for dancers), spiritual (for some priests) or psychological (for actors in the 'naturalistic' strain of theater and filmmaking). The transformation from reality to performance can be dealt with as a social ritual, a religious ritual or a purely aesthetic ritual: avant-garde or performance theater often combines and contrasts two or more of these forms, e.g. by claiming social televance for an aesthetic performance. Schechner's work demonstrates how forms of performance are important for every culture and in every walk of life, and may be called chatacteristic of human experience in general.

The theatre makers who infuenced Byrne, and with whom he collaborated, like Wilson and Akalaitis, without exception focus their works on the interplay and the conflict of such different forms of performance. Wilson's proposal to make a theatrical counterpatt for the Los Angeles Olympic Games (one of the wotld's most visible performance festivals, one might say) is but one example. Byme's inquiry into the nature of musical performances has benefited considerably from such work. His music addresses a range of questions about the communicative nature of popular music: Is it the thythm? Is it the ritual quality of the perfomance? A mythical communion of band and audience? $A$ shared ieserwoir of archetypes? A form of theatre? A religious phenomenon? is it culturally deter- 
mined, or just the opposite, an inherent aspect of human nature? The example of performance theatre shows that one should not look for the answer in any single one of these aspects, but instead in the interaction and the conflicts between them.

The three artists and theorists I have singled out here, Kosuth, Eno and Schechner, are too different to be reduced to one single denominator; and each of them in turn functions within a field of heterogeneous theoretical influences. By describing Byrne's music, films and photography within their originall context, they will be shown to be the result of a continuing exchange with conceptual themes and traditions. To represent the different influences within Byrne's work, I have made ample use of quotations. These many snippets from books and interviews help to create a sense of the heterogeneity that is so characteristic of Byrne's work and concepts.

\section{A COMPARATIVE APPROACH TO PERFORMANCE}

The second part of the book places Byrne's work within a wider horizon by elaborating the theories behind its comparative outlook. First, chapter 6 considers Bytne's interest in myths and rituals from different places, ages and cultures, and in the biological foundations of human behaviour. Byrne has often mentioned the works of Joseph Campbell and Carl Gustav Jung as influential for his work; it is something he has in common with a lot of artists who started working in the 1960 's and '70's. Jung and Campbell see myths as a general and formative aspect of human consciousness; but as will be shown, they have difficulties in applying this idea consistently to their contemporary societies.

By using Richard Schechner's theories, the role of myths in present, scientific and media-conscious society can be interpreted in considerable detail. In chapter 7, Byrne's work is compared to that of three outstanding makers of performance theatre in New York. A central strategy in the work of Robert Wilson, "The Wooster Group and Laurie Anderson is the juxtaposition and confrontation of irreconcilable myths; against the background of their work, Byrne's attempts stand out more clearly.

Schechner has investigated ritual and performative aspects in several traditions, which means that his work blends into cultural anthropology. His interest in the dialectical tension between performance and reality has predisposed him to deal critically with assumptions of authenticity and objectivity. Schechner has noted that the method of participatory observation that is traditionally central to ethnographic fieldwork in fact creates a theatrical situation; acknowledging the truth in this observation, several cultural anthropologists have quoted both Schechner and makers of theatrical performance for their insight in the inescapable interweaving 
of several realisms. As Schechner writes about New York's performance theater, "This kind of theater displays its ambixalence; it is explicitly reflexive."47

This is even more relevant when a performance incorporates elements from different cultures. Like Bob Scholte and Joseph Kosuth, Schechner tries to understand how using aesthetics interculturally relates directly to social theory. ${ }^{48}$ Chapter 8 addresses this interrelation of anthropology and performance, to highlight the questions that accompany Byrne's attempts to combine popular music with anthropology. Byrne's TV documentary about Candomblé, for example, was an attempt to "make a film on a foreign culture that would be entirely visual and not translate the entire experience in Western terms" $4 \%$. Of course, such an attempt to capture and understand another cultural system raises a series of probing questions about the possibilities and paradoxes that are inwolved in translating experience from one culture to another. This is especially true when one of these cultures, the American, is so much more powerful than the other in terms of politics, money, and technology. Similar questions are raised explicitly in many of Byrne's works. Addressing these themes, several anthropologists, ethnomusicologists, and art critics have directed criticism and praise at Byrne's work; their insights are discussed in chapter 8.

\section{A POETICS OF REFLEXIVITY}

Just as Byme's work can be seen with greater clarity in the wider context of performance theory, a greater insight in its poetics can be provided by comparing it to a tradition of artistic and philosophical reflexivity. The third and last part of this book is an attempt to sketch such a tradition. Its point of departure is the insight that Joseph Kosuth's dictum "being an artist means questioning the nature of art" fully applies to Byrne. Through its polyattentive, heterogeneous, and collaborative qualities, Byme's work advocates a specific sensibility. When the conceptual aspects of this sensibility are investigated and followed, it shows itself to be insistently reflexive. As an introduction to this reflexive sensibility, it may be compared to another essay by Susan Sontag, "One Culture and the New Sensibility" (1965), in which Sontag argues that the interplay of industrial technology and artistic developments results in the creation of a new sensibility:

This new sensibility is rooted, as it must be, in our experience, experiences which are new in the hiscory of humanity - in extreme social and physical mobility; in the crowdedness of the human scene (both people and material commodities multiplying at a dizzying rate); in the availability of new sensations such as speed (physical speed, as in airplane travel; speed of images, as in the cinema); and in the pan-cultural perspective on the arts that is possible through the mass reproduction of art obm jects. ${ }^{50}$ 
In the creation of this new sensibility, art serves the function of modifying consciousness and organizing new modes of sensibility; Sontag noted that in this light, the accepted distinction between high, serious art and low, popular culture appears extremely shallow ${ }^{51}$. She stresses that

human sensory axiareness has not merely a biology but a specific history, each culture placing a premium on certain senses and inhibiting others... Here is where art (among other things) enters... Western man may be said to have been undergoing a massive sensory anesthesia (a concomitant of the process that Max Weber calls "Bureaucratic rationalization") at least since the Industrial Rewolution, with moden art finctioning as a kind of shock therapy for both confounding and unclosing our senses. ${ }^{52}$

Of course, this historical and cross-cultural interest in changing sensibilities has its own tradition. To understand how Byrne's strategic location at the intersection of mass media, conceptualism, and reflexive anthropology helps to grasp the ongoing redistribution of sensibilities and of mimetic forces, his work must be considered against the background of this tradition.

My account of the concepts that are needed to think critically about sensibility, in combination with the development of new methods for making art, starts with the early German Romantics who were active from 1795 to 1801 . These speculative poets, critics and thinkers, Novalis and Friedrich Schlegel in particular, concentrated on the possibilities of combining artistic sensibility with philosophical reflexivity. They expressly wanted to do away with the established division between artistic creation and theoretical reflection, not only intermingling the arts with each other, which produced the notion of the Gesamiknustwerk, but also insisting that reflection is essential to art. A summary of this aesthetic will show the inner coherence of an aesthetic and artistic practice that values the general sensitization to experience over specialized expertise in the separate artforms. As the work of the early Romantics testifies, the general insight that sensibility has a historical dimension will easily lead to an interest in different mythologies and in the profusion of religious innovations. For all these reasons, the work of Schlegel and Novalis, known also as Jena romanticism, forms an excellent background for the further discussion of Byrne's mixture of conceptualism with both popular and serious sensibilities. An exposition of ideas that had already been fully developed before the nimeteenth century, is also an antidote against the postmodern illusion that such hybrid mixtures are uniguely contemporary. The philosophical poetics of Novalis and Schlegel provides an analysis of the requirements of a form of reflexive interpretation that enhances one's subjective and mimetic sensibilities. In this respect, their poetics can be contrasted to the post-structuralist tendency to reduce all experience to the experience of text.

The early Romantic poetics also provides a fresh insight to the work of Walter Benjamin and Theodor W. Adomo. Even though their work reflects the historical 
experience of the first half of the twentieth century, their attempts to understand modernity in terms of an ongoing confrontation between naturalism and symbolism, or between a spreading anaesthesia and a growing sensibility, remain influential today. The concept of criticism of Schlegel and Novalis was the subject of Benjamin's first major publication, his dissertation. His later critical essays on film, photography, storytelling and history, essays that, like "The Work of Art in the Age of Mechanical Reproduction" (1936) have become canonical for later critics and artists, are understood here as an attempt to renew the early Romantic tradition by applying its insights to later historical and aesthetic developments.

Novalis already reflected on the mass reproduction of art (at that time only of literature) in 1798. He knew that his own work was destined to end in the catalogues of book fairs, between the ever-increasing mass of printed works. But he took a positive view of the monstrous multiplication of the number of books, considering it to be a condition for an increased sensibility:

Every man is capable of change without measure... I would like to see in front of me a whole collection of books, covering the entire range of arts and sciences, as the product of my spirt. And this goes for exerything. [Goethe's novel] Wilhelm Meister's Lehrjahre-we now have only one-we should have as many Lehrjahre, written in the same spirit, as possible-the collective character development of all people who have ever lived. ${ }^{53}$

Benjamin wanted to illuminate the cultural production and reproduction of sensibility as much as possible. He acknowledged Goethe's insight that subjective experience resides in a shaded and turbid medium where knowledge can never completely overcome mythology, yet sided with the early Romantics' demand for reflexive criticism within the medium of art. This aesthetic philosophy is the foundation of a great number of reflexive attempts in contemporary art; one may encounter Benjamin's texts in Laurie Anderson's performances and in Kosuth's museum shows, as well as in Byrne's work.

Adorno was Benjamin's first philosophical disciple. While he tended to be more critical of mass reproduced art than Benjamin, Adorno's writings on modern experience equally combine different artistic and philosophical strands into a reflexive Gesasntkunstwerk. Even though Adomo's musical insights are exclusively based in the German development of "serious" music from Beethoven to Schönberg, his philosophical concepts have influenced many recent studies on music, as diverse as essays on heavy metal in the 1970's and on listening to Chinese popular music on a Walkman ${ }^{54}$. The theoretical efforts of Benjamin and Adorno have temained to be inspiring because they fully underwrite artistic attempts to make art more reflexive, and to produce more convincing Gesamtkunstwerke, while reflecting at the same time on the destructive historical effects of attempts to produce a society that resembles a homogeneous total artwork. 
The works of Adorno and Benjamin are exceptional in their critical reflections on the aesthetic of daily experience. Time and again, in books such as Benjamin's "Arcades Project" and Adorno and Horkheimer's "Dialectics of Enlightenment", they demonstrate how common sense is the result of the interaction of the separate senses with the surrounding cultural environment, which means that our immediate and "narural" sensibility is in fact the product of complex mediations, truly a second nature. Their philosophical work provides insight in the ways in which our sensibility mimetically copies the pressures and influences of society and technology. Of course, Benjamin could not foresee how performance theater would take up influences that he championed, combining influences of Brecht and surrealism; Adorno could not have dreamt that John Cage, who at one time took lessons in composition with Arnold Schönbetg; would become more influential than his teacher. The continuing interest in their historical work testifies to the topicality of its approach, questioning the aesthetic forces within contemporary society from within. But their insights demand to be updated. They could not foresee the developments in science and technology, in the electronic media, or the ongoing economic globalization, and their influence on the ways in which life is lived.

Because of the unique position of Byrne's work at the point where mass media intersect with artistic experiments and with cultural anthropology, an interpretation of Bytne's work and its conceptual dimensions has its place here. To develop this interpretation to its fullest extent, the final chapter of this book is an attempt to update the reflexive and anthropological turn in aesthetics that is found both in the early Romantics and in the work of Benjamin and Adorno. It considers three contemporary approaches to reflexive anthropology: Bruno Latour's anthropology of science; Pierre Bourdieu's reflexive anthropology of aesthetic distinctions; and Arjun Appadurai's account of the transcultural globalization of electronic mass media.

Latour describes how we, today, live in communities whose social bonds come from objects that have been fabricated in scientific laboratories, so that our sensibilities are challenged by growing networks of increasingly hybrid and heterogeneous elements. Pierre Bourdieu has argued that every aesthetic sensibility, whether it is tuned to serious and difficult artworks or to the immediate pleasures of entertainment, in fact corresponds to one's position in the social field, where it constructs a habitus, to use his terminology. Bourdieu has analyzed the habitus of television journalists to show that it often results in an unconscious collective effort at homogenisation and banalization. This, of course, is exactly what artistic attempts at heterogeneity and complexity stand opposed to. Appadurai, finally, describes the rapid worldwide flow of mass-mediated images, scripts, and sensations as introducing a growing instability in the production of modern sensibilities. He shows how internationally standardized media imagery is transformed locally 
to produce repertoires of irony, anger, humor, and resistance: processes that are reflected in much of Byrne's work.

The work of these three theorists can help to understand how the very fiber of our experience is interwoven with the work that goes on in distant electronic labotatories, where new models for experience are produced and tested. In an allegorical short story titled "Lifestyle", Byrne wrote how "the abstract has entered the concrete". 55 The truth of this implies that it is not exaggerated to surround a series of popsongs, films and photos with such an elaborate philosophical and theoretical framework. Every aspect of experience can be, and has been, subjected to experiment, conceptualized and reconceptualized, analyzed and allegorized. This does not mean that interpretation can replace the experience of art. However much a detour through theory and philosophy may lead away from its sensuousness, in the end it should add to its pleasures. 



\section{PART I}

CONCEPTUAL WORK IN THE MASS MEDIA 


\section{CHAPTER 2}

\section{Music as a mimetic arena}

\section{THE MIMETIC POTENTIAL OF MUSIC}

We tend to think and to speak of music as if it were one single entity. 1 Yet there are numerous musical cultures, each of them with its own distinct sounds, instruments, musical forms, and roles appointed to music and musicians. To discuss the musical development of Byme and the Talking Heads, which has over the course of his carcer incorporated elements from several musical cultures, the question must be addressed in which terms his music is best interpreted. How to understand different 'musics' each on their own terms? At this point, two approaches in the interpretation of music offer themselves. There is an authoritative musicological tradition that insists that music has to be understood strictly on its own terms, as a formal compositional structure. Within the academic world, objections against this strict approach have been formulated by sociologists and cultural historians who deal with music, as well as by ethnomusicologists, who insist that music can not be understood as pure, absolute sound, but has to be appreciated within a wider context. ${ }^{2}$ Such oppositions reflect breaches within musical experience itself, which is full of divisions between genres and practices, each of them accompanied by hierarchies of value that distinguish between primitive versus sophisticated, authentic versus manipulated, moral versus immoral.

The Western classical tradition of music was established during the nincteenth century, when symphony orchestras, symphony halls, music schools and other musical institutions were founded that were all dedicated to concerts where silent and motionless listening was the norm. Here, music was taken to be an essence in 
itself; the separation of music from poetry, dance and ritual was supposed to have been completed, which meant that music was now an absolute entity, an autonomous abstract world that could be entered, enjoyed and analyzed only on its own abstract and formal terms. Purely instrumental music, based on a written score, formed the ideal for this tradition; Beethoven was seen as its canonical example. This ideal was shaped in the course of a long history: it was already under way when Christianity accepted music only as a purcly spiritual art, requiring the separation of music from bodily responses.

Classical music was accompanied by the development of musicology, an academic discipline that was geared to study Western classical music and the ensuing tradition of 'serious' modern music by analyzing its musical events strictly in terms of the musical text, the score. Yet this tradition is just one form of musical behaviour among many. The history of Europe has seen many forms of protest against this disembodiment of music, from the fourteenth century dance mania and the nineteenth century waltz craze to Dixieland and disco fashions. ${ }^{3}$ The essentialism that typifies classical musicology is quite unsuitable for understanding such other forms of music. Its concentration on the musical object, the text, neglects the listener, a fact that leaves musicology basically unable to explain thow a listener is able to enjoy music. Indeed, musicollogists have often denounced all forms of listening that are not strictly formal-structural as debased and unseemly.

To understand music beyond the formal musicological approach, the work of sociologists, cultural historians and ethnomusicologists is indispensable. They explain how music is connected to its surroundings: often in combination with dancing and with words, and often with rituals, but always in a social or institutional context that helps to define the musical event. It follows from such explanations that it is a mistake to suppose that every corporeal, verbal, visual, ritual or social aspect of musical events is basically a superfluous addition to the music itself, and can be categorized as 'non-musical', since that subtraction only results in making the musical event inexplicable. This doesn't mean, of course, that the formalism of classical music is unmusical. There is nothing wrong with the attempt to concentrate the experience of music on pure sound, as in the ideal of absolute music; but even in that case, the anti-mimericism of this musical formalism should not be taken for granted. Beethoven may again serve as an example. While his oeuvre has come to typify absolute music, the "Ode to Joy" is nevertheless considered an example of the opposite tendency, that of the musical Gesamikunsiwerk, fusing music with poetry and with moral and political purposes beyond the score, creating a "gospel of a higher community" And notwithstanding the preference of many influential theorists for absolute music, classical composers of course wrote opera's as well as symphonies, and songs as well as sonatas.

When music is not understood as a formal and abstract structure that is essenthally self-sufficient, it may be understood in terms of mimesis. Mimesis means 
imitation, copying, mirtoring, representing and translating, music exists as an exchange with its surtoundings. People hum tunes they remember, dancers move to a rhythm, writers have compared their books to symphonies, fashion designers look at pop stars for inspitation; and musicians and composers catefully choose the examples they want to copy and perhaps, eventually, surpass. This process of creating and recreating is endlessly intricate, and goes beyond music; it has been suggested that the creation of an individual identity, a self, is a mimetic process. This process encompasses, amongst other things, that one "tries out the very shape of a perception in one's own body; the musculature of the body is physiologically connected to percepts; and even ideational activity, not only perception, involves such embodying hence [the Freudian term] "ideational mimetics". Just as speech can be understood as thought activating the vocal chords and tongue; so thinking itself involves innervation of all of one's features and sense organs." $\mathrm{As}$ an introduction to the notion of music as a mimetic arena, three aspects of musical experience must be presented: the bodily experience of music, the metaphorical quality of music, and the presence of music in the contemporary envitonment.

Musical therapy and neuropsychology have detailed the effects of music on the human body. Music directly influences the neurovegetative system: heart activity, the frequency of breathing, blood pressure and gland secretion; music can also result in unconscious muscular actions. The sound level of music alone ascertains that such changes take place, independent of the conscious will of the listener. ${ }^{7}$ To. evaluate the cultural meaning of such changes, sociologist Simon Firith has proposed that such universal and unconscious bodily responses to music should be related to psychologist Paul Ekman's division of the entire spectrum of body language in four segments. The furst of these segments is universally human: the direct physical expressions of emotional states like ecstasy, delight, anger, aggression, timidity and so forth. The second is the semi-conscious, intentional acting out of described emotions, which is culturally specific; this includes tones of voice and verbal 'gesturing'. Then there are the bodily manipulations, the picking, scratching, rubbing and biting of one part of the body by another; and the last, fourth category contains the body movements which are wholly symbolic or emblematic, understood only by those who know the code, the rules for proper in terptetation.8 Unconscious bodily responses to music clearly belong to the first, universal segment.

As this is the case, purely symbolic aspects of music retain a relationship with this level. The human voice in patticular is a product of the body, and it follows that listening to singing always may include attention to the direct expression of the singer's body. There is always an inarticulate undercurrent to singing, from the sheer physical pleasure of singing itself to the sounds of tears and laughter, of the physical experiences that are expressed beyond the singer's conscious control. A great deal of the enjoyment from singing derives from the interplay of this "inat- 
diculate articulacy" of the body with the conscious articulacy of the singer and the song."

The telationship of music to bodily pleasures has sometimes, especially by rock ideologues, been simplified to the formula "rock music basically equals sex". Simon Frith has quite elegantly demonstrated that this equation is finally a product of European high cultural ideology ${ }^{10}$, and has argued that the sensuous quality of music is not just that it makes us experience our body, but also that it makes us experience inner time. ${ }^{11}$ Building on the phenomenological analysis of the experience of time and music, he finds that "if "the present" is actually defined by a quality of attention, then music does indeed expand the moment by framing it. And it is precisely this 'time attention' which defines musical pleasure."12 His conclusion is, that music "offers us not argument but experience, and for a moment-for moments - that experience involves ideal time, an ideal defined by the integration of what is routinely kept separate - the individual and the social, the mind and the body, change and stillness; the different and the same, the already past and the still to come, desire and fulfillment. Music is in this respect like sex, and rhythm is crucial to this-rhythm not as "releasing" physical urges but as expanding the time in which we can, as it were, live in the present tense."13

As Frith expands on this, he ascertains that music gives us a way of making sense of the world: "musical response is, by" its nature, a process of musical identification; aesthetic response is, by its nature, an ethical agreement."14 As an aesthetic, make-believe version of reality, music is, still according to Frith, inherently transcendent. "Transcendence" is as much part of the popular as of the serious music aesthetic, but in pop transcendence articulates not music's independence of social forces but a kind of alternative experience of them. (Of course, in the end, the same is true of 'serious' music too). Music constructs our sense of identity through the experience it offers of the body, time, and sociability, experiences that enable us to place ourselves in imaginative cultural natratives. Such a fusion of imaginative fantasy and bodily practice marks as well the integration of aesthetics and ethics." 15 And in connection to this, Frith claims that a form of antiessentialism is a necessary part of musical experience, as a consequence of music's failure to register the separations of body and mind upon which so many essential differences between people depend; he mentions the differences between black and white, female and male, gay and straight, and those between nations. ${ }^{16}$ However, this last conclusion may be too assertive in identifying musical antiessentialism with political correctness; after all, music has always been used just as well to sanction and sanctify the distinctions which a society considers to be of the essence.

This anti-essentialist understanding of music is quite different from the traditional idea that music should be understood strictly on its own (presumably: musicological) terms. Frith has clarified his point of view by responding to an essay by 
post-structuralist philosopher Roland Barthes. In "The Grain of the Voice", Barthes reflects on the interpretation of music by raising the question how language manages when it has to interpret music. His answer: "Alas, it seens, very badly. If one looks at the normal practice of music criticism (or, which is often the same thing, of conversations "on" music), it can readily be seen that a work (or its performance) is only ever translated into the poorest of linguistic categories: the adjective."17 Frith endorses what Barthes disapproves of: "Barthes may have been contemptuous of the use of adjectives in bourgeois music criticism, but music is; in fact, an adjectival experience. Henry Kingsbury notes, for example, that in the bulk of contemporary theoretical texts, music is not so much an entity occasionally described with anthropomorphic terms as it is itself an anthropomorphic, figurative representation'."18 According to this, the essential quality of music is its capacity to highlight the metaphorical-or minetic-relationships that shape human experience.

Apart from the corporeal and the metaphorical qualities of music, its technological transmission must be taken into account. Nowadays we hear most music via recordings. Live music is the exception rather than the nule. Thanks to the flexibility of electronic equipment, music is everywhere, no longer framed by a special event with its own time and place. This has had two important effects: music has been individualized, since compact disk players, walkmen, radio's and so on have become first of all commodities for individual use; and at the same time, music has moved from the foreground into the background of social life, ${ }^{19}$ since recorded music does not command the attention of a group of people in the way a live performance does. In other words, music has lost a great deal of its compelling, ritual quality; its aura has been diminished. In the background, music is present as muzak and as other people's music spilling over, but most prominently as the soundtrack for films, television programs and commercials. As Frith explains the importance of this use of music, "listeners take musical meanings from films, from the cinema"s in which we've learned what emotions and cultures and stories sound like." 20 In his view, although film scholars and studies of popular music usually neglect soundtracks, it could be argued that they are the most significant form of contemporary popular music, since they contribute so much to the popular understanding and interpretation of instrumental music."21

As a result, our musical environment is much more diverse and fragmented than traditional musicology cares to consider. One of the musicologists and music critics who have tried to come to terms with these shifts in the social function of music is John Rockwell, who for some years held the influential position of music critic with the New York Times. His book "All American Music: Composition in the Late Twentieth Century" describes contemporaty classical or "serious" composers and musical experimentalists, composers of electronic music, jazz, film 'sound effects', Latin music, Broadway musicals, as well rock: Rockwell discusses 
Neil Young and Talking Heads/David Byrne next to Ornette Coleman, Enst Krenels; Eddie Palmiert, Walter Murch and Elliott Carter. This determination to write about new American music as it really is, is founded on the belief that "experimental music, vernacular music and non-Western music are important and enjoyable, too, and that a 'music critic' has tio business excluding entire traditions that most of the world thought of as 'music' fust because they don't conform to his own cultural prejudices." 22 . All this diversity represents a confrontation between cultures and traditions, somehow vaguely audible as backgtound music in the mass media. This background informs its audience of a wide-tanging, semiconscious musical vocabulary, since it renders a wide scala of emotional effects with more or less success. This is the contemporaty world of music, the context for any musical gesture or meaning.

This environment may be conceptualized as a kind of mimetic arena, a theatre in which many media (sound, language, dance, images and so on) and experiences are negotiated. This is central to David Byrne's understanding of music. When he points to the political, social, and spiritual meanings of music, or draws comparisons between music and graphic design, between music and computers, and between music and nature, ${ }^{23}$ he draws attention to the mimetic dimension of musical experience. Byrne approaches music as a medium in which the mimetic process itself is represented: his music is not "pure", but instead it highlights the selecting mechanisms that control the translating, copying and imitating practices that shape a musical experience. A discussion of his music has to focus on the ways in which it represents mimesis.

To understand popular music in general, insights in its physiological, metaphorical and technological presence may be combined. When it is lifted out of its context and analyzed in formal musicological terms, as is sometimes done, pop is usually changed beyond recognition. For the listener, music exists as imaginative sounds-not as the notes that musicologists analyze. It is at least uncertain, for example, that it is fitting to analyze the Beatles' music in terms of Aeolian clusters and so forth. The whole conceptual apparatus of musicology appears to be mostly irrelevant for understanding the experience of popular music. ${ }^{24}$

Breaking away from traditional musicology are descriptions of, for example, rock and roll ${ }^{25}$, in terms of "instant communication". ${ }^{26}$ The ensuing questions are: what has enabled rock and roll to communicate so successfully? What made it so easy for a large audience to identify with the songs and their singers? Rock is rhythmically simple, primally satisfying in its underpinning of solid common time; John Rockwell has explained that the best rock is, compared to a great deal of musical composition, "barbaric in the best sense-more direct, more passionate, more aggressive in the face of human feeling" than much contemporary art allows itself to be. ${ }^{27}$ It is music that distinctly aims for a physical response of the listener, a certain rising excitement, dancing perhaps. 
A gtrat deal of popular music aims to give shape to the listener's proprioception; the voices and rhythms that stand out in pop songs are interpreted as a matrix for the experience of the self. The term "proprioception' means, literally, the way we sense ourselves ${ }^{28}$ within our body: we feel movement through the structures of our muscles and bones, we get feedback from our internal organs and we feel our position in space thanks to the intricate structure of our inner ear. Our feeling of reality is grounded in this unconscious presence of our body, which adds to the five senses (sight, hearing, taste, smell, touch) the fundamental dimensions of feeling tired or awake, hungry or satisfied, relaxed or tense, and so on. This is the directness that rock and roll aims for; only the recognition of a song as vehicle for the self implies immediacy, the instantaneous quality of the communication. Nevertheless, the recognition that a certain type of music may function this way is also in many respects culturally mediated.

When music succeeds in communicating (when a hit song 'hits', for example), it opens up a miniature theatre within the listener, in which the listener witnesses himself or herself within a world as defined by the song. Exery element of the song, thythm and melody, the quality of the voices (typical of pop music is that every melodic instrument can be manipulated and textured as a volice with its own grain and characteristics, including the voice of the singer), the lyric, the format of verse and chorus, and all other components (dance, video, image...) are geared to this communication. What Alfred Jarry described as the iridiscent mental kaleidoscope $^{29}$ may be understood as pertaining to this inner theatre; W/alter Benjamin has written about it as "bodily presence of mind": "Each morning the day lies like a fresh shirt on our bed; this incomparably fine, incomparably tightly woven tissue of pure prediction fits us perfectly. The happiness of the next twenty-four hours clepends on our ability, on waking, to pick it up."30

Rock and roll has always depended on mass media, radio, television and cinema, to train a large audience to recognize and enjoy it. Growing up in modern industrialized society includes, for the large majority of the people, spending a great deal of time in front of the television, as well as hearing a great deal of popular songs and related sounds (advertising tunes, jingles, $T V$ - and film scores), over and over again. This intensive training enables mass audiences to distinguish immediately between many musical styles, gentes and messages, and by the 1970 's popular music had developed into a medium that was able to communicate a wide range of contents; not only steteotypes of fun, romantic clichés and emotional consumerism, but also messianism, unfettered Dionysian lust, youth rebellion, subtle autobiography, mass spectacle, bohemianism, political protest as well as combinations of all these and more.

David Byme has commented on this experience of popular music: "When I grew up and first started hearing rock music, pop, and soul, it was the sound that really struck me. The words were, for the most part, pretty stupid. But it was the 
sound, the texture of the guitat and drums, the way one song sounded so completely different than another. The texture a group of musicians arrives at, in support of melody or lyrics, can be at least as important as the melody line or lyrics or whatever. It can make a statement that supports or contradicts it." $3 \|$ Songs are perceived in a great variety of ways: as almost neglected background music, as music to dance to, as harmonious melody, as fashion statement, (sub) cultural style guide, catchy half-heard song line, closely studied text, and so on. The underlying assumption is one of identification: the listener is asked to identify with the mood, the style and the content of the song, as well as with the artist. Or, less simplistic and more realistically: the listener is invited to compare his or her own personality with the persona presented by the song and by the singer, to try out and enjoy the possibilities for identification as well as contrast. The expression 'mimetic arena' is meant to imply all this.

The subsequent sections of this chapter describe the first five Talking Heads albums, plus a couple of Byrne's other efforts, in considerable detail, in order to high light the mimetic strategies that these collections of songs represent. The first two Talking Heads records, "77" and "More Songs about Buildings and Food", contained songs that were unusually direct and clear in rendering the tensions within the complex arena of pop. After that, the band changed its format and presentation, gradually turning from the romantic concept of rock as a means of individual expression, towards the collective production of musical meaning. But to begin with, the next section looks at Byrne's artistic attempts previous to the founding of the Talking Heads. These experiments betray the wish to oppose all forms of imitation and representation: a characteristic way of preparing an independent stance towards mimesis.

\section{ARTISTIC PREPARATIONS: THE REJECTION OF MIMESIS}

Byrne's mature work began with the 'Talking Heads, and his earliest attempts at making att are of interest only insofar as they form the preparation for the mature work. In tetrospect, Byrne seems to have prepared himself for his later career in two ways: by experimenting with music and performance art, and by investigating the possibilities of conceptual art.

Byme recalls experimenting with music since he was about fifteen: "I did record ... multitracked performances of feedback. Tape cut-up experiments. That is, I recorded lots of sounds onto tape, and then cut up the tape at random and spliced it back together without knowing what order the sounds were in. They were primitive, multitracked things with multiple performances at different tape speeds. I also made a version of The Turtles "Happy Together" with Tupperware tubs for drums." 32 Apart from this tinkering with sounds, fan-book writers have recorded a succession of musical groups in which Byrne took part since he was in 
junior high school. His first band, "The Revelations", played top 40 songs. This was followed by solo folk perfotmances in high school; later, Bytne played ukelele and fiddle in a duo called Bizadi, with his friend Mark Kehoe, who played accordion. ${ }^{33}$ After that came a band called alternately "The Artistics" and "The Autistics", mainly remembered for playing as loud as possible. ${ }^{34}$

In the heydays of hippies and counterculture, it is not too surprising that these playful musical enterprises offered many occasions for experimenting. Some of these experiments were neighbouring on performance art: at a Bizadi show, "Kehoe and Byrne were soaring and squeezing their way through "Pennies from Heaven", when Byme produced a dead fish wrapped in alluminum foil. He put it down on stage and stamped on it. Then Kehoe stamped on it. Then Byrne. Then Kehoe again." 35 Later, while Byrne studied art at the Rhode Island School of Design, another Bizadi gig was turned into a spectacle: "They did "Pennies from Heaven", and during an instrumental interlude David shaved his beard off. ... Someone gave him a can of beer from the first row, and he sort of soaked his beard down and shaved it, bleeding." experience. Naomi [another art student] had an easel with Russian words written on shirt cardboards on it. She kept exposing new Russian words while Mark played the accordion and David cut himself to pieces. David had on a hat with a woman's high-heeled shoe and electric lights on it. I remember rivulets of blood pouring down his neck as people groaned in sympathy."

Bytne would also transcribe TV quiz shows such as "The Price Is Right", and give dramatic readings of his transcriptions in coffeehouses. ${ }^{38}$

Apart from these capers, Byrne spent two years in art schools. In 1970, he went to the Rhode Island School of Design, where he followed the Bauhaus 'Theory Course, a function design program, as well as a course in conceptual art; in 1971, he went to Battimore, to the Maryland Institute's College of Art. Looking back on his experience with art schools, a disillusioned Byme has called them "an expensive way to meet like-minded individuals one's own age." ${ }^{35}$ At these schools, Byrne rejected painting and chose instead to make disposable Xerox art and to put together collages from Polaroid snapshots. He also started making lists of statements and questions, assembling these into complex questionnaires. In the early 1970 's, throughout the art world similar attempts could be found, which demonstrate a thorough suspicion of all artistic expression and find the personality of the artist superfluous. It is an approach that influenced Byrne profoundly.

Byrne was interested in the cutting edge of conceptual art, especially in the Art \& Language movement that had been founded in 1968 in England and New York simultaneously. This group of artists was determined to oppose the antiintellectualism and the focus on heroic artistic personalities that had, in their view, been associated with painting and sculpture in the fifties and sixties. Instead, they wanted to establish forms of art production and distribution that would not fit the 
ustal gallery-and-museum-system. Art \& Language especially opposed the traditional division of art and criticism. Instead of 'illusionist' artworks, the group produced critical texts that combined a Marxist critique of society with a Wittgensteinian criticiue of language and representations ${ }^{40}$ Accordingly, the critical analysis of the consumption of art and culture was seen as the crucial task of the artist. Byrne was fascinated by this kind of artwork, and "thought it was the ultimate in eliminating all the superfluous stuff in art and being left with nothing but the idea. ${ }^{2}+1$

Itr Byme's own early attempts at making art, conceptualism took the form of a distant questioning of life and of the function of ant in life. He would distribute questionnaires: one example asked the receiver to "write an objective account of every cat accident in which you have been a participant. Each account should be about one or two paragraphs in length. Please concentrate your account(s) on the actual accident(s) and the events immediately surrounding the accident(s)." 42 Another questionnaire consisted of foutteen statements about UFO's, for example:

1. Some flying saucers have tried to communicate with us.

2. All UFO reports can be explaned as either well understood happenings or as hoaxes.

6. Most peoplle would not report seeing a UFO for fear of losing a job.

14. Thete have never been any UFO sightings in Soviet Russia.

Respondents were asked to rate these statements by choosing between four options:" definitely false, probably false, probably true and definitely true. ${ }^{43}$ Another piece from this period was titled "Number of Consecutive Days withont Error", with three slots in which one might put numbers, the idea being that one would come home from work at the end of the day and keep tabs on one's errors. ${ }^{44}$

Works like these place their audience under the obligation to look at one's own life from a distance, with the complete detachment that is needed to judge one's accidents, errors, delusions and prejudices objectively; which brings up the question whether such detachment is possible at all.

Along these lines, Byrne was working on "lists of statements that are thematic - statements about economics, about possibilities for the futute, some of which are silly and some of which are serious. Lists about basic belief statements, not all of which $I$ believed in, but $I$ tried to think of and organize ones that people tend to build their lives around. Things they accept as given. I was just organizing things like that. Then I got further along to the point where I wanted to work out a sort of Nielsen rating system ${ }^{45}$ for visual arts, sort of a cross thing between viewers and buyers and artists. It seemed very cold but I thought it would serve a Function." 拈

On a later occasion, in 1986, Byrne published a description of this system that deserves to be quoted at length: 
"When I moved to New York about 1974, I was writing some songs, sont of dabbling . . playing a litte bit of music to myself; I newer thought l'd make a lixing at it. Most of ny time was spent working out ideas for what I called the "Nielsen Rating System for the Arts", the idea being to develop a system that would open up lines of communication between vewers and wisual artists. It would work in two ways--the viewer would find out what sort of things were ont there that affected and moved him or her... and the artists, in tum, could find out who they were talking to. If an artist would rather talk to someone else, then he or she could find out what that someone was interested in-and what kind of visual language to speak.

The whole system involved a lot of computer termituals, cross-referencing, answering multiple choice and yes/no questions, and checking true/false statements. Then, all of that infomation would go into a giant computer that everyone had access to, artists and viewers alike. This mndom selection of people would be asked questions like: What did they think visual art was for?... Why did they like straight lines better than squiggly lines?... Would they just as soon watch stuff on television?.. Did they like art better in books or in museums? .. W Was making something ugly a way of making it romantic?... And so on.

In the back of my mind, I must have known that this whole system was kind of stupid and unworkable on the practical level, but on another level it did taise some interesting questions. Fot instance, are visual artists really interested in what the audience thinks? Do artists really believe that they are the antennae of society? Does the audience believe that? Does the audience hope the artists believe that?

The assumption behind this proposed system is that visual art has a practical and real value, that even decoration is nor meaningless, and that somethow, through all this question asking and answering, the real value of this staff to people's lives might emerge-art would turn into a product, $a$ commodity in a kind of Marxist sense, as opposed to the current popular viewpoint in which att is valued as a tare one-of-a-kind jewel or as a religious icon, a unique expression of a savage soul. My assumption at the time was that one result of this system might be that att production would in crease, and at the same time prices would drop. The visual artist might, in the course of using as system like this over a number of years, reach a wider and wider audience and do so without diluting the content or depth of his or her work.

A "functional but not craftlike" way of treating wisual art might teturn folks to an attitude that existed in the very early part of the European medieval period-and still exists in much of the world-where such a heavy value is not placed on the individual experience. Somerimes thete seems to be evidence of a slight return to this way of thinking, which might actually be a good thing ... it might be the only way that a lot of people can live together."s-1?

One more example, recorded by biographer Jerome Davis, will serve to round off the image of Byrne's early attempts to make art. According to Davis, just after Byrne had moved to New York in 1974,

he had a grand ambition: to make his life into a work of conceptual art, to design a persona and then animate it. He wanted to create an artificial personality. What would make it art would be not just the creation, but that no one would know that the creation David Byrne wasn't real.

But what form would this created persona take? That had Byme stumped.

Finally he hit on the answer: Byrne would become a systems awalyst. He explained to Andrea [his girlfiend at that time] that he would devote his entire life to computer programming. Ho would call it a life system; it would be an art project. And he would do so anonymouslly. ${ }^{\text {HS }}$ 
How to take these attempts to conceptualize art and life? A psychological explanation offers itself, naturally, to the biographer. Jerome Davis offers the explanation that this is the folly of a very talented young man who is brought to despair by his inability to find a medium that will suit his talents, and therefore fantasizes about turning his entire life into an obscure plece of art But when biography is set aside, this idea to remake one's entire life as an art project tells of a search for transcendence, and of a strong predilection to analyze life in its entirety.

Similarly, Byrne's ponderings on a functional way of treating visual art can easily be ridiculed. After all, television's domination by ratings has resulted in countless programs that aim for the greatest common denominator of the audience by adhering to the blandest formats; if put into practice, Byrne's system for dealing with visual art would probably lead to similar results. And his predilection for the European early middle ages, with its non-individualistic outlook, as an ideal form of communal life which "might be the only way that a lot of people can live together" invites the objection that at the end of the twentieth century, a lot more people live together on earth than in, say, the seventh century. Moreover, the idea that computers or other modern machines might bring about such a return of imaginary medieval social harmony is the stock and trade of science fiction writers, a cliché that has already been coined by nineteenth-century romantics.

But such criticism is misdirected. After all, Byrne neither chose computer programming as a career, nor did he go into art-market analysis. ${ }^{49}$ Perhaps these musings are best seen as an ambitious and programmatic attitucle: the determination not to accept life as it presents itself, but to understand its offer of mimetic packages in analytical and conceptual terms. Likewise, art is not simply embraced for its beauty, but is asked to prove its functionality, both for the individual viewer and for society as a whole. Rather than accepting the label "conceptual art" for them, we should see these ponderings on art and life as a form of curiosity that may still lack the appropriate concepts to address its subject, but that is definitely a prerequisite for finding and developing such concepts. Considered in this light, they demonstrate Byrne's willingness to distance himself radically from the established idea of art as emotional self-expression. This form of conceptualism may help to uncover the aesthetic orientations, the "Basic belief statements" or mythologies that underlie everyday communication and mimetic lifestyles. In retrospect, this is an artistic project with a wide scope: to uncover basic aesthetic orientations that function within present society, by taking into account the many important non-individualistic functions of art, in design, the mass media, advertising and so on. "The Talking Heads allowed Byrne to try this in the domain of popular music. 


\section{THE TALKING HEADS" FIRST TWO RECORDS}

Byme founded the Talking Heads in 1974 with two friends, Chais Frants and Tina Weymouth. Both had studied painting and finished art school before moving to New York. Later, they invited Jerry Harrison to join them. He had played in several rock groups (Jonathan Richman's "Modern Lovers" was one of them) and studied architecture at Harvard. Apart from the fact that in the maleclominated world of rock it was a bit unusual to have a female bass player, the band had a standard rock line-up: Byrne sang and played guitar, Frantz drummed, Weymouth played bass, and Harrison played guitar and synthesizer, filling out the sound of the original trio.

The 'Talking Heads' songs were mostly organized in the verse-and-chorus pattern of the standard Top 40 tune; a generally recognized form that made it possible to investigate the other aspects of popular music. They did this with the puritanical and analytical ethos of conceptual art, seeking to strip away everything that was not of the essence. Not only were drum and guitar solos shunned, but every aspect of playing and performing came under close scrutiny. Instead of dressing up for performances, they decided to wear average middle-class street clothes; instead of the flashing coloured lights typical of rock shows, the Talking Heads opted just to leave on the house lights during concerts. Byrne said about this: "I think, in the broadest sense, it's political to go on stage and play rock music and not dress up... It's a political act not to place oneself above the audience." Choosing not to impose a specific image on the audience, the main focus was on the songs, the lyrics and their rendition. The band spent a lot of time discussing these. Even the name of the band was chosen to imply this. When the band members were compiling long lists of possible names, a friend, Wayne Zieve, pointed out the term 'talking heads' in a TV Gwide. Originally, this is a term used by TV cameramen to describe program formats that are visually limired to face shots. As Zieve explains it, "Talking Heads' just came from my impression of the band. David really didn't sing that much. He would yell a little bit, but it was more like he was talking, he was giving information. It seemed like a cerebral enough name for them." 51 According to Tina Weymouth, "it was the only name that had so many connotations to it that... the group would define the name, not the name define the group". 52

The impact and the attraction of popular music are based on its capacity to present a multitude of forms simultaneously, drawing attention not to the isolated formal qualities of the music, the lyric or the singing voice, but to their combination in one single instant. However, for the sake of a careful description of the Talking Heads' songs, I shall try to give separate descriptions of their musical texture, vocal rendition, lyrics, and the resulting personae of the songs, the distin- 
guishing qualities of the recording, the visual image, and the musical and artistic context.

The textute of the Talking Heads" music is defined by contrasts. As Brian Eno described them, "David and Jerry together made a brilliant thythm guitartst, while Chris and Tina were perfectly poised between pop and soul. Alogether it was an approach to thythm which was rather unique David/Jerry's edgy, spiky guitat work over Tina's rolling, wavy bass lines over Chris's powerful and solid drumming. It created a field of charged thythmic space-stark but tense, always slightly off-balance and therefore always moving forward."53 "This forward drive was disrupted by the division of the songs into the chonus-and-verse pattern. John Rockwell wrote in the New York Times that the disjunctions berween the sections of the songs were "so sharp and stylized that they take on an abstractly formal interest." He added that "Miss Weymouth's hypnotically repetitive bass lines, Mr. Byrne's alternately impressionistic and driving guitar chordings and Mr. Frantz's light, flexible drumming all make for a sound with no obvious precedent on the undergtound citcuit or in music itself.. The abrupt layering of their music recalls planes of colout in minimalist art." 34

The other element of the Talking Heads' music is Byrne's singing voice, an oddly choked tenor. As his singing style lacks the affectation of black styles that typifies so many white rock singers, it has been dubbed "hyperwaucasian", or more bluntly: "a squawk" 55 . As stated before, it is usually the voice which defines the quality of a song's persona for the listener, since a voice stands for the person more directly than any other musical device; it offers the listener immediate access to the body that brings forth the voice, as we all recognize what it is to speak and to sing. In a felicitous comparison, Byrne"s "highwitched delivery" has been likened to "the vocal equivalent of nervously clenching and twisting hands" 5 . This is emphasized even more by Byrne's frequent use of inarticulate groans and shouts, and by his vocalizing on meaningless syllables. The unresolved tensions which Byrne's singing thus transmits, focus the listeners' attention to the way in which a personal identity is created and the tensions that underlie this identity; the difficulty of selecting models to imitate. This performance suggests that it is hard to know one's own voice in the middle of the babble of different voices in which we talk to ourselves, especially when the media present so many powerful and convincing examples. Is it even feasible to have a single, stable vocal identity? Jonathan Rée has written a suitable description of the accomplishment this would requite: "You glimpse the possibility that it is quite arbitrary to try to mark off certain of your vocal performances and nominate them as one voice, the woice that really belongs to you: do you really possess an ownmost, innermost voice which has the power to clamp quotation marks round the others and shrug them off as "funny'?"s? 
The lyrics of the early Talking Heads' recorcls, usually written by Bytne, tun parallel to the music and the singing by presenting mental states that are full of unesolved contradictions. A typical example of Byme"s somgwriting is "Tentative De. cisions", a song that doesn't identify itself with the position of someone in love, but instead presents an attempt to analyze and abstract one's way out of emotional tensions and amorous misunderstandings:

Now that I can release my tension, let me make cleat my best intentions.

Girls ask: can I define decision?

Boys ask: can I describe their function?

Oh the boys want to talk, would like to talk about these problems

And the girls say they'te concerned... (that they are)

Concemed with decisiveness.

And it's a hard logic to follow, and the girls get lost [repeat with rewerial of gender]

The lyrics were important to Byme. Their function was discussed extensively within the band: "We decided not to sing songs about being in a rock band. I think we decided not to sing any dance songs or any sex songs to begin with. Instead, to think of an approach to our subjects which might be interesting. We originally thought we would use conversational language instead of the rock row cabulary" that had developed to the point where it was easy to hash out rock lyrics. Because it was so easy and so commonplace, it meant that they were not really communicating very much, if at all." "We try not to do anything distracting fon stage because we want people to listen to our lyrics, which are kind of unique." "ss

The first song Byrne wrote was "Psycho Killer", a song that became his trademark for some time. He commented: "It was the first song I actually ever wrote. What inspired it was-well, Alice Cooper was really big then and I just thought it'd be interesting to do a song in something approaching that mock-ghoulish vein he was pumping, but give certain twists. Like Alice had all these safety gauges worked out so that it wouldn't connect with anything remotely dangerous. It was all 'it's okay folks, it's only a showl'. I just liked the idea of writing a song that was more real." 59

The approach Byrne held in mind while writing the song was that of Randy Newman, who excels in songs that are written-and sung - in the voice and from the unpleasant perspective of failed dramatic personae: the alcoholic, the racist bigot, the sexual pervert. By accepting the moral shapelessness of these personae as a given, Newman implicates his audience in a world of idiosyncratic cruelties, more dreadful and less entertaining than his musical vocabulary of piano-based rock and roll combined with lavish movie score-instrumentation would suggest. ${ }^{6 / 1}$ Indeed, the casual, popular form of these songs, so easy to pick up and hum along with, adds to their impact: isn't it just as easy to fall in with the shapelessness? 
Accordingly, Byme wrote a song from the perspective of a psychopathic character, presenting it in a nonjudgmental way as oversensitive.

I can't seem to face up to the facts.

I'm tense and nerwous and 1 can't relax...

Psycho killer, q'est-ce que c'est? , fa fa ta fa fa fa

better run ron run run run run tiun away...

You statt a conwersation, you can't even finish it! You'te talking a lot, but you'te not saying anything!

When $I$ have nothing to say, my lips are sealed

Say something once, why say it again?

Ce que j'ai fait, ce soir là.

Ce qu'elle a dit, ce soir là.

Réalisant mon espoir,

je me lance, vers la gloire... OK...

Frantz and Weymouth helped with the French lines; Byrne later claimed that it was a "natural delusion that a psychotic killer would imagine himself as very refined and use a foreign language to talk to himself." "61 Avoiding the spectacular as.pects of murder, Byrne highlighted a concern for polite and ordered conversation instead, and borrowed the "fa fa fa" from an old Otis Redding song ("Fa $\mathrm{Fa} \mathrm{Fa}$ $\mathrm{Fa}$ ", or "Sad Song"), to make sure that the result was a pop song with a strong thythmic drive that everybody could relate to. Byme rehearsed the song tirelessly, changing the rhythm, the chords, the song structure repeatedly before recording. ${ }^{62}$

For an audience trying to relate to it, "Psycho Killer" is a bundle of contradictions. What does it mean to dance to the musings of a psycho killer? Is the song meant as satire or realism? Is a psychotic murderer's stream of consciousness really made up of such uncomfortably common elements? Is it a commentary on the world of pop, with its onset of mythical heroes and emotional tole models, which may inspire fear: as easily as fun? Later, however, Byrne decided he had better stay away from such loaded and sensational subjects. ${ }^{63}$

A good example of that is "Stay Hungry", a song written by Byrne together with Frantz, from the Talking Heads" second album "More Songs About Buildings And Food". As Frantz explained the song, he had seen "those muscle magazines called "Stay Hungry". Boy meets girl, and the girl likes his muscles, and the boy thinks "Tve gotta stay in shape if I'm gonna keep this girll."

I think that we can signify our lowe now.

Gitrl, you can initiate an impulse of love.

Stay hungry, stay hungry, stay hungry.

Move a muscle, move a muscle, move a muscle.

Make a motion, make a motion, make a motion. 
Pull it tighter, pull it tighter, pull it tightet...

Here"s that whthm again.

Here"s my shoulder blade.

Here's the sound I made.

Here's the picture I saved.

Here I am.

Typical for Byrne's songwriting is the twist from self-motivating rhetoric "Stay hungty, move a muscle"), sung in a driving voice, to a wistful, self-reflexive perspective ("Here's that rhythm again. Here's my shoulder blade. ... Here I am,") He strove to combine divergent emotional vectors in his lyrics, as in "Don"t Worry About The Government" (from the "77" album):

My building has every convenience. It's going to make life easy for me. It's going to be easy to get things done. I will relax, along with my loved ones. Loved ones, visit the building. Take the highway, park, and come up and see me. I'll be working but if you cone visit, Ill put down what l'un doing. My friends are important. Don't you worry about me... don't you worry about me.

I see the states across this big nation. I see the laws made in Washington, D.C. I think of the ones I consider my favourites. I think of the people that are working for me ... I'm a lucky guy to live in my building. They all need buildings to belp them along.

Byrne explained: "It's hard to say exactly what kind of sentiment I was trying to express with that song because there were several different things mixed together. Basically I wanted to have a rock song with pastoral imagery so that's how I started off. I also wanted to write a song about the government, with the completely opposite point of view, a more critical song. It's from the point of view of someone who does their job, pleased with their level in life, pleased with their appliances in their apartment, pleased that their building is in pleasant surroundings and that it's a nice drive out there... The antithesis of the way I feel, but something I got caught up in for a short time and thought I should pur down. It's a rate thing for that point of view to be expressed in songs these days." expansion of the pastoral imagery to the entire USA and its legal system gives the whole song general metaphorical quality (is the government like a comfortable building, or the other way round?), while the last line turns away from the expressed contentment and to present it suddenly as questionable.

Buildings turn up in many of Byme's songs. ${ }^{16}$ 'The Talking Heads' first single, "Love $\rightarrow$ Building on Fire", deals with "two loves":

When my love stands next to your love,

I can't define love when it's not love.

It's not love, it's not love.

Which is my face, which is a building, which is on fire. 
The second album, aptly titled "More Songs About Buildings And Food", included the song "The Big Country":

I see the shapes I remember from maps. I see the shorelinc, Il see the whitecaps. A baseball diamond, nice weather down there. I see the school and the houses where the kids are Places to park by the factories and buildings. ....

(AND I SAY): I wouldn't liwe there if you paid me. I couldn't liwe like that, no siree! I could $n^{\text {'t }}$ do the things the way those people do 6 ?

Buildings are of course easily recognized metaphors that may stand for every structure that frames someone's life: as popular songs claim to express inner experience directly, this metaphor can represent anything that shapes or opposes that experience from the outside. Every listener is able to flesh out this rhetorical figure with a personal interpretation.

These lyrics are primarily meant to be heard, not read, which gives them the added qualities of a voice, which is again embedded in music. All this produces a persona that the listener may enter for a few minutes. The songs suggest mental states, or fragments thereof, without resolution or conclusion. Making sense of them, deciding what is spontaneous and what manipulated or repressed, is up to the listener; this stands in the way of direct emotional identification.

A parallel to this can be found in the cover that Byrne designed for "More Songs About Buildings And Food". The front cover consists of a grid of $23 \times 23$ Polaroid photos of the band members, each photo rendering a small detail. As these snaps almost, but not quite fit their neighbours, due to small changes in position and lighting, the result is a tecognizable but uneasy, rifted group portrait; a photographic, cubist grid. The back cover reproduces 'Portrait USA', a computerprocessed synthesis of satellite photos that shows the entire landmass of the USA in a single smooth image. This first color photomosaic of the United States was originally produced by General Electric with the assistance of the National Geographic Society and NASA. The juxtaposition-the ordinary image of four persons made problematic, the image of a huge country presented as if it could be taken in in a single glance-forms a fitting backdrop for the song's characters, struggling with role models. Severall covers for later albums would present variations on this theme.

So far, the songs have been described without paying attention to their tecording, the process that is crucial to most popular music. ${ }^{68}$ After all, the many sound effects like echo and reverb, the extra instrumental and vocal overlays, and the mix that ultimately decides the quality of a song are all produced in the recording studio. Tony Bongiovi, who produced their first album, had been suggested to the Talking Heads by their record company as someone who might give their unusual and somewhat weird sound a more accessible form. Bongiovi let the band make endless recordings of single instruments, and tried to persuade them to 
add melodic extra's to their songs, trumpets, steeldrums and a cello, to dress up their sparse sound. To Byme, however, all this determined conventionality was restricting, not liberating. ${ }^{69}$

Their second album was produced by Brian Eno, who brought a completely different approach to the process of recording. As he explained it himself, "because of the development of recording technology, [in the early seventies] a whole host of compositional possibilities that were quite new to music came into existence. Most of these had to do with two closely related new areas-the development of the texture of sound itself as a focus for compositional attention, and the ability to create with electronics virtual acoustic spaces... There was still the suggestion that playing with sound itself was a 'merely' technical job-something engineers and producers did-as opposed to the serious creative work of writing songs and playing instruments."70 Eno treated the recording studio as an important creative tool, and approached the recording process as one of conceptual decisions, to the point of developing "Oblique Strategies" (together with painter $\mathrm{Pe}$ ter Schmidt), a set of cards that serve the purpose "to try to derail normal thinking habits when they've proven ineffective, and to suggest new ways of approaching problems." "71 For example, the first of these cards reads: "Honour thy error as a hidden intention."

Eno used his knowledge of the many studio filters and effects to clarify the distinctions that define a musical space, to highlight specific sonic gestures and to add colour and contours to the instruments' voices; by doing so he could avoid the routine sound of most pop records. He preferred a direct way of working in the studio, accepting the inevitable 'leak over' of sounds from one recording track to another, to concentrate on the creative choices.

The result can be heard in the Talking Heads" cover version of (Reverend) Al Green's hit "Take Me to the River". In his song, Green had managed to combine soul with gospel, erotic longing with religious desire, tying it all up in a single effervescent metaphor: "Take me to the river. Wash me in the water". While recording their version, the Talking Headls decided to use only the recorded basis tracks of their instruments. Instead of the usual adding of extra instrumental tracks, they chose to add only single notes to the already recorded instruments. Eno then treated these additions with a synthesizer in the same way he had treated the snare drum, giving it a delay, an echo, to produce an 'underwater' sound. ${ }^{72}$ Just as typical is an irregular tinkling, jangling sound on the song "Warning Sign" that was accidentally recorded along with Byrne's singing: he danced around with keys in his pocket, and their noise was registered. A regular producer would have insisted on re-recording, but not Eno- "it fits the thythm so we left it on there", Byme later said. ${ }^{73}$

To complete this attempt to unravel the meaning of the first Talking Heads albums, they have to be placed in a wider historical context. Among the ingredi- 
ents that made rock music in the sixties and seventies such a success were the mutual influence of black and white styles, the new sound technologies, the new affluence of young audiences, as well as the unprecedented combination of wealthy consumer societies, flooded by media images of war and suffering. This resulted in a mass market for music that convincingly supported fun as well as rebellion, often both at the same time. This cultural sphere encouraged a great deal of innovation and experimentation in popular music. But by the middle of the seventies, the sexy and rebellious image of rock had been co-opted by the industries of music, television and film, which made it impossible to sustain the populist and idealist aesthetic that had shaped the ideology of rock in the sixties. Of course, the industry had made rock possible in the first place; but now the sounds, textures and styles were channeled into well-defined genres, easily identifiable in order to be easily marketed, Sound textures became more and more inflated: 'supergroups' like Yes, Emerson, Lake and Palmer and Procol Harum, and their more conventional counterparts Kansas, Foreigner and Boston came out of this development. In the words of John Rockwell, such bands are best seen as a blend of middle-ofthe-road sentimentality and empty virtuosity augmented by the recording studio. ${ }^{74}$

Punk came along to oppose all this, but it established itself as a new gente of simplistic negativism, easily identifiable, at least in Britain, by the use of safety pins. Together with New York bands like Television, the Ramones, Richard Hell, the Patti Smith Group, Blondie, and Cleveland's Pere Ubu, the Talking Heads were part of a musical scene that stood for uncluttered, unsentimental directness. Among these, the Talking Heads stood out by questioning what directness in music is. The songs of " 77 " convey an intuitive experience, but that experience is made up of frankly conflicting and uncontrollable emotions, as well as by outside forces; Byrne sang lines like: "This boy is in motion / Some density moved right beside me / I want my sentence right here, but now I'm far away" ("Happy Day" $)$. Talking Heads used the idiom of rock music, a sound that had captured the experience of a generation, to convey the idea that its aesthetic of spontaneous and direct expression of authentic passions, with its romantic ideology of rock and rebellion, were somehow insufficient. While Byme and Eno were looking for conceptrually richer interpretations of popular music, the Talking Heads recorded a third album, Fear of Music. In retrospect, this album documents a transition from the aesthetic of rock to a more collective orientation.

\section{EXPERIMENTS WTH RIYTHMS, TEXTURES AND PERSONAE}

In 1979, the "Talking Heads recorded their third album, "Fear Of Music", again with Eno as producer. The album documents a moment of transition in Byrne's songwriting. It contains an array of experimental possibilities that he would only later explore fully. The songs of the two first albums had mostly been fully devel- 
oped before they were recorded; now, to avoid tepeating himself, Bytne began to rely on the opportunity to construct a song in the process of recording by breaking down a musical texture into separate tracks that can be erased and replaced at will, and by applying electronic effects to any selected sound. As Byine explnined this deliberate cut and-paste process: "There was a song that we used to perfom live, "Electricity", which we re-arranged for the album with Jerty [Harrison] play. ing guitar instead of synthesizer; but it still didn't translate to tape. Brian [Find] and I listened to it over and over again and then I suggested starting to remove things from the mix. First, my rocal came out, and then all the othet parts, and all we were left with was the snare drum and some of my guitar. The problem was that, since the old parts were ingrained in our heads we couldn't come up with anything new to replace them. So what we did was work on the parts simultaneously but without each other's knowledge. Brian would play half a bass part and I would play half a bass part and then we'd put them together as if it was one part. We did the same with the guitars and came up with some chord progressions that I wouldn't have been able to come up with otherwise."75 "I Zimbta", the song that opens the album, also resulted from such studio composing. Byme had been listening to records of African drumming, and wanted to construct a song in a similar way. He accumulated seven guitar wiffs, rhythmic and melodic patterns, and worked on them until they could conceivably proceed from one to another-to find that this kind of music no longer lent itself easily to the chorus-and-verse format $^{76}$ Eno applied the 'psychedelic' effects that occur when dramatic 'vocal' qualities like straining, groaning and stammering are electronically added to instrumental melodic phrases with unprecedented precision, "a hyper-sensitivity in which every little sonic gesture has dizzying ramifications."7n.

Bytne also experimented with his voice, singing his songs "Heaven" and "Air" phrase by phrase into a tape recorder and trying to make each syllable stretch over" two or three notes. "For another song, "Drugs", he exercised wntil he was out of breath and then sang while jogging in place. He tried singing the lyric of "Electric Guitar" as if he were mentally retarded $^{39}$, exaggerating so much that he had to tecord it again.

Moreover, he adopted a distancing approach to writing. He wrote instructions to himself to write a song about a certain subject, applying what he called "nontational logic": starting with a mad premise and proceeding from there as if it made sense.8" "Animals", for example, was written "to disagree with the idea that animals are... noble savages - ike the way noble savages are looked upon as living in harmony with their surtoundings and with each other. I thought I'd present a contrary point of view of animals as obstinate beings with lots of problems of their own; and we shouldn't pay any attention to them." 
1. know the animals are laughing at us They don"t even know what a joke is I. won't follow animal's advice I don't care if they re laughing at us...

Other lyrics adopt similarly quaint premises, while often referring to the meaning and uses of music. The chorus of "Heaven" states:" Heaven is a place where nothing ever happens"; the verses suggest that everyone tries hard to reach such a place of eternal fulfillment-be it a bar, a party or a kiss. The song also contains the lines "The band in heaven plays my favourite song. They play it once again, they play it all night long." "Electric Guitar" presents the guitar, often the personification of the hero in rock music ${ }^{82}$, in troubled situations:

An electric guitar is brought to a court of law:

The judge and the jury (twelve members of the jury)

all listening to records

This is a crime against the state

This is the verdict they reach:

Never listen to electric guitar..

"Life During Wartime" mentions roadblocks, truckloads of weapons, anonymous graves and gunfire to present an image that is familiar from the TV news and from films. This is combined with a protagonist who explains his situation in loose scenes: changing passports and looks, staying away from the window, burning his notebooks since they won't help him survive. He also mentions his personal concerns: no longer being able to go to disco's and clubs, to stay in college, or to play records. The lyrics are indeterminate, so that they can be interpreted as a casual and intimate evocation of low-intensity guerilla warfare in an American city, as a metaphor for an adolescent identity crises, or even as both together.

An exception to this kind of songwriting is "I Zimbra", the song that opens the album. To fit the rhythmic texture of this piece of music, Eno suggested using "Gadji Beri Bimba" a Vers obne Worte or poem without words by Hugo Ball, the organizer, poet and dramaturgist of the Dada-movement. Ball wrote this text in 1916 , describing it as a form of poetry in which "the balancing of the vowels is gauged and distributed only to the value of the initial line". ${ }^{83}$ The Talking Heads renamed the poem "I Zimbra" after its last words, used by Byme as a summarizing and explosive shout:

gadji beri bimba clandridi

lauli lonni cadori gadjam

a bim beri glassala glandride

a glassala tuffrm $i$ zirnbra ${ }^{84}$ 
How to interpret the use of this nonsense poem? Since it is unlikely that conceptually working artists would not consider the implications of quoting Ball, it is safe to look beyond the syllables, and beyond the experiment of singing a song without meaningfull lyric. The use of Hugo Ball's phonetical poem epitomizes Dada, the reaction to the breakdown of reason in World War I by a small group of artists who promoted nonsense as an antidote and found that nonsense was able to provide a meeting ground for the artistic avant-garde and political protest. The text stands for the breakdown of conventional language. It is revealing that in June 1916, the month in which he performed 'Gadji Beri Bimba' for the first time, Ball wrote and performed an avantgarde narivity play that also consisted only of mean ingless sounds. ${ }^{85}$ When language is reduced to mere vocalizations, to meaningless sounds, that implies a demand for a new source of meaning.

The overall atmosphere of "Fear of Music" is spooky and melancholic. 'The personae of its songs are stuck in obsessive patterns of thought, isolated from their surroundings. For Byrne, it was the product of a period of transition, in which he was redefining his position towards rock music as an aesthetic form. Together with Eno, he turned away from the song format of rock. They did this not only by using the studio as a tool for composing songs, dissecting and reassembling the crude but catchy exuberance of rock. They combined their practical work on the Talking Heads' music with a search for a more philosophical understanding of popular music. For that purpose, Eno and Byrne looked mainly at the African tradition of music and art. They listened to African and Oriental music, often buying LP's with only the sleeve design as an indication of what kind of music they might contain, and studied ethnomusicological literature. Eno went on a musical field trip to Ghana, Byrne visited Bali, where he witnessed some musical rituals.

For the Talking Heads as a band, it was lucky that the not so theoretically inclined members were also investigating African music and its Latin and AfroAmerican derivarions. In 1979, Chris Frantz and Tina Weymouth, the band's thythm section, traveled about the Caribbean, whete they visited musical Vodun rituals in Haiti and spent some time with the famous reggae musicians Sly Dunbar and Robbie Shakespeare in Jamaica. They brought a large set of Haitian drums home to New York to practice on. At the same time, Jerry Harrison worked as a producer for singer Nona Hendryx and bass player Busta Jones, Afro- Americans who would later play in the expanded version of the Talking Heads. ${ }^{86}$ When Byrne and Eno had assembled a loose conceptual framework to reinterpret and articulate the African musical tradition within their own Western context of art, mass media, and pop, Harrison, Weymouth and Firantz were ready to play it.

These innovations resulted in a series of innovative albums: Talking Heads' "Remain In Light" (1980), Eno and Byrne"s collaboration "My Life in the Bush of Ghosts" (1981), Byrne's solo album "The Catharine Wheel" (1981) and the Talk- 
ing Heads" "Speaking In Tongues" (1983). Before discussing them, the next section describes their theoretical background, as compiled by Byme and Eno.

\section{THE COMMUNAL PRODUCTION OF MUSICAL MEANING}

In 1980, when the Talking Heads issued "Remain In Light", Byrne added a small bibliography to the press handout. He hoped that it might result in getting him more interesting interviews and reviews. ${ }^{87}$ It mentioned three or four books: John Miller Chernoff: "African Rhythm and African Sensibility: Aesthetics And Social Action in African Musical Idioms" (1979); Robert Farris Thompson: "African Art In Motion: Icon and Act" (1974); and Christopher Alexander; "The Timeless Way of Building" (1979), together with an accompanying volume by Alexander and others, titled "A Pattern Language" (1977).

Of these authors, only Chernoff deals specifically with music, which explains why his book will receive most attention. "African Rhythm and African Sensibility" is a study of the social meaning of music and dance in Westafrican societies, as well as a reflexive autobiography and travelogue of an American anthropologist who dedicated ten years of his life to receive training as an African drummer. The book, that describes African drumming as a community of interlocking parts, is a remarkable combination of scholarly discipline with personal candour; David Byrne recommended it as "one of the few books I know of that talks of the political, social, and spiritual meanings of music. I was moved. It was so nice I read it twice." $"$ ss

R. F. Thompson, professor for African and Afro-American art history at Yale University, is a groundbreaking historian of Afro-American art and aesthetics. Part anthropologist, part att critic, part musicologist, part student of religion and philosophy, Thompson is able to explain how African arts are anything but primitive, informed as they are by aesthetic, social and metaphysical traditions. These are equally relevant to music, sculpture, textiles, architecture, religion and idiogrammatic writing. The subject of "African Art In Motion" is the unity of the arts in African performance, which Thompson describes and celebrates as

a sensible approach in which one medium is never absolutely emphasized over others. Sculprure is not the central art, but neither is the dance, for both depend on words and music and even dreams and divination. Music, dance, and visual objects are all important, separate or together; and if motion conveys stature to music and art, sculpture deepens motion by condensation of several actions into one. These unities demand that we stat with the shated norms of performance. ${ }^{89}$

These norms are united in the aesthetical concept of coolness:

a matrix from which stem ideas about being generous, clear, percussively patterned, harmonized with others, balanced, finished, socially petfected, worthy of destiny. In other words, the criterion of coolness seems to wite and animate all the other canons... The metaphor of the cool in African 
symbolism far exceeds notions of moderation in coldness and degree of self-control and imperturbability. In Africa coolness is an all-embracing positive attribute which combines notions of composure, silence, vitality, healing, and social purification. Composure intersects with silence; vitulity intersects with healing in the sense of restoration of shining health, the body politic is "healed" in socist reconciliations... Coolness thus emerges as a metaphor of right living, uniting the special strength of the elder with the warrior, women with men. ${ }^{90}$

Just as R.F. Thompson encourages his readers to consider the ethical and social implications of artistic performance, $C$. Alexander is an architect who emphasizes the social and performative dimension of architectural design. In "The Timeless Way of Building", Alexander opposes the conventional role of the architect as the genius who makes the master plan, and proposes to substitute this 'grand design' by gtadual and collective processes of planning and constructing the architectural environment. Alexander proposes to base these planning processes on a collection of communally adopted planning principles. Explicit and easily grasped patterns should help a community to realize an organically built environment for itself, one that gradually adapts itself to the wishes of those who actually use the buildings.

It is easy to see that what these books have in common. They challenge the conventional approach to aesthetics that isolates individual artists, artworks, or spectators, and draw attention instead to the communal production of aesthetical meanings. I doubt whether many tock journalists actually found the time to study these books, but interviews with Byrne and Eno from this period give evidence of their enthusiastic lecturing on this collective aesthetic. Moreover, Byrne's praise for their theoretical work would later lead to collaborations with both Chernoff and Thompson.

In an attempt to explain why Chernoff's book impressed him so deeply, during an interview Byrne contrasted it with the capitalistic context of rock music. $\mathrm{He}$ turned to Max Weber's famous sociological monograph on religion and capitalism in the USA to explain how music and economy are related:

Max Weber wrote.. "The Protestant Ethic and the Spirit of Capitalism". He was attempting to explain how a peoples' spiritual foundations lead them to a particular economic way of life, how their religious and moral upbringing leads them to a social and economic attitude. I think this is true for rock musicians as much as anyone. They've grown up in a society that values competition, the whole dog-eat-dog beat-out-the-other-guy kind of thing. So they're bound to play music in the same way: trying to out-solo the other guy, trying to play louder than the other guy, et cetera. All that's very different than the kind of music we're playing, whete you have to leave a lot of holes in what you're playing in order for the other parts to be heard, where the whole thing doesn't take off unless you can hear lots of different peoples" parts popping in here and there. "This is not to say we negare ourselves as individuals, but that we get something by restricting our individual freedoms that we couldn't get otherwise. The whole feeling this music generates for me-methe whole community of interlacking patts - is totally different than what tock does. Presently I don't feel I have any conncetion to tock and toll. In a lot of rock music people tend to play all the time, ot as least as much as they can get away with.", 
Byrne's model for this musical community was African drumming as described by Chernoff. His book begins by admitung that African music as such does not require a theotetical representation or an explicitly interpretative understanding. ${ }^{92}$ The basic assumption of the African aesthetic is exactly that its meaning depends on joining, on contributing something to the event, for example by dancing or by clapping one"s hands: "without participation, there is no meaning". ${ }^{3}$. This is a fundamental difference with Western classical music, which presupposes the detached attitude that is traditionally seen as a requirement for aesthetic pleasure. ${ }^{0.4}$

As Chernoff explains, in African music there are always at least two rhythms going on that are not unified by a single main beat or basic meter. The music is essentially polyrhythmic, or, to use the correct musicological term, polymetric, because the different instruments of an ensemble have to be notated in different meters. In the resulting music, "the diverse rhythms establish themselves in intricate and changing relationships to each other analogously to the way that tones establish harmony in Western music". 95 As one rhythm contrasts with another, it accentuates certain aspects of it, thereby giving it contour and meaning. Within a single ensemble, African drummers play apart from each other, allowing their rhythms to intertwine, to clash and conflict. There is a common beat, for otherwise the music would be impossible to play-but this common, unifying beat is not accented, in fact not even played at all: it is kept hidden, perhaps clicked with the tongue or in an other way demonstrated with a part of the body, 'danced', 96 This leaves the music incomplete: the organizing ingredient still has to be added, a task that falls to the audience, the dancers or listeners. "Essentially, this simply means that African music, with few exceptions, is to be regarded as music for the dance, although the 'dance' involved may be entirely a mental one... The assumption by an African musician that his audience is supplying these fundamental beats permits him to elaborate his rhythms with these as a base, whereas the European tradition requires such close attention to their conctete expression that rhythmic elaboration is limited for the most part to mere ornament." understood by dancing to it: then the music, although it may be played by a full orchestra, is transformed into an accompaniment for dancing. In Chernoff's words: "The listener must be actively engaged in making sense of the music; the music itself does not become the concentrated focus of an event, as at a concert." "ys

In this kind of music, the essence of the composition is the basic organization of rhythms with their shifting accents and emphases and with patterns of "question and answer' known as call-and-response. 'The master-drummer or singer, if there is one, can add further interest to this weaving of multiple cross-rhythms by placing different accents. Although the compositions of the dances are fixed by tradition, their organization does leave room for improvisation. The individual thythms, each of which is beaten on a specific drum, all know several variations, 
and drummers are expected to vary theit thythms to suit the occasion. $A$ good drummer has to keep the dance inreresting for the dancers by adding enough variations, but he also has to take care not to exhaust their energy. ${ }^{99}$ 'The musicians and their audience share a responsibility for making the occasion a pleasant one; and in that context the music also has to fulfill its responsibilities by demonstrating the proper behavior. This responsibility is increased by the fact that the drummers can literally use their drums to talk. ${ }^{100}$ Drummers of traditional dances can weave proverbs into their music, or comment on the dancers, or proverbial names of the ancestors of those present, and thereby have an important function in ceremonies like weddings, funerals and the inauguration of a new chief.

Considered separately, many of the rhythms of African music are not exceptionally difficult. They can very well be copied by Westemers, even though they have grown up in a quite different musical environment. What is difficult for Western ears, is to hear and to distinguish the different thythms and to appreciate the complex rhythmic structure that is woven by them. The aesthetic ideal that is striven for is not that of a perfectly performed composition, but rather to create a wealth of possibilities for combining and crossing thythms: "the music is organ" ized to be open to the rhythmic interpretation a drummer, a listener, or a dancer wishes to contribute. The music is perhaps best considered as an arrangement of gaps where one may add a rhythm, rather than as a dense pattern of sound." The best drummers do not distinguish themselves by the intensity or the capriciousness of their improvisations, but by their ability to clatify and entich the complexity and the movement of the whole musical event. ${ }^{102}$ The stylistic criterium by which the drummers are judged is not their musical virtuosity as such, but their use of musical style to respect and if possible improve the dynamics of the musical and social relationships. This requires balance and restraint. Without these qualities, "the African musician loses aesthetic command, and the music abdicates its social authority, becoming hot, intense, limited, pretentious, overly personal, boring, irrelevant, and ultimately alienating." finding and maintaining an interesting and dynamic balance between the varying rhythms, and at the same time between the diverse participants in the occasion, be it a ceremony or a feast. Chernoff underlines that a certain style of drumming has to be accompanied by an explicitly ethical or moral sense of purpose, and concludes: "music-making in Africa is above all an occasion for the demonstration of character." 104

In his book, Chernoff quotes R. F. Thompson to explain this more fully: "Multiple meter essentially uses dancers as further voices in a polymetric choir. The conversation is additive, cool in its expressions of community. The balance struck between the meters and the bodily orchestration seems to communicate a soothing wholeness rather than a "hot" specialization... Dialogue in apart performing... [and in] call-and-response... [is] a means of putting innovation and 
tradition, invention and imitation, into amicable relationships with one another." Thus to perform music and dance is finally to establish a community, which means that an moral edification message can go hand in hand with entertainment, excitement with decorum.

This music promotes, and is in its turn favoured by, a truly pluralistic sensibility. Chemoff contradicts the nostalgic bias that regards so-called traditional societies as determined by stable pattens of culture, patterns that are uncritically ac cepted and that serve to make every event richly meaningful. Instead, he stresses that life in Aftican societies is charactetised by diversity and discontinuity of experience. People often build their identities from ellements that may seem mutually exclusive in Western eyes: nationalistic and tribalistic, Animist and Christian or Muslim, traditional and Westernized identities are combined. This music is not necessarily confined to small village communities either, but functions in situations determined by tapid change, urbanization, congestion and noise, poverty, unemployment, uprootedness and family dispersion. 106 In such situations, according to Chetnoff, "Equanimity with multiple rhythms and the silent beat can and does serve to inform social relations with a cosmopolitan attitude of toleration, tationality, and pragmatism." 107 Within this musical context, "singlemindedness of purpose would be equivalent to poverty of expression." 10 .

Byme and Eno promoted such ideas in a series of interviews. In a joint interview, when asked why Africa had become so important for them, Byme explained that

"We both grew up listening to music that had its roots in Africa... The African music we listen to isn't that different-in spirit, anyway-than a lot of thythm and blues, or funk, that we're quite accustomed to and that most of [Talking Heads'] music is based on. It's not that big a leap."

"It has melodies you can understand, thythms you can understand," Eno says... "The other thing about Africa is that both of us, and many other people in the world are interested in discovering whether thete are moral philosophies-not a word one bandies lighty in the contemporary rock pretes, 1 must siay."

"There"s a wery different kind of spirituality" in Africa than what we grew up with", Bytne notes. As opposed to our "sober, very serious" appronch, "in Africa and a lot of other cultures, probably most of the cultures in the world, things that sire considered spiritual-performances, music-nte also exciring and fun. People have a good time; it's not sacted in the sense that you can't talk while a performance is going on, or have a drink or smoke a cigatete. There isn't that separation of pleasure and spiritual things." "ivg

Looking back on this period over ten years later, Byme recapitulated: "When we listened to a lot of African, Latin and American funk music, one thing that was common to all of them was that the rhythms were syncopated, which means that there is more than one rhythm happening at once. The structure of the music was that the whole was greater than the sum of its parts and that each part was just a little piece - together they made something that was not evident in any one piece. 
What seemed wonderful about that idea was that it was a musical metaphor for a utopian community." 110

Eno and Byme were trying to copy and translate Chemoff's model of African music in their own work. This music essentially has to be performed live, based as it is on a direct and meaningful exchange with the audience. It is therefore questionable whether it is possible to imitate this communal model of musical meanings in Western popular music, since that usually separates playing and listening.

A sociological description of the processes of making and hearing populat music in the West points to some of the problems that such a translation has to confront: "The glass booths and baffles that isolate the musician from his fellow musicians; the abstracted audience; the sense of producing an object and of massproducing a commodity; the deconstruction of time by takes and its reconstruction by splicing - these are strong metaphors of modern life. Their mirror images in the listener's experience are solitude; the occlusion of the musician; the use of music as an object and a commodity; the collapse of a public architecture of time and the creation of a private interior design of time. Since they contradict everything that music-making once seemed to be, they are paradoxes." 11

Byrne and Eno set out to combine African musical forms that rely on direct interaction and participation to make music meaningful, with the practice of recorded music that is reproduced in the media, music that produces indirect and abstract relations between musician and audience. They investigated this paradox in making their album "My Life In The Bush Of Ghosts", a record that served as a laboratory for further experiments with the Talking Heads on their fourth album, "Remain In Light". In either case, they did not solve this contradiction; they rather articulated it in a new way, and thus developed innovative mimetic responses to the conflicting attractions of individualistic versus communal experience, of the meaningful experiences offered by the mass media versus that of faceto-face relations.

\section{SOLITARY VOICES EMBEDDED IN COMMUNAL RHYTHMS}

The first album that resulted from this new conceptualization of populat music is "My Life in the Bush of Ghosts", a collabotation by Brian Eno and David Byrne. Instead of songs sung by Byrne, the record contains 'found voices' of preachers, exorcists and singers from the United States and the Arabian Middle East. Eno and Byrne had made tapes of highly emotional voices from U.S. radio stations, and added moving, lamenting voices from records. They edited all these trance-like voices by isolating and repeating significant fragments, and embedded each resulting vocal in a texture of thythms and small sonic gestures. These textures were constructed in the studio, where Byrne and Eno played on regular guitars, basses, synthesizers and drums, as well as on a range of 'found objects", in- 
cluding an amplified guitar case and studio floor as well as "coiled spring over car muffler" and plastic water buckets 112 . They invited a series of guest musicians to play percussive instruments and bass.

The record presents those impassioned and entranced voices embedded in a texnre of syncopated thythms. This collage has an "ethnic-funk psychedelic"113 overall sound and can be enjoyed as a series of intriguing surface patterns of voices and rthythms. But the record contains other levels of meaning, disclosing themselves when the listener tries to identify with the voices, as is habitual in the tradition of popular music. 'This attempt is bound to fail; in this respect these collages may be compared to the songs on "Fear of Music", which repudiate direct identification with the personae of the lyrics. Yet on that album, Byrne's energetic deliverance, his central mediating role as a singer, together with his story-telling lyrics invite the listener to consider the presented personae as real in a naturalistic sense, as recognizable, passing mental states. The organization of those songs in chorus-and-verse format also allowed an audience to recognize a song as a distinct persona, creating a unified perspective by alternating direct emotional approaches (in the choruses) with more distanced perspectives (in the verses) "I Zimbra", the song that prefigured the collages of "My Life in the Bush of Ghosts", was the single exception to this format.

"My Life in the Bush of Ghosts" differs in important respects. There is no single unifying and mediating voice, the lyrics do not outline a persona in a situation, and the music is not organized in a chorus-and-verse pattern. The lytics and voices as such do not solicit a direct identification, and there is no conventional organization of emotional perspective. These are voices that seem to have lost their aesthetic command and their social authority; to borrow Chemoff's words for such music, they are hot, intense, overly personal and pretentious.

The opening track of the album, titled "America is Waiting", is a good example. It reproduces the voice of someone who is referted to on the record sleeve as an "unidentified indignant radio host, San Francisco, April 1980"" An outraged male voice exclaims: "America is waiting for a message of some sort or another". Later on in the track, the same voice is heard to say, "No will whatsoever. No will whatsoever. Absolutely no integrity", and similar condemnations. The editing of this recorded voice by Byrne and Eno, with its alienating use of fragmentation and reperition, emphasizes the peculiar qualities of the speaker's statement. The speakers" motal indignation seems to require that the entire American nation must emotionally identify itself with his position to make reconciliation possible. This is a request of mythical dimensions. The title of the album, "My Life in the Bush of Ghosts", suggests that we live in an environment that is filled with such messages. Eno and Byme adopted this title from a novel by Nigerian writer Amos Tutuola. His book is a ghost story that tells of a defenseless little boy who travels through the jungle, where he is time and again caught by ghosts that subject him to hair- 
raising experiences, on a joumey where logic and continuity are time and again suspended. The unmistakable implication is, that the media landscape may have a similar effect on an unprotected or destabilized audience.

Perhaps the texture of thythms and sonic gestures that were added by Byme and Eno can provide the sense of perspective that makes it possible to understand the extreme emotions that are projected by the voice fragments. The musical texture may be considered as an environment that envelopes those disembodied, rance-like voices, helping them to relate to their surroundings. This interpretation would be in keeping with Chernoffs expose of the aesthetic and spiritual meanings of such rhythmic patterns: they are an invitation to join the dance and thereby the community. This invites an interpretation of the album as offering a thythmic invitation to such hot, uncomfortable, pretentious voices in the media landscape to be cooled in a communal and musical celebration; this seems to me the only interpretation that is in keeping with the African aesthetic as explained by $R$. $F^{*}$ Thompson and J.M. Chemoff. As Thompson quotes some African spokesmen, "it cools the town when you dance... when you finish... you are restored to tepose... and reconciliation with your family. [The chiefs of the town] keep themselves peaceful when they are dancing - this is reassuring to the townsmen;" and: "the heads of the dance cult are people who are "cool", who like "to laugh and play" and who do not look for "cases" (1.e., litigation)."114 Chernoff repeatedly emphasizes that the ideal character that is presupposed in African polythythmic music is calm, "cool' instead of 'hot', showing collectedness of mind.115 This kind of char.acter in indispensable to mediate the different powerfully vital thythms, as well as to take part in the potentially always conflicting social situation.

This composure is not emphasized to deny that thythms and dances are used to help participants enter a trance; it is meant to point out that the most important aspect of such a trances is that one may leave them, and join the community. Chemoff writes that "when Africans allow a person to become possessed or iclentifed with power, as when they celebtate or pratse a particular cult god whose rlyythm 'rides' or 'comes up' to a dancer, they are using music and dance as a technique of religious experience, and as we noted, they do so most often under strictly controlled circumstances in the presence of a religious figure, a specialist at cooling down hot" people."116 And: "One does not dance to go into trance but to come out of a trance, to join a diversified assembly with a separate contribution, for dancing is a reminder that one is only part of the whole."

The voices presented by Byrne and Eno lack coolness: they seem possessed, entranced. The added rhythms mimic the overexcited qualities of those voices, but in doing so they provide these isolated wocal personae with a musical context, symbolic of a community that invites the singers and speakers to cool down. Of course, Chemoff writes about the cooling down of actual people, while Byrne and Eno deal with media representations. The dance to which Ino and Bytne enlist 
their selection of found voices is only performed as a hypothetical exercise, so to speak. Yet that exercise is not without importance, since we live possibly quite as much in a world of media voices as in an assembly of teal human speakers. Our society is not complete without its plethora of represented presences, both voices and images; to keep one's cool in this environment, everyone has to find ways to include these influential mimetic presences in his experience.

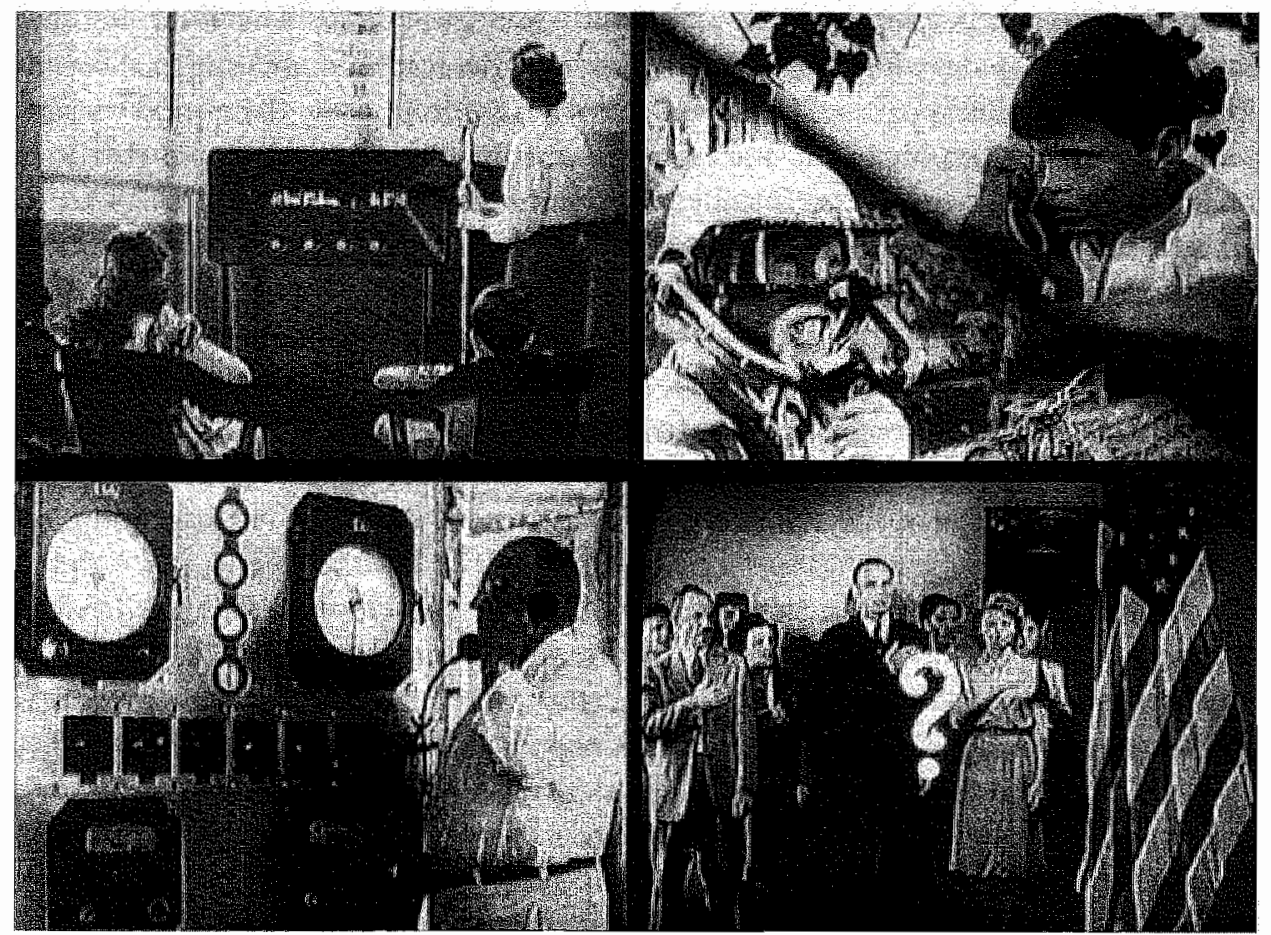

2 Four examples of the footage in Bruce Conner's film "America Is Waiting"

That Byme meant something allong these lines, can be seen in Bruce Conner's film "America Is Waiting", a short film made to accompany the track like a video clip. Byrne acted as producer for this film. Conner is an experimental filmmaker who had begun alteady in 1958 to make up experimental films exclusively out of existing footage. Using clips from old pictures in complex and ironic juxtapositions, Conner opposes the viewer's expected response to familiar footage to convey another, opposed meaning. ${ }^{118}$ As visual accompaniment to Byrne and Eno"s "America Is Waiting", Conner combined images of radar stations and thythmically moving exploding clouds with shots of families entering bomb shelters, children playing with toy grenade launchers, operating impressive and enigmatic machinery, and similar, mostly innocent representations of war from American film and TV 
culture. In the final images of his film, a sheep is peacefully standing in a meadow, when suddenly a wolf appears that had been hiding behind it. Of course, the use of found footage is a direct parallel to the use of found woices; the film but adds another layer of meaning to the musical texture.

When the Talking Heads began working towards their fourth album, Byrne and Eno introduced the process of using tape tracks as a medium for collage and composition. Byrne did not feel inclined to write songs and take them to the band for rehearsals. He proposed to the other members that the rehearsals should not be rehearsals of songs, but a way to sharpen their skills: "one person coming up with something, somebodly else coming up with a part that thythmically locks in with it." 119 The recording process was similar to these preparations: developing an interesting and satisfying texture of repetirive tracks by adding new layers and deleting expandable older tracks. ${ }^{120}$

Making a Talking Heads album implied that Byrne would have to sing and write most of the lyrics, and as soon as there was enough music for an album, he started working on the lyrics. He wrote collages for which he used material from diverging sources: phrases from radio evangelists in different parts of the U.S.A.; a record of John Dean's testimony during the Watergate trials; a record of ex-slaves telling stories; newspaper headlines; as well as the books by Chernoff and Thompson. ${ }^{121}$

Byrne reconsidered the relationship of the singing to the music as well. Where his previous songs created dramatic tension by changing the music underneath his vocal melody, now he was forced to find another device to create drama, because the music basically repeated root patterns over and over again. Byrne described the musical material as follows: "On both albums there are very few chord changes, it's very modal so that any solos have to be within a prescribed set of notes. You can't jump into chord melodies and things like that." 122 Together with Eno he came up with the solution of complex vocal arrangements, group vocals and vocals that go on top of other vocals, as well as added solo instruments weaving in and out of the rhythmic pattern. ${ }^{123}$

The outcome of this way of songwriting no longer resembles conventional rock music. "Born Under Punches", the opening song of "Remain In Light", is a good example. It opens with an echoing shout, followed immediately by the onset of a driving, syncopated thythm, punctuated by parrot-like squeaks, a passages like the sound of electronic pinball machines (actually a guitar solo, locked into a Lexicon digital delay and then electronically divided into fragments and rearranged ${ }^{124}$ ), shouts of animals and the like. While Byrne sings some of his lines in a voice that emulates hysterical wailing, he switches to a more authotitative voice to render intermittent comments (here printed in italics): 
Im not a drowning man!

And l'm not a butring building!

I'm a thmbler!

Drowning cannot hurt a man!

Fire cannot huri a man.

Not the Governysent Man.

At the same time, a choir of forcefal female voices repeats: "And the heat goes on-goes on-Where the hand has been-And the heat goes on-goes on-" While these strong voices continue, a more timid choir of male voices sings

All I want is to breathe.

Thank you. Thank you.

Worn't you breathe with me?

Find a little space... So we move in-between

And heep one step ahead of yourself.

I'm so thin.

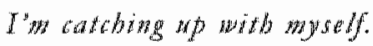

Again, the italic lines are sung by Byrne alone, with great emphasis. The result is a complicated balancing act, in which the models of traditional African drumming, and of funk music as its latest American derivation, are used as a medium for the interpretation of contemporary metropolitan culture. The songs combine elements of the persona (Byrne's familiar theme of the individual under stress) with elements of what literary studies call the "topos", the common meeting place, in its dense texture of individual voice and choirs. And the musical texture is the result of improvisations, audible in the call-and-response patterning of thythms and signals, yet formally structured through the extensive use of recording studio technology.

Critics have compared "Remain In Light" to Picasso's "Demoiselles d'Avignon", singled out by art historians as the paradigmatic culbist painting, also the first painting to combine African and European pictorial traditions. This comparison is helpful: as cubism combines irreconcilable perspectives within a single painting, so Byme, Eno and the other members of the Talking Heads constructed 'songs' that succeed in combining different perspectives on emotion within a single musical texture. The album as a whole suggests that people can be involved as accomplices in their own emotions, even as they try to suppress them, deny them, or appear to be overwhelmed against their conscious will. Most of these characterfields seem to be prey to inner contradictions, but the album also includes a joyous hymn ("The Great Curve") to the transcending and divine power of sexuality and of nature. ${ }^{125}$ Such lyrics can not be rearranged into coherent descriptive stories, but have to be accepted as force fields, groupings of illogical metaphors that sometimes reinforce, but often countermand each other. Some songs can be taken as character portraits, but remain open to interpretations that see them as moods that may be experienced by most people in the course of their life, or as enlargements of fleeting daydream delusions, like the musing lyric to "Seen. And Not Seen": 
He would see faces in movies, on T.V. in magnzmes, and in books.. He thought that some of these faces might be tight for him... And through the years, by keeping an ideal facial structure fixed in his mind... Or somewhere in the back of his mind... That he might, by force of will, cause his face to approach those of his ideal.. The change would be wery subde... It might take ten years or so... Gradually his face would change its shape...

This addresses the media images that surround us, and the task of somehow incorporating them, while suggesting that this task poses dangerous difficulties. ${ }^{26}$ The community presupposed by African drumming is here found in the interplay of personality and mass media.

The song "Once In A Lifetime" is another example of this thematic, clatified further by the videoclip that Byrne made for it. The lyrics to this song describe a form of bafflement, a process of self-reflection that manages to combine everyday routine with a sense of spiritual panic ${ }^{127}$ :

And you may find yourself behind the wheel of a large amtomobile.

And you may find yourself in a beautiful house, with a beautiful wife.

And you may ask yourself - Well... how did I get here?

...

And you may ask yourself: What is that beautiful house?

And you may ask yourself: Where does that highway go to?

And you may ask yourself: Am I right? . . Am I wrong?

And you may say to yourself: MY GODI. . WHAT HAVE I DONE?

Byme directed a videoclip to accompany this song. The clip features Byrne, who is wearing a gray, fifties-style suit with bow tie and dark-framed glasses, impersonating a hybrid between a TV evangelist and someone undergoing religious convetsion. He executes movements that send his body jolting and twitching. Byrne has explained that this physical vocabulary was based on body movements and gestures of preachers and other people who go into trances. Choreographer Toni Basil helped him to formularise those spasms and movements and make them into a dance. As Bytne explained, "It took a lot of rehearsals, the dancing part of it was meant to be a sort of halfway point between dance and a series of muscular spasms."12s Together they had visited the University of California in L.A. to study film footage of different styles of dance, of preachers and of peoples in trance. According to Toni Basil, the movements were more considered as acting than as dance per se. ${ }^{129}$

Byme used a number of devices to put this performance in context. First, the video image of his dancing is mirrored and projected in fourfold as its own background, which formalizes and distances the performance. Second, the motions that Byrne makes are shown to be copied from anthropological film footage of foreign cultures, as the 'original' (authentic?) gestures are periodically shown on a screen in the background, in a didactic style of montage (which, by the way, is 
completely familiax since it is used daily by news magazines). Part of this anthropological footage was taken from "Studies in Nigerian Dance 2" by Peggy Hatper, another sequence came from Japan. Third, Byrne is shown in very short sequences, now against a background of ominously lighted fog, now profusely sweating while his head is steadied by hands that come from above (whose?), now situing quictly, dressed casually and obviously relaxed while lip-synching to his own voice. In a clip of only 3 minutes and 24 seconds, such repeated and diverse contextualizations produce uncertainty in the viewer, an effect that Byme explicitly aims to create: "Lyrically or imagistically ot musically, it's most exciting when you can't quite get a handle on it." 130
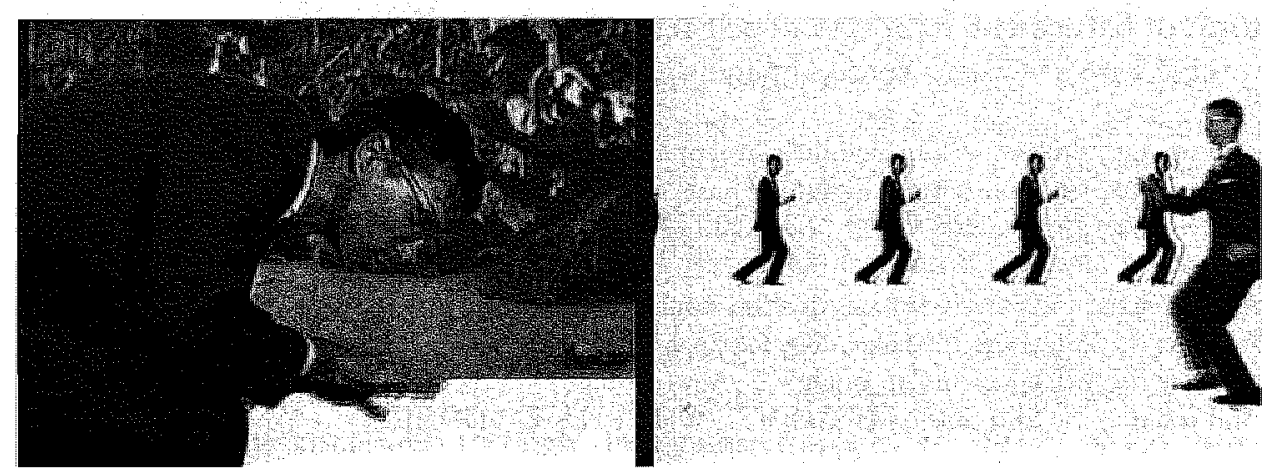

3 Stills taken from Byme's first video clip, for "Once In A Lifetime".

Left: Byme in his ecstatic preacher persona, imitating the African dancers shown in the background (footage from "Studies in Nigerian Dance 2").

Right: Byrne's jerky, near-spastic movenents are highlighted by repeating his image, mirrored and multiplied, in the background.

In this clip, Byrne creates a performative field that is both constructed and spontaneous. The spectator cannot reach a final conclusion about Byme's own position towards his lyrics and other material, and so misses a focus that might enable him to take up a definite standpoint towards the work himself. And yet at the same time Byrne lays bare his sources of inspiration, the artistic devices he uses to overstep the conventions of rock music. His interest in radio and television evangelists had provided him with ample material to reflect on the meanings of publicized emotional performances-something which rock singers have in common with tele-evangelists, who use the media to preach, testify, convert, collect money and even to heal members of their audience, relying fully on the direct effectiveness of their media presence. Byme observed the contradictions in their performances: "Sometimes their delivery is real ecstatic, but what they're saying is so conservative and moralistic. It's hard to reconcile the fact that these guys are going absolutely berserk while they're telling everyone to behave themselves. And 
they re madly raving, jumping all over the place. In that kind of preaching-like in a music piece - as much is said in the delivery and the phrasing as in the words. What's important isn't what's literally being said."'s1

The lyrics of "Remain In Light" should not be taken for direct personal statements, in the tradition of rock as expressive romanticism. It is rather the structural organization of the songs that forms a statement. This organization does not portray spiritual and emotional states as purely individual affaits, but as complex, tempotary compromises that include collective elements. In doing so, the record provides a perspective on subjective consciousness that exceeds the conventions of most rock and pop. Instead of projecting a single strong personal emotion, here personae are presented as problematic unities that struggle to contain several mimetic impulses at once, including projections from the media. ${ }^{132}$ Nevertheless, "Remain In Light" was received well by critics and audience alike." 13.3

The band chose to perform the new songs in live concerts, a decision that was far from obvious since the material couldn't possibly be played live by only four musicians. Because of that, the group invited a number of musicians to join them. Nona Hendryx, formerly of LaBelle, and Dolette McDonald sang back-up vocals; Adrian Belew, who had played with Frank Zappa and David Bowie, played lead and thythm guitar; Bernie Worrell, former member of the influential funk groups Parliament and Funkadelic, played keyboards; Steven Scales played percussion and Busta Jones was the second bass player. The Talking Heads now were an unusual mix of a white rock group with an art background in arts, combined with a black funk band. The band was also composed of men and women-an unusual line up for a pop group, an artistic and political statement in itself. ${ }^{134}$ (Later, there were a several changes in this line-up. In 1982, Dolette McDonald sang the backing vocals alone; later, Lynn Mabry and Edna Holt replaced Hendryx and McDonald. Alex Weir replaced Adrian Belew, and Raymond Jones sometimes replaced Bernie Worrell.) This worked out very well. Tina Weymouth commented: "It was lucky, things falling into place. And l'we never seen a bunch of people so happy on stage." 13 "

David Bytne was even more enthusiastic in interviews: "The feeling onstage is nothing at all like performing rock or pop songs, which relieves me greatly. I think some of the other musicians feel the same way. "Spiritual" is a sort of dangerous word to use because of the western definition of the word, but that is how I describe the music. A lot of spiritual music which has its roots in Africa is very exciting and people have a lot of fun dancing to it. It's casual, too."136 He explained: "There's just less of a feeling of a performer projecting his own ego to a crowd, which rock and roll seems to be about. For me, there's more of a feeling of community - a group of people working and playing together. The kind of thing we're doing now deals with a different series of metaphors than pop music... The nature of the music is to inspire a mystical communion among the musicians and the 
audience through repetitive rhythms and so on. On a good night, it can become a transcendent experience that is mainly to do with a lot of people feeling that they"re locking together and fitting together into one thing which is very different from the other music." 137

Byme delighted in presenting characters that were caught up in contradicting forces within the context of the Talking Heads' music, because the music articulated the possibility of an alternative experience of mimetic projections. During performances the often imitated people in spiritual ecstasy, and as singer he mediated the emotionall appeal of the music. When asked whether as a singer he wanted to assume a spiritual role, Byme replied that he "didn't want to take on the role of being a prophet or a shaman on-stage. That can turn into a caricature that gets hokey after a while. There may be elements of that, but I didn't want to set myself up as a prophet or anything like that. I just wanted to say that we are part of that and so are lots of other people."138 The voices, gestures and roles that Byrne assumes as a singer, borrowed from T.V. preachers, politicians, shamans and a range of others, are simultaneously acted simulations and real personal experiences, and they are used as a humoristic and ironical, critical demonstrations of the human propensity for self-creation and delusion.

\section{ANTHROPOMORPHIC ASPECTS OF MUSIC}

Byme's interest in conceptual approaches that treat individual and community as united by a single musical and mimetic matrix, instead of separating them, has repeatedly been mentioned already. Chernoff's investigation of African music is an excellent example. During the period of their collaboration, Byrne and Eno further investigated the biological and anthropological preconditions of musical sensibility, asking how music does exert its mimetic influence on a person's mood, bringing to the fore specific aspects of a personality, even changing a personality over the course of time. How precisely does musical mimesis affect the unconscious? They looked for answers by reading a number of books that provide an overview of this complex and mysterious field, where biology and neurology mingle with psychology, musicology and anthropology.

Moreover, Byrne began to explore the methods of performance theatre, with its emphasis on the corporeal presence of the actor. He had seen how Robert Wilson constructed his plays, as well as the way the Mabou Mines theatre and the Wooster Group work, and he applied their ways of developing a performance to his own work. ${ }^{139} \mathrm{He}$ also explored the psychological theories of Carl Gustav Jung, who posits the existence of a biological unconscious, shared by all human beings, to explain the dramatic influence of certain archetypical symbols. All these theoretical influences come together in a loose patchwork, a mosaic of ideas abont the anthropomorphic qualities of music that informs Byrne's work. 
Byme and Eno both read and admited "The limperial Animal" (1971) by Lionel Tiger and Robin Fox. ${ }^{40}$ This classic of contemporary ethology combines Darwin's theory of evolution with the insights in human behaviour and culnure that have been developed in cultural anthropology and sociology. Btiefly summarized, this attempt at synthesis states that human behaviour is by and latge characterized by the fact that homo sapiens is a mammal from the order of the primates. Man has evolved further than the other primates because his forebears went out hunting. The demands of the hunt on the individual and on the ribe have favoured the development of the cerebral cortex, which made possible an elaborate language and culture, as well as more complex tools. And that is what we are, according to Tiger and Fox: "We remain Upper Paleolithic hunters, fine-honed machines designed for the efficient pursuit of game."141 They apply the insights of ethology to mankind in order to uncover what they name its Biogrammat": the whole complex of hereditary fixed possibilities and preferences of behaviour. In doing so, they do not claim that man is governed by instinct, or that biological inheritance is mote important that history and culture, but point out that there is a connection between evolution, heredity and culture. "We behave culturally because it is in out nature to behave culturally, because natural selection has produced an animal that has to behave culturally, that has to invent rules, make myths, speak languages, and form men's clubs, in the same way that the hamadryas baboon has to fotm hatems, adopt infants, and bite its wives on the neck."142

It is obvious that human nature makes possible a huge scala of cultures and forms of behaviour: the invention of agriculture, cities and finally industry and out contemporary complex societies. But this historical development is only a moment on the time scale of evolution, which means it has not influenced our hereditary qualities. Human physical qualities, but also our social behavior, emotions, patterns of learning, loving, and hating, were fully evolved before the tise of historical civilizations. "We have to make the imaginative and unsetting leap into understanding that agricultural and industrial civilizations bave pw wothing into the basic wiring of the buman animal. We are wired for hunting - for the emotions, the excitements, the curiosities, the regulatities, the fears, and the social relationships that were needed to survive in the hunting way of life. And we are wired basically on a primate model." 143

Tiget and Fox start from the notion that in pre-historical times the hunt was reserved for men, which has led to a physical but also emotional predilection for this kind of behaviour in men. This preference may be sublimated in economical. activities, but also in music.

It appears still to be the case that the uncertainty and particular sensitivity of the hunt and its metta phor galvanizes men more than women, and boys more than girls. It is the band of men who play music like warriors, who worry a melody, tum it around, pass it back and forth, hide from it altogether, pair up, split up, combine to chase it, come crashing or singing around, and then drive to 
John Cage"s famous "theatre event no. 1", generally considered to be the moment of birth of American performance art. 159

As fits his poetics, Olson's writing is characterized by the wish not to represent anything in language, but to express living or kinetic force as such. ${ }^{160} \mathrm{He}$ opens brackets that he never closes again, writes ungrammarical sentences, interior monologues that feel no teason to adhere to the reasoning of orderly argumentative discourse and rely instead on the non-sequirur and on parataxis ${ }^{161}$. This is $\mathrm{Ol}$ son's description of proprioception, published in 1965:

PROPRIOCEPTTON:

$$
\begin{aligned}
& \text { the data of depth sensibility/the "body' of us as } \\
& \text { object which spontaneously or of its own order } \\
& \text { prodnces experience of, "depth" Viz } \\
& \text { SENSIBILITY WTTHN THE ORGANISM }
\end{aligned}
$$

BY MOVEMENT OF ITS OWN TISSUES

here, then,
the soul is
proprioceptive
even the hard" (solid, palpable), that one's life
is informed from and by one's own literal body-i
...
$1 / 2$ of the picture-what they call the SOUL,
the intermediaty, the intervening thing, the
interruptor, the resistor. The self, 162

Theatre makers have consciously induced proprioceptic changes for their performances, using physical training to produce a specific state of alertness that temporatily transforms the actor. Petformance scholar Richard Schechner gives this description: "The performance text is put into the body of the performer through a training whose bases are integral parts of the performance text itself. Once in the body of the performer, the performance text is manifest during performances." 163 Such performance events can closely resemble religious possession, trance and other ecstatic forms, and several methods have been devised to include such forms in the theatre. Polish director Jerzy Grotowski (1934-1999) is an example of this. Schechner, who has trained with Grotowski, has described his method:

Grotowski believes there are cettain sound, rhythms, gestures, and movements whose effects are "objective" - that is, based on physiological and/or archetypal systems. Heartbeat, breathing patterns, certain pirches and precise progressions of sound, certain facial displays, body and hand positions, and mowements constitute for Grotowski an intercultural or universal performative system. 164

This work includes a rigorous investigation of vartous liturgical and ritual genres-an investigation whose purpose it is to identify in performative terms-that is, in ways that can be taught, repeated, 
and creatively varied-sequences of "objective drama"... Grotowski"s work is intercultural, draning on techniques whose performative/pspcho-physiological basis is shared anong many, if not all, cul tures. 16.5

Schechner has also written about research by Felicitas D. Goodman, who has done neurological and anthropological research into the nature of glossolalia, better known as 'speaking in tongues'. Schechner quotes: "Received wisdom used to hold that there were a number of different religious trances, but since the early 1980 s, researchers have come to realize that there is only one neurophysiological change which underlies a number of different religious experiences." 1 \%6 Goodman writes about glossolalia:

I discovered that these nonordinary utterances, often but not always without any semantic content, shared certain remarkable propercies. These traits, such as accent and intonation patterns were not related to the native tongue of the speaker: Americans, Japanese, and Maya Indians, for instance, all exhibited them in the same way. I came to the conclusion that they were nonlinguistic in ortigin instead of obeying rules of language, most probably were caused by the striking bodily changes that I oloserved in speakers in tongues. ${ }^{167}$

According to Goodman, the 'tongues' patterns are not only unrelated to specific languages, but are also not related to religions in the ideological sense. This means that people ate not made to speak in tongues by their beliefs, the opposite is true: the speaking in tongues is driving religious belief.

Such perspectives on human behaviour have an immediate relevance for Byme's work. He has explained his interest in religious behaviour in these words:

It has a huge influence on human behaviour. It is at the root of a lot of economical and social behaviour. The kinds of music that are made today ate based on religious music. Ant in principle is religious ot spiritual. And yet the source, religion in itself, is almost bankrupt. It has lost ts meaning to many people. At a certain moment we have stated to belicve that things like rituals were for primitive people and that we might get rid of things like that through science, and might neglect them. But finally it turned out that we have simply replaced them by new things: science, pop music, art ... communism (grins). But the structures and images that religions have produced are still there...

You might say that the creative process, the music, has become my teligion. Perhaps I am somewhat nave in that way "but I believe intensely in the enormous forces and influences of music. $^{108}$

And he has said about the process of improvisation and refinement that underlies all kinds of performances: "T could see that gospel preachers had refined a sermon over many performances so that it would bridge into a song... Jazz musicians" spontaneous improvisations grow out of years of practice... I could see it in the most gut-wrenching and moving acts; the performance had been-sometimes unconsciously- worked over. This isn't cynical. It's a process that is built into our organism, a kind of learning curve."' 6 ? 
The last influence to be introduced briefly here is C. G. Jung's theory of the collective unconscious. Jung posits the existence of a biological unconscious, collective unconscious. As Jung postulates, "The psyche is not of today; its ancestry goes back many millions of years. Individual consciousness is only the flower and the fruit of a season, sprung from the perennial rhizome beneath the earth; and it would find itself in better accord with the truth if it took the rhizome into its calculations." "170 According to this theory,

Creative fantasy also draws upon the forgotten and long buried primitive mind with its host of images, which are to be found in the mythologies of all ages and all peoples. The sum of these images constitutes the collective unconscious, a hetitage which is potentially present in every individual. It is the psychic correlate of the differentiation of the human brain. This is the reason why mythological images are able to arise spontaneously over and over again, and to agree with one another not only in all the corners of the wide earth, but at all times. As they are present always and everywhere, it is an entitely natural proceeding to telate mythologems, which may be very far apart both temporally and ethnically, to an individual fantasy system. ${ }^{m}$

Jung found that the mythical fantasies which arise out of the unconscious serve a real purpose, since they are the origin of thought which is directed towards reality. Archetypes and mythical symbols may help to achieve this inner development, as well as a successful passage through the transitions which everyone has to achieve in life, going from childhood to puberty, from maturity to middle and old age. Byrne has repeatedly applied these ideas in his work, as the following fragments from an extensive interview by art critic John Howell make clear:

Howell: Remember the classic book everybody was reading in the sixties, Man and his Symbols by Carl Jung? On one page you'd see an East Tennessee snake handler, on the next a witch doctor holding a snake in his hand.

Byme: Yeah. It's great to do that in film or video, because you get a real visceral sense of it. . . .

Howell: Sotme people may feel that it's surface culturemongeting, that as you develop a deeper understanding of different cultures you tealize that you can't match them up just because a certain witch doctor has something in common with Emest Angley [a televangelist], who is definitely a product of advanced Western capitalism.

Bytne: But I like a lot of it. For me, it put things in perspective. .. I mean that I can look at a move or something and see how the various archetypes are being used. ${ }^{172}$

The following sections will show in detail how Byme included notions of the anthropomorphic aspects of music, art and ritual in his work.

\section{ARCHETYPICAL CONFLICTS: "WE'RE GOIN"BOOM BOOM BOOM"}

After recording "Remain In Light", the members of the band turned their attention to different projects. Jerry Harrison tecorded a solo album "The Red and the Black". Chris Frantz and Tina Weymouth, who felt that the conceptualism 
of Eno and Byme was exaggerated and ostentatious (Weymouth told the press: "I didn't read those books"173), started their own band, the Tom Tom Club, aiming to be as unpretentious as possible. Their happy and simple sound was a success. "Genius of Love" and "Wordy Rappinghood" were hit singles, and their first al bum sold more copies than any previous Talking Heads album.

Byrne had meanwhile accepted a request by choreographer 'Twyla Tharp to create a scote for a full-length ballet. The general theme of the ballet was to be humanity's capacity for estrangement, with topics like a horrible family, nuclear annihilation and paradise lost-paradise regained 174 . The commission provided Byrne with an opportunity to write music and songs without the constraints of the pop-song format, and with ample room to deal with archetypical conflicts within both the family and society. The ballet was performed on Broadway in the fall of 1981; the accompanying record, "Songs from the Broadway Production of The Catherine Wheel", was Byrne's first solo album; it was also a continuation of his experiments with African music as a model.

A commission to compose and record ballet music naturally sets its own demands. Tharp, who had set choreographies to music by the Beach Boys and other pop groups before, explicitly wanted to avoid having her dancers always moving to a straightforward beat, as that would be constricting and predictable. ${ }^{175}$ Byme would provide rhythms for Tharp to try in rehearsals, or reversely watch a finished section of the dance and write music that would give the impression of generating that movement. Moreover, he invited John Chernoff, the author of "African Rhythm and African Sensibility", to collaborate on the score. Chernoff played a variety of drums and percussion instruments on half of its twenty-three sections; he incidentally played piano and guitar as well. He was credited as co-composer for four sections of the ballet, including the song 'Big Business'. What Byrne and Chernoff made, was a simplified version of African polyrhythmic music, to achieve a strong connection between music and dance that opened up room for choreographic freedom. According to Byrne, "there were so many rhythms going on that, no matter which way the dancers moved, they seemed to be connected with the music. It wasn't a simple four/four boom-thud, boom-thud." "176 Chernoff later told about their experimental way of working, influenced by John Cage's prepared piano: "On "Big Business", I played the parts of a drum orchestra with pencil erasers on a guitar while [Byme] worked the frets. On "Combat", I played the parts of a different drum ensemble on a piano he had modified by wrapping masking tape around some of the strings. I could deal with any of that, but I realized that even the pop musicians I knew in Africa, who were so interested in developing a sound which could cross the ocean, might have been perplexed." "n?

The instrumental sections of the album show Byme's limitations and strengths as a composer. The musical texture consists of layer over layer of small, thythmic impulses. Drums and percussion as well as bass, synthesizers and guitars all have a 
thythmic function as well as - often a suggestion of melody: not quite a tune, but two or three notes that suggest a direction, comparable to the way a large number of small compass needles can indicate the curve of a magnetic field. Every instrument is given its own accent and colouring, its own pulsating, often nearvocal qualities. Most important is that every instrument, every sound almost, functions not only as a part in a musical texture but also can be perceived as a performative or proprioceptive suggestion. Byrne's grasp of music is not that of a classically trained composer, a talent he has never claimed; but his music demonstrates an ability to perceive music simultaneously as an independent structure and as a subjective driving force.

This is most clear when the suggestion of a musical persona is strengthened by singing, when voice and lytics allow the listener to identify with the musical intention. In most popular music, melody and thythm function solely as support for this level, the singer conveying his or her emotional persona. In Byrne's songs of this period, everything is organized to eradicate the distinction between singing and music. This continuity is achieved by alternating the singing with vocalizing, by organizing the vocal melodies in the short thythmic fragments, and by giving intimate, voice-like qualities to most instruments. Not the vocals alone, but the whole musical texture functions as the song's persona. Byrne described this as follows: "The sound of the singing, the sound of the instruments and the sound of the thythm, all those sounds together open a door through which the text can enter. In fact, when that door is not open, the lyrics do not matter very much."178

One of the songs of "The Catherine Wheel", "What A Day That Was", contains a description of a mythic, archetypal conflict. To the lyric have been added, in italics, Byrne's wordless vocalizing and shouting. The orthography, as printed on the record sleeve, is vernacular, stressing that this is the notation of a voice:

Well I'm dressed up so nice

An' l'm doin' my best

Yes I'm startin' over..

Startin' over in another place

Lemme tell you a story

Big chief with a golden crown

He's got tings on his finger

And then he walks up, up to the throne

He's makin' shapes with his hands

An' don't choo dare sit down

Now don't choo date jump back

And don't choo date stick out!

And on the first day, we had everything we could hold

Ooh and then we let it fall 
And on the second day, there was nothing else left to do Oola what a day that was.

$$
a a-b a a c a .
$$

There are 50,000 beggars

Roaming in the streets

They have lost all there possessions

They have nothing left to eat

Down come a bolt of lightning

Now an electrical storm

Starts a chain reaction

Go pull a fire alarm

Im dreaming of a city

It was my own invention

And I put the wheels in motion

A time for big decisions

And on the fitst day, there was nothing else left inside Ooh what they were looking for.

And on the second day, I had everything I could stand

Ooh what a day that was.

Ob a day that was.

Oob that's the way it goes

There's a million ways- to get things done

Thete's a million ways-to make things work out.

$$
\text { oxom-baa-baa. i i whóá abbaba }
$$

Well T'm going right through

And the light came down

Well they're roundin' em up

from all ower town

They"re movin' forward and back

They"re movin' backwards and front

And they'te enjoying themselves

Moving in ev'ry direction

So if you feel like you're in a whirlpool

You feel like going home

And if you feel like talking to someone

Who knows the difference between right and wrong

And on the first day I had everything all at hand

Ooh who could've asked for more

And on the second day there was nothing left we could hold

Ooh-what a day that wats.

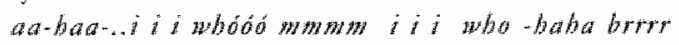


Were go(in) boom boom boom That's the way we live And in a great big toom and That" the way we live. [tefrain repeated four times]

a $a-h a a l$

This text has some remarkable formal characteristics. First, there are repeated shifts in its implied perspective, as shown by the pronouns shifting freely between "I", "you", "we", "he" and "they". The perspective also shifts from solitary musings to storytelling, from factual observation (in the beginning of the 1980's, the number of beggars in New York City was indeed estimated to have reached 50,000 ) to dreaming. The distant present of a mythological "big chief with a golden crown" mingles with the here and now, as if all of mankind's history is relevant to the interpretation of every single event within that history.

That this effect is indeed intended, seems to be affirmed by the way every persona within the song is characterized by gestures and postures: one is dressed up nice, makes shapes with one's hands, avoids jumping back and sticking out, lets fall what one holds, and roams through streets. "Well I'm going right through / And the light came down" also appears to evoke an intuitive experience, as does "They're movin' forward and back / They're movin' backwards and front / And they're enjoying themselves / Moving in ev'ry direction". Such gestures are appropriate for a ballet; moreover, they suggest that such experiences have a ritual, proprioceptic basis that belongs to the human condition.

In the last quatrain, the dizzying shifts of perspective, time and space, result in moral confusion. "So if you feel like you'te in a whirlpool / You feel like going home / And if you feel like talking to someone / Who knows the difference between right and wrong" - this asks for reassurance, but the lyric has only a riddle to offer as its conclusion: "We're go(in') boom boom boom/ That's the way we live/ And in a great big room and/ That's the way we live."

"This chorus is emphasized by a fourfold repetition, but even more by its rendition. While the whole song is accompanied by an engaging rhythm that supports the singing, as well as by choir-like synthesizer-sounds that highlight Byrne's vocal, now his singing is intertwined with distupting, plaintive synthesizer accents. This indicates that 'going boom boom boom' is not just dancing to a strong rhythmic pulse, but rather like being thrown from one side of a room to the other, or of repeatedly being thrown out of perspective-berween a paradisiacal "first day" and a catastrophic "second day", or between the position of a king and that of a beggar.

This may amount to a conclusion-put into words, it would be something like: however disrupted, the situation is still open. Perhaps Chernoffs book has again been a source of inspiration here; where he writes that, within the development of Afro-American styles, songs continue to serve as guides in practical philosophy to 
the people who listen to then ${ }^{179}$, in his footnotes he quotes a most appropnate observation made by R.F. Thompson:

When Just Barreto wrote the Newspaper Sbirt nambo in 1950 he succeded in capturing what it felt like to live in the fifties. The scene is Mexico City in June 1950. A Negro man has fashioned himself a shirt out of newspaper. He studies the material of his shirt, and the cloth of scare headines frankly worries him. His shirt tells ham war is raging in Korea, and he summarizes the news with onomatopoeia: BEEM! BOMB! BOME! BOOM! Perez Prado [who recorded this song] undercuts his anxiety with a piano solo which tinkles with insouciance. Air taid sirens sound. In the heart of the crisis, the mambo builds up and, to a cowbell-stressed thythm, blasts out its most affimative sounds. The man chants praise of his shiit, a chorus answers in call-and-resporse fashion, and the mambo ends. A capsule allegory; the man does not recoil in fear though he is sensibly alamed. 'Look,' he says, 'life is delicious and to be savored in spite of doom. "190

Even though the perspective of Byme's lyric shifts time and again, there is no real development. The different aspects combine to form one 'inner theatre': when the song ends, the result is a sketchy outline. Again, this reveals how for Byrne the essence of music is not the inner development of musical themes and forms, but rather a medium for personal and social experience, dramatic as much as musical. ${ }^{181}$

\section{PERSONA AS MIMETIC TEXTURE: "SPEAKING IN TONGUES"}

The fifth Talking Heads album; "Speaking In Tongues" (1983), continued to develop the style and thematic of "Remain In Light" and "My Life in the Bush of Ghosts". It was, by the way, the first Talking Heads album to sell more than a million copies in America. ${ }^{182}$ Once again, the music is a dense and funky texture of small rhythmical motifs, interspersed with a good many quirky accents. "This time, however, it is unified by a relaxed and steady beat, and Byrne's singing voice is less strained. The songs once again have a conventional chorus and verse format, and are no longer built of overlapping choirs. The resulting sound is less rigorous, hectic and intellectual; the album breathes a direct and lytical atmosphere. Part of the explanation for this is that Brian Eno was no longer involved: the album was produced by the four original members of Talking Heads, making all the music together. ${ }^{183}$

"Speaking In Tongues" was recorded in the studio, but benefited from the experience of performing the material of "Remain In Light" live: these new songs were meant for live performance from the start. Looking back on his studio experiments with Eno, and comparing them to his later experience of playing live with excellent funk musicians ${ }^{184}$, Byrne reflected:

To some extent, we were rediscovering the whecl. I mean, we listened to a lot of travel music and worked on things by layering little pieces of thythm and sound and building up a thythm piece by piece that in the end sometimes sounded like one good funk drummer, or one medrocre funk drum- 
metl But it's very different to discover something by starting from the bottom and re-discovering it and purting all the pieces back together than by looking out the window and just seeing. It's like kids who take their car engine apart and then put it back together again. You have a very different relaconship with the automobille if you"ve done that than if you just look at an old cat and go, "that's a great cat."

Byme's new songs still operate within the dramatic-musical field that is characterized by the oppostitions of persona and topos, of solitary voice and community (or choir), of improvised social exchange and fixed herarchy; but the rendered experience is as passionately heartfelt as the voices in raptute on "My Life in the Bush of Ghosts". This passionate, yet rehearsed spontaneity is the underlying theme of the album.

Brian Eno has told that to him, "My Life in the Bush of Ghosts" was "basically a technical exercise in using pre-existing vocals 'to see where that takes us'.... It wasn't a conscious decision when we started doing the album, but we nearly always found that the vocals that sounded the best came from spiritual or religious sources. It's one of the only abvious places on radio where people are passionate. On radio, people train themselves to be cool, monotonous- to be in control. The only voices you hear that aren't like that are voices in a passion about something, and on radio that nearly always means religion. Those were the most interesting voices on radio. Gradually, we started to notice that the album was shaping up to have that identity, so it became a conscious decision to work on it that way, with that spirit running through the album."18\% Byrne explained about the meaning of the used found vocals, many of them in foreign languages: "The vocal can be quite moving without literally meaning anything. That alone implies a lot: the phonerics and texture of a vocal have their own meaning. I'm sure no one would disagree with that, but most people tend to think that lytics are most important.... A lot of people don't realize that the sound of a voice, phrasing or phonetic structures are affecting them at least as much as the words. Usually lyrics that are a little bit mysterious, that don"t quite come out and say what they mean, are the more powerful. They deal with things in a metaphysical way."187

This outlines the task that Bytne set himself when writing the lytics for "Speaking In Tongues": to compose words that would allow him to convey with credibility a series of passions, a number of personae "moved by an inner spirit' or in a state of emotional transport that are beyond literal expression. The expression "speaking in tongues" of course takes its meaning from the Biblical story of the day of Pentacost. 18 . Bytne has commented at length about 'speaking in tongues' and about the lyrics he wrote for the album:

The expression "speaking in tongues' also implies an unknown, unexisting language. And I am trying to find a new language for songs. I don't consider lytics to be like poetry, they are a completely separate discipline.. 
1 belleve that people who spieak in tongues are in a certain sense very happy that they are able to do something like that It gives them an inner peace. It makes them feel somehow to be at one with the universe, or something like that. It does not matter how idiotic that may seem; when it works for them, who can tell me it is wrong....

I am trying to use a kind of language as it occurs in mythology. Almost as if that language is a kind of code. As if someone were reading a magical text, using it to conjure an event. This tine, I hate concentrated on the lyrics more than ever befone; I'we worked harder on whem than for "Remain In Light".

On most songs of "Speaking In Tongues" I wanted to show that you could use texts that fiterally made no sense at all. Groups of words that depicted something or evoked a certain mood or feeling. That was rather difficult, but I considered it to be an interesting challenge. It meant the words had to fit together on a purely auditive level. You had to extricate yourself from the idea they had to mean something, they went beyond that. ${ }^{190}$

A song that refers directly to glossolalia and "holy rollers" is "Slippery People" (holy rollers" is the nickname for Pentecostalian ${ }^{191}$ Christians, because their glossolalia often goes together with writhing movements on the floor):

what about the ume?

you were rollin' over

fell on your face

you must be having fun ...

put away that gun

this part is simple

ty to recognize

what is in your mind

God help us!

help us loose our minds

these slippery people

help us understand

[chorus:] what's the matter with him? he's altright
I see his face the lord won't mind
don't play no games
love from the bottom to the top
$\begin{array}{ll}\text { turn like a wheel } & \text { he's alright } \\ \text { see for yourself } & \text { the lord won't mind } \\ \text { we'te gonna move } & \text { tight now } \\ \text { turn like a wheel inside a wheel }\end{array}$

Byrne explicitly differentiates his lyrics from traditional, written poetry. He wrote and sang them to be very pliable, to the effect that they "seemed to sink into the music, to color the sound without assigning literal meaning"12?.

The songs on Speaking In Tongues are designed to convey a range of archetypical emotions. Loose, metaphorical phrases and slogans suggest such states. 'To 
render these lyrics; Byme added many effects to his regular tather unsteady high tenor, contrasting it with a dramatically deep and strained voice, and with whispers, shouts, moans and such. The songs do not necessarily convey mental states as specific as glossolalia or trance, but suggest ecstatic moods: falling in love head over heels in "Girlfriend Is Better"; trasting love in "This Must Be The Place (Naive Melody)". Although this is the most direct and intuitive love song that Byme wrote-in interviews he dedicated it to his wife-its lyric is also a deliberate construction: the line "Sing into my mouth" was based on a picture of Eskimo's singing into each other's mouths, an image Byrne found extremely beautiful; another line, "You've got a face with a view", was a conscious attempt to connect a face to a landscape, suggestive of the love of nature expressed by nineteenth-century landscape poetry. ${ }^{193}$

These songs do not present individual characters, but elementary and easily recognized emotional states. Exuberance in "I Get Wild / Wild gravity" and "Pull Up The Roots"; overburdening guilt in "Swamp". This song is Byme's version of Mabou Mines" theatre production "Dead End Kids: A Story of Nuclear Power". Byrne's contributed a score to the film that was later made out of the play; it will be discussed in a later chapter.

The lyric of "Pull Up 'The Roots" may be heard as an expression of Byrne's own excitement while performing these songs:

coloted lights and shiney curtains... I'll take you there, I'll take you there ev'rything has been forgiven ... pull up the roots, pull up the roots

well I have a good time ... when 1 go out of my mind and it's a wonderful place ... and I can't wait to be there and I hear beautiful sounds ... coming outa the ground. gonna take us a whille ... but we'll go hundreds of times

"The song that opens the album is an energetic funk song, titled "Buming Down The House"; Byrne designed and directed a videoclip for this song, which was a thit single "The lyric begins as follows:

watch out you might get what you'te after

cool babies strange but not a stranger

I'm an or-di-na-ry guy

burning down the house...

There's your ticket pack your bags time for jumpin" overboard the transportation is here

close enough but not too far, maybe you know where you are

fightin fire with fire 
Byrne's own comments on these lines: "The phrase "burning down the house" I first heard at a P-Funk concert, I think. And I think I might have misheard something else, but that's what I thought I heard. It seems to me to imply letting go, and giving it up, tearing things up. It's kind of an old idea, that to transcend things you have to smash them. In this case, burn them up!"195. Theorist Dick Febdidge has noted that the video for "Burning down the House" works within a explicitly Jungian framework. In a BBC television interview, Byme explained:

The symbollism of the song's title (Buming down the House) was about projection and projected imagery, it symbolised rebirth and destroying some sort of transitory personality, and shedding a shell and coming out with a new one... So on one level, the wideo is about that and it's about one group of performers, us, being substituted by another, by a group of impostors. I get replaced by a little kid and the others get replaced by other people... the use of projection, a lot of projected images... is about one personality or one image being lagered on top of another... That was meant to be the subliminal basis of that video. ${ }^{196}$

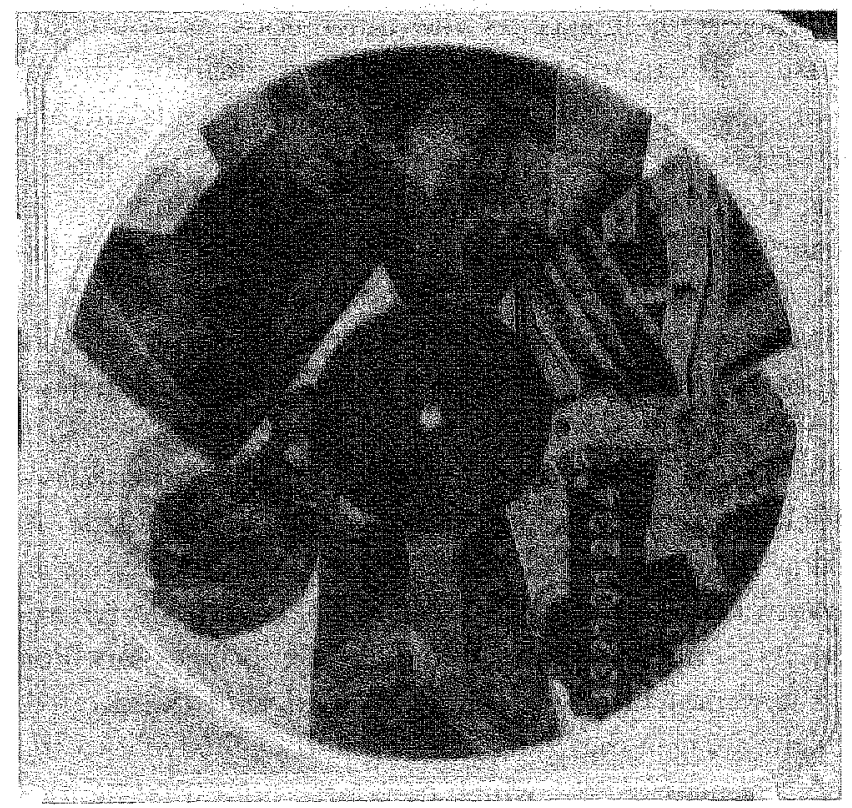

4 Robert Rauschenberg's cover for "Speaking In Tongues".

On Byrne's request, Robert Rauschenbetg designed an album cover for Speaking In Tongues: a circular collage of colour photos, separated for puinting in its com ponents cyan-blue, magenta-red, and yellow. The blue separation is printed on the back of a transparent plastic record sleeve, the yellow on the front, and the magenta on a plastic circle that is riveted to the sleeve but can be revolved. This cre. 
ates a 'dial-a-picture' system, as the photos on the red component have been shuffled so that one has to turn the added part of the sleeve in order to get a clear, full-colour picture of a part of the collage. The photos that Rauschenberg used for his collage ate a random selection of arbitrary objects like a bicycle and a garden hose, and of photos from magazines; advertising and the like. ${ }^{197}$

This collage is programmatic for Byrne's work at the time. Rauschenberg is a living emblem of a tradition that was relevant to Byrne: the Black Mountain experimental approach of Cage, Rauschenberg, Cunningham, and Olson, as well as the anti-formalism of the sixties and of the theme of circulation between high art and public media. As critic Brian O'Doherty has written about Rauschenberg's work, it "introduced into the museum and its high-art ambience not just the vernaculat object but something much more important, the vermacular glance... The vernacular glance is what carries us through the city every day, a mode of almost unconscious, or at least divided, attention. Since we usually are moving, it tags the unexpected and quickly makes it into the familiar, filing surpllus information into safe categories. Casually self-interested, it accepts the miraculous as routine... Everything is close up, in transit... It can tolerate everything but meaning (the attempt to understand instead of recognize) and sensory deprivation (voids and absences). It is superficial in the best sense." 198

The parallel to the Talking Heads' songs is obvious: as the photomontage is turned to form now one image, now another, so the songs slip from one halfecstatic mood into an other, from one archetypical (and thus quite common) worldview into the next. 'This suggests an everyday universe of commonplace myths, subjective states that are most of the time not registered consciouslyByrne's predominant theme.

However, in the end only 50,000 albums were issued with Rauschenberg's cover, because it was too difficult to reproduce in a larger edition. Byrne came up with a clesign for the remaining million-or-so albums sleeves: a painted circle in the center, with photos of overturned chairs in the four corners. His design resembles a (Jungian) mandala. According to Jung, mandalas symbolize "nothing less than a psychic centre of the personality not to be identified with the ego"199, and they are "concerned with the images that refer directly and exclusively to the new centre as it comes into consciousness" 200 - which of course quite fits the idea of 'speaking in tongues'. Jung even describes a mandala, as seen in a dream, which corresponds closely to Byrne's cover design: "A circular table with four chairs round it. Table and chairs are empty." 201 The interpretation that Jung provided for this mandala is, that this mandala is not yet in use'.202 The formal quality of Byrne's montage, with its combination of photography and painting, does not correspond directly to Jung's concept of an image that refers directly to a psychic centre that emerges from the unconscious. And yet: what could be more fitting 
for an attempt to present archetypical textures in an album of recorded pop songs, to make them accessible for everyone's understanding? 


\section{CHAPTER 3}

\section{Film and performance theatre}

\section{A CONCERT IN THE CINEMA: "STOP MAKING SENSE"}

Insofar as music is purely auditive, tecords and $C D$ 's are a great medium to capture and distribute it. But when 'music' is meant to include dance and drama, purely auditive media can reproduce only a segment of the entire performance. During the $1980^{\prime} \mathrm{s}$, Byrne turned increasingly towards film and theatre, since are able to include this wider range of performance modes. The combination of film with popular music brought the Talking Heads, and especially Byrne, their greatest popularity, and it also allowed Byrne to experiment with the working methods of the performance theatre hat he admired. On the other hand, since filmmaking in general is much more expensive than the process of recording music, the economic pressures of the film industry almost exclude artistic experimenting, as Byme would learn by experience.

When the Talking Heads had expanded to a group of eight or nine musicians, they gradually elaborated their live concerts. The Tom Tom Club usually opened concerts, with a short set of infectiously rhythmical songs that were simple, playful and refreshing. The Talking Heads then played a selection of songs that spanned their development, from the tense rock of their early years to the thythmic complexity of "Remain In Light" and the lavish funk of "Speaking In Tongues". On stage, the musicians were arranged in two lines, with drums, percussion, and synthesizers elevated on black risers in the back of the stage. This sober, formal presentation was designed to showcase the dramatic aspects of the concert and the songs that were performed. Byme had developed a number of routines that acted 
out the personae of his songs; now by jogging in place, now by singing through a megaphone to give his woice a tinny and distant sound, or by skipping with an imaginary rope, and running around the stage, disappearing behind the black risers to come out again at the other side.

In 1983, Byrme worked with theatre director Robert Wilson: he contributed a musical score to Wison's international performance theatre project "the CIVIL wars". He had been following Wilson's work for some time. In 1976, "Einstein on the Beach" had impressed him because of its deliberate slowing down of time, and because of its sense of theater as a plotless environment, an atmosphere you can leave and teturn to in the course of the performance." In his productions, Wilson regularly separates the wisual elements from text and music. He then uses extremely detailed and formalized lighting to single out and frame the movements of a single actor, or to present a single prop or a backdrop in exquisite, individual light. For the Talking Heads' 1983 U.S. tour, Byme used some of Wilson's methods. He approached each song as a little play, with its own lighting design, and devised a little, intimate dance that he did together with an upright lamp.

The show was ready to be captured visually, and Byrne felt that cinema would be the right format. When the band was approached by director Jonathan Demme with a proposal to make a documentary concert film, Byrne jumped at the opportunity. The band was able to provide the necessary budget of $\$ 1,200,000$, and the film, named "Stop Making Sense", was shot in December 1983, cluring four concerts at the Pantages "Theatre in Hollywood.

The idea of the film was to give a cinema audience the best possible experience of the concert as such. Abstractions were avoided. No dressing room interviews, no glances behind the scenes of a touring band, no comments from roadies, fans of tout manager. Demme also used restraint in shooting the fllm, using long takes of musicians instead of countless quick cuts, and avoiding artificial ways to create excitement and involvement, such as special effects and regular cutaways to an enthusiastic audience." Instead, he presented the musicians as if each were a character that revealed itself in the course of the film, and the band as a group of people with its own patterns of interaction. To help establish their individual identities, he filmed most shots of the musicians from fixed positions, thus creating a series of stable perspectives for the film's audience.

Demme used the many perspectives on the stage that were provided by several cameras to highlight the interaction between the musicians, their intense concentration and pleasure in making music. By not always zooming in on a lead solo"s, showing another musician's responses to that solo instead, the film presents the band as nine diffetent characters enjoying themselves together. Byme in particular clearly has a lot of fun on stage, dancing with the others, mimicking their movements and being mimicked in turn. Even while the cinema audience misses the direct crowd experience of the live concert, it is presented with a more direct, in- 
timate and close-up experience of the band than it would be able to have during a regular concert. Because of this, "Stop Making Sense". was widely hailed as the best rock film ever made, and won the prize of America's National Society of Film Critics for best documentary of 1984 .

There is a second aspect to the film. Byme had thrown himself into finding gestures for his song personae, bringing to bear his growing experience with performance theatre, and even inviting director Joanne Akalaitis of New York's avant-garde theatre Mabou Mines to come see the band's rehearsals and to give him advice. ${ }^{3}$ Typical for the anti-illusionary approach that is often characteristic of performance theatre is that the film openly shows the stagehands, slide projectors, screens and light assistants that are used during the concert. The grossly oversized white suit that Byme wears during the second half of the concert is also designed to make Byme explicitly look dressed up.

Another performative addition: for the second half of "Stop Making Sense", screens were lowered behind the band, on which three billboard-size slides could be projected next to each other. Most of these projections combine three isolated words or groups of words: DOLL FACE | PUBLIC LIBRARY | ONION, and: VIDEO GAME | SANDWICH | DIAMONDS; later followed by indications of time: BEFORE | YOU'RE | AWAKE, by photos of arms, buttocks and knees, cityscapes, bookshelves. These words and pictures are not introduced and remain unexplained. They draw attention, but withstand attempts at interpretation; they only serve as a reminder that here, as in life, a great deal of potential information necessarily remains undigested and not interpreted.

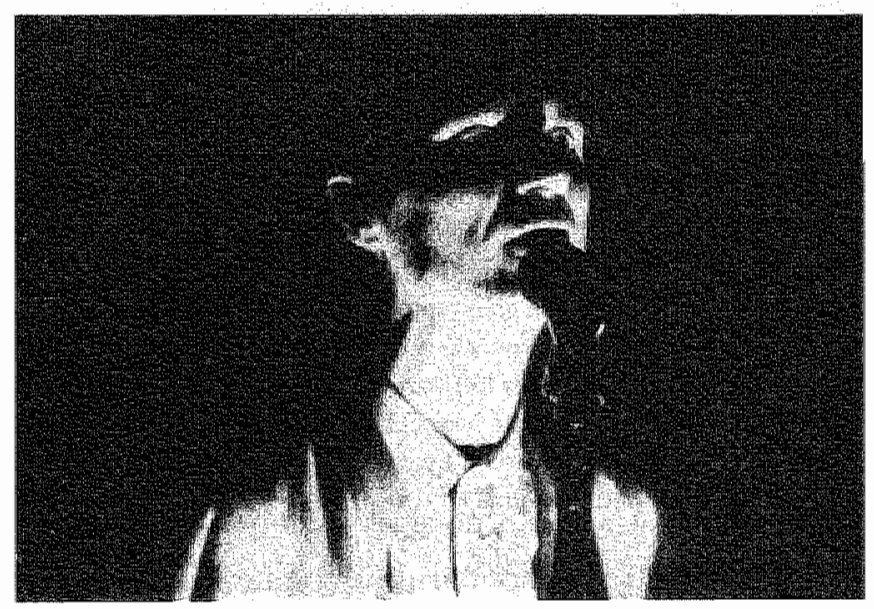

5 Byme's face illuminated to present a ghost-like mask. Photo Hugh Brown / Dave Friedman, from the booklet that accompanied the "Stop Making Sense" album. 
But the central performative aspect of "Stop Making Sense" is the way in which Byme represents the personae of the songs. In "Psycho Killer", "Swamp" and "Once In A Lifetime", Byme stumbles and staggers actoss the stage like a buffeted rag doll, as if thrown about by some irresistible mythical force. During "What $A$ Day That Was", lighting from underneath transforms Byme's face into an archetypical mask, made up out of loose parts: chin, mouth, underside of the nose, and eyes form an impersonal, skull-like face that shudders and trembles. A similar effect is produced when the band is sillinouetted against a backdrop, creating the illusion that there are two bands: one of shadowy giants and another of tiny humans. Towards the end of the movie, Byne's personae find more happiness, in songs like "This Must Be the Place (Naive Melody)" and "Girlfriend Is Better". All in all, this development suggests an abstracted story of a man who is overwhelmed by outside forces and suffers an identity crisis, but somehow finds a way of dealing with it through the music, and achieves a kind of ballance. As told by Byme: "the implied story... was of this man who frees himself from his demons and finds release and salvation in his big suit.. He can cut loose in this house made of a business suit." "4

The film begins with a close-up of Byrne's shoes walking on stage. He sets down a boom box and switches it on; it produces a mechanical beat. Byrne then starts strumming his guitar, and launches into "Psycho Killer"-but later in that song, while he moves around the stage, he lets himself repeatedly be thrown off balance by the very thythm he started. Starting with this opening scene, the film clearly deals with simulated and self-inducted psychosis. Art critic Carter Ratcliff has singled out this aspect:

[Byme insists that] in a world of institutions, "lifestyles', and scenes designed to absorb the self, all selves with even a trace of authenticity must acknowledge that they are-but must also object to being-patched together. Selfhood is a state of resistance to the seemingly natural fate of absorption. Its first tactic is to admit that singulatity lives by means of artifice: images, fictions, thetoric. Next, the surviving self must acknowlectge the shakiness of all that artifice constructs.

Near the end of "Stop Making Sense" ns shadow appears against the back wall of the stage-it is Byrne's body distorted by the light beam's angle. Then the giant suit looms into view, at least doubling the wolume of his body, and you realize that the shadow was a distortion of a distortion. During a big-suit song, "Once In A Liferime," Byme arranges his left hand in the form of a duch"s head and quacks it at his own face. "How do I work this?" asks the lyric. The singer is asking about himself, the creature he has invented for use in the world. Enforced by suit, stage, and camera lens, the general fatness insists that Byme's self-images are definitely images, if not so definitely selves. ${ }^{5}$

"Stop Making Sense" succeeds in capturing such duplicitous combinations of musical enthusiasm with delusion and disillusion. The film demonstrates how enthusiasm and other forms of possession are not just artistic illusions, but form the ritual aspect of the interactions of the individual with his surroundings. Byme had always approached songwriting as if he were making small mimetic atena's, theat- 
tical performances in which voices and thythms confront each other, interact, and sometimes harmonize. From now on, he would repeatedly tairn to film as a medium that allows to elaborate and clarify such performances:

When nine songs of the Stop Making Sense soundtrack were issued as a live record, Byme added to the album a series of statements that he wrote with help of Michael Hodgson and Jeff Ayetoff. These statements circle around performance and music, questioning them from irregular perspectives. These are some examples that deal with music:

TIPS FOR PERFORMERS: Singing is a trick to get people to listen to music for longer than they would ordinarily. There is no music in space. People will pay to watch people make sounds.

IIIE ON EARTH: People look ridiculous when they're in ecstasy. Sound is wotth money.

THE SPACE PEOPLE: The Space People think factories are musical instruments. They sing along with them. Each song lasts from 8 a.m. to 5 p.m. No music on weekends.

IN THE FUTURE: In the funtre, lowe will be taught on television and by listening to pop songs.

Such statements invite the reader to consider the meaning and the function of musical performance, and suggest that neither is quite as clear as it might have appeared. The back of the album cover bears a series of questions, recalling questions for an interview with Byrne, but one to which no answers are provided. The opening question reads: "Why "Stop Making Sense"?

The development of the Talking Heads was summed up so definitely by the film that after the "Speaking In Tongues" tour, they would not play live again. When the other band members asked Byrne to tour with the songs of his film "True Stories" in 1987, he came up with a proposal for concerts at drive-in movie theatres, that would have actors come onstage between songs; ${ }_{3}^{\text {"6 }}$ suggestions that the others did not take to. After "Stop Making Sense", Byrne would be as much engaged in the dramatic, ritual and visual aspects of performance as in the purely musical.

A CONCERT PUT IN CONTEXT" "TALKING HEADS VS. THE "TL I EVISION"

Because Byme felt that the Talking Heads' concerts were somewhat cinematic, and deserved the sound quality, the large screen, and the concentrated audience that the cinema provides, he did not want to put the show on television as it was.? When British television director Geoff Dunlop proposed making a television documentary about a Talking Heads concert, Byrne accepted and collaborated as an artistic advisor, determined to address the specific qualities of television. He had always been interested in 'TV, had written a song about a couple that is dissatisfied with the offered programmes and responds by making their own life and relationship into a TV show ("Found A Job", on "More Songs about Build- 
ings and Food"), and made video clips. This documentary was a new opportunity to deal with the distracting flow of programmes and channels. A comparison of the one hour long documentary, titled "Talking Heads versus The Television", with "Stop Making Sense", shows how Byrne tries to bring out the special performative qualities of every form in which his songs are presented.

Dunlop filmed a Talking Heads concert in 1984 in London's Wembley Arena. Contrasting with "Stop Making Sense", his documentary does include shots of the band in the dressing room, during the sound check, as well as segments from an interview with Byrne: this time, the concert is interrupted, and placed within several distinct contexts. This of course detracts from the involving qualities of the concert, but it does fall in with the casual experience of watching TV, where the programme is as often as not seen within the context of other programmes, and, more to the point, within the context of the viewer's own house and the lives going on there.

Instead of neglecting such distractions, which inevitable frame the viewer's experience, Dunlop's documentary addresses them openly and thoroughly, a choice that makes "Talking Heads vs. The Television" as remarkable as "Stop Making Sense". Dunlop wanted to deal openly with the diverging performative situations of a live concert and of television viewing. Byrne agreed with this emphasis on television and the media environment, but insisted on including religious, anthropological and ethnographic material as well. He helped Dunlop go through a great deal of existing footage that might be included, and suggested points where that footage would correspond to the Talking Heads' concert. Byme allso convinced Dunlop not to use anthropological or religious footage that made its subjects look foolish. ${ }^{8}$ It took a long time to secure telleases of all the footage used in the montage, and that was partly responsible for the fact that "Talking Heads vs. The Television" was finally broadcast in 1989 , five years after the concert was filmed.

The documentary opens with white noise and images to represent the whole chain of production and reception of television: TV assembly lines, commercials for satellite TV, a flood of diverse imagery and a TV host making a declamatory announcement: "...and receive all the television there is to see in North America!" The concert venue is introduced in a similar way, connecting the Talking Heads concert to a number of other spectacular performances: "The name of this place is Wembley Arena, venue for rock concerts, Horse of the Year show, Holiday on Ice, tennis, Harlem Globetrotters, 5-a-side football..."

The first song that the band plays, "Life During Wartime" is placed firmly within the context of TV viewing by illustrating it with found television footage. The lyric of this song presents the inner monologue of someone, a spy, terrorist, guerrilla or criminal, who is in hiding in a city and views his situation. He considers his resources: passports, visas, food rations, phone taps, a partner, and thinks longingly of the regular life from which he has cut himself off: the world of parties 
and disco, of education in night school or college, of carefree fooling around and kissing. Ideas for this lyric may well have come from television. Duning the thousands of hours of television viewing that are part of a regular upbringing, crime films and thrillers teach everyone what the wotld looks like from the position of the outlaw, the lone warrior or the spy. It is thus debatable whether the use of TV footage lifts the song out of its context, the Talking Heads concert, or returns it to its original context, the excitements and distractions of the home theatre.

"Iife During Wartime" is contextualized and illustrated by found footage in at least five distinctively different ways. Footage lifted from police series and thrillers is used to create an atmosphere of tension and excitement. Later in the song, the television sound of wailing police sirens replaces a screeching guitar solo. Some of the footage is connected to the words of the song. A breathtaking example of montage juxtaposes a spectacular cameta movement, lifted from a car chase through a big city, when the camera swipes in a 180 degree tilt over tall building blocks, with a similar shot of Byrne singing ecstatically. And the soundtrack is interrupted completely by a brief documentary segment about inner city warfare, with footage of ruined building blocks.

This approach is addressed in a voice-over by Byrne, which accompanies the introductory scenes that precede the first song:

I try to take ordinary things and make them be seen in a new light, by breaking them up into bits and trying to reorganize them ... I wanted to make boring things seem dramatic, instead of dramatic things seem boring. An ordinary thing put into an extraordinary place isn't ordinary anymore. like scratching your head in front of a few thousand people isn't the same as scratching it in front of your family... When the performance is successful, something transcendent happens, that has to do with the audience and the musicians losing their ego's, immersing themselves into sort of one identity. It need only happen in a performance for thirty seconds or 80 , and that justities the whole thing.

The contextualizing strategy of "Talking Heads versus The Television" is emphasized further by the use of ethnographical and religious footage: women and men from different cultures, dancing in ecstatic trance; people dancing to music in subSahata Africa, Japan, Italy, an Arab country and China; footage of Americans describing their personal experiences of a divine presence; and shots of television preachers who use the TV to broadcast healing rituals, shouting: "Put your hand against mine." "Heal, in the name of Jesus"" "It"l pour through that wbe right into you."

The ethnographic footage of people in ecstasy is accompanied by Byrne's comments on the soundtrack:

I guess I might be considered religious in some sense. If most religions originated in a combination of a sense of awe and excitement, and a little bit of fear. People look ridiculous when they'e in ccstasy, whether it's religious ecstasy or sexual ecstasy. They really look sort of distorted. People look ridiculious when they kiss... But, you know, people know that... they don't fecl ridiculous. 
This is continued a little later, following footage of several Americans who testify to their personal experience of God:

They combine excitement with spirituality, they take ordinary language and transform it into something exciting. It seemed like something that was yery close to what I was doing. Maybe not what they were saying, maybe, but... the way they were saying it, and a little bit what they were saying as well.

And after the song "Slippery People", which has been illustrated with footage of breakdancers, acrobatic dancing in Africa, whirling derwishes, a highly disciplined dance in a mosque, and Chinese children waving flags while executing a dance, Byrne comments:

Some of my ideas about music in other cuttures might be wrong, but I don't think that matters. In some way probably the misinterpreting other kinds of music and using it to my own ends, I think, is justified, and I think it's a good thing.

This is a statement with far-reaching implications. The whole documentary suggests, by means of its editing, that popular music should be considered simultaneously in the frame of mediation by the media industry, and in the frame of transcultural comparisons of musical rituals. It openly states that it can offer no secure point of view from where this interpretative quicksand could be overseen, and admits freely that mistakes and misinterpretations are inevitable.

Byrne shows his analytical predilection when he voices the opinion that "people look ridiculous when they're in ecstasy", and when he recapitulates the development of the Talking Heads in pejorative terms of 'artifice' and 'pantomime':

When the band began, I think the band and myself wanted to strip away all... the artifice of performing. We wanted to, as litile as possible, make it seem like we were puting on a show. We wanted to go on stage wearing our street clothes and not move around much. Gradually we ended up bringing things back in that were at one point unacceptable. I think it just became matret of realizing that you are up on stage, that it is a pantomime.

Yet at the same time he presents himself while singing and dancing ecstatically, and expressly states as his belief that a form of ritual "transcendence" justifies the Talking Heads' concerts. Byme oscillates between an ironic, analytical approach and the enthusiasm that takes him over during the performance-and he uses his conceptual and theoretical interest to balance the two.

\footnotetext{
"THE KNEE PLAYS", A SCORE FOR ROBERT WILSON"S PERPORMANCE THEATRE
}

Next to his work for "Stop Making Sense" and next to touring with the Talking Heads, in 1983 and 1984 Byme contributed music and ideas to a theatre 
project by Robert Wilson. Wilson was preparing an enormous twelve hour-long pageant that would be part of the 1984 Olympic Arts festival in Los Angeles. Wilson's play, "the CIVIL warS-a tree is best measured when it is down", was planned as an artistic counterpart to the Olympic Games as such. Just like the Games presented sportsmen from all over the world, Wilson wanted to present wars, myths and historical figures from all over the world, woven into a single tapestry. His play would be built around the American Civil War, with Lincoln and Robert $\mathbb{E}$. Lee as central figures. Wilson worked from the assumption that civil war is endemic to human history, an almost integral part of civilization: hence the typography of the piece's title, meshing the words 'civils' and 'civil wars'. The enw tire production was planned to consist of five sections that were rehearsed and produced in five different countries, each with its own myths and wars: France, Germany, Holland, Italy, and Japan. Each country allso contributed historical and mythical figures: Frederic the Great, Voltaire, Mata Hari, Captain Nemo, Admiral Perry, Lincoln, Madame Curie, the Japanese sun goddess, Garibaldi, soldiers, the earth mother, animals, a forest, Hercules and many others. These five sections were divided into fifteen scenes, separated from each other by the fourteen interludes or knee plays." Among the contributors were composers Philip Glass and Hans Peter Kuhn, and playwright Heiner Müller.

Wilson originally asked Byme to make scores for a few different sections, but-due to time limitations-Byrne could do only one. He chose "The Knee Plays" because of its more economical scale, which allowed it to tour and reach a wider audience. ${ }^{10}$ Although each of the parts was produced separately, Wilson could not find the necessary financial backing to complete his project and bring the sections together. His play was never produced in its entirety, neither at the 1984 Olympics, nor later. The sections differed in quality; while the Italian and Dutch sections had a static and rather superficial quality, the German section was cricically acclaimed as outstanding and fascinating. The "Knee Plays", produced in Minneapolis, was the only part of a scale that was modest enough to tour successfully for a few years. Before discussing Byme's contribution, Willson"s theatre requires an introduction.

Robert Wilson (1941) is one of America's leading avant-garde theatre directors. His work cuts across traditional gentes, continually challenging the conventional divisions of drama, dance, opera, and visual art. He has made over one hundred productions; the most important are the play without words "Deafman Glance" (1970), the mystical opera "Einstein On The Beach" (1976), and "the CIVIL. warS" (1984), an attempt to decipher history in a single Gesamtkunstwerk. Wilson is interested in exploring perception; ${ }^{11}$ his theatre is a laboratory which experiments with perceptual barriers and discontinuities. He works hard to separate the visual, aural and textual elements of his productions ${ }^{12}$, treating each of these ele- 
ments with a formal precision of its own, demonstrating in the process a strong predilection for simple manipulations and permutations of isolated details.

The inadequacies of human perception are a central theme of Wilson's work. In the early days of his career, Wilson made works through collaborations with Christopher Knowles, an autistic boy of about fourteen, who was partially cut off from the exterior world, and with Raymond Andrews, an eleven year-old deaf mute boy. Wilson tried to create theatre productions that dealt with reality in ways that were similar to their perception of the exterior world, and asked Knowles to perform on the stage with him..$^{13}$

Robert Wilson "bellieves that everyone sees and hears on two different levels. We experience sensations of the world around us on what he calls an "exterior screen'. But we also become awate of things on an 'interior screen'-dreams and daydreams for example. Blind people only 'see' things on an interior visual screen and deaf people can only 'hear' sounds on an interior audial screen. Wilson found that in his long performances the spectator's interior-exterior audial-visual screens become one. Interior and exterior images mingle so that they are indistinguishable. Wilson says that people somerimes 'see" things on stage that are not actually there." 14 In his theatre, Wilson tries to present an opportunity for inner reflection on the limits of our perception, by slowing down and formalizing the events on stage.

Wilson planned the "Knee Plays" as fourteen short vigmettes, a series of poetic transformations that represent the history of mankind. ${ }^{15}$ Byrne's first contribution was an idea for staging these transformations. At the first workshop in Tokyo, he suggested a modular construction of folding and unfolding squares, which would make it possible to transform a boat into a book, a book into a tree. ${ }^{16}$ Wilson's theatre is predominantly visual, but the visual scene does not overwhelm the text (if there is one) or the music; rather, W/ilson sees them as parallel events that should somehow reinforce one another. ${ }^{17}$

For his music, Byme started from the requirements of the entire project. The "Knee Plays" were meant as five-minute interludes between the longer scenes of the opera: they would have to come on-stage quickly, and "the music had to be percussive to cover up the noises of hammering or sawing or pushing big wooden props behind the curtain."18 As he has told it, Byrne initially wanted to work with Japanese percussionists, since Wilson's way of working as a director has been inspired by the traditional Japanese Noh theatre. But he found that the results he got sounded too imitative, too Japan-esque. So he chose a completely different approach, using brass band music instead. He was especially inspired by New Orleans' Dirty Dozen Brass Band, a marching band that plays fast, syncopated versions of New Orleans traditional standards, but mixes these with modern jazz pieces by Charlie Parker, Thelonious Monk and others. Byrne felt that such brash sounds might provide a use ful counterpoint to Philip Glass' minimal music and to 
the ethereal, slow-motion drana that Wilson mounts on the stage, where action is often, in Byrne's words, "reduced to just a gesture or an eyrebrow arch" ${ }^{19}$ In fact, Byme rehearsed for a while with the Dirry Dozen Brass Band, but found that their spontaneous way of playing did not fit his design for a completely written out score that would be performed more or less the same every night. 20

Almost half of the score for "The Knee Plays", as recorded in 1984, consists of rearrangements for brass, drums and percussion of American traditional gospels, such as "In The Upper Room" as arranged by The Baptist Methodist Choir Church of God, and "I've Tried" as arranged by Swan's Silvertone Singers. Since he is unable to read or write music, Byme used an Emulator synthesizer to compose his own contributions, by recording parts on a tape that was later transcribed for the musicians. The lyrics he wrote are unabashedly avantgardistic. See, for example, his use of random elements in "Things To Do" (sometimes titled: "I've Tried"):

Number one: Try to (walking quickly) be

Numbert two: Count to ten, smile, count to ten

Number three: Big shoes

Number four: Warching big shoes

Number five: Buying things and spending money

Numbet six: Counting things:

Number seven: Inventing facial expressions

Number eight: Parking

Number nine: Fixing things

Number ten: Writing letters ...

Byrne recites this list without expression, leaving it up to the listener whether thete is a meaning to such a recital. Does it offer a deadpan view of the human condition or just a random collection of meaningless actions? Is there a difference between these two? Such a list can be compared to Byne's use of words for background projections during "Stop Making Sense" concerts: there, combinations of words, such as "CABLE TV | AIRPLANE CRASH | BURNT TOAST" and "COWBOYS | DOCTORS | PARTIES" also put the audience's associative powers to the test.

Another example of Byrne's lyrics is this quotation from "In The Furure":

In the future everyone will have the same haircut and the same clothes,

In the furure everyone will be very fat from the starchy diet.

In the future everyone will be very thin from not having enough to eat.

In the future it will be next to impossible to tell gitls from boys, even in bed.

In the furure men will be 'super-masculine' and women will be 'ultra-feminine' . .

This list of contradictory predictions goes on for a long time, and the listener cannot help but wonder whether there is a point of view from which they make sense. Is it all a mockery of silly predictions? Will the future never turn out as we 
fear or hope? Have all these predictions already been realized somewhere, which implies that we are already living in the future? The contradictions remain untesolved, leaving the audience to reflect on its interpretative faculties and its possible shortcomings.

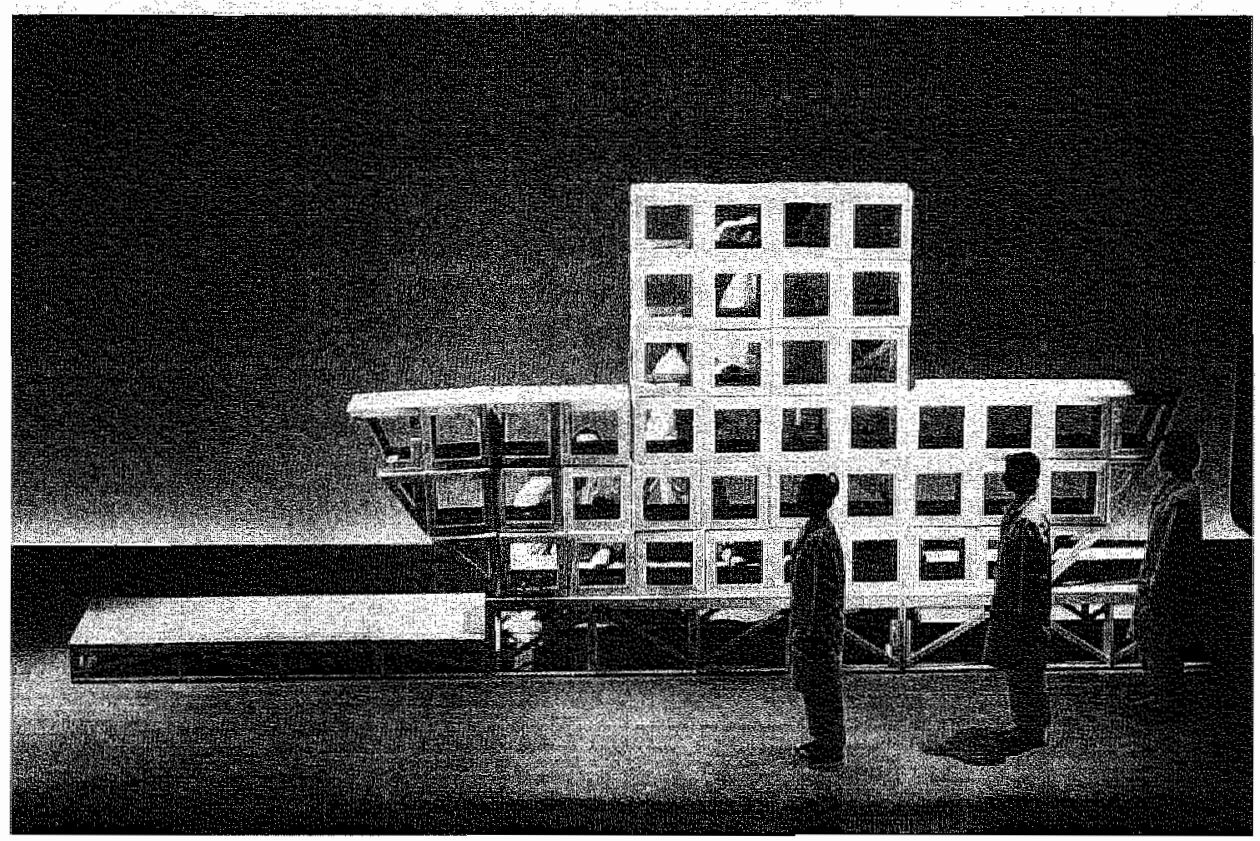

6 On the stage of "The Knee Plays", "The Sound of Business" accompanied the methodical construction of a boat out of square modules. Photo: Waiker Art Center, Minneapolis.

The music for "The Sound of Business" is more compelling than most selections of "the Knee Plays". A snare drum beats a constant, metronome-like four/four beat that is syncopated by simple but insisting, descending brass themes and by percussion, with an overall effect of relentless drive. The lyric, again not sung but recited, fits this sensation. This is the full text:

They were driving south on the highway. Their business was in another town, bigger than the town they were driving from. Business took place during office hours, in both towns. This drive was considered business. The feeling of passing other cars was also considered business: the feeling of business being done; the feeling of drifting slowly through a field of moving vehicles. This was the real speed: the speed of business. Matk the numbers on the speedometer!

One of them was playing with the radio, slowly changing channels from one station to another, sometimes listening to both channels at once. On one channel a man was talking to another man on the relephone.

The other channel was playing oldies, gone for good:

Listening Wind 
Puzzle Hour

Peachwood Serenade

Sunshine and Sugar

Golden Windows

Taste of Believing

Camival Gixl.

Love Walks Away

Wishing Well

Knew You Could

A Face Like That

Datk Highway

Shaken Venus

Coloured Wheds

Visit Me Quick

Lonesome Money

School of Heartache

Painted Smiles

The sound of business being done.

This sketches a situation that is in every respect in between: between towns, between cars, between radio stations, between conversation and music, berween past and present (or between forgetfulness and memory), while the list of songtitles descends from sweetness and light to a suggestion of sordid remorse. The experience of driving a car should be added to this. Corporeal immobility combined with alert attention to the road and the surrounding countryside that speed along, which irresistibly leads to a shifting of one's attention to and fro, inside and outside. This is an everyday experience (it has often been singled out and sung of as the quintessential, possibly sublime experience of the United States), but one that makes it hard to produce an intuitive grasp of inner and outer reality, since neither is quite able to do justice to this immobilized speeding.

"The Sound of Business" demonstrates how even the most mundane of experiences, such as driving, contain layer over layer of aesthetic mediation. Cities, cars, radio stations, the telephone, conversations, pop songs: all these media produce their own aesthetic experience. In the song, the overlapping layers are not centered or balanced by a notion of proprioception: the music is not dance music, and the external third-person perspective of the text, together with Byme's neutral declamation, suggests detachment. After the last words of the text have been spoken, the music keeps on pounding for three more minutes, as if to underline its independent, unrelenting quality.

The stately quality of Byme's score, using traditional gospels, clearly signals sanctioned religion. This effect is opposed by the lyrics, which describe mundane matters that are usually considered to be outside or below the sphere of religion. Apart from driving in a car, the lyrics deal with the selection of clothes for a social occasion ("Today Is An Important Occasion") and with choosing food in a su- 
permarket ("Social Studies"). All in all, something of the solemnity of the gospeis is transferred to Byme"s descriptions of the everyday, to suggest that such ordinary scenes of contemporary Western civilization do in fact take on a ritual quality.

\section{"LITTLE CREATURES" AND THE VIDEO CLIP" ROAD TO NOWHERE"}

After working with Wilson, Byrne planned a feature film, "True Stories". His iclea was to focus on isolated details of conventional, everyday American life, to allow the audience to experience it as truly amazing. Like Robert Wilson"s opera's, the film should be a kind of "total theatre", a Gesanutleunstwerk that combined all his interests. He began to look for financing and to scout locations for the film, which was set in Texas. In 1985, he asked the three other original members of Talking Heads to join him in recording a series of uncharacteristically conventional, sweet and melodic pop songs that he had written. Half of these songs were instrumental tracks to be included in the movie, where they would be sung by actors. The rest was released as a Talking Heads album, called "TLittle Creatures". These songs were written and recordled in the traditional country-pop format, with some minor gospel and Cajun influences. They are copied from songs that might be heard around the clock from country radio stations; a sound that represents parochial America, the "backbone of the nation".

But the songs appear to be unaxware of the existence of any convention. They are determinedly naive, and completely devoid of the sense of guilt and judgment that pervades so much country music. "Creatures of Love", a song that is (if only because of its title) programmatic for the album, tells about love in this way:

A woman made a man

A man he made an house

And when they lay together.

lirtle creatures all cotne out

Well I've seen sex and I think it's allight

It makes those little creatures cone to life

I can laugh of l' can turn away ...

It's oksay to be afraid

When the blue spark hits your brain

We can love one another

I've been told that it's okay.

The music projects a wide-eyed innocence and directness, often resulting in a quirky humour. The drums are recorded unfiltered, with a prominent role for the 
snare drum; the guitars play sweet, melodious accents, joined by a lulling steel guitar; and Byrne's soft; straightforward singing is joined by "Tina Weymouth singing second woice:

We are creatures of love, We are creatures of love...

A man can dirve a car

And a woman can be a boss

I'm a monkey and a flower

I'm everything at once...

The album as a whole breathes surrender and acceptance. It finds these in unusual circumstances, and brings them forward with an all-encompassing gesture that is hard to accept, and even confrontational, insofar as it suggests by its very sound alone that this atmosphere is-or should be?-the basic disposition of parochial America.

"And She Was", the first song on the album, recounts a pleasant, epiphanic experience of levitation. Floating over her neighbourhood, a woman hears the nearby highway breathing, sees the lights of her neighbour's house as well as a nearby factory. As the chorus goes: "The world was moving, she was / floating above it (and she was) / She was glad about it... no doubt about it / She isn't sure about where she's gone". Byme has told how this song, with its pastoral feeling, was inspired by someone's description of an $\mathbb{U}$ SD-trip.

"Television Man" presents the experience of watching TV as both intimate and overwhelming: "I'm looking and I'm dreaming for the first time. I'm inside and I'm outside at the same time. And everything is real. Do I like the way I feel? When the world crashes in, into my living room - Television made me what I am. People like to put the television down. But we are just good friends. (I'm a) television man." While the album was recorded, its working title was "In Defense of "Television"21. The song shows the tube to be a kind of demi-god, influencing the lives of mere mortals beyond their understanding, always ready to transport consciousness to distant scenes and places.

Television has aptly been called, "our third parent": an authority which remains to some extent unquestionable because it has helped to shape our personality from the very start. As every wiewer must somehow intuitively know, television tends to decontextualize every content, thereby forcing the viewer to give up his claim for fully conscious interpretation, to drink in and enjoy the transmissions instead. It is quite nomal to meet more people on the screen than in real life. Moreover, these TV acquaintances have been produced and edited to make them more emotionally appealing. Thus, TV interprets the world for us, even while viewers are free to choose their own favourite networks and programmes. This is the Creation that Byrne portrays in "Little Creatures", the collective dreams of 
convenient emotion. The wide-eyed and frank celebtation of humans as such deeply conventional creatures is somewhat unnerving.

This perspective of innocence and acceptance is put up front by the album cover. In 1985, Bytne gave a commission to make a cover painting to Howard Finster, a naive painter who is "part gifted self-taught artist, part visionary minister of the Gospel, part eccentric. His work embodies a contemporary paradox-it is admired by the art world and coveted by collectors, but it is created primarily as a way of conveying religious teachings. It is at once powerful and witty, and imbued with the intense energy of evangelical Christianity"22. Byrne sent Finster Polaroids of the members of the Talking Heads, a previous album and an accompanying letter, but left the design up to him. In the letter, Byrne described how he wrote the words to one of his songs, and how he thought the inspiration was similar to the way Finster made his paintings. ${ }^{23}$

The resulting cover shows the four band members in an imaginary landscape, full of small handwritten spiritual admonishings. David, front center, like Atlas carries a globe on his shoulders, bearing captions like "world on my shoulder", "get under the load with me", and "who knows the worlld's weight?" The painting is signed in the lower right hand corner: "David Byme is now on T.V. I am listening to him while painting this art 3:15 past midnight April-12-1985. This is my $4000,411^{\text {th }}$ piece of art work. By Howard Finster from God in visions of other worlds beyond the light of the sun." 24

Several songs from "Little Creatures" were made into wideo clips, perhaps as an attempt to compensate for not touring. Chris Frantz came up with the concept for "Stay Up Late", Jerry Harrison and Tina Weymouth designed "The Lady Don't Mind" (the clip was directed by Jim Jarmusch), and David Byrne provided a scenario to have "And She Was" made into an animation. Most critical attention went to "Road to Nowhere", a clip that was storyboarded by Byrne and directed by Byme together with Steven R. Johnson. This was a state-of-the-art videoclip, jampacked with computer animated iconic images. "25 "Road to Nowhere" is a happy, imiting, sing-along song about being "on a road to nowhere" "We're on the ride to paradise".

The clip opens with a long shot of the "Hi Vista Community Hall", in what looks like a small town in the American Midwest. Inside the hall, a tracking shot reveals a group of women, men and children, looking non-professional and strictly "ordinary", who sing the opening lines of what sounds like a hymn. This moment cuts to an open road, stretching off into an open landscape. Now Byrne's voice takes over to lead the rest of the song, and the video continues as a series of rapid cuts of image-sequences and iconic images, using computer techniques like Paintbox and chromakey to combine several images within the picture space.

This includes a sequence of a condensed life, in which a young man and a woman meet, embrace, produce a baby, grow middle aged as their daughter grows 
in leaps and bounds, then age: An old man in a loincloth steps into a cardboard box and closes the flaps over his head; later in the video, a toddler in a diaper crawls out of the same box. These micro-stories are interspersed with a food of iconic images of people: Byrne running on the spot, a man and a woman climbing up a ladder, men in bondage masks and suits hitting each other with suitcases, a young woman spinning round in a wide ballroom gown, a man on a chair falling over, and so on. These are again combined with a stream of other images: Byrne's face, miming the song, within the rotating frame of an (animated) cube, an empty classical plinth, an empty highway, and a series of successive round objects: a basketball, a birchday cake, a globe dripping with blood, a smiling round cartoon face, a vortex of water spiraling down a hole, and so on. Then, there is a "surrealistic" collage/animation sequence of Byme sitting on a throne while his hair moves of its own accord, while in the background and on his jacket flowers, apples, hubcaps and eyes grow, transform, dance and blink. The end of the video shows a highway in an empty landscape, with the members of the band standing along the shoulder, wearing the props and costumes they wore in the video. The camera than goes up to the choir of the first scene, standing in the middle of the road (to nowhere?), and halts there. ${ }^{26}$

How to interpret such a veritable Pandora's Box of possible references, crossreferences and juxtapositions? Byrne's clip has been singled out by Dick Hebdidge as an excellent example of postmodern sensibility, proving that the grand metanarratives are no longer valid-an interpretation that will be considered more closely below, in chapter 9. In a BBC interview, Byme responded to the suggestion that "Road to Nowhere" illustrated a rather nihilistic vision: "To keep the meaning of the song, in order not to trivialise it... you had to say that this includes everything, that this is all-inclusive... We're not talking about one depressed person on the Road to Nowhere or one group of people, or one group of musicians. We're talking about everything you can think of. And we tried to imply that by putting in all those things. ... We try to slide in the scary stuff with the funny stuff." 27 In yet another interview, Byrne explained that to him, songs like "Road to Nowhere" are about surtender, not alienation. ${ }^{28}$

But it seems wisest not to use the clip as the foundation for a greater vision. A general defining characteristic of pop videos is the substitution of referential density for narrative coherence. ${ }^{29}$ 'The crux of Byrne's video can be found right there: in the self-conscious and deliberate combination of a very simple sing-along song, which tells the listener that we are all on the road which leads both to Paradise and nowhere, with a dense stream of images which suggest more meaning and a deeper sense, but do not deliver. This is simultaneously wise and vapid, hilarious and bitter, energetic and cloying. Is the "Road to Nowhere" simply the road to "Now-Here", to the unattainable immediacy of a life without interfering mediations, or is "nowhere" simply the vanishing point of the central perspective in 
which the video has framed the road? The video works through its combination of music and images, and its deepest meaning is to be found tight there, in that juxtaposing texture.

More encompassing interpretations should not build upon this clip. It's better to consider it as a prologue for Byrne's much more ambitious feature film, "True Stories". After all, that film begins and ends also with a shot of an empty highway in an open, empty landscape.

\section{"TRUE STORIES": BYRNE'S GESAMTKUNSTWERK}

In 1986, Byme released "True Stories", a feature film about the lifestyles of people in Virgil, an imaginary small town in Texas. Working with Jonathan Demme, he had picked up enough of the technicalities of filmmaking; and after putting up the clevelopment money for the film himself, he found the Talking Heads' record company, Warner Bros., willing to finance his movie. ${ }^{30}$

In "True Stories", Byrne has freely combined elements and methods from New York's theatrical avant garde with everyday representations, 'art forms' like tabloid newspapers, soaps, karaoke singing, fashion shows, malls, parades, and many others. It has with good reason been described as "a film about performance-performance in everyday life, a vernacular Gesamtkunstzperk." 31 The film contained so many ways in which everyday life is stylized, ritualized or enacted that it is a kaleidoscope of mimetic strategies. To avoid confusion, it should be noted that in 1986, apart from the film, Byrne published a book, also titled "True Stories"; an album of the film score, "Sounds from True Stories"; and with the Talking Heads, he recorded a "True Stories" album, which contains Talking Heads' versions of songs which had mostly been sung by the actors in the film.

In the film, Byme appears in the role of the narrator. He drives around in a big red convertible car, or walks through the town, while he addressing his comments on the scenery directly to the cinema audience, or engages the film's characters into revealing conversations. At the end of the film, the narrator uncovers something of its meaning. While he is driving, he begins by mentioning his car:

This is not a tental cat: This is privately owned. Well... I've really enjoged forgetting... When I first come to a place I notice all the litrle details. I notice the way the sky looks, the colour of white paper. The way people walk, doorknobs, everything. Then I get used to the place and I don't notice the place anymote. So only by forgetting can I see the place again as it really is.

This is Byme's intention: to give his audience an opportunity to see America as it really is, by circumventing preconceived notions of that reality. In his introduction for the book, Byrne has set out part of the film"s origin: 
This film began, not as one story or script, but with a lot of stories found in warious newxpaper artides, along with some dramatic visual deas tepresented by drawings I made. Movies are a combination of sounds and pictures, and stories are a trick to get you to keep paying attention. Wirh a few exceptions, almost all the story ideas in the movie came out of tabloid newspapers, most notably the Weekly World News. I couldn't have made this stuff up...

The way this film framework was constructed was inspited a little bit by my work with Robert Wilson, by his working process. He often begins work on at theater piece with mainly visual ideas and then layers the sound and dialogue on top of that....

1 then tried to integrate the music in the film into the time and the tegion. ... People don't suddenly burst into song for uniustified reasons, as they did in old-fashioned musicals. Neither do they pantomime a story, as they do in tock videos. Instead, the songs expand on the personalitics and characters and on the milieu in and around the town where the story is set. Although the songs don't necessarily advance the story line, they do give relatively placid people-like you or ne-a justificaton for becoming vibrant and full of energy, for expressing themselves and exposing their insides to everyone else in the town....

In The Stories I stay away from loaded subjects-sex, violence, and political intrigne-because as soon as you get on those subjects, everybody alteady has preconceived ideas about them. I deal with stuff that"s too dumb for people to have bothered to formulate opinions on ${ }^{32}$

Byrne paid careful attention to the development of a story that would allow his film to contain a large number of unrelated stories. He wanted to make a film that "kept zipping along" ${ }^{33}$ so that it might attract a much wider audience than the more or less professional art audience; but at the same time he wanted to avoid the kind of plot that would get in the way of the required "polyattentiveness". In his opinion, "The story is just a trick to hold your attention. It opens the door and lets the real movie in." ${ }^{34}$ He collaborated with two scriptwriters, Beth Henley and Steve Tobolowsky ${ }^{35}$, revising the script time and again to get just the right amount of a conventional storyline and still have every chance to highlight the performances and rituals of everyday life. Byrne has expressed strong feelings about this balance, criticizing the domineering quality of most film plots: "Most movies show you something and tell you how you're supposed to feel about it. They're edited in a way that tells you what you're supposed to be looking at before you decide that's what you want to be looking at." "36 Later, he expanded: "Once that natrative engine is set in motion, everything has to keep it running. ... It seems like you're looking at life with blinders on. When it works, it's like you're experiencing a contemporary vision of an old myth. It has a lot of power when something in the story strikes a rhythm or chord, when it means something to you. But when it doesn't, when it's just a bunch of cops chasing after a bag of cocaine, it may keep your interest but it seems like a kind of fascist way of looking at life. Anything that's peripheral to the story gets shoved out." "s?

In "True Stories", he consciously avoided this natrow perspective: "Sometimes the momentum that is generated in one scene overlaps into another and carries you through; you never stop to question how you got to this place. ... You're dealing with little bits of feeling and impulses and impressions that are jumbled up 
in the mind, tather than putting them into a rigidly defined hierarchy. Maybe that is closer to the way things are actually perceived or felt: Sometimes it works. Some things get communicated, even though it's hard to specify." 38

The final script for "True Stories" wove two storylines together. The film documents the preparations for a "Celebration of Specialness" in a fictitious, but very normal Texan town. It introduces key members of the community, shows the parade to celebrate the 150 th birthday of the State of Texas, as well as a theatrical evening, a talent show that takes place in a specially erected prefab theatre outside the town. Of course, this story ptovides many opportunities to showcase people, places and performances in short semi-documentary vignettes, opportunities that Byrne has made much of. For this story, Byrne acts as narrator, in a fashion that may be compared to that of a TV weatherman. This allows him to comment directly on matters like city development, the uses of music, shopping and architecture.

A second storyline follows a self-proclaimed conventional man, Louis Fyne, on his search for a woman to marry. He meets and rejects several possible candidates, turns to a Vodun "curandero" or folk healer/psychiatrist for help, and finally meets the woman he marries through his appearance as a singer during the theatrical "Celebration of Specialness".

The film's personae do not portray the contradictory, "rounded" characters of real people. Instead, they are exaggerations of archetypal qualities, like stubbornness, laziness, or unfounded optimism, simplifications that Byme lifted out of tabloid papers. Since everyone shares such qualities to a certain extent, they are easy to recognize and to identify with. Louis Fyne uses "The Bear" as his nickname, and describes himself as mediocrity turned flesh (yet remains loveable); the women he dates are cast as "Lazy Woman", "Lying Woman" and "Cute Woman". The town of Virgil also features a male and a female Civic Leader, a Computer Guy and a Preacher, a Healer (Mr. Tucker) and a Slick Seducer (Ramon).

The film opens with the notice: TRUE STORIES - A FILM ABOUT A BUNCH OF PEOPLE IN VIRGIL. TEXAS. The opening scene shows a dirt road in a completely that landscape; the hotizon is exactly in the middle of the frame. In the disance, a little girl in a white dress is walking towards the camera. She is humming to herself, and makes buzzing and whistling sounds that imitate the invisible, but audible insects and birds living in that area. She takes turns, clasps her arms together, walks backward for a while. She is singing and dancing to herself, contemplatively.

This scene recreates a solo performance by Meredith Monk, "Songs from the Hill" 39 ; Monk taught the girl how to recreate her original performance. Then the girl begins to hum a melody, a repetitive motif that is, shottly, taken up by musical instruments on the soundtrack, a thirteen-note sequence in $4 / 4$, vaguely reminis- 
cent of similar motifs by Philip Glass. 40 Then, the narrator begins to speak, a voilce-over in a friendly and straightforward tone: $\$ 1$

This is where the town begins. This part of the country has been through a lot of changes Non all small ones either. I think they are in the process of going through another one. You know, there is bound to be at least one person who remembers when everyching was just open land. Like it is atght here. And some people can just look at the land, just look at it, and tell you what happened there.

This whole area was once under water... almost still looks like it. After that, there was a period when dinosauts roamed all over the place. I used to be fascinated by dinosaurs when I was a kid... a lot of kids were. Recently, the bones of a woman who lived here 20,000 years ago were found here. They nicknamed her "Midland Minnie". The first inhabitants here referred to themselves simplyas "the people." Other groups they came in contact with were referted to as "friends." "Texas" comes from the Caddoan word for friend. However, the Caddo were amongst the first to be wiped out by settlers. A group of Spanish settlers offered the Indians the chance to becone slaves. The Indians thought about it, decided it was not a good idea, and killed the Spaniards. The Spaniards were fighting the Mexicans. The Mexicans fought the Americans. The Americans were fighting the Wichitas. The Wichitas were fighting the Tankowas. The Tankowas fought the Comanches. The Comanches fought everyone.

Meanwhile, most of the people who now lived here spoke Spanish. Covert military operations to seize Texas for the U.S. of A. were begun in 1835. Eventually, they did get Texas. Land grabbers and milioad companies moved in. The economy boomed. Some people got rich. First on cotton, then cattle, then oil. And now, microelectronics. The silicon-based crarsistor was first proposed here, in 1949. In 1958, Mr. Jack Kilby invented the integrated circuit. He was working at Texas Instruments then. He doesn't work there anymore.

This is the 150th anniversary of the State of Texas. Prince Chatlie, Duke of Windsor, Prince of Wales, even he came here for the sesquicentennial opening ceremonies. This, out here, this is Virgil, Texas. Their celebration is going to happen this Friday. They are going to have a patade that runs down Main Street in the morning. And then, outside of town, that night, they are going to have a tallent show, 42

This condensed history of Texas is illustrated by a quick montage of old film footage and photos. There is a clip of a growling dinosaur from the classic "One Million B.C.", directed by Hal Roach in 1940; a publicity photo of Raquel Welch decked out in prehistoric leather for the 1966 remake of the same film; a still from the TV show "Little House on the Prairie"; documentary footage of Buffalo Bill Cody; and all sorts of imagery from old black-and-white Wild West films. ${ }^{4}$. The film switches back to colour when this is followed by photos of transistors, a chip and Jack Kilby, and by a series of images of the map of Texas, contours filled with all kinds of produce and other contents. As the whirting and clicking of a slide projector becomes audible on the soundtrack, Byrne appears in front of a projection screen, introduces the (imaginary) town of Virgil, then opens a slit in the projection screen and steps through, into the film: the next scene shows him driving a ted convertible in an open landscape, confiding in his audience: "You know, in a couple of years, this is probably all going to be built up." 

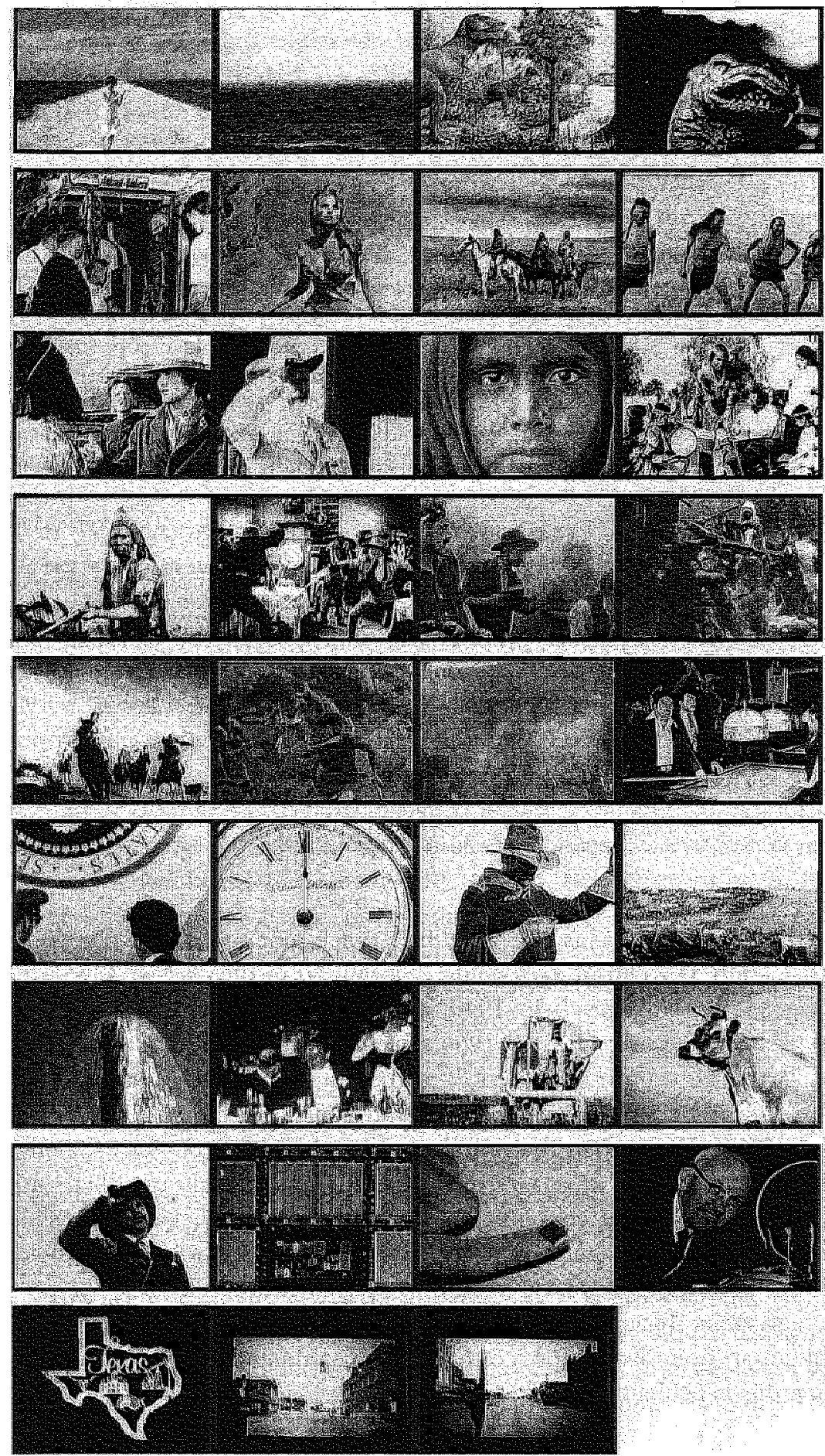

7 At the beginning of "True Stories", the natural history of Texas is abbreviated in a two-minute compilation of found footage and photos. 
All this is acceptable in the cinema, where long years of watching films, $T V$ and videoclips pay off. The repetitive musical motif smoothens the sudden transition from the little ginl to the dinosaut; the nutshell rendition of history is plausible and vaguely familiar, while the accompanying imagery oscillates between simple illustration and ironical distancing; as history is clearly represented here as it has been reflected in entertainment. In the cinema, the audience is now prepared for the fact that subsequent events may be shown from a wide wariety of perspectives.

This historical sequence moves tapidly from pre-historical sea, dinosaur and first woman (Eve instead of Adam?) to the recotded history of Texas, a deadly dance of genocide, subjugation and war, the last episode of which is the seizing of Texas by the USA. Then, history is transformed into economic history with it rapid succession of booms. Finally, Virgil"s "Celebration of Specialness" is placed in this succession. This telescoping history is very similar to the perspective of natural history, with its uncanny use of timescales that radically surpass personal experience. It may be compared to the "timescale of evolution" as presented by evolutionary biology: "If we made an hour-long film to represent the history of tool-making man, industrial man would flash by in a few seconds at the end-he would barely be seen." 44 And if much of the history of mankind resembles a cruel and foolish merry-go-round, that, too, fits the perspective of natural history.

In this sequence, Byrne has managed to combine the glitzy decontextualizing style that is endemic on television, history reduced to bite size entertaining samples, with its diametrically opposed counterpart: the "larger perspective" in which the majority of human activities appear as vain and idle. Neither style cancels or levels the other: like the voice-over and the images, they set each other off as necessary complements within a single orchestration. As Byme has commented: "I like that type of footage on the level that it sort of widens the movie out, takes it out of the sphere of just dealing with certain people or a certain relationship. Plus, stock footage and bits and pieces of found stuff bring in other times and places just by virtue of the texture. You can throw in other references and put the story through a prism or kaleidoscope."45

The main part of "True Stories" is a densely packed collage of "vernaculat per. formances". It comprises, along with a treasure-trove of conversational clichés, interior decorating, architecture, city planning, popular music, fashion, shopping, television advertising, dating, economic development, religion. The film ends, after "The Bear" has found a wife (nature has run its coutse), when the little girl from the opening scene reappears, making the same sounds, but now walking away from the camera. Over the film's credits, a final song is heard: the Talking Heads, playing "City Of Dreams", a plaintive country ballad. The lyric sums up the film: 
Fow Germany and Europe

And Southem U.S.A.

They made this little town hete

That we live in to this day

The children of the white man

Saw Indians on TV

And heard about the legend

How theit city was a dream...

CHORUS

We live in the city of dreams

We drive on the highway of fire

Should we awake

And find it gane

Remember this, out favotite town

This is Byrne's intention: to show American reality as it is sustained by dreams, by private and collective fictionalization. To accomplish this, the scenario switches regularly from dialogue and interacting to private musing (or singing, or performing) by the characters and to commentary from the outside (often by the narrator). The result is a steadfast, carefully blended mixture of documentary and fantasy. Even the characters are made up of found material: Louis "the bear" Fyne was created out of several magazine articles about bachelors ${ }^{46}$; the "Computer Guy" is a mixture of interviews by Steven Jobs (founder and later CEO of Apple Macintosh) and articles on computer buffs sending signals to outer space ${ }^{47}$ (plus, perhaps, Byrne's earlier dream of becoming an anonymous systems analyst); and so on. Throughout the film, open references to such sources are made, to make the people and their lives as transparent as possible. The "computer guy" tells the narrator that

It's a lot like music... computers are something like that... you can never explain the feelings of the connections to someone else. Figuring something out that's never been understood before is a rhythmic expertence. . Steve Jobs said that, he used to be head of Apple... Computers are as much vinears of expression as linguage 48

Louis Fyne, the central character, tells himself, in his country and western song "People Like Us", backed by "The Country Bachelors" the story that he is common man made flesh:

In 1950 when I was born

Papa couldn't afford to buy us much

He said be proud of what you are

There's something special about people like us ...

What good is freedom?

God laughs at people like us ...

Millions of people ate waitin' on love

And this is a song about people like us... ${ }^{4}$ " 
This is not meant to be a true sociological, religious or even autobiographical tepresentation: it is thith only insofar as it is indeed accepted by someone as a personal reality, and in consequence is made true by his behaviour. Compare the character of "the lying woman": all her stories about herself are obviously untrue. She is a factory worker, but in her stories she is constantly surrounded by the rich and famous: "Remember when I went out with Burt Reynolds?" "When I was a nurse in Vietnam I was stuck out in the middle of the jungle with the real Rambo." "I just work at Varicorp for a hobby." "I believe that part of my extra psychic ability is connected up with my being botn with a tail..." and so on..$^{50} \mathrm{Bla-}$ tantly untrue, these stories are still true insofar as they demonstrate the desire for a more exciting life.

Such definitions of truth as constructed, as opposed to given, have a prominent place in the social sciences, for example in the so-called situational analysis of William I. Thomas, who wrote: "If men define situations as real, they are real in their consequences." 51 The stories in "True Stories" are not meant as representations of an objective, impersonal reality; they are model scenarios for the ways in which people fashion their personalities. Such stories are a part of social practice, not self-contained discourse. And since they are aimed first and foremost towards the character's definition of the self and of her or his intimate relationships, that practice is to an extent ritual. The truth in question is first and foremost a ritual truth.

A good example of the archetypal qualities that are personified in the film's characters is the role of Ramon, a Hispanic worker in Virgil's computer plant. While flirting with his co-workers, Ramon claims to be able to read the music of their soul, as if it were a radio station. Expanding on this, he bursts into a song: "Baby your mind is a radio / the receiver is in my head / Baby I'm tuned to your wavelength..." The most likely source for this idea is Jung's psychoanalytical theory. According to Jung, everyone's unconscious contains an inner figure of the opposite sex, a personification of the feminine psychological tendencies in a man (called the anima) and of male tendencies in a woman (the animus). In this theory, the anima is for instance responsible for the fact that a man is able to find the right marriage partner. "Even more vital is the role that the anima plays in putting a man's mind in tune with the right inner values and thereby opening the way into more profound inner depths. It is as if an inner "radio" becomes tuned to a certain wavelength that excludes irrelevancies but allows the voice of the Great Man [the inner self] to be heard. In establishing this inner "radio" reception, the anima takes on the role of guide, or mediator, to the world within and to the Self." 52

Or consider Byrne's commentary on a shopping mall, in a section that is marked off by a title reading SHOPPING IS A FEELING: 
Shopping malls have replaced the town square as the center of many American cities. Shopping has become the thing that brings people together. The music is always playing bere. What time is it? No. time to look back....

People here are inventing their own systems of belief... inventing it... selling it... making it up as they go along.

Visually, the film carefully maintains a similar balance. The open landscape with the central horizon functions as a visual theme, providing a neutral and transparent $^{53}$ background throughout. Byrne developed his approach to the visual side (set design, choice of locations and so forth) of "Ttue Stories" by using tecent color photographs by, amongst others, William Eggleston, Len Jenshel, Joel Sternfeld and Stuart Klipper for inspiration ${ }^{54}$ Their focus, as shown by the photos by Eggleston and Jenshel in the "True Stories" book, is not on humans in action, but on the landscape, the intricate decor and the debris that surrounds their acrion everywhere. When brought to the viewer's attention, such scenery-usually neglected because of its familiarity - seems to function independently, not so much as the result of conscious human decisions, but as an influence which people only mimic, as chameleons imitate their surroundings. This theme, too, is explicitly broached, when the Narrator drives up to a club: "You gotta see this... it might be part of Virgil's Celebration of Specialness. Or it might not be... Maybe you've seen it on TV... Maybe you missed it... but it's different here... Hope you don't mind loud music..." Inside the club, a series of people lip-synch along with a Talking Heads song, "Wild Wild Life", imitating rock stars like Billy Idol, Prince and Madonna. Byrne wrote about this scene:

The song itself becomes a vehicle that can say anything they want it to. Some gestures and movements are obviously derived from well-known sources: television shows... movies... and, most recently, tock videos.

Odd to think that some lip-synchers ane imitating chancters in wideos, who are really musicians imitating other chatacters, ${ }^{55}$

This shows Byrne's awareness of the complex layering of performance in contemporary life, where life may imitate the media, as well as the other way round. The film itself is also part of this complex, especially where it brings together several well-known makers of performance theatre, either in person or in quotations. The presence of actor Spalding Gray (who plays the role of 'civic leader' Earl Culver) is perhaps the most obvious example: his very presence may be said to connote a great deal about performance.

Gray is a founding member of the Wooster Group of New York, famous and somewhat notorious for mixing their theatrical performances with elements of "real life". An example of is the autobiogtaphical trilogy by Spalding Gray and the Wooster Group, the "Rhode Island Trilogy", that was developed in the late "70's and early 80 's. ${ }^{56}$ Gray has said about this work that 
As long as he played characters, even if developed through observations of people; he could "only guess at knowing the other". He realized that he did nor want to study odhers as objects, he wanted to explore himself as other. He no longer wanted to pretend to be a chancter outside himself. He wanted to perform his own actions and be reflective at the same time on stage before an audience. He says it became a kind of "public confession of his reflectiveness. Ir became, "Look at me, I am one who sees himself seeing himself."

The middle piece of the trilogy, "Rumstick Road", deals with the suicide of Gray's mother, Bette Gray. Spalding Gray and director Elizabeth LeCompte explored this suicide. In this play, they included taped interviews by Spalding Gray with his father and grandmothers. In the words of a theatre critic, they used the suicide "as a metaphor for social and psychological dislocation, a focal point for a cultural investigation. They do not attempt to represent, but to explote what it means to represent." 58 A lot of critical and polemical attention was focused on the use within the plays of the interviews with members of the Gray family. There is a moment in the play when Spalding Gray turns to the audience and tells it that his grandmother has asked him not to play the tape of her, and then he goes ahead and plays it anyhow. It is an act of transgression, a violation that is especially pointed out as such, confronting both the audience and the material. ${ }^{59}$

LeCompte and Gray violate the rights of another speaker in a similar way. Spalding Gray, in his autobiographical role of 'Spud', "recreates a telephone conversation with a psychiatrist who treated his mother. He performs his half of the interview 'live" while the doctor's responses are played from a tape recording of the call made without the doctor's knowledge (the program uses a pseudonym, Dr. Henry Bradford, to identify him). ${ }^{360}$ The doctor attempts to reassure Gray that his mother got the right treatment, defending the electric shock therapy he administered before her suicide, and even says: "And don't be frightened by a hereditary disposition... You may not necessarily get it." "61

This kind of performance has so many ramificarions that it is impossible to understand them in a distanced way. The psychiatrist is exploited since his privacy is violated; the electric shock therapy might also be considered a violation of privacy, in spite of the institution 'psychiatry' that may be seen to exclude violence; for Spalding Gray the suicide of his mother was a brutal shock, that he shares through the performance with the audience. Here the canons of art are consciously broken, since everything is considered as potential performance material, which means the canons of life are broken at the same time. The result is a painful, all-encompassing irony that includes the artists and the audience, making it clear that none of them is standing on safe ground from where everything else can be judged. There is no simple straightforward authenticity outside the reach of performance. ${ }^{62}$

Although Byrne stays away from violent subject material, his own presence in his film can be taken as a milder demonstration of the same insight. ${ }^{.33} \mathrm{He}$ is pre- 
sent as the narrator, but also with the other Talking Heads, who appear in a video clip-like collage of scenes from TV commercials (watched from her bed by the "lazy woman"), in which they are commodified to the extreme. Whille they lipsyne their song "Love For Sale", they are dunked in chocolate sauce, wrapped in brightly coloured foil, to be finally unwrapped and eaten.
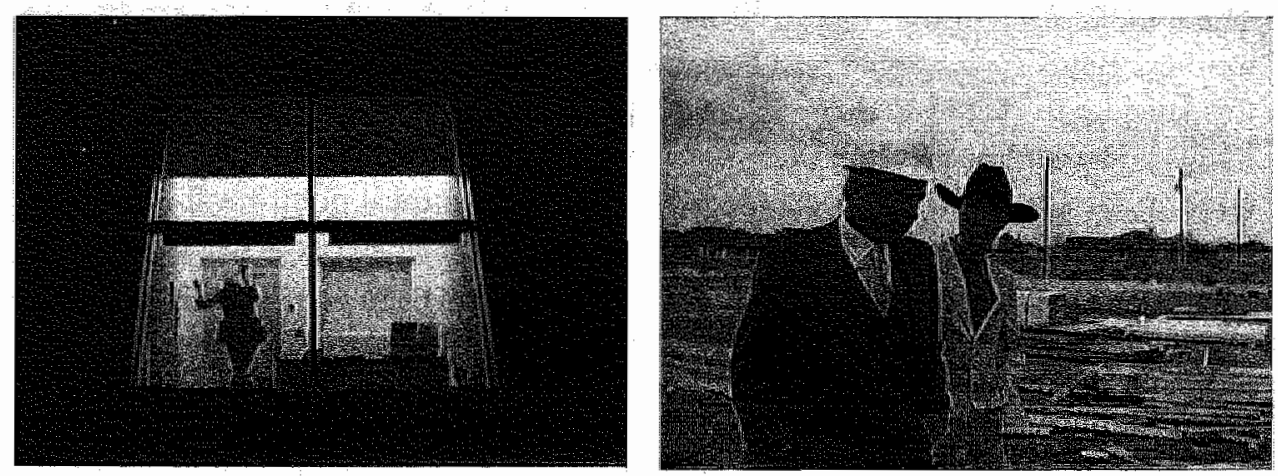

8 The presence of performance theatre in "True Stories".

Leftu a dance scene in Robert Wilson's style.

Right: Spalding Gray and David Byrne, in their roles of mayor and narrator.

The influence of Meredith Monk and of Robert Wilson on "True Stories" has already been mentioned, but it should be noted that Byrne also included a clear visual quotation of Wilson's work. The film contains an isolated scene of an executive at the local computer plant, an older man in a gray suit, alone in a cube-like office at night, where he is dancing and twirling around. The formal layout of this scene and its choreography both recall the "space ship" scene in "Einstein On The Beach", the opera by Robert Wilson and Philip Glass. ${ }^{64}$

There is another short peripheral scene during which three men perform a "gas station dance", making slow unusual movements as in a quaint choreography. The scene may recall vernacular, task-like dances- "to display the practical intelligence of the body in pursuit of a mundane, goal-oriented type of action", as the groundbreaking postmodern dance of New York's Judson Dance Theater has been characterized." In the "True Stories" book, this scene is described as "Two kids being given a drunk test by Police in front of a 7-11 store. One walks backward with his arms outstretched, and the other, with his eyes closed, slowly attempts to touch the tip of his nose with his finger."

As a last aspect of the film, its view of religion has to be considered. After all, religion is meant to bring a meaningful coherence to life, to protect what is sacred and to sanctify the community. Byme's description of shopping malls, which "bring people together and let them invent their own systems of belief", might fit 
this functional approach to religion. But the film contains at least three other instances.

First, the film features a conservative preacher sermonizing to his congregation about the hidden relationships that cause the demise of morality, sketching and suggesting an all-encompassing conspiracy. The sermon contains some ridiculous absurdities as well as suggestive remarks about "government commissions" and the CIA, and turns into a rendition by the preacher, a gospel choir and the congregation of the song "Puzzling Evidence" (a driving, insistent song, written by Byrne).

In a somewhat analogous scene, Earl Culver, the "ciwic leader" of the town and reputedly the man who has brought the "Varicorp" computer company (the major sponsor of the "Celebration of Specialness") to Virgil, holds forth on the impact of the computer revolution. Using the food on the dinner table in front of him to illustrate his epiphany, he explains the changing economy:

They don't wotk for money anymore... or to earn a place in heaven... which was a big motivating factor once, believe you me. Economics has become a spititual thing. They"te working and inventing because they like it! It's al whole new philosophy... I must admit, it frightens me a little bit. "They don't see any difference between working... and not working. Everything is a part of one's life... [enraptured, addressing his children:] Linda... Larry ... there's no concept of weekends anymorelor

And last, there is the character of Mr. Tucker. He is "a black man in his fifties with a very calm, serene demeanor" "68, who works as the home assistant of the Lazy Woman. At home, he has built an elaborate altar that combines AfroAtlantic iconography with statues and images of Christian saints ${ }^{69}$ There, he works as a "curandero", a Vodun folk healer. Louis "the bear" Fyne turns to him for help when he fails to find a suitable partner. Mr. Tucker cures him by "discharging the negative forces he has received", telling him, amongst other things, to drink three soda waters a day, that is: to drink half and throw the other half away. He also puts a Polaroid photo of Louis Fyne on his altar, which he will use later in a ritual prayer. Following the prayer, he starts to dance and sing:

It might hmm-mmm-mm-man... it might rain money.

It might hm-hi-hi-hi... it might tain fire.

Now I'm gonna call,

Gonna call on Legba.

Get yourself a sign

Ger your love and desine.

Rompicndo la monotonía del tiempo Rompiendo la monotonía del riempo

Papa Legba, come and open the gate Papa Legba, to the ciry of camps 
Now, we tre your children

Come and ride your horse

This song, "Papa Legba", is another one of the songs Byrne wrote for the film and also recorded with the Talking Heads. Papa Legba is an important god in the Vodun pantheon; when he takes possession of one of his disciples in a trance, the god is said to "ride his horse" monotonía del tiempo", breaking the monotony of time, as well as the prescription to drink three soda waters and throw half away, were lifted directly out of an article about folk healers in the Texas Monthly of June 1977.72

These religious manifestations are presented in the film, not discussed or judged on a more general narrative or conceptual level. Nevertheless, they invite comparisons. It is interesting to note, then, that computers have been introduced as creating new connections that may well be compared to music, a thythmic experience. In the "spiritualized" computer economy, however, "there's no concept of weekends anymore". In other words, one of the most basic social ordenings of time is wiped out, leaving a calendar without thythm. "Breaking the monotony of time", as Mr. Tucker aims to do, is in comparison the more musical religion.

At its release, "True Stories" generated a flood of media attention, as may be expected when at rock star enhances his fame by directing a self-conceived feature film. TIME magazine capped the wave of publicity by devoting a cover story to Byrne, allowing him to design his own cover (something only Robert Rauschenberg had done before), and addressing him as "Rock's Renaissance Man". Naturally, the film also elicited critical interpretations.

Several critics have tried to answer the question what the objective of Byme's irony is. Barbara Kruger, a New York-based artist/critic whose own artwork tried to tevive traditions of visual agit-prop from the 1920 's, dismissed "True Stories" as condescending. In her opinion, Byme is the smart artist who looks down on the provincial scenes that his film depicts, inviting his audience to laugh at the expense of the represented culture. In her words, the film is "the apotheosis of the travel film, a touristic glance at the "other" as it shops, works, and celebrates its way through its heartland habitat. ... His Virgil exudes a kind of madhouse allure in which he, the attendant, gently shows the inmates to their cells." "7.3.

Filmcritic Richard McKim addresses the same question: "Byrne's running commentary as our guide is obviously ironical in its wide-eyed, deadpan enthusiasm. The question is, ironical in what sense?... A natural first teaction is to suppose that Byrne's irony is sarcastic, the joke being that modem Virgil is really a wasteland. But... in the director's vision, we all really do share our guide's ingenuous joy in the trappings of consumer culture... Byme wants to disabuse us of the prejudice that people like those in Virgil are worthy only of ridicule from hip Northeastem intellectual types such as Byme is perceived to be... His ironic point 
is that Virgil's people are both normal despite their weirdness and special despite their normality. The specialness that interests Byme most is the spark of original creative vitality that he sees in all his characters..." ${ }^{3 \% 4}$ But McKim still has some reservations; it seems to him that Bytne "adopts the olld "noble savage" notion" towards the small town Texans that his film depicts. ${ }^{75}$

An academic critic, Martin Schechter, has interpreted "True Stories" as a postmodemist nartative, an example of "the possibility of contemporaneous nonmimetic re-readings, of instantaneous "ironization", of being washed away in the stream of a constant shifting social real." ${ }^{.76}$ According to Schecter ${ }_{*}$ Byrne gocs beyond irony by systematically dismantling and deconstructing the traditional organizing distinctions between inside and outside, between character and author, between truth and fiction. ${ }^{77}$

All these critics raise questions about the relations between performance, irony, and the epistemological problem that underlies the anthropological endeavour: to what extent can someone from one culture produce a correct and authentic representarion of other cultures? In later chapters, each of these questions will be addressed at lenght.

\section{PERFORMANCE THEATRE ON FILM: "DEAD END KIDS"}

Time and again in this book it has been mentioned how performance theater inspired Byme's work. The last sections of this chapter describe two unsuccessful attempts to translate the performance theatre that inspired Byrne profoundly into film. The first attempt is JoAnne Akalaitis' film version of her Mabou Mines' production "Dead End Kids". The film was shown at the Toronto Fillm Festival but never released. In 1986, it was one of four films to come out of New York's SoHo art community: JoAnne Akalaitis" "Dead End Kids", Laurie Ander" son's "Home of the Brave", Jim Jarmusch' "Down By Law", and Byrne"s "True Stories". ${ }^{78}$ Two years later, Byrne once more collaborated with Robert Wilson on a music-theatre production, "The Forest". They originally hoped to produce two versions of "The Forest", one for the theatre and one on film, but due to budgetary problems, the film version never got made. Still, both film projects deserve attention, since they provide a more detailed insight in the influence of performance theatre on Byrne's work. Moreover, they are demonstrations of the interpretative and critical potential of such large-scale performative works.

"Dead End Kids: a story of nuclear power" was a play developed and directed by JoAnne Akalatis, performed by Mabou Mines at New York's Public Theater during the 1980-1981 season. Mabou Mines had been established in 1970 by, amongst others, Ruth Maleczech, Lee Breuer (her husband), and JoAnne Akalaitis. They founded their group to experiment with theatrical productions which extended conventional narrative theater by working collaboratively and by combin- 
ing distinct acting techniques, ${ }^{75}$ mixing and contrasting, for example, the naturalism of Stanislavski (or Method Acting) with the distancing and alienation of Brecht and the ritualism of Artaud ${ }^{80}$ Composer Philip Glass (then married to Akalaitis) was another founding member. He composed music for several productions, and the Mabou Mines performed his "Music for Voices".

Akalaitis used her experience with this kind of theatrical "bricolage" 1 to construct a play about the history of physical science, its origin in alchemy, the development and use of nuclear weapons and nuclear power. The piece is "a kind of alchemical grand guignol", as a character within the film describes it. This complex story, full of historical quotations, is told in a multiplicity of performative and dramatic forms, ranging from a nightclub act to a TV quiz show, from forties-style musical dance to outtakes from Goethe's "Faust", and from scientific exposition to TV-style street interviews. Byrne admired the stage production, and when a very low-budget film was made out of it, he agreed to help. Byme and Philip Glass, both then at the apex of their fame, have brief cameo appearances in the film. Moreover, Byrne agreed to contribute some music to the score of the film. He later explained how he "was starting to put together a little home studio, and I thought it was a chance for me to learn how to work the equipment, experiment with some new sounds and have some place for it to go." ${ }^{2} 2$ However, the stage production did not translate so easily into film, and the film was not released. My description of "Dead End Kids" is based on a copy of the film on videotape, which lacks credit titles. ${ }^{83}$

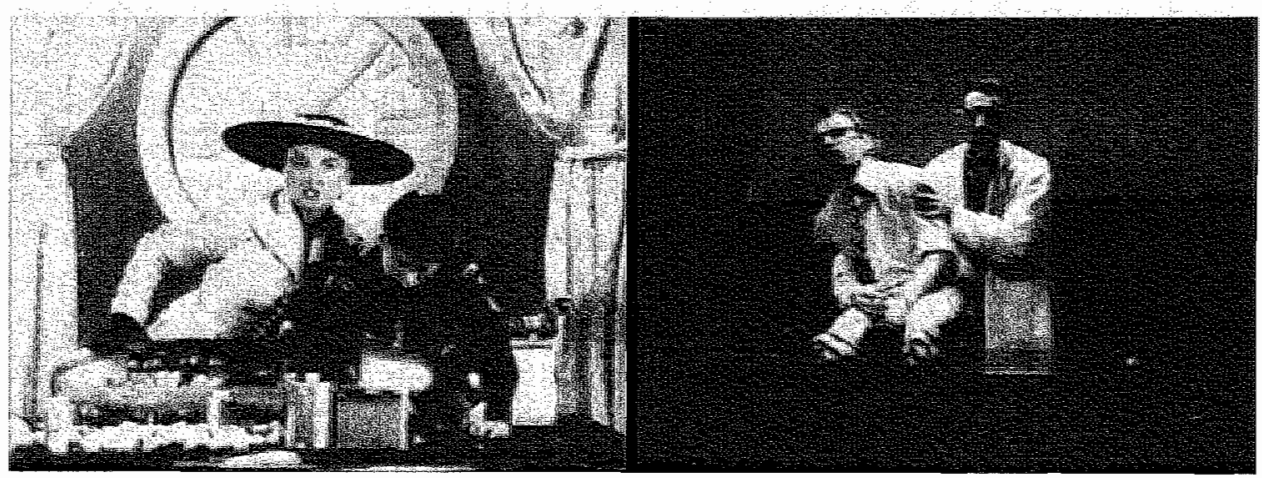

9 Scenves from Mabou Mines" film "Dead End Kids".

Left: a "TV quiz show that instructs viewers how to build a hydrogen bomb at home.

Right: a scientist demonstrates medical effects of nuclear fall-out.

Central to "Dead End Kids" is a double perspective, in which scientific developments appeat simultaneously as spiritual developments. This is established by a title card, a quotation from the work of Carl Jung: 
Medieval atchemy prepared the way for the greatest intervention in the divine world that nan has epesa attempted. Alchemy was the dawn of the scientific age, when the demon of the scientific spirit compelled the forces of nature to serve man to an extent that had newer been known before.

The film explains that there are two competing views on alchemy: one is convinced that the alchemists were just medieval crackpots, while the other sees the alchemic ideal of transmutation as a quest for the perfection of the soul. The possibility of spiritual relevance is also found in modern physics, for example with Marie and Pierre Curie, fascinated by the mysterious X-ray; Pierre Curie is quoted as saying "one must make of life a dream-and of that dream a reality." A crucial quotation for the film is a statement by J. Robert Oppenhemer, the physicist who directed the Manhattan Project, in the course of which the arom bomb was made. In 1946, Oppenheimer said:

In some sort of cnude sense, which no vulgarity, no humor, no overstatement can extinguish, we physicists have known sin, and that is knowledge we cannot loose.

The second half of the film consists mainly of "vulgarities, humor, and overstatements", implying, to say the least, that a quest for the perfection of the soul might be in order. "This part of the play considers the many different ways in which vernacular culture has absorbed the existence of atomic energy and atomic weapons. Presented are, among other examples, a song-and-dance musical routine about dropping the atomic bombs on Japan (perhaps a re-enactment by Mabou Mines of a historical musical routine?"), and a 1950's exhibition about "atomic energy for peace", set in a New York highschool, which includes such items as an "atomic coffee-pot" and "atomic long johns". The summit of vulgarity is reached in a nightclub scene that concludes the film. Jacky Dale, a second-rate entertainer, has already been shown in short scenes throughout the film to have a repertoire that consists only of corny sexual jokes. "What did the elephant say to the naked man? - How do you breathe through that thing!") Now, in his nightclub, he brings a young woman, Tracy, out of the audience up on stage to assist him. (The actress playing this role also is presented in the film playing a schoolteacher, the role of "Marie Curie", and the lead singer in the musical toutine. This doubling surrounds each separate appearance with reverberating meanings.) Dale takes the carcass of a dead, plucked and decapitated chicken out of the crotch of his pants, and asks his assistant to hold this for him, to help him demonstrate the effects of radiation on poultry. He reads these effects from a government publication of the same title; intermittently, the film shows outtakes of a scientific-looking demonstration of similar effects on a man.

Jacky Dale: Tracy, I want you to demonstrate the effects: [quoting] "Initially, there is a shaking of the head." What? A problem?

Tracy: There is just the neck here. 
Jacky Dale: Can you give the bird some head, please? Speak into the microphone...? Gotchal!

Jacky Dale: [quoting] "Then, depression sets in." M \& M's for breakfast, you know the scene... In a trimphant tone of voice:] Bird depression, ladies and gentlemen... !"

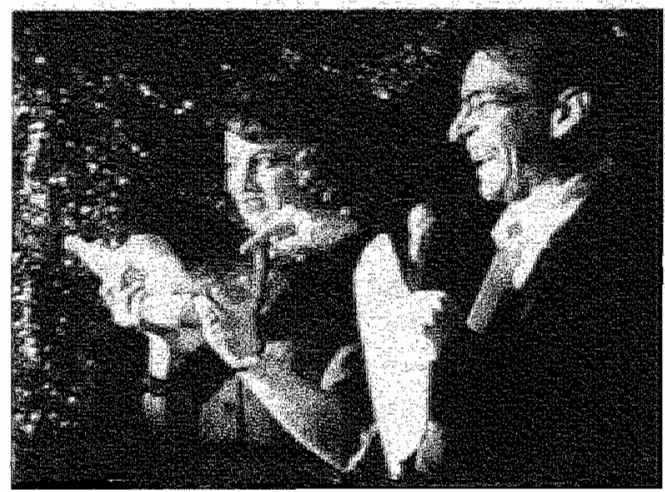

10 "Dead End Kids": The nightclub scene with the dead chicken.

\section{Compare Richard Schechner's commentary on this scene:}

The final scene of Dead End Kids-the Mabou Mines performance piece that's all about nucleat energy, experimentation, and holocaust-is a parody of a sleazy nightclub act. The comic invites a young woman (a plant) from the audience onto the stage. He makes sex jokes with / against her. He uses as a prop a dead plucked chicken-the kind you get at the supermarket. This prop is naked flesh, dead yet invalnerablte, not being used to feed anyone but to stand for the penis, the vagina, the insides of the body, the victims of atomic bombs, the raw meat we are when we are nothing else. And have you ever noticed how chicken skin is the color of some Asians? The audience reacts strongly to this scene. Some offended, some amused, some sickened. "This scene-which people adwised director Jo Ann Akalaitis to drop-is a scary commentary on the current level of consciousness not only stbout things muclear but the whole drift of our species towatd globacide ${ }^{84}$

Byrne's musical contribution to the soundtrack of "Dead End Kids" is mostly unobtrusive and purely functional: an insistent, metallic, rhythmical throbbing for the opening titles, the ticking of an alarm clock, some modulating organ chords to underline alchemical quotations, and the like: sounds that provide an atmosphere, an auditive envitonment for the rest of the film. ${ }^{85}$ This contribution to "Dead End Kids" is less relevant than the contribution that the play makes towards an understanding of Byme's artistic background and preferences.

\section{"THE FOREST": A MUSIC-THEATER PIECE}

After "The Knee Plays", Byrne worked once more with Robert Wilson, but this time he took more influence on the concept of the entire production. Wilson 
approached Byrne when the city of West Berlin asked him to make a play for the occasion of the city's 750th anniversary in 1988. Byme, who had been reading a number of books on mythology for his work, suggested using the epic of Gilgamesh, a mythical story he liked. He suggested that the story of Gilgamesh could be combined with a German theme by setting it in Germany during the Industrial Revolution, around 1860 . Byrne also wanted to present the project in a permanently fixed form, like TV or film: " That way if the stage work can't tour, a lot of people can still see an interpretation in this other form. That idea evolved to the point where there would be two very different interpretations of the same story or scenario.... Bob [Wilson] to a large extent designed the stage work according to his vision and I designed the visual ideas for the film." "s6

For Wilson, "The Forest" began a new chapter in his work. In the beginning of his career, he produced silent, completely non-narrative visual theater pieces (which Wrilson often calls "opera's"), which earned his work the title of "theater of visions". When text was introduced, in "A Letter for Queen Victoria", the text was like "concrete poetry-words that one wasn't supposed to think about so much but just listen to-transparent, like weather in a room". ${ }^{87}$ After that, collaborating with Philip Glass, Wilson made "Einstein on the Beach", an opera, although not performed by technically skilled singers; later, Wilson would work with star singers such as Jessye Norman, and direct opera's like Alceste and Salomé.

Another development in his own pieces occured through his collaboration with Heiner Müller, the East-German playwright. Müller is often considered to be the foremost successor to Bertolt Brecht, but his texts go beyond the tradition that was established by Brecht. Müller prefers to use language as material, independent of any personal point of view, and has words repeated or spoken backwards to emphasize this independence. Although his texts that are bitingly expressionistic and violently political, the Brechtian "alienation effect", which Brecht used to suggest that conflicts might be resolved from a proletarian viewpoint, is generalized in Müller's work: here, no viewpoint is left which might allow for a solution. Wilson's collabotation with Muller started with the German part of "the CIVIL warS", and Müller provided Wilson with texts that demand interpretation--the very thing which Wilson had always tried to avoid in his theater. As Wilson said, "Heiner's texts are texts you want to think about. So one has to deliver it in a different way, because this is not the weather in the room. ... It's something we must think about for it to be understood-something to contemplate." Still, Wilson refuses to present a single clear interpretation in his productions: "You can have interpretations, but you can't have one interpretation. A stage action is not thought about that way and Heiner's texts are that way also."

'The Forest' was built around a combination of Gilgamesh, considered to be the oldest preserved story in the world, and the theme of the Industrial Revolution. The Gilgamesh epic tells the story of Gilgamesh, two thirds divine and only 
one third human, a harsh and despotic niler over the city Uruk, in ancient Babyloni Answering the complaints of Uruk's inhabitants, the gods create a rival for Gilgamesh: Enkidu; a wid man, creature of the forest. When Gilgamesh is told of the existence of this man, he sends a whore into the forest to seduce him, and his plot succeds. Enkidulleaves the forest, confronts Gilgamesh and wrestles with him. When nether is able to beat the other; the two become friends and set out on a series of heroic and mythical adventures, challenging the gods. In the end, divine vengeance causes Enkidu to fall ill and die, leaving Gilgamesh to mourn him.

This is a mythical story about the telationship of civilization and nature, about the upheaval of building cities and creating social hierarchies. "To transpose this myth to the era of the Industrial Rewolution, as Byrne proposed, amounts to an attempt to fathom the mythical dimensions of the nimeteenth century. As Bytne explained his intentions,

This tale speaks about the relationship between nature and culture, civilisation versus animals in nature, and about immortality and death. The old story was kind of weaving together a number of themes simultaneously in a way that seemed fairly contemporary, and in a way that I thought had relevance to a lot of things that we're thinking about now.

Many of these topics surfaced and were widely discussed and talked about during the Industrial Rewolution. It seemed to me that here was a period when most of the ideas that we live with now, most of our pseudo-modern feelings about nature being beautiful and cities being ugly, assumptions about God being in nature, and man not being patt of that natute; of all these slkewed assumptions were brought forward during this period ower a hundred years ago. It's strange to see that we believe in most of the same things now, even though the industrial culture is on its way out. .. It's not really a culture of big machines anymore. At least not for most of us. And yet we still live with the biases, assumptions, and beliefs that come out of this age. We are filled up with these beliefs in our schools, in out newspapers, in television, in music, and in art and literature. One of the discoveries 1 made in working on this project is that we're a lot less modern than we think we are. We need to "take stock", to be aware of our prejudices, before we can safely take the "next step" "wis

Later, looking back on the whole project, he added:

The more I did research on Germany during the Industrial Revolution, the more it seemed that the whole concern is currently replaying itself, with the industrialists taking one side and the romantics taking the other. It was an education for me A lot of what we tend to consider modern, Twenteth Century thought came about during that period. Like the idea of traveling to see nature, to look at the mountains or the ocean or big vistas. We do that. We go on vacations to Italy to see romantic villages. That romanticization of nature and of a simple life seems to bave come out of a reaction to the Industrial Revolution. You can trace it even further back if you want to. We still work from those assumptions, even though we might try to throw them off. I can be kind of cynical about it, but I'm as susceptible to it as anyone. I do the same thing; I go to the mountains and see the big vistas, and I'm awestruck. ${ }^{\text {yt }}$ 
The text for "The Forest" was written by Heiner Muller (te-using material from one of his plays, "Zement"92) together with Darryl Pinckney, after discussions with Wilson and Byrne, as told by Wilson: "after many discussions about what the text could be, the nature of the text and how the text could be used; and what the content would be. The political subject matter concerning that eta, that time, is something we'd talked about. But it is also structured in such a way that it could look at the subject from our time, or we could look at it from an earlier time or we could look at it even from a future time. So you wouldn't want to take just a political viewpoint. We're not limited just to that era [around 1860 ] but it may be that through that era that we see a larger picture."

In the theater programme for "The Forest", Darryl Pinckney has recounted the results of his research on the metaphorical connotations of the word 'forest':

The forest has always had its ideological uses, not the least of which was to support unsavory nationalist tendencies. Lore about the land and spiritual habitats disgused, in part, economic destiny. The forest as undebauched witness, as evidence of ecstasy in the laws of nature, exists only in our baggage of romantic imagery, in the deep perspective of works by, say, Moriz von Schwind and Caspar David Friedrich, in the limitations of our contemplation of literature as artifact. No developer was ever detetred by the forest songs of Nowalis and even Weber's forester was inspited by ambition. 'Today it is possible to take a Khmer-Rouge atcitude toward a vast expansen empty it out like a capital city and start over. Darwin once said that the suffering of lower animals throughout time was more than he could bear to think of. If the forest has lost its demonic power, the fairy talle has not. The neurotic pattern of expectations derived from the forest as a source of terror has been transferred like a cargo of timber. Eichendorff's dread moved to the city landscape once the metropolis was persuasively recast as the jungle, the labyrinth of strange feeling. The forest has been upstaged by the city....

In an age of tapid travel, of appreciation of nature as a social accomplishment like opera, the idea of the forest is tourist entertainment: ideally it is a setting, radically it is a set with sound effects. And yet a new generation of purists, of heirs to the Transcendentalists, of disciples of anti-social tefinements, wants to hoe beans and listen to mysterious sounds in the dark. The forest appeals to urban creatures of progressive political postures because it can be imagined as a victim. Opposition to the destruction of the forest from the Urals to the Amazon is a cause that sings with high purpose. The salvation of the forest is not as troublesome a crusade as, say, preventing starvation in the "Third World. The forest has better manners than the Third World, though the forest, too, just keses dying and not without noise and upheaval. But there are no ungrateful arciculations of selidetemination. The forest cannot resent its spokespeople....

The world-wide, man-made threat to the forest, and by extension to the convironment as a whole, restores to us an epic image, an approaching unity of condition that contains more than at little of that lost, dearly missed millenarian feeling. ${ }^{94}$

But before any text was used, Wilson designed the work as a silent production: "What I did was to stage the work as a dumb play, where there is no text. I did all the blocking, the staging. I designed the scenery and I videotaped a workshop with people where the staging was mapped out. It's not complete but it's more or less thought out for all seven acts. The authors, the writers and the composer, 
David [Byme], have taken that videotape, those timings, those ideas, and are scoring it. ... I essentially made the [visual] book of the work and from that book music and text are being written."

Byrne's music was his own version of the late nineteenth-century romantic symphonic style. He prepared for this by immersing himself in the music of Wagner, Bruckner, Mendelssohn-Bartholdy, Mahler, Strauss, Janacek and Sibelius ("Finnlandia") ${ }^{95}$, but made no attempt to clo justice to this music on its own terms. On the contrary, he tried to listen in a naive way: "I wasn't trained in music; I didn't go to music school and learn the ins and outs of musical composition. So when I was making this music, it was a naive take on it." Byme's wager is that his lack of musicological knowledge may be compensated by an awareness of the cultural mediation of music: he deliberately accepts, and includes, the musical prejudices that have accumulated in the course of the twentieth century between his musical tastes (presumably shated by his audience) and that of the late romantic composers. Byrne has mentioned two mediating forces. First, the tradition of film music, "like a Hollywood soundtrack for an epic that might have been made in the Thirties or Forties, which is not surprising, I guess, because it seems that those composers carried on the Romantic music tradition from the nineteenth century, while the classic composers were busy with serial music and dissonance. Sometimes the music can sound kind of corny or a little bit too much, but in a way that might express more of what people were feeling during the period than more modern or contemporary music might."97 Second, pop music: Bytne compares the overwhelming symphonic sound to "heavy metal, played with strings and brass. ... Of course there are differences, but the attitude was partly the same" $" 18$, Because the original story of Gilgamesh came from the Middle East, Byrne also tried to mix in occasional references to the East.

Lacking the training of a classical composer, Byrne used electronic keyboards or guitars plugged into electronic keyboatds, imitating the sounds of classical instruments. Then he worked with arranger and orchestrator Jimmie Haskell, deciding rogether which instruments would play which parts, and which harmonies would be expressed in which section. The music for the knee plays (interludes) of "The Forest" was improvised by the orchestra. As Byme told it,

For example, I watched one of the dances that Suzushi [Hanayag] had choreographed and for some renson I thought of the sound of a rollercoaster. So 1 drew a rollerconster going up and down and put different chotds for the orchestrat at the tops and the botroms.

The musicians were conducted when to go up and when to go down; they could choose any note they wanted within that chord, but they had to try to slide together. It worked out prety well. This is music that was written with visual images in mind. Whether it stands on its own remains to be seen. Often it works best when it goes against the images, when it's telling us something different; when the images, the texts and the music are all informing us of different aspects of the same thing 
Byme wrote but a few song lyrics for "The Forest". The first one mixes mythical "ur" scenes of family life, pastoral beauty and sudden violence with standard tock nihilism ("one and two and three and four, I don't care and I don't know"):

I'm only rine years old and my mother makes me sing she gives me lessons it is money down the drain stand up (and) wipe your ass with pages from the times creep down the hallway see my daddy (die) this golden aftemoon the green grass. all around love peace and happiness in nature's groves resound(s) and this is why we fight and why we come to blows in this our universe God only knows

my life is beautiful my bed is soft and warm wake up my little lambs soon it will be dawn all things ate wonderful home is never far your poppa hears you now heat him crying

I am invisible in nations one and all a baby's innocence the guardian of the soul in joyful hamony with woices raised on high the tiger and the lambs lie side by side one and two and three and four hold on tight and don't let go sticks and stones will break your bones God has left us on our own one and two and three and four I don't care and I don't know hold on tight and don't let

gor..." mat

In the play, this song text is mixed and interrupted (as indicated here by the short horizontal lines) by other textual elements, provided by Pinckney and Müller: "I feel this because I feel nothing at all I think this because this is nothing nothing nothing part of night and silence and of the fact that I likewise am a nothingness negative and interspatial", and: "and I looked upon the characters of the rock and they were changed and the characters were S S SI II LL LL EN EN CE CE".

Wilson's production refuses to understand theater as a representation of reality, the basic convention of Western theater. "The Forest" does not only deal with the themes of the forest and all its associations, and with nature versus modem industry, it also reflects on the possibility of presenting reality in the theater, and does not have the usual confidence in separating a presupposed reality from its theatrical interpretation. It does not mainly tell a story on the level of meaning, but on the level of all the elements of the theater: scenery, lighting, music, text, actors, and all their harmonizing and contrasting combinations. ${ }^{161} \mathrm{As}$ Wilson has concluded: 
The texts can be music for the play. The texts can be something else. What I hear is what I hear what I see is what I see. And seldom in life do they ever relate. We can"t comprehend what we say. We can't comprehend what we do. We can only do it. No one can tell us how to do it. Socrates says, the baby is botn knowing everything; what we need to do is the uncovering of the knowledge that's already there. So the authentic expetience in the theater is the uncovering. Theater is not something we can comprehend, its something we can experience. What's necessary in the theater is the audience. What happens in the audience is the mixing. It's different with each person. WE can't mix Heiner's texts and David's music and my images; the audience will do it. 10 ?

As theater scholat and critic Bonnie Marranca wrote about "The Forest", it "subverts the sense of making, and (for audiences) of viewing theatre from one's own cultural center" According to her, Wilson sweeps the dreams of different cultures and ages for his production, in an attempt to make his theater into a global and historical archive.

\section{BYRNE'S VERSION OF "THE FOREST", A FILM THAT NEVER GOT MADE}

Although Wilson/ Byrne's "The Forest" was presented not only in West Berlin but also in New York, only a restricted number of theatre goers could see the production. Wilson had been able to present his production (which cost 3,7 million German Marks) thanks to a major financial contribution by the German state lottery. Bytne had hoped to make "The Forest" into a film that could be seen by a wider audience, but tan into financial difficulties. It had already not been easy to find the budget to make "True Stories", which was somewhere between 2 and 3 million dollar. ${ }^{104}$ "The budget for "The Forest" was considerably higher; it was estimated at $\$ 7$ million, of 10 million DM. ${ }^{105}$ As Byrne told the story afterwards,

Wim Wenders [the director] was helping as a kind of producer. He had some people who helped us doing a budget and the budget was too high. First I did a kind of treatment of how the story could be done, so that told me what kind of lacations might be needed. Then II worked with an English writer, Michael Hirst, to do a real film script, and we did one.

So we used the script as a basis for a budget, we looked at locations but because it was to be set during the industrial revolution, during this period in the mid-towate eighteen-hundreds in Germany, it was impossible to find locations. So many things had been changed, so many things destroyed, that it was impossible. 'To find an old street, an old castle, a factory, all these things, we were having to look all over the country, which made it far too expensive. Someone looked into the idea of doing it in Prague, but by then Prague was no longer as cheap for making films as it was at one point. It could have been done mabe, but it was too much money. It should have been a kind of att film. And to do it for as much money as the budget was, people would have wanted it to be more commercial, more successful, more popular. I thought, well, I don't want all those pressures so TIl just have to leave it.

I thought it would be like.. in a way like the silent films or the early sound films, or even the Sergio Leone westerns, where the music was composed before the film was shot, so they could have the 
music playing while they were shooting scenes; you could kind of choreograph the cameral mowement to the music, the way it was done in those westerns.

"The Forest" was never made into a film, in spite of Byrne's preparations. Music critic John Rockwell compared Byrne's film treatment with the stage version; his comparison gives an impression of Byrne's approach: "Mr. Wilson's "Forest" tells more of the "Gilgamesh" tale. Mr. Byrne"s fascinating film treatment deals more in realistic settings crosscut with striking visions. It also introduces new characters (playful, teenage gods) and stops short of the climactic battle with the dragon [of the Gilgamesh-epic]."107 Hirst more or less finished a script, but the ending was never resolved. ${ }^{108}$ When I asked to see the script in 1999, neither David Byme not his personal assistant was able to find it; all versions that had been made have gone missing from his office, as may happen when successive office assistants each use their own methods for filing, or when computer systems are updated and exchanged.

The unresolved questions of romanticism and of the contemporary forms and relevance of mythology have continued to inspire Byrne, who wrote: "To me "The Forest"' is less a piece than a process. A process of discovering what it is we are made of. What kinds of ideas, what prejudices, what propaganda fills us up, what we think is beautiful and what we think is ugly, what we consider Nature and what we think is God."109 When asked for his own ideas about nature, Byrne has answered that he tried "not to be romantical about it. It also has something terrible about it, is full of death and plagues. It has an order with a chaotic element." 10

An elementary collage that Byrne made for "The Forest" combines a contemporary magazine ad with an almost similar image in the style of Caspar David Friedrich. Both images present people silhouetted by backlighting (a style Wilson used in his stage lighting design for "The Forest"), thereby producing a heroic juxtaposition of man and nature that is still functioning.

Yet another aspect of the contemporary romantic problematic can be seen in a letter that Byrne made public in August 1992, when questions of forest conservation resulted in a heated political debate in the United States. It was published on the Internet under the title "David Byrne about saving forests". Whether one considers such a letter to be a part of Byrne's artistic work or not, it certainly results from the same reflections and considerations:

By now we've all heard about the ongoing destrucrion of the rain forest in South America, Borneo and other parts of the world. If it continues unabated, life as we know it will never be the same.

But imagine you live in one of those countries. It would be pretry irritating to have a bunch of rich celebrities from wealthy nations telling you to stop, especially when their country got rich partly by cutting down its own forests.

We should manage our own forests better before we tell everyone else what to do. We squandered our resources to become one of the richest nations on Earth. We must learn to manage what we have left. Now. 
equal justice to the culture of the researcher and the culture of the researched. Byrne's appeal to save the original forests in the U.S.A. echoes such concerns where he admits that "rich celebrities from wealthy nations" are not in the position to moralize about the destruction of the rain forests, because their own country is involved in the exploitation of such natural resources.

After "True Stories", Byrne addressed the relation between anthropology and music in varying ways. He recorded another album with the Talking Heads, continuing to erase the musical boundaries between American and African pop music. He explicitly took up the role of the anthropologist by directing an anthropological documentary about African-based religion and music in Brazil's Bahia region. He investigated other aspects of music as a medium for intercultural exchange by recording and touring with a Latin orchestra, and by founding a record label, Luaka Bop, that would mainly issue "world music", that is: popular music that presents voices, textures and dramatic situations that did not have their origin in the homogenized mainstream of Western pop.

Naturally, all this does not make Byrne the equal of the professional anthropologist, prepared by academic training and criticism to deal with cultural discrepancies. On the other hand, the cultural landscape all over the world is increasingly influenced by the mass media, by film, television and popular music. Cultural anthropologists have taken notice of this. As one of them, anthropologist Arjun Appadurai, has written in a study on the cultural dimensions of globalization, "Modernity At Large", the cultural imagination everywhere is influenced by the mass media:

Because of the rapid way in which they move through claily life routines, electronic media provide resources for self-imagining as an everyday social project. As with mediation, so with motion. The story of mass migrations (voluntary and forced) is hardly a new feature of human history. But when it is juxtoposed with the rapid flow of mass mediated inages, scripts, and sensations, we have a new order of instability in the production of modern subjectivities. 2

Although Byme is not a trained anthropologist, his position as a pop star and filmmaker has provided him with ways to respond to this situation that are not open to the professionals in the discipline. For such reasons, it is relevant to consider a part of Byrne's work with the requirements of a reflexive anthropology in mind.

\section{THE 'TALKING HEADS' WAST RECORD}

More or less simultaneously with Byrne's work on "The Forest", the Talking Heads made a new album, "Naked", released in 1988. Musically, this album is a continuation of the development of "Remain In Light" and "Speaking In Tongues". It combines popular music from America with that from Africa. This 
time, they wanted to collaborate directly with African musicians.3 The band went to Paris to record, where they invited percussionists, guitarists and somerimes a keyboard player with African backgrounds: "the idea was that the groove would be determined by the interaction of everybody ... we really felt that we were... jumping cultural boundaries." 4 An example of this is the song "(Nothing But) Flowers", where Byme intertwined his guitar solos with those by Yves N'Djock from the Cameroons, and was very happy when both parts combined in a very natural, easy way. According to anthropologist/ethnomusicologist John Miller Chemoff, "Naked" is an album "that you could take to Africa and play in a disco, and the people there would enjoy the grooves and be dancing to it. But it's Talking Heads, definitely and identifiably so." 5 .

Byrne wrote the lyrics after the musical tracks had been recorded. The words reflect his interest in the tension between nature and civilization, by highlighting different aspects of that opposition without taking resort to a resolution. "Totally nude" ends with the lines "We don't need clothes and we don't need money / So civilized / I guess you wonder where you are / Nature boy, nature man, take me along / Deep in the woods we're undiscovered." But on the other hand, the Jyric of "(Nothing but) Flowers" derides the wish for a trestored natural paradise: "There was a shopping mall / Now it's all covered with flowers / If this is paradise / I wish I had a lawnmower"

This time, politics, sex and violence are not left out of the picture, as in "True Stories", but included in rather bleak sketches. In "The Facts Of Life", sex is characterized in the words "Love is a machine without a driver": "Chromosomes / Designer jeans / Chimpansees / And human beings: Machines of love..."

All the personae of Byme's songs seem to be suspended in nature, caught up in its violent and chaotic processes, whether they are the North American voters in "The Democratic Circus" or the workers in "Cool Water", which reads like a description of Sebastião Salgado's famous photos of miners in Brazil: "Our backs are breaking... Up from hollow earth... From end to end... The noise begins... In the human battle stations... And the big one's coming in. / Work, work, work, work... Work till holes are filled..."

Byrne's lyrics continue to juxtapose different attitudes, quotations (William Blake's "angels and prostitutes might look the same" on "Ruby Dear") and voices within each single song. This is made clear by Byrne's explanation of his lyrics for the song "Blind" (with a chorus in which Byrne tepeatedly snarls "blindl"):

It"s pure imagination, but it comes out of reading the daily paper. It's a cry of anguish. It's a man crying, rather than a woman. And I think it's directed at the authorities. Someone has been killed, or badly beaten, and someone else is looking out a window. Terrible things are happening, civil strife. It definitely goes beyond lack of sight. The mote it's repeated, the more references are implied and the more it resonates with all the meanings within that word or phrase. And you're asking yourself and the listener to be aware of all that ${ }^{\circ}$ 
The Talking Heads" members felt they had been amongst the first pop musicians who had been trying to bring African music into their own style, and that they had made themselves more a part of that music than, for example, Paul Simon, who worked with South African musicians on his "Graceland" album. ${ }^{7}$ The three other members wanted to tour to try out their musical mixture in live concerts, to revive the excitement of the earlier tours, and also to earn money: the Talking Heads had been offered chances to make "Fifteen million [dollar] net", or even two million dollar for two weeks of touring. ${ }^{8}$ But Byme decided not to, preferring to concentrate on his own projects instead. This in fact meant the end of the band.

John Miller Chernoff wrote about "Naked" that the music demonstrates "a maturity that has developed from the band's musical explorations". According to him, Talking Heads had mastered the African idioms: "This is not easy to do. A lot of people tried it-you know the names. I'm sure Paul Simon's Graceland sold a million times mote than Naked, but Graceland isn't unified and true to its idioms like Naked is. David Byme can create things that have the integrity of the idiom and yet still have a kind of modemized edge." But perhaps the combination of American rock with African pop was too successful, the fusion too complete, the result too homogeneous to retain the differences of the diverging sources and traditions. In later attempts, Byrne would present African and Afro-American musical traditions more directly. There, he would address more openly the distance between his own way of working, with its basis in the American mass media, and other cullural traditions.

\section{"ILÉ AIYÉ": AN ETHNOGRAPHIC DOCUMENTARY ON MUSICAL RITUA}

In 1988, Byrne went to the Brazilian province of Bahia to shoot a 50 minute documentary about Candomblé, an Afro-Atlantic religion. He had visited Bahia fort the first time in " 87 , when he was invited to present "True Stories" in the Rio de Janeiro film festival. Listening to Brazilian pop songs, Byrne had learned of Bahia's reputation as a source of music and creativity, and when he visited the region, he had the impression that it was as much like going to Africa as it was going to Brazil." He also had some background knowledge; he had befriended Robert Farris 'Thompson, professor of African and Afro-American art at Yale University. Thompson had invited Bytne visit a Haitian vodun initiation ceremony. (According to Thompson, "vodun", not 'voodoo' is the respectful way to refer to this much-maligned African-rooted religion."12) In that ceremony, two blacks and two whites would pass the fire test, holding their hands briefly in a scalding-hot mixture without feeling anything, as proof of self-control and oneness with the spirit. The successful completion of the "canzo" would be celebrated with dancing and spirit possessions. ${ }^{13}$ In an interview with Thompson, who 
wrote: "one could say that David Byme is nowadays as much ethnographer as he is rock artist" $"$, Byrne said:

I only have at rudimentary knowledge of [Afro-American religions: Hatian vodun and Cuban and Brazilian orisha, Yoruba deities] at the moment, but 1 think the first thing you discover is that they are berign, they're healthy. They re not some kind of crepy cult that's casting spells. That's kind of the first thing you discover, that the preconceived or stereotyped notions are basically wrong. ... Artistically, you notice that this is the route where a lot of music and sensibility and attitude finds its way into pop music and popular culcure. .. Even us white kids who grew up on rock \& toll have a common linkage with rhythms from Kongo, and the orisha ate not as distant as they might seem. ${ }_{4}$,

When Byme was approached to do a documentary with music for Japanese TV, he suggested Candomblé as the subject, because he considered it to be the most open, least secretive Afro-American religion, also the religion that is least oppressed by its government. Thompson helped him by providing some indispensable names, locations and contacts. ${ }^{16}$

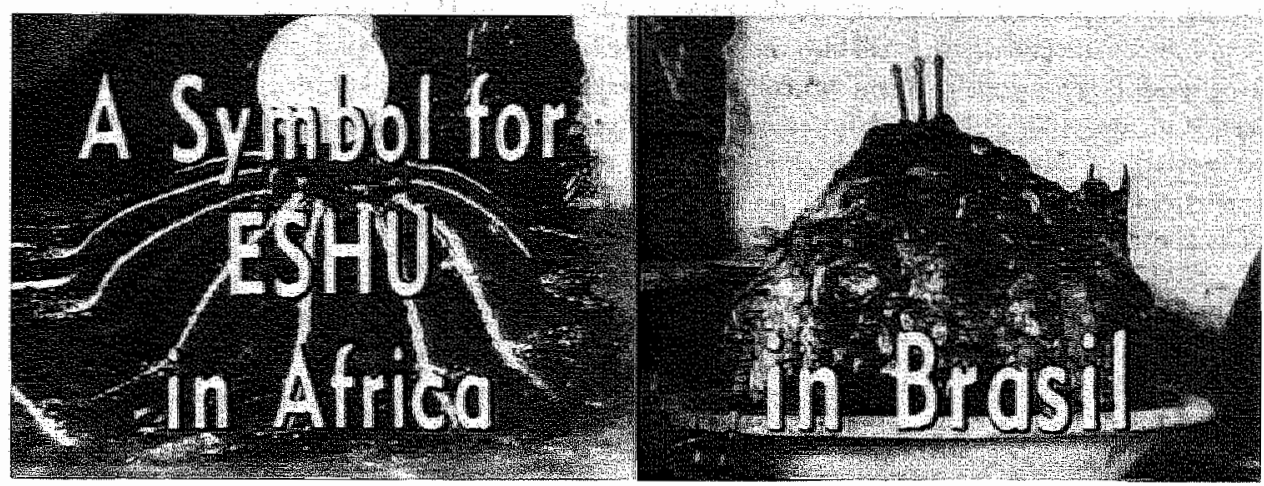

11 A didactic combination of inages from "Ilé Alyé, The House of Life"."

Whereas in "True Stories", Byrne was very much present in the film as "the narrator", providing the spectator with some ironic distance from the presented scenes, in "Ilé Aiye" he deliberately stayed out of the film. His presence, wandering around Bahia and sharing his personal impressions and excitement with the viewer, would have been a selling tool for the film; but "Jlé Aiyé" does not provide a single privileged point of view, no authority figure giving a brief historical overview, no voice-over. ${ }^{17}$ Instead of all that, Byme intended his documentary to immerse the viewer in Afro-Brazilian culture. According to Byrne, "It is a culture that the Brazilians thenselves have described as a mush, a stew, a blend of many sometimes apparently contradictory elements, and I wanted to convey this musical and cultural beautiful mess. I knew I wanted to use music video and other techniques to convey past and present at the same time, to show correspondences and 
connections visually, without a woice-over explaining everything. So the result was sometimes confusing for some people, but that's part of the feeling I wanted to convey." 18

Simply showing the Candomble rituals, its costumes, its drumming, its use of trance and its festive offerings might be the best way to enable the viewer to pick up something of its experience. The information that is indispensable to grasp the meaning of the events is presented in subtitles, or is implied by combining a main image with an inset image, or by the interweaving of forms of music on the soundtrack. There are voice-overs, as well, but they present only the voices of insiders and participants. Together, these convey a great deal of information, explaining how the slaves transported from Africa managed to keep alive their spiritual ceremonies:

Each of these ceremonies is dedicated to a specific god or Orisha. Orisha's have their own thythms, which are played in a proper otder. Everyone, led by the head priest or priestess, sings songs of praise. "The initiated women and men dance, using gestures associated with the atrributes of each Orisha. It is a poem in movement and song that speaks on many levels at once.

Some of the initates may fall into trance, filled with the energy and spirit of the Orishat that riles their head. It is a joyous moment when the honoured guest has artived at his or her own party. The people in trance ate led out, and dressed in the attire characteristic of their Orisha. They ate now addressed as gods and welcomed back in, where all enjoy their dancing and soak up their gift of divine energy or "Ashe". We ate in the presence of an energy or refined life-form that one can think of as god-like. They threw a party for the gods and the gods came...

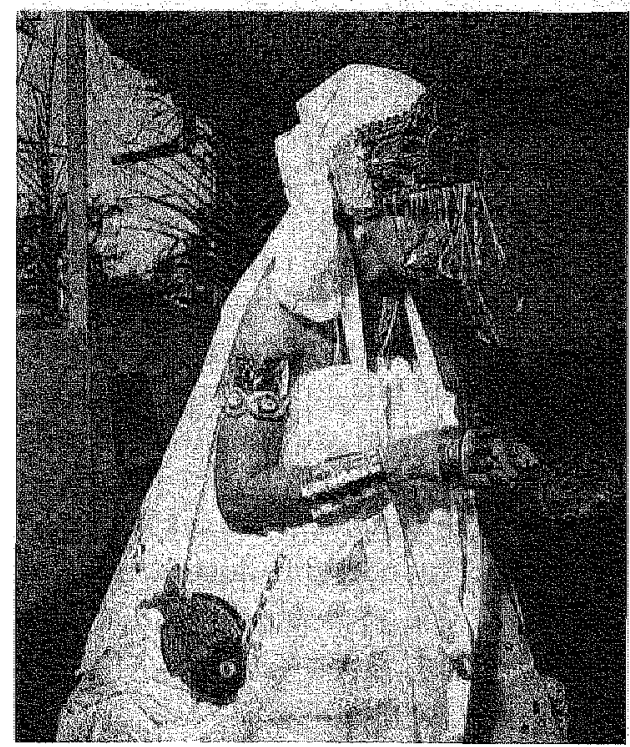

12 A publiciry photo for "Tlé Aiyé": a Candomble priestess, dressed to receive the divine spirit. Photo: Phyllis Gstembo. 
And a Candomble priestess, Zézé, tells of her own expetience: "It is wonderful to be able to receive another being in yourself, a being who comes to say something, a being who comes to heal..."

The documentary also registers some aspects the intricate cultural thybridization that formed Candomble. It explains that, when "animistic" ceremonies were repressed by Catholic government, Candomble survived by associating the Orishas with Catholic Saints. To complicate the situation further, there are also popular, secular expressions of Candomblé: "Tlé Aiyé" contains a short portrait of the "Sons of Gandhi", a carnival society, which uses the same rhythms. Its members celebrate, and also try to imitate, the non-violent life of the Mahatma. Byme also filmed the preparations for the Candomble ceremony, the washing of all the white ceremonial clothes, the cleaning of jewellery, the preparations in the "terreiro" or temple ground, scrubbing, leaves being strewn over the ground, and so on. "Ilé Aiyé" also shows a group of little children who practise sacred thythms on buckets and other improvised drums. All this helps to establish a sense of how Candomble is woven into the texture of the society. And Byrne included a good deal of footage from other filmmakers. He was convinced that "it was important to use a lot of other footage that showed that we weren't shooting one isolated event in place and time and that this stuff had been going on for a long time. The old black-and-white footage gives you that idea that this has been going on for a while-and that it happens in varying ways in different places. The footage has different textures." 19

Byme's documentary was shown on television in the USA as a part of PBS" "Alive From Off Center"-series. ${ }^{20}$ In Japan only, it was also available on laserdisk. In 1989, Bytne wrote liner notes for that edition, in which he enthusiastically embraces the spirituality of Candomblé:

Candomble is art, religion, music, theater, gastronomy, datnce, poetry, and mote all at once. If one looks at it (as an outsider) as an "instructive" play or dance then we see art that fulfils irs highest function: onienting us as to out place in the universe. And it does it in a very deep manner. It is at way of life that "instructs" without dogma (there are no written texts, sutras, torahs, or bibles). The instruction is almost by osmosis... one learns about balance of forces by listening, watching, and participating gesturally. It is a religion that, like the oriental principle of yin and yang, conceives not of an absolute good and evil or even a motality independent of circumstances, but of balance... of being in tune with the continum of natural cycles and processes....

Even the sacrifice and offering is a metaphor. In Candomble, the sacrifice of an animal, fowl, or: foodstuffs implies that we ate at one with the food we ear. We ate all part of the natural cycle of birth, ceath, decomposition... (where we become food for the living)... and life again. As we cat at plant or animal, it is with the knowledge that it has given its' life for us and we are aware that we too will someday participate in that some aspect of nature's cycle. It is at more humble kind of spirituality than some of us are used to...

Anyone who has grown up listening to rock and roll (or Latin music, gospel, be-bop, etc., ctc.) will not find the Candomblé expetience that strange. Music that has grown out of the Afro-Atantic tradition inspires, in those who enioy it, an altered state of consciousness and a joyous release. Re- 
fined, intensified, and ritualized it becomes a relligion... while in the secular sphere one gets a "taste", a bricf moment when one is aware and conscious of being a part of something greater than itself.
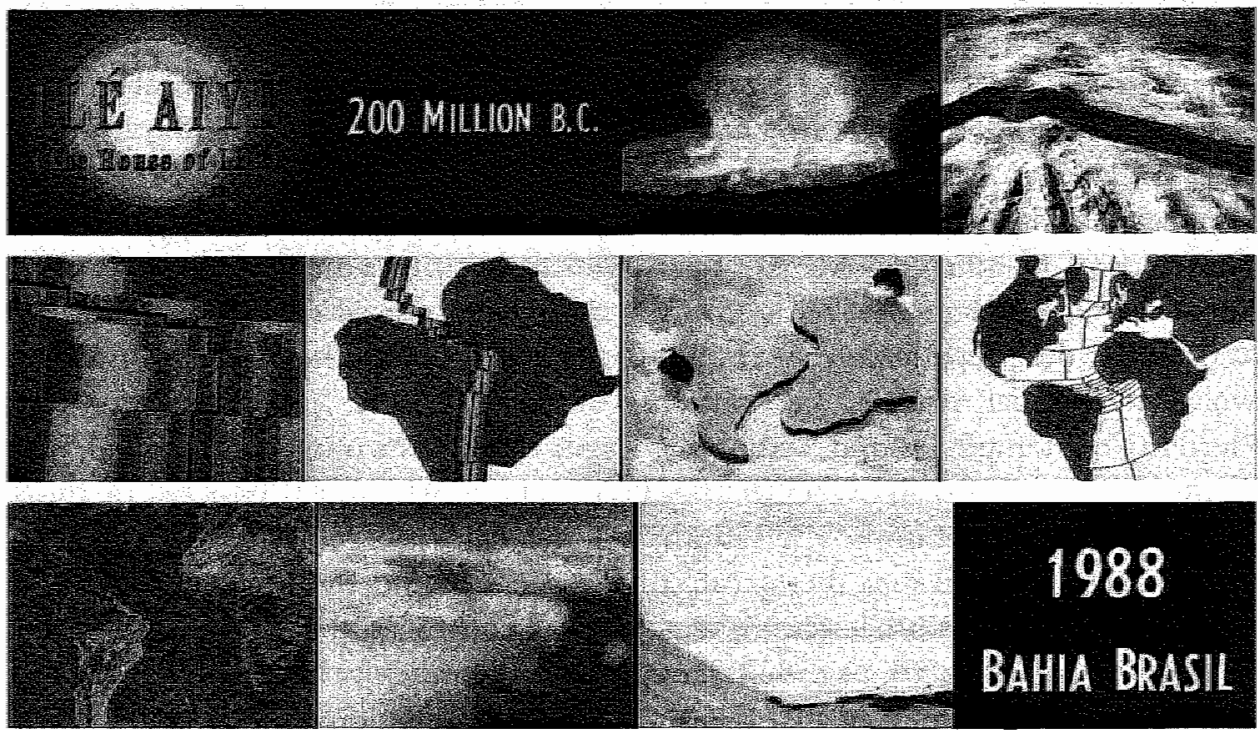

\section{8}

\section{BAHIA BRASIL}

13 The title sequence of "Tlé Aiyé": an ironic and diverse series of "establishing shots", linking Africa to South America.

If Candomblé instructs by osmosis, "Tlé Aiyé" attempts to do the same in an unassuming way. The use of the soundtrack to introduce the Orisha exemplifies this. Additions to the sound of drums beating out the rhythms clarify their meaning for the uninitiated viewer. An insistent metallic clanging portrays Ogun, the Iron Warrior; otgan music helps define the presence of Omulu, the Earth god, reigning over health and sickness, who has become associated with Saint Lazarus; a small segment of a light, melodiously swaying popsong devoted to Oshun or freshwater, the god of sweetness and love, implies the wider influence of Candomblé in Brazilian popular culture. Spelled out in words, this kind of montage of sounds may take on the appearance of a laborious construction, but when heard while watching the film, it is a series of added musical perspectives which may help to bring one's own relevant associations to bear on the Candomblé ceremonies.

A television critic, Ed Siegel, observed about the documentary: "David Byrne shows none of the humor and irony that he has shown toward American evangelicals. Is ZéZé [a Candombléan] any different from [American tele-evangelist] Tammy Faye Bakker, and is Candombléan culture any less an opiate than Western religions? ${ }^{21}$

Perhaps the act of transporting a musical ritual electronically, taking it from direct interaction between living people to a widely dispersed, MTV-conscious tele- 
vision audience has so many implications that an ironic posture is unnecessary. Byme, at least, was glad that he had been able "to do something almost completely without irony: because I was looking at this other culture. ${ }^{.922}$

\section{"REI MOMO": INCORPORATING A FOREIGN SENSIBILITY}

In 1989, Byrne recorded his first solo album of pop songs: "Rei Momo". The songs were each based on a Latin thythm (cumbia, orisa, merengue, mapeyé, bomba, cha cha cha, samba, charanga and bolero), and recorded with a choice selection from New York's Latin musicians. Of course, this development had been prepared by Byrne's work with the Talking Heads. Still, there is a noticeable difference between expanding one"s own musical style-American rock-by'including Afro-American and African elements, and adapting a musical form that has been developed mostly outside Euro-American culture. Latin music blends traditional African rhythms with the Western emphasis on melody and harmony. When he recorded, and later toured, with a Latin orchestra, Byrne was taking a step that may be compared-without exaggerating, since Byrne insists on the importance of music - to the transformation of an ethnographer who no longer studies a foreign culture as an outsider, but finds that the foreign culture has become deeply relevant for himself and "goes native".

The sensibility of Latin music differs from that of rock, in that it remains based on the communicative exchange of rhythmic patterns that characterizes African drumming and dancing. On this point, J.M. Chernoff has quoted R.F. Thompson's description of Latin dancing in "the world of Spanish Harlem ballrooms, where Puerto Ricans improvise constantly varying steps - dancing apart while their partners maintain a recurrent movement. These men "interrupt" the movement of their women in a call-and-response manner, for they begin a new step or flourish considerably before their partners have finished the execution of their basic movements." 23

In Chernoffs opinion, compared to Latin rhythms "It is particularly difficult to dance to white rock music... because the main-beat emphasis is retained and the use of off-beat accentuation and multiple rhythms is restricted. There is no room inside the music for movement." 24 Of course, rock songs have been used to display many emotional textures, but the dominating, foursquare beat seems rather appropriate to convey emotions of passive acceptance, interiorized melancholy, or the diametrically opposed, explosive assertion of pent-up inner convictions. Latin music is less given to such moods, since its musical foundation is rather dedicated to the open exchange of dramatic action.

To someone who has grown up with rock music, Latin music therefore has to sound superficial, lacking force and depth of conviction. As Byrne wrote in 1988 about Brazilian pop music: "I first heard music like this about nine years ago. I 
didn't "get it" then-I couldn't hear it for what it was... The "lightness" of much Brazilian pop music is often mistaken or confused for American middle-of-theroad bland radio ballads. We have come to associate lightness, subtlety and easy thythms with shallowness and music wthout guts. It is a mistake that can blind us to much of the world's great music" $" 25$

To Byme, Latin music must have presented a challenge: a tradition that was much doser to African thythms than rock or even funk, and also a tradition that had developed its own popularizations and its own stars. He combined this tradition with his own approach to songwriting on "Rei Momo". Around that time, he also began to present other strands of songwriting in the Latin tradition, which were little known outside Latin America, on album collections. This started his record label, "Iuaka Bop".

Byme had gradually gravitated towards Latin music. One night at "Sounds Of Brazil", a New York nightclub that specializes in African, Brazilian, and Caribbean music, Celia Cruz, the undisputed "Queen of Mambo" in the fifties who was later known as the "Queen of Salsa", invited Byrne with her on stage to play guitar. There, Byrne met Cruz's trumpet player and arranger, Angel Fernandez, whom he asked to arrange horn lines for "Mr. Jones", a song on the Talking Heads' "Naked" album. 26 Later, he recorded a Latin song, "Loco de Amor" with Ray Barretto's band for the soundtrack of a Jonathan Demme film, "Something Wild". Following that, he decided to write songs for an entire Latin album. He asked percussionist Milton Cardona to listen to his demo recordings and to suggest traditional thythms that would fit each particular song. Byrne later held forth on how each of these thythms brought a complete musical framework with it:

Ir's very interesting for me to see how matny tules there are. Thetre are usually at least three percussionists. If you say you're doing a certain kind of song, each of the percussionists knows what to do. When they get to a particular section, the song will have a chorus section and the bongo player will put down his bongos and pick up a bell and start playing a bell part. He knows what kind of part to play. .. If you say the thythm of a particular song is montuno, that tells you what cach person plays, the kind of lines the piano player plays. If you want, it rells you what kind of brass parts there are and if the song is romatnic or not: ${ }^{27}$

Afterwards, Byme would often suggest minor changes, and layer his own melodies and lyrics on top of the thythms. The resulting overall sound is a slightly crooked mixture. Bytne's voice is still nerwous, slightly wavering, telling of private reservations, qualinies that set it apart from the rhythmic patterns, which arte unreserved, sensuous and full of bravado. In hasty, generalizing terms: a white voice singing black music. "You're supenwhite!" one of the musicians reportedly told Byrne. ${ }^{29}$ On top of that, the studio production of the album used so many overdubs that the result in some places sounds studied and constructed. 
Yet, a touch of wryness in the music seems to fit Byrne's lyrics, which are as dispersed as ever, bespeaking of the impossibility to resolve the contradictions which arise on all sides, sometimes ironic, sometimes painful. That some songs combine English verses with Spanish choruses is only fitting.

The following fragment from the lyric of one song, "The Call Of The Wild", presents three actions that have a common goal: to bring light into the dark;

Abert Einstein wrote equations

God told Noah "Build an ark"

Johnny Mathis sings Cole Porter

To bring light into the dark...

But who could suggest a common ground for these three kinds of illumination? Who could even claim a comfortable understanding of one of them? The General Theory of Relativity sketches a universe that has properties which refute our dayto-day experience and intuitions; the story of the ark is as much as the story of God's willful extermination of mankind; Johnny Mathis is not the entertainer with whom either Byme or his audience would want to identify-and yet, adding another ironic twist, Byrne has recorded a Cole Porter song, just like Mathis. ${ }^{30}$

Other lyrics present half-surreal sketches of violence and repression mixed with longing ("Don't Want To Be Part Of Your World", "Carnival Eyes") or, in the album's opening song "Independence Day", use a hodgepodge of quotes from children's songs, highway signs, colloquial expressions and such to express an infectious and hilatious sense of freedom and independence:

This compass points in two directions

And North and South are both the same

We'll look forward to the good times

Come our Independence Day

Hey Lady! You make me giggle

We'll squaggle like honeymooners do

I'm struck by lightnin', it's frightnin'

So excitin', on Independence Day

"Rei Momo" is Portuguese for "King Mask" or "King Grin". As Byrne told during in interview, "Rei Momo" is a "cartoon of a teally rotund guy who's elected carnival king in Brazil. They give him a crown and pay respect to him, but they make fun of him, too." "Persona" is the Latin word for mask, a meaning that has developed into that of a personal character; originally, "per-sona" meant "sounding through", that through which a voice manifests itself. That this reference to the original meaning of the word "person" is not too far-fetched is at least suggested by Byrne"s song "Make Believe Mambo": 
Fe can be a macho man

Now he's a game show host

One minute hilarious comedian

Now he an undercower cop...

So how can we be stmangers

He's got no personality

It's just a clever imitation

Of the people on TV

These lines sketch a persona that borrows its personality directly from the television, in swift acts of mimicry-a mechanism that anyone who has grown up in a consumer society knows intimately. Here, it is depicted with such bluntness and exaggeration (compared, at least, to the more subtle treatment of the same theme in "Seen And Not Seen", on "Remain In Light") that this seems to call for strong condemnation, be it in political, aesthetical or religious terms. But the catchy chorus of the "Make Believe Mambo" invites the audience to sing along; it expresses tolerance instead of condemnation, implying that everyone is somehow included in this world of make believe:

Oh - let the poor boy dream

Oh . - livin ${ }^{3}$ make bellieve

I can be you and you can be me

In my munda, todo el mundo

Ex'ryone's happy and ev'ryone's free

Todo mundo, mundo mambo

Byrne was well aware that "Rei Momo" was an uneasy experiment, "probably too Anglo for the Larin radio stations and definitely too Latin for the rock stations that used to play Talking Heads." ${ }_{32}$ Together with his musical advisors, he also chose to neglect the traditional divisions within the Latin tradition, which define that samba has to come from Brazil, metengue from Santa Domingo, cumbia from Columbia, and so on. Instead, they provided an overview of different Latin thythms. Angel Fernandez, who arranged the songs for the "Rei Momo" concert tour, said about this variety: "you would normally need fifteen bands to do what we do. You would have a salsa, or a merengue, and never the twain would meet." 33

These are but a few aspects of the complications and divisions in the cultural arena that Byrne had entered. After all, the shared history of Latin America and the United States has been anything but harmonious. As a result, the combination of a white rock star with an orchestra of mostly coloured musicians (there were musicians with a Latin background as well as Brazilians and Anglo-Americans), inevitably reverberated with echoes of imperialism, racism and disdain for the 
otherness of a foreign culture the more so because Byme presented his own version of traditional rhythms. It was very easy ro insinuate that Byme was simply adding a bit of exotic flavour to his image, like so many rock stars did. At the end of the $1980 \%$, Paul Simon and Sting were but two of the most wisible pop artists to make use of African and Brazilian musicians, Madonna, Peter Gabriel, and Malcolm Mc Laren are some other examples. Byrne, with his intellectual and artistic affilations, was perhaps the most vulnerable to accusations of cultural tourism. and artistic exploitation. His strategy was to bring the underlying tensions, prejudices and contradictions out into the open. After all, that Latin music formed something of a ghetto in the U.S. ${ }^{34}$ was not his responsibility. Bytne could argue that he had simply stopped to respect the lines of segregation: "Instead of saying. "Let's go fat afield and find something exotic, something that'll be a new gimmick, a new sound," I can literally walk two blocks and see and hear a great deal of this music coming out of cats, coming out of doorways." 35

With the help of Angel Fernandez, Byrne put together an band of fourteen musicians, plus Brazilian singer Margareth Menezes, creating a big band orchestra that could play all the Latin and Brazilian styles as well as some Talking Heads" songs. This band made a world tour, taking pains to ensure that it included not only Japan, North America and Europe (usually the entire "world" of pop music) but also Central and South America. As Byrne has commented, there "audiences might be more familiar with the rhythms. I wanted them to hear first-hand what we were doing, and if there were to be any criticisms or complaints, I would be there to take them, face to face." If the album was constructed and gave the music a quality which might strike a listener hungry for "authenticity" as studied, flat and therefore unconvincing ${ }^{37}$, the live performances were simply exuberant, doing away with all reservations.

Byrne later published a Rei Momo tour diary ${ }^{38}$ which he had kept during the South American leg of the tour, in which he dealt with the complex questions sur rounding the authenticity and legitimacy of the project. The basic idea throughout this diary is, that music or thythms are not limited to a single people, but can be played by others, too. ${ }^{39}$ Byme notices repeatedly how the music that he embraces often seems to be neglected by the music industry in South America: "Throughout: most of our South American jaunt we heard very little local music, and if we did, it often sounded like a copy of North American styles." 40 He gives a sociological explanation for the lack of Brazilian music on Btazilian radio stations: "There"s a samba station in Rio, but you can't hear any Brazilian music, or very, very little in Säo Paulo and very, very little ... in Pôrto Alegre... it's the pressure of the multinationals ... but probably it's also that samba, the local music, is considered lowclass, the music of the poor. But rock-and-toll and jazz and other kinds of music are "refined", partly because they're foreign, and they are the music of the middle 
and upper classes. So all the kids aspire to listen to the music that might put their listening habits in another class." 41

A second theme throughout the diary is the history of political repression. Byme mentions musicians who were killed or exiled from Chile, Argentina, and Brazil. ${ }^{2}$ In Rio the Janeiro, he notes that due to the ticket price, he is playing to an almost entirely white audience, a very limited section of the population of the city. ${ }^{43}$ In São Paulo, he records a remark of musician Tom Zé about the people of the Brazilian Northeast: "for nine generations they've been undernourished and [had not] enough protein for their brains. Now if they make a little money, they receive more protein, and their brains become starved for stimulus. And what do they get? They get television, soap opera's." 44 He also passes on a conversation with one of the Brazilian percussionists in the touring orchestra, Cafe, saying that he "felt the had to leave Brazil to play Brazilian music! That it was very sad, people turning away from the riches of their own culture."45 Apart from documenting some of the hassle of a touring band, problems with stage checks, blowing fuses, air conditioning systems on fire, jamming, drinking, doing interviews and all that, Byme's "Rei Momo" diary openly and intelligently presents the cultural contradictions that surrounded the tour.

In the middle of the tour, the orchestra was joined by a new dnummer, Oscar Salas. Byme noted in his diary how his style of using more of the drum kit instead of Latin percussion gave the rhythms a sharper, slightly more muscular flavor. ${ }^{46}$ This was the musical direction he wanted to pursue next, since it would give him the opportunity to integrate his love for Latin rhythms with his more rockoriented past. In 1992, Byrne made a film of one of his concerts, called "Between The Teeth". He felt that the concert was "a kind of culmination of working with the Latin musicians in "Rei Momo" and then mixing in funk musicians and some of my other things. Here was a time when it was all coming together. It was a show that had an identity of its own, not an identity that takes from all those traditionals. So I thought, let's put this on film because after this I'll probably go and do something different." ${ }^{\text {, }}$ "

The film both opens and closes with solos by Byrne. He demonstrates his ability as a solo performer in six songs, including an a capella rendition of Captain Beefheart's "Well". But the heart of the film is a series of songs with the band, combining everything from samba and mambo to rhythm \& blues and pop. The personae that are presented here are contorted and interrupted by their surroundings as well as twisted and turned by their own impulses, and as Byme sweats and wipes his wet hait out of his eyes, singing, playing guitar, shouting, now hoarse, now almost crooning, producing a mad laugh where his lines demand it, his act seems to condense into a single statement. 


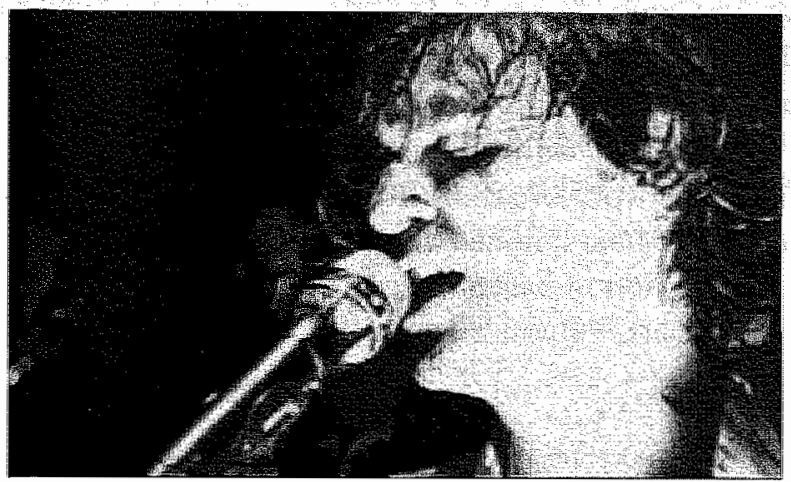

14 A scene from "Between The Teeth": Byme exerting himself while singing.

This film was more cheaply made and more basic than "Stop Making Sense"; but it captures a musical theater that is much more direct, physical and cruel-in Artaud's sense - than the older film. The song titles alone indicate this: "Something Ain't Right", "Life During Wartime", "Women vs. Men", "Hanging Upside Down", "Lie To Me", "She"s Mad", "Blind". Several songs ate interrupted by sharp breaks, shifting from a foursquare rock beat to the more open Latin rhythms, and vice versa, which causes the dramatic situation to shift between melancholy inwardness and extraverted interaction. Tensions are displayed and emphasized, not resolved. The "Make Believe Mambo" is an example in case: the song is no longer arranged as a unity. Instead, the two opening quatrains get a subdued organ accompaniment while the rest of the song is rendered full-blast, combining a Latin swing with rock, with Byrne singing at the top of his woice, sometimes shouting and laughing sardonically. This is topped by a ripping Latin trumpet solo by Ite Jerez, and followed by a finale, an arrangement for the brass quarter of the band with metronome-like percussion (evoking Byme's "Knee Plays"). This forms a clear break with the already strained rendition of the song. The overall impression is one of turmoil, of forces that refuse to be united in harmony. When interpreted as a commentary on 'make believe', this performance stresses its painful inadequacy: its patterns of call-and-response are devoid of respect and of continuity.

\section{SOUNDTRACKS FOR ANTHROPOLOGICAL ART DOCUMENTARIES}

Byrne made soundtracks to accompany four short documentaries by Philip Haas. "A Young Man's Dream" and "A Woman's Secret" document traditional sculptors in Madagascar and painters in Papua New Guinea. "The Giant Woman" and "The Lightning Man" are documentaries about two forms of Australian Abo- 
riginal painting. These documentaries were presented as an appendix to "Magiciens de la Terre", the great exhibition in Paris' Centre Georges Pompidou of traditional artists from cultures all over the world, held in 1989. This exhibition, which combined contemporary Western art with traditional non-Western art, was hailed as a step towards recognizing the work of artists from non-western cultures; at the same time, it was denounced by post-colonial critics for neglecting the influence of modernization on attists in non-western countries, presenting only what seems like "untouched" authenticity." Byme's approach is interesting in this respect. He tells albout his contribution:

Philip asked if I wanted to do music for some of his documentaries that he was doing for the Magiciens de la Tetre show in Parts, and I agreed, if I coulk do "unconventional" type scoring. Which I did. The rnusic for the abotiginal artists" film, for example, was inspired by a statement that the aboriginal artises made. When Philip asked them what kind of music they would like, they said Jimi Hendrix, and they usually liked the rave-up noisy drone-y ends of those songs better than the melodic parts: So I thought, hmmm, sounds like Glenn Branca style would be good...so I did the whole score with retuncd guitars, played in various unconventional ways, droning on, creating textures. They liked it, and I was happy.

Although this description might suggest a very loud soundtrack (Branca is notorious in that respect), Byrne's music is in fact unobtrusive and fits easily into the atmosphere of the sober documentaries.

For "A Young Man's Dream", he made music which is vaguely reminiscent of the instrumental passages of "The Catherine Wheel". Remarkable here is that the music of the soundtrack, recorded in the studio by Byrne, sometimes mingles with the music that has been recorded by Haas, while he was filming in Madagascar. When a group of women is seen singing and clapping, Byrne adds a bass rhythm; and when men are playing a self-made three string guitar, he adds some modest electric guitar notes. This mix of "authentic" music with -inauthentic? but in what tespect? - musical elements made in another country, coming from another culture, can either be interpreted as a form of harassment, or as a willingness to engage directly with others, instead of keeping them at a safe, scientifically justified distance.

\section{LUAKA BOP: A REGORD LABEL AGAINST HOMOGENEITY}

While he was filming "Ilé Aiye", and recording "Rei Momo", Byrne laid the foundation for his own record label, "Luaka Bop". This grew out of his habit of going into record stores to buy records blindly, without knowing what to expect. In the mid-eighties, Byrne had picked up some Brazillian records by Milton Nascimento and Caetano Veloso, which he found unusually inspiring. He began to make cassettes with his personal favourites for friends, and later decided to produce an album: "Beleza Tropical, Brazil Classics 1, compiled by David Byrne". 
Anxious to provide a context that would give the songs their full relevance, Byme printed not only the original lyrics with their English translations, appropriate footnotes added, but also two small essays, one by himself and one by Arto Lindsay, a musician from New York"s new wave-scene who was born in Brazil. Lindsay mainly provided historical and musicological backgtound, mentioning the "Tropicalismo" movement around singers Gaetano Veloso and Gilberto Gil, heirs of Brazil's 1920"s "Antropophagia" avant-garde: Byrne expressed his delight with the sophistication of Brazilian pop, and emphasized that its sweetness should not be confused with superficiality.

It is hard for us to imagine this music as being in any way dangetous, but the militny regime that ruled Brazil during the late 60 's and early 70 's found it quite threatening. ... Maybe these songs are a more human form of political pop than our rabble-rousing rock-epics which often sound too close to national anthems ot marches for me. ${ }^{50}$

This record was followed by compilations of other Brazilian styles, samba and forró, both presented with equall care. In the notes for "Brazil Classics 2: $\mathrm{O}$ Samba", which presents samba as intimately related to Candomblé, Byrne wrote an enthusiastic eulogy, titled "Philosophy of Samba":

Samba, like many other Afromatin music forms, propels and ignites the lower body-the hips, the butt, the pelvis, etc.-by letting the downbeat "float". By de-emphasizing the first beat of each measure a thythm becomes more sensual and ethereal; one "floats" outside the time and space of earthly existence. Repetition creates a timeless, communal otherwotld, a floating ethereal cycle that is both rooted in biological thythms and in the beyond of meta-biological.

Any activation of the hips-sex-butt-pelvis telates to the source of all life, the womb. This music is definitely a respectful prayer in honor of the sweet, the feminine, the great mother-the sensuous life-giving aspects of ourselves and our liwes-and to the Earth, the mother of us all. To shake your rump is to be environmentally aware...

Like all art, it is what it is, but it's something greater besides.

Parallel to these Brazilian collections, Luaka Bop presented three collections of Cuban music: one of "trovador" (troubadour) Silvio Rodriguez, one of Cuban dance hits of the ' 60 's and '70's, and one of new directions in Cuban popular music, including versions of reggae and of hard rock that are usually not associated with Cuba, the birth ground of son, mambo and salsa. Because Cuban music was banned from the USA from 1961 until 1988, when U.S. Congress allowed the importation of master tapes (it remained illegal to hire Cuban musicians, which was considered "trading with the enemy"), these collections helped to fill a gap in the tradition.

In 1995, David Byrne and Yale Evelev, by then the manager of Luaka Bop, presented two other collections. "Telling Stories To The Sea" is a collection of African-Portuguese music, from Angola, Cape Verde and São Tomé, but also from emigrants in Lisbon, Rotterdam and Germany. "The Soul of Black Peru" 
shows yet another facet of the African diaspora: Afro-Peruvian music. In liner notes, Fietta Jarque describes this mixture as "a unique blend of Spanish, Andean and African traditions. The language comes from Spain... from the Andes come the pantheistic religiosity common to both African and Andean cultures... and from Africa come the visceral and seductive thythms." Byrne added in the liner notes, "This is a sectet music... It's not the guys with the flutes and drums in woolly hats -it's music of the black Peruvian communities. Black Peruvians? Yes, Peru was involved in the slave trade too-and this wonderful, funky music is part of that legacy."

Byrne and Evelev do not choose the music they release on the basis of an explicit programme for the label, but follow their personal preferences. In recent years, Luaka Bop has mainly presented albums by individual bands and singers, instead of compilations. Bloque, King Changó and Los Amigos Invisibles are angry, loud and energetic bands from Colombia, Mexico, and Venezuela; Vijaya Anand composes and produces pop songs for Indian film musicals; Shoukichi Kina plays a blend of folk-rock that is unique to Okinawa, Japan. The USA are represented by, among others, Geggy Tah and Jim White (descriptions of their music might read "introspective Los Angeles funk surrealism" and "acid-folk Bible Belt angst"). Zap Mama, from Belgium, combines African and European melodies; Cornershop makes Britpunk with an Indian twang. Waldemar Bastos from Angola sings love songs for his war-torn country. Djur Djura, a Berber-Algerian woman singer living in Paris, sings of courage and love against the background of a repressive and fierce patriarchal tradition, civil war, colonialism and exile. Tom Zé, from the Brazilian northeast, combines experimental melodies and thythms with concrete poetry and sarcastic wit.

Thete is no common denominator to be found here. And yet, retrospectively, overlooking the first decade of Luaka Bop, it seems possible to formulate the label's policy. It does not look for "authentic" world music, for exotic musical forms that have remained untouched by Western influences. ${ }^{51}$ Instead, these musicians excel in connecting strands from different traditions, one of which is the global presence of Western pop. As Byme wrote in 1998, in his liner notes for "Beleza Tropical 2":

Sadly not only in the musical arena, but also in economic and social aspects, the Brazilians outpace us; they are the future. The world becomes more Brazilian every day - the Brazillanization of the great first world powers like the U.S. and U.K. Some call it globalization, some neo-liberalismo: the growing gap between rich and poor, thrown into high gear by Reagan and Thatcher, and proceeding unchecked, the destruction and waste of natural resources, every politician up for salle to multiple nations-these are all symptoms-soon we'll catch up to Brazil. One can only hope that we'll catch. up musically as well, and that their funky spirituality and inventiweness will also be emulated by each country in their own way. 
Instead of giving in to the sleek superficiality that is ptomoted by the record in dustry, the musicians of Luaka Bop seek to present their own musical experiences without effacing the inner contradictions. Their songs are more diverse, pungent and bitter than the hit parade, more politically realistic and honest about global modemization than most "world music". Anyone who has grown up with pop can find an entrance into these songs. Just having an entrance may be a long way from understanding their experience fully: but it is unusual anyhow to find, in the often isolationist medium of popular songs, the diversity and richness of contemporary history.

\section{BYRNE'S SOLO ALBUMS}

After "Rei Momo", Byrne has recorded four solo albums: "Uh-Oh" (1992); "David Byrne" (1994); "Feelings" (1997); and "Look into the Eyeball" (2001). "Feelings" was followed by an album of DJ remixes of the songs, titled "The Visible Man" (also 1997). Byrne's songs bristle with contrasts: the chorus may oppose the verse, the melody lines may go against the rhythm, lyrical lines clash with factual statements. For "Uh-Oh", Byme has co-written songs with Angel Fernandez (Latin influence from New York) as well as with satirical Texan country singer Terry Allen; arrangements are by Fernandez as well as by Tom Zé. (Some of these songs are included in "Between the Teeth".) "Feelings" was made in collaboration with a particularly great number of musicians, bands and producers ${ }^{52}$, resulting in songs that combine Cajun with Indian sitar, or Country \& Western with jungle. Byrne compares his songs to snapshots of mental states.

Byrne's songs do not project a single, self-contained voice, the way that Neil Young or Bob Dylan's voices have an identity of their own-vocal identities that are characteristic and convincing. Instead, Byrne orchestrates his voice in capricious patterns, where sarcasm clashes with mellifluousness. In this respect, his solo albums have been influenced by Brazil's "Tropicalismo"-songwriters like Caetano Veloso and Tom Zé: the songs contain a multiplicity of diverging mimetic impulses. The musical and cultural versatility of these albums is admirable, although at times the song material seems to possess more dramatic potential than is fully realized in the recording. Byme's solo albums do not make artistic statements that are as as unified and accessible as those presented by his albums with the Talking Heads, which helps to explain why they do not reach the same mass audience.

In concert, Byme is often able to overcome such limitations. A fine example is the way he concluded his concerts during his 1991 tour. During the concert, the presented song material from his entire career, including songs with the Talking Heads, songs written for Robert Wilson or for films by Wim Wenders and Jonathan Demme, as well as his latest songs. To end his show, as a kind of bonus, he 
interpreted a song that was a hit by Whitney Houston, "I Wanna Dance With Somebody". This is poppy, run of the mill dance-and-sex material, and one might expect Byrne to give this kind of song an ironic, distancing treatment. But the only irony was in the absence of irony: Byrne embraced the song, singing it as joyfully and exuberantly as Whitney Houston: "I want to dance with somebody / I want to feel the heat with somebody / with somebody who loves me." But he followed it immediately with a song of his own, "The Accident", a jagged, discordant arrangement for strings, clarinet, upright bass and tympani. The lyric evokes the disruptive aspect of life:

\footnotetext{
When you see an accident, do not turn your head and look away

I can see detectives are sifting through the wreckage we have made

It starts with only one kiss

It changes everything

$\ldots$

TV crews arrive on the scence

And the anchormen they break down and weep

Living proof that things ate not what they seem

It takes all these wild and wonderful things

To set me free
}

A tock star and an artist with a sensitivity that has been shapened by the legacy of John Cage, Bytne combines the most popular, natural sentiment with a sensibility for the random and painful face of reality.

\section{OTHER PROJECTS AND COLLABORATTONS}

Brief sketches of collaborations with other artists must suffice to tound off this overview of Byrne's work. The list does not aim to be complete, but to present some interesting additions to the map of Byrne's widespread artistic connections.

In 1985, Byme did a performance, "The Tourist Way of Knowledge" for a benefit for The Kitchen, New York's downtown center for experimental performance, theater and music. It is recorded on "Two Moon July", a video compilation.

In 1986, Byrne wrote two lyrics for Philip Glass, "Liquid Days" and "Open the Kingdom". Glass began by asking Byme to write words he could then set to music, and later invited Laurie Anderson, Paul Simon and Suzanne Vega to complete an album, named "Songs from Liquid Days".

Byrne contributed one-third of the music, somewhat Chinese-sounding versions of minimalism, to the score of "The Last Emperor", Bernardo Bertolucci's 1987 
film about the life of $\mathrm{Pu} \mathrm{Yi}$, China's last emperor. Other composers were Cong Si and Ryuichi Sakamoto. Bertolucci's spectacular film was the most expensive independent production in the history of European cinema, and was awarded with many Oscars, one of them for Byrne. (Later, Byme would contribute songs to scores for films by Jonathan Demme ("Married to the Mob" and "Something. Wild"), Wim Wenders ("Until The End Of The World") and Wayne Wang ("Blue In The Face"). The last movie featured songs by several Luaka Bop-artists.

Byme appeared in Obie Benz's documentary "Heavy Petting" (1989), about the sexual mores of America just before the sexual revolution. Footage from Hollywood films and from sex education films is combined with teenage reminiscences of Judith Malina (co-founder of "The Living Theatre"), Abbie Hoffman, Allen Ginsberg, Laurie Anderson, William Burroughs and others.

Together with editor David Wild, Byrne produced a $21 / 2$ minute film, "April 16, 1989 " out of footage for "Storytelling Giant", the compilation of Tallking Heads videoclips. Out of narrative sequences, they made a non-narrative, funny clip of actors just about to say their lines. The film was shown at the New York Film Festival.

In 1990, Byrne composed "High Life for Nine Instruments" for the Balanescu string quartet. He used his guitar to write all the lines for strings, over a vaguely African High-life groove.

In 1992, the four members of Talking Heads wrote reminiscent liner notes for a compilation album, "Sand in the Vaseline". Byrne began his notes by telling how the band had set out, but then turned to a condensed, factual description of the drugs he had used over the years, covering a wide spectrum from marijuana to speed, cocaine, heroine and a few other substances. He wanted to make clear once and for all that he had been a part of the rock and roll lifestyle, even though he did not go off the deep end. ${ }^{53} \mathrm{He}$ concluded this with some thoughts on drugs in general, shifting his perspective from one sentence to the next: "The wide spread use of drugs is a symptom of a sick society. The war on drugs is bullshit. Especially since the CLA is one of the biggest dealers around. Drugs raise money and keep young black males (mostly) docile." Of course, this amounts to a "confession", but it also demonstrates an honest, documentary approach.

In 1993, Byrne made a contribution to "Caged/Uncaged - a rock / experimental homage to John Cage", created by the Institute for Contemporary Art in New York to be presented at the 45th Venice Biennale of that year. Byrne used two of Gage's "Indeterminacy" stories and intertwined one of his own, making it hard to 
determine where one story ends and another begins. They are set in a chaotic and sampled background, but supported by a steady rock beat.

In the "98/"99 season, Byme expanded his role as promoter of musical diversity by hosting a television show, PBS"s weekly "Sessions at West 54th", showing live performances. An interesting example featured two acts: Ozomatli, an ethnically mixed consont from Los Angeles playing an amalgamation of hiphop, ska, salsa, funk and jaz, and David Byme himself, performing with a small band, combined with the Balanescu string quartet.

Byme and the Balanescu quartet played three songs by Byme. In conversation with Alexander Balanescu, Bytne asked why he had decided to take the string quartet outside the classical world, getting the reply that Balanescu had wanted to address the body more, to get less exclusively intellectual. "They finished their set with a cover version of "The Model", a song by the German synthesizer band Kraftwerk, known for its coldness: a real challenge for the quartet, as Balanescu said, since they have to take care not to make Kraftwerk sound too warm, too nice.

Byrne then introduced Ozomatli, calling them "a revolution you can dance to" and asking members of the band to explain their background. They met during a labour conflict, a strike that was meant to start a union for poor inner city youth in L.A. The purpose of this, as Byrne, quoting Chomsky, expressed it: "to oppose the manufacture of apathy in the U.S.A." 5.4

Bytne has described his experience with the pressure on television to homogenize this show: "Here is PBS, public television in the United States. Granted that it is the United States, there is commercial pressure everywhere, but I was surprised at how much other kinds of pressure there were on a show like this... They were under constant pressure from big record companies to put specific acts on, and under pressure from the subscriber stations. Each city decides whether they want the show that year or not. So they have to sell it to all these places, and some of them go: "We don't want none of that rap music down here." Or whatever. So they're under political pressures this way too... With a station that doesn't have advertisers and all that kind of thing, you would think that there would be a little bit more openness and freedom, but it is still very complicated." 55

In 1999, Bytne made a musical soundscape (including material from "Feelings" and "The Visible Man") for Belgian choreographer Wim Vandekeybus" ballet "In Spite of Wishing and Wanting". Vandekeybus uses a dance vocabulary from outside the world of ballet and combines it with film to create the non-narrative theater that has always inspired Byrne. 
In 2002, Bytne wrote lytics and sang the vocal for a track by the Btitish dance act X-Press 2. He sang about being lazy to an energetic dance accompaniment. The song was unremarkable, but turned into a minor hit in the U.K.

Finally, in 2002, twenty-five years after releasing their first album, the Talking Heads were inducted in the "Rock and Roll Hall of Fame". 


\section{CHAPTER 5}

\section{Photography and books}

\section{PHOTOGRAPHY AS A MIMETIC ARENA}

In 1990, Byrne began to exhibit his photographs in art galleries. In the years to follow, he exhibited photoworks in galleries and museums all over the world, and published three books of photographs. To some extent, this was a new artistic career, which Byrne pursued independent of his music. Then again, he has repeatedly drawn comparisons between photography and design on the one hand, and music on the other. To introduce Byrne's photography, some remarks on the mimetic arena of photography will be useful.

The photographic process provides a point of departure. The camera produces images through its system of lenses, film, shutter, followed by the developing and printing processes; and these images contain a detailed and precise reproduction of an aspect of reality. Everybody knows this, and everybody can take a picture, simply by pressing the button on most modern cameras. Of course, most photographers are aware of the fact that each step in the photographic process can be carefully chosen to obtain a specific photo: the link between reality and image is not simply one of mechanical causality, it can be influenced decisively by manipulating the light, the frame, the lenses, the choice of film, aperture time, diaphragm, et cetera. The field in which photographs function, however, is infinitely wider than the photochemical or photo-electronic processes that are required to make a photo. In broad terms of its subject matter, photography ranges far and wide, endlessly depicting natural and historical phenomena. The uses that are made of pho- 
tographs are just as diverse and complicated as their subjects, ranging from the family album to joumalism, advertising, science, art, and so on.

Photographs, moreover, have to be seen to fulfill their function, and seeing implies an interpretation, which depends on the sensibility, the conventions, the prejudices, and the training of the spectator, and on the context in which the photos are presented. The interpretation of a photo depends considerably on the avallable information about the photo, on the caption in the newspaper, as well as on the circumstances: photos are seen differently in a museum than in a book, or in private. And since more and more photos are present in the environment, reproduced on the sides of trucks, on notice boards, on identity papers and in hospital rooms, on boxes for cereals or washing powder, on TV, in magazines, and so on, most people have developed their own repertoire of responses to photographic images. Byrne's photography mostly tries to attract the attention of the spectator towards the investigation of this mimetic field.

Two perspectives on the interpretation of photographs are particularly relevant for Byrne's photoworks. One of these is the contemporary interpretation of phom tographs in terms of artistic performance. Such interpretations analyze photos in terms of a complex social interaction, in which several mimetic genres and poses combine and overlap: the private snapshot versus artistic formal quality, social reportage, scientific document, glossy publicity photo, and other mimetic projections have been investigated by many photographers working in the art world.

A second perspective that has influenced Byrne's photography is the Jungian interpretation of visual art, including photography, in terms of psychological symbolism. Jung's widely read book "Man and his Symbols" (1964) included hundreds and hundreds of reproductions of artworks and photographs to demonstrate that such symbolism can be found everywhere in the history of mankind. According to the Jungian analysis of symbols,

The history of symbolism shows that everything can assume symbolic significance: natural objects (like stones, platis, animals, men, mountains and valleys, sun and moon, wind, water, and fire), or man-made things (like houses, boats, or cars), or even abstact forms (like the numbers, or the triangle, the square, and the circle). In fact, the whole cosmos is a potential symbol.2

In his photographs, Byrne applies both these approaches; sometimes in combination, sometimes ranging from one perspective to the other.

\section{DESIGN AND PHOTOGRAPHY}

From the very start of the Talking Heads, the band members were involved in their presentation and in the design of their albums. Byrne took influence on the way the band was portrayed photographically, and designed the first rwo album covers. The use of NASA's "Portrait USA" for "More Songs About Build- 
ings And Food" began a series of group portraits that use special imageprocessing technologies. Byme and Hartison came up with a thermograph or heat-sensitive photo for the inner sleeve of "Fear Of Music", Weymouth and Frantz with computer portraits (at that time a rare sight) of the band's members for "Remain In Light". Fourteen years later, for his solo album "David Byrne", Byme presented a photographic investigation of his body which consisted of a studio portrait, studies of hands and feet, fingers and toes, an elbow, the neck and an eye, extreme close-ups of body hair and skin, X-rays of his molars and his chest, computer scan photos of different cross-sections of the spine, as well as a series of cell photos. This investigation obviously subverts the concept of the photographic portrait as revealing the intimate artistic personality, as by revealing more and more physical detail the photos become more and more impersonal.

The importance of photographers like Eggleston, Jenshel, Sternfeld, Klipper for the "True Strories" film has already been mentioned. In the "True Stories" book, Byrne combined their photos with his own photos, newspaper photos and clippings plus film stills and a version of the script. In his introduction, he wrote:

I'm hoping that this book will be the equivalent of the way we experience people and things in their environments. Out there lots of different things are going on the same time. You can change your focus from one thing to another and still keep the first thing in yout mind. You can look through other people"s eyes, or look with a changing point of view, at the same place. You can stand at one spot and focus on different things and really look at them in different ways simultaneously. It's an effect that sometimes can be achieved in the theater, but... It's easicr in a book, ${ }^{3}$

Another way of combining heterogeneous images was used for "What The Songs Look Like: Contemporary Artists Interpret Talking Heads Songs" (1987). Graphic designer Frank. Olinsky came up with the idea to make this book, for which some fifty contempotary artists would illustrate as many Talking Heads' songs. Byme embraced the idea, and helped select the artists: an unusual, international mix of fine artists, illustrators, photographers, and even an advertising agency, Studio Dumbar from The Netherlands. An unusual mix, since fine artists are usually very careful to protect their creative originality, and do not to like to be associated with illustrators who do commissioned work. But here, work by avant-garde luminaries like Robert Rauschenberg and Nam June Paik as well as work from a younger generation of artists such as Jennie Holzer, William Wegman, Jean-Michel Basquiat, Duane Michals and Krysztof Wodiczko can be found on the same pages as that of illustrators Sue Coe, Joost Swarte, Glen Baxter and Russell Mills. In the book, the lyrics were printed in justified columns, to resemble newsprint. Bytne contributed a collage made of twenty Polaroid photos, ${ }^{4}$ and wrote an introduction in which he addressed the ways in which images acquire meaning:

When the government or a comporation uses a picture, a specific meaning is intended. What are these pictures selling? 
If you knew an atomic war had broken out and you had at the most a half-hour to live, what would you choose to look at?

If you were putting a personal ad in the paper and couldn't use a picture of yourself, what image would you use?

$\ldots$

If these pietures are news, then the words can be thought of as captions, or, if the words are news, then the pictures ate the hatd evidence.

What are these pictures sellingt They re not selling tecords ${ }^{3}$

In 1989, Byrne published a photographic project, "We Eat We Are Eaten", in art magazine Artforum. ${ }^{6}$ On three double pages, photos on the right pages show public places or sanctuaries - an ex-voto room in a Brazilian church, a concrete monkey in the Tiger Balm gardlens park in Hong Kong, a roadside shrine in Japanwhile the pages on the left contain photographs of small objects. The objects are a bowl of feathers, a wrapped cloth bundle, and a metal block with a T-shaped recess. Each photo is identical in size; captions underneath the photos identify their subjects. Formally, the shapes of the objects more or less resemble shapes found in the photos on the opposite page, but their relation remains undefined. Are the objects as sacred as the church and the shrine? Or are these sanctified places as substantial, yet as opaque as the objects? The project's title, "We Eat We Are Eaten", places everything within the natural cycle of animal life, inviting the viewer to speculate on what is eaten here. Is meaningless presence eaten by the attribution of meaning? Is one meaning consumed by another, mote powerful? Is the search for meaning in artworks rebuffed by such windows on distant realities?

In second project, an insert in the Switzetland-based international art magazine "Parkett" (1990), Byrne continued this questioning. 'This time, he presented photographs taken in Tokyo and Hong Kong, of anonymously constructed sites: a lobby, "TV sets, jumbled street scenery, together with texts that dare the reader to interpret the textures found in these sites, to understand them as masks that reveal, tather than hide, the culture that produced them. "What does concrete joined to rosewood mean? In what context? Who cates?"

Again in 1990, Joseph Kosuth invited Byrne to take part in a small exhibition that he was curating, "Reproduced Authentic". This took place to celebrate the opening of a Tokio gallery. Apart from Kosuth and Byrne, Barbara Kruget, Sol LeWitt, Haim Steinbach and Jeff Wall took part in the exhibition. LeW/tt was very influential in early minimalism and conceptualism, while the others, including Kosuth, belong to a somewhat younger genetation of artists, each somehow investigating the social forcefield of representation. The concept of the exhibition was very specific: each artist was to send and image by fax from New Yotk to Tokyo, where the receiving fax machine printed high-resolution images on acetate. These in turn were used as photonegatives from which single black and white enlargements were made and shown. Kosuth's concept was that the shared medium 
would question the authenticity of the final prints, resulting in a "philosophically shared space" in which the larger theme of authenticity and its relevance for contemporary art would be broached. Kosuth's own contribution was titled "Ex Libris, W.B. (Tokyo), $1990^{\prime \prime}$ and consisted of a line from Walter Benjamin's essay "The Work of Art in the Age of Mechanical Reproduction", translated into Japanese. In English, the line reads: "One of the foremost tasks of art has always been the creation of a demand that could be fully satisfied only later." 10 Byrne's contribution, titled "Evil Eye II", was "a photo of Diana the huntress accompanied by Cupids, painted on a dinner plate in a kitschy approximation of an 18 th-century French style. The image is covered with flies, at which Diana seems to be swatting with her bow. Scrawled on top of the image are the Chinese characters for "violence", "envy", hatred", "anger", "fear", "greed", "jealousy", and "lies", at which she also seems to swat."11 Together, these three projects define the conceptual space which Bytne's photographic work tries to map.

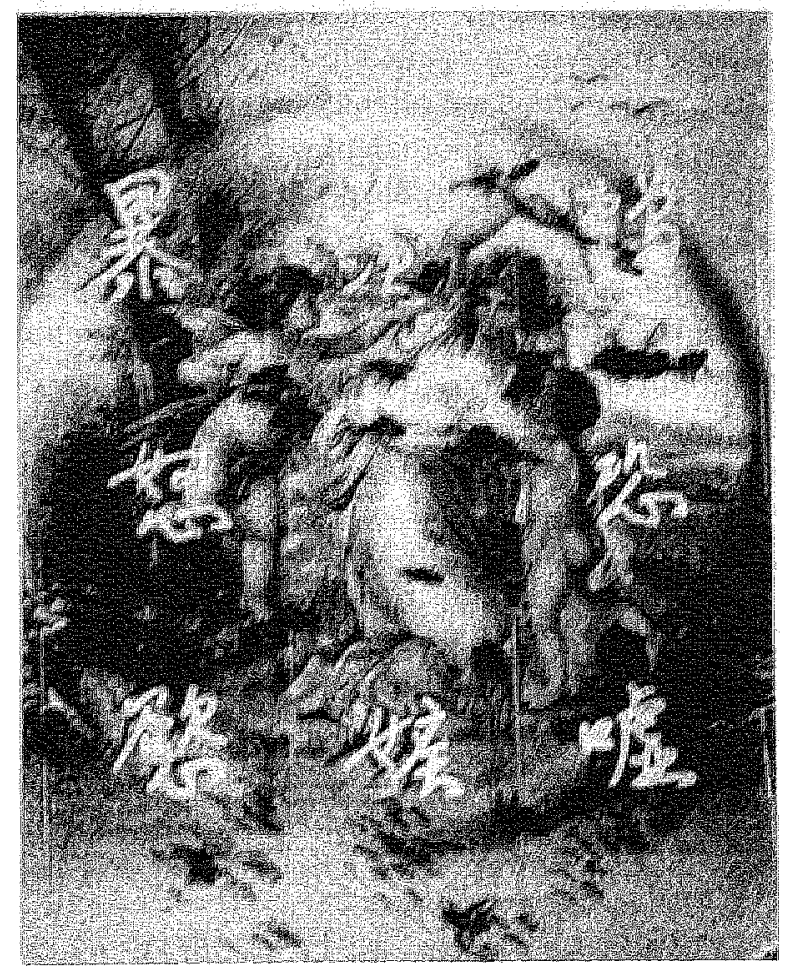

15 David Byrne: "Evil Eye I".

After this start, Byrne showed his photoworks internationally in galleries and att centers, sometimes having as many as ten solo shows in a single year. Prizes for 
his work rose steadily, a single photo, in an edition of 10 , would cost $\$ 700$ in 1994, and might fetch two or two-and-a-half times as much at art fairs in 1998. Composite works, like "Sleepless Nights II", consisting of 20 cibachromes, printed in an edition of 3 , would be prized at $\$ 7000.12$ His work was included in the collections of the Massachusetts Museum of Contemporary Art and the San Francisco Museum of Modern Art.

As might be expected, Byrne experimented with different ways to show his photographs. For his first solo museum exhibition at the Massachusetts Museum of Contemporary Art (1996), he designed an audioguide to accompany his work with a soundscape. He also included in this show a large miniature model of an American city, with some 400 model buildings and a huge train set, which he had found in storage at the museum. And he exhibited photos in anonymous public places, like commercial billboards, by having his work mounted in lightboxes on public toilets in San Francisco's Tenderloin District.

This diversity reflects the manifold ways in which imagery is present in daily life and influences the ways we see ourselves and the world: they try to make the spectator aware of his habits of seeing. As Byrne remarked in the introduction to the "True Stories" book, such shifts of perspective are often easiest to achieve in a book. So far, he has published three books of photography: "Strange Ritual" (1995), "Your Action World" (1998), and "The New Sins" (2001). The overall thematic of these books is motivation, both sacred and profane. Byme tries to capture these motivations indirectly, not by photographing people, but by comparing the scenery, the signs and the surroundings with which they surround themselves.

\section{"STRANGE RITUAL": DOCUMENTS OF SACRALIZATION}

Byrne's "Strange Ritual" book contains over one hundred colourphotos, most of them filling either a whole page or two opposite pages, plus some series that combine twelve or twenty photographs, arranged in neat grids. The pictures present a wide range of subjects: religious imagery and icons from several of the world's religions, film posters, posters depicting traffic accidents, double exposures of bungalows, hotel room fixtures, stacks of supermarket articles, shop window displays, handwritten messages, and studio photographs of individual objects and books. There are no portraits or photographs of living people, although many people are depicted in the posters and in the religious images.

The photographs are interspersed with texts; "Strange Ritual" is a book of pictures and words, as its subtitle states. "These words are as diverse as the pictures. A song lyric, "Strange Ritual" from the "David Byrne" CD opens the book. General hypotheses about contemporary culture each run along the bottom of several pages, like ticker tape, asking questions like: 
Will our consciousness be a complete pastiche? A patchwork of sounds, smells, and tastes?

We spend our lives listening to ourselves, watching ourselves, seeing how we are reflected, how we are responded to by others, and then we fine tune ourselves in onder to project accurately what it is we think we are. ${ }^{13}$

Then there are lists. Lists of potential houses for the Messiah, of Gods and Goddesses, of things that could be "at the center of my world", of things to worship, of ways to pay a debt. Four longer texts fill one or two pages: a short essay on the shifting of cultural and political meanings in Russia after the cold war ended, two diary fragments, a piece on the cultural influence of an imaginary TV channel called "Lifestyle". An afterword, and an interview with Byrne about his photography. On top of this, there are many words, names, titles, brand names, inscriptions and texts in the pictures.

The photos might be interpreted as a reflection of Byrne's career in music. Photos of hotel rooms date back to 1979 , when Byrne was on tour with the Talking Heads; scenes in Texas were taken while shooting "True Stoties". Photos made in a Berlin steel foundry relate to "The Forest", just as pictures from Bahia and from a Candomblé temple are connected with "Tlé Aiye". Film posters from Madras can be connected to Byrne's label Luaka Bop, which issued an album of Indian film music. But "Strange Ritual" is no photographic travelogue, and to look at it as such is to miss their meaning. Byrne has pointed out a formal distinction in his photo work: "I'm doing two different kinds of photography. There's what you'd call documentary photography, where something catches my eye and I want to see how it looks photographed, and there are other times when it's completely the opposite way, where I have a very clear idea of what I want and I need to create it either by combining some images, or setting something up in the studio, or taking a stock image and then putting a photograph on top of it." cording to an alseady classical distinction, proposed by John Szarkowsky, leader of the Department of Photography of New York's Museum of Modern Art, photography can be approached "as a means of self-expression (as a mirror)", and "as a method of exploration (as a window)". ${ }^{15}$ Byme freely combines both approaches, but casually erases the distinction:

Windows are mirtors through which we see ourselves reflected. Our wiew is coloured by our prejudices, history, and class. We see reflected our perceptions of the landscape, the skyline, the people on the street, the weather, and whot they mean to us. Photographs are also mirrors. In them we see reflected our own internal biases, our own assumptions, our own presuppositions. Tellevision is a mirror through which we see reflected our own internal culture, our personal lusts and fears, desites and hatreds. We see our concepts of knowledge-what it is and is not-what emotion is made of, and what constitutes feeling and what constitutes fact-rand whete the difference lies. What we don't see is a reflection of our face, we see instead a reflection of our interior. An X-ray mirror. ${ }^{\text {in }}$ 
This text runs under four double-page photos: one of trompe l'owil painted doors, one of which has been ripped off to reveal a reall door behind it; one of a wall in a hall, on which a simplified landscape has been painted; one of windows with luxurious draperies, and one of a wall mirror in which only a draped white curtain is reflected.

In this way, the photography is bracketed in language. While the pictures frame their subjects, they are framed in turn by words-challenging the reader to find their meaning mirrored in the photos. This framing and reframing suggests that everything in the photos is also framed, made meaningfull on purpose, thetorical and therefore theatrical.

Byrne's writing may give the impression of being heavy-handed. 17 Too literary for a book of photography, too much burdened by theory for literature, they seem to usurp the attention that should by right be held by the photography, the art. Then again, the writing may well remind the viewer not to take isolated photos too seriously, weighing their lines, their colours, the framing, the disposition of all the formal aesthetic qualities of photography. The writing invites the spectator to shun conventional, purely formalistic approaches to photogxaphy, as demonstrated in descriptions such as this one: "He [Byrne] plays with lines, using his camera to give six pipes, a bright red rail and the joints between tilles almost a higher, abstract meaning. Straight and slanting fields alternate thythmically." 18 Instead of this, the texts invite to look beyond exclusively formal aspects, which can only, inevitably, suggest that pictures always have a transcendental quality. Look instead, if you will, at the depicted subject matter, and realize that even in the absence of portraiture, every photo contains dramatic suggestions of the people who have invested its subject with meanings. ${ }^{19}$ The words remind the spectator that Byrne, in the act of photographing, is a member of that audience, partaking of the ritual, adding a layer of new meaning to the thicker strata of meaning already out there.

Byme's photos, like his texts, mix the sacted and the banal, the deliberate and the unintended, the collectively shared religion and the individual obsession, finding in all these a common denominator:

It is as if, in the store windows and comers of rooms, minor sacraments are offered up to us, and we only need to squint through the viewfinder to see them. There is a crazy beauty in these places that I am compelled to document. Contemporaty att exhibitions that only lack documentation, ${ }^{2}$ is

Documentation, then, is perhaps the best description to apply to Byrne's writings: documentation for both the seen and the unseen sites of meaning, of investing matter with the immaterial, of "sacrilization", as he puts it." All things considered, "Strange Ritual" is overtly conceptual: less interested in visual qualities as such than in the complex relationships between people and their visual environment. 


\section{"YOUR ACTION WORLD": PROFANE MOTIVATIONS}

Byrne's next book, "Your Action World" (1998), was inspired by corporate reports and motivational pamphlets. As Byrne said about this material, it is at "Literature that is a kind of non-literature. There are, as far as I know, no "serious" writers working in this field or in this genre. And yet these forms of litetature that we encounter every day: catalogues, junk mail, instruction manuals and advertising, have a profound effect on our sense of the world, on our sense of our selves: More than half our daily reading material is made by hacks and corporations." 22

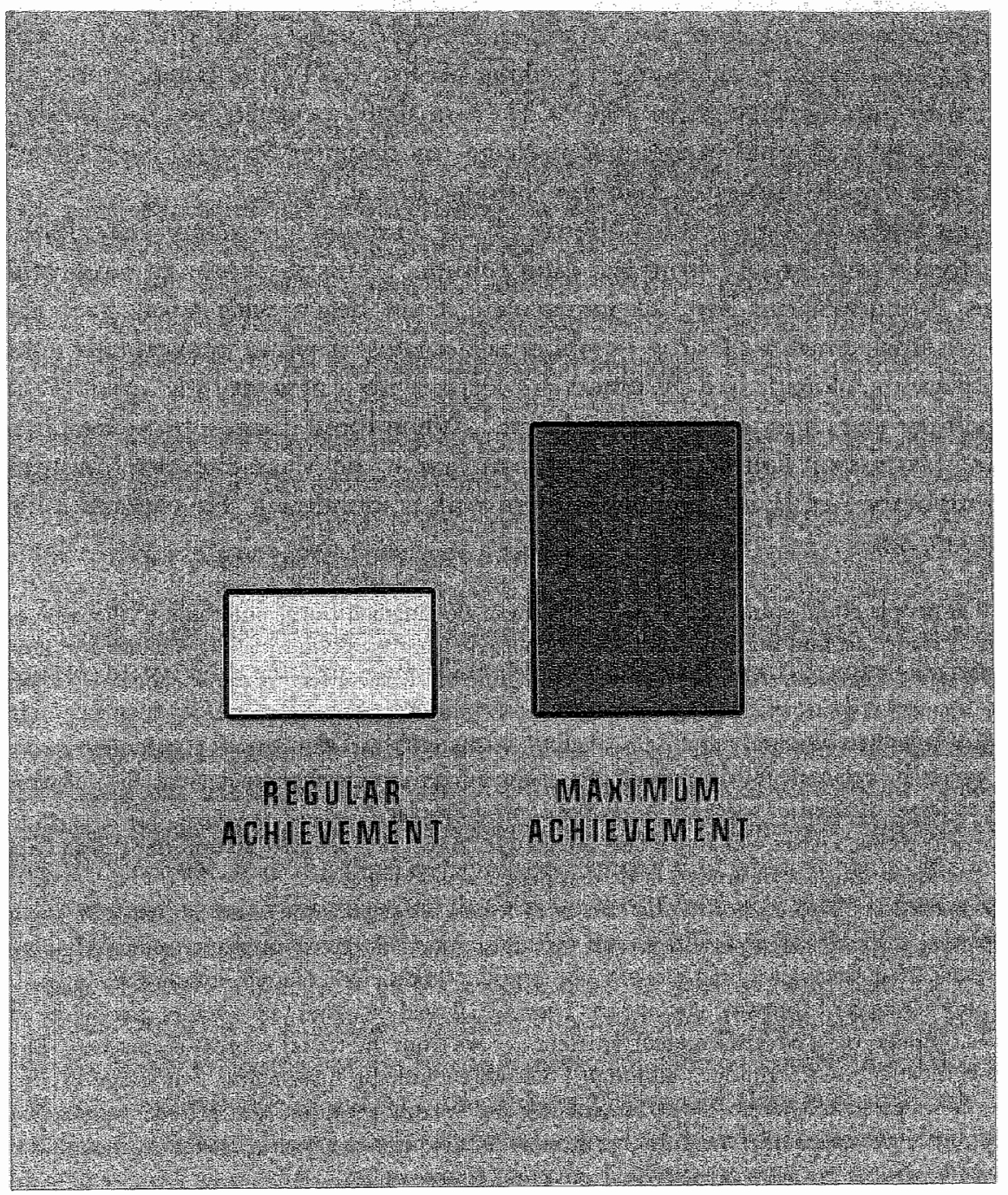

16. A page from "Your Action World", preceding a series of photos of bland hotel interiors. 
"Your Action World" is an oversized book, closer to the dimensions of a tabloid newspaper than to those of a paperback. The book, with a flexible cover out of yellow, synthetic material, is sold in a close-fitting transparent plastic shopping bag. Part of the book's title is printed on the bag, part on the cover, which means that the title is illegible as soon as the book is taken out of its bag. Again, the imagery is diverse. There are monochrome pages in bright colours, computerenhanced images, single photographs and collages of photos, photos of fout David Byrne dolls, a photo-novella; coloured photos of security cameras, a series of stone plinths bearing the names and logos of corporarions, and so on. These photos are ordered in sections and each section is introduced by a graphic representation of abstract concepts. For example: ACTIVE versus PROACTIVE, each word set under a diagtam suggesting a slacking off for ACTIVE (a falling line), and a sustained brimming fullness for PROACTIVE (a slightly curved horizontal line). Photography, text, graphic design and package (by designer Stephan Sagmeister) are even more closely integrated than the "Strange Ritual" book.

The first series of images, titled "Better Living Through Chemistry", combines touristic images with images from the drug culture. Touristic photos of land- and cityscapes (London's Big Ben, an immaculate azure beach with palm tree) are overlaid by small photos of drug paraphernalia against a white background, and with motivational slogans like "Winners are losers with a new attitude" and "You can't touch the stars and still remain at home". When these images, presented like advertising posters on lightboxes, were shown first at the Massachusetts Museum of Contemporary Art, Byrne combined them with a soundtrack. He explained his reasons to do so:

I realized that people could come into a room with these glowing lightboxes and think to themselves "how pretry", glance around for a moment, and then leave, like they do in most art galleries and museums. How could I get them to linger just long enough to allow the effect of the images to wotk on them?...

1 decided to imitate the museum "Acoustiguide"... the walkman-like devices common in many muscums which, by delivering intriguing and interesting information in short sequential doses, forces the wearer to linger in front of some of the works of art in display...

I warted to create a work which parallels the images. And I decided that 20 minutes would be a good and reasonable amount of time to hope that people would linger...

The texts used in "Your Action World" are both found texts and some written by myself. Some texts are existing inspirational and motivational messages, much like those on the images, and some are from travel brochutes describing farwway places and cultures. Others are Cangsta Rap lyrics... which are another kind of tomantic inspiration. They are all read by either voice actors (people hired to do voices on madio or in advertisements), amateurs or are from the found sources themselves. The music also is mostly "found" music... although I did write a little bit myself. It is a montage of music used for news progtams, cheap TV documentaries and low budget films. This is music maybe not identical to, but very very similar to, music we hear every day. It is our own soundtrack, the soundtrack to certain parts of our lives, written by anonymous strangers, ${ }^{23}$ 
In the book itself, the drugs/tourism images and motivational slogans are also shown in combination with a list of businesslike marketing tips, e.g.:

5. Use animals, pets and sports in your marketing communications.

9. Be cateful about teasing that involves uncettainty and suspense.

11. Always provide elosure. Be careful about change, change creates stress.

Of course, many artists before Byrne have situated their work in this sphere, where communication is both a technology and a form of merchandise. As Byme has said about advertisements, in a remark that characterizes such communication, "We might intellectually say we don't like them, but we do... They're ambiguous, dangerous, and exciting." 44 Of course, Byrne was not the first to notice this. In his own generation, Jenny Holzer, Jeff Koons and Barbara Kruger were there before him, and they many predecessors.

In their collaborative design, Byme and Sagmeister try to demonstrate how farreaching the influence of advertising on the perception of reality is. Today, even simple colours are signs tather than just colours. To prove this, the bright monochrome and bicoloured pages included in "Your Action World" bear tiny captions, printed unobtrusively, upside-down, in the lower left corners of the page. They give the code for the colours: Green and blue $=$ Bell Atlantic. Red and yellow $=$ Mc Donalds. Green $=$ Benetton. Red $=$ Coke. All in all, "Your Action World" is the secularized and industrialized counterpart to "Strange Ritual", an attempt to portray the world of commercial motivation.

\section{"THE NEW SINS": A CATECHISM OF CHAOS}

In 2001, Byrne accepted a commission to contribute to the Bienal of Valencia, Spain. He came up with "The New Sins", a bilingual English/Spanish book of text and photos. The English text is identical to the Spanish version, but both texts are accompanied by different photos. Its design imitates religious literature, especially the catechisms that are often presented at graduations and religious initiations. Pocket-sized, bound in wine-red imitation leather and with a cover that is lettered in gold, it is the kind of book one might find on a hotel room bedside table, or receive as a present from the Witnesses of Jehovah, the Christian Scientists, or followers of Scientology. The book fits Byme's long-standing interest in sacred rituals, dating back at least to his imitation of the gestures and rhetoric of evangelists, in "Once in A Lifetime". Byrne's "Strange Ritual" ends with a series of photos of quasi-religious books, bearing titles like "How To Do All Things", "The Book of $\mathbb{K}$ nowledge", and "You Can Live Forever in Paradise on Earth". Byme's analysis of these photos is that "there's a host of hilarious contradictions at wotk there: books are meant to be read, not to be photographed. Their function has been perverted and destroyed-any possibility of reading them has been denied. 
The titles, in general, promise the world and in most cases deliver disappointment. Photographically, they are treated as precious, rare items when mostly, they are just beautiful junk." 25 In a sense, "The New Sins" is Byrne's own version of these books.

Imitating catechisms and other religious literature, the first page offers blank spaces where the giver may write to whom the book is given, by whom it is presented, and on which occasion. Other traits of such literature have been copied with equal care. The texts is rife with "key words" printed in red, in capitals or underlined; many words and phrases begin with capitals; and ample use is made of thetorical questions, non-sequitur arguments and bewildering admonishings and metaphors. The general drift of the text, however, is an appeal to the reader the art-conscious, culturally reflexive, contemporary reader - to find structures of belief in unsuspected locations, outside the traditional framework of religion.

Byrne writes: "God created Sins!... Sins are woven into the fabric of our lives.... To abandon and ignore sin is to ignore and reject God's handiwork. Sins are made by Him - to enjoy and use until they have been eventually understood." And he continues: "Each culture and the society make their sins — sins are not eternal, fixed and forever. They are constantly and eternally in flux... Murder on the battlefield is an act of bravery, but in the home or in a public bathroom would be seen in a less flattering light. Is this a "bending" of moral standards for the economic gain of war, as the Marxists would have us believe? Or, as the Social Darwinists maintain, are we simply animals at heart, creatures of habit and instinct...??26

Explaining his notion of new sins, Byrne writes that they are usually mistaken for virtues. ${ }^{27}$ He enumerates ten of these virtues: charity, sense of humor, beauty, thrift, ambition, hope, intelligence/knowledge, contentment, sweetness, honesty, and cleanliness. Each is characterized by a brief explanation and a photograph, mixing humor, teligious metaphor, exaggeration and irony:

Hope carries more weight than all the other sins put together... Hope allows us to deceive ourselves into thinking that life is parceled into discrete chunks - that our liwes are stories with beginnings, middles and ends. That there IS narrative, linearity, and not chaos, chance and luck. Chaos is bearsiful $\geq 2$

A fold-out page in the middle of the book adds some more categories of sinning, in the form of a hierarchic Inferno (after Dante): sins of extreme self-control (a category that includes 'serious pop musicians'), sins of self-denial, sins of extreme logic, and sins of ideological adherence.

"The New Sins" employs several strategies to avoid closure, the most prominent of which are its many imitative features. The front cover carries a legend stating "translated out of the original tongues with the former translations diligently compared and revised." The Old Testament is mimicked, in sentences as "The 
Heart is like the Sea, wherein dwells the Leviathan, and creeping things innumerable." 29 And apart from the graphic features, the juxtaposition of photos and text is often undermining any projection of symbolic meanings; or, in reverse, the photos prove that everything can assume symbolic significance, as was suggested by Jung's theory.

As the text has it, "The pictures in this book will explain what the text obscures. The text is merely a distraction, a set of brakes, a device to get you to look at the pictures for longer than you would ordinarily." 30 One of the conclusions in the text, if it is that, may be taken as such, but not without reserve and caution:

We must think and feel AS NEVER BEFORE! ... We must judge our own sins! We must take the joy, the chaos, the tesponsibility and the pain and make them our own. Consume them and subsume them. Devour them and let them pass through ${ }^{31}$

Like Byrne's other photoworks, but more emphatically, "The New Sins" deals with the projection of symbolic meanings. The book demonstrates reflexively, by imitating, how mimetic impulses coagulate into the substance of mythology. The text plays with the notion that symbols and myths might be superfluous: "If the prevailing order in the contemporary world is scientific and logical, then faith the ultimate illogical act - becomes the enemy. If materialism, data and things one can touch, see and hear are all important, then mystical, invisible forces are to be eradicated at all costs. These unquantifiable forces are dangerous, threatening, for they could topple the Order of the World." 32 Against this modern credo, it reminds its readers that the history of mankind is one of ongoing re-enchantment: "The world has been beguiled, bewitched, enchanted, charmed, entertained, enthralled, delighted and captivated." 33

Byrne has framed two special forms of mimetic attribution of meaning in two exhibitions. "The Wedding Party" was an exhibition of his own photos combined with objects, investigating the beneficial aspects of fetishism. "Gesture, Posture, and Bad Attitude in Contemporary News Photography" was an exhibition of newspaper photos of politicians, for which Byrne acted as curator. "This was an attempt to highlight the ways in which news photographers add to the image of politicians, adding to their personal respectability and chatisma, or detracting from it.

\section{"THE WEDDING PARTY"}

"The Wedding Party" (1998) was an exhibition of large scale photographs by Byrne, portraying dressed objects and sculptures that Byrne had made together with his wife, actress and costume designer Adelle Lutz. The work is an attempt to inspire regular, everyday objects, like a radio, a vase with flowers, cutlery, an alarm clock and a table, with an aura. To bestow to the ordinary the dignity of the un- 
known, is to romanticize it ${ }^{34}$; Byme has tepeatedly formulated the same idea as the underlying principle of his method:

I try to take ordinary things and make them be seen in a new light, by breaking them up into bits and trying to teorganize them. ... I want to make boting things seem dramatic, instead of dramatic things seem boring. An ordinary thing put into an extraordinary place isn't ordinary anymore. ${ }^{35}$

"The Wedding Party" was inspired by Byrne's interest in Afro-American religions such as Vodou, religions that ritually invest regular objects with sacred properties by wrapping or dressing them in fabric, or by feeding them with offerings. Inspired by an exhibition of the sacred arts of Haitian Vodou, Byrne asked himself: "What if this dressing process were applied to other objects? Would it give them life and a sense of power? Would they likewise be treated by this ritual treatment? Could ordinary objects be given a kind of dangerous lifelike aura by merely dressing them? ... what if objects that already were somewhat anthropomorphic furniture, for example, were dressed in this way? Would it be simultaneously funny and powerful?"3s

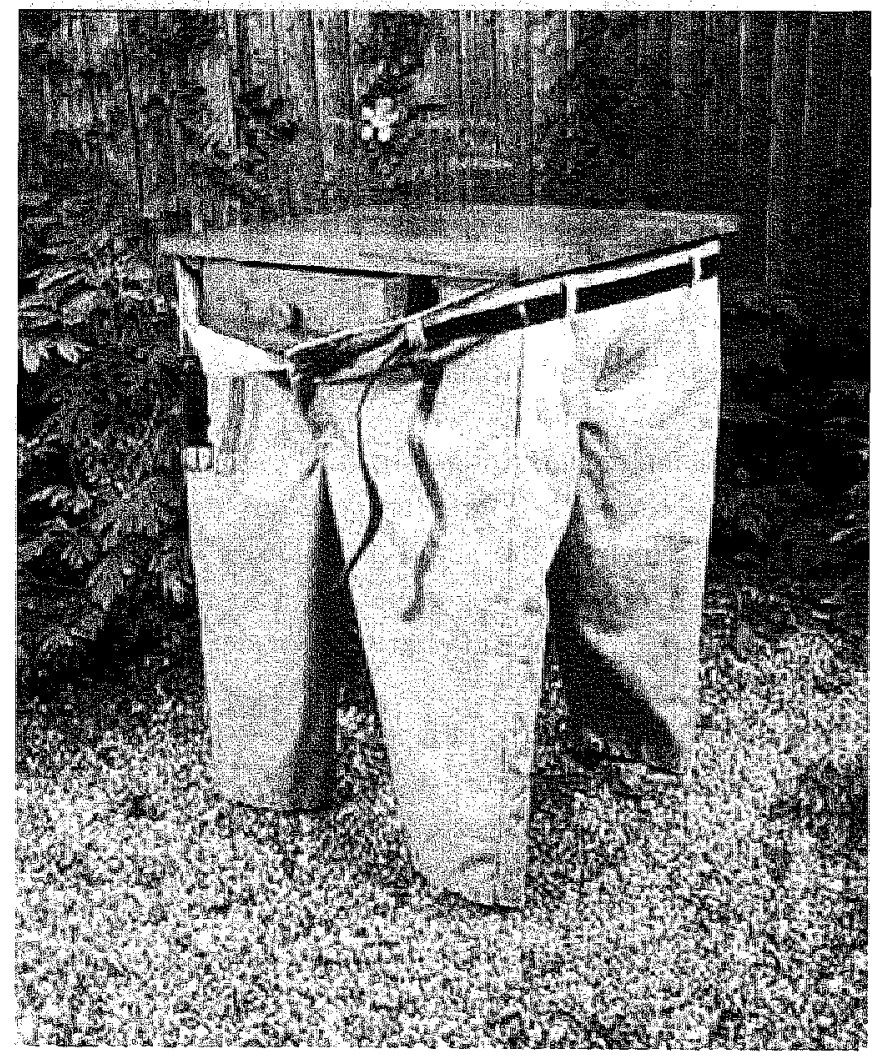

17 The Wedding Party: Tio Gullermo (framed Cibachrome and plexiglass, edition of 5$), 1998$. 
Once his objects had been completed, Byme found that they had indeed become animated, as he had intended, but in a completely different way. "T realized that instead of creating fetish objects, objects with powerful aufa's, as I'd originally intended, we had created little people. ... Rather than being contemporary votive objects they were caricatures of uncles, aunts and other family relatives... and when grouped together the images looked like a motley group assembled for a wedding portrait." 37

Sacralization is a central theme is Byrne's work, as it was in early Romanticism. For after all, sacralization is nothing else than the realization of an undefinably wider subjectivity. As Novalis wrote:

Everything arbitrary, coincidental, individual may become our ongan for the world. A face, a star, a region, an old tree, etc. may make an epoch in our interior. This is the great realism of the serwice of fetishes ${ }^{3 \%}$

This is coincides perfectly with Byrne's statement that

The impulse to attribute human attributes to objects is not stupid or wrong, as many scientists keep telling us time and again... we cannot be separated from the objects that surround as. They animate and initate us just as much as we imitate objects and animate them. By breathing a soul into dead objects, we feel and understand that the world is truly alive, not just existing as an aggregate of dead objects and lifeless landscapes, ${ }^{39}$

In chapter 10 , this comparison between Novalis' aesthetic philosophy of early Romanticism and Byrne's performative experiments in the popular arts will be elaborated further.

\section{THE DANCE OF POLITICS, DOCUMENTED IN PRESS PHOTOGRAPHY}

In the spring of 2001, Byrne curated an exhibition of news photographs for Apex, a New York (Lower Manhattan) art organization dedicated to facilitate exhibitions by different curators. Byrne selected regular news photos, taken mostly over the last decade, and intended for the daily press. The photos thus function within the strict parameters of daily news coverage. He had them all printed in black and white, almost all as identically sized prints, to reveal their similarities. Together, these photos are intended by Byrne to reveal what he calls 'The Dance of Politics'. The show was named "Gesture, Posture, and Bad Attitude in Contemporary News Photography".

In an accompanying leaflet, Byrne explains his curatorial concept: "The photos I have chosen represent a documentation of a sort of choreographed performance. A dance of politics." He proposes to the reader to consider his selection of press photos as if they represented a highly elaborate contemporary performance, taking place in over 100 cities. This imaginary production would be run simulta- 
neously in all the world's capital cities", as such, it could be understood as a conceptual extrapolation of Robert Wilson's "CIVIL warS". Like many postmodern choreographers, Byme proposes to understand routines that have been lifted from everyday life as dance forms, each with their own specific formal requirements. In the leaflet, Byme writes:

Just as singers have stereotypical moves and gestures, so do those whose profession is the art of politics. It is learned by studying one's peers, one's predecessors and countless hours of TV vieving. Viewing with a special eye - for the ordinary member of the public seems to be completely unaware, at least consciously, of the staging and work that has gone into their news programs.

However, students of quotidian movement, dysfunctional neurologically damaged patients and now ourselves - are awate of the conspiracy. An aesthetic conspiracy so vast that even its originators are no longer aware of its existence. The deception, if that is what it is, has even deceived the deceivers. Perfect. It is as it should be - even the choreographer, the artist, is charmed by his or her own work.

In the theatre of politics, most performers are dressed in the uniform of respectability: dark suit, white shirt, sober tie. Typical staging artangements include displays of tasteful, classical furniture and art, or shining cars, in combination with the paraphernalia of the mass media: microphones, cameras, studio monitors and the like. Gestures are slowed down, sometimes almost frozen, and often repeated to provide the assembled photographers and cameramen with the opportunity to make their shot.

Byrne mixes these images of politicians with other news photos: dramatic scenes of people in turmoil, crying, hiding from gunfire, or showing "bad attitude": a small Asian girl smoking a cigar, overly emotional men (fighting? witnesses of war or of disaster? who knows, once the caption and the article have been removed from the photo?') The contrast helps to make clear that the photos of politicians, almost without exception, project composure and reasonable consideration, which includes a serious face and a controlled posture.

In a recent essay on the way in which television represents politics, French sociologist Pierre Bourdieu has commented on the extremely limited information that IV provides for the majority of the people for whom IV is the only source of political information. According to him, television offers "precious little, except for what can be learned from seeing people, how they look, and how they talkthings even the most culturally disadvantaged can deciphet, and which can do more than a little to distance many of them from a good many politicians." Byrne's exhibition of contemporary news photography could be interpreted as making a similar point about press photos.

This chapter on photography and books concludes this first part of the book, cataloguing Byme's work and concepts from circa 1975 until 2002. In 2002, David Byme turns fifty, an age at which many artists are only halfway in their career and artistic development. In the years to come, that might turn out to be true for 
Bytne, too; but who can predict the shapes and masks that his work will assume in the future? 
PART II

THEORIES OF PERFORMANCE 


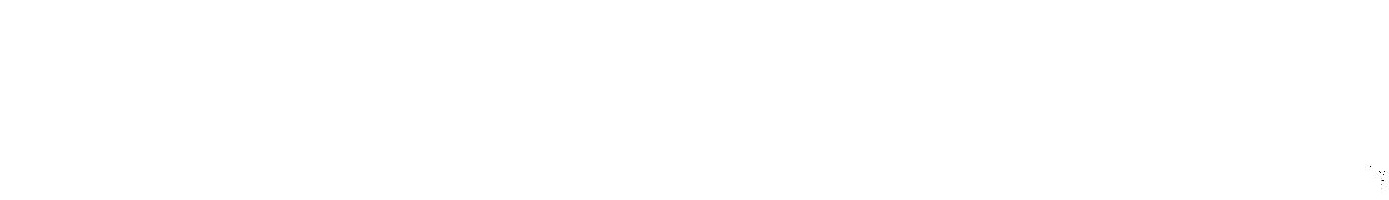




\title{
CHAPTER 6
}

\section{Exploring the foundations of performance}

\author{
BYRNE'S THEORETICAL ORIENTATION
}

As a performing artist, Byrne is not hampered by the methodological prescriptions and disciplinary constraints that characterize the work of the acadenic professional. When he invites an ethnomusicologist to record with him, or mentions an architectural theorist in a handout to the press, he does not have to concern himself with the position of these scholars within the schools and debates that define their respective fields. His aim is first of all to come up with a better record, or to challenge joumalists to write mote interesting interviews. The artistic performance is both the point of departure and the destination of Byrne's theoretical excursions. All the same, theoretical concerns have always been part and parcel of Byme's work: his theoretical orientation has enabled him maintain a consistent artistic identity, even while switching rapicly between media and gentes. Moreover, without an encompassing theoretical orientation, Byrne would not have been able to work within the popular media without giving in completely to commercial pressures and conventions. For these reasons, an overview of his theoretical orientation has much to offer towards a further understanding of Byrne's work.

Byrne has borrowed freely from a wide range of sciences: psychiatrists, neu rologists, psychoanalysts, art historians, cultural anthropologists, sociobiologists, and more. It would not be very helpful to summarize every book in this somewhat haphazard selection, or to connect all these theories to one another. Rather than trying to be exhaustive, this chapter is restricted to two theoretical approaches to 
performance, both of which claim to be relevant for understanding human behaviour in general. The first of these is the idea of a collective unconscious, a biological basis for the myths that can be found in every human society, as elaborated by psychoanalyst Carl Gustav Jung and, in a separate but related manner, by Joseph Campbell. The other approach is the sociobiological perspective as put forward by Lionel Tiger and Robin Fox, the idea that the social sciences should be integrated with the study of the evolutionary characteristics of the human species.

This interest in psychological archetypes and in sociobiology shows Byme to be a child of his day and age. As was pointed out in the introduction, Jung was widely read during the 1960 's and ' 70 's. Sociobiology similarly attracted a great deal of attention and debate in the ' 70 's and ' 80 's, especially after the publication of Edward O. Wilson's "Sociobiology: The New Synthesis" in 1975. But however open to trendy interpretations and superficial readings these theories may be, the encompassing biological and comparative perspective on cultures and societies that the sociobiology of Tiger and Fox has in common with Jung does imply a specific orientation. It forbids an outlook on cultures that presents them as fundamentally incommensurable; and this is true not only of cultures, but also of art forms; it also does away with the notion that the humanities and the sciences are incommensurable. Opposed to such compartmentalization, it positively invites comparisons across cultures, art forms and disciplines. Of course, such comparisons may end up in misinterpretation - but this price has to be paid to avoid a more serious mistake: the belief that cultural complexes are basically incomparable.

Another characteristic of this theoretical orientation is that it is not deterministic in outlook. Though it wishes to consider all human behaviour from a biological point of view, it does not follow that the heterogeneity of behaviour is determined by a few simple underlying mechanisms. On the contrary, more insight in the biological foundations of human psychological and social behavior may result in an increasing freedom to switch between different mental states, between rituals and genres, and thus result not in determinism, but in cultural innovation.

Such broad generalizations about cultural exchange may result in nothing so much as a desire for detailed examples. The question to what extent the emphasis on evolutionary, pre-historical properties really has something to add to an understanding of modernity will be broached in general terms in the last section of this chapter. But the detailed answer to this question can only be given in the next two chapters, which compare Byrne's work to the contemporary theory of performance theatre, as well as to the recent work in cultural anthropology that compares the capacity of ethnography to produce cultural translations to similar attempts at translation by visual artists, filmmakers, musicians, and theatre makers.

To avoid misunderstanding: the purpose of this chapter is not to suggest that Byme's work is exclusively guided by academic theorizing. When I asked him 
about books that had been inspiting him, Byme fitst mentioned a number of scientific monographs, and then added: "These are all non-fiction books, but it would be a mistake to think that fiction or television or mowies or artworks or performances don't have as strong an effect on one's outlook or worldview" "Scientific theories function in combination with other forms of cultural representation. Nevertheless, these theories fulful an important role: they help to see parallels in different kinds of performance and in different cultural spheres, and give direction and shape to the creative process. Theories help to produce work that is not simply performative, but uses performative methods to reflect on the nature of performance.

\section{THE UBLUUTY OF MYTh, ACCORDING TO JUNG AND CAMPBEL}

Byrne has mentioned the work on psychology by Carl Gustav Jung (18751961) and the studies of the world's myths by Joseph Campbell (1904-1987) as sources of inspiration. Both scholars have included a great deal of material in their work: their comparisons of myths from many different cultures and ages demonstrate that mythology has accompanied mankind always and everywhere. Jung, moreover, has posited that the effectiveness of mythic symbols to organize the human passions is grounded in archetypes, ptimary mental patterns shared by large groups of people, in what Jung has termed the "collective unconscious". This theory is the foundation of Campbell's work, which means that in respect to the study of myths as cultural forces, both oeuvres are closely related. Since Byme is interested in Jung's work on archetypes and symbols tather than in his psychiatric method, it is legitimate to discuss Jung's work here in combination with Campbell's.

Campbell has given this description of the meaning of myths: "A mythology is an organization of symbolic narratives and images that are metaphotical of the possibilities of human experience and fulfillment in a given society at a given time."2 Following Jung, he considers mythology to be a function of biology: "every organ of the body has a different energy impulse, an impulse to action, and the experience of the conflicts of these different energies inside, is what constitutes the psyche... mythology is the expression in personified images of these enetgies." "3

Campbell points out that all children spontaneously form animistic conceptions, symbolic fantasies about the origin of their world and its inhabitants. Such animistic ideas can be elaborated and organized into myths, which give a symbolic form to some of the basic facts of human consciousness: insofar as these are biological and therefore universal (for example a child's dependence on its elders, the organization of the senses, the basic drives), myths from different cultures are analogous, which means it is possible to translate and compare them. And the 
same is true of forms of ritualization and sanctification which are, similarly, elaborations of symbolic fantasies. Mythology, considered in this way, is closely linked to the human psyche. But it remains to answer the question what the relevance of mythology is for adults, and especially for adults in a modern society which prides itself on its independence from nature.

To grasp the outlines of this ambitious intellectual project, it is helpful to compare the Jungian approach to Freudian psychoanalysis. As Campbell sketches this contrast; "The Jungian unconsciousness is based on a biological point of view. The energies that inform the body are the energies that inform our dreams. But these dreams are inflected by our personal experiences. The Freudian unconscious, which Jung called the personal unconscious, is basically biographical, not biological." "These different conceptions of the unconscious correspond to different conceptions of the adult psyche. Freud was inclined to think that a healthy adult mind does not need a mythology. The Freudian unconscious is but the result of the mental repression of thoughts and impulses which it cannot consciously accept; a healthy ego doesn't need to revert to this mechanism. Instead, a healthy adult relies on contact with other people, and on the experience of reality that is communicated in this exchange, to form his understanding of the world. According to Freud, religion is merely the accepted form of mythology in modern civilization; in due course, it should therefore give way to enlightened scientific realism, which is able to unmask all myths as mere illusion.

Jung, on the other hand, considered myths to be a valid source of motivation, shaping psychic energy throughout life; according to him, the adult mind is the mind which knows and accepts its own mythical foundations. Campbell has summarized this view:

C.G. Jung ... identifies two fundamentally different systems of unconsciously motivated response in the human being. One he terms the personal unconscious. It is based on a context of forgotten, neglected, or suppressed memory images derived from personal experience (infantile impressions, shocks, frustrations, satisfactions, etc.), such as Sigmund Freud tecognized and analyzed in his thetsupy. The other he wames the collective unconscious....

"The primary image (xirtim $/$ icher Bild) [jung writes], which I have termed 'archetype", is always collective, ie. common to at least whole peoples or petiods of history. The chief mythological motifs of all times and races are very probably of this order; for example, in the dreams and fantasies of neurotics of pure Negto stock I have been able to identify a series of motifs of Grek mythology."

"The primary image", he then suggests, "is a memory deposit, an engtam, derived from a condensation of innumerable similar experiences... the psychic expression of an anatomically, physiologically determined natural tendency..$^{5}$

This Jungian theory of archetypes is a development of the earliet theory of "elementary ideas" (Elementargedanken) of Adolf Bastian (1826-1905), a theory that stressed the psychological, spontaneous aspects of culture as primary, contrasting 
these with the ethnological aspect of culture. This theory, as summarized by Campbell,

assumes that there is in the structure and functioning of the psyche a cercain degree of spontaneity and consequent uniformity throughout the hiscory and domain of the human species-an order of psychological laws inhering in the structure of the body, which has not milically allered since the perod of the Aurignacian caves and can be as readily identifed in the jungles of Brazil as in the cafes of Paris, as readily in the igloos of Baffin Land as in the harens of Marrakech.?

Therefore Jung is able to posit the existence of a biological unconscious, called the collective unconscious, shared by all human beings. As Jung postulates, "the psyche is not of today; its ancestry goes back many millions of years. Individual consciousness is only the flower and the fruit of a season, sprung from the perennial thizome beneath the earth; and it would find itself in better accord with the truth if it took the rhizome into its calculations." "Thus,

Creative fantasy also draws upon the forgotten and long buried primitive mind with ths host of images, which are to be found in the mythologies of all ages and all peoples. The sun of these images constitutes the collective unconscious, a heritage which is potentially present in every individual. It is the psychic correlate of the differentiation of the human brain. This is the reason why mythological images are able to arise spontaneously over and over again, and to agtee with one another not only in all the comers of the wide carth, but at all times. As they are present always and everywhere, it is an entirely natural proceeding to relate mythologems, which may be wery far apart both tempomilly and ethnically, to an individual fantasy system."

Jung's psychology of the unconscious is directly derived from the romantic philosophy of nature, which posits the organic unity of man and nature. In contrast to the rationalism of the Enlightenment, which separated body and mind, this romantic thinking holds that the cosmos forms a unity which comprises both mind and matter, history and nature. The unconscious is seen as the location where the transition from animal to psychic life takes place. This philosophy of nature is otganized around the idea of the organism that unfolds from its original seed, according to an inborn law. In Jungian psychology, conscious identity unfolds organically from the unconscious. ${ }^{10}$ The unconscious is, for Jung, an carly stage of the conscious mind: a stage which has to be overcome, but which also contains within itself the force to realize the overcoming.

Some biologists have concluded from the helplessness of newborn babies that all people are born prematurely, since they lack the capacity to survive independenty. In this context, Jung has called myth the second womb, which holds the prematurely born human being for a while within the realm of nature, until it is finally released into the historical and cultural world- - a release which is, according to Jung, often paid for by regression. "The unconscious remains the fertile soil for all creative activity, as demonstrated by the history of religions, by mass psychology and by the psychic life of anyone who has ever hoped or striven for some- 
thing. Still, for the average personality it is better that the whole gamut of associatons which is based in the unconscious is curbed by consciousness. ${ }^{12}$ This predominantly positive conception of the unconscious stands in contrast to the Freudian emphasis on the unconscious as product of repression, with the ideal of the "I" which results from the mediation with other people and with external reality, and strives towatds autonomy which is based upon scientific insights. ${ }^{13}$

According to Jung, the mythical fantasies which arise out of the unconscious serve a real purpose, since they are the origin of thought which is directed towards reality. Archetypes and mythical symbols may help to achieve this inner development, as well as a successful passage through the transitions which everyone has to achieve in life, going from childhood to puberty, from maturity to middle and old age. This theory is the basis for Jung's method of "amplification", in which the therapist helps the parient by clarifying his or her symbolic representations by means of analog imagery from the history of mankind. ${ }^{14}$ A crucial aspect of this method is that it emphasizes the similarity of psychotic delusions and the symbolism of myths and religions. ${ }^{15}$ Jung wrote: "I am therefore of the opinion that in general, psychic energy or libido creates the God-image by making use of archetypal patterns, and that man in consequence worships the psychic force active within him as something divine."16 According to him, "the genesis of this figure is a natural process with a teleological orientation in which the cause anticipates the goal. As it is a natural process, it cannot be decided whether the God-image is created or whether it creates itself." 17 "It is a psychological fact that an archetype can seize hold of an ego and even compel it to act as it- the archetype-wills."18

His conviction that archetypical symbols arise organically and teleologically from human nature provided Jung with the justification for lifting symbolic material from its original context. In his search for archetypes, Jung combined material from dreams, myths, fairytales, children's fantasies, delusions, spiritual traditions, alchemic teachings and from the dogmatic formulations of revealed religions, without regard for the different ways in which an individual believes in them. In response to this deliberate practice of decontextualization, anthropologists have pointed out time and again that symbols must not be lifted from the contexts within which they have their value, if they are to be interpreted correctly. ${ }^{19}$

Joseph Campbell was well aware of this debate. He compared his own Jungian perspective to the ethnological (or sociological) viewpoint as formulated by A.R. Radcliffe-Brown in his study on "The Andaman Islanders":

A society depends for its existence on the presence in the minds of its members of a certain system of sentiments by which the conduct of the individual is tegulated in conformity with the needs of society. Every feature of the social system itself and every event or object that in any way affects the well-being or the colhesion of the society becomes an object of this system of sentiments. In buman socity the semtiments in question are not instate but are developed in the isdividnal by the action of the society upon fin [italics by Camplell]. The ceremonial customs of a society are a means 
by which the sentiments in question are given collective expression on approprate occasions. The ceremonial (i.e. collective) expression of any sentiments serves both to maintain it at the requisite degree of intersity in the mind of the individual and to transmit if from one generation to another. Without such expression the sentiments involwed could not exist. ${ }^{3 i h}$

In reaction to this, Campbell wrote that "no one has yet devised an effective method for distinguishing between the innate and the acquired, the natural and the culturally conditionied, the "elementary" and the "ethnic" aspects of such human-cultural catalysts and their evoked responses"21, concluding that that is reason enough to pursue a romantic-biological approach to the world's mythologies: His own four-volume overview of the world's mythologies, "The Masks of God" (1959-1968) bears witness of this conviction. The potential advantages of this perspective are readily seen, since the functionalistic perspective of Radcliffe-Brown and so many other anthropologists and sociologists remains unable to explain the content of rites and symbols ${ }^{22}$.

The romantic idea of continuity between nature and society, and between unconscious, mythical symbols and historical and cultural maturity, does not prepare for a critical approach to the functions of myth in contemporary society. Should the mythologically aware artist or scholar take up the role of the shaman, introducing his audience to the collective unconscious with its passionate visions of underworld and heaven, of inspiration beyond the functional and pragmatic? In the context of popular music, the idea that entertainers and pop stats are best interpreted as practitioners of a form of shamanism is not uncommon, and considering the passionate enthusiasm which such stars are able to evoke in some fans, the idea is not far-fetched. ${ }^{23}$ But how to investigate the relationship between myths, archetypical passions and inspirations, and historical reality?

Neither Jung nor Campbell have been successful in explaining how their insights in the nature of myths may be applied critically to the problems of contempotary societies. Lacking the concepts to distinguish society from mythology, they tend to interpret the wide diversity of mythological materials, regardless of its social status, as immediately relevant. A striking example of this lack of attention to the complex relation of mythologies and politics can be found in Jung's article "Wotan" from 1936, his analysis of National-Socialism:

We are always convinced that the modern world is a reasonable world, basing our opinions on cconomic, political, and psychological factors. But if we may forget for a moment that we are living in the year of Our Lord 1936, and, laying aside our well-meaning, all-toomuman reasonableness, may burden God or the gods with the responsibility for contemporary events instead of man, we would find Wotan quite suitable as a causal hypothesis. In fact I venture the heretical suggestion that the unfathomable depths of Wotan's character explain mote of National Socialism than all three reasonable factors put together...

Perhaps we may sum up this general phenomenon as Exgriffenbest-a state of being seized or possessed... 
For the sake of better understanding, and to avoid prejudice, we could of course dispose with the name "Wotan" and speak instead of the furom tentonicus... The imptessive thing about the Gernan phenomenon is that one man, who is obviously "possessed", has infected a whole nation to such an exterit that everything is set in motion and has statted rolling on its course towath perdition. ${ }^{2 *}$

Jung's hypothesis is clear: functionalistic analyses, whether dealing with economic, political, or psychollogical factors, are insufficient to explain the demonic enthusiasm generated by the National-Socialist movement. While Hitler's personality may be understood as an individual pathology, his enormous success in communicating his vision, however despicable, requires an interpretation that goes beyond the individual: The human psyche in general is able to transform its receptivity, to respond and adapt to different dispositions (each with their own "entelechy", to link Jung's "archetype" to the older Aristotelian philosophy that seems to have inspired it). One form of furious and aggressive obsession might be addressed, according to Jung, under the mythical guise of Wotan, which he considers to be a specific Nordic form of Dionysianism.

So far, this is an intriguing, but disappointingly simplistic attempt to understand the nature of the psyche more fully than a rationalistic psychology (as presupposed in economic theories) or an purely individualistic psycho-analytical theory are able to: by assuming that different models of coordinating perception and proprioception are easily communicated and manipulated for political reasons. However, Jung did not consider the models of education and the historical circumstances that have fostered this specific mental receptivity; instead, he tried to apply his mythological insights immediately. This tesulted in embarrassing simplifications; after writing "Wotan", Jung wanted to advise Hitler to have oaks planted in honor of Wotan, because the cult of Wotan would be, because of its archetypical inscription, more familiar and more essential to the stability of the German soul than Jewish-Christian religious concepts. ${ }^{25}$ Here, the scientific study of myths is no longer clearly distinguishable from mythic zealotry and misdirected attempts at large-scale shamanism.

Campbell, too, has hesitated between stressing the eternal truth of mythical insight and the demand to respond to the needs of contemporary society. He wrote: "Every mythology is scheduled or composed in the service of a certain society... The experiences of that society in that horizon are what are the living elements in the myth, what grabs people and holds them to the society in which they're dwelling:" ${ }^{26}$ He occasionally fell back on Nietzsche's idea of the dysfunctionality of the Judeo-Christian condemnation of (human) nature, and concludes: "The society of the planet is the only valid one now... The themes of myths will be the same a hundred years from now as they were four thousand years ago, the basic themes. But the evolving situation is one community to which the myth is in service, and the other is the natural and scientific field of experience that one is having. There's no use having a mythology that's talking about something that was true in 4000 
B.C. but is no longer true."27 Here, a lack of attention to the way in which mythical themes are mediated results in arbitrary, unspecific and unsubstantiated claims about "eternal" nature and the historical present.

Byrne uses the work of Campbell and Jung to bring a comparative perspective to the forms of archetypical enthusiasm and to the exchanges of proprioceptic sensibilities that fascinate him. Examples of this have been discussed in chapter 2, where mention was also made of Byme"s refusal to get stuck in his role of the rock star as a shamanic prophet, a role that the success of the Talking Heads had laid at his feet.

Generally speaking, Jung and Campbell are at their most convincing in their basic hypothesis: human behaviour has to be understood in relation to human nature and the patterns of passion and enthusiasm generated by that nature; it is reductive to relate these patterns exclusively to their social and cultural functions, or to the individual character. Compared to such rigid perspectives, their emphasis on common human properties may stimulate tesearch into exchanges of caltural patterns. But such research, whether it takes the form of scholarly dissertations or of art, should take care to include the specific conditions under which archerypes are mediated.

\section{EVOLUTIONARY FOUNDATIONS OF HUMAN CULTURE}

David Byrne and Brian Eno both read and admired "The Imperial Animal" (1971) by anthropologist Lionel Tiger and sociologist Robin Fox. ${ }^{28}$ This classic of contemporary ethology combines Darwin's theory of evolution with insights in human behaviour and cultures from cultural anthropology and sociology. In brief, this attempt at synthesis states that human behaviour is by and large characterized by the fact that homo sapiens is a mammal from the order of the primates. Man has evolved further than the other primates because his forebears went out hunt: ing. The demands of the hunt on the individual and on the tribe have favored the development of the cerebral cortex, which made possible an elaborate language and culture, as well as more complex tools. And that is what we are, according to Tiger and Fox: "We remain Upper Paleolithic hunters, fine-honed machines designed for the efficient pursuit of game."29 They apply the insights of ethology to mankind in order to uncover what they name its 'biogrammar": the whole complex of hereditary fixed possibilities and preferences of behaviour. In doing so, they do not wish to claim that man is governed by instinct, or that biological inheritance is more important that history and culture, but to point out that there is a connection between evolution, heredity and culture. "In sum: we behave culturally because it is in our nature to behave culturally, because natural selection has produced an animal that has to behave culturally, that has to invent rules, make 
myths, speak languages, and form men's clubs, in the same way that the hamadryas baboon has to form harems, adopt infants, and bite its wives on the neck." 30

It is obvious that human nature makes possible a huge array of cultures and forms of behaviour: the invention of agriculture, cities and finally industry and our contempotary complex societies. But this historical development is only a moment on the timescale of evolution, which means it has not influenced our hereditary qualities.

The first upright and big-brained human - Howno erewtas - is usually credited with about one million yeats of history. How sapiens is half a million years old, while the appearance of truly modern man - Cra-Magman - dates from forty to fifty thousand years ago. This is our time scale frot the evolution not onlly of physique but also of social behavior, emotions, patterns of learning, lowing, and hating ${ }^{31}$

Tiger and Fox conclude that therefore,

We have to make the imaginative and unsetting leap into understanding that agricultural and in dustrial civilizations bate put notbing into the basic wiring of the baman animal. We are wired for hunting - for the emotions, the excitements, the curiosities, the regularities, the fears, and the social relationships that were needed to survive in the hunting way of life. And we are wired basically on a primate model. 32

On this basis, Tiger and Fox immerse themselwes in the nature of man: the evolutionary foundations of politics, the relations between mother and child, berween men and women and amongst men; the special position of the male adolescent, the typically human traits of economic behaviour and of formal training. Everywhere they point out similarities in the behaviour and societies of primates and of humans, in order to lay bare the tensions between the demands of culture and our built-in patterns of behaviour.

The range of human behaviour shows a predictable variety, write Tiger and Fox. "The standard repertoire includes "a society with laws about incest and how and whom to marry; rules about property; habits of taboo and ritual avoidance." ${ }^{2 / 33}$ Other standards are the exchange of gifts, courtship ceremonies, initiations, tespect for the supernatural, elaborate fussing about the adomment of young females, men's clubs, gambling, weapons and tools. Regardless of the society in question, "Our biogrammarian would be sure to find the following, too: myths and legends, dancing, psychosis and neurosis, adultery, homosexuality, homicide, suicide, loyalty, desertion, juvenile delinquents, senile fools, and various shrewd practitioners to cure or take advantage of the various ills from which communities and people suffer." 34

Tiger and Fox's description of the function of music is noteworthy in this context. They start from the notion that in pre-historical times the hunt was reserved for men, which has led to a physical but also emotional predilection for this kind 
of behaviour in men. This preference may be sublimated in economical activities, but also in music.

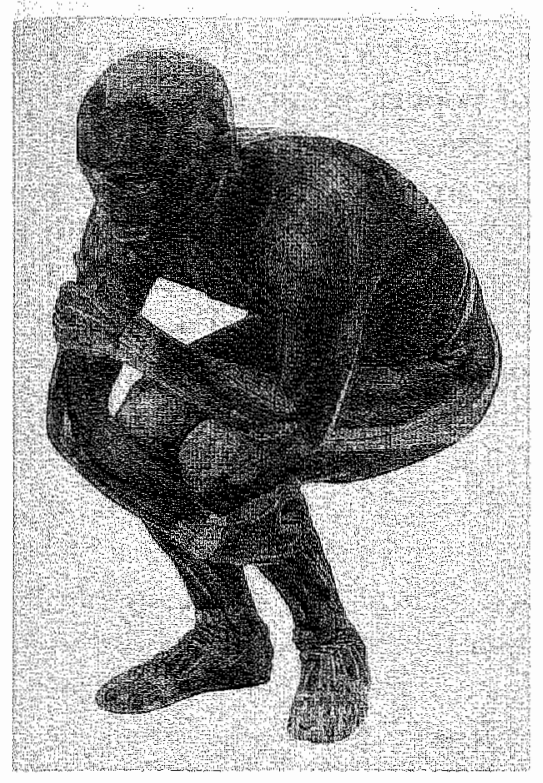

18 Byrne dressed in a muscle-suit, an costume he wore on stage to perform a few songs during his "Feelings" tour. Photo by Phyllis Galembo, from the cover of Byrne"s "The Visible Man" $(1997)$.

It appears still to be the case that the uncertainty and particular sensitivity of the hunt and its metaphor galvanizes men more than women, and boys more than girls. It is the band of men who play music like warriors, who worry a melody, turn it around, pass it back and forth, hide from it allom gether, pair up, split up, combine to chase it, come crashing or singing around, and then drive to some utterly expert and exhausted point of rest when the improvisation is done and when the millisecond mutual awareness has paid off in a satisfaction only an improvising musician can understand as an essential huxury for his being... This is an almost pure emotional analogue of the hunt; music is not only the food of love but of predation too. ${ }^{35}$

Fox and Tiger's view on music has to be combined with their analysis of the position of male adolescents. In baboon societies, adolescent males have to make a difficult transition from their position as children, with the femalles of the group, to their new role as mature baboons. Since the older males have monopolized the power over the group and over the women, the adolescents have no other alternative than to take a place in the (dangerous) periphery of the group, trying to acquire a place amongst the powerful from that margin. This position in-between roles is inherently full of tensions:

Adolescent males suffer confused instructions from the old progran: become mature; remain dependent; show affection to girls and hardness to boys; accuse the dominants of being too powerful, yet admire their power; and perhaps begin dimly to shape out some way of reproducing. The job of reproducing is easy and fast and also immensely pleasurable. But reproduction, like justice, must not 
only be done, it must be seen to be done. Some social andogue of the actual of potential copularion must be established - the fraternity pin, the bibiscus behind the ear, the exchange of love fetishes or food ${ }^{36}$

Taken together, these two quotes present an interesting background against which to review the nature, thematics and functions of popular music in general. This attempt to decipher the "biogtammar" of music shows an interesting parallel to Jung's conviction that music is "dealing with deep archetypal material", a conviction which resulted in his hatred of "background music" as one of many mediated distractions reducing the ability of children and adults to concentrate. ${ }^{37}$ But it is crucial to remember that the biogrammar sketched by Tiger and Fox does not determine cultural behaviour, or presuppose biological reductionism. On the contrary, the underlying assumption of the book is that more insight in the biogrammar may help to produce a more balanced and civil society.

Human violence is an example in case, and it is central to Tiger and Fox, who express their concern about the ongoing worldwide arms-race and advocate what they call a "species-centered ethic" 38 . They remind their readers that man has the same propensity to aggression and violence as other primates, but has added tools and language, wreapons and concepts ${ }^{39}$. In primate societies, aggression can be curbed: "Ethologists speak of the "ritualization of aggression"- - but the aggression has to be ritualized because it is so reall. And ritual does not always work." 10 In human society, ritualization has to take on a new dimension:

Systems of ideas, atritudes, beliefs, and values can differ profoundly, and if our system is to be llegitimate, than yours must be illegitinate and very easily seen as a threat. In this conflict of symbols, be they nationalistic, neligious, linguistic, class, ethnic, or whatever, the truly human skills evolved for local-level person-to-person living can play litte part, although we must constantly attempt to utitize them. But the controls that we must institute-the titualizations we must invent- to deal with the gargantuan clashes of arms between coalinions of nations, or Christians and Muslims, or the proletariat and the forces of capitalist oppression, or the thitd world and imperialism, etc, are something of a different order from the ritualizations that constrained our evolving watrior ancestors for all those millions of years. The new controls have to be, like the causes of conflict, highty symbolic."

This appeal to inwent new forms of ritualization seems to be most televant to performance and to Byme's work. (In passing, it is interesting to note the difference between this approach and the long-term perspective set out by sociobiologist Edward O. Wilson. Wilson sketches the possibility that mankind changes its own genetic nature to become more intelligent, creative and emotionally responsive; as he writes, "New patterns of sociality could be installed in bits and pieces." + Wilson is more rationalistic and less interested in the human capacity for reflexive 

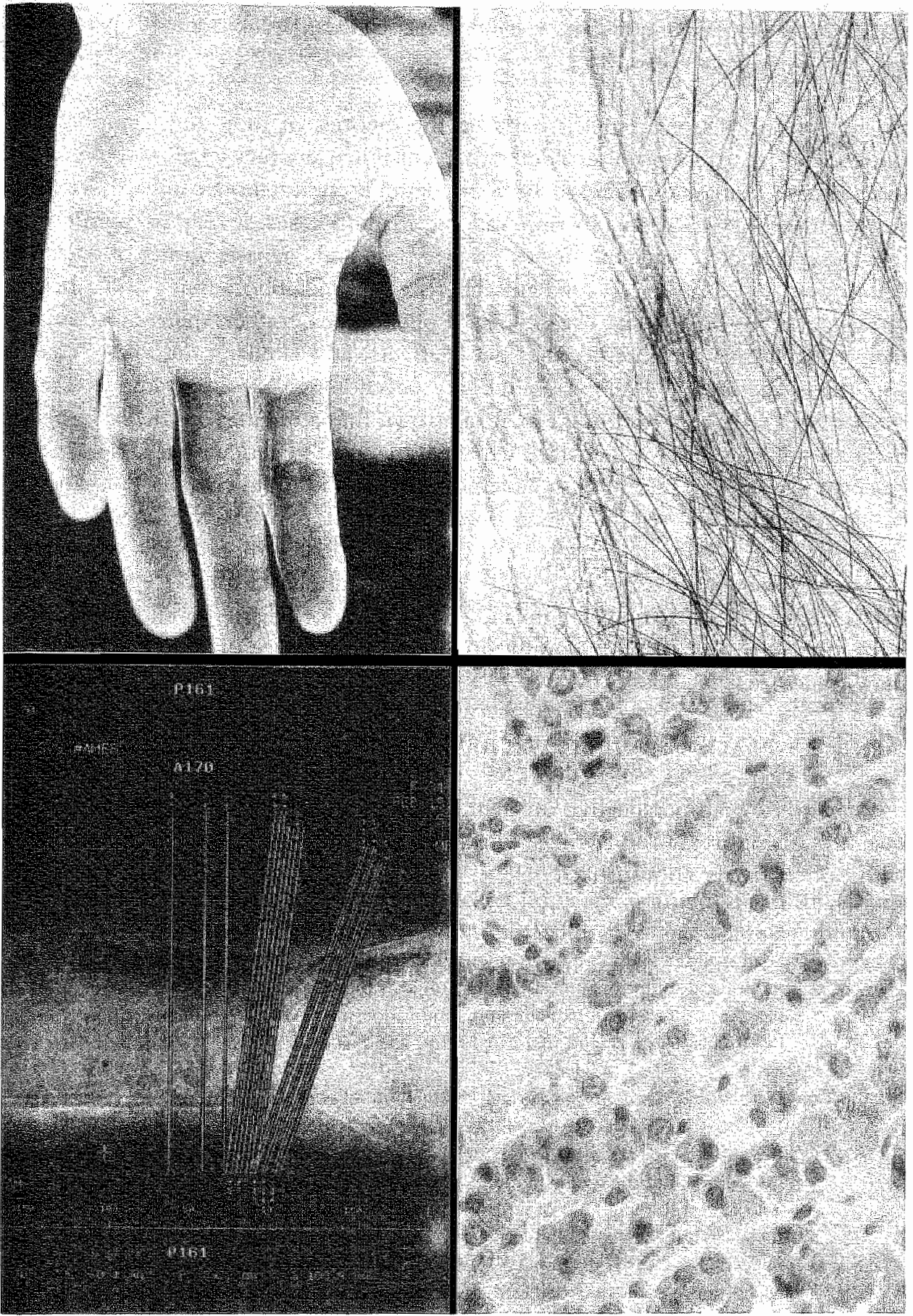

19 Four photos from the special edition of the solo album "David Byme" (1994). Fxamining the notion of personal identity: on which level of the body can the individual still be recognized? Top: Byrne"s lefi hand; his skin and hair (photos by Jean Baptiste Mondino) Bottom: CAT (computer-aided tomography)-scan of Byrne's torso; cell photo 
ritualization than Tiger and Fox; it is no surprise when Byrne states his preference for their work over Wilson's.43)

It isn't hard to discern parallels between the theories of Jung and Campbell and those of Tiger and Fox: the older term "collective unconscious" resembles the more recent "biogrammar", but lacks the latter"s connotations of hard scientific facts, genetic research, and so on. And yet, in both cases, it may be pointed out that the existence of such entities as "archetypes" and "genetic wiring of social telationships" is questionable. Jungian archetypes are metaphors that fulfill a heuristic function in comparing psychological phenomena, rather than substantiated facts with known and predictable causal effects; and similar cautionary remarks apply to sociobiology and to evolutionary psychology.44 Nobody knows exactly how strands of DNA are related to a full-grown human being; or what changes in hereditary traits may have occurred while people lived in agricultural and industrial civilizations; or the exact ways in which our minds and brain create a fluid and dynamic order out of "the blooming buzzing confusion of the world which confronts us moment by moment". 45 For all these reasons, theoretical explanations that relate culture to nature necessarily contain symbolical aspects. That does not mean that such explanations are invalid and should not be attempted. On the contrary, they help to grasp the complexity and heterogeneity of human nature and human history.

\section{THE PLACE OF POETIC ARGHETYPES IN MODERNITY}

The Jungian perspective on mythologies and symbols as having archetypal qualities is important for Byrne's work. He has said this clearly in an interview with Robert Farris Thompson:

Thompson: How do you envision God?

Byrne: Well, I certainly don't believe in an old bearded man up there. I see God as an force that guides and unites our finest actions and sensibilities. We might call it God because we have no other way of explaining it. And it doesn't ait causal rationality, where you say, "well, this happens, and that causes this, and this causes that." It's at mote poetic reality.

Thompson: How would God operate through the medium of rock \& roll?

Byrne: It's the principle that unites all the mlements: the text and the sound, the thythm and the attitude. It's an irmmedinte understanding. l've spent years and years trying to pur it into words, but the understanding comes in an instant.

The fact of it being kind of an epiphany still remains unexplained. I'm not trying to be mystical, but they could be within ourselves. They could be, you know, Jungian things, collective-unconscious archetypes. That kind of rationalizing of it is something I can accept more easily than deities that are out there and separate from us...

Thompson: Do you think we learn from daring to go through the obsessive state? 
Byme: Yeah, yeah. Leaming that you can do that is respecting things outside the rational: Respecting things outside of daily living.

Thompson: Rock \& Roll is an obsessive state: Xou dared enter unto that obsessive state. What kind of insights have you gotten from it?

Byme: Rock music makes the obsessive okay and turns it into a creative act. Rock deflects that energy and channels it into something creative. Which is odd, because at a certain point you realize that it's not enough to just be obsessive in front of an audience. There's also craft to it. ${ }^{46}$

Byme considers archetypes as the unifying principle behind the "Gesamtkunstwerk" of the song, and music as a way to channel obsessive energies into creative use. Another statement which elaborates on this concept is: "there will always be younger musicians who have a more frantic set of hormones rushing through the body" 47 , which provides a more ethological explanation for the link between music and obsession. During concerts, Byrne's performance style is often a simulation of obsessive behavioral styles, a simulation which may well, for brief moments, induce a trance. As Dick Hebdidge has noted, one of these styles is a "flat, deadpan expressionless ("impersonal") modernist mode of delivery... Byrne's face... assumes the blank look of someone bringing news from nowhere. This anti-expressionism-a kind of simulated psychosis - has been the mode of address favoured by the modernist avant garde at least since Tristan Tzara and probably since the "Banquet Years", and Alfred Jarry's Ubu." 48.

The influence of Jung's notice of the mandala on Byrne has already been noted at the end of chapter 2, where the cover of "Speaking In Tongues" was discussed. Another mandala can be seen in "True Stories", during the family dinner scene. In this scene, civic leader Earl Culver has an epiphany about the changing economy, with its new notions of time and spirituality. He illustrates his vision by rearranging the food on the table into a diagram of clange and growth which looks like a mandala." Byrne's lyrics provide more examples, such as the phrases "turn like a wheel inside a wheel" and "open the door and let them in / inside a circle around

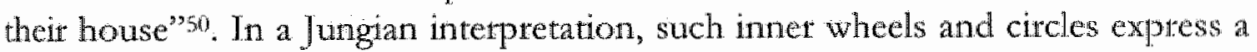
totality that corresponds, in Jung's own terms, "not to the ego but to the self as the summation of the total personality. (The centre within the circle is a very wellknow allegory of the nature of God.) $)^{m 1}$

Indeed, a Jungian perspective on the individual can be found in all Byme's films. "Stop Making Sense", according to Bytne, tells a story: "the implied story of that whole show was of this man who frees himself from his demons and finds release and salvation in his big suit. ... He can cut loose in this house made of a business suit." 52 And in connection with his film "llé Aiye"., Byme wrote about the Orisha"s, the gods said to "rule the head" of the Candomble initiates who fall into trance: 
In psychological terms, one might think of them as akin to the psychological archetypes of the collective unconscious: the Mother, the OId Wise Man, the Seductress, etc. The archetypes of the collective unconscious are; and always have been, representations of all our god(s) and demons, whether they appear in religion, myth, or in a Hollywood movie. In this way the trance can be seen. as coming from within rather than being a possession by sur outside entity, as is commonly supposed. The person in trance has allowed an aspect of their unconscious to become manifest and dominate their consciousness for a few hours. It seems quite cathartic not only for them, but for the observers as well. One does not need to go into trance oneself to receive some of the benefits. ${ }^{5.3}$

Jung has elaborated individual dreams and visions by comparing them to material gathered from all over the world, in order to build a general theory of the unconscious. Byrne generally agrees with Jung's general connecting of the origin of thought and nature. He has written: "There's a subconscious cut-and-paste going on in our head that doesn't seem too strange at all. It seems like the most natural thing in the world." ${ }^{54}$ But Byme is more cautious than Jung about making romantic claims of a unity of man and nature: he "tries not to be too romantical about nature. It also has something terrible about it, is full of death and plagues. It has an order with a chaotic element." 55 In Byrne's aesthetic, structural clarity and integrity are not naturally given: one has to listen with an open ear to the many reverberations of a certain form and it often takes an effort to create a structure which makes those reverberations transparent. In Byrne's view, people are just as likely to ignore and neglect their own impulses and energies as to acknowledge them; separations are as fundamental as connections. ${ }^{56}$ One may conclude that in Byrne's work, the formalist capacity for separating and isolating the many layers and forms of meaning is as fundamental as the opposing tendency towards integration and harmony. Only the combination of these opposed tendencies makes it possible to approach performative traditions reflexively, by commenting on their integrative as well as their disconnecting qualities.

That Byrne's work investigates ways in which archetypal energies develop, unfold, or wither in modernity, is demonstrated not only by his work, but also by his interest in theoretical descriptions of that confrontation. Brief representations of two of these theories - one concerned with modern architecture, the other with the industrial revolution-will uncover something of the intricate and far-teaching dimensions of this subject.

In preparation of the film version of "The Forest", that placed the myth of Gilgamesh in the industrial revolution, Byrne read "Pandaemonium: The Coming of the Machine Age as Seen by Contemporary Observers". This historical anthology had been collected by the English filmmaker and literary scholar Humphrey Jennings; it was published posthumously in 1985. In his introduction and commentary, Jennings made clear that his purpose was to examine the transformation of imagination and of human emotions in the course of the industrial revolution. As Jennings wrote, 
Poetry was created in primitive and feudal societies-pattiatchal societics-and in these societies the subjects with which the poet dealt wete not then poetical subjects; they wete wital everyday facts and necessities-religion-the cosmos and the fate of the human soul... kingshif - the chatricter of the man in power and the fate of the people under him. As agticulture was the principal means of subsistence of these societies, the language and the metaphors of poetry (what is called "flowery" language) are full of agricultural memories.

But in a process (conflict) which culminated between 1660 and 1880 the peasarts were destroyed and the land capitalised-the power of money-capital-substituted for the power of the Crown and the religion. The poet-as an individual-reacted to this major crisis of his career in many differing ways but it must be admitted not very successfully. We cannot say that any poet understood this process - much less applied it to his own view of the world or in any way modified his writings through it.

But the written language itself-the poets' raw material-did nor stand about unusedunwritten. I mean that the conflict between animism and materialism - between poetry and science-the conflicts between agriculture and industrialization - the fundamental class conflicts-did not go untecorded. Pootry survived s?

Jennings employs a distinction between "the means of vision", which he circumscribes as "matter (sense impressions) transformed and reborn by Imagination: turned into an inage", and "the means of production-matter is transformed and reborn by Labour". ${ }^{58}$ His perspective is more historical than that of Jung or Campbell:

In the wwo hundred years 1660-1860 the means of production were violently and fundamentally altered - alrered by the accumulation of capital, the freedom of trade, the invention of machines, the phillosophy of materialism, the discoveries of science.

In what sense have the Means of Vision kept pace with these alterations? I am referring not to the Arts as a commodity for Bond Street, or as a piece of snobbery in Mayfair, or as a means of propaganda in Bloomsbury, or as a method of escapism in Hampstead... but to the Means of Vision by which "the emotional side of our nature" (Darwin's phrase) is kept alive and satisfied and fedour nature as Human Beings in the anthracite drifts of South Wales, in the cotton belt of Lancashire, in the forges of Motherwell-how the emotional side of their nature has been used, altered, tem pered, appealed to in these two hundred years.

Man as we see him today lives by production and by wision. It is dioultatul if the can live by one alone. $5 x$

As the film version of "The Forest" could not be made, there is no way to know how-and whether-Jennings" historical anthology would have inspired Byrne's film. Nevertheless the issue he taises, the question how the emotional side of our nature interacts with an industrial society and with the industrialized production of mythical performances by the media, is thematic throughout Byrne's work.

Another theoretical approach to the interaction of human nature with industrial society was mentioned by Byrne in his press statement that accompanied the release of Talking Heads" "Remain In $\mathbb{L i g h t " ~ a l b u m ~ i n ~ 1 9 8 0 . ~ I t ~ i s ~ a ~ t h e o r y ~ o f ~ p l a n - ~}$ ning and development that was put forward by architect Christopher Alexander. At first glance untelated to Jennings' research, but on closet inspection addressing 
similar questions, Alexander has emphasizes the relevance of an "animistic" or organic and emotional approach for contemporary architecture. Alexander, who walues the organic quality of many examples of traditional architecture, has unfolded a method which hopes to secure that quality for new buildings and neighborhoods.

As Alexander has summarized his own intentions, his book "The Timeless Way of Building" (1979) "describes a theory of planning and building which is, essentially, a modern post-industrial version of the age-old pre-industrial and traditional processes which shaped the world's most beautiful towns and buildings for thousands of years." Alexander does not take organic unity for granted: according to his design philosophy, it has to be consciously given space, to enable it to develop gradually. He diametrically opposes the casting of the architect in the role of the genius, the one who comes up with the master plan, because "the master plan... cannot create a whole. It can create a totality, but not a whole. It can create totalitarian order, but not organic order." 61 .Alexander has put forward six principles to replace conventional master planning and the centralized allocation of financial budgets by procedures that require all users of a building or neighborhood to be involved:

1. Planning and construction will be guided by a process which allows the whole to emerge gradially from local acts.

2. All decisions about what to build, and how to build it, will be in the hands of the users.

3. The construction undertaken in each budgetary period will be weighed overwhelmingly towards small projects.

4. All design and construction will be guided by a collection of communally adopted planning principles called patterns.

5. The well being of the whole will be protected by an annual diagnosis which explains, in detail, which spaces are alive and which ones dead, at any given monent in the history of the community.

6. Hinilly, the slow emergence of organic order in the whole will be assured by a funding process which regulates the stream of individual projects put forward by users ${ }^{6 ?}$

Participation of everyone in the community in the design is one of Alexander's principles. This is combined with the use of architectonic archetypes, "an explicit set of instructions for designing and building, which defines patterns at every scale, from the structure of a region to the nailing of a window: set out in such a way that laymen can use it to design a satisfying and ecologically appropriate environment for themselves and their activities." 6.3 Alexander has set out to define patterns which are alive, letting the inner forces of their users loose and free, instead of dead, keeping them locked in inner conflict: architectonical patterns which provide rules of thumb for the placing of windows, entrances, porches, relations between interior and exterior, and so on. As he summarizes his design philosophy, "every pattern we define must be formulated in the form of a rule which estab- 
lishes a relationship between a context, a system of forces which arises in that context, and a configuration which allows these forces to resolve themselves in that context." Building patterns are thus combined into a patten language, the mould of a tradition which allows a community to shape architectural space in accordance with the diversity of its activities and relationships, by means of a continuous process of small adaptations. Everyone should be able to use this language, and it should cover every facet of the human experience; but Alexander holds modern architecture with its procedures of centralized financing and planning responsible for the demise of this tradition: "in the early phases of industrial society which we have experienced recently, the pattern languages die." 65 Alexander stands squarely opposed to the Cartesian model of blueprint mationality which underpins the ubiquitous International Style in architecture: he categorizes that style under the label "the breakdown of language". 60 His key example of a degenerated architectural language is the so-called shelf office, with its monotonous floors full of small, identical office cubicles.

Alexander's orientation enables him to use examples from a variety of cultures; he proposes to embed architecture so thoroughly in the life of a community that it becomes a living tradition, a functioning mythology. It isn't difficult to discern parallels between Alexander's approach to architecture and John Miller Chernofes description of African thythm and African sensibility as a community of interlocking parts. Both are equally directed towards participation. And in both perspectives, this participation has a sacted aspect; Alexander writes that the aim of his pattern languages is, that "A language gives you back your confidence in what seemed once like trivial things." $G 7$ It "shows us what we know already, only daren't admit because it seems so childish, so primitive." 68 "Your mind is a medium within which the creative spark that jumps between the pattern and the world can happen. You yourself are only the medium for this creative spark, not its originator." 6 " Alexander's conclusion amounts to a mystical experience of building: "Patadoxically you learn that you can only make a building live when you are free enough to reject even the very patterns which are helping you. ... It may seen to you that pattern languages are useless then. But it is just your pattern language which helps you become egoless." "7o

Byrne's "True Stories" contains a few dialectical reflections on Alexander's theoretical condemnation of the Intemational Style. Even though Bytne agrees that "Philip Johnson and Mies van der Rohe and all these people have failed"', he is aware of the subtle ironies that spring up in the wake of modernist absolutism. He considers the banal and utterly unremarkable metal warehouses to be a minimalistic form of modernism, and notices that "When those structures were plunked down on the flat Texas landscape, they looked like pieces of art stuck on a plinth or isolated in the white space of a gallery."72 In the "True Stories" book, Byrne wites how "Metal buildings are the dream that modern architects had at 
the beginning of the century come true, but they themselves don't realize it. ... You order them out of a catalog. Just pick out your color, the size you want, number of square feet, style, and what you need it for... It takes people in a socalled uncultured or unsophisticated area like this to be open to the potentials of this kind of structure." where organic languages of architecture are completely absent, it does not follow that all emotion is eradicated: people will invent new ways to invest their environment with emotional value.

At other times, Bytne has pointed out literary treatments of the confrontations of myth and modernity. In relation to "The Forest", he has mentioned Richard Kapucinski's "The Emperor", a description of the quasi-medieval court over which emperor Haile Selassie of Ethiopia ruled during most of the twentieth century. "An example which Byrne has called a "neglected classic"75 is Eduardo Galeano"s monumental trilogy "Memory Of Fire", a history of Latin America that extensively documents the ongoing, often deplorable ways in which myths have fueled the historical developments in that continent over the last five hundred years. These examples demonstrate how an absorbing interest in the interplay of myth, human nature and modernization defines Byrne's theoretical orientation. 


\section{CHAPTER 7}

\section{Performance theory in the theatre}

\section{RICHARD SCHECHNER'S THEORY OF PEREORMNCE}

Richard Schechner (1934) is professor of performance studies at New York University. By focusing on artistic performances, Schechner's work succeeds in being much more specific about the interplay of human nature, myth and society than the broad generalizations of Jung and Campbell, while his conceptual horizon retains many similarities to that of these older scholars. His theoretical work is informed by personal experience as a theater director: in 1967, he founded the Performance Group, an Off-Off-Broadway theater collective that was based in a former garage in Manhattan's Wooster Street. Nor satisfied to present the theater andience with a brief passing illusion, the Performance Group was a ritualistic theater group which sought to break down the barriers between art and life, between performance space and audience space, and between production elements, aiming for a lasting transformation." Following Artaud, Breche and other innovators, Schechner wanted to produce performances that would have an influence on life outside the theater as well; in his case, a political effect. In 1970, the Performance Group was joined by Spalding Gray as a performer and by Elizabeth LeCompte as assistant director. From 1974 onwards, they produced their own pieces, in a collaboration that gradually developed into the Wooster Group. In 1980, Schechner disbanded the Performance Group, leaving the Wooster Group to produce their own plays. ${ }^{2}$ Since then, he has worked mainly as a theorist. Schechner founded the Department of Performance Studies at NYU, and is editor of The Drama Review: a journal of performance studies. Schechner's theorizing is 
cminently suitable to explore the work of Mabou Mines, Robert Wilson, the Wooster Group, and Laurie Anderson. As inspiration, as collabotators, and as comparison, their experments in total theater are directly relevant for Byme's own wotth.

The following overview of Schechner's seminal work is based on three of his books: "The End of Humanism: Writings on Performance" (1982), "Between Theater \& Anthropology" (1985), and "The Future of Ritual: Writings on Culture and Performance" (1993). These "writings" are not systematically constructed, but purposely mix theorizing with detaled fieldwork observations, criticism, polemic, and political reflections. As such, they are hard to summarize. But instead of a complete and fixed theory, a general strategy for understanding performance is to be found in his work.

Performance, in Schechner's view, is an arena where general ideas clash and mingle with everyday reality; he wants to provide detailed accounts of the resulting interplay. He describes how the universal presence of myths, dreams, the evocative potential of the body to present meanings, and the interaction of the individual with society, are actualized time and again in drama and ritual. To him, the ritual aspects of theater are at least as important as the narrative content of a play.

Schechner therefore considers conventional Euro-American theatre to be severely limited, at best a somewhat eccentric example of what petformance can accomplish. This theatrical tradition is typified by the central role of the text: a fixed text which exists independent of its performance. All elements of this theater: the actors, the staging, costumes and so on are used to serve the text, to bring it to life. A typical playtext will deal with the origin and resolution of a conflict; the quality of its performance is judged by the spectators in relation to other performances, in terms of artistic value. "For too long, in theater at least, performance knowledge has been identified with knowing the great dramatic texts... What performers and directors did was acknowledged but segregated." In Schechner"s view, this separation is responsible for a theater that aims only at a temporary suspension of disbelief, transporting the audience for a short period to the makebelief world of the play, a few hours of enchantment, returning it afterwards to ordinary life without aiming at durable change.

Experimental theater, as Schechner understands it, is the attempt to abolish neat separations between reality and text, text and performance, performance and audience. Each element of the performance can take pride of place. Schechnet presents a triangular model of theatrical elements, in which traditionally, in EuroAmerican theatre, text and narration form the basis, while music, rhythm and movement form one of the sicles, and architecture plus scenography the other. In experimental theater, each side of this triangle can form the basis of a production, generating radically different events, in which "sometimes the actor dominated, somerimes movements and dance, sometimes the visual, sometimes the sonic, 
sometimes the scenographic/architectural." Therefore, each expenimental performance should be approached as "a brajding of various performance "languages", none of which can always claim primacy". 6

The separation of performance and audience may be overcome by audience participation, environmental staging, and attempts at collective creativity. In Schechner's analysis, such experiments demonstrate how classical Western theater is but one tradition within a much wider range of established performance gentes; the full range might include "events like the Mass, professional football, psychodrama, whirling dervishes in devotion, Sumo wrestling". ${ }^{8}$ Instead of the text of the play, which exists separately, Schechner wants to analyze the performance in its entirety, which he terms alternately the performance "text", "score" or "braid".

Artaud and Brecht had looked to non-European forms of theater and ritual to support their proposals for theatrical innovations; a logical step after the conclusion that the European tradition is too limited. Many later directors have done the same, and Schechner casts his theatrical theories in a cross-cultural perspective by detailed observations of a wide range of performative events: Ramlila of Ramnagar, a thirty-one-day ritual drama of notth India; Kathakali performer training in southwest India; Noh in Japan; Balinese theater; Javanese Wayang Kulit; the Waehma festival of the Yaqui indians in Arizona; Papua New Guinea dances; and others. To support these observations, he sketches a general theory of performative events.

Schechner emphasizes the "liminal" position of art, its position in between categories, between science and mythical or magical thought. He quotes Claude Lévi-Strauss: "Art lies half-way between scientific knowledge and mythical or magical thought". As Schechner writes, "A limen is a threshold, a border: a place you cross over to get from one space to another... In ordinary life people negotiate limens swiftly and easily... But artists intentionally exaggerate extend blow up elaborate make huge the limen... The "work of art" is (in) the limen; and so is the "work of" ceremony, ritual, and other operations of human behaviour that appear to have no "good" (i.e, pragmatic) reason for existing (like religion)."11

Schechner describes this liminal zone as the meetingplace of two worlds, "two realms of experience, the only two realms performance ever deals with: the world of contingent existence as ordinary objects and persons and the world of transcendent existence as magical implements, gods, demons, characters. It isn't that a performer stops being himself or herself when he or she becomes anothermultiple selves coexist in an unresolved dialectical tension." All behaviour in this liminal zone or "play frame" is "restored behaviour", which Schechner characterizes as follows:

Restored behaviour is living behaviour treated as a film director treats a strip of film. These strips of behaviour can be rearranged or reconstructed; they ate independent of the causal systems (social, psychological, technological) that brought them into existence. They have a life of their own."2 
Pur in personal tetms, restored behaviour is "me behaving as if 1 am someone else" of "as if I am. "beside myself or "not myself', as when in trance. But this "someone else" may also be "me in another state of feeling/being", as if there were mulriple "me"s" in each person. The difference between performing myself-acting out a dream, reexperiencing a childhood trauma, showing you what I did yesterday -and more formal presentations of self...-is a difference of degree, not kind: ${ }^{2}$

Because of this, performance behaviour is not free and easy, as the word 'play' may suggest; it is known and practiced behaviour, often rehearsed and learned, or generated by rules that dictate the outcome, as in sports, or revealed during the performance itself by elders or gurus. ${ }^{14}$

A performer doesn't stop being himself or herself when he or she assumes another identity; in performance, multiple selves coexist in an unresolved dialectical tension. Performance behaviour is therefore anything but free and easy; it is highly determined and practiced, rehearsed and learned. As if to underline the importance of learning to enter and leave the liminal zone successfully, Schechner distinguishes seven phases in a complete performance sequence: training, workshops, rehearsals, warm-ups, performance, cool-down, and aftermath. ${ }^{15}$ Naturally, different genres and cultures emphasize different parts of the sequence.

According to Schechner, there is a continuum of performances that stretches from such strictly individual performances to acting, whether in drama, dance or ritual, and taking part in social actions and cultural performances, performance events that do not find their origin within a single individual. Such events feed back into the actions of individuals. 16 Therefore, restored behaviour and ordinary life are linked like the two sides of a Mobius strip, each turning into the other. ${ }^{17}$ This approach to performance as restored behaviour is

a theory that includes the ontogenesis of individuals, the social action of ritual, and the symbolic, even fictive, action of art. Clearly these overlap: their underlying process is identical. A performance takes place in the "not me ... not not me" between performers; between performers and texts; betweet performets, texts, and environment; between performers, texts, environment, and audience. The latger the ficld of "between", the stronger the pertormance. "The antistructure that is performance swells until it threatens to burst. The trick is to extend it to the bursting point but no further. If is the ambition of all performances to expand this field until it includes all beings, things, and telations. This can't happen. The field is precarious because it is subjuncrive, liminal, transitional it rests not on how things wre but on how things are not; its existence depends on agreenents kept among all participants, including the andience. ${ }^{18}$

During a performance, while executing restored behaviour, for the petformer,

Elements that are "not me" become "me" without losing their "not me-ness". This is the peculiar but necessary double negativity that characterzes symbolic actions. While performing, a performer experiences his own self not directly but through the medium of experiencing the others. While performing, he no longer has a "me" but has a "not not me", and this double negative relationship also 
shows how restored behaviour is simultaneously private and social. A person performing recovers his own self only by going out of limself and meeting the others-by entering a social field 19

One of the crucial differences between different kinds of performances is, whether the actors and the audience return afterwards to ordinary life in more or less the same place where they started from, or whether they are forever changed by the performance. Schechner calls the latter "transformations", as opposed to "transportations", temporary excursions to the performative world ${ }^{20}$ Examples of transformations are initiation rites and ceremonies, such as a wedding, a graduation and a bar mitzvah. Usually this distinction between transportation and transformation is held to be synonymous with that between theater and ritual, but Schechner explains how transformation and transportation often coexist in one and the same event. During initiations, only the initiated are ritually transformed, while all other participants afterwards return to their ordinary life at the point where they had left it.21

Physical training is often an important part of the preparation for a performance, which may set its aim at making att "out of the living tissue of the performer" ${ }^{32}$. In Western performance, this is traditionally so in ballet, modern dance, and also in many popular performances (circus acrobats, living statues in busy streets, sports and so on), and a similar physical intensity is often central to performance theater. Physical training helps to produce a specific state of alertness, a proprioceptic change, and that ability transforms the performer: "The performance text is put into the body of the performer through a training whose bases are integral parts of the performance text itself. Once in the body of the performer, the performance text is manifest during performances..."23. Such performance events can closely resemble religious possession, trance and other ecstatic forms. In fact, several Western theatre makers have devised methods to include such forms; Polish director Jerzy Grotowsk (1934-1999) is a good example (both Richard Schechner and JoAnne Akalaitis/Mabou Mines have trained with him):

Part of the work of [Grotowsk's theater] laboratory is to transform various linurgical/performative modes and items into technical/performative modes and items. This work includes a rigorous investigation of various liturgical and ritual genres - an investigation whose purpose it is to identify in performative terms - that is, in ways that can be taught, repeated, and creatively varied-sequences of "objective drama"... Grotowski's work is intercultural, drawing on techniques whose performatwe/psycho-physiological basis is shared among many, if not all, cultures. ${ }^{24}$

As such experiments demonstrate, performance is relevant for so many reaches of human culture and life that the question comes up to which extent performance is typical for human nature as such. This is a question which Schechner has addressed repeatedly; 25 most comprehensively in "The Future of Ritual", where he establishes the ethological origins of performance: 
Ethologically speaking, nitual is ordinary behaviour transformed by means of condensation, exaggeration; repetition, and thythm into specialized sequences of behawiour serving specific functions usually baving to do with mating, hieratehy, or territoriality. 20

Nonhwman primates such as chimpanzees and gorillas behave in some respects very much like humans. Some of their actions closely resemble performance. Exen if nonhuman primates cannot speak as humans do... they can express and communicate feelings. ${ }^{27}$

In both anmals and humans tituals arise or are devised around disruptive, turbullent, and ambivalent interactions where faulty communication can lead to violent or even fatal encounters. Rituals, and the behaviour arts associated with them, are overdetermined, full of redundancy, repetition, and exaggemation. This metamessage of "You get the message, don't youl?!" (a question surrounded by emphasis) says that what a titual communicates is very important yet ptoblenatic. ... [Rituals] are anbivalent symbolic actions pointing at the real transactions even as they help people avoid too direct a confrontation with these events. 2 st

But people usually act consciously, base their actions on cognitive insight. How can the rational, cognitive quality of human behaviout, the need the construct plausible stories and explanations, be combined with the ritual propensity, which can short-circuit thought? According to Schechner,

The contradiction can be resolved by supposing that ritualizing-the performance of tritual-is not a simple, one-step, one-way operation. My own experience from running many performance workshops during the past twenty-five years, is that thythmic activities-especially if movement and sound-making are carefully coordinated and maintained for long periods of time-invariably lead to feelings of "identical opposites": omnipotence/vulnerability, tranquility/readiness for the most demanding physical action. In other words, the narrative-cognitive stimulus works from the cerebral cortex down while the movement-sonic stimulus works from the lower brain up. Performing a ritual, or a ritualized theater piece or exercise, is both narrative (cognitive) and affective. These work together to form the experience of titualizing ${ }^{25}$

\section{Schechner's conclusion is that this ambivalence is crucial to performance:}

At some point in human history people began performing their dreams and elaborating on them. These were not facts nor were they imaginary. They were performances of events between fact and imagination. These virtual actualities, staged as rituals, shared the authority of recollection with the play of inngination. Artful elaborations... have been decisive in human history at least since paleolithic times. These performed dreams appear always to have been erotic and violent. Human creativity still works this playfield betwixt and benween the ethological, the neurological and the social. ${ }^{30}$

Performers can't really say who they are. Unique among animals, humans cary and express multiple and ambivalent identities simultaneously... multiple selves coexist in an unresolved dialectical tension. ${ }^{31}$

To make relevant performance theater, it's not enough to study examples in other cultures. To make theater that may achieve transformation as well as transportation, theater makers need to address the relevant nituals and performances of their 
own society. And if performance and ritual are indeed typical for humanity per se, where are they in the West? To answer this question, Schechner has been looking at sports, television, street demonstrations, all kinds of performances outside the traditional theater, and at media stardom, asking the question how their sense of urgency could be reinstated in the theater. He analyzes examples of Western performance which are normally not considered as art or theater: a Black church in Brooklyn; re-enactments of history in historical theme parks; Shaker dances and their re-enactments; a sadomasochistic sex theater in Manhattan; and street festivals, carnivals and demonstrations. In each case, he aims for stronger, thicker, comparative interpretations of performative events.

Schechner sets the beginning of the American theater avant-garde at 1952, starting with the legendary John Cage-Merce Cunningham performance at Black Mountain College in 1952.32 His own work in the theater had strong collectivist and political overtones, as did a great deal of performance theatre in the 1960 's and early' 70 's, but that ended with activism in the society-at-large. ${ }^{33}$

In the present, Schechner distinguishes four kinds of performances: oral, traditional, modern, and postmodem. ${ }^{34}$

Oral performance is the oldest: here, the performer often identifies completely with the role in a trance; the performance is without written script, and often serves to support the religious-ideological order.

Traditional performance fixes such oral performances into fixed scores. Examples are Noh theatre, and medieval European cycle plays, emerging from Church ritual and popular entertainments.

Modern theater was developed, in Europe only, during the Renaissance, out of the traditional forms. It is based on narrative texts, and its works are often critical of the existing social-political-economic order.

Schechner sees the postmodern theater in opposition to the modem, deriving not from the modern but from oral and traditional forms, producing works that are mostly non-political and non-ideological, and that work with information bits instead of with fully developed narrative. "Performance art comes out of the meeting of popular entertainment (especially tock, punk, and new-wave music), happenings (with their sources in visual arts, the music of John Cage, and theories of indeterminacy), theater and dance." 35

And he tentatively sketches the outline of another form of performance, perhaps a fifth form, although Schechner hesitates here. He names this the "restored performance":

Restorations are increasing. Maybe this is because films seem to bring us genuine expeniences of carlier times in ways more fleshed out and genuine than archeological or written accounts do. Far from being bereft of performance forms it's hard to lose any these days. The combination of easy travel, appetite for the exotic (we for New Guinea dances, Papua's for rock ' $n$ ' roll), and postmodern techniques-and consciousness-of assembling experience out of interchangeable bits results in per- 
formances of "this place/time" being put on cut of context in "that place/time." ... It assumes that spectatots, and restorers, can shift tempotal channels. Moving through a restored enwironment involves swift adjustments of frame and accurate processing of multiplex signals. 36

Schechner, whose own work as a theater director relied on audience participation and on the immediacy of ritual forms, has emphasized that the more distancing postmodern forms of performance are therefore often nihilistic, formalistic, and individualistic to the point of becoming narcissist. Restored performances (historical theme parks, reenactments of historical or exotic rituals, restored prehistorical villages and so on) tend to smooth over their artificial, performed chatacter: documentary, fiction and history are merged, the distinctions erased or made to look insubstantial. "Of course theater is fake, but it celebrates its fakery while restored villages slyly try to hide theirs. This sly faking is on the increase." 38 Schechner adds to this the warning that, because of their apolitical stance, these forms tend merge and to slide into the stabilized aesthetic of Disneyland. ${ }^{39}$

This is not the place to adopt or refute Schechner's pessimistic warning. But there can't be much doubt that life in contemporary societies requires many swift adjustments of frame, accurate processing of multiplex signals and shifting temporal channels. Schechner's own analysis of TV news shows implies as much. Such shows are skillfully put together out of many separate news items, international disasters, political events, local tragedies, sports, business news, weather report, and commercials. "It is all framed as "news", and while apparently satisfying our society's demand for facticity, it [Schechner here elaborates as example a reportage of a fire which killed two children, reported as a video "slice of life"] is actually (soap opera) tragedy... Two messages, "this is theater" and "this is life" are broadcast simultaneously." 40 In this example of TV news, as Schechner concludes, "The ritual is in the format, in the programming, not in the content as such... The sense of "real life" is nested in the ritual format." 4 " He quotes playwright Jack Richardson, who described this ritual:

To be bound at a prescribed time to millions of others, to shate with them an identical image and test to be shown again and again the same polished day divided into the same neat sections of sigm nificance, to be assured by the traditional sign-off of the on-the-spot network subaltern who gives his name as testimony to the truth of what we've witnessed, to be convinced by immediate and portentous comment that we have participated in a day of deep and novel events and fully understood their meaning-what more could one ask for in the way of titual than all of this? 32 ?

Life is increasingly lived by shifting across the frames and rhythms of institutions, corporations and cultures. Performances that want to be relevant in such circumstances need to deal with these shifts. This category of performance, tentarively pointed at by Schechner as the combination of "postmodern performance" with "restored performance", requires a closer inspection. In Schechner"s analysis, such theater both has a tendency to deteriorate into slyly faked entertainment, while on 
the other hand, it opens up the opportunity of exploring the combination of different performance forms, of putting acting and nonacting side by side. What may result then is a form of theater about which Schechner writes, mentioning, among others, works by Robert Wilson and Spalding Gray as examples: "This kind of theater displays its ambivalence; it is explicitly reflexive." 43 Only in such individual works can performance theatre accomplish its goal of demonstrating how transportation and transformation combine in cultural shifts. According to Schechner,

the theater of the 1960s and 1970 's was... a theater of whole performance texts consisting of movements, stage placement and tableaux, music (and other sonic elenents), visuals including settings, envitonments, costumes, projections, and a number of nonactor performers: masks, puppets, projections, films. The dream of "total theater" envisioned in Euro-American culture by Wagner was realized by artists as diverse as Grotowski, Laurie Anderson, Richard Foreman, Robert Wilson, Mabou Mines (Lee Breuer, JoAnn Akalaitis), Elizabeth LeCompte, and others.44

But within this "total theater", a measure of Brechtian, and discinctly unWagnerian "Verfremdung" is injected. It is this moment of alienation that allows for reflection:

The distance between the character and the performer allows a commentary to be inserted; for Brecht this was most often a political commentary, but it could also be-as it is for postmodern dancers and performance artists-an aesthetic or personal commentary... Brecht ... emphasizes techniques necessary for this kind of acting: acting where the rransformation of consciousness is not only intentionally incomplete but also revealed as such to the spectators, who delight in the unresolved dialectic. ${ }^{45}$

The transportation that the theater produces by inducing the audience to suspend its disbelief and to enter the flow of the performance, is thus interrupted. This is a risky device, since the performance may lose momentum and become flat and studied; or it may induce the audience to apply mote of its own presuppositions to the performance, to invest enough to be willing to reconsider one's own desire to belief, thereby turning transportation into transformation, into a change-however slight - of one's awateness.

The following three sections are dedicated to three methods to accomplish this: the work of Robert Wilson, the Wooster Group, directed by Elizabeth LeCompte, and Laurie Anderson. Each of their bodies of work is wide-ranging in content, a layered and technologically complex collage of materials and performance forms, and demonstrates also, in each case, the artists' history in the theater, her or his accumulated experience in staging performances. The point is not to provide descriptions of these works in their entirety-they have been documented in detail elsewhere ${ }^{46}$ - but to investigate the theoretical insights that have helped to shape these productions. 


\section{ROBERT WLLSON: HIGHLIGHTING PERCEPTUAL} DISCONTINUITIES

Robert Wilson (1941) is the leading American avant-garde theater director. His work cuts across traditional gentes, continually challenging the conventional divisions of drama, dance, opera, and visual art. He has made over one hundred ptoductions; the most important are the play without words "Deafman Glance" (1970), the mystical opera "Einstein On The Beach" (1976), and "the CIVIL. watS" (1984), an attempt to decipher history in a single Gesamteunstwerk.

Wilson is interested in exploring perception; his theater is a laboratory which experiments with the perceptions of both audience and actors. He has developed a repertoire of highly formal methods to ensure that his performances do not repeat theatrical conventions. ${ }^{47} \mathrm{He}$ works hard to separate the visual, aural and textual elements of his productions, treating each of these elements with a formal precision of its own, demonstrating in the process a strong predilection for simple manipulations and permutations of isolated details. An actors' hand movements, certain phrases, a lighting design, someone's position on the stage, props and sets are each treated independently and given their own structural architecture or choreography. Wilson:

I know it's hell to separate text and movement and maintain two different rhythms. It takes time to train yourself to keep tongue and body working against each other. But things happen with the body that have nothing to do with what we say. It's more interesting if the mind and the body are in two different places, occupying different zones of reality. ${ }^{48}$

Wilson trained, before turning to the theater, as a painter and an architect, and is known for his ability to create strikingly beautiful tableaux vivants. As he designs an unusually high number of productions each year, recently often staging classical plays and opera's for European theaters, a part of his productions may offer just that. But in his best work, something more is produced: an opportunity for the members of the audience to reflect on the way they themselves combine their perceptions with emotion, and on the limits of the capacity to absorb and interpret simultaneous processes. Since such realizations get projected onto the performance - as motivation of the personae on the stage — the inner, personal reality of the spectator complements the stage performance. By withholding an interpretative scheme, Wilson's theater reveals the limitations and the insufficiency of one's attempts at perceiving and understanding reality. When this perceived insufficiency is projected on the staged events, their meaning is revealed: it is a vision of human history as swayed by the inadequacies of human communication.

The main subject of Wilson's work is the ambivalences in upbringing that may lead to child abuse and to the passing on of violence throughout the generations. ${ }^{4}$ Wilson's trademark as a director is the slowing down of theatrical time, having ac- 
tors execute specific tasks in extreme slow motion or tepeating actions time and again with only minor but deliberate changes. To convince actors that this way of working, which goes against their training, makes sense, during rehearsals Wilson often tells them about the psychological studies of mothers and infants conducted by Dr. Daniel Stern at Columbia University:

In the sixties I saw films of over 300 mothers picking up crying babies. Seen at a normal tate of projection, the mothers would reach for the baby and comfort it. Stern slowed the films thown. In eight out of ten cases the initial reaction of the mother was itritation or anger. Mother lunged at child; child retreated. The body moves faster that the mind, and the body doesn't lie. The body says things that have nothing to do with what the tongue is saying. When the mothers $\mathrm{saw}$ the films in slow motion, they were hortified. "But I love my baby," they protested. "They could not admit their ambiwam lence towvard their children. What happens between humans in one second is complicated and con traclictory. ${ }^{\text {so }}$

While the content of the staged events is often highly emotional and violent, portraying historical figures of general, mythical importance (Stalin, Einstein, Fread, Queen Victoria, Lincoln, and so on) their execution is completely unemotional, and no open violence whatsoever is directed at the spectator. 51 There is, however, an undercurrent of destruction: Wilson often instructs his actors to think about murdering the audience. For the audience, this results in a delaying of the attempt to interpret the performance.

Wilson has developed his approach to theater gradually and deliberately. The first steps in his development have been summarized as follows by theater scholar Theodore Shank:

In 1969 Wilson formed the Byrd Hoffman School of Byrds to work with people of all backgtounds and capabilities and provide opportunities for them to interact and develop theit individual porenials. Although he later used professional performers, in the early productions handicapped people worked on an equal basis with other untrained people he know or found on the street. He uses physical activity to sensitize the body and theteby expand consciousness....

Slow motion over such an extended period of time alters drastically the way we perceive the porformance. It tends to carry one beyond boredom, beyond the point of being intated by the slowness, and one vends to adapt by slipping into a mencal state that is less acutely conscious than normal. (One of the ingtedients of boredom-a feeling of being trapped-is absent because spectators are told they should fecl free to go in and out of the auditorium as they wish.) This state of reduced consciousness makes possible the intended mode of perception.

Wilson believes that everyone sees and hears on two different levels. We cxperience sensations of the world around us on what he calls an 'exteriot screen'. But we also become axware of things on an 'interior screen'--dreams and daydreams for instance. Bilind people only "sce' things on an interior visual screen and deaf people can only 'hear' sounds on an interior audial screen. Wilson found that in his long performances the spectator's interior-exterior audial-visual screens become one. Irutcrior and exterior images mingle so that they ate indistinguishable. Wilson says that people sometimes 'sec' things on stage that are not actually there.

The development of this concept resulted from his work with two adolescent boys-Raymond Andrews, the deaf mute who played the title role in "Deafman Glanice", and Christopher Knowles, 
the autistic fourteen-yeat-old who became Wilson's collaboratot on several productions. Both boys were partially cut off from the exterior world Andrews as a result of being unable to hear or speak, and Knowles because of brain damage which caused him to be absorbed in fantasy. They were less conscious than odher people, more closed off from the objective world, more absorbed with inner images than with external teality. They were in a kind of trance. Both of them, Wilson came to reall ize, had highly developed interior screens. He became interested in discovering how they stmuctured their perceptions in order to understand what their worlds were like. Then, with their help, Wilson created productiong that attempted to deal with reality in similar ways.

... in the course of workshops for "Deafman Glance" they discovered that repetition of simple movements was a means of tuning to interior screens, a practice used by people in other culnures to enter a trance. 52

Because of all these factors, it has been concluded that Wilson uses "the phenomenology of autism as an aesthetic anchor of his theater. ${ }^{153}$ He applies the experience of perceptual barriers to every human being:

We have to be blind and deaf, as well as hearing and seeing all the time. And we function that way, all of us, as deaf people and as blind people. By deaf and blind I mean that you blinked your eyes, so for a fraction of a second you were blind, or maybe you were dreaming, or maybe there was a negative innge. So we're all functioning as blind people. And at the same time we all function as deaf people. There's the noise going on outside of here. Maybe I can hear it, but then I statt doing something else and I don't hear it. We'te always shifung in and out of these interior/exterior audio-visual screens. So not to consider this or allow this is missing something. It's part of hearing and seeing. ${ }^{54}$

The liminal zone which the theater produces is used by Wilson to investigate the meeting ground of vision, hearing, language and the body:

Somebody may be technically dingnosed as deaf, but he hears. The body hears. So it's stupid for us to say he's deaf because he does hear. The body hears. It's stupid for me to say that you'te not deaf. The traditional definition of seeing and hearing doesn't mean anything. Or maybe it does, but in a different sense. 55

What I try to set up in the theater is a situation where I can hear, and where I can see... And so ofwen I can't hear. Because what l'm seeing is interfering. And I can't see because what l'm hearing is preventing me from seeing... [In] this theater that I do, we try to set up a situation where there is simply time for interiot reflection... What happens for me is that theater frequently becomes too aggressive... the box, the frame, is rigidly defined for the audio screen and the visual screen. ${ }^{56}$

\section{Naturally, Wilson detects this rigid framing also in film:}

Film gets too boxed in, it's too closed. Theater, I think, is another experiential thing that happens. "The nature of film is that the edges become deftned. I think there could be a way of making film. I've often thought if you made a siltent film and put radio plays with it, so that the space of the radio drams that you have in the visual book is free, or the space you have in the silent movie for the radio or audio drama is free, if you could put that together, you would destroy the frames. But I'm not sure. I still think there's a danger. Film is something that becomes too fascistic and too dictating. Not necessarily - but there's that tendency. It lulls us into a state of mind that's dangerous. 5 ? 
And his treatment of text and nartative similarly distrusts closute. Wilson says of himself that he can't direct a play acconding to psychological insights: "I personally can't think psychologically... You could call my way of directing antiStanislawski." The whole figure of man remains ultinately unknowable, as it is, Wilson seems to believe, in our daily experiences outside the theatet. 59 When he wrote the text of "I Was Sitting on My Patio / This Guy Appeared I Thought / I was Hallucinating", he sometimes kept the television on, playing at low volume, to incorporate phrases he heard." And while rehearsing another play, "Golden Windows", he explained:

If you'te speaking a line, especially in at text as fragmented as this one, the silence is a continuation of the sound... Whether you're speaking or not speaking, it's the same thing John Cage says there's no such thing as silence... When you stop speaking, you're still always aware of sound. It's one continuous movement. It's not stop and start. And the same with [physical.] movement [as with sound] 61

Whereas conventional plays are interpretations of a text, Wilson's theater presents material for a narrative directly on the level of all that comprises theater. One might say that he has universalized the Brechtian Verfrowdwngseffekt to encompass interpretation in general:

Brechtian theater breaks the spell by drawing attention to the conventions by which we distinguish the virtual (art) from the actual (life). Wilson, being his own brand of mystic rathes than a Brechtian skeptic, tried instead to counter a spell with a spell-to displace the virtual space of drama with the virtual space of visual art. Yet this space retains the theatrical chatge of such residual "elements" as light, time, and human scale and movement. ${ }^{62}$

It has been said that in Wilson's theater, understanding is suspended: the processes of perception have to take the place of interpretation ${ }^{63}$ As one of Wilson's collaborators, dancer Lucinda Childs, has explained, it is the spectator's job to make sense out of what he sees and to decide if it's chaos or order, formed or formless, or if that matters. ${ }^{64}$ Indeed, Wilson scholar Arthur Holmberg has stated that "Much of the behaviour one sees in a Wilson production would be diagnosed as schizoid. Wilson's theater stares into a psychic abyss; the theme of madness runs through his work." "6s Especially in his collaborations with Heiner Müller, whose texts present history as a sequence of brutalities, Wilson's performances present history as a stage that is governed by traumatic inadequacies of perception and understanding. The Cologne section of "the CIVIL warS" was one of Wilson's outstanding productions, as his collaboration with Müller allowed him many opportunities to experiment with the slowing down of time as a mechanism to enable one to deal with psychic terror. ${ }^{66}$

When private associations merge with Wilson's staged visions, the experience may be likened to an epiphany; one's very presence in the audience, now fasci- 
nated by the spectacle, now distracted and lost in one's own associations, becomes the main arena of perception and interpretation. As Holmberg wrote,

Wilson heightens his visual images to the level of symbol, making them resonate to the depths of consciousness and beyond. "It is not surprising;" Jung writes, "when an archerypal sicuation occurs, we suddenly feel an extrordinary sense of release, as though transported or caught up by an overwhelming power. At such monents we are no longer individuals, but the race; the voice of all mankind tesounds in us." Many such moments occur in Wilson's mythopoetic universe. Through archetypes, Wilson's theater suggests more than it states bo

The ultimate intention of Wilson's theater has been described by critic and scholat Bonnie Marranca as "a romantic, utopian one... As a romantic, Wilson looks toward the purification of a cruel, unjust world and a return to an Edenic society." 68 Later, she has stated that his way of working, by combining material from several cultures, "subverts the sense of making, and (for audiences) of viewing theater from one's own cultural center." 69 Playwright Heiner Müller has expressed this somewhat differently: "What's productive about Wilson's use of myths on stage is the anthropological impulse: getting to know the animal "man", how it functions, how it moves, where it comes from." Arthur Holmberg also places Wilson firmly within the romantic tradition:

On the one hand, his layering against each other of multiple, dissonant, and simultaneous realities dramatzes the Kantian split between object and subject. We can never penetrate the thing in itself; we are locked into individual perceptions and subjective interpretations. The perceiving subject is radically distinct from the perceived object. On the other hand, Wilson's Naturpbilosopbie (the arigins of this tradition go back to Schelling) belies the hope to merge with nature, ttanscending this breach between subject and object. The knowledge of separation brings with it the nostalgia for union....

Visual images give Wilson more resources to circumnavigate the limits of language than are available to poets... Consequently, the opportunities for explosions of "intuitive apprehension" that whe us "beyond the vel of words" are far greater on a stage than in an sonnet."

In his work, Wilson demonstrates how human experience as such, and therefore history, is characterized by the limitations of perception, and by discontinuous transportations and transformations; that makes his theater as reflexive as Schechner's theorizing.

THE WOOSTER GROUP: THE HISTORICAL REALITY OF HALI, UCINATIONS

Whereas Wilson's theater is visionary and tends towards the mystical, the theater of the Wooster Group searches to confront its actual subject matter uncompromisingly and at the most literal level. ${ }^{72}$ Working as an ensemble under the direction of Elizabeth LeCompte, the Wooster Group presents real events, using 
the stage to assemble and condense the dramatic contrasts of that reality, ${ }^{2,3}$ marking the "discontinuities and dislocations... collisions between different energies, personae and media" 74 which arise inevitably in restored performance, both inside and outside the theater.

The process of making a theatrical production in this way is long and intricate, since it requires that narrative content can be examined as having exclusively formal properties, which can be made into a musical or architectonic collage, while these purely formal manipulations have to be considered again for their natrative implications. Formal abstraction and realism have to enter into a dense dialogue.

Spalding Gray has recounted how he, personally, entered such a dialogue, which he calls "personal-abstract" movement, "5 while doing dance improvisations at Robert Wilson's loft. There, he experienced

a flow of feeling that $I$ could not name because the flow, which was directly connected to the physiw cal flow of body movement, happened so quickly and in a continum that it was more difficult to pin down and name. There was only direct unmediated expression... for the first time I experienced being held together with a group of performers by something other than words... Ar last 1 had room for intemal reflection. I could think as I moved. I began to have a dialogue with myself. My thoughts were freer because they were not ted down to a psychological story line of a particular text. At first I was just moving and experiencing direct feeling... but as I did this more and more, and got familiat with it, there was more room for reflection. ${ }^{\text {it }}$

The trilogy of autobiographical plays which Gray and the Wooster Gtoup produced was therefore based on "a constitution of personal energy rather that a psychological exploration of personality" choreography, produced out of concrete actions with a clear intent, physical impulses which were not "conceived of as a manifestation of hidden desires or psychological obscurities. To the spectator, personal-abstract movement may appear abstract and ambiguous because he does not share in the performer's chain of associations: he is deprived of the contingent activity and the original context in which the movement was developed. For him, the action enunciates opportunities for meaning rather than a fixed denotative value."

To bring this method out in mote detail, I shall give a brief description of a later production of the Wooster Group: "I.S.D. (...Just the High Points...)", developed and played over the period from 1983 to 1985 . "L.S.D.", to abbreviate the title, is a play in four acts. Its focus is the enthusiasm for L.S.D. of Timothy Leary, ptofessor of psychology at Harvard, and his friends, harbingers of the drug culture that was such an impottant part of sixties counterculture, with its promise to transform consciousness.

The first act of "L.S.D." is organized around the writings of Leary and his circle of friends, scientists and beat poets: Aldous Huxley, Arthur Koestler, Alan Watts, William Burroughs, Jack Kerouac, Allen Ginsberg, John Bryan, Dr. Charles 
Slack. A portrait of their thinking is produced in a straightforward manner: eight actors sit behind a long table facing the audience, and read fragments, most chosen at random, from their books. On some evenings, this would include a fragment from a letter by Allen Ginsburg, written in 1961:

Leary was gteat here, calmed everyone, Bill [Burroughs] dug him... They both go to Harvard whete Bill will experiment with white noise \& sensory deprivation machines etc.

leary told me he agreed with Bill that Poetry was finished. Because he felt the world was really mov. ing on to a new super consciousness that might eliminate words and ldeas...

I think Bill \& Leary at Harvard are going to start a beatiful consciousness alteration of the whole world-actually for ren-Leary thinks it's the beginning of a new world. ${ }^{79}$

This reading is organized like a quiz show: the men speak into microphones, and their readings are timed and limited strictly to 60 seconds by a buzzer; they are also interrupted by the only female actor, sitting off to one side, speaking selected memories of Leary's babysitter, memories which bring out the darker, unheroic aspects of the household, the self-mythologizing, the machismo promiscuity, and the paranoia. When the play was performed in Amsterdam, the audience was invited to ask for requests from favorite books and authors, underlining the fact that everyone is already somehow acquainted with beat poetry and drug culture.

The second act of the play is a speedy, revved-up version of Arthur Miller's "The Crucible", ${ }^{80}$ In his play, Miller uses the historical Salem witch trials as a clear allegory of the McCarthy era with its hysterical anti-communism, highlighting the use of ideology to justify fallse accusations and betrayal. The Wooster Group's rendition of "The Crucible" emphasizes the disbalance in power by amplifying only the men's voices, and makes the hilariousness and the hysteria tangible by the sheer brilliance of its precise high-speed timing, suggesting parallels between "The Crucible" and Leary's L.S.D.-cult by means of this choreography of abandon, by the structure of the stage set and because of the central motif of interrogation.

The third act is a combination of act 1 and 2. It is an exact recreation by the actors on stage of a videotape that was shot during a disintegrating rehearsal of act 2; disintegrating because the actors had taken L.S.D. and just picked tandom parts to do. This was a deliberate decision by Elizabeth LeCompte to break several rules at once; it was, as she commented, "the worst thing you could do in the early seventies. And that was to take LSD to make art." "The result, as LeCompte saw it, was "pretty horrendously boring. They couldn't remember their lines. And you know when people laugh at themselves, and they think it's funny? But it's not funny, it's indulgent and... kind of... horrible?" 82 This chaos (somewhere in the middle, one of the actors asks, "Umm, are we staying on the play or are we doing Leary stuff too?"83) evolves into a reenactment of a "bad trip" in the Leary household; near the end, some actors pick up musical instruments and form a band to play the Velvet Underground's troubled and melancholic song "Pale Blue Eyes". 
Another historical scene that gets reenacted is William Burroughs's shooting of his wife, Joan Vollner; she was addicted to benzedrine, he to heroin. What really happened is not known; in one version that Burroughs has told afterwards, it was an accident, in another version, also told by Burroughs, it was a fatal variation on the Wilhelm Tell-trick and he tried to shoot a champagne glass that his wife balanced on her head. The Wooster Group presented both the violence and the riddle by having only part of the shooting acted out, the rest of it presented on a video monitor, thus avoiding too much coherence.

Act four brings a further disintegration of the energy, the mixture of messianism and hysteria. Excerpts are read from a 1982 debate between Timothy Leary and CIA-agent $G$. Gordon Liddy (of Watergate-notoriety), full of evidence of Liddy's violent state-supported cynicism and of the victims made by L..S.D. When the moderator of the debate finally asks Leary how he feels, his concluding words. are: "I feel very sad." $\$ 4$ The play then ends with a dance, which can be interpreted-following the many clues provided throughout the performance-equally as a dance by the "witches" of Salem, a dance by hippies high on L.S.D., or a dance by a sleazy tourist-entertainment group, imitating Mexicans or Cubans. For this dance, actress Kate Valk lies down on the raised interrogating platform and actor Matthew Hansell straddles her, his legs stretching invisibly behind him, and seats his torso on top of her hips, the two forming a trampe l'oesil unity. He whistles into a microphone while "he" moves "his" legs in time to the music. On either side, these movements are copied by sneakers, held by other performers, smashing down on the platform. The image on a video monitor, standing to the side of the platform, is affected by these violent smashes, so that the image almost disappears into video snow. The video image is a question (and a quote from "The (Crucible"): WHAT IS THIS DANCING?"

"L.S.D. (...Just the High Points...)" was, to use director Peter Sellars' words, a "high-energy show-biz media-blitzed theatrical gtandslam"s. At the same time, it is very densely layered; "because there is so much detail, too much certainly to be taken in during a single performance, each viewer's experience of the work is quite different." "LG "L.S.D." tries to question every aspect of its content material, including its representation, and as a result of that, it leaves many loose ends. My own example of the play may serve as a telling example.

My experience of this performance was puzzling to myself. I knew very well that it was about Leary and "The Crucible". Yet I perceived the piece as a whole as if it was somehow about the Amsterclam squatter movement of the period 1975-'85, an idealistic movement in which I had taken part, which had gradually nurned violent. The squatters' utopian attempts at reconnecting public and private space, at widening the liminal, zone which society allows itself by combining the intimacy of living in a house with defiance of private property, resulted in street battles, which frustrated and puzzled me. It seemed to me that "L.S.D." somehow 
offered a better explanation of this violence than any other I knew of at that time-and while that perception was obviously contradicted by the textual content of the performance, it was an accurate and personally acute interpretation of its choreography. With hindsight; to me this experience confirms Robert Wilson's insight that people in the theater may perceive things that are not actually part of the performance:

And of course, the performance was deliberately constructed to contain ambivalences on many levels. As actor Ron Vawter saw it,

Certainly in L.S.D. we [the Wooster Group] were addressing our origins in the Performance Group. Many of the things that were going on in [Timothy Leary's] Millbrook house, the drugs, the breaking down of social inhibitions, all went into the kind of theater we developed from. It's such a part of all of our pasts that it had to be there. And the guru-Richard] Schechner always thought of himself as a. gun. Theater was just a part of it. We newer liwed together in a collective, but our lives revolwed around a kind of guru-follower, ashram, sixties experience, which has good and bad memories for me. And one of the reasons why, when we deal with the sixties in the piece, we keep waffling back and forth, is because we feel a great deal of ambivalence-Were these people inspired? They did change ways of thinking and perceiwing-Were they destructive? They were obviously both. ${ }^{97}$

"History as Hallucination" is the title that theater scholar David Savran has given to his detailed description of "L.S.D." "s8 Savran interprets the play through Michel Foucault's Nietzschean vision of history as an "endlessly repeated play of dominations" ${ }^{89}$ One might also say that LeCompte has succeeded in mixing two different hallucinations, diverse transportations and transformations reflecting and opposing each other, to produce something which finally is sobriety: the performance culminates in: "I feel very sad" and: "What Is This Dancing?"90

\section{LAURIE ANDERSON: STORYTELLING IN AN ELECTRONIC}

\section{ANDSCAPE}

Laurie Anderson is perhaps equally well known as performance artist and as pop star. RoseLee Goldberg, in her "Performance Art: from Futurism to the Present" considers her major performance work "United States" (1979-1983) as a breakthrough: "as far as the public was concerned, "United States" marked the beginning of the 'coming out' of performance into the mass culture." son's successes and failures in popular music are especially relevant here, in so far as they highlight both the similarities and the incompatibilities of performance theatre and mass-marketed popular music.

"United States" was an eight-hour-long amalgam of some seventy-eight short visual and musical stories that she had collected over more than six years, and the culmination of a longer artistic development. Anderson had studied art history and sculpture, and had experimented throughout the " 70 's with intimate forms of performance, and with hybrid combinations of sculpture and electronic media. 
Seeing "Einstein On The Beach" by Robert Wilson and Philip Glass inspired her to expand her sketchy performances to epic proportions." The result was "United States", "a performance portrait of the country"93 in four parts: Transportation, Politics, Money, and Love.

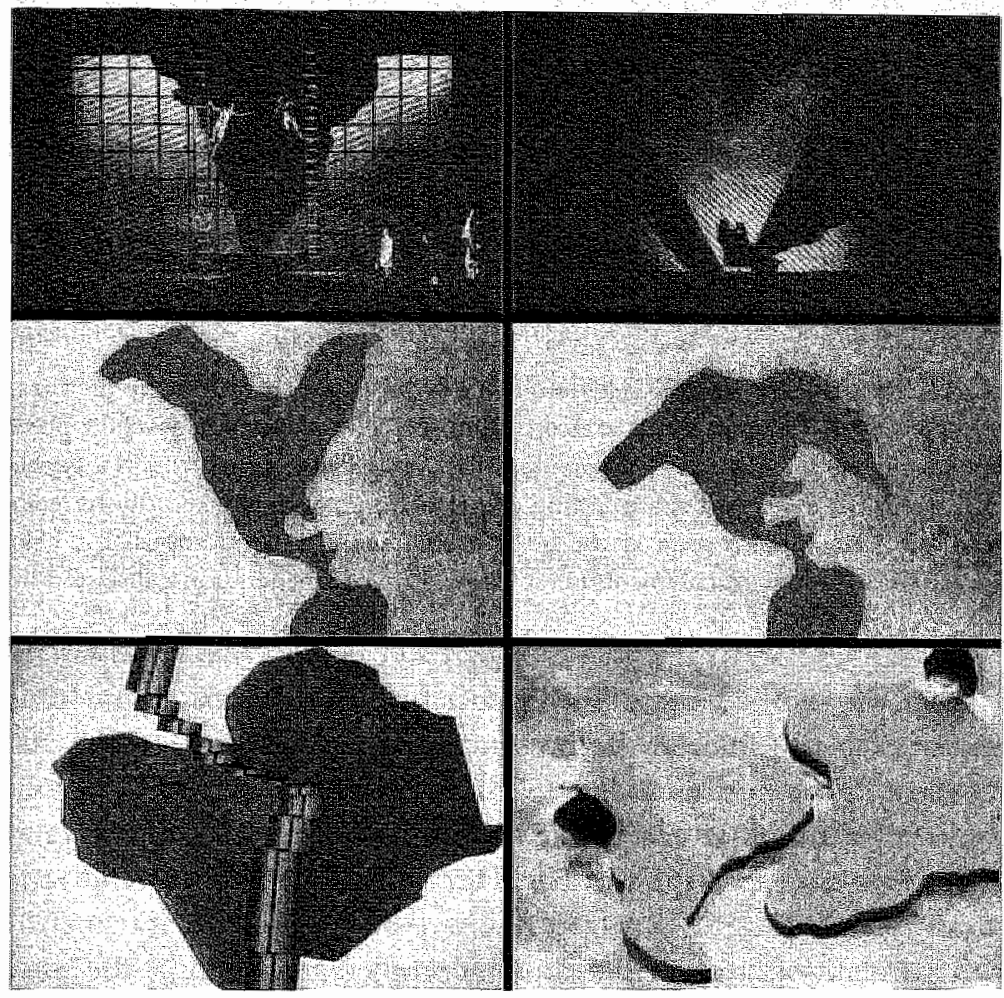

20 loons of the continents used as a means of theatrical experiment, to reexamine the notion of a fixed and stable foundation for history.

Top: Robert Wilson's "the CIVIL wars". Photos from the Suhtkamp-bools of that title.

Middle: Laurie Anderson's "United States". Photos from her book "Stories from the Nerve Bible".

Bottom: David Bytne's "Tlé Aiye". Video stillss.

Anderson's performance style is laconic and anecdotal, her storytelling does not aim towards definite conclusions bur towards an open siruation: "In all of the work I've ever done, my whole intention was not to map out meanings but to make a field situation. I'm interested in facts, images, and theories which resonate against each other, not in offering solutions." personal stories, childhood memories and such with political material. Looking back, she estimated that maybe a third of "United States" was quite political, and 
the test personal anecdote." Critics have often concentrated on the political content In an essay on Anderson's work from 1969 to 1983, Janet Kardon has concluded that her wotk

is a world of the defenseless self, indeed of the disembodied self searching for a place in a placeless universe; encountering the opaque codes of the cynical "they": the generators of the anonymous language (advertising, commercials, instructions, the official, posted dos and don'ts of everyday life) that is appropriated unconsciously in our fantasies and dreams, Once again, in Anderson's world we come, as in classic Pop Art, to the terror, banality and awe of the capitalist Word. Anderson has monumentalized the Word by extending and shifting the time in which the Word appears, carefully bringing it into a structure that is built architecturally-but which exists episode by episode- to exhibit chas and discontinuity.

\section{RoseLee Goldberg similarly describes "United States" as}

a flattened landiscape that the media evolution had left behind: projected hand-drawn pictures, blown-up photographs taken from TV scteens and truncated film formed operatic-size backdrops to songs about life as a "cloooosed circuit'. She sung and spoke a love song 'let $\mathrm{x}=\mathrm{x}$ ', through a vocalizer that made her voice sound like a robot's, suggesting a melancholy splicing of emotions with technological know-how. 'O Superman', a song at the heart of the show, was an appeal for help against the manipulation of the controlling media culture; it was the cry of a generation exhausted by media artifice."?

About the second part of "United States", "Politics", Craig Owens wrote that while most performers wish to establish the presence and participation of the audience, Anderson's stage "presence" is indirect: "She no longer performs directly for her audience, but only through an electronic medium. While the media literally magnify her presence, they also strip it from her. Her work thus extends and amplifies the feeling of estrangement."

Such political intexpretations are correct, but incomplete, neglecting the ambivalent stance that Anderson"s performances take. If they oppose the landscape of technology, they are also completely dependent on electronic technology. This is but a superficial paradox; at the heart of Anderson's work lies a much more personal ambiwalence, the recognition that the disparities of life in a mediated society are both debilitating and energizing. Debilitating, insofar as they enforce a passive acceptance of discontinuity, making it overwhelmingly clear that attempts at shaping one's life into a convincing personal natrative are futile-energizing, insofar as these mediated estrangements emancipate impulses and character traits which would otherwise lie fallow. This ambivalence has been noted by Henry M. Sayre:

Anderson is the artist of a "new noise", working in a new tertitory. She has an almost uncanny ability to locate festive impulses within technological society, to draw those impulses out of us. As we recognize in her wanderings our own homelessness, her noise becomes recogrizably ours. This recognitton is all she gives us-the sense that we are in it together, that her straregy of subversion is potenw tially, at lesst, our own. 
Anderson's theater braids stories, images and songs into a texture which is kept flexible by wotdplay and juxtapositions, creating a personal identity that is cast into ever changing metaphorical roles. This effect is strengthened by the fact that her physical presence on the stage is unassuming, giving her persona every opportanity to identify emotionally with whatever role the electronic media offer. Her performance style is not based on gesture or dance, or on the expression proprioceptive qualities, but shows instead how much of perception is heteronomous, produced and directed by outside forces. Throughout "United States", she alters her voice by means of a harmonizer which drops it a full octave, giving it a deep male resonance. This voice is modeled on the voices of Ronald Reagan and William Burroughs, it is simultaneously the voice of authority and the voice of technology. "Ino "I am in my body", Anderson has said, "as other people are in their cars." 101

This complex, disembodied, technologically mediated quality of experience may help to explain why the songs from "United States" were so widely recognized that Anderson became a popstar overnight. "O Superman", the song of which originally only a thousand singles had been pressed, became a hit that went to number two on the British charts and grossed over a million dollars. ${ }^{102}$ To be able to fill the oxders for this single, Anderson signed a contract with Warner Brothers, which helped her to produce the complete version of "United States". (Anderson ironically included her dealings with the record company in Part 3: "Well I was out in L.A. recently on music business ... And I said: Listen, I've got a vision. I see myself as part of a long tradition of American humor. You knowBugs Bunny, Daffy Duck, Porky Pig."103) She recorded two albums of "United States" songs: "Big Science" (1982), which has an austere electronic sound, and "Mister Heartbreak" (1984) which next to "United States" material contains new songs and has a sound more like ordinary easy pop music, as it was recorded with help of established stars like Nile Rodgers, Peter Gabriel and Adrian Belew.

Laurie Ancletson subsequently undertook a lengthy "Mister Heartbreak" tour, directed her own documentary concert film "Home Of "The Brave" (1986) which she supported by a new world tour, the "Natural History" Tour (1986), singing with a band and back-up vocalists. This enabled her to find a large new audience, but in retrospective, she was not happy about the resulting mixture of pop routines and performance art, describing the overall effect as "glossy" and "showoffish". "The "Natural History" Tour was outlined as a combination of pop culture accessibility (the title punningly refers to the Beatles' "Magical Mystery 'Tour") with the melancholic vision of conflicting realiries that characterizes performance theater. Anderson started this show with an unaccompanied reading of a famous text by Walter Benjamin, his ninth thesis on the concept of history: 
There a picture by Klec called "Angelus Novus". An angel is presented in it who looks as if he were about to move away from something at which he is stating. His eyes are wide open, mouth agape, wings spread. The angel of history must look like that. His face is tumed toward the past. Where a chain of events appears to ws, be sees one single catastrophe which relentlessly piles wreckage upon wreckage, and hurls them before our feet. The angel would like to stay, awaken the dead, and make whole what has been smashed. But at stom is blowing from Paradise; it has got caught in his wings with such wiolence that the angel can no longer close them. The storm drives him irresistbly into the future to which his back is turned, while the pile of debris before him grows toward the sky. That which we call progress is thits storm. ${ }^{105}$

This allegory places all of history in a bitter light, showing only the shortcomings of attempts to give meaning to history, the cracks between stories through which reality may be seen as barren and meaningless. It is an utterly dramatic text, written by Benjamin in 1940 as his philosophical testament, shortly before he committed suicide while trying to escape a Europe that was overrun by the Nazi's and their allies. "Natural History" is a key concept of Benjamin's philosophy, a symbol of his intention to reinterpret European history as a theater of illusions, a symbolic reality which can never completely hide the struggle for domination and survival, which shows how nature is still the governing force within history. Benjamin's motto might have fitted Anderson's method of braiding and juxtaposing stories, of mingling personal anecdote with political symbols. 106 But her "Natural History" tour was in this respect disfigured by the attempt to organize a performance around conventional popsong formats, formats which deflated most attempts at creating the ambivalent and allegorical forcefields of meaning which bring out the best of Anderson's work.

In retrospect, Anderson has admitted that essential qualities of her work were ruined by the attempt to give them a mass appeal. The laconic personal quality which is indispensable to bring out the ambivalence of Anderson's stories evaporated when she built her performance around song conventions; all the more so because she felt that for her, the need to build a rapport with the musicians excluded the possibility of creating an intimate contact with the audience. ${ }^{107}$ She felt pressure to fulfill a demand: "[...] up to that point, I'd always thought, "what would I really enjoy doing?" and this was more like, "Here's how we can strategize." "In So she wrote some new songs, "Baby Doll" and "Whose Shoes" which she felt later were best forgotten, as singing them was, as she said, just humiliating ${ }^{10 \%}$. Scared by the pressures of international success, she retreated behind her technological devices: "at some point I was using the gadgets as a defense... I went into technicolor." "10 As the result of all this, Anderson later concluded that "Natural History" "missed the "through line", the loose plot of performance."111 Instead of evoking the presence of blind forces within history, which "United States" had done so convincingly by constantly letting Anderson's stories "falling away" into other media, "Natural History" itself fell prey to just these forces-a 
conclusion which Anderson herself seems to share. Later she retumed to performing solo, refusing to be overwhelmed either by media strategies or by technology.

If, as Schechner supposes, performance and ordinary life are intertwined, Anderson's best work demonstrates convincingly that botder traffic between these zones is increasingly controlled by electronic media. While they may be used to construct a performative field in which ambivalences can develop their critical potential, they also embody the commercial pressures and expectations which may undo that freedom. 

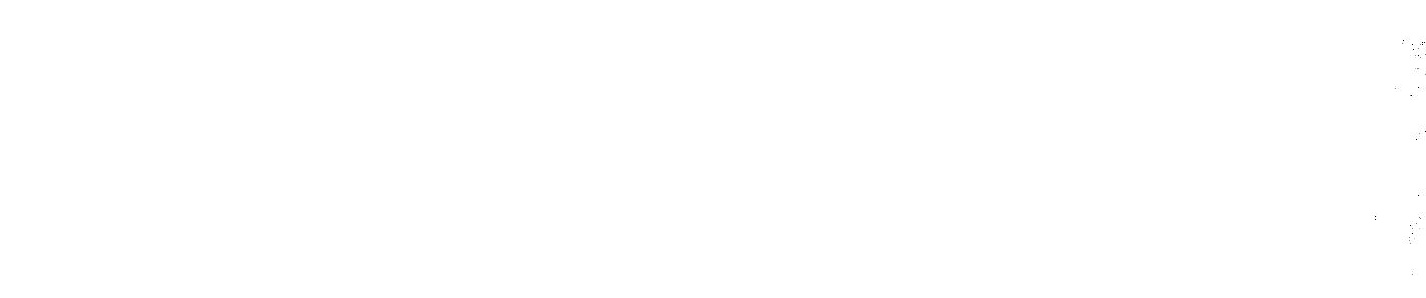

s. 


\section{CHAPTER 8}

\section{Anthropology and performance}

\section{COMBINING PERFORMANCE AND ANTHROPOLOGY}

While they attempted to sketch convincing portraits of other, foreign cultures, anthropologists have often wanted to provide a clearer view of their own culture at the same time. Ftanz Boas, generally regarded as the founder of American anthropology, already wrote some hundred years ago that the greater educational importance of the anthropological method is "to impress us with the relative value of all forms of culture, and thus serve as a check to an exaggerated valuation of the standpoint of oux own period, which we are only too liable to consider the ultimate goal of human evolution". In more recent times, Clifford Geertz has suggested that we are living more and mote in the midst of an enormous collage." Accordingly, in his opinion, "The job of ethnography, or one of them anyway, is indeed to provide, like the arts and history, narratives and scenarios to refocus our attention; not, however, ones that render us acceptable to ourselves by representing others as gathered into worlds we don't want and can't arrive at, but ones which make us visible to ourselves by representing us and everyone else as cast into the midst of a world full of irremovable strangenesses we can't keep clear of."3. This picture of anthropology as the purveyor of reflexive and alienating scenarios suggests that anthropology and performance theory should have a lot in common. This terrain has been partially mapped by Richard Schechner, and it is clear that the anthropologists whom Byme has cited as influential and inspirational for his work were equally interested in this overlapping of art and anthropology. As is to be expected, scholars working in this ambivalent 


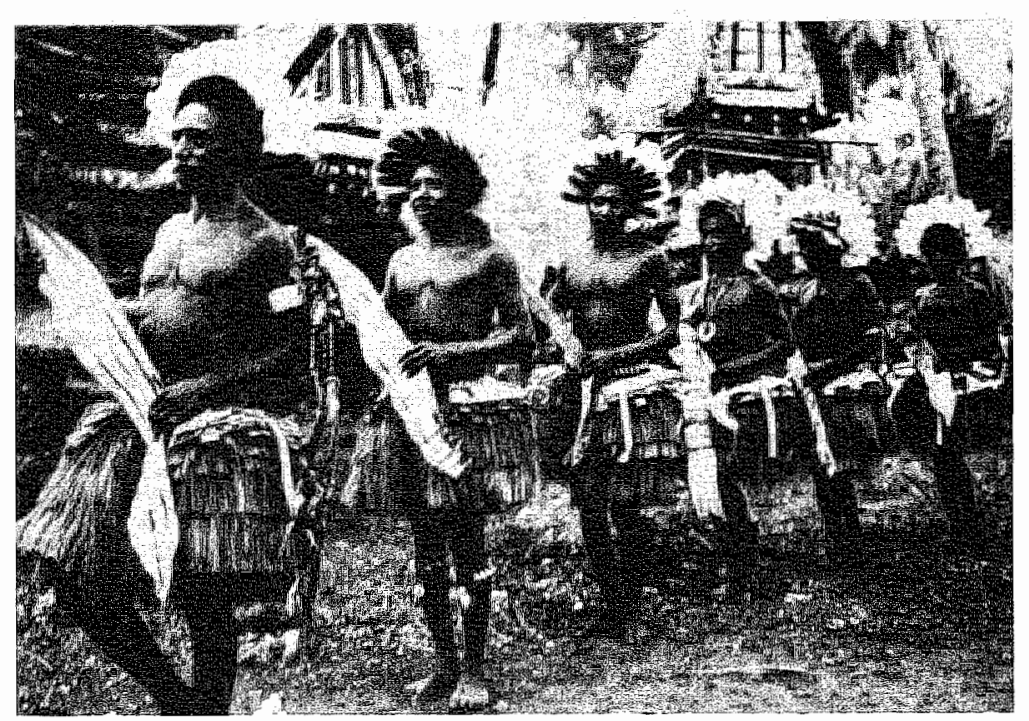

21 Top: "Classical" anthtopology. Photo taken from a handbook: R. M. Keesing"s "Cultural An" thropology. A Contemporary Perspective". Original caption: "Trobriand men don women's gass skirts for a dance. Reversal of polarities in the milawila." Photo" Australian News and Information Bureau.

Next page left: "Performed" anthropology. Photo from Richard Schechner"s "Berween Theater and Anthropology". Original caption: "A Papua New Guinea Tubuan initiand approaches for outdoor rites in the "performed ethnography" staged at the University of Virginia by Mini Geotge under the guidance of Victor and Edith Tumet. Photo: Pamella Freese.

Next page right: Filmed performed anthropology. Photo from David Byrne's "True Stories"book. A still from the fashion show-scene, costumes designed by Adelle Lutz, Bytne's wife. Photo: Mark Lipson.

terrain have also produced the most insightful criticisms of Byrne's anthropological experiments.

The development of an anthropology of performance may help to escape the dilemma that has been introduced by comparing the Jungian perspective on myths with the ethnological, functionalist viewpoint of Radcliffe-Brown. The Jungian neglect for the context of myths, and his distegard for the many differing ways in which mythical material can be understood and used, stands diametrically opposed to the approach that explains myths, ceremonies and customs exclusively by relating them to their function within the social system. Cultural anthropologists have of course been aware for a long time that this kind of dichotomy between function and meaning is stifling. One of the anthropologists who tried to reveal in his work the many-layeted functions of symbols was Victor Turner. He wanted to describe how "individual concerns are systematically related to public concerns; collectively enacted drama's have private and unconscious meanings." "Turner later collaborated with Schechner to deepen this kind of research, finding the role of 

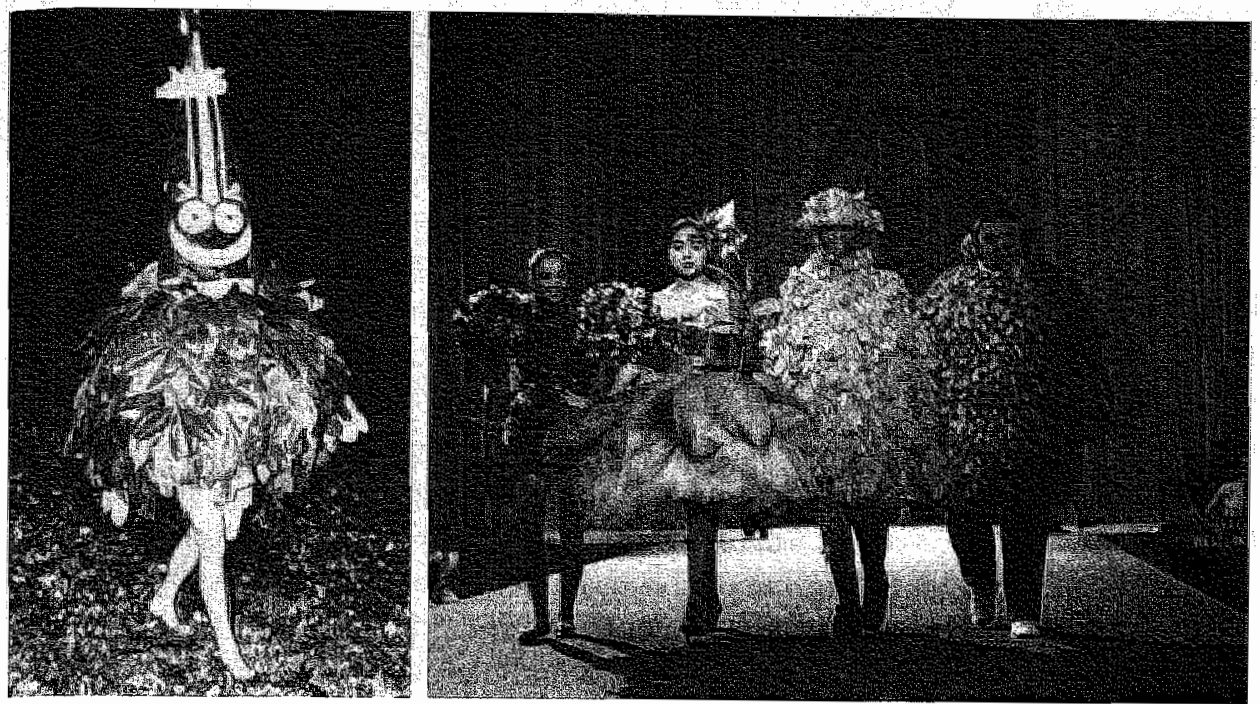

The fashion show-scene in "True Stories" oscillates bewween pure entertainment fother costumes imitate brick walls and wedding cakes) and the insightful transparency that is the purpose of performed anthropology. Impossible to decide for one or the other. But then, who could tell, just by looking at these photos, whether those Trobtiand men and that anthropology student in Virginian are, underneath theit costumes, engaged in serious ritual, feeling ridiculous, or having a good timert

the observing cultural anthropologist and that of the interfering theatre director to be complementary. He wrote about Schechner that "He might just be the catalyst anthropologists need to get them thinking about what Dilthey called "]ivedthrough experience", and about the dramatic perspective on culture: "Actors are deeply aware of how the human body can be made by costume, cosmertics, and stylization a matrix of living meaning, at once epitomizing and evaluating the sociallife of the times."

Schechner has written repeatedly about the interdisciplinary complexity that results from such investigations. He has pointed out that using aesthetics interculturally relates directly to social theory" and has emphasized how, the other way round, "The situation precipitated by the freldworker is a theatrical one: he is there to see, and he is seen. But what role does the freldworker play" He is not a petformer and not not a performer, not a spectator and not not a spectator. He is in between two roles just as he is in between two cultures. In the field he represents-whether he wants or not - his culture of origin; and back home he tepte- 
sents the culture he has studied." The very presence of the fieldworker is, as Schechner remarks, an invitation to playacting ${ }^{8}$ and according to him the soft sciences are therefore, in the final analysis, extensions of the arts and humanities, just as ordinary life and performed life are related to each other like the two sides of a Mäbius strip.?

This performative aspect of cultutal anthropology is an outstanding character istic of the anthropological research that Byrne has cired as inspiring. It is therefore illuminating to regard Byrne's work in combination with the theories of Richard Sichechner. Byme has occasionally read The Drama Review, Schechner's magazine, and his friendship with Robert Farris Thompson also links him to Schechner's Department of Performance Studies, where Thompson has regularly been a visiting professor. And naturally, Schechner's work has numerous connections with New York's performance theater, a network of influences and collaborations that has been equally important for Byrne. These connections reveal a loose, but nevertheless real community of common artistic methods and aims. ${ }^{10}$

After the conceptual and minimalistic beginning of the Talking Heads, when the band kept theit concerts as sober as possible, Byrne gradually accepted that performing inevitably has a theatrical dimension. Unwilling to accept the conventional models for rock singers, he looked at non-Western examples: "Around 1979, when I was on the verge of admitting more irrational things into music and into what I was thinking, I also noticed that people who put on theatrical performances in the East-in Japan and Bali-just seemed to be doing it for themselves or for their community. They seemed to accept that you had to get dressed up if you were going to go onstage." 11

And when he wanted to develop a personal repertoire of gestures and movements, Byme did it by looking at footage of preachers, shamans, people getting the spirit in churches (as documented in "Talking Heads versus The Television"), making a dance vocabulary out of that. Byme's performance style of the first half on the " 80 's was deliberately constructed "restored behaviour", made with methods that had been developed by theater pioneers such as Peter Brook, Grotowski, and Schechner.

Schechner's theorizing helps to interpret elements of Byrne's work. Consider one of Byrne's more far-reaching statements, in his photo book "Strange Ritual", where it runs along the bottom of fourteen consecutive pages, as a subtitle to photos made in Hong Kong, New York, Tokyo and Roppongi (compare this to the already mentioned line from "Social Studies" (from "The Knee Plays"): "T thought that if I ate the food of the area that I was visiting that I might assimilate the point of view of the people there, as if the point of view was somehow in the food."): 


\section{MY MALAYSIAN CHLDHOOD}

When far from home, the Nex Yorker or Los Angelino, feeling a pang of homesicknes, may desire Thail food tather than his or her indigerous com on the cob and Jello. With so many of oui cultures being made up of bits and pieces of other cultures, our sense of self becomes confused with our sense of the "others" who have joined us. The Parisian may long for an evening out at an African nightclub when visiting Africa. The Japanese visiting Burma may long for McDonald's or fresh spaghetti. Are our changing palettes a taste of what is to come? Will we eventually imagine ourselves ns someone else and appropriate their history, their tragedies, their manners and foibles? Will our identrives become so thotoughly confused that what once was our original "base" cullure recedes to a dwindling remnant? We are they and they are we. Will we dream of imagined childhood in Dakar? Of lost loves and departed friends in Malaysia? Will our consciousiness be a complete pastiche? A patchwork of sounds, smells, and tastes-colonized by whatever attracts us? By delicious frod, sensuous textures, and beatifull men and women? Will we be consumed by our favorite things? Will we miss the smells and the dust we never experienced? Will the "exotic" eventually become so commonplace, so much a part of our culture, that the word will become meaningless? Will the old Europe, the old America, be the new exoticism? It is already, isn ${ }^{\prime} t$ it?

This text may be read as a straightforward application of an insight that has also been voiced by Schechner: interculturalism is replacing internationalism, which implies that people should have the liberty to choose their own culture, in addition to the culture into which they were born. ${ }^{12}$ Schechner, like Bytne, compares this choice to the gastronomic panorama:

Out current wiew, I think, is soaked with a kind of belief in generic racism, the assumption that only blacks can be African (in the full black African sense) or that kids from Brooklyn can't be Amerindians. But as cultures more and more come to be performative actions, and information links among them emetge into view, people will choose cultures the way many of us now choose what foods to ent. $^{1.3}$

Schecher is writing here in an essayistic mode; his text bears the pessimistic title "The Crash of Performative Circumstances. A Modernist Discourse on Postmodemism". His political perspective shows itself in the way he continues his text: "Pm awate of the cruel irony here: altogether too many of the world's people not only can't choose what foods to eat, but even whether they can eat or not."14 People have more often been forced to adopt second cultures because of wars and economic pressures than out of free choice, as Schechner points out. Yet this does not imply that Byme's version of interculturalism is naive. Both Byrne and Schechner have underlined that this choosing of one's culture is never as easy as it might be made out. Schechner, who considers himself a New York atheist Jew, converted to Hinduism to obtain access to temples where he wanted to study sacred Hindu performances. In his description of his conversion ceremony, he notes his own worried unease about the involved duplicity, but also about the damaging. influence of this ceremony on his Jewishness. ${ }^{15}$ 
Byme, by upbringing a Scottish Protestant, immersed himself in Afro-Latin culture. Milton Cardona, who was the conga and drum player in the Rei Momo band, and is a priest of Santoria (a religion that is similar to Vodun and Candomblé), has said that he was impressed by Byrne's knowledge of deities and ceremonial practices, demonstrating a deep involvement. ${ }^{16}$ Byrne has taken part in Candomblé ceremonies: "T've had shells thrown to find out what my orisha is... I've made offerings and done that kind of thing. I believe that the religion holds a lot of truths and its attitude and sensibility seem to embrace all aspects of human living. It doesn't fust say that religion or spirituality is just something where you are quiet and somber. It can be sexy, for instance."17 And in his "Rei Momo" tour diary, Bytrne has described missing Bahia, an experience that probably sparked his idea of being homesick for a foreign culture. As he wrote, during a stay in Curitiba, in Brazil, some 1000 miles south of Bahia, "I visited a kind of crafts bazaar in the square. There were a few Northeasterners, some Bahianas-women from Bahiaall dressed in white, selling acarajé, carurí and vatapá, the African-derived foods of the Northeast. So I order that for lunch. I miss Bahia, I was so moved by my stay there a couple of years ago."18

Nevertheless, Byrne admits to a certain remaining distance and foreignness: "I don't think you can appropriate a sensibility wholesale. You can't really transplant it. I think someone foreign can only absorb it on their own terms. You might be able to approach the way someone else feels about it, but you'll never get it in the same way."

\section{THE ANTLROPOLOGY OF AFRICAN AND AFRO-AMERICAN} PERTORMANCES

The cultural anthropologists who Byrne has named as influential for his work are without exception immersed in African and Afro-American aestherics. These anthropologists and/or performers are Zora Neale Hurston, a black woman anthropologist who studied with Franz Boas; independent experimental filmmaker Maya Deren; as well as John Miller Chernoff and Robert Farris Thompson. Of course the African aesthetic has been a presence in Western popular culture for a long time. African-influenced musical forms like jazz, mambo, blues, soul, and tap have familiarized certain African standards, which may therefore strike a Western listener or spectator as somewhat familiar. But western popular music was also shaped by Euro-American traditions, and by the dominating presence of the mass media; determining influences which ascertain that African music still is foreign and "other" to Euro-American ears. This means that African art and music may offer a fresh view of Western popular culture, by providing contrasting forms of performance and of sensibility. 
John Miller Chemoffs "African Rhythm and African Sensibility" has already been summarized, but it deserves to be remembered here that his book is simultaneously a musicological and ethnographical study, and the autobiographical account of Chernoffs training in Ghana as an Ewe and Dagomba drummer. It thus combines scholarship with participation, with a thorough immersion in African life; as Chernoff writes; "by the time I lost my desite to write anything about what I was learning, I had begun to appreciate the African way of life as a personal alternative." ${ }^{20}$ Chernoff relates how his training as a drummer included the participation in a ritual initiation, about which he was told that "it really did not matter if I understood all the details, that if we went through the ceremony properly, it would work." 21 Just going through the motions is as relevant as believing and intellectually understanding for one's experience of a culture. Chernoffs book derives a special charm from his ability to use his training as an anthropologist to write about the meaning of drumming, while simultaneously employing his experience as a drummer to highlight the meaning of cultural exchange.

Along with Chernoffs "African Rhythm and African Sensibility" and Christopher Alexander's "The Timeless Way of Building", Robert Farris Thompson's "African Art in Motion" (1974) was the third book that Byrne mentioned in the press rellease of the Talking Heads" "Remain In Light". As mentioned before, the subject of Thompson's book is the unity of the arts in African performance. I.ike Schechner, who emphasizes that drama arises out of the combination of text and narration with music and movement and with scenography and architecture, Thompson writes that in Africa each artistic medium depends on the others: "Sculpture is not the central art, but neither is the dance, for both depend on words and music and even dreams and divination. Music, dance, and visual objects are all important, separate or together; and if motion conveys stature to music and art, sculpture deepens motion by condensation of several actions into one. These unities demand that we start with the shated norms of performance..."22 By explaining the African concept of coolness-distinct from its current Western derivative-Thompson encourages his readers to consider the ethical and social implications of artistic performance. He combines a thorough knowledge of African arts (he did fieldwork in many West and Central African cultures ${ }^{23}$ ) with energetic enthusiasm for their performance. Thompson is white, born in Texas; but when I met him at a symposium in Maastricht, The Netherlands, an African member of the audience remarked in admiration that he was "really a black man", thus acknowledging his full participation in Aftican culture. Similarly, Chernoff was given the name of the ancestral grandfather of all Dagomba drummers, in acknowledgment of the depth of his interest and participation. ${ }^{2.4}$

Zora Neale Hurston (1891-1960) ${ }^{25}$ wrote ethnographic essays about the customs, religions, music, speech and humor of rural Black America, as well as political essays on segtegation, novels and an autobiography. All of her work is work in 
This analysis makes perfectly clear why Byme cites Deren with admiration. Indeed, when music videos became an enormous populat success, Byme originally "believed that here, at last, was the vindication of the earlier, mote obscure, avantgarde short filmmakers I admired: Bruce Conner, Maya Deren, Vanderbeek, Warhol... I could go on and on:" 33

Deren, Hurston, Chernoff and Thompson are very different anthropologists. But what they share is that for each of them, the anthropological endeavor of representing a culture has an artistic dimension. All their works do not pretend to have at their disposal an adequate and neutral terminology in which a foreign culture may be described without distortions. Instead, they accept that a valid translation of the aesthetic of one culture into that of another is an effort which requires inventiveness, and the conviction that one's own aesthetic and language may be widened and enriched in the process of translation. Anthropological studies of aesthetics are in this respect avantgardistic undertakings in themselves.

\section{COMBINING ANTHROPOLOGY AND ART: CRITICAL APPROACHES}

This insight is anything but new; it can be found in the works of countless artists and theorists. The conceptual horizon opened up by this realization is of course much too wide to oversee in its entirety, there are a great many cultures, each with their complicated history of influences and transformations. The process of globalization of the world's economies is accompanied by the intensification of cultural translations, with the result that, as Schechner wrote, cultures more and mote come to be performative actions. This section is meant to offer just an impression of the complications of this domain, by looking at some recent literature on attists as ethnographers, on film and anthropology and on music and anthropology.

In "The Rerurn of the Real: "The Avant-Garde at the End of the Century" (1996), New York based art historian Hal Foster has dedicated a chapter to "The Artist as Ethnographer". Foster here suggests that a new artistic paradigm has emerged in what he describes as "advanced art on the left": the artists as ethnographer ${ }^{34}$ Foster focuses on artworks which wish to involve their audience in a consideration of its own culture and community in the widest sense, works which assume the form of an "ethnographic mapping of a given institution or a related community"3. According to Foster, himself closely related to New York's Whitney Museum and Dia Art Foundation, such works become problematic when they are commissioned and even franchised by art instututions; he is suspicious of the ironies which this institutionalization of the critique of institutions produces. ${ }^{36}$

Foster wants to present a critical overview of the philosophical implications of this combination. He uses Walter Benjamin's text "The Author as Producer" to frame his own essay with the question whether artists who want to present an- 
thropological material in their work do not assume the impossible position of "an ideological patron". ${ }^{37}$ Foster's densely argumented and reflexive text presents an overview of twentieth-century theoretical positions in philosophy and art to make the point that in the art of the 1980's and ' 90 's, there can be found a turn towards anthropology which values anthropology for five reasons: 1) because it is the science of alterity, with its potential for subversion and transformation; 2) because it is the science of culture, placing art in the wider social field; 3) because ethnography is contextual, which automatically guarantees a critical understanding of the wider relevance of art; 4) because anthropology is seen as interdisciplinary, and 5) because it is seen as reflexive. ${ }^{38}$ Foster points out that artistic attempts to assume the role of an anthropologist may result in a hypocritical ambivalence, as it allows all kinds of tomantic projections to return in a new, more complex disguise. Foster's suspicion is that "the quasi-anthropological role set up for the artist can promote a presuming as much as a questioning of ethnogtaphic authority, an evasion as often as an extension of institutional critique." "He issues two general warnings: first, given the globalization of the economy, it can no longer be supposed that any culture exists in a pure "outside" which is no part of the world system; second, this is also true of cultural identities. ${ }^{40}$ Artistic attempts to transcend one's own cultural presuppositions, to make the "selP" into an "other", may easily "flip into self-absorption, in which the project of an "ethnographic self-fashioning" becomes the practice of a philosophical narcissism." that museums and other art institutions may illuminate a great many cultural practices by making an ethnogtaphic turn, but that the final meaning of such practices still depends on a resonance outside the discourses of the world of high art-a world so elevated that "the real" is able to take a leave of absence there.

"Picturing Culture: Explorations of Film and Anthropology" (2000) by Jay Ruby considers combinations of anthropology with the mass media of recorded music and film. For the purpose of this book, it may suffice to consider only the conclusions that Ruby draws from his historical overview. He advocates a strict position: ethnographic filmmaking should be the exclusive province of academically trained anthropologists who are interested in making pictorial ethnographies. ${ }^{42} \mathrm{He}$ argues that this would necessitate a radical break with current practices of documentary and ethnographic filmmaking, since they are restricted by the canonical formats of television as well as by incisive financial pressures.

Ruby finds that in order to visualize the many theoretical distinctions that are necessary to document forms of cultural behaviour, "ethnographic filmmakers should ally themselves with experimental filmmakers, who are content to produce works with no commercial potential designed for a very small audience." 43 At this point, Ruby turns to the work of Richard Schechner, Victor Turner and others to introduce the concept of culture as performance, as improvised mixed-media scenario. As Ruby remarks, ethnographic filmmaking may tesemble transformative 
rituals when the film does not document reality passively, but reveals culture by provoking new perspectives: "ciné-trance" is the term which filmmaker Jean Rouch coined for this form. ${ }^{44}$ A diametrically opposed possibility is the filming of long stretches of daily life in which nothing dramatic happens, presenting social reality in its most prosaic aspects. Ruby, quoting Talal Asad, delibetately undermines the convention that anthropological research is best represented in the form of an article for a scientific journal:

If [Walter] Benjamin was right in proposing that twanslation may require not a mechanical reproduction of the original but a harmonization with its intentio, it follows that there is no reason why this should be done only in the same mode. Indeed, it could be atgued that 'translating' an alien form of life, another culture, is not always done best through the representational discourse of ethnography, that under certain conditions a dramatic performance, the execution of a dance, or the playing of a piece of music might be more apt.45

Ruby then points to performance artists: "Laurie Anderson, Spalding Gray... Coco Fusco and Guillermo Gomez-Pena are able to interweave the personal/autobiographical as description with the theoretical in a way that resembles Geertz's notion of thick description." 46 Ruby advacates experiments, and concludes somewhat resignedly that the very situation of ethnographic filmmaking is so complex that no general theory is possible beyond a critical and reflexive attitude towards realism, natrative and communication. "Ethnographic filmmakers must disassociate themselves from...naive realism and produce films that will become viewed as the filmmakers' construction of the social construction of the actuality of the people portrayed - an interpretation of someone else's interpretation.... It is therefore necessary to consider ways to subvert audiences' assumptions about films" mimetic capacities." 4 ?

"Music Grooves" (1994) by Charles Keil and Steven Feld documents the combined efforts of two ethnomusicologists to grasp theoretically the impact of the participation in, and mediation and commodification of music in different cultures. They share an affinity for a Marxist perspective, emphasizing that music worldwide is less and less made live for direct participation, and more and more owned and controlled for reasons of profit. ${ }^{48}$ Only a few points from this diversity of essays and dialogues may be repeated here.

First of all, both authors underline the crucial importance of participating in music, of "grooving", whether expressed by James Brown or in academic terms:

Y'know, one thing about music: It's the key to eserything, the universal language of man's commitment to be together. .. "Cause, see what the music is doing? It's so vast, so beyond our thinking, because it reaches your soul and you can feel befote you can see, that it's mind over matter. You say "ouch" and you don"t even know where the pain is coming from, but the feeling is real.4" 
The significant feature of musical communication is not that it is untranslatable and ineducible to the verbal mode but that its generality and multiplicity of possible messages and interpretations brings out a special kind of "feelingful" activity and engagement on part of the listener, a form of pleasure that unites the material and mental dimensions of musical experience as fully embodied.

According to Charles Keil, the varying kinds of textural discrepancies which characterize all kinds of music encourage an emotional and animistic sense of participation which is anterior to collective representations. ${ }^{51}$ Ethnomusicologists should try to understand the participatory discrepancies of different musical cultures by looking at cultures as "patterns-in-experience" and by understanding musical works as "affecting presences". 52

The technological and commercial reproduction of popular musical styles, recreated through ritual, complicates the forms of participation with confusing notions of class and culture. Popular styles always define and legitimate themselves in relation to the dominant class and its media, but this defining process is an interplay of copying and repudiating elements of upper-class culture. According to Keil, participating in music is not by definition an innocent matter, and he points at crucial ambivalences:

Participation is the opposite of alienation from nature, from society, from the body, from labor, and is therefore worth holding onto wherever we can still find some of it, the two exceptions to this rule being those large-scale nation-state organizations with aggressive purposes, where participation becomes the very essence of fascism, and those participations fueled by feat and desperation, where cargo-cult beliefs can and often do have disastrous consequences. The rites of fascist patticipation are easily recognized (and, one hopes, avoided) because they are enacted on a large scale and heighten the inequalicies: society over nature, society over other societies, men over women, men over other men. ${ }^{53}$

Participation is fascism. It becomes the bundle, all the rods united for greater strength, with the sum of the parts being greater than that of the individuals. When it's done nation-state style, it is a hortot. ... So yes, you are playing with fire when talking about participation. My notion is that we have got to make the world safe for small-scale, decentralized, diversified participations... Everybody requites participatory consciousness. That is how we evolved, and we are tuned up to participate. The people who are not getting that, who are not involved in music and dance and trance locally, are susceptible to false identifications and participations, to all the nonsolutions to their problems that the State offers. ${ }^{5}$

Since the popularity of rock and roll, contemporary popular music has produced a mutual influencing of American and African popular music. Here, admiration and appropriation combine to form even more complex patterns, for example in Mick Jagger's idolization of Muddy Waters, or in Paul Simon's use of South African pop styles on his album "Graceland" (1986). Although both sides benefit from these collaborations, Keil and Feld point out that the playing field is far from equal: "layers and varieties of appropriation, circulation, and traffic in musical grooves, 
and concomitant embeddings and solidifications of musical ownership ${ }^{355}$ result in benefits that are not unevenly distributed.

When James Brown broke down complex African polythythms and incorporated them into derise funk and soul dance tracks, critics didn't speak of a powerful African-American star moving in on African musical turf. And when, ten years later, Fela Anikulapo Kut seized the essence of the James Brown scratch gutat technique and made it the centerpiece of his Afro-Beat, critics didn't speak of a powerful African stat moving in on African-Ametican turf. That's because the economic stakes in this traffuc wete small, and the circulation had the tevitalizing dynamic of roots. But when Talking Heads moved in on both James Btown and Fela Anikulapo Kuti and used scratch, funk, Afro-Beat, and jufu thythms as the basic grooves for "Remain In l.ight", something else happened. The economic stakes, however much attention was drawn to the originators as a result, were increased, the gap between the lion's share and the originator"s share enlarged, and the critical discourse on race and nit 3 -offs was immediate and heated ${ }^{56}$

But in the end, as Feld acknowledges, pop stars can't do much about the nearmonopolistic structure of the music business as such. ${ }^{57}$

Feld goes on to analyze the practices behind the recent emergence of "world music" and "world beat" as a musical term. He distinguishes four elements: 1) the major record companies more and more dominate the independents, just as Western pop stars more and more dominate non-Western musicians; 2) "world beat", providing a danceable pulse, tends to dominate other forms of "world music"; 3 ) third- and fourth-world musicians and first-world fans tend to fall into patterns of exhibitionism and spectatorship; 4) the struggle between homogenizing and heterogenizing musical forces escalates: questions of authenticity, the dynamics of appropriation and musical ownership are increasingly politicized. ${ }^{58}$ In this field full of tensions, pop stars like David Byrne, Peter Gabriel and Grateful Dead's drummer Mickey Hart are able to combine "curatorial, promotional, and collaborative roles, as well as entrepreneurial and appropriative roles", which makes it possible to understand how "in the critical discourse surrounding the production and circulation of world beat, assertions of altruism and generosity appear as frequently as accusations of cannibalism and colonialism".59 Feld quotes Jacques Attali's book "Noise: 'The Political Economy of Music", which introduces an allencompassing, Marxist-Hegelian perspective on the issues at stake:

In this network, each spectator has a solitary relation with a material object; the consumption of music is individualized, a simulacrum of ritual sacrifice, a blind spectacle. The network is no longer a foim of sociality, an opportunity for spectators to meet and communicate, but wather a tool making the inctividual stockpiling of music possible on a large scale. Here again, the new network first appears in music as the herald of a new stage in the organization of capitalism, that of the repetitive mass production of all social relations. ${ }^{\text {(i) }}$

Feld himself has made recordings in Bosavi, Papua New Guinea, which were issued on CD as "Voices of the Rainforest" (1991) on Mickey Hart's Rykodisc la- 
bel, tuming years of ethnomusicological research into what he calls "a popular commodity". Feld admits to all kinds of embarrassment and ambivalence about this marriage of purely academic studies with unabashed commercialism, ambivalently asking of himself: "Does this mean that "Voices of the Rainforest" is a falsely idealized portrait of Bosavi's current acoustic ecology, romantic at best, deceptive at worst? Certain critical viewpoints could position it that way, and an honest response could only accept why those concerns are voiced and acknowledge the currency of their politics. After all, "Voices of the Rainforest" transparently embodies the highest of postmodern ironies: it presents for us a world uncontaminated by technology, but one that is hearable only because it has been brought to us courtesy of the most high-tech audio field and studio techniques currently available." ${ }^{\prime \prime 1}$ Feld fills several pages with such self-undermining doubts without arriving at a solution. In this respect, his critical judgment of Byme's work appears to be rather unfounded. On the one hand, Feld places Byrne's compilations of Brazilian samba classics and Cuban musics on the same level as "benign yet setious analyses of international pop genres". ${ }^{62}$ On the other hand, he sarcastically dismisses Byme's work in popularizing ethnomusicology. Feld writes about Byme's "Ilé Aiyé":

[It] provides another angle on the process of dissolving oppositional mutuality through genre blurring; arty and stylish, yet very much in the conventional mold of PBS "documentary" (syrupy nartaton featuring nuggets of ancient wisdom of others, plenty of sunsets and gytating bodies), the film predictably has no tume or place tox locating candomble in local politics, econony, or society. Bytnc the curator is so busy transporting us into a world of "purely musical being" that the question of musical control, as Amy Taubin pointed out in a typically acute "Village Voice" column (11 July) 1989), only surfaces, in small print titles, at the very end: "Original score by David Byme, performed by (long list of Brazilian musicians). ${ }^{6}$

But since Feld does not make his own detailed analysis of Byrne's documentary, his dismissal remains unserious. To oppose Feld's opinion, one might analyze in detail how Byme used the soundtrack to do exactly what Jay Ruby asks of documentaries: producing a soundtrack that is the filmmaker's construction of the social construction of the actuality of the music and the people portrayed, an interpretation of someone else's interpretation. And one could point to the humorous scene in "Ilé Aiye" in which a woman goes to the matket to buy a goat for a ceremony. She haggles with the salesman, accusing him of trying to sell her the goat at a higher price only because she is being filmed. Combined with Byrne's careful historical positioning of Candomblé in Ilé Aiye, this shows that Feld's critique is simply unfounded. F. Feld claims for his own collaboration with Mickey Hart that "the symbolic statement Mickey is making is about the potential to empower silent or muted voices and cultures through the rock and roll recording and distribution mainstream." "65 I see no reason to treat Byme's work less generously. 
What can be concluded from these critical descriptions of anthropological studies in the scholarty monograph, in the art museum, the cinema, the theatre, the dance hall, on television and on CD? Every medium of representation and participation has its own strengths and pirfalls, and no medium or genre has the power to transcend the many cruel ironies that have so often characterized the meeting of different cuitures. Walter Benjamin, who is often invoked by contemporary theorists for his insight in the difficulties of symbolic representation, wrote in "The Author as Producer" that the dramatic laboratory should take the place of the dramatic Gesamneunstwerk. That is the common goal of both anthropology and performance: to allow us to experience little more of the collage we live in, by presenting the glue and the discontinuities together with the participatory enthusiasms. 
PART III

A POETICS OF REFLEXIVITY 


\section{CHAPTER 9}

\section{Towards a philosophy of mimesis}

\section{SHORTCOMINGS OF PHILOSOPHICAL POSTMODERNISM}

Since Byrne's work is conceptually atticulate, and openly employs a diversity of theoretical insights, it has elicited several philosophical interpretations. But how to explain Byrne's mediations of fantasy and rationality, of myth and historical reality, of art and culture in general? Postmodernism may seem to be the obvious candidate for this philosophical opening. Byrne's work has been labeled "postmodern" so often that this certainly deserves consideration. But while Byrne's work certainly deserves to be called postmodern in terms of a certain arthistorical periodization, I am convinced that this label is inadequate when it comes to understanding the conceptual horizon and the characteristic, philosophical derermination of the wortls.

In the historical chronology of art, post-modern means nothing more than "what came after modernism"; modernism being the canonized formalism of high modernism that is exemplified by serialism in music, by the International Style in architecture, and by the attempts to represent the unrepresentable by means of abstraction in painting. These formal approaches to art were libetating at the beginning of the twentieth century, when they allowed artists to rid themselves of the widespread heritage of romanticism. But after World War II they were institutionalized to the extent that they formed a restrictive canon of what was and what was not legitimate in artistic research and innovation. Many artists and critics have rebelled against these canonical restrictions, out of a conviction that there are other, more challenging aspects of art to be investigated. In opposition to the natrow modernist definitions of formalism, these aspects were sometimes dubbed 
"informal", but it is likewise possible to interpret this "postmodern" attitude as the acknowledgment of the infinit variety of possible formal perspectives. ${ }^{1}$

Clearly Byrne has much in common with these artists, who are the direct predecessors of his work, or his contemporaries. John Cage, for example, is often singled out as a trailblazer of postmodernism, and Byme has duly paid homage to his influence. Robert Rauschenberg is similarly credited to have opened up new possibilities for painting after the heyday of abstract expressionism, so the fact that the designed, on Byrne's request, an album cover for the Talking Heads, links Byrne to another figurehead of artistic postmodernism. More in general, both performance art and performance theatre strongly oppose the attitudes of high modernism, and form indicators of a postmodern attitude. In this chtonological meaning, Byrne's work may certainly be called postmodernist, as many theorists have not hesitated to do. 2

But does this offhand attribution of Byrne's work to postmodernism also provide a useful indication of Byrne's conceptual and philosophical orientation? Should it be taken to imply an affinity with French post-structuralist philosophies, as has been suggested by Dick Hebdidge, Martin Schecter, and several other theorists in the field of cultural studies? Both post-modernism and post-structuralism are defined indirectly, as positions that have overcome and left behind an older, better defined but more restrictive position, and as a result of that these terms are inherently cloudy and hard to pin down. I shall outline what I take to be the central tenets of post-structuralism, and then argue why these tenets are incommensurable with basic conceptions of Byme's work.

Post-structuralist philosophers take their departure from a fundamental hypothesis of structural linguistics. This hypothesis is, that there is no natural link whatsoever between signifier and signified, or between a sign and its object. This is to say that language is meaningful solely because of the structural differentiations within the system of signifiers, the sign system that constitutes a specific linguistic code. As soon as the illusion of naturalness that accompanies every aspect of language has been disposed of, it becomes clear that these structural differentiations are strictly conventional, and in the last analysis arbitrary. Classical structuralism uses this hypothesis for the scientific investigation of the systemic organization of linguistic structures. Post-structuralism strategically applies the general principle of structural linguistics, the absence of a natural link between signifier and signified, to decipher all kinds of phenomena as textual. These texts are assumed to be based on naturalistic, mimetic and realistic assumptions which may be deciphered and unmasked as such, a procedure which may at will be called reading, writing, rewriting, questioning, putting in brackets, undermining, recoding, discontinuation, and so on. Of course, this destruction and discontinuation of traditional, supposedly natural texts takes place within a new text, which itself is inevitably also structured, and must therefore produce its own effective 
illusions of naturalness, continuity, self-evident authenticity, etcetera. This doublefaced movement, the simultaneity of the destruction and the construction of verisimilitude and candour, is usually addressed as "deconstruction", following a playful terminological innovation by Jacques Derrida. The gist of poststructuralist decodings and te-contextualizations is thus the insight that while languages present reality as inherently meaningful, they are also inherently producing entropy.

In this light, modernism appears as the attempt to attribute systematically fixed meanings to reality in general. Post-structuralism understands this attempt as either naive or desperate, but anyhow as inherently violent, and celebrates entropy as the best conceivable antidote. ${ }^{3}$

This philosophical program has produced a highly diverse and heterogeneous literature, not only because diversification of languages is programmatic, but also because prominent representatives like Barthes, Foucault and Lyotard have repeatedly revised their stance, and because the differences between the many proponents of poststructuralism have been the subject of lively debates. The result is a quickly proliferating literature, in which conventions of all kinds-historical, social, philosophical, as well as culinary, horticultural, or architectural-are screened and derailed.

Byrne's work indeed contains some indications that suggest that it belongs within the post-structuralist movement. Not only has he been inspired by some seminal post-structuralist texts, like Roland Barthes' "Empire of Signs" and "Image-Music-Text"; more to the point is that his work evidently plays with texts, combines fragments from different sources, and places texts within new and unexpected situations. It suffices to recall the lyrics for "Remain In Light", or the use of newspaper articles in the scenario for "True Stories". And undermining the fixed, quasi-natural conventions of narration is the very trademark of the theatre makers whose work has been so important for Byrne.

Intertextuality is certainly important for Byrne's work; but to interpret it solcly in terms of post-structuralist thinking results in neglecting half of it. The model of the text tends to obscure the participatory and social basis of a performance event. Moreover, the model of the text tends to favour the written over the visual, the visual over the aural, and the aural over the tactile, the olfactory, and the proprioceptive, or in other words: the discursive and the historical over the nondiscursive, the mimetic and the natural. Byrne's work resists this tendency. When it combines languages, it is to bring out and perhaps to transform their mimetic and ritual dimension, not to unveil their arbitrary character. Byrne has explained this:

We vll understand and "fend" these various "languages" - music, art cinema. We have grown up undewstanding the grammar of movie eding, for example. A completely artificial and made up way of implying a narative and connectwity between scenes and wisual events, but one that we we agreed to, and have learned to accept. It's a language, a grammar without text, without words... yet is com- 
petely understood by everyone. In the same way, we tead a smile or a frown, and don't need someone to wy "I'm happy" or "Im angry". And it gets much more complex. Our animal natures understand whole host of non-verbal gestures, body signals and wordless vocal sounds and texturts. These are used by advertisers, by artists, by designers and every other visually and musically oniented profession, "They use these loaded colors, shapes, gestures, sounds and beats to speak to ws. Yet almost none of this stuff is easily translatable into conventional language, into words and text.

Because we in the West ate so text based these non-verbal languages are considered secondary, almost as if they don't teally exist unless their messages can be expressed in words. And when they ate, usually unsuccessfully, translated into words then we fel like we have finally gained control ower them. But in reading the translation we sense that something is wrong, that something is missing: And that missing element is what the arts have in common ${ }^{4}$

Byrne's works form an excellent example of a suggestion made by Simon Frith, to stop dealing with performances of popular music, and with performances in general, as if they are texts:

I am less interested in theories of text than of context, less interested in performance as a means by which a text is represented, "licensed," or made "excessive" than in performance as an experience (or set of experiences) of sociability (it has always seemed to me ironic that the academic effect of Jacgines Detrida's musings on what it means to treat a text as an event has been the systematic study of events as texts).

I'm sure, similarly, that postmodern theorists (also much concened with performance issues) have more to learn from a study of popular music than popular music theorists have to learn from postmodernism. ${ }^{5}$

As examples of the shortcomings of post-structuralism, I want to consider three post-structuralist interpretations of works by Bytne.

In her book "Rocking Around the Clock: Music Television, Postmodernism \& Consumer Culture", E. Ann Kaplan gives an interpretation of Byme's video clip "Buming Down The House". Her interpretation is based on Jacques Lacan's (post-) structurallist version of psychomanalytical theory:

The creative use of metaphot in "Burning Down The House," and the aesthetic intelligence underlying the video's construction, typify much of David Byme's work. Here the trope of "house" can be taken in the senses of both the histotical subject and of the public sphere; it works on both levels at once, suggesting the archaism and inadectuacy of the family as an institution, while also implying that the State no longer has the ability to create a meaningful society. The symbolic sub-urban house dominates the video as an image constantly returned to; its side wall (facing the camera) functions like a screen on which different images are projected (Byme's haunted face, blown up latge; tlames; the concert audience with the search light panning across them, suggesting hostile authority over people). The performets themselves symbolize family members, Byme's child self alternating with his aclut one. At one point the various faces of the family members superimpose themselves on one another, representing the aim of family life to shape its members in one mould, "Everything stuck together," "s the lyric notes. At another point, the band menbers mimic the burden familly members impose on one another by climbing on each other's backs while the words on the track note, "] don't know what you expect of me." The final images suggest isolation and fragmentation, as we see Byme's back, apparently facing emptiness rather than people; and his disconnected face superim- 
posed over a panning shot of an empty road. Throughour, the staccato words and the deliberately mechanically orchestrated beat, together with the blank faces and robot-like mowements of the performers, convey the sense of a world dewoid of, and disillusioned with, earlier famillat comforts. ${ }^{\circ}$

Kaplan categorizes Byrne's video, together with Laurie Anderson's "Tanguage Is A Virus", in a rubtic "socially conscious", which she defines by the terms "varied style; themes are the struggle for autonomy, problematic love, cultural critique and both parent and public figures"?

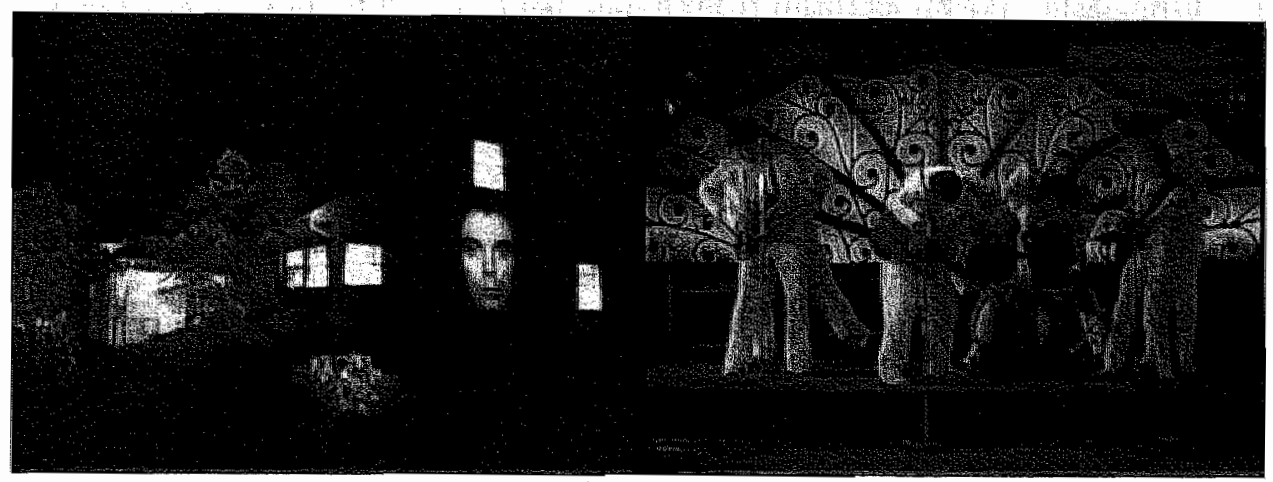

22 Two stills from Byrne's video clip for Talking Heads" "Burning Down The House".

Her analysis, however, suffers from her exclusive concentration on the image (in terms of the Lacanian "gaze") and a corresponding neglect of the music. Her description "deliberately mechanically orchestrated beat" does not begin to do justice to the rhythm; several new wave bands of the early 1980's recorded deliberately mechanical beats, but they are easily distinguished from the Talking Heads? funky texture.

While Kaplan succeeds brilliantly in showing how suggestive Byme's song and imagery are, her analysis is more closed off than the song itself. Maybe this is because she has mistead the lyric; Byme does not sing "I don't know what you expect of me", but "T don't know what you expect, staring into the TV setfighting fire with. fire". This line implies an audience, and gives it its own freedom to interpret. (Another mistake: the band members do not climb on each other's backs; they have "doubles" in the video, and are climbed, and hindered, by these doubles, who try to play their instruments as well.)

The risk of such interpretations is that they tend to apply a theoretical framework to an artwork, instead of analyzing the work on its own terms in order to weigh their theoretical relevance. 'This is particularly regrettable when the applied theory blocks out the work's own theoretical inspiration. As Byrne himself explained his video, it symbolised rebirth and destroying some sort of transitory personality, and shedding a shell and coming out with a new one. ${ }^{8}$ A comparison of 
Byme's interpretation, inspited by Jung's mythologizing, intimate and romantic version of psycho-analytical theory, with Lacan's (post-) structuralist and distancing version of psycho-analysis might perhaps produce interesting results, if its understanding of the video clip would pay equal attention to the music and the image, each with its own participatory appeal and perspectival shifts.

A second post-structuralist interpretation, of Byrne's film "True Stories", has been given by Martin Schecter in a review titled "Beyond the Text: $S($ h)ifting through Postmodernism", published in the American Journal of Semiotics. Schecter distinguishes postmodernism from traditional forms of natrative, which he defines as realistic or mimetic, and introduces postmodernism as "a form of narrative determined to replicate the high-speed cultural experiences also explained by post-structuralism. Media, technology, story-telling, capitalism, sexual and gender identity and power, the "aesthetics" of culture these all reappear as consistent postmodem themes, whose actions are seen to contribute in one way or another to this breakdown of "frames" previously assume to be "natural", (or, if you prefer, previously teceived ideologically)." According to Schecter, this leads to "the possibility of contemporaneous non-mimetic re-readings, of instantaneous "ironization", of being washed away in the stream of a constant shifting social teal..." Schecter introduces "True Stories" as follows:

Only that which is already a commodity can tesist commodification", Eagleton (1986: 141) has written, perhaps wryly, but not untruthfully. Such is the starting point for David Bytne, who in his aptly titled Trae Storien attempts a more conscientious escape from the reified culture of late capitalism. The only way we have to appreciate the further complexity of Byrne's film... is to abandon a conception of postmodernism as "parody" and bring in the idea of "double gesture", a term that I believe has connotations associated with a more specific Derridian questioning of metaphysical presence... The most deconstructive quality is the way Byme systematically dismantles the traditional. organizing distinctions between outside and inside, between character and author, berween truth and fiction. Here, Byme goes theyond simple parody: he creates in his text an nundecidable merging, a senies of variously origuating images with no discernible hietarchical relation to "truth"."

Schecter's analysis of the film deserves to be quoted at length:

The textuality of the images eventually extends out through work and recreational space, married. and single life, over the entire suburban landscape. Every image of the Texan landscape has been already written, like the prefabricated buildings that can be ordered from ont of a catalogue and put up over night. Engulfed by a capitalist culture that's extended beyond the point of reification,... Byme presents us with very much a utopia/apocalypse, and "who", indeed, "could say it isn't beautfull"? This powerful moment is the tilm's center, borh formally and thematically: the image of identicall tract homes, the empty blue sky, the two-car garages, the parallel lines, ready to consume hope, glory, sadness, fear-every possible emotion-for there is indeed no "outside" to this American text, no escape, no alternatives, no specch that hasn't been already written, no emotion that hasn't been already felt, no outlandish character ot innocent child who isn't already scripted into the "celebration of specialness" and accounted for. "Texas" both literally and figuratively extends to the horizon. Who would dare say it isn't beautiful? Who ronld say at? For the language, the objective space, 
with which to judge the un beautiful no longet exists; it has been swallowed up, partitioned, retup holstered, made "beaudiful". Yet this is exactly the critique the film wishes to make.

Byme paints a picure of a hyperreal America quite similar to Baudrillard's. The ditference, howeyer, is that Byrne lets himself inhabit, metge with, (one might go as far to say, take responsibiliy for) the culture he discusses, and this proves his point all the betrer. More so than Baudriliard, it is Byme who is the preeminent deconstructive artist, for while Baudrillard travels America and critiques it from Paris (from a critical distance), Byrne is America's accomplice. ${ }^{\prime \prime}$

This argumentation may for one moment appear as the highest praise; but in his conclusion, Schecter condemns Byrne's film for moral reasons:

Certainly, such pleasure-in-the-text malies us aware of the contingent, political nature of our consciousness, of our narrative traditions, of our cultural "real". But what then? Are we justified in asking for more?

Should we wish also for another type of art, in which the artist, and audience, can enjoy, establish, something other than just the power of critique? An art that does more than frolic in the ruins?

Schecter's critique, then, is that Byrne is too much the accomplice of his characters and cultural landscape. He expects a film which so clearly presents Texan (or American) culture as a densely layered tableau to come up with a definite moral and political conclusion, an expectation which "True Stories" refuses to fulfill.

In his analysis of "True Stories", Schecter alludes to what has become the credo of post-structuralism, Dertida's resolutely exorbitant methodological proposition "There is nothing outside of the text". ${ }^{13}$ This proposition is meant to mean: there is no mimetic link between a text and an outside reality, no natural, realistic and self-evidently sensible possibility to understand teality. As Schecter comments on "True Stories", "there is indeed no "outside" to this American text, no escape, no alternatives, no speech that hasn't been already written, no emotion that hasn't been already felt, no outlandish character or innocent child who isn't already scripted into the "celebration of specialness" and accounted for."1"

Schecter compares Bytne unfavourably to novelist Kathy Acker, because "Byme points to the failure of culture but offers no alternatives", whereas "Acker is able to install powerful intelligent commentary (the commentary of poststructuralism) that indeed is never fully undermined."15 Schecter simply lacks reAlexivity where he defines postmodernism as the explicit questioning of representational conventions that are shared between artist and audience, yet assumes that post-structuralism itself is immune to such questioning, and able to present a tentative but authoritative metaphysical ground.16 For Schecter, philosophy clearly remains beyond and above the domain of art and mimesis- not quite what the notion of intertextuality, when applied to philosophy, implies.

Whereas Schecter condemns Byrne's work because of its alledged "postmodemism", Dick Hebdidge has written a text on Byrne's videoclip "Road to No- 
where" in which he also emphasizes Byme's postmodernist stance, but celebrates this as a thoroughly positive quality. Hebdidge wants to take his leave from the position of the modernist intellectual; he tries "at last to come down to earth, to renounce the grand postures of the totalising intellectual... and to speak instead in a small voice, as a finite, gendered being bounded by particular horizons, perspectives, experiences, knowledge." 17 According to him,

The siruation looks and sometimes feels despetate but we have to live inside it (there is no going. back). In the Post, within a world of fragments, small locations, microchips, salvation has pethaps been miniaturised, cut down to size. We can begin to draw small lessons from unsuspected sources... In what I hope is an apptopriately playful-butt-careful postmodem spirit, I want to use the "Talking Heads? video "Road to Nowhere" to explore some of the habitable dimensions-some of the more frutiful lines of response-which may be opened up within the desperate situation in which we find ourselves today. 18

\section{Hebdidge situates Byrne as follows:}

Talking Jeads sett out to problematise (poke sertous fun at) sucla category divisions [between "popular" and "serious" cultural forms and critical issues] and atre thus a properly postmodemist band. David Bytne, the group"s founder and focaliser, sets out to atticulate a particular postmodern structure of feeling; to addiress Barthes" sensibility "of the second degree"-a sensibiliny fascinated by the pulse of signification, and the play of representational and generic codes... Byrne's work involves a high degree of more or less explicit mediation on the blurring of levels, categories, signs, identities, which, as we have seen, characterise the discourse of postmodernism. However, unlike many of those who desctibe the "post modem" from the (fatally removed) vantage point of the critic, Byrne inhabits the space of postmodernism and offers the audience ways into that space which, whilst not being comfortable, are nonetheless viable and-ultimately if nor immediately-pleasurable.19

In the imagery of the video, Hebdidge finds references to Godard, Buñuel, Dali, Muybridge, Warhol, Rosenquist, Duchamp, Magritte, Tzara, Jarry and many others" $^{20}$; he concludes that "the Road to Nowbere presents itself (amongst other things) as an affirmative allegory on the "loss of [masculine] mastery". It implies that dethronement is not to be resisted, or resented but accepted and welcomed." 211 Hebclidge feels the clip evokes "a pregnant laugh that might help us to usher in a new order" "2.; "Because Bytne is right (and why not a pop star-an organic intellectual of the airwaves-instead of a professor?); the great metanarratives can no longer be allowed to frame a sane assessment of our situation, can no longer be returned to as the ground upon which our explanations, accounts and actions can be legitimately posited."23

Hebdidge's analysis of "Road to Nowhere" has been singled out as an influential postmodern text, and held up to students as exemplary. ${ }^{2+}$ But while he concentrates on the visual imagery to produce his far-reaching interpretation, he all but neglects the sing-along, march-along music that underpins the stream of images: a music that by itself suggests a very different kind of interpretation. During the en- 
tire clip, while the stream of imagery may be said to blut codes of tepresentation, the music elicits participation within a clearly defined, traditional musical framework. Hebdidge also fails to compate the nideo of "Road to Nowhere" to Byme"s video for "Love For Sale", an adaptation of a sequence from "True Stories". This video is similar in that it presents a stream of imagery undetpinned by a simple sing-along style song. This time, however, almost all imagery has been lifted from TV commercials. During the clip, Byme and the other members of Talking Heads are treated as so much merchandise: they are dunked in chocolate sauce and then wrapped as chocolate dolls. Again, this suggests a different perspective: not the blurring and mediating of every level of discoutse, but a critique of ubiquitous commodification. There is good reason to doubt whether post-structuralist philosophy is really able to accommodate the mimetic strategies of Byme's working method and conceptual influences.

\section{THE ROLE OF MIMESIS}

Byrne's best works refer to more than one performative tradition, which makes it possible to perceive the work on several levels: as part of a collective tradition, as an individual comment on that tradition, and as a performance that reflects on performative forms. This also produces an ambivalence: such works may simultaneously be authenticated by one tradition and shown to be less than authentic by another. Central to much of the work, especially the songs, is a comparison between enthusiasms: even where a form of performance is itonically imitated, it is not only made to appear ridiculous, since the irony also contains an aspect of self-itony, of admitring to comparable enthusiasms. Thus passionate enthusiasm, whether delusive or not, is acknowledged as a fact of life, an aspect of mankind's innate properties. In each of Byrne's mote comprehensive works, there is an acknowledgment of anchetypal passions, which helps to ascertain that the most diverging forms of performance may at least refer to a common foundation in human nature.

Bytne's work investigates this oscillating between the authentic and the inauthentic, as if it is meant to function as a catalyst in the complex and mysterious process that transforms one into the other. Several aspects of the work combine to guarantee this catalytic function. To begin with, almost all of Byrne's work is made accessible through mass reproduction. Fwen for the works that originate in collaboration with Robert Wilson, where the spectator has to be present in the theatre for the experience, Byme seeks to transfer the work to film, or to have it go on tour. And although his photoworks function well in the somewhat exclusive atmosphere of galleties and muscums, by collecting them in books Byrne makes them accessible to large audiences. This reliance on the technologies of mass reproduction assures that the reception of the work has a collective aspect, taking 
place within the mass media environment that is central to many contemporary nituals and myths.

Such methods of working reinforce one another. An attempt to combine diffetent performative traditions within one work requires that each of these traditions be presented in such a way that it can be taken on its own merits-and not be shrugged off in a simple ironic gesture. And to acknowledge mankind's basic nature in a performance is often a casual matter, especially when work includes direct physical involvement: copying singing styles and voices, dance steps, gestures, and postures of the body. This mimetic acknowledgement also helps to combine ironic distancing with recognition. And insofar as Byme's work is guided by the desire to make an intersecting of performance styles happen, this prevents the raising of rigid bartiers between performance forms: between "primitive" and "sophisticated" cultures, between high art and popular entertainment, and between the politically or culturally correct and authentic, and the commercial.

In this respect, it has to be remembered that Byrne is deeply interested in Jung's theory of archetypes-a theory that is diametrically opposed to Derrida's philosophy of writing, insofar as it posits a natural, biological basis which governs patterns of enthusiasm and therefore underlies all human cultures. ${ }^{25}$ The ethological theories of Tiger and Fox are equally incompatible with post-structuralist tenets. Because of their repudiation of all claims that conventions of any kind may be founded in nature, postmodernism and post-structuralism generally tend to neglect the natural sciences, as well as research in the natural origins of human cultures. Byrne's work does not exclude the possibility of a mimetic link between the text and outside reality. On the contrary, it forms an inquiry into the very nature and the contemporary forms of that connection. Rather than relying on a fixed and pre-existing mimetic convention, Byrne has made those conventions into a central theme of his work.

Performance scholar Michael Taussig, a colleague of Richard Schechner at New York University, has commented on this inadequacy of postmodernism that "postmodernism has relentlessly instructed us that reality is artifice yet, so it seems to me, not enough surprise has been expressed as to how we nevertheless get on with living, pretending - thanks to the mimetic faculty - that we live facts, not fictions." 26 Taussig points out that mimesis is the crossroads where history and human nature meet. It is human nature to adapt, to become socialized and adult by copying the model of the environment. This means that identities are constructed, as the theories of social constructionism tell us. But academic conclusions that "sex is a social construction", "race is a social construction", "the nation is an invention" and so forth do not answer the pertinent question "How come culture appears so natural?" ${ }^{37}$ As Taussig writes, 
thanks to new social conditions and new techniques of reproduction (such as cinema and mass production of imagery), modernity has ushered in a veritable tebirth, a techarging and retooling the mimetic faculty... it scems to me that we are forthwith invited if not forced into the inner sanctum of mimetic mysteries where, in imitating, we will find distance from the mitated and hence gain some release fom the suffocating hold of "constructionism" no less than the dreadfully passive wiew of nature it upholds. ${ }^{23}$

If there is a contemporary philosophy that is able to accommodate the interpretative strategies of Byrne's work to its fullest measure, it has to be able to see beyond the standard of code and intertextuality. For that purpose, Michael Taussig has made extensive use of the insights of Walter Benjamin, Adorno and Horkheimer. In a later chapter, I shall do the same; but before turning to their work, I want to inspect what may at fist sight be an unlikely candidate for the position of "contemporary philosophy of mimesis and poetics": the theories of early Romanticism that were developed more than two hundred years ago in Germany.

\section{THE REFLEXIVE POTENTIAL OF EARLY ROMANTICISM}

The early Romantic literary and philosophical theory of Germany, also known as Jena Romanticism, originated in the short period from 1795 to 1801. Since then, its reputation has wavered. For the longest time, early Romanticism was either neglected or thrown together with Romanticism in general; it was but rarely seen in its distinctive qualities. Only in the twentieth century was early Romanticism perceived as an artistically and philosophically distinct undertaking, which anticipated and sometimes inspired avant-gardist attitudes that arose only much later. Walter Benjamin already perceived and elaborated the relevance of early Romanticism in his early works, especially in his 1919 study "The Concept of Criticism in German Romanticism", which is dedicated exclusively to early Romanticism-but Benjamin's work only became widely known after 1970. Also after 1970, more complete editions of the works of the early Romantic school were published, which helped to establish a wider recognition of their distinct position. ${ }^{29}$

The label 'Romanticism' is misleading when it is associated with the later Romantic movement in Germany, since that was often characterized by a reactionary atritude, whereas the early Romanrics were all in favor of the democratic and cosmopolitan convictions of the French Revolution. Indeed, early Romanticism is so distinct in its theory and practice that is has been remarked that most conventional criticism domesticates their radical insights, and that this is at least in part due to the inability of subsequent artistic movements to sustain the Romantics' level of theoretical sophistication: "Wide areas of European literature of the nineteenth and twentieth centuries appear as regressive with regards to the truths that come to light in the last quarter of the eighteenth century." 30 Indeed, compared to early 
Romanticism, a large part, perhaps even the main part of later artistic and aesthetic endeavours, tomantic as well as modernistic, is inadequate and ideological in its straightforward assumptions of total symbolic unity and lacking in selfcriticism. In this respect, early Romanticism is not unlike postmodernism; both "seem to assume a twisted posture towards modernism marked by a radical reflection on its conditions". 31 In early Romanticism, this reflection on the limitations of art and philosophy takes the form of language games, irony and indirect communication, combined with a sharp polemic against aesthetic absolutism.

The early Romantics strove to dewelop a positive critique that would open up the symbolic artwork from within. They interpteted this as a reflexive development of the symbol, and speculated that this development might provide a deeper insight in the nature of language, the arts, and culture. This reflexive development of artistic truth was to take the form of a universal encyclopedia, including not only the arts, but equally philosophy, the sciences, and religion, in an infinity of crossovers. This amounts to nothing less than a transformation of philosophy and aesthetics, an "aesthetic turn", as recent commentators have described the writing of Friedrich Schlegel and Novalis:

These authors ate not so much concerned with establishing a poetics, the nature of the beautiful, or its place in systematic philosophy. Rather, they concentrate on the concrete possibilicies of paiesis, that is, the creation and production of new forms of reflection. It is their express desire to confound, and thus break open, established lines of demarcation between philosophy and art, between science and morality. In their pursuit of an eternal poiesis, they do not so much posit art as the crowning achievement and overcoming of reflexive thought; rather, they regard aesthetics as a merging of the finite and the infinite; they engage in the "gay science" of mixing and relating the most heterogeneous discourses at their proposal. ${ }^{32}$

A good example of this mixing of heterogeneous discourses can be found in a short anonymous text, known as "The Earliest Program of German Idealism" that presents the critical tendencies of eatly Romanticism as if it had been its matnifesto. 33 It proclaims "overthrow of all superstition, persecution of the priesthood that recently has been feigning reason, through reason itselp" and proclaims its conviction that "the highest act of reason is an aesthetic act, in that reason embraces all ideas", to conclude:

At the same time, we hear so often that the masses must have a sensuous religion. Not only the masses, but also the philosopher is in need of it. Monotheism of reason and of the heart, polytheism of imagination and of art, that is what we need!

First, I will speak of an idea that, as fau as I know, has not yet occurred to anyone-we must have a new mythology, but this mythology must serve ideas, it must become a mythology of rearon.

Until we make ideas aesthetic, that is, mythological, they are of no interest to the people and, conversely, until mythology is reasonable, the philosopher must be ashamed of it. Thus, in the end, enlightened and unenlightened must shake hands, mythology must become philosophical, and the 
people reasonable, and philosophy must become nxythological in order to make the philosophers sensuous.

Because of its practice of combining and mixing heterogeneous art forms and concepts, in combination with its wish to produce a new mythology, carly Romanticism may tightly be considered the godfather of the heterogeneous $G e$ samulkwnstwerk. As such, it provides a model for the interpretation of Byme's work: it allows to bring together and to reflect critically on Byrne"s crucial interests in the interrelatedness of the arts and the Gesamtkunstwerk, on comparative mythology and sacralization, on performance theatre and mimesis, and on natural history as the ultimate framework for any interpretation.

The early Romantic pursuit of an eternal poiesis is strikingly similar to Bytne's pursuit of the mediating process of performance styles and performance media. As a philosophy, early Romanticism is defined by its firm conviction that no form of human knowledge can be completely outside the domain of mimesis and poiesis. The unfettered development of this insight characterizes their work. This again runs parallel with what I have shown to be a consistent point of departure of Bytne's work: the conviction that nothing can be completely outside the domain of performance. It is therefore quite relevant for a further understanding of Byrne's work to uncover the critical possibilities within the early Romantic tradition. To this end, chapter 10 elaborates the model of early Romanticism in some of its encyclopedic dimensions, and shows its relevance for the avant-garde aesthetic.

Although the parallels between of Byrne's work and the positions of early Romanticism are striking, a complete identification would amount to an anachronism. The reflexive potential of early Romanticism is not an a-historical fact, but-on the contrary - a historically mediated possibility. The potential of poiesis and mimesis has not remained unchanged over the last two hundred years: the history of every art form shows drastic changes, that have been brought about at least in part by the enormous social and technological developments.

To show how early Romanticism can be made relevant and fruitful for the present, chapter 11 turns to the work of Frankfurt School philosophers Walter Benjamin (1892-1940) and Theodor W. Adorno (1903-1969), whose writings play such an important role in twentieth century aesthetics. Early Romanticism is a helpful background for valuing their works afresh, because it helps to realize the extent to which the books of Adorno and Benjamin are theoretical Gesamteunstwerke in themselves, reflexively combining poetry with history and philosophy (Benjamin), or music with philosophy and sociology (Adorno). Understanding the experimental and poietical aspects of their work also helps to avoid the widespread but staid interpretation of their positions that opposes Adorno as a sour despiser of everything popular in the arts to Benjamin as a deliberately 
blunt supporter of technological innovation in mass media art. Their combined philosophies may be understood as a critical elaboration and more contemporary realization of the early Romantics' reflexive aestheric. The resulting confrontation between modernity and the early Romantic aestheric is a helpful context for the furthet interpretation of Byrne's work as a new, vernacular, heterogeneous and collaborative Gesantleanstwerk. 


\section{CHAPTER 10}

\section{The model of early Romanticism}

\section{REFLEXIVE AESTHETICS: THE MATTER OF SUBJECTIVITY}

The general theme that connects the early Romantics with the philosophers of their period is their wish for a correct description of subjectivity. This description was expected to provide, at one go, the foundation for metaphysical, scientific, political and aesthetic insight. At this focal point, the early Romantics substituted sensibility and style for the almost mathematical chains of reasoning of the philosophy of their age; and they carefully provided reasons for this turnabout.

To grasp the critical potential of this early Romantic turn, it must be compared to the two philosophers who influenced it directly, Immanuel Kant and Johann Gortlieb Fichte. Kant's elaborate and sophisticated version of rationalism underpinned all the innovative developments in German philosophy at the end of the eighteenth century. Fichte's attempt to outdo Kant by providing a new, strictly subjective foundation for philosophy prompted the early Romantics, especially Friedrich Schlegel and Novalis, to develop their own vision of philosophy and at as mutually dependent forms of understanding. Their aim was not only to retain the level of critical thinking of these philosophets, but to complete it by adding the artistic dimension that had formerly been left out. As Novalis remarked: "Fichte's and Kant's method has not yet been presented thoroughly and precisely enough. Neither of them knows yet how to experiment with lightness and multiplicity-not at all poetically. Everything is still so stiff, so fearful." This led the early Romantics to bring issues to the foreground that had been neglected by philosophical rationalism: historical experience, individual peculiarities of language, 
culture, artistic syles, religious experience, the realm of the emotions, and so on. To present this view, Schlegel and Nowalis produced a stream of philosophical fragments, studies, essays, poems, novels, as well as literary studies and translations, in collaboration with a circle of friends: historian of literature August Wilhelm Schlggel (Friedrich's brother), theologian Friedrich Schleiermacher, and the novelists Tieck and Wackentoder. Their works are tied together loosely by the general outlook of early Romantic thinking, an ongoing series of crossovers betwoen the subjective and the objective, resulting in the mutual permeating of opposing aspects of experience.

Both Kant and Fichte had provicled absolutist accounts of subjectivity, accounts that were in many aspects closely related to the Cartesian version of rationalism, based on the assumption of a purely rational thinking substance, the famous "cogito". Such accounts of rational subjectivity rely exclusively on the identification of consciousness with strict rationality: they purposely refrain from all at tempts at psychological veracity. Descartes had even gone so far as to declare that subjectivity is able to work out secure knowledge of everything in nature strictly by itself, without recurrance to observation and experiment. Kant's account of subjectivity was much mote self-critical than this solipsistic approach. He set our firm limits to pure rational thinking: by itself, it should only be able to work out the logical categoties which allow for an orderly artangement of all experience of nature. Apart from this pure logical reason, Kantian practical reason was able to produce a fixed and purely formal nule by which to measure all ethical guidelines and laws, the categorical imperative: "Act only on the maxim through which you can at the same time will that it should become a universal law". But this meant that he Kantian theory of rational subjectivity was divided in itself. In terms of pure logical reason, Kant saw man as fully determined by his nature, while in terms of practical reason, he declated that man is free to live a responsible life. Of course, this paradoxical account of human subjectivity was not quite sarisfying to either- Kant or his admirers.

At this point, Fichte wanted to improve on Kantian philosophy. Philosophical rationalism has to presuppose a subject that is completely certain of itself, to prowide the basis for all its endeavouts. But how can a subject be assured of its own subjectivity - the more so if it can not even tell once and for all whether it is diwinely free, or determined by its natural properties? If consciousness is to know itself directly, this knowledge has to be based on an immediate form of perception, without the interference of any object: a pure and inmediate knowledge for which the tetm "intellectual intuition" was coined. According to Kant, intellectual intuition can not exist, because pure subjectivity can never be the object of a perception of any kind. Trying to perceive its own subjectivity, the subject finds itself going round in circles. ${ }^{2}$ For him, subjectivity remains an evident given, that somehow resists further analysis. But according to Fichte and other philosophical ideal- 
ists, subjectivity can perceive itself by means of intellectual intuition insofat as it is active. As active, self-consciousness is both subject and object and therefore able to know itself. This idealistic philosophy therefore encourages the active identification of the human subjects with other realities-for example the state, religion, a specific cultural tradition, ot even the forces and processes of nature. By means of historical developments, such as political revolutions and the hamessing of the natural powers, all aspects of reality might finally obtain the absolute dignity that Kant had formerly reserved for the rationalistic principle of a universal ethical law.

Of interest here is, that the early Romantics cane up with a thitd solution for the question whether subjectivity can find its foundation within itself. These philosophers especially Friedich Schlegel and Novalis, but in agreenent with Schelling and Hölderlin concentrated on the pivotal role of aesthetic experience, mot as an ornamental and beautifying addition to rational certainty, but as the only self-sufficient basis for a philosophical subjectivity. They concluded that human consciousness may obtain immediate knowledge of itself, not through the logical knot that Fichte had proposed, but simply in the process of every aesthetic experience. They gladly accepted the implication that this subjectivity could not be absohute, and exchanged that ideal for a vision of subjectivity as floating or hovering everywhere:

For Novalis, the absolute $I$ is not a positive or clear point of transcendence that serves as an anchor for the subject, as it does in Fichte. Nowalis suggests, on the contrary, that the subject does not have transcendent anchors that stabilize it: "The whole rests somewhat like the players of a game in which people sit in a circle without chairs, one resting upon the other's knee. ${ }^{* 3}$

According to the early Romantics, subjectivity is unable to find its fundaments within itself. The absolute identity of subjectivity can not be found within consciousness. (They argued that the very term "intellectual intuition" or "intellectual perception" already proves this, as it differentiates between intellect and perception/intuition." The foundation of subjectivity is not to be found in an analysis or a self-perception of the thinking self, but beyond it: in a feeling, a spirit or a beliet: that precedes and accompanies consciousness. Philosophy has to accept this impossibility of the thinking subject to provide itself with an absolute foundation. Art may help to illuminate the origins of subjectivity, but its illumination will always remain an interpretation, and never result in absolute and final knowledge.

Walter Benjamin has summarized this romantic philosophy of the aesthetic by comparing it with the (closely related and influential, yet quite distinct) idealistic philosophies. According to him, romantic philosophy distinguishes itself from idealism by stating that reflexivity does not take place within an "T", a subject that is able to dialectically posit itself, creating itself and its object out of pure thought, but within a medium of thinking: this medium is further identified by Benjamin as language and as art. Romantic reflexivity does not produce its own object, by 
means of dialectical logic, but only its own form: by means of aesthetic reflection. ${ }^{5}$ Reflexivity is therefore a formal characteristic of a work of art, and as such always and in every respect open to critical reflection; nowhere does it claim absolute dignity, originary authenticity or some similar attribute that might be used to raise the work above all criticism:

Logical philosophical concepts are, as Kant already argued, unable to reveal the essence of reality and of human experience. The romantics still insisted on such revelation, but accepted that this could be achieved only indirectly, by using style instead of logical argument. Style may indlicate what cannot be explained systematically, by using the indirect means of irony and allegory; philosophy has to tum to poetry to fulfill its purpose. Romanticism has accordingly been defined as "the philosophy which in its speculations abandons the pretension to reach the absolute by reflection, and which supplements this lack by the medium of art" ${ }^{3}{ }^{6} \mathrm{No}-$ valis wrote:

Through the voluntary renunciation of the absolute, infinite and free activity arises within us. This activity is the only possible absolute that can be given to us and that we find through our inability to reach and recognize an absolute. We can only recognize this given absolute negatrvely, by acting and finding that we cannot reach what we are searching for through any action.?

In philosophical terms, early Romanticism is neither a version of tationalism nor of absolute idealism, with its dialectic logic that is always able to conclude in a final synthesis, but an aesthetic that is moved by a "negative dialectic": the insight that consciousness can never know itself absolutely, but only in fragments and flashes, and most clearly in the many mirrors of artworks.

And yet it is a misconception to oppose this aesthetic philosophy to rationalism, since Kantian rationalism remains an important source of inspiration. The Kantian model of subjectivity is a rigorously logical abstraction, disconnected from the real human being with its natural faculties and desires. It is constructed to support scientific knowledge as well as a legal system that underpins a rational society. According to Kant, this exclusively reasonable subject is, in spite of its abstract quality, truly creative, since it is able to shape experience. It is a genuine rationalistic insight that we partly produce phenomena according to the viewpoint we assume; according to Kant, all knowledge contains a poetical element. ${ }^{9}$ Kant did very little with this insight: his theory of knowledge concerns itself mainly with mathematics and physics, conceived in mechanistic terms. But the early Romantics gave their full attention to art and history as the comprehensive forms of human experience, and fully developed the poetical element of subjectivity in these areas.

They disapproved of the rationalistic tendency to value scientific knowledge, modeled after mathematics and mechanicistic physics, over all other aspects of reality, and gladly accepted the consequences of this strategy, namely that it is simply impossible to find a fixed form for a model of subjectivity that is fully enjoying all 
its natural faculties. Novalis and Schlegel agreed that no single aspect of these faculties, nor the combination of all their possible perspectives, is able to provide absolute truth, or a single encompassing standpoint. They embraced the complexity and confusion that are so typical of the aesthetic sensibility, declaring that "a good confusion has more value than a bad order" ${ }^{310}$, the more so since order is comm pleted and stable, while confusion may, by means of self-enlightenment, lead to progress and further perfection. ${ }^{11}$

Novalis expressed time and again, in many variations, that it is impossible to fixate subjectivity. "Man is... nothing fixed-He can and should be something determined and undetermined at the same time:" "Everything can be $I$ and is $I$ or should be I", and: "I is finally nothing." "Pluralism is our most inner being, and perhaps every man contributes a peculiar part to what I am thinking and doing, as likewise I take part in the thoughts of other people." "Genius is perhaps only the result of such an inner plural." "Man is actually cbaos." 12 Subjectivity, as a part of nature, mixed up in manifold relationships, floating and free, is interpreted as a plurality and a unity at once: "genius" is the term the romantics used to express this. ${ }^{13}$ Although the term "genius" first of all emphasizes the harmony between the diverging faculties that together make up a subject, it also implies and acknowledges the dissonance within man. According to the early romantics, the quality of genius is common to every individual, it is presupposed in every form of common sense and not reserved for a few individuals of extraordinary talent. These, Novalis calls "genius of genius"14, a superlative expression that will be shown to characterize his thinking and writing.

This inner harmony is experienced only through feeling, intuitively. According to Kantian rationalism, for this reason such an intuitive sensibility can not be a part of a theory of knowledge. Kant therefore relegated this aesthetic experience to the sphere of judgments of taste, which according to his philosophy are the result of a rwo-layered experience of ourselves: first, a euphony among our faculties, and second, a reflection on that euphony that intensifies the first-level experience and encompasses it, ${ }^{15} \mathrm{Kant}$ judged this aesthetic experience to be inferior to scientific knowledge. But he also tentatively admitted that the harmonious experience of the beauty of nature, together with its sublime qualities, indicates a possible reconciliation of science and ethics, determinism and freedom. By admitting this, he suggested that this experience deserved a central position in this entire philosophical system. He also emphasized that beauty is not to be enjoyed in isolation, since it presupposes reflection, which in turn presupposes intersubjectivity, the interaction of distinct minds. 16 Because of this, every judgment of taste forms a contribution towards the development of an aesthetic community, based on a developing common sense. ${ }^{17}$ Kant even went so far as to assume the idea that a universal voice (that would presumably articulate the harmonious ideas of all mankind) might arise from this. ${ }^{18}$ 
But for the early Romantics, aesthetic experience is not an afterthought, as it was for Kant, who presented it as a late addition to his systems of scientific and ethical knowledge. For them, it is truly central: they try to ground the unity of mind through aesthetic activity, in which the most disparate elements are brought into contact. Accordingly, they conceive of aesthetic activity as "an endless, necessary process in which meanings are constantly made and remade. According to Novalis, the human imagination as productive fantasy can relate and synthesize the most heterogeneous realms."19 Kant assumed that scientific knowledge is produced by the subject by the application of a fixed set of logical categories; but Novalis maintains that fiction, illusion and fantasy are the necessary means of all synthesis, that is, of all knowledge. ${ }^{20}$

This synthesis takes place in art. Art is the representation of the inner condition of individual chaotic genius, and as such it is a crucial contribution to rationality, a form of enlightenment. In early Romantic philosophy, the value of poetry (as paradigmatic artform) is unparallelled, because poetry is the regenerative medium, in which the misunderstandings and the self-ignorance of the subject may be realized and dissolved. ${ }^{21}$ As such, art is anything but irrational: it is the precondition of rationality. According to Novalis, art is the most substantial reality: "the more poetical, the more true."22 Subjectivity, as a precondition of all knowledge, is not a fixed given, but a continuously developing condition. Art has the potential to develop subjectivity, to enable it to find itself, to help it recognise itself in the greatest possible diversity of phenomena. Art is not a vacation from the obligations of everyclay life, but the opposite: it underpins all scientific and ethical endeavours. This evaluation of art differs so far from more conventional apptoaches that a few exemplary aspects of it require separate attention.

If every act of knowing implies fiction and poetical activity, it follows that idealism and realism are no longer strictly separate. The harmonious euphony between the faculties of the subject is no longer distinct from the universe-and Novalis has indeed entertained the notion of "universal harmony". This notion functions as a premise that allows Novalis to conceive of the different fields, disciplines, and human faculties as reciprocally illuminating each other. ${ }^{23}$ This highly symbolical view of reality does not provide closure; Novalis accepted that it would remain forever incomplete. "The fact that universal harmony is the precondition for Novalis's project does not mean that such a project, culminating in a "golden age", can ever be reached. On the contrary, Nowalis, very much like Friedrich Schlegel, conceives of the pursuit of his encyclopedic project and of magic idealism as a never-ending aesthetic activity." 24

Novalis and Schlegel used their contrafactual assumption of a harmonious universe to experiment with nearly impossible demands: they often ask of opposites to begin to resemble each other, thus inciting reality to become more harmonious than would seem possible. This procedure is typical of early Romanticism: it is its 
very core. Examples abound, and some quotations can help to make clear what is at stake here. Schlegel wrote that

[man and woman should] exchange roles and in childish high spirits compete to see who can mimic the other more convincingly, 25

Some of Novalis" remarks on politics closely resemble Schlegel's ideas about the relation of the sexes:

There will be a time, and this soon, when people will geneally be convinced that no king can subsist without a republic and no republic without a king, that both are like body and soul, and that a king without a republic and a republic without a king ate words without significance. $\%$

Commenting on Novalis' politics, Ernst Behler has written that he was "most strongly disposed to the magic words of a revolutionary philosophy of history: the golden age in the past and the corresponding future realm of perfection. Yet, through constant oscillation between these two poles,... he secured himself against either a one-sidedly utopian ox a pessimistic philosophy of history and saw the true historical status of the human being as something between the two extremes." 27 "What is important in this context is Novalis" emphasis on interaction, on a reciptocal saturation of two utterly opposed political systems, democracy and monarchy."28. Novalis also compared politics to religion:

The time must come when political entheism [i.e. monotheism] and pantheism are most intimately connected as interactive members."

Opposing Kant, who presented nature and morality as mutually exclusive spheres of reality, Novalis demanded that the two intermingle:

RORMATIVE THEORY OF NATURE. Nanure must becone moral. We are its ducators - its moral tangents - its moral stimuli. ${ }^{3 i 0}$

That the inner nature of man is in continuous exchange with the external world, is crucial to the early Romantics. Novalis, again:

We naturally undetstand everything that is foreign only by makimg our self foretgn - changing our self - observing our self. ${ }^{3}$

The poet uses things and words like a keyboard and all of poesy is based on the active association of ideas - on self-activating, intentional, ideal production of chance - (chance - or free catena(tion)..$^{32}$

It may be concluded that according to this theory, subjectivity at its best is in a state of flux ${ }^{33}$ or flow, able to experience a highly divergent and fragmented reality as if it were harmonious. Early Romanticism provides a model of aestheric experi- 
ence as participation participation of the arts in each other, of mankind in the arts and of man in nature, et cetera. Aesthetic experience is an active presupposition in every form of knowledge and in every moxal act. By renouncing the pretension of absolute knowledge (whether in the atts, religion, science, politics or philosophy), carly Romanticism gains the freedom to fully and freely experience mimesis, performance, and interptetation.

This detour through eighteenth-century German rationalism and idealism shows how a small shift of philosophical perspective may begin a transformation of formalistic solipsism into heterogeneous sensibility. If this already indicates an affinity between eatly Romanticism and contemporary art, this affinity may be illuminated further by a characterization of early Romantic artistic and aesthetic processes.

\section{ART AS PHILOSOPHY, PHILOSOPHY AS ART}

Just as subjectivity is not a fixed given but an ongoing exchange, so a work of art is, according to early Romantic theory and practice, not subordinated to fixed rules or genres. Making art is a process of playful intermingling: thus it is impossible to delineate 'the' romantic artwork. The heterogeneity that was an explicit aim of the early Romantic aesthetic makes it impossible to summarize their work concisely. Instead, this paragraph analyzes five aspects of the early Romantic aesthetic: mimesis, reflexivity, the Gesamtkunstwerk, the idea of a new mythology and finally their theory of representation.

Until the early Romantics challenged this view, mimesis-the imitation of nature-was generally taken to be the single defining characteristic of art. This notion was transformed in the theory and practice of early Romanticism, not because mimesis was teplaced by self-expression, as in later romantic art, but because mimesis was combined with reflexivity. The understanding that diverging traditions and artforms are all open be combined in an artistic process of mimesis and reflexivity leads to the notion of the "Gesamtkmstmerk", the artistic synthesis that is typical of early Romantic ideas.

Because a Gesamtkwntwerk is the sum of the sensibilities of many people, it has many of the characteristics of a mythology, or of a religion. Accordingly, the views of Novalis and Schlegel views on myths and religion ate an integral part of their philosophy, that will help to substantiate the claims that have been made for the reflexive potential of early Romanticism.

All these concepts combine in yet another way to produce an original wiew on representarion, one that emphatically approaches all symbolic representation in the medium of irony, Interrelated as they are, these five aspects of the early Romantic aesthetic shape the sensibility of this group of poets and philosophers. 
The early Romantics did away with the generally accepted notion that making art should be understood as the imitation of nature, executed according to established rules. ${ }^{34}$ Novalis wrote that "The artist takes the essence of his art out of himselfnot the least suspicion of imitation can touch him." 35 But it would be precipitated to conclude, just because the romantics opposed the fixed forms and conventions of classicism, that they opposed mimesis as such. What the early Romantics opposed is tather the notion that reality may be known scientifically and realistically before it is experienced aesthetically. In other words: they contested the notion that an artist should fully know the subject matter of his or her work before it has been made. According to them, making art is a mimetic process; but the riles of this imitative game are established while it is being played, and not laid down beforehand.

Opposing the notion of copying nature, they insist that art in itself is a part of nature, nature contemplating itself, imitating itself, developing itself. ${ }^{36}$ They encourage the artist to express his inner nature, to represent the infinitely changing facets and associations of inner life. But since this subjectivity is unable, according to early Romantic philosophy, to find a fixed foundation within itself, this inner nature may well be perceived as an imitative representation of outer nature. Art no longer simply imitates nature, but mimesis has become a two-way process. In Novalis" words: "Nature should become art and art should become a second nature." 37 This implies a subjectivity that is willing to know, understand and accept its own impulses, its inner nature.

Nature will become motal - when out of real lowe for art - it submits to art — does, what art wants -art, when out of real love for nature - it lives for nature, and works after nature. Both have to do it at once of their own wish - for their own sake - and of the other's wish, for sake of the strange other. They have to meer in themselves with the other and with themselwes in the other. ${ }^{3 *}$

Art is in this conception both imitation, which means a following of rules and the acceptance of genres of representation, and the production of new rules, the establishment of new forms, the conventions of the future. These two are inseparably intertwined. Mimesis has not become superfluous, but is shown to entail new, formerly unthought of possibilities.

The tradition of Western philosophy has always acknowledged the importance of mimesis, but this was often done with the purpose of restricting its impulses. As Plato wrote in an exemplary passage of his "Republic":

Have you not observed that imitations, if continued from youth fat into life, settle down into habits and (second) nature in the body, the speech, and the thought?

Yes, inced, said he.

We will not allow our charges, whom we expect to prove good men, being men, to play the parts of women and imitate a woman young or old wrangling with her husband, defying heaven, loudly 
boasting, fortunate in her own conceit, or involwed in misfottune and possessed by grief and lamentation-3tall hess a woman that is stck, in love, or in labor.

Most certanly not the teplied.

Nor may they imitate slaves, female and male, doing the office of slaves...

Well, then, neighing horses and lowing bulls, and the roise of riwers and the roar of the sea and the thunder and ewerything of that knd - will they imitate these?s?

Plato attached great importance to mimesis (and to music, especially music with sung words), and thetefore feared and forbade any mimetic practice that might lead to an undermining of the social hierarchy. The free and rational male citizen was opposed to slaves, emotional women and the forces of nature, and this hierarchy had to be protected from the effect of role-taking, imitation and the ensuing identifications and confusion. In the arts, Plato likewise opposed all mixing of attistic genres, as well as the unrestricted imitation of all kinds of behavior, sound effects, and combinations of different rhythms in poetry and music..

A recent commentary explains about Novalis and Schlegel:

They ate guided in this pursuit [of an etemal potesis] by the one principle that Plato considered most dangetous (ot socially pernicious) with tespect to at: mimesis. Through the mimeric gesture, one assumes roles that are not one's own; one plays with and thus disturbs notions of the proper, of what belongs rightfully in a place. The possibiling of mimesis points to the discursive nature of the universe, to the fact, that is, that representations become attached to things, and that these representations can also be detached from things and used differenty. An artist can usurp the words of others. S/he can be anarchic. Poiesis in Novalis and Friedtich Schlegel refers to this anarchy, to the production of an aesthetic chaos. "The purpose of such chaos is to reconceptualize social and cliscursive hiemarchies. ${ }^{\text {.40 }}$

But although poetics and politics are undoubtedly connected, it would be a mistake to conclude that political purposes were guiding their artistic innovations. It is rather the other way round: the wish for a methodical liberation of the arts from all restrictions and prescriptions had political implications. This also helps to explain why the early Romantics never developed a consistent political program: their central purpose was the methodical development of a full understanding of liberal artistic development. According to Walter Benjamin, whose discussion of the works of Friedrich Schlegel and Novalis still remains the most thorough study of their philosophy ${ }^{41}$, such a methodical understanding is to be developed reflexively.

Since the term 'reflexivity" carries several technical and methodological implications, it deserves an introduction. ${ }^{42}$ The Latin verb 'reflectere' simply means 'to ply back', and the meaning that has evolved from this is 'to think once again about what is known': the mental testing and comparing of the mind's knowledge. In this process, the thinking self focuses on itself as a microcosm which is able to get to know external objects, or to conduct an act of knowledge: reflexivity, therefore, is the process of thinking critically about thinking. According to Immanuel Kant, 
reflection is the act by which we discover the subjective conditions under which we arrive at concepts. ${ }^{43}$

Descriptions of reflexivity in terms of 'the subject' or 'the self as microcosm' are still vague. A much more precise analysis has been made by Walter Benjamin, in his dissertation on "The Concept of Criticism in German Romanticism". This is a reconstruction of the concept of art criticism of Novalis and Friedrich Schlegel, who Benjamin considered to be the main representatives of early German Romanticism. ${ }^{44}$ Their philosophy of criticism is based on the phenomenon of thinking that self-consciously reflects upon itself. This process of reflexivity is without ending: thought thinking about thinking can always return to reflect upon itself, which then results in thought thinking about thinking about thinking, and so on. According to the romantics, as opposed to their contemporaties, Germany's idealist philosophers, this potentially endless process of teflexivity does not constitute a sovereign subject, an "I" (as proposed in the philosophies of Fichte and Hegel), but only a medium: the medium of art.

For Novalis and Schlegel, themselves poets and novelists, this art was first of all literature. They considered every work of literature as a reflection, one single stage in the endless process of reflexivity. Every artwork, to them, is by definition preliminary and fragmentary: the process of reflexivity that has been condensed in the work of art can always be continued. Indeed, it deserves to be continued. The very fact that the work of art embodies a series of teflections is what gives the work its dignity, its positive value, because according to romantic theory, "reflection does not take its course into an empty infinity, but is in itself substantial and filled". 45 In other words: the early Romantics systematically thought of artworks as reflections on the traditions of artmaking, and realized that no artwork alone embodies a complete and fulfilled tradition. Therefore, every work of art by definition has its shortcomings, its unfulfilled promises, its rough edges. This does not in any way devalue it. On the contrary, the tradition of literature and the promises incorporated in that tradition depend on the individual works: the mote these works demonstrate their own fragmentary character of unfinished (and therefore: ongoing) reflexivity, the greater their dignity as works of art. This does not mean that the early Romantics disliked well-rounded works, on the contrary. But they did insist that even an immaculately formed literary work is but a stage in an ongoing reflexive process. As Benjamin wrote: "Thus, form is the objective expression of the reflection proper to the work, the reflection that constitutes its essence." 40 This led him to the conclusion that "the idea of art as a medium thus creates for the first time the possibility of an undogmatic or free formalism-a liberal formalism, as the Romantics would say." 47 This liberality is remarkably unlike later romantic positions. Novalis, for example, "proposed to become "at least politicaliy as well as religiously tolerant" and to concede the possibility that "a human being could be inclined differently from us". Such tolerance would eventually lead to the 
"sublime conviction of a relativity of each positive form" and thereby to the "true independence of a mature spirit with regard to every form that is nothing but a tool for it". ${ }^{48}$

According to this philosophy, the absolute subjectivity that was the goal of idealist philosophy is only to be developed in the medium of art, where it can never reach absolute completion. This development starts when the formal properties of a work of art are considered critically. A critical examination awakens the reflections in the work and continues them: this continuation is nothing else than the creation of a more reflexive new work. Criticism thus takes place within the sphere of art: it is not an external judgment, but an internal development. Instead of opposing critical subjectivity to the medium of art, in early Romantic theory the two are identified.

Schlegel and Novalis were well aware that this philosophy has mystical traits. According to Novalis, philosophy "is a mystical ... pervasive idea, driving us ceaselessly in all directions". ${ }^{49}$ It dissolves the subject by emphasizing the reality of reflection over the reality of physical personal identity. As Schlegel wrote, "everything is in us... we are only a part of ourselves."50

Early Romantic theory tends to appreciate the idea of art as the medium of reflection and of developing subjectivity mote than the individual artwork. Although it is the form of the individual work that defines the coherence of its reflections, this coherence may always be dissolved by further reflection: that is the highest purpose of the individual work. ${ }^{51}$ And yet the only legitimate criticism of an artwork is another work: a work that has incorporated its predecessor within a new form and adds a new level of reflection, creating a stronger coherence that is based on the earlier work.

This aesthetic does not prescribe any specific form or gente to the artist. Reflection may start anywhere, choose anything as its point of departure, or as its content material, and develop its own mimetic rules: that is implied by its liberal formalism. This philosophical romanticism is quite distant from the much more widespread notion of romantic art as the free expression of the personality, the arbitrary subjectivity of the artist. ${ }^{52}$ Indeed, as Benjamin underlines, reflexive art is characterized by sobriety ${ }^{53}$; he quotes Novalis' opinion that romantic art has to be remunerable, reliably repeated and mechanical. ${ }^{54}$

Typical of the romantic work of art is not its point of departure, which may well be intimately personal, but its ensuing methodical and formal development. This has produced two properly romantic forms: the Bildungsroman and the $G_{e}$ samtkunstwerk. The Bildungsroman or novel of character development presents the education of its main protagonist by documenting his reactions to a series of artworks. This allows the novelist to make a methodical use of other works of art, quotations and descriptions of works of literature, music and the visual arts and their impressions they make upon the protagonists, incorporating them within the 
new novel: a clear model of mimesis and reflexivity working together. The overriding theme is the self-transformation of the protagonist by this reflexive process, as well as the quintessentrally romantic insight that this transformation is necessarily incomplete and fragmentary.

The Gesamtkinstwerk similarly brings together a multiplicity of artworksand it could be argued that the Bildungsroman is the individualistic version of the Gesamtkunstwerk, that is aimed at a collective reception. It orchestrates different artforms to play most effectively upon the full range of sensibilities of its audience, by combining, as in opera, music and drama with lyrical poetry and scenographic spectacle. The idea of a Gesamtleunstaverk is inherent to the early romantic conception of art, as a fragment by Novalis shows:

Poetry is the representation of the beart-the inner world in its entirety. Its medium alone, words, already indicate this, because they are after all the external revelation of the forces of this inner world. Exactly what sculpture is to the shaped external world and music to the tones. Effect is its complete opposite-insofar as it is plastic-yet there exists a musical poetry, which brings the heart itself in a manifold play of movements. ${ }^{5.5}$

Similar ideas were not uncommon in German aesthetics around 1800. They can be found in the works of Schiller and of Schelling, although the term Gesamteunstwerk with all it implies was minted later, around 1850 , by Richard Wagner $^{56}$.

The romantic ideal of the Gesamtkunstwerk was the performance of a new, living mythology, a new foundation for all social conventions, uniting artistic perception with religion and philosophy in a form that addresses the widest audience there is. This idea can be traced from Hölderlin, Novalis and Schelling to Wagner, Nietzsche and further. ${ }^{57}$ They always phrased their artistic utopias in terms of a comparison with the - highly idealized-Greek tragedy. But in fact the Greek tragedy only fascinated them because of a single question: is it possible to retum to an artistic practice that produces the experience of a legitimate communality, under the conditions of modern society with its atomized individuals and its generalized alienation? ${ }^{258}$ These romantics have always pointed to music as the medium to realize this communal experience, claiming that music is the language of intoxication, and therefore the antidote against isolationist individualism.5" "When in good company, one should always listen to music by way of a pause", Novalis wrote. ${ }^{60}$ The individual returns to a sense of community when he or she (the way in which women are included or excluded is often most revealing for: romantic theorizing; early Romanticism proves its liberalism here ${ }^{(1)}$ ) is absorbed in the choir, returned to the brotherhood of man and reconciled with nature. As Nierzsche wrote: 
Under the magieal Dionysian influence, not only the ties between man and man are tied once mote: also alienated, hostile or subjugated nature celebrates her feast of reconciliation with her lost son, man.... Now, with this gospel of cosmic hamony [Nietzsche thinks of Beethoven's "Ode to Joy" in the fourth movement of his Ninth Symphony], everyone feels not only unified, reconciled, merged with his neighbour, but one, as if the veil of the Maja had been torn and was only fluttering in shreds in front of the mystcal $\mathrm{U}$-union [primondial unity]. Singing and dancing, man expresses himself as a theniber of a higher unity: 62

In romantic theory, this musical community has been conceived of in different, even directly opposed ways. The later Nietzsche was, like Wagner, notoriously anti-democratic, but in this respect his theories were in open conflict with the ideas of Friedrich and August Wilhelm Schlegel. They conceptualized the Greek tragic choir as an audience that has been included in the play as its immanent reflection, simultaneously audience, judge, and critic, and therefore the ideal spectator, the voice of mankind. ${ }^{.3}$ Novalis wrote that "The theatre is the active reflection of man about himself." ${ }^{44}$ Accordingly, every active reflection, for example political or religious activities, may be seen as theatre: "In the state, every action is meant to be seen - in the people, everything is drama. The life of the people is a theatrical play." ${ }^{5} \mathrm{He}$ also mentions Christianity as a form of theatrical play. ${ }^{66}$

The question whether a critical, reflexive moment has to be present into the very heart of the Gesamtkunsinerk, as brought forward by both Schlegels, or must be excluded from it, as was most often Nietzsche's opinion, is decisive for the course of romantic aesthetics. The exclusion of reflexivity results in an art and an aesthetics that is unable, and even on metaphysical grounds unwilling, to distinguish between sentimental bombast, plain madness, and artistic epiphany, and the resulting amalgam is only too characteristic of later Romanticism. As a result, the later romantic tradition, with its model of the artist as the individual genius, is seriously flawed. The "individual genius" of art was often uncritically identified not only with particular artists, revered as demi-gods, but also with nations (the vision of Germany as the pre-eminent "Kulturstaat"), races, and all forms of sects and cults. When using early Romanticism as a model, these more shady, antimodern aspects of the Romantic tradition should not be neglected. They will allways accompany the more critical Romanticism, as potentially seductive but damaging possibilities. Because of this history, the importance of reflexivity for genuine early Romanticism can hardly be emphasized enough.

The wish to create a new artistic mythology is of course identical with the wish to re-establish religion. At the end of the eighteenth century, this was a highly topical matter in western Europe. Not only had the Enlightenment prepared European literary and philosophical circles for a thorough reconsideration of the Christian articles of faith and of the Christian view of the world. The French revolution had depossessed the Catholic church and, in the process of deChristianization of 1793 , consecrated Paris' Notre Dame cathedral to Reason- 
granting divine and absolute dignity to rationalism. As one might expect, the early Romantics have reflected liberally and copiously on the meaning and form of religion.

In the domain of teligion, the attractive allure of the divine absolute, together with the philosophical conviction that knowledge of the absolute is impossible, resulted in vehement oscillations between irony and enthusiasm, between scepticism and pantheism, and between Protestantism and Catholicism. (Most of the early Romantics came from Protestant backgrounds. Yet (later) Romanticism in general is known, by and large, as a defense of Catholicism against Enlightenment influences.) Tracing some of these oscillating figures will help to broaden the understanding of the romantic aesthetic.

In so far as it is truly romantic-according to the definitions outlined above-the early Romantic view of religion is characterized by the insight that knowledge of the absolute is impossible. Instead of knowledge, feeling takes pride of place. In 1799, Novalis wrote an essay titled "Christendom or Europe", in which he sketched a utopian vision of Europe, as a renaissance of Medieval Christendom: "Only religion can reawaken Europe and return its people to security". 67 But this form of christianity would have to have overcome the division between Catholicism and Protestantism, its dogmatic form (which Novalis calls "accidental") as well as its respect for national borciers; first of all, it would consist in the joyous embrace of religiosity as such. ${ }^{8}$ This coincides with the insights of Friedrich Schleiermacher, the early Romantic theologian who was to become the founder of modern Protestant theology. In his book "On Religion: Speeches to its Cultured Despisers" (1799), Schleiermacher defined religion as "feeling and intuition of the universe", and "the sense of the Infinite in the finite".

This religious feeling is the focus of the speculations of Novalis and Schlegel. It can be found everywhere: Novalis wrote that "There is no religion, that would not be Christianity." 69 And: "It is remarkable that the association of voluptuous. ness, religion, and cruelty has not already long ago made people notice their close affinity and their common tendency. "There is only one temple in the world and that is the human body. Nothing is more sacred than this lofty figure."71 "All our inclinations seem to be nothing, if not applied religion." "It is impossible to develop this apprehension of religiosity into a universal system of religious knowledge: what remains of the knowledge of the absolute is only the momentary and fragmentary, point-like synthesis, in Romantic terminology the "Witz" or wit. ${ }^{73}$ Novalis has accordingly synthesized his own philosophy of religion in a single italicized word, published as a self-reliant fragment, built (as the German language allows) out of three concepts:

\section{Experimentalreligionslehre}

[experimental teligious doctrine, or methodical experimenting with religion]. 
True to its philosophical convictions, this romantic doctrine takes a liberal and artistic course. As Novalis observed, "The history of Christ is most certainly as much a poem as it is a history, and anyhow only those histories are history, which can also be a fable." 75 And as a poem, this history is subject to critical reflection: it can and should be rewritten and improved by other artists. Novalis:

On the concept of a Gospel. Is it not conceivable to produce several gospels? Does it have to be completely histonicalt $O_{H}$ is history nothing but a vehicle? Isn't there a Gospet of the fatiare as well?-Unite wirh Tieck and Schlegel and Schleiermacher for this purpose. ${ }^{\text {it }}$

Consider the sheer audacity of this: Novalis testingly proposes to challenge, perhaps even replace the four evangelists of the New Testament by himself and his friends. In "Christendom or Europe" he had characterized the content of the bible as a "rough and abstract design of religion" "7, and in his miscellaneous fragments "Pollen", he noted that "If the spirit sanctifies, every true book is a bible."7s Man should be completely free is his choice of mediator between himself and the divine, Novalis decided. ${ }^{79}$ The combination of writers that he proposed is nevertheless remarkable. Friedrich Schlegel, the most important theorist of the early Romantics, published his autobiographical erotic novel "Lucinde" in 1799, a book that was received by the general public as a manifest of obscenity ${ }^{80}$. (In 1808, Schlegel would convert to Catholicism, a move he described in 1806 as follows: "To become a Catholic does not mean to change religion, but basically just to acknowledge it." "Bl) Ludwig Tieck was the great novelist and storyteller of the early Romantics, also known to have written macabre and bloody pulp-stories for money ${ }^{\mathrm{A2}}$. Together with Schleiermacher's Protestant theology and Novalis' own mysticism and talent for symbolical poetry, this quartet might have produced a truly remarkable "gospel"!

To complete this brief sketch of the Romantic approach to religion, a few aspects of Friedrich Schlegel's philosophy deserve to be highlighted. Schlegel once jotted down in his notebooks a pseudo-mathematical formula to express his ideas on are and religion.

He used 'dividing by zero' to indicate an idea that had been raised to an absolute level; so that $\frac{F}{0}$, for example, stands for the absolutely fantastical. The entire formula reads:

The poetic ideal $=\frac{\sqrt[\frac{1}{0}]{F S M \frac{1}{0}}}{0}=\operatorname{God}$

Here, the letter $\mathrm{F}$ indicates fantasy, $\mathrm{S}$ indicates sentiment or feeling, and $\mathrm{M}$ indicates the mimetic power. The mathematical form of raising something to a higher power was used by the early Romantics as an expression for reflection. Therefore 
this formula can be explained in words: the product of the absolutely Fantastic $(\mathbf{F})$ with the absolutely Sentimental (S) with the absolutely Mimical (M, the ironical presence of the author in the work), raised to an infinite power, (or: infinitely reflected) equals God. The divine, in other words, is the product of artistic sactilizattion.

Because it embraces all forms of sentiment, fantasy and mimesis without distinction, such an attitude may develop into pantheism, and in his Jena period, Friedrich Schlegel with his companions Schleiermacher and Novalis developed a pantheisric religion of nature. ${ }^{83}$ But Schlegel soon became dissatisfied with it, because pantheism embraces both the arabesque forms and infinite surprises of nature and the brute and abysmal qualities of matter, natural beauty as well as evil and $\sin$. He turned to the study of comparative mythology to help him develop a further discussion of pantheism, following his conviction that "it is hardly possible to find a mythology in which no traces are present of the true concept of divinity, however disfigured by exotic infusions." ${ }^{84}$ His turn towards traditional Cathollicism may perhaps be interpreted as a turn away from undifferentiated pantheism towards a more intersubjective religiosity: a form of religiosity that accepts only those forms of nature as sacred in which another subjectivity, a "Thou", manifests itself. ${ }^{85}$ At the same time, catholicism as an established tradition may have presented itself to Schlegel as the best available medium for communication. Whatever may be the truth in such speculations, Schlegel's later life and work as a catholic propagandist in service of the Austrian government are of no concern here. Relevant for early Romanticism are two aspects of Schlegel's aesthetic of religion. First, there is his emphasis on liberality:

To disguise, as in cross-dressing, a few Biblical histories in the guise of the Homeric epic, to tepresent others with the frankness of Herodot and with the strictness of a Tacit in the style of classical history, or to review the whole Bible as the work of a single author; that would seem paradoxical to everyone, irtitate a good many, appear tasteless and superfluous to some. But may anything seem superfluous, that could make teligion more liberal? 86

Strictly speaking, nothing is religious that is not a product of freedom.

This completely liberal artistic religiosity may reflexively recognize itself in anything and everything, "hover on the wings of poetic reflection between the presented and the presenting, free from all real and ideal interest, and continually taise this reflection to a higher power, thus multiplying itself as in an endless row of mirrors." "This religiosity of frec-floating sentiment might be compared to an artists' metaphysics: a license to speculate freely, without hindsight for outside responsibilities. Friedrich Schlegel wrote in 1800: "Only he who has his own religion, an original view of the infinite, can be an artist." ${ }^{\prime \prime 9}$, and in a similar spirit, 
Friedrich Schelling said, in 1803, that "Every truly creative individual must himself create his own mythology."

A second important insight is that mythology and religion stand for the possibility of universal communication, universal comprehensibility. This was elaborated by August Wilhelm Schlegel: "Myth, like language, is a general, a necessary product of the human poetic power, an arche-poetry of humanity" ${ }^{91}$ According to the early Romantics, the mythologizing tendency of the human mind is a basic aspect of our nature, without which human experience would not be possible. ${ }^{92}$ Human experience is always in part imaginary and metaphorical, and A.W. Schlegel concludes that "The original action of the imagination is the one through which our own existence and the entire outer world gains reality for us." ${ }^{\prime 93}$

Friedrich Schlegel shared these insights, but made more radical demands. He stated that his age lacked a coherent mythology; addressing the poets of his period, he said: "You above all others must know what I mean. You yourselves have written poetry, and while doing so much often have felt the absence of a firm basis for your activity, a matrix, a sky, a living atmosphere." ${ }^{44}$ He feels that a new and rejuvenated mythology may be obtained soon. It is identical to romantic poetry and philosophy: "The new mythology... must be forged from the deepest depths of the spirit; it must be the most artful of all works of art, for it must encompass all others; a new bed and a new vessel for the ancient, eternal fountainhead of poetry, and even the infinite poem concealing the seeds of all other poems." ${ }^{355}$ Again, we see here the early romantic theme of demanding that two opposites permeate each other absolutely: a new mythology should be both individual and universal. A recent commentary says that "As such, myth, like philosophy in the Jena lectures, is in a state of becoming. A work of shifting assemblages, it is intimately tied to the heterogeneous philosophical text that creatively mixes dis courses." ${ }^{.96}$ Once again, this means that this is a goal deserving of great effort, even when its final realization is impossible.

The early Romantic aesthetic contains a theory of representation; perhaps it is more correct to say that it may be read as a theory of representation. As mentioned before, the romantic use of mimesis holds that representations may be detached from things and used differently. If this tendency is pursued to its final consequence, everything may represent everything, and the romantics indeed liked to consider this as a hypothetical possibility. It logically corresponds, as commentators have noted, to the notion of reciprocal representation:

In terms of a universal theory of signification, the notion of "reciprocal tepresentation" means that cverything, every object, sign, or explanation, can be a sign for everything else-what Nowalis refers to as the "mutual attraction of the sign and the signiffed" (Universal Brouillon 137 ). A precondition for this mutual atraction, especially for the notion of reciprocal representation, is the postulate of a universal harmony. Novalis has to start from this premise in order to conceive of the different fields, disciplines, and human faculties as reciprocally illuminating each other.? 
This theory of representation requires every sign to be utterly and absolutely symbolic - so much so, that any representation must inevitably fall short. This makes irony indispensable to the early rommantics, as the stylistic means to communicate the self-conscious insight that representations fall short of their mark. Irony not only helps to produce the humorous state that allows the mind to hover freely, it also fulfills the serious task of reminding the reader of the preliminary status of every representation.

The consequences of this theory are most far-reaching when it comes to symbolism. It is only too easy to forget the rhetorical nature of symbolic representations-of the divine, of human characteristics, or of nature-and to identify the symbol with nature itself. This identification may in turn become the basis of an ideology, of illusory certainty; the very stuff of which historical blindness is woven. Irony may help to endure the tension between representation and reality, between ego and world. According to the Romantics, this means that symbolic truths must interpreted critically, as historical and contingent representations without a properly absolute core. Such interpretations are allegorical, as they decipher representations as containing unsaid historical or natural motives: the "eternal" symbolic meaning disintegrates into a product of natural history. But the early Romantics equally realized that the disintegration can not be the last word. Novalis expressed this as follows:

As necessary as it perhaps is that everything periodically be brought into flux in order to bring fordh new, necessary mixtures and give rise to mew, purer crystallizations, it is nevertheless just as essential to temper this crisis and hinder total dissolution so that a stock remain intact, a core to which the new mass can attach itself and atound which it can grow in new, beautiful forms... Would it not be foolish to make a crisis permanent... Pys

Early Romanticism is utterly allegorical insofar as it illuminates the inevitable shortcomings of every symbol. This however represents the attempt to produce, reflexively, a higher symbolism. ${ }^{99}$

In comparison with post-structuralism, early Romanticism has the distinct advantage of a positive point of departure. Compared with the structuralist principle that no natural link between signifier and signified can exist, Novalis" formula of a "mutnal attraction of the sign and the signified"lon, a formula that forms the foundation of his "mystical theory of language" 101 , may provide a deeper insight in the nature of language, art, and culture, because it allows not only a negative critique of all symbols, a destructive approach from the outside, but equally a positive critique from the inside, which the early Romantics understood as a reflexive development of the symbol. 


\section{THE EARLY ROMANTIC AESTHETIC AND BYRNE'S WORK}

As mentioned before, the early Romantics were not able to found a tradivion. Novalis died in 1801, 28 years old, and around that time the Jena circle fell apart for a number of reasons. Their ideas about the unfettered formal liberty of the arts, about mimesis combined with reflexivity, about the possibility of a renewed mythology and about a magical representation that would be both symbolic and allegorical have influenced many later artists and philosophers. Still, their influence has been scartered: they did not produce a solid chain of tradition. Keeping this in mind, early Romanticism may be considered a source of later avantgardistic tendencies, in which art is no longer tied to external rules but set free to develop its own forms, to incorporate mimetically whatever is needed to come up with convincing results.

Early Romanticism prescribes a completely free formalism, a crucial quality of avant-garde works, to the arts. Moreover, the arts are set the task of producing a new communal experience, a new mythology, a new religion: nothing less than the quest for a new society, that other defining trait of a genuine avant-garde. A number of surprisingly avantgardistic statements is to be found in the work of the early Romantics. Novalis formulates the aesthetic position of avant-garde work in general: "The highest works of art are simply unpleasant-They are ideals, which can-and should -only approximately please us-aesthetical imperatives", ${ }^{102}$ Art is unpleasant insofar as it is disruptive, does away with conventions and produces chaos and melancholy. 'These tendencies are not missing from Novalis' conscious reflections: he brings up the idea that art has to be a "purposely arranged chaos"103, an idea that only much later was applied by the symbolists" purposely deranging of the sensibilities, by the surrealists in their practice of "automatic writing" and by John Cage in his experiments with chance.

This acceptance of chaos is an integral part of early romantic aesthetic. Novalis writes: "Man is really choos." 104 _ but this chaos represents an infinit potential. According to Novalis,

The world of the fairy tale is the compleze opposite of the world of truth (history) - and precisely for that reason so completely similar to it - just as dowos is similar to the completed creation....

In the fun world everything is ats it in the former world - and yet enerything is completely different. The fotwre world is Rearonable Chaos - chaos that has pemeated itself - that is inside and outside of itself - 6 haos ${ }^{2}$ or $\infty .105$

Friedrich Schlegel wrote, more succinctly, that "Irony is the clear consciousness of an eternal agility, of an infinitely abundant chaos." 106 A certain chaos is the very precondition of the changeability that the true romantic--like his successor, the avant-gardist-surmises to be present everywhere, and most certainly everywhere in human affairs. 
Man's inner nature is anything but rationally clear and distinct, it is confused and complex - but because of that chaotic complexity, man is able to imitate everything in nature, to assume an endless mimetic capacity, and thereby to lend meaning to everything in nature. ${ }^{107}$ If a truthful representation of this chaos is received as incomprehensible, the early Romantics were willing to take this into the bargain. Friedrich Schlegel even wrote, in truly avantgardistic spirit, an apology for incomprehensibility. It contains a deeply ironic rematk that may be interpreted as the definitive reply to authoritarian (or Platonic) fears of unchained mimesis and its incomprehensible results:

But is incomprehensibility actually something so completely reprehensible, so base? I think that the welfare of families and nations rests on it. If I am not utterly decelved, states and systems, the most artificial works of thumankind, are often so artificial that one cannot admire the wisdom of their creator enough. ${ }^{108}$

Schlegel seems to imply that, like nature, history with its succession of states and systems remains, in the final instance, incomprehensible, open for new interpretations, and is therefore best regarded with a good dose of irony and humour. An insight that has never been absent from avant-gardist enterptises, however absolute their declarations may have sounded.

Of interest here is the affinity between Byme's work and the aesthetic of early Romanticism. It would perhaps be feasible, although far-fetched, to establish a historical chain of influences that would connect Byme to the early Romantics, for example through John. Cage's ideas about randomness and incomprehensibility in ant (and through to Joyce, and through him to early Romanticism) or through Robert Wilson's approach to the Gesantkanstwerk, (comparing this to Brecht, then Wagner, then early Romanticism). But more important are the inner similarities between Byme's work and this philosophy. Take Byrne's description of the authenticity of his own of experience:

New York is one of the world's most culturally mixed ciries. Every day I experience little tastes of a wide variety of cultures. A Haitan cab driver playing his music cassettes, Thai noodles for lunch served by a Midwestern woman... and today I"m interviewing a woman from Indonesia who now liwes in Paris. So I really don"t know where I am anymore. My sense of place is global.

Eventually this dislocation, a pleasant feeling of floating, will seep into my dreamn, into my unconscious. And from there into my senses... my taste buds, my ears and eyes. I will become a different kind of being.

This seems to echo Novalis' conviction that man is nothing fixed, and that we may understand everything that is foreign only by making ourselves foreign, by changing and observing ourselves.

Richard Schechner's description of performance behaviour as transforming elements that are "not me" into "me" without losing their "not me-ness" may be 
interpteted as belonging to a tradition that was started by the early Romantics, with their insistence on poiesis and reflexivity as founding activities of a subjectivity that never congeals into the absolute identity of an "T". That performances combine narrative and cognitive elements with affective, emotional stimuli, as Schechner holds, working with unresolved tensions between the ethological, the neurological and the social, is but a more contemporary way of expressing these ideas. Schechner's detalled explanations of performative processes may be used to throw a new light on Novalis" suggestion that the theatre is the active reflection of man about himself; it is more than merely an anachronism to suggest that for Novalis, reflection was by its own nature performative.

Byrne's way of making music is based on mimetic exchanges between the self and the foreign, as demonstrated by experiments with many musical combinations and reciprocal representations: conceptual rock with funk, with Latin and African rhythms, with the nineteenth-century European symphonic tradition, with Chinese music, and so on. His ability to keep observing and questioning his own performances results in a consistently reflexive quality, and in the combination of popular forms with theoretical notions. The idea of art as a reflexive medium, rather than as a collection of individual works, may be recognized in Byme's preference for trying out new collaborations and combinations of artforms and genres. The irony that pervades his work is a result of this reflexivity-just as it was for the early Romantics.

Byme's interest throughout his career in comparative mythology and in sacralization is another indication of his affinity with Novalis and Schlegel. The reflexive approach to the subject's participation in symbolic realities, combined with the insight that such participation is always tinged by a certain tandomness, brings about an approach that looks at religion, ritual and myth as an ongoing process of change, instead of a series of fixed dogmas. Byme's tendency towards mysticism and pantheism, is another trait he shares with early Romanticism's philosophy of a hovering, floating subjectivity. This remarkable affinity requires a further elaboration.

Of course, the distance between the rather prowincial eighteenth-century Jena and today's New York City is stupendous, forbidding a direct identification of early Romantic poiesis with Byrne's working methods. Novalis and Schlegel had to develop their aesthetic philosophy in a peculiar vacuum, separated from the strong practical impulses of modern society. There was no modern industry or trade in Germany to respond to the scientific innovations of their generation, and Germany's political, educational and religious institutions of their day and age met the philosophical conceptions of early Romanticism with immobility and indifference, withholding them every opportunity for practical influence. And as poets, they were unable to find a major city, a wider stage that would have allowed their work to find a bigger and better audience. 110 If their "magical idealism" seems 
unworldly and unreal, that may also be explained at least in part by its lack of opportunities to enter into a direct exchange with the practical realities of modernity: Even if one accepts as feasible the notion of a hovering subjectivity that is mixed up in manifold relationships, one may still ask whether human nature and historical teality do not put insurmountable obstacles in the way of this flexible mimetic experience. Doesn't the experience of modernity teach that subjectivity is inevitably determined by the forces of the economy, by social institutions, by cultural pattems? Are the forces of circumstance, the hard facts of reality not of greater importance than poetic flights of fancy?


23. A collage by David Byrne, combining a magazine advertisement for Nike Air running shoes with a typical example of romantic landscape painting, to highlight the presence of romanticism in contemporary culture. The advertising text spells out the romantic quest for the sublime experience of nature: "... surpassing youtself ... running ahead of a threatening thunderstorm". Collage from the theatre programme for "The Forest", by Robert Wilson and David Bytne.

Reading the fragmentary philosophy of the early Romantics, one gets the impression that a new, truly libetal mythology will transfigure society instantaneously. They present the optimistic face of modernity, where all that is solid melts into air, as enthusiastic innovation will overcome every obstacle. The dark face, the other experience of modernity is melancholic; it is the realization that modern politics and modern technology may also produce new dependencies and new oppressions, bringing about a cultural sensibility that is dulled and homogenized, turning authenticity into a most unlikely quality. Through the industrial reproduction and marketing of an aesthetic sensibility, its mimetic qualities are all too often replaced by homogeneity. Such a melancholic view of contemporary culture is as much a presence in Byrne's work as the opposite, optimistic idea of a free and limitless exchange. As he explains: "I want to be both outside my culture and my sociery and be part of them. I want to be a part of popular culture... to swim in the great river of shit but somehow not get any on me." "11 
And of course, over the last two centuries the arts, as medium of early Romantic reflexivity, have been changed completely. Representations have been transformed by the technologies of reproducing image and sound, by photography, radio, grammophone, film, and television. These new media, the media of Byme's work, have changed the attempts to produce a Gesamtkunstaverk from the bottom up, just as religion and mythology have been transformed by modernization in general. Even the relevance and the inner quality of mimesis and reflexivity have been affected by the rationalization of so many aspects of life. For all these reasons, the model of early Romanticism needs to be updated, before it can be used to interpret contemporary cultural phenomena.

The interplay of reflexive poiesis and modernization, and the resulting experience that modernization may liberate as well as stifle mimetic forces, is the central thematic of the work of Walter Benjamin and Theodor W. Adomo. Their essays and books on such matters as the potential of art to give an adequate reflection of modernization, on theory as the indispensable means to grasp the mimetic dimensions of modern city life, and on the question whether mass entertainment is inevitable a homogenizing force, have been unusually influential. Their friendship and their debates offer mote insight in the confrontation of the early Romantic aesthetic and modernity than any other philosophical body of work. For these reasons, the next chapter presents an overview of their work, including their views on photography as an atuthentic artform, on the combination of Marxist and Jungian theory to understand the mimetic experience of modernity, and on the ways in which fun and entertainment may repress reflexivity. These questions are still debated in contemporary performance theory, and they dominate Byrne's reflections on his own work. For all these reasons, the work of Benjamin and Adomo may serve as an intermediary between the early Romantics of the end of the eighteenth century, and the attempts at reflexive performance at the end of the twentieth and the beginning of the twenty-first. 


\title{
CHAPTER 11
}

\section{Benjamin and Adorno on myths in modernity}

\author{
SUBJECTIVITY BETWEEN NATURALISM AND SYMBOLISM
}

The general background of the work of Benjamin and Adomo is the confrontation between naturalism and symbolism. Towards the end of the nineteenth century, naturalism and realism succeeded romanticism, and denied the romantic belief in the importance of fantasy. Their central insight was that the realities of human existence are not shaped poetically, but determined by the hard facts of modern life, in circumstances that depend directly on economic forces: industrialization, rapidly expanding cities, increasing national and international competition. Instead of artistic experiments with form, the program of naturalism entailed the detailed representation of the facts of human nature as shaped by its environment. Naturalistic artists strove to give a disillusioned insight in unadorned reality. To obtain realistic effects, they made use of established standards of representation, fixed mimetic recipes, that could well be adapted to the latest theoretical insights of scientific positivism, and just as easily be adapted to the moral claims of some version of socialism, social Darwinism, nationalism or christianity to provide the true insight in human nature. Generally speaking, the acherents of naturalism and realism set out to debunk the very idea that there could be something substantial to poetic subjectivity, and they could point to a great deal of evidence to support this claim.

Symbolism was in many respects a reaction against the naturalistic claim on art; it represents the attempt to free art from all moral, political and scientific responsibility. Opposing the demands of mimetic realism, the symbolists proclaimed 
"l'art pour l'art", an art as responsible only to itself, completely free in the pursuit of beauty. And in direct opposition to the wish for commercial success and for practical influence of many naturalistic writers, the symbolists expressly reserved their esoteric work for an audience of insiders. More than anything else, this rift between naturalism and symbolism, with ramifications that go far beyond purely artistic matters, characterizes the aestheric of Walter Benjamin and Theodor W. Adorno. In their chilldhood and during their education, both fell under the spell of symbollism, and the symbolist canon would profoundly influence their insights in literature, the visual arts and music throughout their life. What distinguishes their work, is the conviction that the esthetic purism of symbolism limits the mimetic process of making art as much as its counterpart, naturalism: just as one proscribes realistic representation as the only adequate response to modern reality, the other forbids it.

In the 1930 's, the decisive years for their collaborative philosophical project, Benjamin and Adorno sought to locate their own philosophy firmlly across this division. Their critical essays on literature, music, philosophy and society insist on the necessity of a dialectic between esoteric artistic experiment and historical reallity. In their own work, they confront artistic innovations, from symbolism to surrealism and from the Wagnerian Gesanteunstwerk to atonal music, with the great naturalistic challenge that they found in the economical, social, and psychological explanations of subjective consciousness as developed by Marx and Weber, Freud and Jung. Insofar as they do not accept any preordained limitations to mimesis, their works can be interpreted as a modernization of early Romanticism, as an attempt to recover the unfettered reflexivity of Novalis and Schlegel for the twentieth century. This may also help explain the ongoing renewal of interest in their work, since new topical versions of naturalism (e.g. genetics) and anti-naturalism (e.g. post-structuralism) abound.

In textbooks and compendia, Adorno and Benjamin are often introduced as Marxist philosophers of art, both affiliated with the Frankfurt School's attempts to modemize Marxism, but irreconcilable in their diverging positions towards the mass media. While Benjamin firmly advocated the political relevance of film, photography and other technology-based artforms, Adorno argued that this resulted in a culture industry that set out to standardize and exploit the sensibility of its audience. Faced with this massive exploitation, for Adorno only the most demanding works of art embodied the potential of authentic reflexivity. This information is in itself correct, but offers little help to understand the contradictions that both Benjamin and Adorno sought to interpret. Before the complicated philosophy of their matute work can be grasped, it must be understood that their attempts to combine naturalistic and symbolistic motifs and strategies necessarily remain inconclusive: an absolute synthesis of the two is impossible. Because of this, all their work has an essayistic quality: their aesthetic philosophy consists of heuristic ex- 
periments, in which opposing positions can be defended tentatively and thetotically in order to open up the conceptual and mimetic horizon.

Characteristic for both. Adomo and Benjamin is that they engage symbolistic and naturalistic motives in a dialectic that remains inconclusive. They do not argue towards a synthesis, but demonstrate how specific aesthetic practices include elements that are usually unrecognized because they belong to the opposite tradition: thus symbolism presupposes elements of naturalism, and vice versa. This proves that both positions should be more open to a reciprocal exchange with the opposing camp than their adherents would care to admit. In his essay on "The Work of Art in the Age of Mechanical Reproduction", Benjamin deliberately discusses the artistic relevance of photography in terms of the "aura" of art. He thus employs a mystical, symbolical concept to further the understanding of a technology of visual representation that had opened up many new possibilities of realistic and natutalistic representation. Similarly, Adorno discussed the poetics of Stefan George and Hugo von Hofmannsthal, two of the most prominent symbolists writing in the German language, in terms of literary strategy, the attempt to establish a monopoly, and technical expertise, in direct opposition to the symbolistic ethos."

Benjamin and Adorno developed their aesthetic out of an intimate, absorbing and near-exclusive interest in the artistic canon of their day and age, a canon that was dictated by symbolism. For Benjamin, this was the spiritual world of poetry and philosophy, as exemplified by the works of Kant and Goethe, Hölderlin, Novalis, Schlegel, and Nietzsche. His early education, parts of which he received from private teachers, allowed him to develop his spiritual interests in the apolitical and purely intellectual atmosphere of the Jugendbe wegung, the German "Youth Movement" that sought to rejuvenate German culture by means of a spiritual renewal. Adorno, eleven years younger than Benjamin, lived an equally protected childhood, in an environment saturated with music. His early years were dominated by two musical "mothers", his own mother, a successful singer before her marriage, and her sister, a well-known pianist. Precocious and highly gifted, Adomo combined his gymnasium education with the conservatory, where he studied piano and composition. Only seventeen years old, he went on to university to study philosophy and musicology.

What mattered most to each of them was the idea of a critical renewal of the symbolic potential of art, as demonstrated by symbolism. As Adomo wrote about Benjamin, he was "more indebted to the George Circle than can be noticed on the surface of his philosophical teachings"2. According to Adorno, what Benjamin learned from George was not only a certain ritualization of his own process of writing; ${ }^{3}$ he also derived from George a monumental gesture of philosophical definition, enchanting the forces of history to bring them to a standstill. ${ }^{4}$ Adomo's relation to composer Anold Schönberg shows many parallels to this: he expected from Schönberg's work a renewal of the forces of music, and considered Schon- 
berg's expressionism and his experiments with atonality to be a critical actualization of the great classical and tomantic musical tradition. After finishing his univeresity doctorate, Adorno went to Vienna to study composition with Alban Berg, and was disappointed when he found that there existed no longer a closely knit Sehonberg circle, analogous to the circle around George ${ }^{5}$ The artistic canon of these wo circles remained important to Benjamin and Adorno throughout their life: Goethe, Holderlin, Novalis, Baudelaire, Mallamé in literature; Bach, Beethoven, Schubert, Wagner, Mahler in music. To a certain extent, this canon has become outdated and academic; today, its pretentions of expressing absolute tnuth may well appear to be downright exotic. Now, Benjamin and Adorno are probably studied most often for their insights in the mass media; but they developed those insights by applying the high technical standards of symbolism to them. The conviction that attworks contain an unsurpassable insight in reality remained of crucial importance to them, in their later work no less than in their idealistic youth; in 1936, when their debates focused on the possibility of a politically relevant marxist aesthetic, Adorno wrote in a letter to Benjamin: "I wouldn't know a better program for materialism than that sentence by Mallarmé in which he defines poetry as not inspired, but made out of words." The following sections of this chapter form no exception in the literature on Adomo and Benjamin insofar as they concentrate on those essays and chapters from their work that present critical reflections on mass technology-based art for a mass audience. And yet, those passages form but a small part of their combined work. Benjamin wrote esoteric monographs on early Romanticism, on Goethe's novel "Elective Affinities", and on seventeenth-century German Tragic Drama; Adorno wrote studies on Beethoven, Wagner, Mahler and Berg, as well as on Schönberg and Strawinsky; in studies like these, they developed the critical standard for theit insights in mass entertainment.

Perhaps it is surprising that Adomo's name is linked here to Benjamin's, and not to that of Max Horkheimer, director of the Frankfurt School and, together with Adomo, co-author of its philosophical standard, the "Dialectic of Enlightenment". As a young man, Horkheimer had written blatandy naturalistic novels; Adomo atwrys found his naturalism a refreshing and necessary counterpoint to hils own esoteric symbolism. Adomo has characterized their collabotation accordingly" "Once you [Horkheimer] said to me that I perceived animals as human whereas you saw humans as animals. "There is something to that." But the decisive influence on Adorno's thinking, an influence that lasted from circa 1928 until his death in 1969, came from Benjamin. Adomo was not only Benjamin's first and only philosophical disciple during his lifetime, who immediately taught Benjamin's work in his university lectures; in the great philosophical studies which he wrote towards the end of his life, "Negative Dialectics" and "Aesthetic Theory", he accorded to Benjamin's thinking the highest rank, at least on the same level with such canonized philosophers as Kant and Hegel.s 
During the ten or twelve years of their collaboration, Benjamin worked on his magnum opus, the "Arcades Project". This was an attempt to capture the transformations of mimetic experience during the nineteenth century, in a reflexive conftontation of the poetics of the early Romantics with the material innowations of that century, including Marx"s theory of historical materialism. For Adorno and Benjamin both, this was an attempt to safeguard their cultural tradition from the sweeping current of aggressive racism and nationalism that exploited the same tradition for its own purposes. To them, the nineteenth century was a liminal phase in history: a reflexive understanding of its transforming power would have to result in a new insight in the present. But Benjamin's "Arcades Project" remained unfinished; until the end of his life, Adomo regretted its failure ${ }^{10}$. Only in 1983 was the book published in its incomplete, fragmentary form, proving the extent to which Benjamin succeeded in his wish to unite poetic subjectivity and the concrete effects of modemization in a process of reciprocal representation.

Benjamin's modernization of poetics entails a new attitude towards the iclea of a new mythology. It was no longer to be an original poetic creation, but rather the reflexive recognition of the important new sources of mythology opened up by modernization, by science, industry, and commerce. This of course was the domain of naturalistic conventions: Benjamin meant to demonstrate that these conventions included rich layers of mythical material, that needed only to be critically represented as such to produce the motives for a mythology of modernity. The poetical work of Baudelaire, of the surtealists and Brecht provided him with models for these reflections. Adorno attempted to do something similar in his work as a music critic, but found this harder, since there is no naturalism in classical music that is as straightforward and as explicit as the naturalism in literature and fine art. He took upon himself the task of elaborating a theory of musical representation, which would enable him to reflect upon the mythical strata embedded deeply within the conventions of classical music.

The complete works of Benjamin and Adorno may be studied as a single Gesamteumstwerk, that oscillates between naturalism, including blunt and apodictic statements on the determining grip on subjectivity of political, economical and technological realities, and the most sublimely romantic convictions. Perhaps it is exaggerating to present their work as a renewal of early Romanticism, yet central motifs of their work prove its pervasive influence. When Adorno jots down in one of his notebooks that music in its innermost composition is identical to Christianiry, and that it could be said that there is only as much music as there is Christianity in the world," it isn't hard to see the similarities with Novalis' remark that there is no religion that would not be Christianity. Benjamin's conviction that Marxism should be combined with the interpretative techniques of the Kabbalah, the tradition of Jewish mysticism, is but another example of the reciprocal illu- 
mination of very different intellectual traditions that was also typical of early Romanticism.

Their great philosophical accomplishment has been to hold on to aesthetic reflexivity, while confronting it with the many nanuralistic determinations of modernity. Their essays include countless reflections on economic determinism, especially its marxist variant, technological determinism, especially in the shift from artistic tepresentation to the technological reproduction of cultural products, and on the ideological amalgamations of consumerism and naturalism. This explains why their work contains so many concepts that originate from incommensurable intellectual backgrounds, but are now densely interwoven and made to respond to each other. The greatest relevance of their works may lie in these experiments with reciprocal representation, encompassing a large part of canonic modern literature, the European tradition of musical composition, as well as modern Getman philosophy and sociology, psychoanalysis and historiography. Three aspects of their joint undertaking are presented in this chapter. First, their study of the new methods of technical reproduction, such as photography, the gramophone and radio; that these technologies are understood as an intersection of symbolic mimesis and of industrialization has already been mentioned. A second aspect is their interpretation of the experience of the modern city as a Gesamtkunstwerk, a product of the collaboration of countless engineers, designers, architects, graphic artists and so on, that can in decisive aspects only be experienced aesthetically. However, as Benjamin points out, this collective product is experienced by the individual, in isolated consumption. Because of that, this experience of modernity, where subjectivity is lifted out of traditional environments to hover in suburbs and over highways, mediated by cinema, newspapers and radio, enjoying historically unprecedented possibilities, but also subordinated to unforeseen social pressures, may remain completely inadequate; that is their ultimate explanation of the political catastrophes of fascism, nazism, and of the destructive modernization of antisemitism. A third aspect is their analysis of entertainment as the typical modern aesthetic experience, an experience that claims for itself neither symbolic truth nor realistic veracity, as long as the act of aesthetic consumption offers some immediate satisfaction. Both Adomo and Benjamin withered important ideological implications behind this commodification of fun. These sections lay the groundwork. for a more profound understanding of the poetics of Byrne's work, an attempt to work reflexively in the field of mass media entertainment, sometimes referring to the same intellectual traditions that Adorno and Benjamin sought to include in their aesthetic reflections. 


\section{IMAGINATION TRANSFORMED BY PHOTOGRAPHY}

Benjamin's 1936 essay "The Work of Art in the Age of Mechanical Reproduction" presents a drastic thought experiment in mimesis and reflexivity as twoway processes. The essay combines an preference for the anti-naturalistic, esoteric elements in the reception of works of art, for which Benjamin uses the term "auratic", with an even greater emphasis on the public, anti-esoteric and politically relevant reception of mass reproduced works of art, such as press photos and films. Benjamin used this combination to write an essay that is in many respects a manifesto, written to underscore the political responsibility of mass produced forms of symbolic representation; because of this quality, the essay has become Benjamin's most widely read text.

The argumentative framework of the artwork-essay is relatively clear and simple. It contrasts a traditional, ritual and symbolic aesthetic with a naturalistic perspective, which Benjamin links directly to the need to recognize the cultural and political transformations that have been brought about by technology and industrialization, which in turn, according to Benjamin, requires a socialist and antifascist political stance. This implies that fascism relies on an anti-modernist, ritualistic aesthetic; if it were possible to use the potential of the mass media to dispel that aesthetic, fascist regimes would be unable to fascinate their mass basis.

It is questionable whether there is much historical evidence for this thesis; but the truth of Benjamin's sturdy political claims rather relies on the truth of his more esoteric aesthetic claims; which are: first, that the aura of works of art is a major element of their reception; and second, that factors of modernization might reduce the importance of the aura. It is easy to read the essay as an exptession of faith in the quasi automatic, photomechanical, realistic representation as the means to do away with subjective fantasies and delusions; Benjamin indeed praises photography and film because they have the revolutionary potential to liberate the arts from the domain of beautiful illusion. ${ }^{13}$ But there are also valid reasons to interpret the essay as an attempt to understand the terrain of photographic realism and of scientific naturalism in the terminology of romanticism and symbolism.

Benjamin uses the term 'aura' to define the specific quality of aesthetic experience that is endangered in the age of technical reproduccability. He defines this term as "the unique experience of distance, however close it may be. If, while resting on a summer aftemoon, you follow with your eyes a mountain range on the horizon or a branch which casts its shadow over you, you experience the aura of those mountains, of that branch." 14 The auratic experience as defined here, is the experience of nature's creative primal force as it encompasses both landscape and spectator. We may understand it as a straightforward application of the concept of reciprocal representation, but in a strictly natural, a-historical version. By dispelling the enchanting, auratic quality from our visual experience of reality, so Benjamin 
ventures, photography helps us to open our eyes to the truth of the historical reality that has become at least as much a determining force as nature.

And yet Benjamin had begun his reflections on photography, some rwenty years earlier, by entertaining the idea that to photograph someone is an immoral $\mathrm{act}^{15}$, - probably for the same reason: because photography neglects or diminishes the authentic qualities, the aura of the photographed object. He still entertained such thoughts when he wrote "The Work of Art in the Age of Technical Reproduction", as shown in a quotation from his essay on Franz Kafka: "The invention of motion pictures and the phonograph came in an age of maximum alienation of men from one another, of unpredictably intervening relationships which have become their only ones. Experiments have proved that a man does not recognize his own gait on film or his own voice on the phonograph."16

Benjamin's formulations aim to break open the homogeneity of life and its representations; as such, they fit fully within the romantic tradition that singles out the disenchanting potential of photography and of the scientific and naturalistic approach to the perception of light and colour. Several romantic poets and painters compared the enlightened view of light and colour as a purely mechanical and mathematical phenomenon unfavourably to older artistic and religious views on light as conveying sacred insights and emotions. The debate was held against the background of Newton's explanation of the nature of light as rays of a distinct colour and refrangibility, of which all relevant properties can be calculated. Newton's theory analyzed all colours in terms of a single prismatic law and thus "disenchanted" the sacred rainbow, a symbol that was most often singled out for discussions about the mythical and poetic properties of colour. ${ }^{17}$ Goethe even developed a colour theory of his own, to defend the artistic and auratic perception of colours against Newton's "destructive" theory. In his "Farbenlehre", Goethe dealt mainly with the mediation of colour perception, rather than with the propagation of light that had been Newton's main subject. In a truly romantic manner, Goethe described light and eye as reciprocally depending on each other:

The eye is the last, highest result of light on the onganical body. As a creature of the light, the eye is capable of everything that the light itself is capalsle of. The light transmits the visible to the eye; the cye transmits it to the whole of man. ${ }^{\text {s }}$

According to Goethe, this fundamental mediation of eye and light was an "Urphänomen", a primal phenomenon of original mythical dignity which forms a "link between subjective quality and objective quantity; thus it provides a scientific epistemology bridging the Kantian abyss between phenomena and noumena." 19 Later scientists have pointed out that Goethe introduced physiological premises into the field that had been unduly neglected by Newton's strictly mathematicalmechanical approach, premises which enabled him to prove Newton wrong on several counts where subtle forms of perception were at stake. ${ }^{20}$ 
By insisting that nature and subject presuppose each other in every mediation of perception, Goethe was able to tedefine color as "Taten und Leiden des Lichtes", as light that is both active and acted upon, actions which Goethe inagined to be enclosed in a hermeneutic circle of interpreting and interpreted perceptive phenomena. The interpretation of these perceptions was, for Goethe, a strictly individual question, one that is necessarily decided by prejudice, since expesimentation is unable to get a grip on it. ${ }^{21}$ According to Goethe, artists stood fully within their rights when they declared that for them a specific colour had a specific taste, or a sensation of warmth. In effect, Goethe declared artistic perception per se to be beyond the reach of enlightened scientific criticism.

Such notions of symbolic perception were very dear to Benjamin. How closely Benjamin's ideas on colour and aura are connected to early Romanticism, becomes evident in a whole seties of fragments that he wrote on the aesthetic of colour, for example in a small text on "Reflection in art and in colour":

Colour in its own world is a spiritual reception; hamony: the rainbow. Man can meet it only in the unselfconscious weavings of fantasy. ... Life inside colour is the promise of the childike spinitual world 22

The notion that the human faculty to perceive the aura has a historical development of its own has also been expressed by Novalis. As a recent commentary on "Novalis" transcendental physics and the sidereal man" explains, Novalis used "the perception of light as defining metaphor for the relation of mind and nature, the internal and external worlds. Perception must be educated. The conscious awareness of the senses Novalis explains as light refracting through a mental prism: ... the refractive capacity of mind may increase, but it may also be retarded. Perhaps, Novalis speculates, it is the sickness of the civilization that causes man to lose this prismatic faculty of mind:

Perhaps it is nothing but the sickly constitution of later men, that causes them to lose the capaciry to blend these scattered colours of their mind again, and to teinstate at will the old simple state of nature, or to induce new and manifold connections between them." 2.

Novalis was well aware of the scientific discoveries of his time, discoveries that were to result soon in the invention of photography. He even knew enough about the camera obscura and about photochemistry to describe, in his "Heinrich von Ofterdingen" a scene in which the modern reader should recognize the accurate description of a photographic negative:

All figures were dark here. The air was like an enormous shadow; in the heavens stood a black radiant body. One could distinguish everything with the greatest clarity, since every figure presented a different tinge of black, and threw a bright shine after itself; light and shadow seemed to have switched their roles here. ${ }^{24}$ 
In "Heintich von Ofterdingen", this description is part of a complex fairy-tale, Novalis" symbolic transformation of his poetical theory of light. It may perhaps be summarized in a formula: for Novalis, "There is a reciprocity of two energies: the energy of nature that beams on man, the energy of man that shines on nature." 25

When a photographic camera intervenes between human perception and nature, it mediates between what Novalis called the energy of nature and the energy of man. The strange distance to its object that we perceive when we look at a photographic image may help us to gain a better understanding of its formal properties: that is the aesthetic potential of technology. The blue flower was Novalis" preferred symbol for the infinite; Benjamin once called photography "the blue flower in the land of technology" 26.

Where Goethe emphasized the absolute independence of artistic intuition in a manner that would later be exploited by the anti-naturalistic symbolists, the early Romantics (and Benjamin) insisted that artistic intuition is not beyond mediation, and also not beyond critical reflection. In his study on the early Romantic's concept of criticism, Benjamin quoted Friedrich Schlegel, who drew on an analogy with light to clarify the medial nature of the absolute:

The idea of the ' $Y$ ' ... is to be regarded ... as the inner light of all ideas. All ideas ate only the re tacted color images of this inner light. In every idea the 'T' is the hidden light; in each thought, one finds oneself. ${ }^{27}$

Further on, Benjamin also quotes Novalis' designations of wit as a "magical color show in the higher spheres", and "the external lightning-flash of the imagination." 28

Benjamin's thesis that modernity should result in a decline of the aura has to be interpreted as an extrapolation of these early Romantic suggestions: press photography and cinema should be making a contributions to a wittier mass audience, an audience that is open to expert reflections on the many ways in which the conditions of its own life are mediated by technology and economy, and therefore able to respond politically to these mediations. He must have been fully aware that this was not a historical prediction, but rather a prophetic and mystical claim on history: he asks of photography that it help to construct an adequate vision of contemporary reality.

Two completely different uses of photography should be combined in this respect. One is the production of new perspectives on empirical reality: from aerial photography to microscopic shots, from social reportage to X-ray photos; photography should demonstrate with the greatest possible clarity how, in the 20 th century, human subjectivity is irrevocably mediated by social and technological innovations. The other is the actualization of the entire tradition of the arts through photographic documentation and reproduction, bringing the sanctified results of 
the art history of the entire world within teach of everyone. To make way for a new mythology, one must first of all be able to understand the old ones better.

What Benjamin effectively demands of photography (and, extrapolating, of fim), is that its images become philosophical, reflecting their own historical aesthetic: allegories of their own symbolical qualities. This is what he means by the term "dialectical image": "The dialectical image is that form of the historical object which satisfies Goethe's requirements for the object of analysis: to exhibit a genuine synthesis. It is the primal phenomenon of history." 29

This photography of the historical transformation of subjectivity, or "dialectical image", is Benjamin's version of the Novalis' "intellectual intuition". It is an intuition that has been updated and made accessible to technology, so that it may become massureproduced and easily accessible instead of esoteric and idiosyncratic. The importance of this accessibility lies in the new potential for critical reflexivity; Benjamin postulates that the modern, technological artwork may be judged, or "tested" as he writes, by audiences made up of millions of spectators, introducing a new sociological and political dimension to the reflexivity that is the medium of art.

The technical possibilities of montage that photography and film offered might help to realize the idea of the Gesamthmstmerk in an historically adequate way, by ending the isolation of the creative individual within his own artistic ritualization. Benjamin had outlined the problems this might pose to creative endeavours: "For the creative person, the medium surtounding his work is so dense that he may find himself unable to penetrate it directly in terms of the response that it requires from its public; he may be able to penetrate it only in an indirect manner. The composet might perhaps see his music, the painter heat his picture, of the poet feel the outline of his poem when he seelss to come as close to it as possible." 30 But this presupposed, of course, that photography and film themselves were not turned into sources of a ritualized, anti-reflexive aesthetic. Benjamin knew very well that most film directors and actors claimed their private, mythical reservoir of creativity, yet insisted that in modern technological society, this was both dangerous and unnecessary.

Benjamin atgued that capitalist industrialization in general had not brought the disenchantment of reality in all its aspects that so many romantics had feared. "To the contrary, it had resulted in a reactivation of mythic powers, of which fascism was the culmination. In "The Work of Art in the Age of Mechanical Reproduction", he postulated that art might undo this mythical disguise of historical reality. In fact, his artwork-essay was but a small part of a greater project, a spin-off from his magnum opus, "The Arcades Project". In that book, Benjamin tried to describe the new ritualization of daily life that had been the result of modernization, to capture the transformations of mimetic experience during the nineteenth century, which was to him the century of modernization. ${ }^{31}$ 


\section{THE MODERN CAPITAL AS A MONTAGE OF MYTHICAL IMAGES}

Benjamin's major study, the uncompleted "Arcades Project", was an attempt to fathom the transformations of art, understood as the medium of subjecvivity and reflexivity, under the influences of modern history: capitalism, industrialization and developing technologies. The "Arcades Project" focuses on Paris; "the Capital of the Nineteenth Century" as Benjamin liked to call it: 'capital" in the threefold ambiguous sense of rule of finance, seat of government, and capital of the arts. Benjamin found all this embodied especially in the Parisian passages, the glass-roofed shopping arcades (forenunners of the department store and the shopping mall), where visitors found themselves surrounded by the latest fashions in clothes and furniture, lighting design, mirrors, advertising, iron construction, as well as by countless other visitors. He liked to consider the arcades as a microcosmos of the nineteenth century, a laboratory where subjectivity found itself reflected in new forms, new media. As a medium for new experiences, with an unprecedented capacity for montage, the arcades may be compared to the cinema and the illustrated press that were the subject of Benjamin's artwork-essay. According to the early Romantic insight that human imagination can synthesize the most heterogeneous realms, and Schlegel"s dictum "we cannot deny that everything is in us ... we are only a part of ourselves" ${ }^{32}$, it is obvious that this amounts to a new form of aesthetic experience. Benjamin referred to the arcades as "the theater of all my struggles and all my ideas", "a world of secret affinities", a "magic encyclopedia" 33 . Yet he expressly did not want to present an exclusively poetic view of nineteenth-century Paris, but a philosophical and methodical critique, a theory that would help to understand the historical development. Benjamin outlined the modernization of aesthetic experience as follows:

From a Europen perspective, things looked this way: In all areas of production, from the Middle Ages until the beginning of the nimeteenth century, the development of technology proceeded at a much slower rate than the development of art. Art could take its time in variously assimilating the nechnological modes of operation. But the transfomation of things that set in around 1800 dictated the tempo to art, and the more breathtaking this tempo became, the more readily the dominion of fashion overspread all fields. Finally, we arrive at the present state of things: the possibility now atrises that art will no longer find time to adapt somchow to technological processes. ${ }^{34}$

Benjamin sketches a world where tradition no longer provides an adequate orientation. This implied that he too had to be especially careful to develop his a valid form of historical interpretation.

Benjamin characterized his method as a Copernican revolution of historical perception. "Copernican revolution" was Kant's preferred expression for his epistemological grounding of scientific objectivity in the depths of the subject. Benjamin considered his historiographical method as a parallel to Kant's work in the 
realm of the humanities ${ }^{35}$; it is an application of Novalis' and Schlegel's aesthetic tum to history. Just as knowing an artwork means experiencing the work personally, making it a part of one's own experience by allowing oneself be transformed by the work, so according to Benjamin history can be known only insofar as it has become a part of one's own experience. ${ }^{36}$ This amounts to a most demanding hermeneutics of history. One has to consider its presuppositions with great care; without them, this "Copernican turn" may easily revert to subjective arbitrariness and to despotic historical claims.

Benjamin's methodical presuppositions can be summatized in three steps. To begin with, every historical actor bases his actions on a perception of reality, which is grounded in aesthetic activity. As such, it is inevitably chaotic and mythological. It may be more or less reflexive and developed, but always remains provisional. Equally important is that this is also true of the historian. Interpretations of the past can never presume to be a true reenactment of the perceptions of past actors, grounded as they are in the prejudices of the present. The historian should attempt to turn this bias into an advantage. As a fundamental part of historical method, the question must be answered what relevance the past holds for the present; in other words, which contemporary myths the past may help to dispel. Writing history thus means: employing the past as a reciprocal representation of the present, in order to reflect and develop the present perception of reality, finally: its poiesis.

These methodological reflections are similar to the hermeneutical considerations of every self-critical modern historiographer. But what distinguishes Benjamin's philosophy of history is his emphasis on the early Romantic aesthetic as its main foundation. Paris, capital of nineteenth-century modernity, is for Benjamin. an enormous Gesamtkunstwerk, producing new dreams and myths for its inhabitants. But no spectator is completely free to experience the city as an artwork, since the forces that have built it, filled it with merchandise and consumers, rule incessantly. Both aspects collide in the arcades, where shop windows full of luxuties and novelties fill each passer-by with dreams of a better existence. These dreams are solitary, as is every decision to buy a luxury item, to follow a fashion, take part in a fad, in order to create a better life; and yet these dreams are determined by collective, industrial and technological mechanisms. In its published form, "The Arcades Project" challenges the reader to consider the thousands of quotations and comments from this double perspective: to understand individual, auratic responses to the city as conditioned by the general forces of modernity, and simultaneously to understand that these mechanisms also presuppose the individual capacity for mythical, dreamlike experience and could not function without them. Once again, Benjamin emphasizes the necessity to combine a poetical, symbolist perspective on history with a naturalistic, theoretical approach. 
The poetical perspective demands that every historical subject is presented as a unique personality, with its own aesthetic and mimetic flux. Consequently, Benjamin presented the history of nineteenth-century Paris as an accumulation of personal, subjective, even idiosynctatic experiences of that city. He gave pride of place to the poets: first Baudelaire (excerpts from his work form more than twenty percent of Benjamin's material), then Hugo, Balzac, Sue and many others. The works of utopian socialists and speculative thinkers like Fourier, Saint-Simon and Blanqui, based on utopian dreams and fantasies, were comparable to those of poets, and were as such inchided by Benjamin. Added are painters (Courbet, Wiertz, Redon), photographers (Nadar) and caricaturists (Daumier, Grandville). On principle, Benjamin accepts facts and insights only as valid historical sources when they have been digested by the individual experience of contemporary witnesses: Ultimately, this should result in the rescue in the medium of history of the unique aesthetic qualities of every individual human being who has ever walked the earth. Benjamin was fully awate of the practical impossibility of this truly Messianic task, yet refused to lower his standards.37

At the same time, Benjamin knew very well that modern life demands an intricate division of labour, identifying people with roles and characters that are conditioned by the most specific social functions: from schoolboy to stockbroker, from sales clerk to collector, prostitute, conspirator, dry nurse, or seller of countermarks. ${ }^{38}$ Paris also offered many ready-made artistic styles and exoticisms for the stylization of experience; Benjamin saw in the profusion of artistic neo-styles (neoclassicism, neo-gothic, neo-renaissance, neo-baroque) and exoticisms (chinoiserie, japonaiserie, the so-called "Indian Gothic", etcetera) a "passion for masks", and writes: "It is here [...] that the "critique" on the nineteenth century - to say it in one word - ought to begin." Underneath the most personall and idiosyncratic expressions, Benjamin wants to perceive the general, collective traits. He expressed this methodological tesolution in an image: "Comparison of the human being with an instrument panel on which are thousands of electric bulbs. Some of them go out at one moment, some at another, <and > come back on again, ${ }^{340}$

Benjamin identified his oscillating position as a writer of history with Friedrich Schlegel's notion that "The historian is a prophet turned backwards." "11 To take the position of a prophet in aesthetical matters means: to base one's work on avant-gardist premises, and that was indeed Benjamin's purpose. He wanted "To encompass both Breton and Le Corbusier - that would mean drawing the spirit of contemporary France like a bow, with which knowledge shoots the moment in the heart." 42 Le Corbusier, a figurehead of modernism, had proposed to erase most of the center of Paris, a center he perceived as outmoded and cluttered, in order to replace its historical buildings by radiant and "rational" skyscrapers. ${ }^{43}$ On the other hand, Breton and Aragon, leaders of the Surtealists, were according to 
Benjamin "the first to perceive the revolutionary energies that appear in the "outmoded' ... by treating the nineteenth century world of things as if it were a world of dreamed things." 44 . The surrealists combined an insight in the chaotic nature of human aesthetic experience with concepts from Marx and Freud. Benjamin's own aesthetic position was in some respects comparable. In his "Arcades Project", he experimented with a philosophy of history that encompassed Marx and Jung: he wanted to combine their insights to illuminate the collective and mythological aspects of modernity.

For this purpose, a valid interpretation of the mythology of the present is crucial; this has occupied Benjamin throughout his work. Already in 1921 he wrote some fragmentary notes for himself about "Capitalism as Religion", remarking that:

A religion may be discemed in capitalism-that is to say, capitalism serves essentially to allay the same anxieties, torments, and disturbances to which the so-called religions offered answers. ...

Capitalism is the celebration of a cult sans rêtye et sans nerwi [without dream or mercy] Therce are no "weekdays." There is no day that is not a feast day, in the terrible sense that all its sacred pomp is unfolded before us; each day commands the utter fealy of each worshiper...

It adds to our understanding of capitalism as a religion to realize that, to begin with, the first heathens certainly did not believe that religion served a "higher," "moral" interest but that it was severely practical. In orher words, religion did not achieve any greater clatity then about its "ideal" or "transcendental" nature than modern capitalism does today. ${ }^{45}$

Some years later, Benjamin commented as follows on the difficulties that consumption presents for an aesthetic philosophy:

Today the most real, mercantile gaze into the heart of things is the advertisement. It tears down the stage upon which contemplation moved, and all but hits us between the eyes with things as a cat, growing to gigantic proportions, careens at us out of a film screen. And just as the film does not present furniture and façades in completed forms for critical inspection, their insistent, jerky nearness alone being sensational, the genuine advertisement hurls things at us with the tempo of a good film. "Thereby "matter-of-factness" is finally dispatched, and in the face of the huge images storead across the walls of houses, where toothpaste and cosmetics lie handy for giants, sentmentality is restored to health and liberated in American style, just as people whom nothing mowes or touches any longer are taught to cry again by films. For the man in the street, howewer, it is money that affects him in this way, brings him into perceived contact with things. ${ }^{46}$

For his "Arcades Project", Benjamin tried to deal with these questions by juxtaposing two authors of special methodological relevance for matters of mythology and capitalism: Jung and Marx. ${ }^{47}$ Benjamin chose to set up the stage for his historical experiment by attempting a reciprocal representation of two diametrically opposed theories of history: the Jungian and the Marxist. Jung treats history as flowing from an eternal source, human nature, with its collective unconscious repertoire of archetypal mental patterns. Marx, on the other hand, conceptualizes his- 
tory as a profound transformation of all aspects of life, driven by the ongoing development of the capitalistic economy that revolutionizes the capacity to exploit nature. Benjamin's plan to let the theories of Marx and Jung reciprocally illuminate each other implies that he has to uncover a mythical and archetypical layer in the Marxist analysis of capitalism; and on the reverse side, that he has to conceptualize the profound transformation of archetypes that is wrought by economical and historical developments.

As Benjamin knew, both theories must undergo a drastic transformation in this dialectical confrontation: Jung's analytical psychology must be transformed by a Marxist interpretation, and Marx's theory of capitalism is reciprocally transformed by the insistence that it must be founded on an aesthetic which may account for man's mythological propensities. Benjamin hoped that these corresponding transformations would yield the philosophical framework for his own theorizing on the properties of art in modern times; a framework that was also used, with some slight modifications, by Adorno in his work on the culture industry, the twentiethcentury mass-produced artworks, made to measure for mass consumption. ${ }^{48}$

As has been sketched in chapter 6 , Jung developed the concept of the collective unconscious as a common human repertoire of archerypes. This repertoire helps to shape the psychic energy of every individual, and thereby may help it to find its putpose in every phase of life. Although Jung was well aware that such patterns of energy and enthusiasm are also conditioned by the individual's historical surroundings, he never developed a specific theory of psychic life that included this cultural conditioning. This was the theme Benjamin wished to develop, "the dissolution of 'mythology' into the space of history." "49 He was particularly interested in the ways in which archetypes are mediated by the history of technology:

Only a thoughtless observer can deny that correspondences come into play berween the world of modern technology and the archaic symbol-world of mythology. Of course, initially the technologicatly new seems nothing more than that. But in the very next childhood memory, its traits are already altered. Every childhood achieves something great and irreplaceable for humanity. By the interest it takes in technological phenomena, by the curiosity it displays before any sort of invencion or maehinery, every cliddhood binds the accomplishments of technology to the old worlds of symbol. There is mothing in the realm of nature that from the outset would be exempt from such a bond. Only, it takes torm not in the auta of novelty but in the auta of the habitual. In memory, childhood, and dream.

On the other side of this confrontation, Marx explained how, ever since the late Middle Ages, capitalism has been the motor of a permanent process of transformation that encompasses the economy, technology and social relations as well as individual perceptions. In his philosophy of history, Marx insisted that capitalism evolves according to its own inherent economic laws, independent of subjective experience. He considers individual convictions to be superficial epiphenomena, seeing how reality is determined by economical relationships that surpass anyone's 
personal consciousness. As a result of this perspective, Marx's later philosophy has strong positivistic and deterministic traits, evident in his conviction that history is governed by economical laws (as explained by Marx in "Capital"), laws that must inexorably lead to the demise of capiralism and the ensuing birth of communism. By and large, according to Marx, the economic basis of any given society determines its cultural superstructure; once the laws that govern the basis are transparent, the interpretation of the superstructure therefore loses most of its relevance; most of it is simply ideological window-dressing to cover up the stark. reality of economic exploitation.

By confronting Marx with Jung, Benjamin demonstrated that capitalism had transformed the role of mythology, not done away with it. He wanted to reinstate consciousness in its pivotal historical role, highlighting the indispensable role of mythical consciousness for the capitalist development. According to Benjamin, "Capitalism was a natural phenomenon with which a new dream-filled sleep came over Europe, and, through it, a reactivation of mythic forces." 51 He quoted from Marx's early writings: "Our election cry must be: reform of consciousness not through dogmas, but through the analysis of mystical consciousness that is unclear to itself, whether it appears in a religious or a political form. Then people will see that the world has long possessed the dream of a thing - and that it only needs to possess the consciousness of this thing in order to really possess it." ${ }^{2}$ All in all, Benjamin's intention was to demonstrate that myths play a role in the heart of capitalism, and that the patterns for personal experience that capitalism generated moulded archetypal images into shapes that were without historical precedent.

With regard to Marxism, this amounts to a fundamental rethinking of some of its central tenets. Most relevant for Benjamin were Marx' insights in the mythological qualities of capitalism, as expressed in the Communist Manifesto of 1848: "Modern bourgeois society with its relations of production, of exchange and of property, a society that has conjured up such gigantic means of production and exchange, is like the sorcerer, who is no longer able to control the powers of the nether world whom he has called up by his spells. ${ }^{. \% 3} 53$ "This mythical quallity is most manifest, according to Marx, in the commodification of all products and of every human relationship. Benjamin quotes a commentary on Marx' "Capital":

"A commodity appears, at first sight, to be a trivial and easily understood thing. Our analysis shows that, in reality, it is a vexed and complicated thing, abounding in metaphysical subtleties and theological niceties." Cut off from the will of man, it alligns itself in a mysterious hierarchy, develops or declines exchangeability, and, in accordance with its own peculiar laws, performs as an actor on a phantom stage. In the language of the commodities exchange, cotton "soars," copper "slumps," com "is active," coall 'is sluggish,' wheat 'is on the road to recovery," and petroleum 'displays a healthy" trend.' Things have gained autonomy, and they take on human features... The commodity has been transformed into an idol that, although the product of human hands, disposes over the human. Marx speaks of the fetish chanacter of the commodity. "This fetish character of the commodity world has its origin in the peculiar social character of the labor that produces commodities... It is only the par- 
vecular social relation berween people that here assumes, in the eyes of these people, the phantasmagorical form of a telation between things. 54

But Benjamin is wary of Marx" tendency to present his own philosophy as an insight in history that stands apart from all mythologies, thanks to its insight in the material essence of society. He criticizes this absolutist aspect of Marxism. It is exactly where Marxism pretends to have access to a ttuth beyond all myth and aesthetic, where it is nothing but a deterministic naturalism, that it becomes mythical itself, so that its dialectical equipment for economic-historical analysis takes on the character of a new theology. 55 Instead of always falling back on its automatic reflexes (histonical and economical determinism), Benjamin thought that the analysis of capitalism has to admit that the analysis of myths is of crucial importance. He argued for a thotough transformation of the Maxist doctrine which maintains that "in the final analysis" the economic infrastructure of any given society determ mines that society's cultural superstructure:

On the doctuine of ideological superstructure ... The economic conditions under which society exists are expressed in the superstructure-precisely as, with the sleeper, an overfull stomach finds not its reflection but its expression in the contents of drearns, which, from a causal point of view, it may be said to "condition". "The collective, from the first, expresses the conditions of its life. These find their exptession in the dream and their interpretation in the awakening. ${ }^{56}$

In his first sketches for the Arcades Project, Benjamin formulated this more directly: "Didn"t Marx teach that the bourgeoisie, as class, can never arrive at a perfectly clear awareness of itself? And if this is the case, isn't one justified in annexing to Marx' thesis the idea of the dream collective (that is, the bourgeois collective)?" He continued: "Wouldn't it be possible, furthermore, to show how the whole set of issues with which this project is concerned is illuminated in the process of the proletariat's becoming conscious of itselp?"57 In effect, Benjamin is thus shifting the basis of Marx' philosophy, replacing its essentialist materialism with a theory of capitalist poiesis, reclaiming a central position for aesthetic experience:

The nincterith century [is] a spacetime [Zeitrasm] (a dreamtime [Zeit-tratw]) in which the individual consciousness more and more secures itself in treflecting, while the collective consciousness sinks into ever deeper sleep. But just as the slecper-in this respect like the madman-sets out on the macrocosmic journey through his own body, and the noises and feelings of his insides, such as blood pressure, intestinal chum, heartbeat, and muscle sensations (which for the waking and salubrious individual converge in a steady surge of health) generate, in the extravagandy heightened inner awareness of the sleeper, illusion or dream imagery which translates and accounts for them, so likewise fot the dreaming collective, which, through the arcades, communes with its own insides. We must follow in its wake so as to expound the mineteenth century-in fashion and advertising, in building and politics - as the outcome of its dream visions. ${ }^{\text {sis }}$ 
Naturally this confrontation of Marx and Jung, in the form of a reciprocal representation, implies an equally drastic shift in the doctrines of Jung. According to Benjamin, the collective unconscious has to be transferred from the timelessness of nature to the historical space of human societies.

It is one of the tacit suppositions of psychoanalysis that the clear-cut ancithesis of sleeping and waking has no value for determining the empincal form of consciousness of the human being but instead yields before an unending vatiety of concrete states of consciousness conditioned by every concervable level of wakefulness within all possible centers. The situation of consciousness as pat temed and checkered by sleep and waking need only be transferred from the individual to the collectiwe. Of course, much that is external to the former is internal to the latter: architecture, fashionyes, even the weather-are, in the interior of the collective, what the sensoria of organs, the feelings of sickness or health, are inside the individual. And so long as they preserve this unconscions, amotphous dream configuration, they are as much natural processes as digestion, breathing, and the like. They stand in the cycle of the eternally selfsame, until the collective seizes upon them in politics and history emerges $5 \%$

This means that the mythicall expression of archetypes is guided by, amongst others, economic factors. Benjamin clearly saw the naivety of Jung's approach to the problems of their own present, especially to the National-Socialist movement that had come to power in Germany. He quoted. Enst Bloch, who considered Jung to be the fascist counterpart to Freud: "Very interesting ... how the fascistization of science had to alter precisely those elements in Freud which still stem from the enlightened, materialistic period of the bourgeoisic... In Jung,... the unconscious... is no longer individual - that is, not an acquired condition in the single... human being, but a stock of primal humanity renewing itself in the present; it is not repression but fruitful teturn." "ro

But Benjamin was also aware of the positive potential of theory of the collective unconscious, and wished to rescue that potential for his philosophy. In his "Theses on the Concept of History", he wrote that the small, spiritual things are always present in history, even when it is seen under the aspect of the class struggle. These "small, spiritual things" are not so different from Jung's "archetypal energies"; Benjamin describes them as "manifest... as courage, humor, cunning, and fortitude". 61 "The task which Benjamin set for himself in the "Arcades Project" was to write the history of the nineteenth century in terms of its mythical existence, or more precise: in terms of the capitalist disposition of archetypal energies.

The momentum of primal history in the past is no longer masked, as it used to be, by the tradition of church and family-this at once the consequence and condition of technology. The old prehistoric dread already envelops the world of our parents because we ourselves ate no longer bound to this world by tradition. The perceptual worlds [Merkwelien] break up more rapidly; what they con tain of the mythic comes more quickly and more brutally to the fore; and aholly different perceptual world must be speedily set up to oppose it. This is how the accelerated tempo of technology appears in the light of the primal history of the present. ${ }^{2}$ 
In a methodical reflection on his plan to write a "primal history of the nineteenth century", Benjamin emphasized that this plan "would be of no interest if it were understood to mean that forms of primal history are to be recovered among the inventory of the nineteenth century. Only where the nineteenth century would be presented as originary form of primal history-in a form, that is to say, in which the whole of primal history groups itself anew in images appropriate to that century - only there does the concept of a primall history of the nineteenth century have meaning."6s

Benjamin has not been able to complete his "Arcades project", and the published material is too rich and heterogeneous to be summarized in a single conclusion. But all his critical reflections on the condition of poiesis and aesthetics in the age of modem capitalism point to a condition in which not just the creative artist, but every individual is surrounded by a dense medium of fragmentary interpretations that no one can penetrate directly and completely. Even stubbom and repeated experimental attempts at reflection, such as Benjamin's own attempts, can succeed only partially.

\section{THE INDUSTRIAL PRODUCTION OF FUN}

Benjamin and Adorno both explored the implications of the film aesthetic, of the technological possibility to evoke a mythology, to unify the experiences of the senses in a single ecstatic interpretation of reality. Benjamin mostly emphasized the liberating potential of this thoroughly modern artform, whereas Adorno mainly investigated the manipulative aesthetic that was developed by the industries of film and television. Both approaches are best read in combination.

Benjamin saw in film an answer to his fear that art might no longer find the time to adapt to technological processes: the technological process that itself has become an artform. Among his many notes for the "Arcades Project" is this one: "Film: unfolding of all the forms of perception, the tempos and thythms, which lie preformed in today"s machines, such that all problems of contemporary art find their definirive formulation only in the context of film." For Benjamin, film was the artform that might be able to represent reality to a mass audience with all the interpretative reflexivity that his aesthetic required. Speculating, he pointed at a cortespondence between the film strip and the conveyor belt ${ }^{65}$ : as one speeded up production, the other should give new strength to aesthetic interpretation. The capacity of film for detailed and realistic representation of an individual within his environment, combined with the possibilities of montage with other individual realities, and finally the projection of films in front of large and scattered audiences: all that combined to form a technologically strengthened aesthetic that would be able to answer every demand of Benjamin's hermeneutic of modernization. Film, then, is the answer to Novalis' complaint that "we lack an electrical and 
magnetic and galvanic eye and ear", the fulfilment of his wish that "all the senses should become eyes. Telescopes." Benjamin wrote about the new synthesis of apperception through the film cameta: "Within the enlargement, space is stretched out; within slow motion, movement expands. ... Through it we first experience an optical unconscious, as in psychoanalysis we first experience the instinctual unconscious." 67

Benjamin's theory of film stresses film's ability to destroy traditional perceptions. He quotes Abel Gance: "Shakespeare, Rembrandt, Beethoven will make films... all legends, all mythologies and all myths, all founders of religion, and the very religions... await their exposed resurrection" and concludes that film aims at the all-embracing liquidation of cultural myths. ${ }^{68}$ In his "Arcades Project", Benjamin comes up with a similar comparison of his own making: "Isn't it an affront to Goethe to make a film of Faust, and isn't there a world of difference between the poem Faust and the film Faust? Yes, certainly. But, again, isn't there a whole world of difference between a bad film of Fatst and a good one? What matter are never the "great" but only the dialectical contrasts, which often seem indistinguishable from nuances. It is nonetheless from them that life is always born anew." "69

Such statements make clear what Benjamin asked of film: to present the combined myths and rituals of Western civilization, in order that a mass audience may decide for itself which of these are useful and fruitful for the present. Benjamin accepts, at least in his Artwork-essay, that this decision will be taken strictly on superficial grounds, as a test that is answered in a condition of distracted superficiality. In the wider context of the "Arcades Project", Benjamin elaborates on the political significance of film:

At no point in time, no matter how utopian, will anyone win the masses over to a higher art; they can be won ovet only to one nearee to them. And the difficulty consists precisely in finding a form for art such that, with the best conscience in the world, one could hold that it is a higher att. 'This will never happen with most of what is propagated by the avant-garde of the bourgeoisic....

The masses positively require from the work of att (which, for them, has its place in the circle of consumer items) something that is warming. Here the flame most reaclily kindled is that of hatred. Its hear, however, burns or sears without providing the "heart's ease" which qualifies art for consumption. Kitsch, on the other hand, is nothing mote than art with a 100 percent, absolute and instantaneous avallability for consumption. Precisely within the consecrated forms of expression, therefore, kitsch and art stand irreconcilably opposed. But for developing, liwing forms, what matters is that they have within them something strrting, useful, wltumately heattening -- that they take "kitsch" dialectically up into themselves, and hence bring themselves near to the masses while yet surmounting the kitsch. Today, perhaps, film alone is equal to this task — ot, at any rate, more ready for it than any other art form. ${ }^{70}$ 
Benjamin's hope is that films can illuminate those effects of modemization which historical experience has not been able to cligest; it should, so to speak, update the collective unconscious."

Adorno, reflecting critically on Benjamin's formulations, emphasizes time and again that films may confirm their audiences in their stereotypical worldview, instead of helping them to revise those stereotypes. Benjamin knew well enough that filmmaking is generally ruled by the demand that invested capital should be guaranteed to return a profit, and duly qualified his hopes for formal experiments with filmmaking ${ }^{2}$. But Adomo, who lived near Hollywood during World War II and had many acquaintances who worked for the film industry, insisted that as long as film and television are nled by financial interests, going to the movies does not result in any form of critical enlightenment, let alone in an insight in the collective unconscious of modernization. He underlined that the ways in which Benjamin had supposed that mass audiences could assimilate films, exhibition and testing, ate categories that ate themselves imbricated with the commodity character that Benjamin wished to oppose. ${ }^{73}$

In response, Adorno sketched the outline of a theory that describes the effect of commercial cinema as "psychoanalysis in reverse"74. Films ought to help the spectator to reflect on unconscious motives, but commercial films are so structured that they sooner accomplish the reverse, addressing the infantile aspects of the spectators, thus producing "regression managed on an industrial scale"75:

Somehow the psychoamalytic concept of a multilayered personality has been taken up by cultural industry, and ... the concept is used in order to ensnate the consumer as completely as possible and in order to engage him psychodynamically in the service of premeditated effects. A clear-cut division into allowed gratifications, forbidden gratifications, and recurrence of the forbidden gratifications in a somewhat modified and deflected form is carried through. ${ }^{76}$

Filim provides models for collective behaviour [that] inheres in the innermost elements of film. The movements which the film represents are mimetic impulses which, prior to all content and meaning incite the wewers and listeners to fall into step as if in a parade. ${ }^{7}$

Many commentators have concluded that Adorno found nothing of true value in films and other mass media. ${ }^{78}$ But that is way too simplistic. Adorno knew that "vestiges of the aesthetic claim to be something autonomous, a world unto itself, remain even within the most trivial product of mass culture." 79 It is true that Adorno did not carefully interpret individual films in detail, something that would have been indispensable to understand the complex interaction of the many mimetic impulses and forces in even a simple film. Instead, he insisted on the respect for the reflective and mimetic faculties of the spectator, a respect he found categorically missing in commercial films.

According to Adorno, commercial entertainment is geared to provide fun without reciprocal reflexivity. It elaborates stereotypical scenario's that address 
only generally recognized fears and desires, and exclude most acknowledgement of more contradictory and heterogeneous mimetic impulses. In the fragmentaty chapter on the culture industry in "Dialectic of Enlightenment", Adomo used the symbolical expression "fun is a medicinal bath". The original words, "Fun ist ein Stahlbad", reverberate with the expression "Krieg ist ein Stahlbad", "war is a medicinal bath", one of the attempts of (pre)nazi German poets to represent the modern battlefield as a mythical renovation and celebration of the deepest layers of human mature. Fun is medicinal insofar as it excludes worrying about the experience of the loser, the outsider, the morally reproachable, the weak, reserving mimetic spontaneity for generally approved models. In that way, entertainment excludes both the disillusions of naturalism and the formal experimentation of early Romanticism: its highly stylized products remain in a neutral, turbid position.

There are, of course, exceptions: Charlie Chaplin, for example. In Benjamin's early Romantic terminology: "Chaplin is most emphatically not the actor or the stat... he is the poet of his films." ${ }^{30}$ In his Artwork-essay, Benjamin used the enormous popular success of Chaplin's films as proof for his inkling that film might find a mass audience receptive to the interpretative labour that he saw as a necessity for an understanding of labyrinth of modernity. "What is new in Chaplin's gestures: He breaks apart human motions of expression into a series of the smallest innervations. Every single one of his movements is put together from a series of hacked-up pieces of motion. Whether one focuses on his walk, on the way he handles his cane, or tips his hat-it is always the same jerky sequence of the smallest motions which raises the law of the filmic sequence of images to that of human motor actions." 82

Adorno wrote twice about Chaplin. First in 1930, when he compared Chaplin's tramp to a strikingly similar passage he had found in Kierkegaard; Adorno used the similarity to portray Chaplin as a truly auratic artist. ${ }^{83} \mathrm{Later}$, he wrote a newspaper portrait of Chaplin, congratulating him on the occasion of his 75 th birthday. He prizes Chaplin as a man with an all-encompassing mimetic capacity, always playing, always performing. In real life, Adorno wrote, Chaplin is not the vagabond clown, but an unusually powerful actor: not the sacrifice, but its very opposite. The innocence of his screen character is the product, in Adomo's analysis, of his capability to project his violent and dominating presence; only through this projection of his culpability, his innocence is produced: he is "a royal tiger turned vegetarian". Adorno lavishes his highest praise on Chaplin, naming him one who is capable to return the very principle of rationality into mimetic forms of response, thereby producing an atonement of the violence with which rationality often reptesses mimesis.

He finishes his portrait by telling an anecdote about meeting Chaplin at a party in Malibu. There, Adomo unthinkingly tried to shake hands with a man who had lost both hands in the war. Touching an iron claw instead of a living hand, he felt 
a shock of hortor, a shock he did not want to show to this man: so he turned his face of shock within a second into a gtimace of politeness-a politeness that must have been hotrible to the mutilated man, as Adomo notes. Directly after this handshake, Chaplin imitated Adorno's performance, rescuing him by transforming the horitor into laughter.

Such tutning points, where an inadequate interpretation is turned around, were what Adorno and Benjamin looked for in film and other mass media. By emphati-

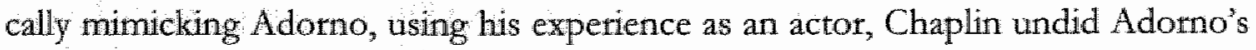
involuntary faux pas. The company, including the amputated man, was set free to see Adomo's mistake for what it was: a sequence of unthinking gestures, an inadequate response to a painful reality. In such instants, the juxtaposition of different mimetic instances may provoke a new illumination of the undetlying perceptive ritualls. As Benjamin once wrote: "Chaplin has become the greatest comic because he has incorporated into himself the deepest fears of his contemporaries." Such instances of performance allow the spectator to renew himself, to refresh the insight in the mimetic conventions that structure the perception of reality.

\section{THE MODERNIZATION OF MIMETIC EXPERIENCE}

The relevance of the aesthetic phillosophy of Benjamin and Adorno for the present must be found in their attempt to understand the modernization of mimetic experience. They held that modernity, with its unprecedented deployment of technological forces, has an enormous potential for the concrete realization of man's dreams and myths, by bringing out to the full the individual's capacities for neciprocal representation. But they found that the processes of modernization of ten isolate the individual from the surrounding society and from nature, resulting in a diminished capacity for mimetic exchange and in a regression of the subject's readiness to reflect consciously on its own aesthetic and historical disposition. Their work points out that human nature, the social and technological division of labor, and artistic traditions are always intertwined, but remain heterogeneous.

This implies that there can be no fixed standard of authenticity. In one of Adorno"s typically paradox formulations: "... authenticity itself becomes a lie the moment it becomes authentic, that is, in reflecting on itself, in postulating itself as genuine..." Instead: "Anything that does not wish to wither should rather take on the stigma of the inauthentic. For it [genuineness] lives on the mimetic heritage. The human is indissolubly linked with imitation: a human being only becomes human at all by imitating other beings." 85 Reflection has to allow for the heterogeneity, for the paradox contrasts that are typical of modernity.

Benjamin and Adomo are cleeply indebted to the German tradition of idealism and tomanticism, to the idea that all mimetic capacities may be absorbed adequately in literature, philosophy and music. Benjamin postulated that language is 
the medium into which all the earlier forces of mimetic representation and interpretation must transform themselves, until they have reached the point where the magic of mimesis is simultaneously liquidated and realized. ${ }^{86}$ Adomo postulated the same for Germany's musical tradition, from Beethoven to Schönberg, which shas wrestled itself from the abyss of the unconscious, that of dream and drive, by nourishing itself on its material like a flame, until, like light, one true day it transformed all contours of music: that is its greatest success between the extremes, no longer play, but truth itself.' makes them refute more mundane, naturalistic perspectives, the critical work of Adorno and Benjamin must appear as elitist, nostalgic, and tied to the particulars their German cultural heritage. Many passages in their work demonstrate an affinity with the most absolutist versions of German symbolism: Benjamin's utterly esoteric treatment of Goethe's "Elective Affinities", and Adorno's scathing condemnation of jazz exemplify this. A typical remark about jazz by Adorno is that "with jazz, subjectivity senselessiy tumbles out of the commodity world into the commodity world; ... no ancient and repressed drives are liberated by these prescribed thythms and prescribed explosions: new, repressed, maimed drives are frozen into masks ..."88; his rejection of jazz was so absolute and generalizing that he even failed to distinguish between, on the one hand, jazz and German Scblager, or between jazz and Elvis Presley.

Commentators have remarked that both Adorno and Benjamin were deeply Eurocentric, part of a generation that had little interest in issues of feminism or anti-colonialism. ${ }^{80}$ But they did always insist that mimetic freedom is irreducible, unwavering in their defense of reflexivity. Their experimental, essayistic interpretations of purely symbolic works of art as representations of social reality in disguise have inspired many later authors, often because they never pretended to an apolitical neutrality ${ }^{90}$. Adorno in particular developed an essayistic style that switches freely between the demonstration that historical results remain within the domain of nature and thus of myth, and the opposite assertion that knowledge of nature invariably is shaped by history. Such reflections often result only in characteristic accusations, where historical phenomena are accused of failing to produce real progress, by changing nature to free mankind of fear, while natural phenomena are called unnatural, insofar as they obscure the historical context that might illuw minate them." But these same confrontations of nature and history, of symbolism and naturalism, serve to make room for ongoing experiments with aesthetic reflexivity, in which Adorno was (at least in his own theory) as willing as Benjamin to go beyond the established canon.

Adorno acknowledged that the historical development of "serious" music had not been fully successful. He insisted that in the final analysis, serious, rational music can not be separated once and for all from light, popular music, and formulated the idea that only kitsch is able to represent adequately the psychic drives in 
their social constellations. ${ }^{92}$ If populat music is infantile in comparison with serious attistic productions, it is nevertheless an important reservoir of mimetic behaviour, and Adorno stresses time and again that the best music does not neglect this reservoir, but represents it. He wrote that the classical tradition and popular, industrially produced consumer art both "bear the stigmata of capitalism, both contain elements of change.... Both are torn halves of an integral freedom, to which, however, they do not add up." "93 "The usual invectives against the commercial abuses in music are superficial. They are misleading about the extent to which phenomena that presuppose commerce, the appeal to an audience that is already perceived as customer, have the potential to develop into compository qualities, intensifying and unshackling the compository powers of production." Adorno insists more on the hovering quality of reflexivity than on the canonical works of music: "Someone who looks peacefully at the sky may be more in the truth, than someone who is correctly following the Eroica" "95

For these reasons, it is a mistake to identify Benjamin and Adorno with fixed positions on mass art, with Benjamin advocating the aura-less reproduction, and Adorno insisting on the auratic original. $\%$ There is no single conclusion, no straightforward condemnation or celebration, to the debates and experimental essays that Benjamin and Adomo devoted to the modernization of early Romantic aesthetics. As Adorno wrote in one of his last letters to Benjamin: "It is my con" viction that all our best thoughts are those, that we cannot think completely. In this sense, it seems to me that the concept of the aura has not been fully "thought out $^{\text {." }}$ "'97

Adorno has written that an experimental essay may start wherever it wants; before it starts to reflect on the ways in which its subject is mediated, it has to accept its immediacy\%. In that spirit, the reflections by Adorno and Benjamin on the transformations of mimetic experience that have been brought about by the mass media may be compared to David Byrne's reflections on popular music. Both insist on confronting the immediate experience of artworks with naturalistic explanations of its functioning. It is no mere coincidence that they have both turned to the theoretical explanations of Marx and Jung, which look for ways to link the direct consciousness of the individual to the society of which the individual is a part, and to the nature of mankind, of which it is but one example.

Byrne's work differs drastically from the essays of Adorno and Benjamin in that it does only rarely refer to a canon of classical-romantic works and symbolism, but mainly to one of mass entertainment, using that as a statting point for artistic reflexivity. His work uses the tradition of performance theatre to reflect on the deterministic qualities of advertising, kitsch and fun, yet they remain within the sphere of entertainment, that great reservoir of mimetic behaviour. Yet, like Benjamin and Adorno, Byrne insistently shapes his poetics by staying close to these mimetic experiences, unfolding them reflexively. 
Adorno and especially Benjamin described how life in the modern city is experienced as a Gesamtkurstwerk, the joint production of many technological experts, a way of life that is experienced to a large extent via media representations. They investigated the mass media to illuminate their inadequacies, and to formulate a better understanding of the experience of contemporary history. That requires that the Gesamtkunstwerk be opened up for detailed inspection, to get to know its inner mechanisms, and to differentiate between the routine repertion of homogenized formulas and the opportunities for genuine reflexivity, and both Benjamin and Adomo always tried to found their work on knowledge of the latest formal and technical developments, convinced as they were that such insights are often decisive for the relevance and the truth content of critical rellections. Byme's work is strategically situated at the crossroads of high-tech mass media entertainment, conceptual art and the mimetic innovations of performance theatre: that means it is in a unique position to open up the enveloping experience of mediatized reality, and to reflect the Gesantkunstwerk of the present as an immense, industrial laboratory of the imagination. 


\section{CHAPTER 12}

\section{The Gesamtkunstwerk as laboratory}

\section{THE EXPERIMENTAL FUNCTIONS OF POIESIS}

In his "Critique of Pure Reason", Kant suggested a Copernican turn, because he wanted to dispel the illusion that human knowledge corresponds directly to the reality of things as they are, and to underline that human reason actively organizes its impressions of things. The early Romantics immediately took up this suggestion, to argue that the creative role of fantasy in the organization of knowledge should be pursued much further than Kant himself was willing to do. This "aesthetic turn" claims a central tole for poiesis in expery form of knowledge, renouncing the search for absolute truth to gain a thorough understanding of the importance of style, in order to perceive the aesthetic dimension of each and every scientific or cultural development. This reflexive aesthetics of early Romanticism can be brought up to date by elaborating the aesthetic and anthropological explanation of Kant's Copernican turn.

Kant emphasized the gradual progress of scientific knowledge, and suggested that this development should be accompanied by a patient and gradual perfectioning of mankind. His enthusiastic readets Novalis and Schlegel were not as patient: they insisted on the immediate liberalization of all knowledge, in all domains of life. Their impatience resembles the demand made by the student movements in the 1960's and '70's, "l' imagination au pouvoir": all power to the imagination. In the academic domain, this upsurge of critical romanticism has helped to produce a growing body of reflexive work: theories that articulate in detail how developments that appear to be objective and factual are inextricably linked to aesthetic 
concerns. This kind of scholarship insists that there is always a style, a mimetic process, a founding mythology at work, even in the most modern scientific accomplishments.

The work of philosopher and anthropologist Bruno Latour is a fine example of this contemporary reflexivity. Latour asks of anthropology that it should come home from the tropics, not just to study subcultures within modemity, but to study modern rationality as such.' Employing a truly imaginative strategy, Latour studies the behavior of moderns scientists as if they were members of an unknown, quixotic tribe: "Whereas other tribes believe in gods or complicated mythologies, the members of this tribe insist that their activity is in no way to be associated with beliefs, a culture, or a mythology. Instead, they claim to be concenned only with "hard facts"."2 Mimetic and aesthetic concerns seem to have been banned from the laboratories where the technologies are developed that influence every aspect of our lives: they appear to spring from a kind of cultural vacuum. By approaching scientists in the laboratory with the methods of the anthropologist, recording their language, customs and conflicts in the same way in which an anthropologist represents the language, customs and conflicts of a foreign culture, Latour demonstrates that nothing could be further from the truth. His "anthropology of science" helps to see science and technology not as absolutely objective, but as a cultural accomplishment of an unusual intricacy, and with unprecedented consequences.

The picture of modern science that Latour proposes is not that of an ongoing discovery of narure's immutable laws, discoveries accompanied by a growing disenchantment over the cold and inhuman universe and by a growing irrelevance towards all forms of mythology. Instead of all that, Latour presents science as the practice of combining all kinds of diverse equipment and concepts in laboratory settings. In the lab, forces of nature are made to perform in new combinations and on a scale that had formerly been hidden. One of the most remarkable aspects of laboratory experiments, according to Jatour, is that modern society has been so willing to transform itself time and again, to incorporate the results of laboratory experiments into society as a whole. To illustrate this, he compares scientific facts to frozen fish: the cold chain that guarantees the temperature and the freshness of the fish has to be maintained, without interruption, from the ocean to a million kitchens-or the fish will be spoiled. In a similar way, scientific facts can travel everywhere, but only when there ate sufficient networks of stable instruments for the measurement and interpretation of these facts - or the facts become irrelevant and absurd. Iike the railroad, the telephone, or cable television, facts are transmitted through networks: a scientific measurement or concept without the proper network of equipment is as inconceivable and as useless as a locomotive without rails, or a telephone without subscription. ${ }^{3}$ 
The picture of modemity that emerges from this anthropological approach is that of a culture that will go to great lengths and expenses to transform itself into an environment that accommodates the innovations from the laboratory. Clocks that tell standard time, schools with fixed graduation levels: modern culture is built of an infinite number of prescribed standards, for everything from the voltage of electricity outlets to scholarly foomotes and from internet protocol to procedures for psychiatric diagnosis. Our material and technological environment relies on these standards to be able to function; so do we.

Anthropologists have studied pre-modern mythologies in terms of the relationships between the social order and the natural order. Pre-modem systems of thought attempt to stabilize this relationship as a whole, by developing myths that represent the socialization of nature in the same categories that preordain the functioning of the actual society. ${ }^{4}$ The resulting identification of the social order with the natural order helps to account for the fascinating, obsessive quality of mythical systems. According to Latour, the quality that distinguishes modernity from pre-modem societies is, that modern society tends to suppose that the social order is completely distinct from the natural order. Latour singles out Kant's Copernican turn as the decisive formulation of this principle; reason no longer has to imitate nature, science has become independent and may now lead. This license to innovate has allowed modern science to introduce all kinds of formetly unknown, hybrid combinations of natural phenomena into the fabric of society.

But the separation of society from nature is of course anything but complete. Anthropologists like Durkheim and Mauss have always insisted that primitive tribes project their social categories on nature. Latour refers to this explanation when he states that modern engineers also, inevitably, mix political and cultural interests with their representations of nature. ${ }^{5}$ Modern Westemers are not absolutely different from all others. Latour frontally attacks the idea that scientific knowledge has its place outside of culture: to the contrary, our culture is made, among countless other things, of such things as biology, electron-microscopes and telecommunication networks. Only the scale on which the modern collective constitutes natural and cultural objects is much bigger than the scale of pre-modern societies.

According to Latour, we moderns have never left the pre-modern anthropological matrix. If the hallmark of modernity should be that the human collective no longer projects its qualities and desites on the surrounding nature, than we have never been modern, and "we are still in the Dark Ages or, if you prefer, we are still in the world's infancy."."

The diagnosis of modern culture to be found in Latour's work is that we differ in only one respect from pre-modern cultures: we live in communities whose social bond comes - to a great extent-from objects fabricated in laboratories. ${ }^{7}$ As a result, the changes of scale and the displacements that laboratory work presup- 
poses can be found everywhere in modern life. And as the networks that distribute successful experiments through society multiply and accumulate, the modern collectives themselves are constructed on a bigger and bigger scale, formed out of networks that incorporate growing numbers of hybrid, heterogeneous elements, ranging from people to instruments, words, chemicals, political interest groups, micro-organisms, etcetera.

Latour emphasizes that we have to acknowledge the extent to which our lives are mediated by nature, society and technology, a mediation that results in the continuous mimetic morphing between human and non-human elements. "This might, in the long run, allow us to do without the distinction between moderm facts and premodern ferishes. Latour proposes what he calls a symmetrical an thropology: a reflexive perspective that refrains from prejudices about modern and premodern projections on nature. In this perspective, both facts and fetishes appear as results of successful projections. When facts are fwell fabricated in a labotatory, they can be used autonomously, as if they were unfabricated, throughout society - that is, once the necessary supportive network has been completed: And when ferishes are well fabricated in a ritual, they are what helps us to act rightly, and form an autonomous source of spiritual power-at least as far as the appropriate ritual has been recognized." All cultures braid together many facts and fetishes; the idea that modernity should have replaced myths and fetishes by facts and technology is preposterous and damaging.

When this is applied to modernity at large, we come to realize that we are deeply attached to the ubiquitous presence of science and technology, to the prosperity and the possibilities that the technological society offers. Societies have expressed their darker as well as their lighter faces in technologies. We know the inhuman face of modernization: death camps installed to commit murder in the most efficient and large-scale manner, the industrialization of war, the proven possibility of nuclear annihilation, the destruction of natural environments, the inequality on a planetary scale. But we also know the deeply human face of technology, as supportive, caring, precise and relliable. As Latour concludes, more than earlier generations, ours has digested, integtated, and perhaps socialized technology. 10

To make clear how Latour's anthropology of modern science may be said to contrin a poetics of modernity, it is useful to return for a moment to Novalis' philosophy, especially to his concept of a natural science. Novalis developed a specifically romantic epistemology of nature. The foundation of this epistemology was his view of inner and outer nature as chaotic and variable. "His poetic theory of the knowledge of nature is based on the idea that everything that is "real, thinks; because this thinking is that of reflection, it can think only itself, or, more precisely, only its own thinking; and because its own thinking is full and substantial, it knows itself at the same time that it thinks itself." 12 "This epistemology does 
not accept an absolute distinction between "T" and "not- 1 ", between subject and object, or man and nature, and insists that we can only know natural objects insofar as these objects know themselves, and insofar as they know us: In Novalis' words: "Perceptibility [is] an attentiveness" 13 , the radical consequences of which he clearly enunciates in this statement: "In all, predicates in which we see the fossil, it sees us." 14 Walter Benjamin concluded in his study on "The Concept of Criti cism in German Romanticism" that for the early Romantics, objective knowledge apart from reflexive self-insight is simply not possible. ${ }^{15}$ Experimentation, the method of the natural sciences, for the romantics has to consist "in the evocation of self-consciousness and self-knowledge in the things observed."16 According to Novalis, anthropology, as the study of man, has to accompany the natural sciences, as the study of nature.

In his commentary, Benjamin has pointed out that in the early Romantic epistemology, the medium of reflection coincides with that of knowing and of perceiving. Whereas the regular natural sciences are infinitely careful when distinguishing the method of observation from the actual perceptions, the romantic sciences combine them in a magical and ironical observation, which enters into a mimetic relationship with the object. ${ }^{17}$ In other words, to be completely valid, a scientific experiment has to be simultaneously an artistic experiment-a truly bold methodological claim.

According to Benjamin, this epistemology was urgently relevant for a deeper understanding of modernization and industrialization. He did his utmost to save early Romanticism for the twentieth century, by applying their philosophical insights to later historical, philosophical and artistic developments. He clearly stood within the romantic, reflexive epistemological tradition of Novalis when he wrote that

The mastery of nature (so the imperialists teach) is the purpose of all technology. But who would trust a cane wielder who proclaimed the mastery of children by adults to be the purpose of education Is not education, above all, the indispensable ordering of the relationship between generacions and therefore mastery (if we are to use this term) of that relationship and not of children? And likewise technology is the mastery of not nature but of the telation between nature and man. Men as a species completed their dewelopment thousands of years ago; but mankind as a species is just begin* ning his. In technology, a pbysis is being organized througl which mankind's contact with the cosmos takes a new and different form from that which it had in nations and families." "'s

To a mind that has been trained to accept the products of science and technology in the spirit of positivism, as unalterable facts (which is how they most often appear in daily practice), this romantic epistemology may appear as a license to remain confused about material reality. To the romantic, on the other hand, the rationalist method appears as a rashly premature choice for an oversimplified sort of clarity. Rationalistic and scientific clarity is produced by separating natural reality 
completely from the reality of aesthetics, mythology and culture, while the romantic epistemology insists that such a separation produces a distorted view of reality, as it is ultimately impossible.

Like the early Romantics, Latour insists that objective knowledge apart from teflexive self-insight is simply not possible. To demonstrate the meaning of this, he has described in detail how a modem botanologist, whom he has accompanied on one of her field trips, does things to plants "that have never occurred since the dawn of the world. The plants find themselves detached, separated, preserved, classified, and tagged. They are then reassembled, reunited, redistributed according to entirely new principles that depend on the researcher, on the discipline of botany, which has been standardized for centuries, and on the institution that shelters them, but they no longer grow as they did in the great forest. The botanist learns new things, and she is transformed accordingly, but the plants are transformed also. From this point of view there is no difference between observation and experience..."21

Latour describes how technology connects us moderns to the world of the laboratory. Laboratories are the places where nature's most spectacular performances have been staged and observed until it became clear-gradually, and by trial and error-how society might be modified so that nature could be made to repeat those performances outside the laboratory. As a result of all this work, daily life is full of nature's rehearsed behaviour, to combine a concept that was coined by Richard Schechner to the work of Latour. We use, enjoy, or fear long distance conversations, digitally recorded and laser-decoded music, new fabrics, genetic engineering, prenatal ultrasound diagnostics, smart bombs guided by laser; as well as international monetary politics, new forms of citizenship, new drug-induced ecstasies, new world records in sports, new and highly innovative traditions. These natural performances have transformed the dimensions of modern society, and go on doing so. A culture based on technology and science has constructed networks that harness invisibly small particles and waves to transform the very tangible reality of life. Where these transformations are gradual, modernization allows for a certain stability, but otherwise, the scales of time and space appear to be shifting incessantly, exploding and imploding, as global developments and technological and economical changes disrupt the frames of experience.

Latour's anthropology of modernity can be interpreted as an updated version of Adorno and Horkheimer's "Dialectic of Enlightenment". According to Horkheimet and Adorno, the Enlightenment has a great potential to release mankind from its fears; but the Enlightenment becomes absolutist and repressive when it excludes mimetic experience and reduces everything to disenchanted facts.

According to Adorno and Horkheimer, projection as such is a necessary part of the mimetic experience. In a certain sense all perception is projection, as Horkheimer and Adomo boldly state ${ }^{22}$; and they base this insight on an anthropological. 
explanation of Kant's Copernican turn: "The system of things, the fixed universal order of which science is merely an abstract expression, is-if we apply the Kantian critique of cognition anthropologically-the unconscious product of the animal organ in the struggle for existence, of automatic projection. ${ }^{23}$ True to earlyRomantic insight, Horkheimer and Adomo insist that this projection has to become reciprocal, so that it may result in a two-way mimesis between subject and object, man and nature:

Between the true object and the undisputed data of the senses, between within moll whout, there is a gulf which the subject must bridge at its own risk. In order to reflect the thing as it is, the subject must return to it mote than he receives from it...

The inner depth of the subject consists in nothing ather than the delicacy and wealth of the extemal world of perceptions...

The possibilities of reconciliation appear not in certainty anaffected by thought, in the preconceptual unity of perception and object, but in their considered opposition. The distinction is made in the subject, which has the external world in its own consciousness and yet recognizes it as something other. Therefore reflection, the life of reason, takes place as conscious projection ${ }^{2}$

Only where the conscious reflection on this projection is absent, when the subject accordingly loses its inner depth, projection turns into the pre-arranged sanctification of prejudice. As Adorno and Horkheimer note,

When the subject is no longer able to teruen to the object what he has received from it, he becomes poorer rather than richer. He loses the reflection in both directions: since he no longer reflects the object, he ceases to reflect apon himself, and loses the ability to differentiate. ${ }^{25}$

Latour writes, in a similar vein: "The modernist Enlightenment, in its republican ideal at least, became, for a while, a popular movement. It struck a chord in all the oppressed atound the world. When facts were accommodated into our collective existence, great clouds of delusion, oppression, manipulation were dissipated." But where this results in an anti-fetishist bias, in an iconoclastic attitude that denounces every transfer of spiritual qualities to non-human entities, the Enlightenment refuses to acknowledge our need for projections: as Latour explains ferishism, a fetish "simply asks to be that which protects bunans against inhumanity and death, the thing that, when removed, turns them into monsters, animals, things." 27 Latour proposes that we should simply accept that "people are tired of being accused of believing in nonexistent things, Allah, jinns, angels, Mary, Gaia, gluons, tetroviruses, tock ' $\mathrm{n}$ ' roll, television, laws, and so on". 28 In orher words: our dealings with narure inevitably have an aesthetic dimension, where all kinds of imaginary entities help to order reality. Modern society may resemble a giant laboratory, but it is still a place where myths, poesis and mimesis are deeply relevant. If modemity resembles a laboratory, it also resembles a communal $G_{e-}$ samtkeunstiverk. 
It remains to be asked to what extent different archetypal projections are adequate to produce reflections on modern, technologically enhanced society and its subjects. The question may be divided in two separate parts. First question: to what extent have modern, electronic mass media transformed these projections? And second: how can we understand the role that these electronic scenarios perform in contemporary communities? The investigations of Bruno Latour do not provide answers to these questions, as they are mostly restricted to the domain of science and technology. But other contemporary anthropologists have attempted to come up with answers.

\section{ELECTRONIC EXTENSIONS OF THE IMAGINATION}

According to French anthropologist and sociologist Pierre Bourdieu, the main role of the mass media, especially television, is that they tend to present a homogenized and banalized picture of reality. Bourdieu's argument may be summarized as follows. TV programmes are complex social constructions, produced within a field of competing mass media. The pressures that are produced within this field (through viewer ratings, the competition for advertising money, the competition for scoops and coverage of news events, and so on) are not clearly visible in the programmes as such; in a constructed image of reality, the social conditions of its construction remain invisible. ${ }^{29}$ Since most people rely primarily on television for their information about politics, "We are getting closer and closer to the point where the social world is primarily described-and in a sense prescribed-by television." "Television enjoys a de facto monopoly on what goes into the heads of a significant part of the population and what they think." 31

Bourdieu's analysis shows how television as a system has produced a specific aesthetic, a technologically produced form of the collective unconscious. He writes about the "unconscious of journalists": "Journalists, with their special "glasses" and their peculiar categories of thought, often ask questions that don't have anything to do with the matter at hand. For example, on the so-called "inner city problem," their heads are full of... phantasms..." 32 If his analysis may be rephrased in the terminology of reflexive romanticism, Bourdieu underlines that television is a socially produced Gesamtk,atnstaverk which allows for very little reflexivity: "This is due partly to the fact that production is a collective enterprise. ... [Within the field of television] no one can ever be sure of being the subject of what is said... We're a lot less original than we think we are. This is particularly true where collective pressures, and particularly competitive pressures, are so strong..."3.3 Television as a whole is constructed in accordance with the mental structures and perceptral categories of its audience, producing an unprecedented homogenization, which "smoothes ovet things, brings them into line, and depoliticizes them." 34 
The entite, mostly unconscious, collective effort that produces television results in banalization and depolitization, "even though, strictly speaking, this activity is without a subject, that is, no one ever thought of or wished for it as such." 35 The unplanned tresult is that television presents a primitive version of politics, a version that withholds the relevant information that all citizens ought to have in order to exercise their democratic rights. Television news offers "precious little, except for what can be leamed from seeing people, how they look, and how they talk - things even the most culturally disadvantaged can decipher, and which can do more than a little to distance many of them from a good many politicians. ${ }^{36}$

In spite of all this, Bourdieu does not conclude that intellectually responsible people should throw away their TV sets and refuse to appear on television. On the contrary: "The audience rating system can and should be contested in the name of democracy". ${ }^{37}$ The television image represents an exceptional force that may be used for the hardest task: "There is nothing more difficult to convey than reality in all its ordinariness." 38

Bourdieu's analysis of television pertains to the situation in a single nation, France. The "so-called inner city problem" to which he refers as an issue that is particularly open for televised misrepresentations, is the term that is used to cover all kinds of problems of migrants living in the poorer neighborhoods. What Bourdieu implicitly addresses here, is the question whethet television is able to present an adequate picture of cultural diversity. The cultural collage found in such neighborhoods presents many opportunities for the projection of archetypal prejudices, and for an enormous variety of mutual misrepresentations. In Bourdieu's analysis, there is little room for hope that the power of television will be used to replace such prejudices by reciprocal representations. But France has traditionally been a nation with a single cultural heritage-although Bourdieu would have been the first one to point out the enormous class differences within this tradition. When the international effects of television are considered, the medium is considerably less homogeneous. Arjun Appadurai, an anthropologist who was born in India and works at the University of Chicago, has attempted a study of such worldwide effects.

In his study of the cultural dimensions of globalization, "Modernity at Large", Appadurai posits that nowadays, people all over the world experience at least five dimensions of shifting cultural flows. He compares these dimensions to changing landscapes: he distinguishes ethnoscapes, mediascapes, technoscapes, financescapes, and ideoscapes. 30 In an attempt to understand these cultural shifts, Appadurai singles out the role that the imagination has to play in the present:

Because of the rapid way in which they move through daily life routines, clectronic media prowide resources for self-imagining as an everyday social project. As with mediation, so with motion. The story of mass migrations (voluntary and forced) is hardly a new feature of buman history. But when 
it is juxtaposed with the rapid low of mass-mediated inages, scripts, and sensations, we have anew order of instability in the production of modern subjectivities. ${ }^{40}$

According to Appadurai, the work of the imagination is "central to all forms of agency, is itself a social fact, and is the key component of the new global order". 4? $L$ ' imagination aw pouvoir, indeed - but Appadurai emphasizes that imagination is not simply unrestricted fantasy: the imagination has to fulfill what he calls, inverting the tidle of Benjamin"s artwork essay, "the work of reproduction in an age of mechanical art". The question he poses is: how do small groups, especially families, deal with the new global realities of shifting cullural environments "as they seek to reproduce themselves and, in doing so, by accidlent reproduce cultural forms themselves?"42 Appadurai argues as follows:

Electronic media decisively change the wider field of mass media and other traditional medin... Electronic media mark and teconstitute a much wider field, in which print mediation and other forms of oral, wisual, and auditory mediation might continue to be important. Through such effects as the telescoping of news into audio-video bytes, through the tension between the public spaces of cinema and the more exclusive spaces of video watching, through the ummediacy of their absorption into public discourse, and through their tendency to be associated with glamour, cosmopolitanism, and the new, electronic media (whether associated with the news, politics, family life, or spectacular entertainment) tend to interrogate, subvert and transform other contextual literacies... They are resources for experiments with self-making in all sorts of societies, for all sorts of persons. They allow scripts for possible lives to be imbricated with the glamour of film stars and fantastic film plots and yet also to be tied to the plausibility of news shows, documentaries, and other black-and-white forms of telemediation and printed text. ${ }^{4}$.

Within families, where parents try to hand on to their children their view of what makes life meaningful, such forms of irony and resistance may increase the pains of cultural reproduction, as Appadurai notes.

The mass medial afford powerful resources for counternodes of identity that youth can project against parental wishes or desires... A central link between the fragilities of cultural reproduction and the role of mass modia in today's wotld is the politics of gender and violence. As fantasies of gendered violence dominate the B-grade film industries that blanket the world , they both reflect and refine gendeted wiolence at home and in the streets, as young men (in particular) are swayed by the macho politics of self-assertion in contexts where they are frequendy denied real agency... As the shapes of cultures grow less bounded and tacit, more fluid and politicized, the work of cultural reproduction becomes a daily hazard.4.

Appadurai acknowledges that the role of the imagination in the contemporary world has to be seen in the perspective of everything we have learned from anthropologists about the functions of art, myth, and legend in all societies. But there is an important difference: "These new mythographies are charters for new social projects, and not just a counterpoint to the certainties of daily life. They move the glacial force of habitus into the quickened beat of improvisation for 
large groups of people." ${ }^{45}$ The roles played by mass media representations may vary wildly. The examples which Appadurai cites, show how television provides the material for improvised mythologies:

There is growing evidience that the consumption of the mass media throughout the world often prowokes resistance, irony, selectivity, and, in general, agency. Terrotists modeling themselves on Rambo-like figures (who have themselves generated a host of non Western counterparts; housewives reading romances and soap operas as part of theit efforts to construct their own lives; Muslim family gatherings listening to speeches by Islamic leaders on cassette tapes; domestic scrvants in South India taking packaged tours to Kashmir: these are all examples of the active way in which media are appropriaced by people throughout the world. $T$-shirts, billboards, and graffiti as well as rap music, street dancing, and slum housing all show that the images of the media are quickly moved into local repertoires of irony, anger, humor, and resistance.46

Thus, television and other electronic media play a part in the production of new communities. The authenticity of such communities may appear as makeshift and hybrid, especially when compared to more traditional, more gradually developed communities - but that does not make them less real.

Both Bourdieu and Appadurai add to a better understanding of television. But most likely the attempt to understand the influence of the media on contemporary culture is too encompassing to be answered satisfactorily. While the media obviously exert an influence over society, they are also part of society, and historical changes affect them both, as cultural historian Robert Sklar has pointed out in a historical study of Hollywood filmmaking, "Movie-Made America" (1.976).

According to Sklar, the defining characteristic of Hollywood is the undiluted commercialism of the film studios. It is the expectation or at least the strong hope of reaping a profit has made the movies unique among the arts. ${ }^{47}$ This commercialism has made possible the development of the immensely resourceful electronic studio's that are central to today's mass media. There, stuntmen and body doubles, lighting technicians and make-up artists, dialogue writers and coaches, directors, editors, actors, composers, musicians and all those other specialists collaborate to produce the most effective performances, to be distributed through a near-global network of cinema's and other outlets by more specialists: marketeers, publicity agents, entrepreneurs, film operators and so on. But how can we interpret, or even just measure, the effect of these most effective fetishes on culture, in the U.S.A. itself or abroad? Sklar reconsidered the long-running moral debate in the U.S.A., in which arguments about the "immotal" influence of film were repeated over a series of decades. His conclusion:

There is no way to show a cause-and-effect relation between Hollywood's pleasure principles and the gradual unloosening of sexull restraints in American life; perhaps the two go together as symptoms of social change which affects them both. But Hollywood's sexual behaviour was the most: publicized frontier of a new morality - or lack of one-during the 1920 s, and there is reasion to be- 
lieve that the Aquarians of Hollywood wete an wanguatd of the increasingly larger role sexual openness has played in American public behavio during the past half-century, 4 t3

Sklar is more outspoken where he discusses the influence of the studio system on the formal qualities of filmmaking: Hollywood has an insistent tendency to subordinate every aspect of filmmaking to the establishment of a single conflict that is resolved within the course of the movie. The exclusive imposition of that format is probably Hollywood's most oppressive influence.

In 1976, the same year that saw the publication of Sklar's book, German independent filmmaker Wim Wenders presented his film "Im Lauf der Zeit" ("Kings of the Road"). One of the characrers in this fillm makes a comment on the influence of movies that has often been repeated:

America has colonized our unconscious.

Of course, the United States are the home of the world's financially and technologically most powerful entertainment industry. The studios of the film, television, music and internet companies are the state-of-the-art electronic laboratories of the imagination, and they have a dominating position on the global market. But according to Appadurai's analysis, the colonized. in this field are not at all powerless. In his vision of shifting landscapes, where so many cultural diasporas are confronting each other, the domination of American producers provides important opportunities to others:

The United States is eminently suited to be a sort of cultural laboratory and a free-trade zone for the generation, circulation, importation, and testing of the materials for a world organized around diasporic diversity. In a sense, this experiment is already under way. The United States is already a huge, fascinating gatage sale for the rest of the world." ${ }^{\text {th }}$

And he sums up a series of examples of the U.S.A.'s cultural influence, ranging from golf vacations for the Japanese and soap-opera ideas for Brazil to supplyside economics for Russia and Christian fundamentalism for Korea, adding: "The role of American musicians, studio's, and record companies in the creation of world beat is an excellent example of this sort of down-home but offshore entrepreneurial mentality." 50

Appadurai emphasizes the cultural and political relevance of the imagination, and points at the ongoing, innovative cultural exchanges that have been made possible by the mass media, while Bourdieu stresses that the electronic mass media tend towards the production of homogenized banalities. Both trends, however contradictory, are real. Their theories, together with Latour's anthropological insights in modem science and technology, provide a broad canvas against which the work of David Byrne may be siruated. This is not to suggest that Bytne's CD's, videos and books of photographs are easily compatible with the schollarly 
monographs and learned essays by these authors: they are not-and yet a comparison should yield interesting insights. As a preparation for the quest for a common ground, it may be helpful to recapitulate some instances of Byrne's work that may be said to demonstrate the theories of Latour, Bourdieu and Appadurai.

Modernity, so Latour insists, is not the demise of mythological transformations and fetishisms, but rather their renewed intensification, as mankind's capacity for such identifications is amplified by technological means. "The Forest", the musictheatre piece by Byrne and Wilson, may be interpreted as a demonstration of a similar idea: to present the industrial revolution, that great victory of science and technology, as if it were an ancient epic. To show how myth has not simply been replaced by machinery, but how the two have reciprocally helped to shape each other: that was the point of this combination of Gilgamesh and German industry. "The Forest" shows how scientific rationality and technological efficiency have transformed archetypal energies, instead of eradicating them. "The Biggest Machine In The World" is the title of a "song" that Byme wrote for "The Forest". The machine that he sings of is not made of cylinders, cogs and levers, but of ecstatic consciousness, annililating the guidelines of everyday common sense to make way for something else. His lyric (quoted in chapter 3) constantly merges peaceful contentment with violent fears, as uttered by a nine-year-old child. Since it is full of mythical imagery, it may be interpreted as a representation of the spontaneous formation of animistic conceptions. The song also contains a condensed and emphatically primitive version of archetypal, obsessive rock and roll, as witnessed by the erratic, "analphabetic" spelling:

Uan end Tu end Sfri end wor

Aj dont keer end $A j$ dont nou.

Hold on tajt end dount let gou.

God, hes left as on aur oun 51

If this represents a machine, it is certainly the mechanism whereby people produce mythical interpretations of their reality: Byrne has described rock and roll as "the obsessive turned into a creative act" ${ }^{2}$.

To see where Byrne locates such creative mythologies in modernity, it is better to turn from "The Forest"-an uncompleted project, after all- to Byrne's film "True Stories", which provides examples in abundance. Take the behaviour of people driving their cars on the American freeways, on which the narrator of the film, played by Byrne, comments: "They're the cathedrals of our time. There are names for the various kinds of freeway drivers. The "slingshotter", the "adventurer", the "marshmallow", the "nomad", the "weaver". It's fancy driving... Things that never had names before now are easily described." "highway culture" does not suffice to portray an anthropological view of technology, consider Byrne's portrait of the shopping mall, that distribution centre of 
mass produced commodities: "The shopping mall has replaced the town square as the center of many American cities. "Shopping" has become the thing that brings people together. The music is always playing here. ${ }^{\prime 5}$. This may well be seen as an illustration of Latour's dictum that we live in communities whose social bond comes from objects fabricated in laboratories.

And since Byme insists that what Latour describes as the mimetic morphing between human and non-human elements is to a great extent a musical operation, it is no accident that he mentions how music is always playing in the mall. Time and again, he mentions musical mimesis: in "True Stories", an assembly line can be made into a thythmic instrument, as can the development of a computer; computers are like music, as are factories. ${ }^{55}$

Just as Byrne's work can be made to provide illustrations for Latour's reflexive anthropology of modernity, so for Bourdieu's critique of television. Perhaps the most convincing example is Byme's description of his own experience of commercial and political pressures when he acted as host for a television music show, as described above ${ }^{56}$. The similarity between Bourdieu's view of televised politics, and Byrne's photography project "The Dance of Politics" has already been mentioned above.

Appadurai's description of the role of electronic media in the development of cultures around the world is echoed-or presaged-even more clearly in the work of Byrne. Like Appadurai, Byrne presents the imagination-for him, first of all musical imagination-as a central form of agency. Writing about performance, Richard Schechner has said that

There is a politics of the imagination, as well as a politics of direct action.. The politics of the imagination is aimed at describing virtual or subjunctive futures, so that these can be steered toward or avoided. The politics of the imagination is real. ${ }^{5}$ ?

Bytne agrees with this way of thinking about the importance of aesthetic imagination. As he has commented on the political relevance of his work:

Rather than feeling that to say something in a political way I have to speak the politician's language, $\mathbb{E}$ can say it in my own way. 1 don't have to say it in an article or statement about a specific policy or action, although I do occasionally, but for the most part it is in the work that I do. It is inside there, it is in the attitude, political and social. and culnural attirudes are in the work and that is where it should stay, that is the language I speak better. This record label [Luaka Bopl is a political work, and I would like to think it has a stronger influence than if I made statements and articles about music: and culture outside the United States. 58

Byrne has explained his position on world music in a New York Times article, "I Hate World Music" (1999):

In my experience, the use of the term world music is a way of dismissing artists or their music as irrelexant to one"s own life. It"s a way of relegating this "thing" into the realm of something exotic 
and therefore cute, weird but safe, because exotica is beautiful but irelevant; they are, by definition, not like us. Maybe that's why I hate the term. It groups exerything and anything that isn't "as" into "them."

This grouping is a convenient way of not seeing a band or artist as a creative indwidual, albeit from a culture somewhat different from that seen on American television...

To restrict your listening to English-langunge pop is like deciding to erat the sane meal for the rest of your life. The "no-surprise surprise," as the Holiday Inn advertisement clains, is reassuring, I guess, but lacks kick. As ridiculous as they often sound, the conservative critics of tock-and-roll, and more recently of techno and tave, are not far off the mark. For at it's best, music truly is subversive and dangerous. Thank the gods.

Hearing the right piece of music at the right time of your life can inspire a radical change, destructive personal behavior or even fascist politics. Sometimes all at the same twe.

On the other hand, music can inspire love, religious ecstasy, cathartic release, social bonding and a glimpse of another dimension. $A$ sense that there is another time, another space and another, better, universe. It can heal a broken heart, offer a shoulder to cry on and a friend when no one dse understands. There ate times when you want to be transported, to get your mind atound some stuff it never encountered before...

The fact is, after listening to some of this music for a while, it probably won't seem exotic any more, even if you still don't understand all the words. Thinking of things as exotic is only cool when it's your sister, your co-worker or wife; it's sometimes beneficial to exoticize that which has become overly familiat. But in other circumstances, viewing people and cultures as exotic is a distancing mechanism that too often allows for exploitation and racism.

Every reflexive anthropologist has to acknowledge that teality is never a level playing field. Individuals, groups, classes and nations differ enormously in their power: financial, technological, cultural, political, and epistemological powers are distributed unevenly-drastically so. If the role of the imagination is central to all forms of agency, as Appadurai thinks, imagination should perhaps begin by reflecting on these inequalities, admitting their presence within the imaginary.

\section{MIMETIC REFJ ELIVITY}

Comparisons between Byrne's work and the theoretical statements of anthropologists such as Appadurai, Latour and Bourdieu do not imply that Byrne's work should be interpreted as a series of illustrations to their theories: to do so would mean to gravely underestimate the importance of the mimetic factor in reflexivity. Byrne is not a scholarly theorist, even though it is perhaps feasible- as has been demonstrated in this book-to lift many fragmentary theoretical reflections from his interviews, statements and writings, reflections that resemble in many respects the fragmentary reflections of so many romantic philosophers.

Perhaps Byrne's work can be characterized as a form of public reflexivity. It is never the artempt to express his own feelings directly. His works are performances about performance, based on restored behaviour of others, which has been "treated as a director treats a strip of film", to use Schechners terms. Byrne's photos show what had already been designed by others; his films show performances 
developed by others; his dances are constructed out of movements by others; his lyrics include phrases by others, or describe other people"s behaviour. The originality lies in the montage, in the editing process of combining, comparing and contrasting. This way of working means that Byme's performances have an inherent potential for reflexivity. ${ }^{52}$ The juxtapositions of so many performative moments are as many comments, each with its positive or negative critical implications. Even "This Must Be The Place (Naive Melody)" (of the Talking Heads' "Speaking In Tongues" album), the song that has the most direct love lyrics Byme ever wrote, is a deliberate construction made out of separate lines: "Sing into my mouth" is based on a picture of Eskimo's singing into each other's mouths, which Byrne found a most beautiful image; "You've got a face with a view" is a description of a face in terms of nineteenth-century landscape poetry. ${ }^{60}$

There are two other decisive characteristics. However much Byrne uses strategies from experimenting artists and however much he works in museums, galleries and theatres, his work is firmly located in the popular media. And-with the exception of photography-this work requires direct physical involvement: copying singing styles and voices, dance steps, gestures, and postures of the body. In other words: Byrne's work is based on the bodily mimesis of performance styles. And it is accessible to its audience through the modern reproductive technologies of cap* tured sounds and images that in their turn reproduce these mimetic accomplishments. The critical implications in Byrne's work have to be found within this mimetic chain, and they deal with the primitive reality of the body and the senses, permeated as that is with cultural meanings.

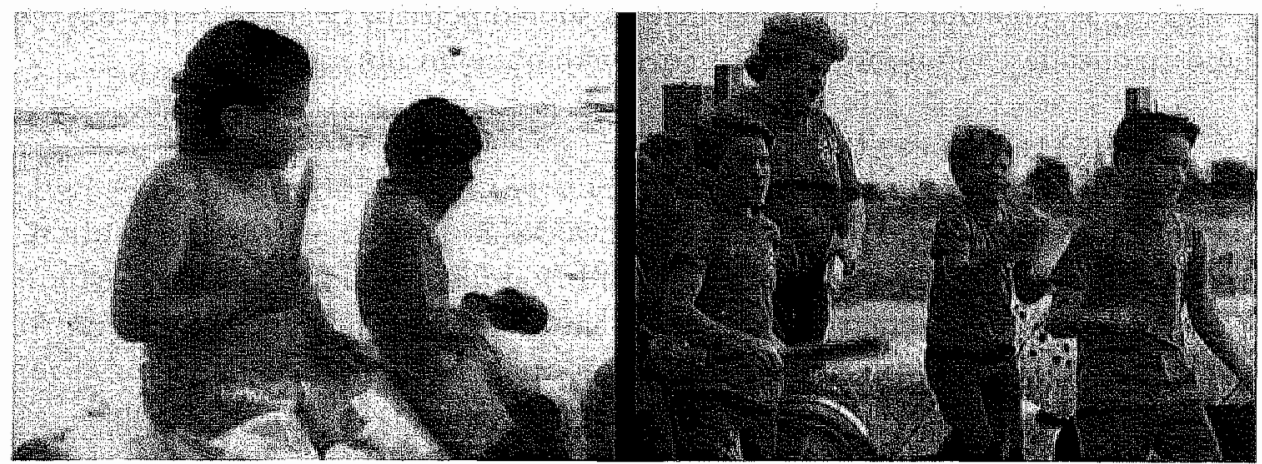

24 Mimetic play is most visible and most powerful in childhood.

Left: children learning to drum the rhythms of the Candomblé cetemony, a scene in Byme's "llé Aiye" documentary.

Right: children drumming and singing Byme's song "Hey Now" "Take me to the shopping mall / Buy me a rubber ball now"), in a scene from "True Stories".

To investigate the implications of this, it is useful to turn to the work of performance theorist Michael Taussig. Following Benjamin, he describes mimesis as "the 
mimetic faculty, the nature that culture uses to create second nature, the faculty to copy, imitate, make models, explore difference, yield into and become Other. The wonder of mimesis lies in the copy drawing on the chatacter and power of the original, to the point whereby the representation may even assume that chatacter and that power." 61 Mimesis, in Taussig's analysis, is the crossroads where history and human nature meet. It is human nature to adapt; to become socialized and adult by copying the model of the environment. This means that identities are constructed, as the theories of social constructionism tell us. But academic conclusions that "sex is a social construction" "race is a social construction", "the nation is an invention" and so forth do not answer the question "How come culture ap" pears so natural?"62 This is why mimesis deserves attention: "pressed into mighty service by society, the mimetic faculty carries out its honest labour suturing nature to artifice and bringing sensuousness to sense by means of what was once called sympathetic magic, granting the copy the character and power of the original, the representation the power of the represented." 63

No society can do without its intricate, complex and fractured web of small delusions: these delusions are needed to keep together the very identity of a society-an unstable property even at the best of times. And small dehusions ate part and parcel of the very nature of culture: when reading, listening to music, looking at a photo or watching a moving picture, we are lifted out of ourselves and projected into those artefacts: our personal identity would be unthinkable without such projections. And the necessary foundation of that identity, the most elemental and primitive of these projections, is our physical integrity, a compound of proprioceptive and projective perceptions. Byrne's work contimuously touches upon such realizations.

The fundamental critical function of art is to remind us that this is so, that our identities as individuals and as parts of the overwhelmingly latger historical and cultural developments is entwined with such animistic delusions-usually called by the more genteel name of "aesthetic illusion". Art may thus provide a new schooling to out mimetic powers. This reminding can take many forms: it can be comical, dreamlike, intoxicating, or bitter, even all of these at one and the same time.

The idea that reflexivity should be a public activity is nothing new, of course. Bourdieu originally presented his critique of television exactly where it would best be able to reach its intended audience: on television. Adomo likewise presented a great deal of his critigue of the culture industry in the mass media. His reputation of negativism, elitism, pessimism and high-modernist myopia is unjust and onesided. In spite of his scathing critique of the homogenizing effects of mass media, Adorno participated in many radio and television broadcasts. Between 1950 and his death in 1969 alone, Adotno participated in over 180 radio programs, not including broadcasts of his musical compositions. Apart from his musical and mu- 
sico-sociological criticism, Adorno also made most of his essays on literature, culture, society, contemporary politics and education public in radio programs. Moreover, he participated in at least thisteen television programs. ${ }^{65}$ One has to conclude that instead of criticizing from a distance, Adorno actively contributed to the reflexive heterogeneity of the mass media. Benjamin similarly used the radio to give his work the widest possible audience, following his own maxim that true literary activity should be able to assume inconspicuous, but socially active forms. ${ }^{66}$

Popsongs are such a form: small, severely limited, but crucial to the contemporary experience of the mimetic faculty. Byrne is unique in combining the status of a rock star, with all that implies in access to the mass media with the experience of making explicitly reflexive performance theatre. To this should be added his being well-versed in diverse anthropological-philosophical theories: as has been shown, Byrne is able to interpret behaviour by following either the mythical-ritual interpretation of Jung and Campbell, or by applying elements of the functionalisticsociological interpretations by Marx and Weber.. This threefold competence, combined with his experience as a "musical anthropologist", makes Bytne an interesting, sometimes incisive commentator in matters of mimetic behaviour.

Byrne makes his work in a liminal zone that may be located between the performance forms that Schechner describes as having "come out of the meeting of popular entertainment (especially rock, punk, and new-wrave music), happenings (with their sources in visual arts, the music of John Cage, and theories of indeterminacy), theater and dance." 67 , the explicitly ambivalent, unresolved theatre of Wilson, the Wooster Group, and Mabou Mines, and the faked "restored performances" of unambivalent mass entertainment. Byme often deals with faked authenticity by describing its mechanisms so frankly that the description alone raises doubts.

Richard Schechner contends that performance should be thought of as the central process which structures reality as human beings perceive and live it. He accordingly thinks of performance theatre, somewhat idealistically, as a model community: "Once you make a whole out of many parts-once you transcend the parts and construct a whole that is "made from" but is also "different than" its parts-you've constructed a social model. Intentionally or not you've constructed a model of the City or an alternative City." 68

This theme of the city as dreamed or as performed comes up repeatedly in Byrne's work. "The underlying idea of performance shaping social reality is exemplified in "Lifestyle", a two-page text halfway between fiction and essay, included in Byrne's "Strange Ritual" book. "Lifestyle" plays with the idea of a television channel that is dedicated completely to broadcasting the life of a single individual. (In 1998, three years after the publication of Strange Ritual, the Hollywood film "The Truman Show" was built around similar premises. Individuals recording 
their personal lives around the clock with web cameras, made accessible over the Internet, do something similar, the now growing populatity of TV "reality shows" where the camera follows groups of people like an omnipresent "big brother" are another example. And then there are people who relive long bygone lifestyles, for as long as a full year, to dramatize archeology for a series of TV documentaties. ${ }^{70}$ )

The text subtly tums on itself and becomes reflexive where a paragraph opens: with "We shift our perspective and see the show from the point of view of vatious audience members." "Lifestyle" oscillates between fiction and philosophy, like the TV channel it depicts with the words "It's exploitative and metaphysical at the same time-the best of both worlds." Byrne emphasizes not the production of the programme, but its reception: "The TV Audience talks about "The Man-The Subject-all the time. He's a surrogate life. People begin adopting his mannerisms as their own." When he realizes the effect of his televised presence, the man be gins to play with his power, which affects the habits of his audience and finally changes the very reality of the nation, even after the man has stopped appearing on television:

The irrationality of the new life has extended beyond the personal, social, and political into the realm of time and space, which, for these individuals [those who did not personally make part in the "Lilestyle Revolution"] no longer behave as they once did. "The physical world itself has become altered, and not just in the minds and behavior patterns of The Viewer Nation. The abstract has infected the concrete. Once seemingly exclusive properties flow with similaritics. Where once there were no connections at all, now amazing interactions take place.

In this short text, televised performance is presented as producing the foundation of reality, with the power to change the very categories in which the social as well as the physical environment is perceived. "Televised performance" of course stands in for culture, an interesting example of typecasting. "Lifestyle" as such may be interpreted as a model of the relationship of performance and reall life. It is a condensed and elliptical version of both "True Stories" and "Ilé Aiyé, The House of Life" insofar as it addresses the ways in which performance models, and in due course structures, reality.

Bytne's work insistently points out how technology changes the imagined quality, and thus the cultural reality, of authenticity:

"Almost everything I have experienced in my life: books, art, music, film, magazines, cars, furniture, clothes, fast or frozen food, even people sometimes, have been in reproduction. Coples... But of course, this IS the authentic for my generation. The idea of an aura of atthenticity surrounding atn object is strange and foreign to us."?

This ongoing process of disenchantment has not withheld Byrne from capturing new qualities of re-enchantment. His photographic work is an attempt to make 
auratic, animistic and fetishistic qualities more manifest, especially in those places where modern prejudice teaches us not to expect them:

Part of my work is to capture and appreciate the worlk of... anonymous artists - arcists designing hotel light fixtures, chairs, curtains, arranging religious relics, and inventing their own scripts and languages Insmllations. Sculptures. Shrines... By considered placement and lighting these items have been given, by their owners, creators, and caretakers, a tiny magical aura, a power beyond their humble ongins:

Just like the old guidebooks show pictures of the churches and tell us which paintings and telics are to be found there. my book [Your Action. World] is a guide to the cool and inspiring places inberween, the ocher places. the hallways, the empty tooms, the poorly designed plazas with no one in them, the yast parking lots and the huge storage facilities. 3

We sense that the things, objeets and places around us are alive, not just the dead matrer that science would have had: ws to believe... And the arts, including photography, are something we have that has temained somewhat uncontaminated... they are a means of touching the parts that the official stuff can't reach. ${ }^{\text {Th4 }}$

In his songs, too, Byrne addresses the influence of the constant presence of the mass media on the imagination, by emphasizing how they influence our very intuition and proprioceptive self-awareness. Many characters in his songs are defined exclusively by their dependence on the media, in lines like "The world crashes in, into my living room: television made me what I am"; "Baby your mind is a radio"; "People like us go and answer the telephone"; "I was born in a house with the television always on"; or "I'll be a video for you"75 Such lines tell in no uncertain terms that subjectivity and mass media have merged. They also demonstrate this merging within the electronic media themselves. If Bourdieu is right in stating that television is perfectly tuned to the imaginative mental structures of its audience, Byrne is among the artists who have succeeded in conveying what this means.

\section{WE ARE THE NOISE BETWEEN STATIONS}

In 1937, John Cage began his text "The Future of Music: Credo" with the words:

Wherever we are, what we hear is mostly noise. When we ignore ir, it discurbs us. When we listen to it, we fand it fascinating. The sonnd of a truck at fifty miles per hour. Static between the stations. Rain. We want to capture and control these sounds, to use them not as sound effects but as musical instruments. it

At that time, Cage was thinking only of experimental, electrical and synthetic ways of making music, ways that would allow the composer to face the entire field of sound and time. Of the musical form of such compositions, he wrote only that its principle would be “the principle of organization or man's common ability to 
think."77 Over the course of the years, Cage would gradually come to underline that what might seem a purely formalistic principle, the idea to include every conceivable extra-musical sound in the realm of music, in fact amounted to hightighting the dramatic aspects of musical performance. In 1954, for example, Cage explained: "If I choose, as I do, music, I get theatre, that, that is, I get that too. Not: just this, the two." "78.

The first generation of American performance artists and performance theatre makers was inspired by Cage's musical and conceptual development. David Byme, who has been inspired throughout his career by the work of this experimental generation, has gratefully acknowledged his debt to Cage. He cid this by admitring that some of his working methods had been developed first by Cage, and by recording a formal homage; but the most moving and encompassing homage can be found in the opening lines of one of Byme's songs:

Yeah, we are the noise

The noise between stations

Byme shares the credits for this song, a Charanga rhythm, with percussionist Johnny Pacheco; "Marching through the Wilderness" is one of the songs on his "Rei Momo" album, halfway between Anglo-Saxon rock and Latin music. This album is not a technical experiment in music, but an attempt to combine two distinct - and as often as not, mutually distrusting-popular cultures. The noise between stations is not only what lies beyond the borders of traditional composition. It is the historical reality of our human condition, our everyday vetnacular experience of the world, filled as it is with mass reproductions of art and of other strips of behaviour.

In this world of reproductions of reptoductions (of reproductions...), it is next to impossible to determine whether an individual work of art will survive its own brief moment of fame. A soon as technological standards have been developed further, an aesthetic aura that was created in the laboratories of the cutrure industry will be seen to be just that: a side effect of technology that was once state-ofthe-art. The evolution of an art-historical canon of mass media based art should not be based on technological brilliance, but on artistic merit.

In this respect, Byrne's work as a whole ate mote relevant than his separate works, because it contains what amounts to a poetics of the vernacular mass media Geramtewnswerk. Just as the Geramternstwerk was defined as the synthesis of different art forms, Byrne's method of working consists of translating diverging performance styles into each other, crossing the barriers between "primitive" and "sophisticated" cultures, between high art and popular entertainment, between the politically correct and the commercial. He succeds in these translations by adhering to a few ptinciples. Throughout his work, there is the acknowledgement of the primitive and the natural in man, either by referral to archetypal passions, or to the 
natural functions of man, to eating, sleeping, sex, security and so on. This ascertains that every conceivable form of performance at least refers to a common foundation. A second principle is that no form of performance is made to appeat simply ridiculous: Byrne's perspective is very often ironical, but his irony includes self-ironization, admitting to comparable enthusiasms, delusions, fetishes and what have you. And of course, Byrne's work is made publicly accessible through mass reproduction. This means that the work does not function primarily in the world of rarefied art objects, but within the texture of modem culture: the sound fragtnents, the stream of televised and printed images, and the commercial teading material which together make up the greater half of our symbolic environment.

These principles amount to an actualization of early Romanticism: they are a contemporary elaboration of their emphasis on reflexivity and reciprocality. A few aspects of this poetics deserve to be highlighted. First of all, it excludes the aggressive sentimentality, the gloating and the making fun of other peoples suffering that is a common feature of many media formats, from pop songs to films and video games. More substantial is that his poetics demands an unusually rich and thick interpretation of the possibility of translations. Singing may be translated in gesture and dance; words into imagery; music into theatre; animism into modernism; ritual elements are to be discovered in the most strictly functionalistic environment, just as functional elements are to be found in ritual environments. Of course, the conviction that performances "languages", however heterogeneous they may be, are not incommensurable does never guarantee that translations will be successful: attempts may simply fail, or otherwise mainly be successful in demonstrating the imperfections and shortcomings of the language, format or culture in question. Several of Byrne's projects have tried to straddle performative traditions that offer very little common ground; but their fragmentary results help to illuminate the common experience that languages are incomplete, understanding only partial, translations uneven.

Byrne's work displays an acute awareness of the need to reflect on all forms of authenticity. He questions the notion of an authentic personality:

We spend our lives listening to ourselves, watching ourselves, seeing how we are reflected, how we ate tresponded to by others, and then we fine tune ourselves in order to project accurately what it is we think we are. ${ }^{\text {\% }}$

Will our consciousness be a complete pastiche? A patchwork of sounds, smells, and tastescolonized by whatever attracts us:

Questioned about these statements by an interviewer, Byrne later explained how the pervasive presence of mass-reproduced objects has changed the contemporary experience of objectivity. He suggests, as has been mentioned above, that the aura that was still present to Benjamin has become even more rare nowadays: 
The idea of an alua of authenticity surtounding an object is strange and forcign to us... 8 :

Here, Byme employs a commonplace understanding of Benjamin's artwork-essay. A more detailed interpretation of Benjamin's reflections may provide more insight in the ways in which proprioception, authenticity, rituals and mass-reproduction technologies intersect. A small dialogue, found in Laurie Anderson's "United States, Part I", "So Happy Birthday", is an excellent example of this:

She said the hardest thing to teach her three-year-old kid was what was alive and what wasn't The phone rings and she holds it out to her kid and says, "It's your Grandma. Talk to Grandma." But she"s holding a piece of plastic. And the kid says to herself: "Wait a minute. Is the phone alive?" Is the TV alive? What about that radio? What is alive in this room and what doesn't have life?" Unfortunately, she doesa't know how to ask these questions.

According to this scene, harder than teaching children how to handle the equipment in our electronic home laboratories, it is to learn how to ask the right questions that might further our understanding of life there. Technical experts are trained to provide factual answers, to accept every strategy to expand the laboratory without asking those childlike questions about the ways in which we mimetically have to adapt to their requirements. To be able to ask the right questions, one needs to consciously unlearn one's routine way of dealing with the media, which has produced that patina of intuitions that Benjamin termed "aura". 'This purposeful unlearning should produce an experience of the socially and technologically constructed aspect of one's intuitions. That Benjamin pointed at this possibility in "The Work of Art in the Age of Mechanical Reproduction" has made this text so dear to many later artists.

In a carefully detailed investigation of the way in which Benjamin presents his argumentation about film as the future of the reflexive aesthetic, Eva Geulen has noted that Benjamin's text does not so much describe a crisis in the arts, but rather stages one. ${ }^{82}$ His hypothesis that the historical experience of fascism necessitates a drastic, technologically radicalized actualization of early Romantic procedures is not based on empirical experience: this radical turn is performed in the text, where Benjamin produces a simultaneity of the technology of filmmaking with the historical development of industrial technology. It is this performative intervention, this juxtaposition of two separate developments, the history of modernity with the history of art, which produces the decline of the aura. In Geulen's analysis,

The theory of aura is the attempt to describe history not only in practical terms, but theoretically as well from a position for which no factual ground exists as yet. In other words, the concept of aura must mark out and localize itself in the essay itself. Auta belongs to the vocabulary of a possible, futural historiography. As anticipation of the furure, the aura achieves intervention in history, stating, in this manner, what is now. That the specificity of traditional att consisted of its aura, can show itself only, when, and in so fat as it has lost this character. The perception of aura arises from its loss. ${ }^{83}$ 
The loss of aura is thus produced on purpose, by the conscious use of the technologies of reproduction. In Benjamin's words:

One might generalize by saying the technique of reproduction detaches the reproduced object from the domain of tradition. By making many reproductions it substitutes a plurality of copies for a tnique existence. And in permitting the reproduction to meet the beholder or listener in his own particular situation, it teactiwates the object reproduced. ${ }^{84}$

What Benjamin formulates here, is that reproduction, by reactivating experience, can be the material equivalent of reflection. His formulation echoes his earlier formulation of reflexivity as thought thinking about thinking about thinking. (And many superlative formulations by Schlegel and Novalis, e.g. about the "genius of genius") Just as for Schechner performance is about performance about performance, so that the identity of the performing subject is hovering, never completed or finished.

Authenticity, expressiveness and emotion are the stock in trade of popular art, especially of popular music, but it would be a mistake to think that popular art is inherently naive about its own authenticity. About rock music in particular, it has been argued that it is "a mass-produced music that carries a critique of its own means of production; it is a mass-consumed music that constructs its own "authentic" audience." $\$ 5$ The tension between the industrially fabricated and marketed product and the authentic image that is indispensable to rock musicians can be found at every level: within the music industry, within the audience, within the musicians and within the music itself. ${ }^{86}$

In response to this ongoing reproduction of authenticities, Byrne's work is not an expression of personal feelings, but a performance about performances, based on restored behaviour of others, "treated as a director treats a strip of film", to use Schechner's expression. Byrne's photos show what had already been designed by others; his films contain performances developed by others; his dance movements are constructed out of movements by others; his lyrics include phrases by others, or describe other people's behaviour.

The originality of this work must be found in the process of montage and imitation, in the editing process of combining, comparing and contrasting. This helps to explain why an understanding of diverse conceptual perspectives may be as relevant for Byrne's work as the capacity to sustain a thythm on guitar, or the ability to frame a picture within the camera, or the social skills needed to direct a film crew: because such knowledge helps to negotiate differences between performance forms, styles and traditions. Technological reproduction and ritual sacralization overlap here, in the mediating processes of performance.

The idea that authentic subjectivity is open to negotiation and reconstruction may be greeted either with suspicion or enthusiasm. An accepting, even embracing attitude toward this openness is often associated with postmodernism. But in the 
post-structuralist philosophy that forms the foundation of a great deal of postmodernist argumentation, the very idea of authenticity as such is frowned upon, and the structuralist tenets on which such philosophy founds itself leaves very little place for the mimetic sensibility that is needed to constitute authentic subjectivity. Emphasizing the universal experience of reproduction, Byrne has written:

There are no esthetic accidents... even the seeming chnos on the streets is intentional... the resulting complaints and criticisms of our urban environment are, in tum, also part of that environment. The occasional rupture is part of the texture. ${ }^{87}$

When asked about the difficulties he encountered in his attempt to create his own personal religion with the help of a camera, Byrne has mused:

We sense that the things, objects and places around us are alive, not just the dead matter that science would have had us to believe. We sense the world around us as a living otganic system... with something like a soul.

...And the arts, including photography, are something we have that has remained somewhat uncontaminated... they are means of touching the parts that the official stuff can't reach. 8 s

The genuine romantic insight that subject and object, self and nature can not be separated completely, but instead presuppose and reflect one another, forms a logical conclusion:

The impulse to attribute human attributes to objects is not stupid or wrong, as many scientists keep telling us time and again... we cannot be separated from the objects that surround us. They animate and imitate us just as much as we imitate objects and animate them. By breathing a soul into dead objects, we feel and understand that the world is truly alive, not just existing as an aggregate of dead objects and lifeless landscapes. 89

This is Byrne's accomplishment: to have used the technology of the mass media to their fullest extent, to demonstrate how these reproductions constitute a ritual performance in which we are ferishistically inwolved, in order to make this experience more reflexive, to experience the humane and inhumane aspects of this in volvement afresh. Instead of the rational, universal voice that the rational tradition of Western aesthetics has supposed to be the final goal of every aesthetic experience, this experience derides such singlemindedness, looking instead for a more active tolerance, understanding that we are to remain the noise between stations. 


\section{Notes}

\section{CHAPTER 1 INTRODUCTION}

1 See Sayre: "The Object of Performance", p. 105.

2 My paraphrase of Rockwell: "All American Music", p. 53-4.

3 Cf. Sayre: "The Object of Performance", p. 106

4 Ibid., p. 113.

5 Rockwell: "All American Music", p. 237.

6 Cf. Goldberg: "Performance Art", p. 177.

7 Howell: "David Byrne", p. 14. See pp. 11-14 of that book and Miles: "Taking Heads", p. 18, for descriptions of these concetts. The full name of The Kitchen is: the Kitchen Centre for Video and Music; on its historical role, see Goldberg, p. 181.

8 Quoted in Howell: "David Bytne", p. 47-8.

9 Bytne, interviewed by the author, 22 February 1999.

10 Miles: "Talking Heads", p. 47-8.

11 Bytme, interviewed by the author, 22 February 1999.

12 Bowman: "Fa fa fa fa fa fa", p. 344.

13 See ibid., p. 325.

14 In the same year, Casebere, Turyn, Wegman, Holzer and Kruger were also present, this time as writers and critics, in "Blasted Allegories: anthology of writings by contemporary artists", published by New York's New Museum of Contemporary Art and the MIT Press.

15 I thank Rick Poynor for pointing this out to me.

16 Byrne: "Strange Ritual.", pages not numbered.

17 Bytne, quoted on a leaflet of the "Alktionsforum Praterinsel", Munich, accompanying lis "98 exhibition.

18 Rockwell: "All American Music",p. 261.

19 Cf. Bowman: "Fa fa fa fa fa fa", p. 365.

20 Ibid., p. 5.

21 See Gracyk: "Rhythm and Noise", p. $220 \mathrm{ff}$. for sources and for a tefutation of Jameson's argument. Jameson also mentions Talking Heads as an example of the postmodern on page 1 of his "The Cultural Turn. Selected Wirtings on the Postmodern".

22 Best and Kellner: "The Postmodern Turn", pp. 34 and 89.

23 Schecter: "Beyond the Text", p. 176.

24 Hebdidge: "Hiding in the Light", p. 240.

25 Sayre: "The Object of Performance", p. 266. 
26 Apart from my own collection and a file lent to me by Rick Pownor, I have used the extensive site www talloing-heads.net.

27 CE. Musician No. 32, April-May 1981, p. 46.

28 Sontag: "Against Interpretation", p. 17.

29 Ibid, p. 23.

30 Ibid, p. 294-304.

31 Ibid, p. 15.

32 See for example Stuart Hall's article "Encoding, Decoding", in During; "The Cultural Studies Reader", p. 507-17.

33 Best and Kellner: "The Postmodern Turn", p. 183. For contrast, compare Paul Rabinow: "Reptesentations Are Social facts", in Clifford and Marcus, "Writing Culture: The Poetics and Polltics of Ethnogtaphy", p. 254, where Rabinow alludes to "Stop Making Sense" (but without mentioning Byma) in a densely argumented article on anthropological representations,

34 Bowman: "Fa fa fa fa fa fa", p. 242-3.

35 Byrne, quoted in John Howell: 'Dawid Byrne", p. 15.

36 Charles Harrison: "Art \& Language: Enkele condities en interesses van de eerste tien jaat" in: "Art \& llanguage" de schilderijen", p. 12-3.

37 On the history of Art \& Language and Kosuth, see: Gabrielle Guercio, Introduction, especially note 15, in Kosuth: "Art after Philosophy and After", p. xlii, and p. 127, note 2.

38 Kosuth: "Art after Philosophy and After", p. 107-28.

39 Cf. Keesing" "Cultural Anthropology", p. 537 f.

40 Kosuth, quoting Scholte, in "Art after Philosophy and After", p. 119.

41 Quoted in Eno and Mills: "More Dark than Shark", p. 76.

42 Ibid., p. 98.

43 Ibid., p. 43; cf. Sayte: "The Object of Performance", p. 113-4.

44 A journalist's label, quoted by Rick Poynor, in Eno and Mills: "More Dark than Shark", p. 72.

45 Rick Poynor, ibid, p. 40.

46 Quoted in Davis: "Talking Heads", p. 101-2.

47 Schechner: "Between Theater and Anthropology", p. 98.

48 Ibid., p. 14.

49 Bowman: "Fa fa fa fa fa fa", p. 336.

50 Sontag: "Against Interptetation", p. 296-7.

51 lbid., p. 298.

52. Ibid, p. 302 .

53 Nowalis: "Werke", p. 418 (Dialog 1, 1798). Author's translation of: "Jeder Mensch ist ohne Maß weränderlich... Ich möchte eine ganze Büchersammlung, aus allen Kunst- tund Wissenschaftsarten, als Werk theines Geistes, wor mir sehn. Und so mit allen. [Goethe's novel] Wilhelm Meisw ters Lehrjahre-haben wir jetzt allein-wir sollten soviel Lehrjahre, in demselben Geist geschrieben, besitzen, als nur möglich wäten - die sämtlichen Lehrjahre aller Menschen, die je gelebt hätten-." Novalis also compared Goethe to Wegdwood, who mass-teproduced Greek vases; see ibid., p. 409.

54 Straw: "Characterizing Rock Music Culture: The case of heavy metal", and Chow: "Listening Otherwise, Music Miniaturized: A different type of question about wevolution". Both in During: "The Cultural Studics Reader", pp. 451 -61 and 462-76.

55 Byme: "Lifestyle", in: "Stmange Rinual" (unnumbered). 


\section{CHAPTER 2 MUSIC AS A MIMETIC ARENA}

1 CF Blaukopf: "Musik im Xandel der Gesellschaft", P. 11 and 215.

2 For the chapters on music, I have relied on a number of such scholats, whose books deserve to be listed bere:

- Kurt Blaukopf: "Musil im Wandel der Gesellschaft" offers an overview of the historical development and the many perspectives of the sociology of music.

- John Miller Chemoff: "African Rhythm and African Sensibility" explains how African drumming is interwowen with the social relations of its community and serves a ritual tole, while it also serves political and spiritual functions.

- Simon Frith's "Sound Effects:" and his "Perfornance Rites" are often seen as the best academic studies of popular music, combining sociological with aesthetic insights.

- Greil Marcus: "Mystery Train" analyzes the intricate relations of artists and audience against the general historical and political background of the USA.

- John Rockwell: "All American Music: Composition in the Late "Twentieth Cenrury" is an attempt to avoind the unsual categorizations of music by discussing classical music next to jazz, film music and rock.

- Theodor W. Adomo is an influence in the backgtound. His sociology of music is debated extensively by Blaukopf and Frith, and to a lesser extent by Rockwell. (His influence can even be found in Chernoff, p. 209-210, where his interpretation of Beethoven"s music is quoted indirectly, via the novel 'Doctor Faustus', Adowno had given its author "Thomas Mann musicological assistance) Adorno occupies a remarkable position, with one foot on either side of the divide between musicological and socio-cultrital approaches to music. His writings are often highly one-sided as composer and musicologist, Adomo demanded absolute musical autonomy, while as a sociologist he used Marxist and Fteudian terminology to condemn all contemporary popular music, especially jazz, as capitalist manipulation. In spite of these fierce exaggerations, Adomo remains an outstanding critic of the mimetic forces at play in music.

Blaukopf: "Musik im Wandel der Gesellschaft", p. 218.

Cf. Friedrich Nietzsche"s description in the first section of his "Birth of Tragedy".

Cf. IJ sseling: "Mumesis", p. 7.

Taussig: "Mimesis and Alterity", p. 46.

Blaukope: "Musik im Wandel der Gesellschaft", p. 218-20.

See the survey of Ekman's theory in Frith: "Perfomance Rites", p. 215-7.

9 Ibid., p. 191-3.

10 Ibid, p. 141.

11. Ibid. p. 144-5

12 Ibid, p. 151.

13 Ibid., p. 157.

14 Ibid., p. 272.

15 Ibid., p. 275

16 Ibid., p. 274

17 Barthes: "Image - Music - Text", p. 179.

18 Frith, "Petformance Rites", p. 263.

19 bid., p. 236-7. 
20 lbid, p. 1.22.

21 lbid., p. 110

22 Rockwell: "All American Music", p. 7.

23 Respectively in this comment on Chernoffs "African Rhythm and African Sensibility", in his "Introducton" to Blackwell: "The End of Print", on the work of graphic designer David Carson; in the film "True Stories", and in the mini-essay ptinted on the sleeve of Byme"s "O Samba" -collection, on the Luala Bop-label.

24 Cf. Fith, "Sound Effects", p. 12-13 and "Perfomance Rites", p. 63-4 and 292-3.

25 A great deal has been written on the terminological distinctions between pop, popular music, folk, tock, rock and roll, and so on; cf. Frith, "Performance Rites", Pp. 75-87; one of Fith"s conclusions is that "The musical label acts as a condensed sociological and ideological argument". However, for the time being I try to use 'popular music' as a general, neutral term, "rock and roll" as the music of Elvis. Presley, Chuck Berry, Bo Diddley et cetera.

26 For example: Marcus, "Mystery Train", p. 6: "The best popular artists create immediate links between people..."

27 This sentence is a paraphrase of descriptions by John Rockwell: "All American Music", p. 238 and 221 .

28 I borrow this term from Louise Steinman: 'The Knowing Body', p. 11-13. Steinman tefers to Charles Olson's essay 'proprioception' as one of her sources; cf. below, paragraph 3.1. The 15th edition of the Encyclopaedia Britannica opens its description of proprioception by defining it as "the perception by an animal of stimuli relating to its own position, posture, equilibrium, or internal condition."

29 Artaud, quoted in Roger Shattuck, The Banquet Years, p. 327.

30 Benjamin, Reflections, p. 89 and p. 90.

31 Bytne, quoted in Gracyk: "Rhythm and Noise", p. 64.

32 Howell: "David Byme", p. 45 and 47.

33 Davis: "Talking Heads - The Biography", p. 5-6.

34 Miles: "Talking Heads" , p. 10.

35 Daxis: "Talking Heads - The Biography", p. 15.

36 Tbid., p. 21 .

37 Ibid.

38 According to his biography in the press kit for "Stop Making Sense".

39 Howell: "Dnvid Byme", p. 47.

40 Cf. Hartison: "Art \& Language: Enkele condities en interesses van de cerste tien jaar" [Art \& Language: Some conditions and interests of the first ten years], in: "Art \& Language - De Schilderijen", p. 12-13.

41 Byrne, quoted in John Howell: "David Byrne", p. 15.

42 The letter stating this question is reproduced in Davis: "Talking Heads, A Biography", between p. 85 and 86 .

43 Ibid.

44 lbid., p. 34.

45 Nielsen is the company that collects viewer ratings for the U.S.-American television system. (For an overview of the effect of such ratings on Annerican mass media, see Herman and Chomsky: "Manufacturing Consent", p. 14-18).

46 Byme, quoted in: Miles, "Talking Heads", p. 2.

47 Bytne, introduction to "What The Songs Look Like", p. 14 
Davis: "Talking Heads - The Biogtaphy", p. 38.

49 Some 30 years later, similar systems have been developed on the Internet. There are websites that alert individual subscribers when the television shows a novie that fits their personal profile of preferences. Think also of the work of conceptual artists Komar \& Malamid, investigating narional preferences for certain genres of painting.

50 Byrne, quoted in Miles: "Tralking Heads", p. 30-31.

51 Wayne Zieve, quoted in Davis: "Talking Heads: A Biography", p. 43.

52 Weymouth, quoted in Miles: "Talking Heads", p. 14

53 Eno, quoted in Davis: "Talking Heads: A Biography", p. 74.

54 John Rackwell quoted in: Miles, Talking Heads, $\mathrm{P}$. 18.

55 Davis: "Talking Heads - A Biography", p. 113, and Rockwell: "All American Music", p. 238.

56 Howell: "David Byrne", p. 12.

57 Jonathan Rée, quoted in Frith: "Performance Rites", p. 198.

58 Byme, quored in Miles: "Talking Heads", pp. 13 and 26

59 Tbid., p. 11.

60 Cf. the chapter on Randy Newman in Greil Marcus" "Mystery Train".

61 Howell: "David Byrme", p. 18.

62 See Davis: "Talking Heads - A Biography", p. 24-5, 29 and 45

63 Miles: "Talking Heads", p. 11.

64. Frantz, quoted in Miles: "Talking Heads", p. 36.

65 Byme, quoted in Miles: "Talking Heads", p. 30.

66 Some examples of lines: "I"m not a burning building", "Two different houses surround you", "I'm visining houses in motion", "And you may find yourself living in a shotgun shack ... And you may find yourself in a beautiful house, with a beautiful wife", all from "Remain In Light": the song "Burning Down The House" on "Speaking In Tongues"; the many houses, rooms, homes and cities on "The Catherine Wheel", which also contains the lines "There's a train running through / Right through the middle of the house"; and Byrne"s later solo album "Reil Momo", containing the line "I walk like a building".

67 Bytre once compared this lyric to an Alain Robbe-Grillet nowel; "just recording things ... just. description". Miles! "Talking Heads", p. 37.

68 This is a central theme of Theodore Gracyk"s "Rhythm and Noise: an Aesthetics of Rock", see chapters 2 and 3 on recording and representing, and on "record consciousness".

69 Davis:" "Talking Heads: A Biography", p. $77-9$.

70 Eno: "A Year - With Swollen Appendices", p. 293.

71. Ibid., P. 34 .

72 Davis: "Talking Heads - A Biography", p. 91.

73 Byrne, quoted in Miles: "Talking Heads", p. 36.

74 Rockwell: "All American Music", p. 234. CE. Davis: "Talking Heads - A Biography", p. 83, on the 'weitdness' of Taiking Heads in this context.

75 Byrne, quoted in Milles: "Talking Heads", p. 39.

76 Ibid.

77 Rockwell: "All American Music", p. 239.

78 Miles: "Talking Heads", p. 40.

79 Davis: "Talking Heads - A Biography", p. 101.

80 See Miles: "Talking Heads", p. 39, and Davis: "Talking Heads - A Biography", p. 99.

81 Davis: "Talking Heads - A Biography", p. 99-100. 
82 "The electric guitar, central sound of rock, has always been treated personally: the archetypical rock image is the guitar hero." Ftrth: "Sound Effects", p. 161.

83 Golclberg: "Performance Art", p. 60-61; see also Teubner: "Hugo Ball", p. 148-53.

84 Ball's poem as printed on the inner slceve of "Fear of Music".

85 The otiginal title was "Ein Krippenspiel Bruitistisch"; see Teubner "Hugo Ball", p. 146-7. Ball st thematic was undoubtedly religious, as his later development shows.

86 Milles: "Tralling Heads", p: 40.

87 Bytne, quoted in Musician 32, April-May 1981, p. 46.

88 Byme; quoted on the back cover of Chernoff's "African Rhythm and African Sensibility'.

89 Thompson: "African Art in Motion", p. XII.

90 Thompson "Aftican Art in Motion", p. 43-5. Cf. Thompson: "An Aesthetic of the Cool".

91 Byme, quoted in Musician 32, Aptil-May 1981, p. 44.

92 Chernoff" "African Music and African Sensibility", p. 1.

93 Ibid, p. 23.

94 Compate, for example, Anne Sheppard's 'Aesthetics: An Introduction to the Philosophy of Art': "It is still a widely accepted notion that one of the charactetistics of the aesthetical way of seeing is distance, aloofness or disinterestedness". Quoted from the Dutch translation, "Filosolie van de kunst", p. 80.

95 Chemoff: "African Music and African Sensibility", p. 46.

96 Ibid, p. 50.

97 Ibid, p. 50, quoting Richatd Waterman" "African. Influence on the Music of the Americas".

98 Ibid, p. 50.

99 Ibid., p. 66-7.

100 Ibicl., p. 75 87.

101 Ibid., p. 113-4.

102 Ibid, p. 121.

103 Jbid., p. 140.

104 Ibid., p. 151.

105 R.F. Thompson, quoted ibid., p. 149 .

106 lbid, p. 155-6.

107 Ibid., p. 157.

108 Ibid., p. 158.

109 David Byme and Btian Eno, interviewed by Scott Isler: "Going, Going, Ghana!"; Trousers Press 61, May 198.

110 Howell, "David Byrne", p. 40.

111 Evan Eisenberg, quoted in Frith: "Performing Rites", p. 226.

112 Miles: "Thilking Heads", p. 41.

113 Byrne, quoted in Miles: "Talking Heads" p. 41.

114 Thompson: "African Art in Motion", p. 44.

115 Chernoff: "African lihythm and African Sensibility", p. 149.

116 Ibid., p. 169.

117 Ibid, p. 150. Cf. Schechner: "Between Theater and Anthropology", p. 126-7: "Extreme care is exercised in bringing the performet out of trance. This is so because trance exhibits qualities of both personality change and inwoluntariness: the trancer clearly needs help "coming back"..."

118 See the Hnterview with Bruce Conner, in Mncdonald: "A Critical Cinema", p. 244-56. Cf. Sklar: "Movie Made America", p. 312-13. 
Byme, quoted in Miles: "Talking Heads", p. 41 .

The songs of "Remain In Light" were produced as collective collages. By improvising every musician had attributed to the results; but both Byrne and Eno could ciaim something akin to the role of musical director. This resulted in quarrels within the band about the authorship of the songs. Finally the eredits were distributed as follows: "all songs written by David Byrne, except David Byme and Brian Eno on 'Crosseyed and Painless", "Bom Under Punches (The Heat Goes $\mathrm{On})^{3}$; all atrangements by the musicians except vocal arrangements by David Byme and Brian Eno." A confusing profusion of authors that shows how the tecorded perfornative field was unusually wide-stretched for a pop record. See Milles: "Talking Heads", p. 45-6, and Davis: "Talking Heads: A Biography", p. 119-21. The actual record label, however, mertions Eno as producer and states that all selections wete written by Byme and Eno, except for "Houses In Motion" and "The Ovedoad", written by Byme, Eno and Hartison.

121 See Miles: "Talking Heads", p. 41 and 44. Musician 32, April-May 1981, p. 45, mentions that the chorus of "Bom Under Punches", "The Heat Goes On" was a New York Post headline ar the time of recotding. Bowman: "Fa fa fa fa fa fa", pp. 172 and 184 , mentions influences from Thompson and Chernoff:

122 Byme, interviewed by Ian Pye: Melody Maker, 29 November 1980, p. 25.

123 Ibid., p. 44.

124. Paul Colbert: "Musicians Only", December 13, 1980, p. 9.

125 Byrne's own explanation: "That [song] started off based on a riff we heard on a Fela [the Nigerian musician Fela Kuti] record. That started off the tecording process, but never made it onto the finished song. And the words were inspired by some reading I had done about the Yoruba religion, or whatever you want to call it. 1 guess it's not a strict religion; 1 mean, it doesn't have a dogma. It's based on the cult of the Great Mother, the Great Woman. The only thing we have left of that kind of sensibility is our idea of Mother Nature. That's the only hold-over from that, but it's a very, very old idea." Record Vol. 3 No. 4, February 1984; p. 27.

126 The lyric shows striking parallels to a text Victor Burgin includecl in his work "Franed" (1977). Burgin is a conceptual artist, strongly influenced by Art\& Language and French structuralism, "Framed" combines a photo of a desolate public environment with a prominent, framed Marlboro advertisement (with a portrait of the rugged "Marlboro Man") and a text tutled "Framed": "A dark-haired woman in her late-fifties hands over a photograph showing the haircut she wants duplicating exactly. The picture shows a very young woman with blond hair cut extremely short. The hairdresser props it by the mirror in which the can see the face of his client watching her own reflection. When he has finished he removes the coton cape from the woman's shoulders. "That"s it", he says. But the woman continues situing, continues staring at her reflection in the mirror." See Grauss (ed.): "Photo-Kunst. Arbeiten aus 150 Jahren", p. 262 3.

127 Compare Byme"s own laconic interpretation: "That's a song that juxtaposes the ordinary with the subline. The chotuses ate about the sublime and submission and ecstasy, and the verses are about the ordinary and not about disliking the suburbs or something like that, as some people have misinterpreted. To me it's mote about someone just being puzzlled about the fact that they exist and they find themselves where they are." Record, Vol. 3 No. 4, February 1984; p. 27.

128 Byrne, interviewed by Adrian Deevoy, in: International Musician and Recotding World, Augusi 1983 , p. 43.

129 Davis: "Talking Heads: A Biography", p. 134

130 Howell, "David Bytne", p. 60. 
131 Byme, interviewed in Musician 32, April-May 1981, p. 46 .

132 That the Talking Heads and Byrne had not yet fully mastered this way of working is suggested by the album"s last song, "The Overload", which lacks inner contrasts of woice, text, thythm and sound. The resulting dark drone is teminiscent of then fashionable British 'doom bands" like The Cure and Joy Division.

133 "The clip for "Once In $A$ Lifetime", directed by Bytne and Toni Basil, was included in the colllection of the Museum of Modem Art. In 1997, Rolling Stone magazine included the altbum in its list of the 200 all-tume great popular records. Other examples from the press: "From 1982 [...] to 1987, when U2 hit their stride, Talking Headls were clearly the best band in the world, both on tecord and in concert. They set out to be modern, and 16 yeats later, they still sound it." Tun de Lisle; The Independent on Sunday, 5 January 1992, p. 15. Compare the cover of Rolling Stone Magazine, January 15th, 1987: TALKING HEADS - Is America's Best Band Byraed Out? and page 34: "The world's smartest rock group [....". In 1984, Esquire magazine named Byme as one of 373 Ameticans under forty who wete changing contemporary society, he was the only "rock" star to be included. See Davis" "Talking Heads - A Biography", p. 125.

134 "Talking Heads were by no means the first tacially integrated band, but their lineup was still unusual. The wideoclip that "Toni Basil directed for the "Remain In Light" song "Crosseyed and Painlessi" would never be played on MTV, since the channel deemed a clip with black breakdancers to be uninteresting for its predominanty white audience. Bowman: "Fa fat fa fa fa", p. 226-7.

135 Miles: "Talking Heads", p. 47.

136 Ibiid.

137 Miles: 'Tallking Heads', p. 47-48.

138 Howell: 'David Byrne', p. 40.

139 Howell: "David Bytne", p. 64.

140 Unpublished interview by the author with David Bytne, March 1990.

141 Tiger and Fon: "The Imperial Animal", p. 21.

142 Ibid, p. 20.

143 Ibid., p. 22; italics in original.

144 Ibid, p. 122-3.

145 Ibid, p. xxv and p. 218.

146 See Miles: "Talking Heads", p. 40. Other sources of inspiration for the album "Fear of Music" that Byme mentioned are Randy Newman's record "Good Old Boys", Neil Young tecords, Oliver Sacks"s book of neurological essays "Awakenings", and records by Britsh new wave group Wire.

147 M. Critchley, "Musicogenic Epilepsy", in Critchley and Henson (ed.): "Music and the Brain", p. 347. According to Critchley, one in ten million adults is the victim of musicogenic epilepsy, many of then with musical abilities above the average. Ibid., p. 349.

148 Sacks: "The Man Who Mistook His Wife for a Hat", p. 177.

149 Ibid., $\mathrm{p} .42$.

150 Ibid.

151 Ibid., p. 49.

152 Ibid., p. 50.

153 Ibid., p. 48.

154 Ibid., p. xi. 
155 Oral poetry conceived of itself "as a form of social praxis (either politically engaged or ritunlistic in orientation), [in opposition to] a written and text-oriented, predominandy lyric tradition in which the poem is sinuated as a self-retlexive object, a wholly contained aesthetic field:" Sayre: "The Object of Performance", p. 177.

156 David Antin: "Modernism and Postmodemism: Approaching the Present in American Poetry", in Kostelanetz (ed.): "The Avant-Garde Tradition in Literature", p. 237.

157 Egbert Faas: "Offene Formen in der modemen Kunst und Literatur", p. $16 \%$.

158 Antin: "Modernism and Postmodernism: Approaching the Present in American Poetry", in Kostelanetz (ed.): "The Avant-Garde Tradition in Literature", p. 240; cf. Olson's essay "Human Universe".

159 For descriptions of this "first happening", paradigmatic for American performance art, Harris: "The Arts at Black Mountain College", p. 226-8, and Duberman: "Black Mountain: An Exploration in Commurity", p. 351-8.

160 Faas: "Offene Formen in der modernen Kunst und Literatur", p. 167.

161 Ibid, p. 160.

162 Olson: "Proprioception", p. 1-2.

163 Schechner: "Berween Theater \& Anthropology", p. 234. Cf. Steinman: "The Knowing Body", passim.

164 Schechner: "Between Theater \& Anthropology", p. 256. See, for examples, "The Future of Ritual", p. 13-14 and 245-50.

165 Grotowski, quoted in: Schechner, "Between Theater \& Anthropology", p. 256.

166 Goodman, quoted in Schechner: "The Future of Rinual", p. 24.1.

167 lbid.

168 Byme, interviewed by Herman van der Horst, Muziekktant Oor 13, 2 July 1983, p. 11.

169 Ibid., p. 43 .

170 Jung: "Symbols of Transformation", p. XXIV.

171 Ibid., p. XXIX.

172 Howell: "David Byrne", p. 68.

173 Davis: "Talking Heads: A Biography", p. 113.

174 See Howell: "David Byme", p. 22; Davis: "Talking Heads: A Biography", p. 126; and Byrne, interviewed by Elly de Waard. Vrij Nederland, 17 July 1982, p. 12.

175 Cf. Howell: "David Byrne", p. 77

176 Howell: "David Byrne", p. 77.

177 Chernoff, Spin Magazine, April 1988, p. 48.

178 Byme, interviewed by Elly de W/aard. Vrij Nederland, 17 July 1982, p. 12.

179 Chemoff: "African Rhythm and African Sensibility", p. 73.

180 Ibid, p. 205 (note 50). Another interesting line of interpretation might follow from Claude Levi-Strauss' dictum that modern societies are different from primitive societies as much as a steam engine differs from a watch: modernity is in constant need of explosions to kep going. (The implicit suggestion that "primitive' societies have no history, howewer, is of coutse non" sense - one might even sumise that the human condition as such goes 'boom boon boom'.)

Yet another source might be Charles Jencks" "The Language of Postmodern Architrecture". It first chapter opens as follows: "Happily, we can date the death of Modern Architecture to a precise moment in time. [...] Modern Architecture died in St. Louis, Missouri on July 15, 1972 at $3.32 \mathrm{pm}$ (or thereabouts) when the infamous Pruitt-Igoe scheme, or rather several of its siab blocks, were given the final coup de grace by dynamite. Previously it had been vandalised, muti- 
lated and defaced by its black inhabitants, and although millions of dollars wete pumped back, trying to keep it alive (fixing the broker elevators, tepaiting smashed windows, repainting), it was finally put cout of tris misery. Boom, boom, boom" (Robert Wilson included filmed footage of these explosions in the Geman part of his CVIL warS.)

Or think of Tristan Tzara's "Dada manifesto" of 1918 : "Philosophy is the problent looking from any angle at life, god, the idea or whatever. Everything one looks at is wrong.... When I call:

DOEAL, DEAL, $\mathrm{DOE} A$

KNOWLEDGE, KNOWLEDGE, KNOWLEDGE

BOOMBOOM, BOOMBOOM, BOOMBOOM,

this is farly accuratie account of progress, the law, motality and all other beautiful qualities which all kinds of very intelligent persons have discussed in so many books to state finally that everyone has danced to the thythm of his own boomboom and was tight as far as his boomboom goes ." Author"s translation, from: Drijkoningen e:a., "Historische Avantgarde", p. 174.

181 One result of this has been, that Byrne's music has been used for a vety high number of ballet and theater productions: probably hundreds all over the world. By 1997, the archives of the Theatre Institute of the Netherlands alone contained records of 20 different Dutch productions which had used Byrne's work.

182 Davis: "Talking Heads - A Biogtaphy", p. 131.

183 This kind of explanation has been put forward often in reviews; for example by John Howell in his monograph on Byrne: 'David Byrne', p. 142 and 144.

184 Bernie Worrell, for example, was a musical prodigy trained at consetwatories in Boston and New York, before he tutned to playing funk. Bowman: "Fa fa fa fa fa fa",p. 180.

185 Byme, interviewed by Anthony DeCurtis, in: Record Vol. 3 No. 4, Februnry 1984, p. 28.

186 Scott Isler: 'Going, Going, Ghanal David Byme and Brian Eno bring Africa to Soho'. Trousers Press 61, May 1981.

187 Jbid,

188 Acts of the Apostles, chapter 2, verse 2-9. "Suddenly there came from the sky what sounded like a strong, driving wind, a noise which filled the whole house where they were situng. And there appeared to them flames like tongues of fire distributed among them and coming to rest on cach one. They were all filled with the Holy Spirit and began to talk in other tongues, as the Spirit gave them power of utterance.

Now there were staying in Jerusalem devout Jews drawn from every nation under heaven. At this sound a crowd of them gathered, and were bewildered because each one heard his own language spoken; they were amazed and in astonishment exclamed, Surely these people who. are speaking are all Galileans! How is it that each of us can hear them in his own native language $p^{\text {xn }}$

189 Byme, interviewed by Herman wan det Horst, Muziekkrant Oor 13, 2 July 1983, p. 11.

190 Dawid Byme in an interview with Herman van der Horst and Bart van de Kamp, Muziekkrant Oor Nr. 1, 11 januari 1986, p. 12.

191 The biblical episode of the Pentacost has always inspired forms of Christianity that stress a persomal experience of God. A major example is twentieth-century Pentecostalism, founded in 1900 in Topeka, Kansas, by evangelist Charles Parham. Parham and his followers claimed to have tecovered the ancient gift of speaking in tongues or glossolalia, and founded their own church (or sect), stressing the role of emotion in religious worship. Pentacostal Holiness theology combines this freewheeling spiritual experience with a rigid and fundamentalist theology, 
claiming the absolute athority of husband over wife, inerrancy of the Bible and teaching the doctrine that at the end of the world, Jesus will hut the unsaved into a lake of tire to suffer endless torture. Nowadays, Pentecostalism claims from 200 up to over 400 million adherents worldwide.

192. Davis: "Talking Heads: A Biography", p. 130.

193 Byme, interview with R.F. Thompson, Rolling Stone Magazine, April 21, 1988, p. 52.

194 The hit was bought through payola: Wamer Bros. paid to get the song on playlists. Although this is common practice in the music industry, this manipulation of the audience meant a decep disillusion for Byrne, that was to have a lasting effect on him. See Bowman: "Fa fa fa fa fa fa", P. $257-8$.

195 Byrne, interviewed by Anthony DeCurtis in: Record Vol. 3, 4, February 1984; p. 27. A different version was told by Tina Weymouth, in the liner notes of the Talking Heads' greatest hits CD "Sand In The Vaseline"; according to her, Byrne heard the line fitst ftom Chris Frantz:

196 Byrne, quoted in Hebdidge: "Hiding In The Light", p. 259, note 1.

197 Rauschenberg had already made similar wotk in the sixties, "Rexolwers" consisting of a series of large transparent disks full of photographically reproduced images, mounted in special holders. These pieces, however, were made for museums or private collectors, whereas the album cover was produced for a mass matket.

198 Brian O'Doherty: "American Masters: The Voice and the Myth", p. 198 and 201.

199 Jung: "Psychology and Alchemy", p. 98

200 Tbid., p. 41.

201 Ibid., P. 186.

202 Tbid.

\section{CHAPTER 3 FILM AND PERTORMANCE THEATRE}

1 Byrne, quoted in Bowman: "Fa fa fa fa fa fa", p. 91.

2 Demme did film such shots, but later decided not to use them. Bowman: "F" fa ta fa fa fa", $p$. 264.

3 When I asked what her advice had been, Byme did not remember: "At one point I got to know JoAnne Akallaitis, and I think I invited ther to a rehearsal, to say, will you look at this and tell me what you think - if you think this is working. I don't remomber what she said, it might have been just only a little bit, but it was obviously helpful." Byme, interviewed by the author, 22 February 1999.

4 Bytne, interviewed by R.F. Thompson, Rolling Stone Magazine, 2* April 1988, p. 52.

5 Carter Ratcliff, Artforum, May 1985, p. 97.

6 Bowman: "Fa fa fa fat fa fa", p. 311, and Rolling Stone Magazine, 15 January 1987, p. 58.

7 Bytne, interviewed by Melinda Camber Potter, The Manipulatot, spting issue 1984, pages unnumbered.

8 Byrne, e-mail to the author, 14 May 1999.

9. Wilson: "the CIVIL warS", p. 60-68 contains an overview. A biting critic|ue of Wilson"s work for the Olympics as depolitization can be found in: Birringer: "Theatre, "Theory, Postmodernism", esp. chapter 10, called "Kneeplay: Can Witches Rly?". In spite of its title, this does not refer to Wilson and Byme"s "Knee Plays".

10 Record, June 1985 , p. 13.

11 Shank: "American Alternative Theatre", p. 134. 
12 As a matter of fact, this is guite in keeping with the initiator of American performance theatre, John Cage, whose collaborations with orher arcists working in different media, like Merce Cunningham or Robert Rauschenberg, usually combined music, dance and decorations more or less at random.

13 Shank: "American Aternative Thearre", p. 126-7.

14 Jbid:

15 For an overview see Willson: "the CIVIL wars", p. 66-8.

16 Byme, interviewed by laurence Shyer: "The Forest: a preview of the next Wilson-Byrne colllabotation", Theater, Summer/ $\mathbb{F}^{2}$ all 1988.

17 Cf. Wilson's statements in an interwew with Dorne Mignot, in: Beeren et al.: "Energieën".

18 Byrre, quoted in: Howell, 'David Byrne", p. 86.

19 Hid.

20 Since Byrne's brass quintet is not accompanded by a piano, it depends on a highly accurate ren. dition for its staccato punctuations. See "Down Beat", October 1985, p. 21.

21 Bowman: "Fa fa fa fa fa fa", p. 283.

22 Quoted from the book jacket of Turner: "Howard Finster".

23 Turnet: "Howatd Finster", p. 161-2.

24 It should perhaps be explained that this was no case of "rockstar exploits naive artist". Finster had an established career as an artist, was represented by New York gallerist Phyllis Kind since 1981, had received a grant from the National Endowment for the Arts in 1981, and was one of America's representatives at the 1984 Venice Biennale. Finster used the commission to further his own purpose: "I'm trying to reach mote people now than I did when I was preaching. On the Talking Heads [album cover] there are twenty-six wholesome verses of mine. That album sold over" a million copxies. I had twenty-six million verses go out and reach the world. That's more than I ever reached in the forty-five years I was pastoring. The rock-and-rollers are my missionaries." "Tutnet: "Howarcl Finster", p. 162; see pages 34,116 and 158 for an account of Finster's career.

25 According to Hebdidge, "Hiding In The Lighe", p. 235, the video was "frequently cited as one of the most technically complex and original micto-narratives yet produced for promotional purposes."

26 A more detailed descriprion has been giwen by Dick Hebdidge: "Hiding In The Light", p. 235 9.

27 Dick Hebdlidge: "Hiding In The Light", p. 259-60, notes 5 and 6.

28 Byrne, interviewed by R.F. Thompson in: Rolling Stone, Aprill 21st, 1988, p. 48.

29 Cf. Kietan Conlon, quoted in Hebdidge: "Hiding In The Light", p. 237 and 259 note 2.

30 Sec Film Comment XXII/5, Sept.-Oct. 1986, p. 63, and Howell: "David Byme", p. 67.

31 Sayre: "The Object of Performance" p. 266.

32 Byrne: "Thue Stories", p.9.

33 Cf. Howell: "David Bytne", p. 63.

34 Byme: "True Stories", p. 15.

35 Richard Corliss, in Film Comment XXII/6, Now. Dec. 1986, p. 17, characterizes their work: "Her plays (Crimes of the Hearr) and movies (Nobody"s Fooll) are at pains to idealize doodlers in the margins of southern propriety, the script that she and her frequent collaborator Stephen Tobolowsky delivered to Byme is crammed with lovable geeks."

36 Byme: "True Stories", p. 15.

37 Howell: "David Byrne", p. 61. 
Thid., p. 64.

39 See Henry M. Sayre, "The Object of Performance", p. 265

40 Ibid. This music of this "Road Song" was composed by Meredith Monk and arranged by Dawid Byrne:

41 David Byrne: "True Stories", p. 22

42 This is the voice-over as spoken in the film; the book contains a slightly different version.

43 Description copied from Sayre: "The Object of Performance", p. $265-6$.

44 Tiger and Fox: "The Imperial Animal", p. 50.

45 Byme, in Howell, "David Byme", p. 68. As noted in "True Stories" titles, the found footage was compiled for Bytne by $\mathrm{M} \& \mathrm{CO}$, a maverick advertising agency from New York.

46 They are reprinted in: David Byrne: "True Stories", p. 40.

47 Tbid., p. 39 and 105 .

48 The actual quotation from Steve Jobs appeared in a Newsweek article, reprinted in Byrne: "True Stories", p. 39.

49. David Byme: "True Stories", p. 176 and 178.

50 Ibid., p. 34, p. 48 , p. 50 , p. 88

51 This statement is linown as the "Thomas "Theorem". See Lewis A. Coser, "Masters of Sociological Thought. Ideas in Historical and Social Context", p. 521

52 M.-L. von Franz: "The process of individuation", in Jung (ed.): "Man and his Symbols", p. 180. Another possible source for the mind as a musical radio can be found in Sacks:" "The Man who Mistook his Wife for a Hat", p. $125 \mathrm{ff}$; here Sacks tells the story of a patient who experienced a radio station in her head that played songs from her childhood in lreland. According to Sacks, these transmissions were caused by epileptic transports which produced authentic childhood reminiscences. (p. 137-8). Byme has read both Jung and SAcks; the may even have combined both stories in his song "Radio Head".

53 For Byme"s ideas around this subject, see "True Stories" p. 42.

54 David Bytne: "True Stories", p. 12

55 Ibid., p. 50.

56 This trilogy is extensively discussed in Savtan: "Breaking the Rules", part II.

57 Shank: "American Alternative Thearre", p. 170-71.

58 Savtan: "Breaking the Rules", p. 81.

59 Tbid., p. 91 and 95.

60 Ibid, p. 92.

61 Fid.

62 Elizabeth LeCompte knows Bytne well, and would like to work with him if the opportunity should arise. She told me this in 1998, when the Wooster Group was the main guest of the Holland Festival.

63 However, Byme's participation also helped him to get the film financed. Howell, "David Bytrue", p. 63 .

64 Also another scene, "an illuminated stage in a barten field at night, seemed to pay homage to Wilson by alluding to the space ship in "Einstein on the Beach". Jody Dalton in EAR Magazine 11, 1988.

65 Sayte: "The Object of Performance", p. 109.

66 Byme: "True Stories", p. 56.

67 lbid, p. 100.

68 Ibid., p. 60 . 
69 A picture and a description of this altat are included in Byrne's "True Stories" book, p. 140 . Documentation of similar alcars can be found in Thompson: "Face of the Gods".

70 Bytne: "True Stories"

71 A general introduction that was used by Byme is Deren: "The Voodoo Gods" (original 1953 title: "Divine Horsemen").

72 Byrne: "True Stories", p. 143.

73 Kruger: "Remote Control", p. 190-92; first published as "The New York Film Festuval" in Artfotum, Sept. 1989 , p. $18-19$.

74t Mckim: "True Stoties" in: Cineaste XV/3, 1987: p. 44 and 45.

75 Tbid., p. 45 .

76 Schecter, "Beyond the Texi", p. 174.

77 Ibid., p. 176.

78 See Film Comment XXII/6, Now.-Dec. 1986, p. 17.

79 See the introduction on Mabou Mines in Martanca: "The Theatre of Images", p. 113-8.

80 See Breuer's essay "The Theatre and Its Trouble", especially paragraph 29, interspersed throughout his bundle "Sister Suzie Cinema": p. 51-3, 66-7, 87-9, 102-3, 123-5.

81 This tem was introduced by anthropologist Claude Lévi-Strauss in "The Savage Mind" to describe "tinkering" with a diversity of materials readily on hand, instead of the homogeneous constructing of the engineer. Richard Schechner has applied it to describe a form of theatre: see his "Between Theater and Anthropology", p. 230.

82 Byme, interview with the author, February 22, 1999

83 This tape was given to me by Byme in 1999.

84 Schechner: "The End of Humanism", p. 118.

85 However, since I have not seen the staged play, I can not distinguish how much of the film"s music (opera, musical, japan-esque sounds) comes from that original production and how much was added by Bytne.

86 Byme, interviewed by liaurence Shyer in: Theater, Summer/Fall 1988.

87 Wilson, interviewed by Jody Dalton, EAR Magazine 11/1988, page 1 of the interview.

88 Ibid.

89 Ibid.

90 Byme, in: Rüter, C., and Weber, G.: "The Forest" (theater programme), chapter VIII, "Music".

91 Byme, quoted in Howell: "David Byme", p. 82.

92 Other sources for the text ate two stories by Edgat Allen Poe, and the "Florentine Codex", a pre-Columbinn work originally written in Aztec. See Marranca: "The Forest as Archive", p. 39.

93 Wilson, interviewed by Jody Dalton, EAR Magazine 11/1988, page 2 of the interview.

94 Pinckney, in: Rüter, C., and Weber, G.: "The Forest" (theater programme), chaprer X., "Textwork".

95 Bytne, interviewed by Manuel Bonik in: Whener, October 1988, p. 5 of the interview; and John Rockwell, New York Times Magnzine, 9/11/1988, p. 86.

96 Bytne, quoted in Howell: "David Byrne", p. 85.

97 Bytre, in: Ritter, C., and Weber, G.: "The Forest" (thearer programme), chapter VIII, "Music".

98 Bytne, interviewed by Manuel Bonik in: Wiener, October 1988, p. 5.

99 Bytre, in: Rüter, C., and Weber, G.: "The Forest" (theater programme), chapter VIII, "Music".

100 Byrne"s "songr", as printed in the theater programme for "The Forest", Act 1.

101 Cf. Wolfgang Wiens, dramaturge for the German part of Wilson's "CIVIL wars", in: Wilson: "the CIVTL, warS", p. $46-8$. 
102 Wilson, in: Rüter, C, and Weber, $G$ : "The Forest" (theater programme), chapter $\mathrm{X}$, "Textwork".

103 Marranca: "The Forest as Archive", p. 43.

104 As told in Howell: "David Byme", p. 63. According to Q Magazine, December 1986, no. 3, p. 29, Despite being the leader of perthaps the most critically celebrated pop group in the world, David still had to peddle the script of "True Stories" tound for a year till hed raised the finance." According to The Guardian of Sept. 16,1986, Warner initially turned Byme's proposall down twice.

105 See Howell: "David Byrne", p. 82, and Manuel Bonik, Wiener, October 1988.

106 Byrne, interview with the author, February 22, 1999.

107 John Rockwell, New York Times Magazine, 9/11/1988, p. 84.

108 Byme, quoted in Howell: "David Byrne", p. 82.

109 Byme, text in the booklet of The Forest-CD, February, 1991.

110 Byme, interviewed by Mannel Bonik, in: Wiener, October 1988, p. 6 .

\section{\begin{tabular}{l|l} 
CHAPTER 4 & ANTHROPOLOGY AND MUSIC
\end{tabular}}

1 CE. Kosuth: "Art after. Philosophy and After", esp. p. 119.

2 Appadurai: "Modemity at Large", p. 4.

3 The booklet with the $\mathrm{CD}$ wersion of "Naked" reviews the complete recording process extensively.

4 Byrne, interviewed by Chemoff." "Spin", April 1988, p. 50.

5 Ibid

6 Byme, interviewed by R.F. Thompson: Rolling Stone Magazine, April 21st, 1988, p. 52 and 116.

7 Ibid, p. 43 .

8 Figures in Bowman: "Fa fa fa fa fa fa", p. 359.

9 Chernoff, Music \& Sound Output, May 1988, p. 42.

10 Chemoff, quoted in Bowman: "Fa fa fa fa $\mathrm{fa} \mathrm{fa}^{\text {" }}, \mathrm{p} .325$.

11 See Howell, "David Byrne"; p. 53.

12 Thompson, Rolling Stone Magazine, April 21st, 1988, p. 42.

13 Tbid.

14 Ibid, p. 44.

15 Ibid., p. 48.

16 Byrne, e-mail to the author, June $15,1999$.

17 CF. Howell: "David Bytne", p. 73.

18 Byme, e-mail to the author, June 15, 199\%.

19 Byrne, quoted in Howell, "David Byme"

20 According to John Howell."David Byrne", p. 33, "Ilé Aiyé" was also exhibited as part of "Magiciens de la Terre", the Parisian exhibition of 1989 that attempted to give an overwiew of artists working in different ctultures all over the world. This is a mistekte, perhaps due to the fact that two documentaries by Philip Haas, for which Byrne made soundtracks, were part of a sideprogram of "Magiciens de la Terre".

21 Quoted in Bowman: "Fa fa fa fa fa fa", p. 336.

22 Byme, interview with the author, February 22, 1990

23 J.M. Chernoff, "African Rhythm and African Sensibility", p. 148.

24 Ibid. 
25 Byrne, liner notes for "Beleza Tropical. Brazil Classics 1; June, 1988.

26 As recorded by Robert Farris Thompson, Rolling Stone Magazine, April $21 \mathrm{st}, 1988$, p. 44 .

27 Byme, in: Howell, "Dawid Byrne", p. 59.

28 This is too general, if only because a few of the musicians are white; yet the general contrast is real Compate Zota Neale Hurston: It is said that Negroes [...] have no reserve. [...] There is no privacy in an African willage." "The Sanctifred Church", p. 60 .

29 De Volkskrant, 13 juni 1997, p. 29.

30 Byrate recorded a cover version of Porter"s "Don't Fence Me In" for a compilation of covers by several artists, "Red Hot \& Blue", an ADDS-benefit.

31 Bytne, interwew with Craig Bromberg, Rolling Stone Magazine, January 11 th, 1990, p. 48.

32 Byme; "The Rei Momo Tour Diary", in: Howell: "David Byrne", p. 107.

33 Quoted by Carl Hindmarch, Elle magazine, January 1990 , p. 35.

34 "Artistically and sociologically, [Latin music] is a ghetto" Rockwell, "All American Music", p. 199. Angel Fernandex explained: "When I played Latin music, I played to people who spoke Spanish and you wouldn't see blacks or Anglos in the crowd wery much. It was like a mation within a nation. Yet we all speak English; we've been bi-cultural for a long time. Many of us grew up in New York and played rock, jazz and funk as well as Latin." Q Magazine, Felbruary 1990, p. 38.

35 Byme, interview with Craig Bromberg, Rolling Stone Magazine, January 11 th, 1990, p. 48.

36 Idem.

37 This was the criticism of Jon Pareles in his New York Times review, quoted in Howell: 'David Byrme', p. 34. One of the presidents of Warner Btothers, Byrne's record company, was of the same opinion; see idem, p. 137.

38 In Howell: "Dawid Byme", p. 105-138.

39 Byrne: "Tour Diary, in Howell: "David Byrne", p. 131.

40 Ibid $_{n}$ p. 134 ; cf. p. 131.

41 Ibid., p. 123-4.

42 lbid. pp. 108, 126, 129.

43 Tbid., p. 119.

44 Ibid., p. 122 .

45 Ibid., p. 125.

46 Ibid. p. 125 and 138.

47 Byme, interview with the nuthor, 1 rebruary 22, 1999.

48 See for an introductory overview: Jan Nederveen Pieterse: "Multiculturalism and Miseums. Discourse about Others in the Age of Globalization" In: Theory, Culture and Sociery, 1997, Vol. 1.1.(4): 123-146.

49 E-mail message to the author, May 14, 1999.

50 Byme, liner notes for "Beleza Tropical - Brazil Classics 1".

51 Compare Byrne's arricle "Crossing Music's Borders: 'T Hate World Music", New York Times, Sundany, October 3, 1999.

52 The full story of "The making of Feelings", as told by Byrne, can be found on Luaka Bop's website.

53 Bowman: "Fa fa fa fa fa", p. 350 .

54 Compare "A Propaganda Model", the introductory chapter of Herman and Chomsky's "Manutacturing Consent" p. 1-35, and the paragraph on "Tone of negativism and apathy" in the same book, p. $118-20$. 
Byme, interview with the author, February $22,1999$.

\section{GHAPTER $5 \mid$ PHOTOGRAPHY AND BOOKS}

1 Cf. Sayre: "The Object of Performance", pp. 35-65, on the thetoric of photography, and Ftizot (ed): " $A \mathrm{New}$ History of Photograplyy", p. 713-7, on 'the inner theater" of photography.

2 Aniela Jaffe, in Jung: "Man and his Symbols", p. 232.

3 Byme: "True Stories", p. 12.

4. According to Jerry Harrison, Byrne originally had selected several of his own artworks for the book, but was conwinced by him to leave them out, refraining from incerpreting his own lytics. Muziekkrant Oor, February 13, 1988, p. 43

5 Talking Heads and Frank Olinsky: "What The Songs Look Lilke", p. 14.

6 Artforum, December 1989, p. 100-105.

7 Parkett no. 23, March 1990. p. 119-129.

8 Tbid., p. 120.

9 Catalogue: "Reproduced Authentic", an exhibition curated by Joseph Kosuth for Galerie Via Eight on the occasion of the opening of Barneys New York. Tokyo, November 3rd-16th, 1990.

10 As related by Azby Brown (AB): "Reproduced Authentic", in: Artforum, February 199\%, p. 141.

11 Ibid. (The Chinese characters are not exactly scrawled on top of the image, but rather on a transpatency covering the plate.)

12 Prizes as stated by Bart de Leenheet, Byrne's gallerist in Mechelen, Belgium.

13 Bytne: "Strange Ritual" (pages not numbered).

14 Byrne, interview by Ken Coupland, in: Graphis, international joutnal of graphic art and applied art, Issue 313,1998, p. 99.

15 This distinction was made by Szarkowski, for "Mirrors and Windows: American Photography" Since 1960" (MoMA, 1978). Quoted in Sayte, "The Object of Performance", p. 35.

16 From: Byrrne, "Strange Ritual" (pages not numbered).

17 Andy Grumberg, writing in The New York THmes Book Review, ptaised Bynne's photos for their "distinctive and offlbeat manner", but described his wtiting as "less sure than his eye". Quoted in ARTnews, October 1996, p. 122.

18 Moze Jacobs: "David Byrmes Amerika", Vrij Nederland, 23 april 1994, p. 41.

19 A press statement, issued by Byme's office: "In particular, the lack of people stands out in his work. On this aspect, Bytne likes to quote writer/critic Wright Morris, who wrote in another context about this quality of photography: "Only in their absence will the observer intuit, in full measure, their presence in the object."

20 Byme, "Strange Ritual", and notes.

21 lbid.

22 Byme, inteniew by Elisabetta d'Enme, Il Manifesto, September $12,1998$.

23 Bytne, interview by Elisabetta d'Erme, Il Manifesto, September 12, 1998. A CD of the soundtrack was published in 1998 by Aktionsforum Praterinsel, Münich, Germany. A comment on the audioguide: "Seeing the show with the headphones on transforms what is a less-than involving show about the manipulations of mass culture into a brainwashing." Sarah Boxer, The New Yotk Times, Sunday, August 18, 1996, p. 35.

24 Quoted by Jackie Bennion, Wired, February 1998, p. 136.

25 Byrne: "Strange Ritual", excerpts from an interview with Chris Titterington (pagges not numbered). 
26 Bytne: "The New Sins", p. 13-15.

27 Hid, p. 23.

28 1bid, p. 39

29 hid, p. 47.

30 lbid $_{4}$, p. 11

31 lbid, p. 87-89.

32 bid, p. 21-23.

33 Thid., p. 59.

34 Novalis; quoted in Wanning: "Novalis" "p. 61 and 144.

35 Byrne, in the documentary "Talking Heads vs. The Television".

36 Byme, press release accompanying the exhibition "The Wedding Party", gallory LipanjePuntin, Trieste, Italy, Nowember 25, 2000 - January 31, 2001.

37 Ibid.

38 Novalis: "Fragmente und Studien 1799-1800", Werke, p. 560.

39 Byme, quoted on a leaflet of the "Aktionsform Praterinsel", Munich, accompanying his 1998 exhibition.

40 Bourdieu: "On Television", p. 18.

\section{CHAPTER 6 | EXPLORING THE FOUNDATIONS OF PERFORMANCE}

1 Unpublished interview by the author with David Byme, March 1990.

2 Campbell: "The Hero's Journey", p. 135.

3. Ibid, p. 159. Cf. Jung: "Symbols of Transformation ", p. 158: archetypes "correspond to the concept of the "pattern of behaviour" in biology."

4. Campbell, "The Hero's Journey", p. 4.5.

5 Campbell, "Primitive Mythology", p. 31-2. Campbell quotes from Jung: "Psychologische Typen".

6 See Campbell, "Primitive Mythologp", p. 32-33

7 libid.

8 Jung: 'Symbols of Transformation', p. XXIV (Foneword to the fourth (Swiss) edirion).

9 Ibid., p. XXIX (Foreword to the second (Geman) edition).

10 See Vandermeersch: "Unresolved Questions in the Freud/Jung Debate". p. 39-42. The classical representative of this romantic conception was E. von Hartmann, by whom Jung was profoundly influenced. Jung also refered explicitly to Fichte and Schelling in his exposition of the unconscious, see Jung, "Symbols of Transformation", p. 29, footnote, and p. 176. Other rom mantic influences were Goethe, Schopenhauer and Nietzsche; cf. p. 43.

11 See Trank: "Der kommende Gott" ${ }^{\text {p p. }} 85$.

12 Vandemeersch: "Untesolved Questions in the Freud/Jung Debate", p. 105-6.

13 Ibid, $\mathrm{p}, 70$.

14 Mbicl., p. 272-3.

15 Mbid., p. 276.

16 لung: "Symbols of Thansfotmation", p. 86.

17 lbtid, p. 60.

18 Bid., p. 66.

19 Cf. Vandetmeersch: "Unresolved Questions in the Freud/Jung Debate", p. 276-7.

20 Camplell: "Primitive Mychology", p. 33-4 
21 Tbid., p. 41 .

22 Cf. Keesing: "Cultural Anthropology", p. 404.

23 See for example Taylor: "The Death and Resurrection Show". Tyylor's book is built around the idea that shamanism has become showbusiness, and accordingly analyzes the work of stars like Charlie Chaplin, Louis Amstrong, Bessie Smith, Bøb Dylan, Jimi Hendrix, David Bowie and John Lennon as forms of shamanism.

24 Jung: "Ciwilization in Ttansition", p. 184-5.

25 As related by Frank, "Der kommende Gotr", p. 33. Campbell wrote in st similar vein: "this is one of the problems of our whole biblical tradition. Here is a mythology that grew out of a social context that is so far away from what we have now that it is not serwicing our psyches." "The Hero"s Journey", p. 204. The very idea that a mythology can have growt out of a social context seems to be foreign to Campbell and Jung's basic tenets; they apply the distinction between "genuine" and "inauthentic" myths uncritically.

26 Campbell: "The Hero's Journey", p. 204.

27 Ibid., p. 205.

28 Unpublished interview by the author with David Byme, March 1990.

29 Tiger and Fox: "The Imperial Animal", p. 21.

30 Ibid. p. 20

3. Tbid., p. 21.

32 Ibid., p. 22; italics in the original.

33 Ibid., p. 14.

34 Ibid., p. 14-5.

35 Ibid., p. 122-3.

36 Ibid., p. 80 .

37 See Keil and Feld: "Music Grooves", p. 189.

38 Tiger and Fox: "The Imperial Animal.", p. xxw.

39 Ibid., p. 211.

40 Ibid., p. 110.

41 Ibid., p. 218.

42 Wilson: "On Human Narure", p. 208. See "The Imperial Animal", p. xvi for Tiger and Fox's reservations about Wilson's theory.

43. Byrne, e-mail to the author, May 141999.

44 For a critical recent overview of evolutionary psychology and sociobiology, sec Steven Rose:

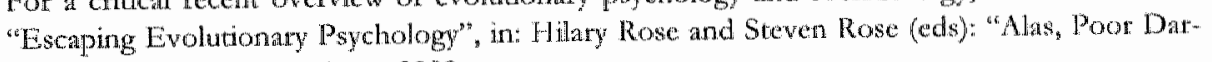
win"; London: Jonathan Cape, 2000.

45 lbid., p. 262.

46 Byrne, interviewed by R. F. Thompson, Rolling Stone Magazine, April 21 st, 1988.

47 Ibicl.

48 Hebdidge: "Hiding In The Light", p. 238.

49 Byme: "True Stories", p. 100.

50 Respectively from the "Speaking In Tongues" song "Slippery People" and from the "Catherine Wheel" song "His Wife Refused".

51 Jung: "Psychology and Alchemy", p. 106.

52 Byrne, interviewed by R.F. Thompson, Rolling Stone Magazine, April $21 \mathrm{st}, 1988$.

53 Byme, liner notes for the laserdisk edition of "llé Aiye".

54 Byme, "The making of Feelings", Luaka Bop website, 1998. 
55 Byrme, interwiew with Manuel Bonik, Wiener, October 1988.

56 Byrne, in the Rolling Stone interview with R.F. Thompson, April 21st, 1988, p. 49: "I think. I persigt in thinking that what we mingt call evil, or the devil or whatever, is people just not listening to themselves. That might be naive. ... the potential for becoming disconnected from the energy source or whatever, becoming disconnected from yourself. That potential is in all of us."

57 Jennings: "Pandaemonium", p. xxrwii.

58. Ibid, p: xxxviii.

59. Tbid.

60 Alexander et. al. "The Oregon Experinent", p. 2.

61. Mbid, p. 10. Cf. Alexander"s. "The Timeless Way of Building", p. 496: "The question is: can the structure emerge, simply from the spontaneous interaction of parts?... Or must it be planned, by a hidden hand, according to a blucprint or plan?... To put this question in perspective 1 whould like to compare it to a question that arose in the early years of biology? "How does an otganism get formed?"

62 Alexander et. al.: "The Oregon Experiment", p. 5-6.

63 Alexander et. al:: "The Oregon Experiment", p. 2.

64 Alexander: "The "Timeless Way of Building", p. 253.

65 Ibid, p. 231 .

66 lbid, p. $225 \mathrm{ff}$.

67 Alexander, "The Timeless Way of Building", p. 545.

68 Ibid., p. 13.

69 Ibid., p. 347.

70 Ibid., p. 542-3.

71 Howell: "David Byme", p. 65.

72 Ibid.

73 Byme: "True Stories", p. 30.

74 Like Jennings' "Pandaemonium", Byme read this in preparation for "The Forest"; New Musical Express, 19 th March, 1988, p. 15.

75 The Independent on Sunday, Arts section, 19 April 1992.

\section{CHAPIERT I PERPORMANCE THEORY IN THE THEATRE}

1 Savan: "Breaking The Rules", p. 2-3. For a description of Schechner's theatre, see Shank, "American Alternative Theatre", p. 93-103.

2 See Savtan: "Breaking The Rules", p. 3-5. Schechner's own version of this history can be found in "Between Theater and Anthropology", p. 261-93.

3 Schechner: "Between "Theater \& Anthropology". p. 21.

4 Schechner: "The End of Humanism", p. 20.

5 Ibid., p. 21.

6 Sethechner: "Between Theater \& Anthropology", p. 23. See p. 221: "the theater of the 1960s and 1970 s was not a thearer of new plays, of literary texts interpreted at all, but a theater of new mise-en scenes - a thearet of whole performance texts consisting of movements, stage placement and rableaux, music (and other sonic elements), visuals including settings, environments, costumes, projections, and a number of nonactor performers: masks, puppets, projections, films." 
Schechner: "Between Theater \& Anthropology", p. 135. An example of the political orientation of Schechner's own experiments is "Guerilla Warfare". Anti-Vietnam War performers "kill a Vietcong" in the streets of New York City, October 1967. Five groups of actors, directed by Schechner, petformed without advance notice at twenty-two locations including Grand central terminal, Lincoln Center for the Performing Arts, Times Square; and the United Nations." See ilbid., p. 49.

8 Hbid, p. 118.

9 Schechner: "The End of Humanism", p. 80, quoting from Léviwstrauss' "The Savage Mind".

10 Schechner: "The End of Humanism", p. 80.

11 Schechner: "Between Theater \& Anthropology", p. 6.

12 Ibid., p. 35.

13 Ibid, p 37.

14 Ibid., p. 118

15 Ibid, p. 16

16 Ibid. p. 37.

17 Ibid., p. 14.

18 mid., p. 113

19 Ibid., p. 111-2.

20 Ibid., p. $125-6$.

21 Ibid, p. 130.

22 Schechner: "The End of Humanism", p. 84.

23 Schechner: "Between Theater \& Anthropology", p. 234. Cf. Steinman: "The Knowing Body".

24 Quotes from a grant proposal by Grotowski, in Schechner: "Between Theater \& Anthropology", p. 256.

25. See especially: "The Natural / Artificial Controversy Renewed", in "The End of Humanism", p. 77-92; "Performer Training Interculturally", in: "Between "Theater \& Anthropology", p. 21360 ; and "The Future of Ritual", in: "The Future of Ritual", p. 228-65.

26 Schechner: "The Future of Ritual", p. 228

27 ibid., p. 229.

28 Tbid., p. 230.

29 Ibid, p. $239-40$.

30 Ibid., p. 263.

31 Schechner: "Between Theatex \& Anthropology", pp. 4 and 6.

32 Schechner: "The End of Humanism", p. 21

33 Ibid., pp. 30 and $66-9$.

34 See for this schematic overview: "The End of Humanism" p. 104-6.

35 Schechner: "Between Theater \& Anthropology", p. 260.

36 Schechner: "The End of Humanism", p. 106.

37 See the extensive and densely argumented chapter on restoration of behaviour in "Between Theater \& Anthropology", p. 35-116.

38 Schechner: "Between Theater \& Anthropology", p. 94

39 Schechner: "The End of Humanism", p. 106.

40 Schechner: "Between "Theater \& Anthropology", p. 314.

41 Ibid., p. 315.

42 Jack Richardson: "Six a'Clock Prays: TV News as Pop Religion" Harper's, December 1975, p. 38; quoted in Schechner: "Between Theater \& Anthropology", p. 314. 
Laurie Anderson: "United States" - book, the full performance is also available as a set of four CD"s; gelections of songs were issued on the albums "Big Science" and "Mister Heartbreak".

The Wooster Group: see Sawran: "L.S.D. (...Jusit the High Points...). History as Hallucination", in "Breaking the Rules", p. 169-220.

47 This is diametrically opposed to Schechner's practice as a director. Wilson: "What I was doing did not resemble the Living Theatre, The Open Theatre, or the Performance Group... I loathed the way their theatre looked." Holmberg. "The Theatre of Robert Wilson", p. 2.

48 Holmberg: "The Theatre of Robert Wilson", p. 139.

49 Jbid., p. 23: "child abuse haunts Wilson's psyche and his work."

50 Wilson, quoted in Holmberg: "The Theatre of Robert Wilson", p. 97.

51. Hans-Thies Ifehmann: "Robert Wilson, Szenograph", in: Parkett 16, 1988, p. 34. However, Willson often instructs actors to think about murdering the audience: "Rehearsing "Quartet", he told Lucinda Childs to pick our particular people she wanted to kill: "I've got a gun. I'm going to shoot the lady in the red sweater in the second tow. But make sure you smile sweetly at her." On the surface impeccable manners. Underneath destructive nge." Holmberg* "The Theatre of Robert Wilson", pu 194.

52. Shank: "American Alternative Theatre", p. 125-7.

53 Marranca: "The "Theatre of Images", p. 44.

54 Wilson, "The Forest", chapter $V$, "Workshop".

55 Ibid.

56 Wilson, quoted in Cole: "Directors in Rehearsal", p. 161.

57 Wilson: "The Forest" "Chapter III, "General Ideas".

58 Wilson: "The Forese", Chapter IX: Rehearsals.

59 Cole: "Directors in Rehearsal", p. 149.

60 Shank: "Alternative American Theatre" "p. 133.

61 Wilson, quoted in Susan Letzler Cole: "Directors in Rehearsal", p. 154.

62 Ellen Levy: "Robert Wilson: Theater History, Theater as History", in Parkett 16, 1988, p. 66.

63 Lehmann, in: Parket 16, 1988, p. 30

6.4 Shank: "American Altemative Theatre", p. 134.

65 Holmberg: "The Theatre of Robert Wilson", p. 194.

66 lbid., pp. 24 and 162 .

67 Ibid, p. 104.

68 Martwanca" "The Thearte of Trnages", p. 40.

69 Maranca, "The Fotest as Archive. Wilson and Interculturalism", in: Performing Arts Journal $33 / 34,1989$, p. 43 .

70 Muller, quoted in Wilson: "The Forest", chapter II: "Gilgamesh Epic".

71 Ibid, p. 119.

72 As noted by director Peter Sellars, in: Savan, Breaking The Rules, p. xv (Foreword).

73 In recent years, the Wooster Group has also produced its own version of plays by authors like Chelhov and O'Neill, reworking them until the spoken drama remains as a single aspect of a dense theatrical choreography for actors, music, stage set, and video.

74 Sarran: "Breaking "The Rules", p. 62. 
82 Ibid.

83 Ibid., p. 200

84 Ibid., p. 217

85 Peter Sellars, Foreword, in Savran: "Breaking The Rules", p. Xv.

86 Ibid.

87 Ron Vawter, quoted in Savran: "Breaking The Rules", p. 183.

88 Savran: "Breaking The Rules", p. 169.

89) Tbid, p. 220.

90 Cf. ibid, p. 218, where Elizabeth LeCompte is quoted, saying: "the questions are still being asked. The reading is from Leary's most recent work. And it culminates in the question, "Dr. Leary, how do you fee?" And "What is this dancing?" from The Crucibie."

91 Goldberg: "Performance Art", p. 191.

92 Howell: "Laurie Anderson", p. 22.

93 Ibid., p. 25

94 Anderson, interview quoted in Sayte: "The Object of Performance", p. 148.

95 See Howell: "Laurie Anderson", p. 50.

96. Kardon: "Language and Image, Theme and Motif", p. 138.

97 Goldberg: "Performance Att.", p. 190-1.

98 Owens, quoted in Sayre: "The Object of Performance", p. 151.

99 Sayre: "The Object of Performance" p. 155.

100 Howell: "Laurie Anderson", p. 22; Sayre: "The Object of Performance", p. 150.

101 Anderson, quoted in Sayre: "The Object of Performance", p. 150 . Anderson likes to disappear on stage, finding disembodied stories mote interesting. See Howell: "Laurie Anderson", p. 59.

102 Howell. "Laurie Anderson", p. 24-5.

103 Anderson: "United States" (unpaged), Part Three.

104 Anderson, in Howell: "Laurie Anderson", p. 48.

105 Walter Benjamin, Nintl thesis on the Concept of History; this translation is a combination of those by Susan Buck-Morss: "The Dialectics of Seeing", p. 95, and by Harry Zohn, in Benjamin: "Illuminations", p. 257 8.

106 That this text of Benjamin's is dear to Anderson is shown by her retrospective of her work, "Stories from the Nerve Bible", which is concluded (on page 282) by a slightly rephrased wet" sion. Here, Anderson has adapted the text to form a more vernacular dialogue: "She said: what is history? And he said: History is an angel / Being blown backwards into the future. / He sadi: History is a pile of debtis, / and the angel wants to go back and fix things, / To repair the things that have been broken. / But there is a storm blowing from paradise/And the storm 
keeps blowing the angel / Backwards into the future. / And this stom, this storm / Is called / Progress."

107 Anderson: "Stories from the Nerve Bible", p. 158. See also p. 285: "because I had to put it [the Natural History tour] together so fast, it never really became a performance."

108 Anderson, in Hownell: "Laurie Anderson", p. 54.

109 Mbid.

110 Andersion, in: ibid, p. 60-1.

111. Anderson: "Stories from the Nerve Bible", p. 230.

\section{CHAPTER 8 ANTHROPOLOGY AND PERFORMANCE}

1 Boas: "The History of Anthropology", in: Stocking (ed.): A Franz Boas Reader", p. 36.

2 Geertz: "The Usies of Diversicy", p. 272.

3 Ibid, p. 271 .

4. Keesing: "Cultural Anthropology", p. 404, writing about T"umet"s "theory of symbolism that transcends the Fteudian and the crudely sociological".

5 Tumer, Foreword, in: Schechner: "Between Theater and Anthropology", p. xii.

6 Schechner: "Between Theater and Anthropology", p. 14.

7 lbid., p. 108.

8 Ibid., p. 107.

9 Ibid., p. 109.

10 In this respect, the parallels between Byme and Laure Anderson are especially strilking both were influenced early on in their careers by Robert Wilson, and later produced scores for him; both made scores for ballet (Byme for Tharpe and Vandenkeybus, Anderson for Trisha Brown in collaboration with Robert Rauschenberg); both contributed lytics to Philip Glass' album "L.iquid Days" (Anderson knew Glass since the early seventies); both worked with Spalding Gray (Anderson provided scores for two of Gray's filmed monologues, "Swimming to Cambodia" and "Monster In A Box"); both have at times recorded with the same musicians, like percussionist David wan Tieghem, bass player Bill Laswell, guitarist Adrian Belew, singer Dolerte McDonald; and when Anderson considered making a documentary film out of her performance, she asked Jonathan Demme for advice, because the had directed Talking Heads" "Srop Making Sense" (See Anderson: "Stories from the Nerve Bible", p. 210.)

11 Byme, in Howell: "David Byme", p. 38.

12 Schechner: "The Find of Humanism", p. 124-5.

13 Ibid., p. 125.

14 Ibicl.

15 Schechner: "The Future of Ritual", p. 1-5.

16 Cardona, quoted by Richard Guilliatt, 20/20 Magazine, November 1989, p. 82

17 Bytne, quoted by Richard Guilliatt, $20 / 20$ Magazine, November 1989 , p. 82.

18 Byrne: "Rei Mono "Tout Diary", p. 122.

19 Bytne, speaking about the sensibility of Candomble, in Howell: "David Byme", p. 51.

20 Chemoff: "African Rhythm and African Sensibility", p. 9.

21 Ibid., p. 12. This could be the source for the scene in Byrne"s "True Stories" in which Mr. "Tucker, as an Afro-American pritest, performs a ritual to help the main character of the film, Louis Fyne, in his search for a wife, saying: "You don't have to believe. If you follow directions you can't go wrong." Bytne: "True Stories", p. 140. 
Thompson: "African Art in Motion", p. XII.

23. Ibid., p. 3.

24 Chemoff: "African Rhythm and African Sensibility", p. 10.

25 About Hurston's debated year of birth: Robert Hemenway, Introduction, p. 10, in: Hurston, "Sporen op een pad".

26 Hurston: "The Sanctified Church", p. 81.

27 Ibid., p. 107.

28 As quoted in Neiman: "Att and Anthropology: The Crossroads", in: October 14, Fall 1980, p. 5. This summary overviexy of Deten's work is based on Neiman's article.

29 Neiman: "Art and Anthropology: The Crossroads", p. 13.

30 Deren: "Divine Horsemen", p. 8; quoted by Annette Michelson, October 14, Fall 1980, p. 49. The Haitians formed the conviction that Deren was a prodigal native daughter Enally returned; see Michelson, l.c.

31 Deten, statement printed on the cover of "Maya Deren: Experimental Films 1943-195" Mystic Fire Video, New York City, 1986.

32 Michelson, "On Reading Deren's Notebook", in: October 1.4, Fall 1980, p. 51.

33 Byme, interview by Ken Coupland, in: Graphis, International Journal of Graphic Art and Applied Art, Issue 313, 1998, p. 98.

34 Foster: "The Return of the Real", p. 172.

35 Here I quote an earlier, more outspoken version of this text: Foster, "The Artist as Ethnographer?" in: Jean Fisher (ed.): "Global Visions", p. 16

36 Ibid.

37 Froster. "The Return of the Real", p. 171.

38 Tbid, p. 182.

39 Ibid., p. 197.

40 Foster, "The Artist as Ethnographer?" in: Jean Fisher (ed.): "Global Visions", p. 14.

41 Ibid.

42 Ruby: "Picturing Culture", p. 239 .

43 Ibid., p. 244.

44 Ibid, p. 247.

45 Ibid, p. 260 . Note that here, I quote Jay Ruby who quotes Dwight Conquergood who quotes Talal Asad (who in his turn quotes Walter Benjamin).

46 Ibid, p. 261.

47 Tbid., p. $275-6$

48 Keil and Feld: "Music Grooves", p. 22.

49 James Brown, quoted in ibid, p. 24. On James Brown as a philosopher caught up in contradictions, see ibid. p. 25-26, and Chemoff, "African Rhythm and African Sensibility", p. 74; Chernoff insists on a philosophical dimension," "a discourse on a mental attitude".

50 Feld, "Communication, Music, and Speech about Music", in Keil and Feld: "Music Grooves", p. 91.

51 Keil, "Participatory Discrepancies and the Power of Music", in Keil and Feld: "Music Grooves", p. 96-100.

52 Feld, describing the terminology of Robert Plant Armstrong, in his "Aesthetes as lconicity, or "Lift-up-over Sounding", in Keil and Feld: "Music Grooves", p. 144.

53 Keil, "Participatory Discrepancies and the Power of Music", "Music Grooves", p. 98.

54 Keil: "Music Grooves",p. 170. 
55 Feld, "Notes on "World Beat", in: "Music Groowe", p. 245. Feld points out here that this is also relevant for Talking Heads" album "Naked".

56 Feld, "Notes on "World Beat", in: "Music Grooves", p. 246.

57 Feld Lollows Simon Frith's analysis: the recond companies work towatds major hits which prow duce the major profits; major contrict artists are only allowed to talke economic and artistic risks in proportion to their record sales, and musicians are laborers selling their services in the marketplace. Feld, "Notes on "World Beat", in: "Music Grooves", p. 245.

58 Feld, "From Schizophonita to Schismogenesis", p. 269-270, in: "Music Grooves".

59 Ibid, p. 271.

60 Jaques Atrali, quoted in: Keil and Feld; "Music Groowes", p. 260.

61 Feld, "From Schizophonia to Schismogenesis", in: "Music Grooves", p. 286.

62 Ibid., p. 271.

63 lbid., p. 272.

641 can $^{2}$ resist the temptation to guote hete what $\mathbb{R}$. $\mathbb{E}$. Thompson wrote me about similar criticism directed against "Rei Momo" "Music is music. Purists and trouble-fêtes acadamiques do not arrest my attention. David can do what he wants." Fax to the author, 29 April 1999.

65 Field: "Music Grooves", p. 303.

\section{CHAPTER 9 TOWARDS A PHILOSOPHY OF MIMESIS}

1 This trminsition ftom modernism to postmodernism is often dealt with in lists of opposing formal traits. See for example: Yvonne Rainer of the Judson Dance Theater on mainstream versus new objects and dance, in Sayre" "The Object of Performance", p. 73. And: Claes Oldenburg on the differences between the personality of the lonely artist working in the studio versus the artist in collaborative stuarions, also in. Sayre: "The Object of Performance", p. 103. Another, more theoretical and longer list has been compiled by literary theorist Ihab Hassan, in "The Dismemberment of Orpheus. Toward a Postmodern Literature", p. 267-8. These lists seem to indicate that the transition into the "postmodern" is not a farewell to formalism, but a welcoming of the infinite possibilities of formalism that lie beyond the modernist canons.

2 See for examples: Fredric Jameson: "The Cultural Turn: selected writings on the postmodem, 1983 1988", p. 1; Andreas Huyssen and Klaus R. Scherpe: "Posmodeme: Zeichen cines kulturellen Wandels", p. 10 and 24; Dick Hebdidge: "Hiding in the Light", p. 11 and 232-40; Steven Best and Douglas Kellner: "The Postmodern Turn", p. 89 and 183; Fred Pfeil, discussed in Best and Kellner, ibid, p. 34, note 8; Will Straw: "Popular Music and Postmodernism in the 1980s", in: Frith et all: "Sound and Vision. The Music Video Reader", p. 16-17; Tim Woods: "Beginning Postmodernism", p. 178-9.

3. See for examples of this celebration of entropy: the well-known conclusion of Michel Foucault's "The Order of "Things", Roland Barthes" essay "The Death of the Author", Jean" François Lyotard's proposal, in in the eight letter of "Le Postmoderne explique aux enfants", to place all writing in front of a new decor, formed by the cosmic big bang on the one hand, and the inevitable death of the sun on the other.

4 Bytne, interviewed by Marco Puntin, II Progetro 4, Trieste, Italy, December 1998, p. 6.

5 Frith: "Performing Rites", p. 204.

6 Kaplan: "Rocking Around The Clock", p. 74-5.

7 Ibid., p. 55.

8 Cf. above, chapter 2 , section 8: Persona as mimetic texture: "Speaking In Tongues". 
9 Schecter "Beyond the Text", p. 174.

10 Ibid., p. 176.

11 Ibid., p. 178.

12 Ibid., p. 180 .

13 Detrida: "Of Grammatology", p. 158.

14 Schecter: "Beyond the Text", p. 178.

15 Ibid., p. 184.

16 Ibid., p. 184. Schectet"s inability to be consistent and reflective may stern from his assumption that aesthetic practices can be realistic without relying on mimesis; see p. 185, note 1. By assum* ing that philosophy offers a mote direct presence of the truth than art, Schecter simply tepents Plato's assumption that metaphysical theory is able to present reality without making use of mimetic representation.

17 Hebdidge: "Hiding in the Light", p. 11.

18 Ibid., p. 232.

19 Ibid., p. 234-5.

20 ibid., p. 237-8.

21 Ibid., p. 240 .

22 J.bid., p. 239.

23 Ibid, p. 240.

24 See Woods: "Beginning Postmodernism", p. 178-9.

25 It may of course be argued that the necessity of making mimetic conventions a central theme of one"s work, instead of accepting them as timeless, natural and given, is just what Derrida means by "there is nothing outside of the text". And after all, Jung's theory of archetypes and Tiger and Fox's biogtammar are indeed theoties, and as such rely on specific discursive conventions. Nevertheless, the core of their argumentation seens to be incommensurable with Derrida's philosophy.

26 Taussig: "Mimesis and Alterity", p. xv.

27 Ibid., p. xvi.

28 Ibid., p. xwiili-xix.

29 Behler: "German Romantic litexary theory", p. 299: "Early Romanticism"... did not originate as a period designation until the beginning of our [20th] century and became an established categoty only during the latter half of it."

30 Schulte-Sasse, quoting Paul de Man, in his "General Introduction-Rontanticism"s Paradoxical Articulation of Desire", in: "Theory as Practice", p. 1.

31 Behler: "German Romantic literary theory", p. 300.

32 Andreas Michel and Assenka Oksiloff: "Romannic Crossovers: Philosophy as Art and Art as Philosophy", in Schulte-Sasse: "Theoty as Practice", p. 158-9.

33. All the following quotations from: "Earliest Program for a System of German Idealism " in. Jochen Schulte-Sasse et al. Theory as Practice: A Critical Anthology of Early German Romantic Writings. p. 72-3. Likely authors of this text are Schelling, Hegel and Holderlin. It is generally considered to be a manifesto of early romanticism. Cf. Bracckmani: "De waarheid wan de kninst", passim. 


\section{CHAPTER IO}

1 Novalis: "The Universal Broullon", fragment 924, in Schulte-Sasse: "Theory as Practice", p. 239.

2 Cf. Frank: "Intellektuale Anschauung", p. 109.

3 Mitman and Strand, "Representing Self and Other in Early German Romanticism", in: Schulre-Sasse, "Theory as Practice", p. 51.

4. Franks "Intellektuale Anschauing", p. 115.

5 Benjamin: "The Concept of Criticism", Selected Writings Volume 1, p. 128 ,

6 Frank: "Einfuhrung in die fruhromantische Asthetik", p. 222; author's translation of: "Ich nenne 'romantisch' die Philosophic, in der die Spekulation auf der Anspruch verzichter, das Absolute durch Reflexion zu erreichen - und diesen Mangel durchs Medium der Kunst supplementivent."

7 Novalis: "Wichte Studies", in Schulte-Sasse: "Theory as Practice", p. 108.

8 C. Frank: "Einfuhrung in die frühromantische Asthetik", p. 300. The term "negative dialectic" refers to Adorno.

9 Kant, quoted in Frank, "Einführung in die frühromantische Asthetilk", p. 44: "idealism der Erscheinungen: wir sind zum Theil Schöpfer derselben aus dem Standpunkte, den wir Annelumen. Dichter."

10 Tieck: "Eine gute Verwirrung ist mehr wert, als eine schlechte Ordnung." Quoted in Frank: "Einfülarung in die frühromantische Asthetik", p. 48 .

11 Novalis: "Werke" "p. 334.

12 Nowalis, in Frank: "Einführung in die frühromantische $\mathrm{Asthetik",} \mathrm{p.} \mathrm{270.} \mathrm{Translations} \mathrm{by} \mathrm{the}$ author.

13 Nowalis: "Werke", p. 310-11.

14 Ibid., p. 327.

15 See Schulte-Sasse: "Theory as Practice", p. 15-16.

16 Roberts: "The Logic of Reflection", p. 31.

17 Kant: "Critique of Judgment", paragraph 20.

18 Ibid., p. 56" "Fere, now, we may perceive that nothing is postulated in the judgment of taste but stuch at universal voice in respect of delight that is not mediated by concepts; consequently, only the possibility of an aestheric judgment capable of being at the same time deemed walld for every one. The judgment of taste itself does not postulate the agreement of ewery one...; it only imputes this agrement to every one..."

19 Michel and Oksiloff: "Romantic Crossovers: Philosophy as Art and A.t as Phillosophy", in Schulte-Sasse" "Theory as Practice", p. 174.

20 Ibid, p. 175.

21 Joclien Frtied, in Behler snd Hörisch: "Die Aktualität der Frühromantik", p. 175.

22 Nowalis: "Te poetischet, ie wahrer," "Worke", p. 413.

23 Michel and Oksiloff, in Schulte-Sasse: "Theory as Practice", p. 176.

24 Ibid., p. 177 .

25 Quoted in Behler: "German Romantic litenry theory", p. 296.

26 Nowalis: "Faith and Love. The King and the Queen", in Behler: "German Romantic literary theory", p. 61.

27 Behlex:" "German Romantic lirerary theory", p. 59. 
28 Tbid, p. 61.

29 Novalis, in Behler: "German Romantic literary theory", p. 60 .

30 Novalis: "The Universal Brouillon", in Schulte-Sasse: "Theory as Practice", p. 228.

31 Ibid., p. 237.

32 Ibid., p. 23940.

33 Cf. Schulte-Sasse: "Theory as Practice", p. 291.

34 On the classical model of art as mimetic imitarion, see Behler: "Gemman Romantic literary theory", p. $301-2$.

35 Noxalis, Werke, p. 393: "Der Künstlet nimmt das Wesen seiner Kunst aus sich - auch nicht der leiseste Verdacht von Nachahmung kann ihn treffen."

36 Ibid., p. 533.

37 Mbid., p. 413: "Natur soll Kunst und Kunst zweite Natur werden."

38 Ibid., p. 450: "ZUKUNFTSLEHRE. (Kosmogogik.) Die Natur wird moralisch sein - wenn sie aus echter Iiebe zur Kunst - sich der Kunst hingibt - tut, was die Kunst will - die: Kunst, wenn sie aus echter Liebe zur Natur - für die Natur lebt, und nach der Natur arbeitet. Beide müssen es zugleich aus eigner Wahl — um ihrer selbst willen - und aus fremder Wahl um des andrer willen, tun. Sie müssen in sich selbst mit dem andera und mit sich selbst im an. dern zusammentreffen."

39 Plato: "Republic", III, 395d-396b.

40 Andreas Michel and Assenka Oksiloff: "Romantic Crossovers: Philosophy as Art and Art as Philosophy", in: Schulte-Sasse, "Theory as Practice", p. 159.

41 Cf. Lisa C. Roetzel, in Schulte-Sasse: "Theory as Practice", p. 381, note 13.

42 The need for a careful introduction is made even greater by the fact that the terms "reflection" and 'reflexivity' have too often been overlooked or neglected in Anglo-American philosophy. The extensive, eight-volume Encyclopedia of Philosophy (Ed. Paul Edwards; Macmillan \& The Free Press, 1967) simply omitted the terms; the more recent Oxford Companion to Philosophy (Ed. Ted Honderich, Oxford U.P., 1995) presents under the lemma "reflexivity" only some logical distinctions of a self-referential binary logical relation.

43 Roberts: "The Logic of Reflection", p. 5.

44 Benjamin: "Selected Writings" Volume 1, p. 118-9.

45 Ibid., p. 129.

46 Ibid., p. 156.

47 Ibid., p. 158

48 Behler: "German Romantic literary theory", p. 60.

49 Novalis, quoted in Benjamin: "Selected Writings" Volume 1, p. 139, transhation altered.

50 Schlegel, quoted in Benjamin: "Selected Writings" Volume 1, p. 131.

51 Benjamin: "the individual work of art should be dissolved in the medium of att ..." "Sellected Writings" Volume 1, p. 153.

52 Cf Benjamin: "The Concept of Criticism" in "Selected Writings" Volume 1, p. 195, note 216 on the wholly false modernization of Romantic doctrines. Thus, the suspicion that romanticism is nothing but the subjectivation of aesthetics, based on Kants concept of the genius, is unfounded. This fear has been expressed by Gadamer in the first patt of his "Trutth and Method'; cf. Frank, "Einführung in die frühromantische $A_{\text {sthetik", }}$ p. 127.

53. Benjamin, "The Concept of Criticism", "Selected Writings" Volume 1, p. 175. 
54 Tid. p. 176. This is one of the connections between Benjamin's early works that ate identifed openlly with his early romancic predecessors, and wis later "marxist' works, like his famous essay "The Work of Art in the Age of Mechanical Reptoduction".

55 Nowalis: "Werke", p. 547, Fragmente und Studien 1799-1800, fragment 141. "Poesie ist Darstellung des Gemüts - det innem Welt in ihrer Gesamtheit. Schon iht Medium, die Worte deuten es an, denn sie sind ja die äuBre Offenbarung jenes innern Kraftreichs. Ganz, was die Plastik zur äußern gestalteten Welt ist und die Musilk zu den Tönen. Effekt ist ihr gerade entgegengestet - insofern sie plastisch ist - doch gibt es eine musikalische Poesie, die das Gemüt selbst in ein mannigfaltiges Spiel won Bewegungen setzt."

56 Schiller: "It is a necessary and natural tesult of its perfection, that without transgressing its natura] borders, the different arts in their effect on the heart become more and more similar to each other. Music in its noblest form has to become shape... the visual arts in their highest perfection must become music". Authot's translation of Schillet: "Uber die ästhetische Erziehung des Mensichen", p. 90.

Schelling: "The most perfect composition of all the atts results from the union of poetry and music by singing, and of poetry and painting by dancing, when these are synthesized once. again; this ptoduces the most complete theatrical performance, such as the drama of the ancients once was. Of that, for us only a caricature remains, the opera, but that still embodies the best possibility to return to us, by using a higher and more noble style of both poetry and the other competing arts, the performance of the classical drama, in its connection with music and singing." in Lingner: "Der Ursprung des Gesamtkunstwerkes aus der Unmöglichkeit "Absow luter Kunst", "Der Hang zum Gesamtkunstwerk", p. 52.

For Wagner, see Lingner, "Dier Ursprung des Gesamtkunstwerkes aus det Unmöglichkeit "Absoluter Kunst", in: "Der Hang zum Gesamtkunstwerk", p. 52. In 1797/1798, Novglis had already written: "An opera, a bullet are in fact plastic poetical concerts - communal arrworks of several plastic instruments. /Acrive interpretations of the heart. Poetry. ${ }^{\prime \prime}$. Novalis: "Werke", $p$. 395.

57 A series of highly informative lectures on this theme has been published by Manfred Frank: "Der kommende Gott", and "Gott im Exil". See for this question especially "Dionysos und die Remaissance des kultischen Dramas (Nietzsche, Wagnet, Johst)", in "Gott im Exil", p. 9-105, and "Der kommende Gotr, p. 229.

58 Frank: "Gott im Exil", p. 65.

59 Tbid., p. 65-7. CE. Frank, "Einfuhltung in die frühtomantische Xstherik", p. 219.

60 Novalis, Werke, p. 382 .

61 Sice on this point for example the introductory essay and the selection of texts on the early romantic theory of the feninine by Lisa C. Roerzel, in: Schulte-Sasse, "Theory as Practice", $\mathrm{p}$. $361-4.62$.

62 Nietzsche, "The Birth of Tragedy", quoted by Frank: "Gott im Exil", p. 65.

63 Frank: "Gott im Exil", p. 67.

64 Novalis: "Werke", p. 559. "Das "Theater ist die tätge Reflexion des Menschen über sich sellbst:."

65 Ibid., p. 338. "Im Staar ist alles Schauhandlung - im Volk alles Schauspiel. Das Leben des Volks ist ein Schauspiel."

66 Ibid., p. 549 .

67 Novalis: "Die Christenheit oder Europa", "Werke", p. 516. About the romantic enthusiasm for the Middle Ages, compare Friedrich Schlegel's remark, which is truly typical of the Romantic 
hermeneutics of history: "essentially we ourselves live in the true Middle Ages and have placed this by mistake in the past.". Quoted in Behler: "Friedrich Schlegel", p. 89.

68 Ibid., p. 516-7.

69 Novalis: "Wexke", p. 531: "Es gibt keine Religion, die nicht Christentum wäre."

70 Ibid, p. 533.

71 Ibid., p. 530. Translation in Schulte-Sasse: "Theory as Practice", p. 387.

72 Ibid, p. 534.

73 Cf. Frank: "Einführung in die frühromantische Asthetik", p. 238.

74. Novalis: "Werke", p. 530.

75 Tbid.

76 Ilbid., p. 520.

77 Ibid., p. 505.

78 Tbid., p. 348

79 Tbid., p. 338.

80 See Behler: "Friedtich Schlegel", p. 68.

81 Schlegel, quoted in: ibid., p. 101.

82 Ibid., p. 60.

83 Cf. ibid., p. 100

84 lbid

85 Ibid., p. 101.

86 Schlegel: "Kritische und theoretische Schriften", p. 104. In a sense, the opening chapters of Enich Auerbach's great study on mimesis, which compare the mimetic straregies of both Bible and Homer, have fulfilled this wish of Schlegel"s.

87 Schlegel: "Kritische und theoretische Schriften", p. 104.

88 Schlegel, Athenäums-fragment 116. Tratnslation Schulte-Sasse: "Theory as Practice", p. 320.

89 Schlegel, translation Schulte-Sasse: "Theory as Practice", p. 326.

90 Schelling, quoted in: Schulte-Sasse: "Theory as Practice", p. 147.

91 A.W. Schlegel, quoted in Behler, "Getman Romantic literaty theory", p. 158.

92 Behler: "Getman Romantic literary theory", p. 159.

93 A.W. Schlegel, quoted in Behler, "Getrnan Romantic literary theory", p. 159.

94 F. Schlegel, quoted in Behler: "German Romantic literary theory", p. 161.

95 F. Schlegel, guoted in ibid, p. 162.

96 Cf. Michel and Oksiloff: "Romantic Crossovers: Philosophy as Art and Art as Philosophy", in Schulte-Sasse:" "Theory as Practice", p. 173.

97 Tbid, p. 176.

98 Novalis, "Faith and Love", in Schulte-Sasse" "Theory as Practice", p. 134; Cf. Schulte-Sasse"s introduction to this anthology, "Romanticism's Paradoxical Articulation of Desire".

99 See for an analysis of this dialectic of symbol and allegory in early romanticism Schulte-Sasse"s introductoty article, especially p. 1-8. The most thorough analysis thas been made by Walter Benjamin in his "Origin of German Tragic Dtama", especially in the section on Symbol and A: legory in Romanticism.

100 Novalis, "The Universal Broullon", fragment 137. Translation Schulte-Sasse" "Theory ats Practice ${ }^{3}$, p. 230

101 Ibid. 
102 Quoted in Frank: "Stil in der Philosophie", p. 87. "Die höchsten Kunstwerke sind schlechthin ungefallig - Es sind Ideale, die uns nur approximando gefallien konnen - und sollen ästhetische Imperative."

103 "absichtliche Zufallspioduktion", quoted in Frank: "Einführung in die frühromantische Asthetilk", p. 355 .

104 Novalis, quoted in Frank: "Einfuhrung in die frühomantische Asthetik, p. 270: "Der Mensch tsr eigentlieh Chaos".

105 Nowalis, in Schulte-Sasse: "Theory as Practice", p. 230-31.

106. Schlegel, quoted in Behler: "German Romantic literary theory", p. 151.

107 The opening of Novallis" first novel "Die Lehrlinge zu Sais" is programmatic: "Manifold ways do men pursue. Whoever follows and compares them, will see wondrous figures come into being, figures that seem to belong to the great coded seript that one descries everywhere, on wings, eggshells, in clouds, in snow, in crystals and rock formations, on freezing waters, in the inside and outside of mountains, plants, animals, men, in the lights of heaven, on touched and bowed discs of pitch and glass, in the filings around a magnet, and in the extraordinary conjunctions of chance. In them, one surmises the key to this magic script, the grammat of it; but this inkling refuses to adjust to a fuxed shape, and seems not to want to become a higher key." For an interptetation see Wanning, "Novalis", p. 162.

108 Schllegel: "On Incomprehensibility", in Schulte-Sasse: "Theory as Practice", p. 126.

109 Bytne, interview by Elisabetta d'Erme, in: Alias, weekly insert with Il Manifesto, Trieste, Italy, September 12, 1998, p. 1 .

110 Dilthey, "Das Etlebnis und die Dichtung", p. $239-40$.

111 Byme, interviewed by Marco Puntin for 11 Progetto, May 1998.

\section{CHAPTER 11 BENJAMIN AND ADORNO ON MYTHS IN MODERNITY}

1 Adorno: "Prisms", pp. 194 and 209.

2 Adotno: "Noten zur Litetatur", Gesammelte Schriften 11, p. 571, translation by the authot. The translation in Buck-Morss: "The Origin of Negative Dialectics", p. 174, is faulty.

3 Adomo: "Noten zur Literatur", Gesammelte Schriften 11, p. 584; cf. Benjamin: "One-Way Street", "Post No Bills: The Writer's Technique in Thirteen Theses", in: Selected Writings, Vol. 1, p. $458-9$.

4. Adtomo, "Noten zur Litentur", Gesammelte Schriften 11, p. 571 .

5 Buck-Morss: "The Origin of Negative Dialectics", p. 15. It is illustrative that Atnold Schönberg and Anton Wobern, as well as Adomo himself, set symbolist poems by George to music.

6 Adomo, letter to Benjamin, 18.3.1936. Adomo - Benjamin, Briefwechsel, p. 170. Cf. Benjamin: "The task of the "Translator", Selected Writings volume 1, p. 259, and Benjamin's remark on Mallarme and l'att pout l'art in his artwork-essay; "Illuminations", p. 224.

7 Adomo: "Open llettex to Max Horkheimer", quoted in Buck-Mors: "The Origin of Negative Dialectics", p. 236 , note 28.

8 See Buck-Morss: "The Origin of Negative Dialectics", passim

9 See Winfried Menninghaus, "Schwellenkunde. Walter Benjamins Passage des Mythos", esp. p. 26-59, "Raum des Mythos, Schwellenkunde".

10 Adomo: "Negative Dialektik", p. $29-30$ ("Darstellung").

11 Adomo: "Beethoven: The Philosophy of Music", p. 163.

12 Benjannin: "Briefe", p. 524. 
13 See the 9 th thesis of Benjanin's Artwork-essay.

14. Benjamin: "Tlluminations" ("The Work of Art in the Era of Mechantcal Reproduction"), p. 2223.

15 Scholem: "Walter Benjamin-die Geschichte einer Freundschafe", p. 89.

16 Benjarnin: Selected Writings 2, p. 814.

17 For this passage I have used Abrams: "The Mirror and the Lamp", p. 303-12.

18 Goethe, quoted in Burwick, "The Damnation of Newton", p. 15; translation by the author.

19 Burwick: "The Dammation of Newton", p. 9, stummarizing Rudolf Steiner's epistemological deferse of Goethe.

20 Ibid., pp. $21,23,25$.

21 Ibid., p. 24.

22 Benjamin: "Die Reflexion in der Kunst und in der Farbe", GS VI, p. 118, author's translation.

23 Burwick, "Novalis: Transcendental Physics and the Sidereal Mars", in "The Damnation of Newron", p. 104. Author's translation.

24 Novalis, quoted in: ibid., p. 111. Author's translation of: "Alle Figuren waren hier dunkel. Die Luft war wie ein ungeheurer Schatten; am Himmel stand ein schwarzer strahlender Körper. Man konnte alles auf das deutlichste unterscheiden, weil jede. Figur einen andern Anstrich von Schwarz zeigte, und einen lichten Schein hinter sich warf; Licht und Schatten schienen hier ilure Rollen vertauscht zu haben." (Novalis, Werke, p. 243.) Cf. Benjamin: Selected Writings 1, p. 133, where Benjamin quotes Friedrich Schlegel: "The idea of the ' $T$ ' ... is to be regarded ... as the inner light of all ideas. All ideas are only the refracted color images of the inner light. In every idea the ' $T$ ' is the hidden light; in each thought, one finds oneself."

25 Burwick: "The Damnation of Nexton", p. 119-20.

26 Benjamin, quoted in Frizot: "A New History of Photography", p. 132.

27 Benjarnin: Selected Writings 1, p. 133.

28 Ibid., p. 141.

29 Ibid., p. 474 [N 9a, 4]. See for this important tetm also: $\mathbf{N} 2 \mathrm{a}, 4$, and $\mathbf{N} 5,2$.

30 Benjamin: Selected W/ritings 1, p. 235.

31 See Menninghaus: "Schwellenkunde. Walter Benjamins Passage des Mythos", esp. p. 26-50, "Raum des Mythos, Schwellenkunde".

32 Schlegel, quoted in Benjamin, "The Concept of Craticism", Selected Writings 1, p. 131.

33 Benjamin: "The Arcades Project", Translators" Foreword, p. $x$.

34 Tbid., p. 171 [G 1,1]. When quoting from "The Arcades Project", for casier reference I have added the conwolute numbers [in brackets].

35 He had already insisted on this necessity in his text "On the Program of the Coming Philosophy", written in 1918. Benjamin, Sellected Writings 1 , p. 100-110.

36 See Berrjarnin, "The Arcades Project", p. 388-9 $\mid \mathrm{K} 1,2 \|$.

37 Benjamin: "The authentic concept of universal history is a messianic concept. Universal history, as it is understood today, is an affait of obscurantists." Ibid., p. 485 [N 18,3].

38 This list is a combination of physiological types which Benjanin quotes from Balzac (Arcades Project, p. 761 [d 8a, 4]) and from Benjamin's own typology as used in the titles of his 'convolutes".

40 Tbid, p. 854 [Mo, 12]. 
41 Scthlegel, "Kritische und theoretische Schriften", p. 85. Quoted in Benjamin, GS I, p. 1237. These methodological reflections underlie Benjamin's allegorical imige of the angel of history, discussed in chapter 7, section 4 , on Laurie Anderson.

42 Benjamin, "The Arcades Project" "p. 459 [N 1a, 5]:

43 CE Corbusier"s "Plan Voisin". In many ways, Corbusier inherited Fourier's ideals.

44 Tiedemann, (quotiag Benjamin), in:" Dialectics at a Standstill", in: ibid., p. 933. Cf. p. 883: "The father of surtealism was Dada, its mother was an arcade." [ho, 1]

45 Benfamin: Selected Writings, Volume 1, p. 288 and 290.

46 Ibid, p. 476.

47 Benjamin, supported in this by Adorno, would have preferred to write about Jung instead of Baudelaire, but could not convince Horkheimer to sponsor this researcin. See Benjamin/Adono: "Briefwechsel", p. 222-3, 230, 239, 257, 263,272, 277.

48 The reciprocal representation of Jung and Marx is identical to the "Dialectic of Enlightenment" as ptoposed by Adorno and Hotkheimer. Benjamin's influence on Adomo after 1929, and on Horkheimer's own writing after 1939, can hardly be overestimated. In 1935, Adono wrote to Benjamin. "T view the Atcades project as not only the center of your philosophy, but the decisive standatd of what can be articulated philosophically today..." (quoted in Buck-Morss, "The Dialectic of Seeing", p. 216). In 1938, to give one mote example, he wrote Benjamin that he considered himself an "Arcades-orthodox", and that he and Horkheimer were "willing to identify with the most extreme experiments of your theory". (letter of 10. November 1938, in Benjamin, GSI, p. 1097-98). As Rolf Wiggershaus has noted, Adorno's philosophical programme in the 1930's was first of all to present Benjamin's ideas within academic circles. (Wiggershaus, "Die Frankfurter Schule", p. 112.)

The mutuall relations of Benjamin, Adorno and Horkheimer have often been disputed by scholars. Apart from the extreme historical circurnstances, this issue is further complicated by the facts that Horkheimer managed the finances of the Frankfurt Institute and exerted financial pressures on Adorno and especially Benjamin; by heated critical debates between Benjamin and Adomo, and by the fact that in the beginning of the 1930 's, Horkheimer did not appreciate the interpretative philosophy of Benjamin and Adomo very highly. (See Wiggerhaus, p. 67) But by the end of the decade, Horkheimer's philosophy was much closer to Benjamin's; see Dubiel: "Wissenschaftsorganisation und politische Erfahrung", p. 106, and Jay: "Dialektische Phantasie", p. 306-8.

A general discussion of Benjamin"s influence on Adomo can be found in Buck-Morss: "The Origin of Negative Dialketics" (throughour; see esp. the pages on their common "Königstein program"). For mote particular details see also Nicholsen: "Exact Imagination, Late Work", esp. chaptets 4 and 5 .

This project was common to Benjanin and Adomo; indeed, it was Adorno who suggested to Benjamin that he should study Jung's work (and Hortheimer who refused to finance Benjamin's research). See Benjamin: "Passagen-Werk", p. 1156-62 (Zeugnisse zur Entsrehungsgeschichte).

49. Benjamin, "The Arendes Project", p. 458 [N 1,9].

50 Ibid, p. $461[\mathbb{N} 2 a, 11$; cf. ibid, p. $390[\mathrm{~K} 1 \mathrm{a}, 3]$.

51 Ibid, p. 391. |K 1a, 8|.

52 Marx, "Frühschriften", quoted in: Benjamin, "The Areades Projece", p. 476 [N 5A, 1].

53. Marx / Engels: "The Communist Manifesto", p. 41. 
54 Benjamin: "The Arcades Project", p. $181-2$ [G 5,1], quotang Oto Rühles "Karl Marx". "The quoted texts from Marx are from the farnous first chapter on the commodity in his "Capital". Cf. Benjamin, ibid., p. $196-7$ [G. 13a, 2]:

55 See Benjamin: "Gesammelte Schriften" I, p. 693, and Buck-Marss: "The Origin of Negative Dialectics", p. 169.

56 Benjamin: "The Arcades Project", p. 392 [K 2,5].

57 Ibid., p. $863\langle 00,67\rangle$ and $\langle 00,68\rangle$.

58 Ibid., p. $389[\mathrm{~K} 1,4]$.

59 Ibid, p. $389-90[\mathrm{~K} 1,5]$.

60 Ibid., p. 393 [K 2a, 5].

61 Benjamin, "Theses on the philosophy of history", in: "Hlluminations", p. 255.

62 Benjanin: "The Arcades Project", p. 46.1-462 [N 2a, 2].

63 Ibid, p. $463[\mathbb{N} 3 a, 2]$.

64 Ibid., p. 394, [K 3, 3].

65 Benjamin, GS I. p. 1040

66 Noralis: "Wir haben kein electrisches und magnetisches und gaivanisches Auge und Ohr." In: Burwick, "The Damnation of Newton", p. 124. "Alle Sinne sollten Augen werden. Fernröhre."; ibid., p. 125.

67 Benjamin, GS I, p. 500. Translation: Buck-Morss, "The Dialectic of Seeing", p. 267.

68 Benjamin: "Jlluminations", p. 221-2.

69 Benjamin: "The Arcades Project", p. 459 [N 1a, 4]. Cf. Benjamin's artwork-essay, on the traditional advantage of even the most provincial performance in the theatre in comparison with film; "Illuminations", p. 243 , note 3 .

70 Benjamin, "The Arcades Project", p. 395, [K 3a, 1].

71 Benjamin quotes Jung: "Because the collective unconscious is ... a deposit of world-processes embedded in the structure of the brain and the sympathetic nervous system, it constitutes ... a sort of timeless and eternal world-image which counterbalances our conscious, momentary picture of the world." The Arcades Project, p. 399, [K 6, 1 .

72 Benjamin, "Illuminations" (artwork-essay), p. 231.

73 Adomo, "Transparencies on film", in: "The Culture Industry", p. 157.

74 Adorno, "How to look at television", in: "The Culture Industry", p. 143 and p. 150. The concepr. "psychoanalysis in reverse" was first minted, as Adomo tells it, by Leo Lowenthal. Cf. Adorno', "Minima Moralia", p. 25" "Every visit to the cinema leaves me, against all my vigilance, stupider and worse." <check, quoted in Kellner, Critical theory and the Culrure Industry: a reassessment, p. 204>

75 Adorno: "Transparencies on fllm", in "The Culture Industry", p, $\Perp 54$.

76 Adomo, "How to look at television", in: "The Culture Industry", p. 143.

77 Adomo: "Transparencies on film", in "The Culture Industry", p. 158.

78 See for example Kellner: "Critical Theory and the Culture Industry: A reassessment".

79 Adorno: "How to look at relewision", in "The Culture Industry", p. 137.

80 Benjamin, GS III, "Rückblick auf Chaplin", p. 157.

81 Benjamin, "The Work of Art in the Age of Mechanical Reproduction", thesis XII.

82 Benjamin, GS I, p. 1040; translation: Buck-Morss, "The Dialectic of Seeing", p. 269-270.

83 Adomo: "Zweimal Chaplin", in: "Ohne Leitbild", p. 89.

84 Ben jamin: "Hitler's Diminished Masculinity", in: Selected Writings Volume 2, p. 792. 
85 Adorno: "Winima Moralia", p. 204; translation quoted from: Documenta X: Politics-Poedics, p. 126.

86 Cf. Benjamin: "On the Mumetic Faculty", Selected Whings woll 2, p. 720-22.

87 Adomo, "Der dialektische Komponist", "Schriften 17", p. 203. "Dem Abgrund des UnbewuBten, dem von Traum und Trieb hat dies Bewabtsein sich entrungen, an seinem Stoff alls Flamme sich genährt, bis sie als Licht eines wahren Tages alle Kontuten der Musik werwandelte: das ist ihr größtes Gelingen zwischen den Extremen, nicht Spiel mehr, sondern Walurheit selber." Author's transiation.

88 Adotno: "Uber Jazz", in: Gesammelte Schriften 17, p. 83-4.

89 Cf. Buck-Motss: The Origin of Negative Dialectics", p. 190, and the introduction in Gibson ard libuin: "Adorno, A Centical Reader", p. 14.

90 Cf. Said." "Adorno as Lateness Itself" in "Gibson and Rubin: "Adomo, A Critical reader", $p$. 206.

91 See Buck-Morss: "The Origin of Negative Diallectics", p. 131

92 Adorno: "Zur geselischaftlichen Lage der Musin", p. 107.

93 Adorno: letter to Walter Benjamin, 18 March 1936. In: Adorno-Benjamin, "Briefwechsel", p. 171. Translation in: Adorno, "The Culture Industr", p. 2.

94 Adorno, Schriften 17, "Anmerkungen zum deutechen Musikleben", p. 172. Author's translation.

95 Adorno, "Einführung in die Musiksoziologie", p. 34. Author"s translation.

96 A typical example of this interpretation can be found in Frith: "Sound Effects", p. 43-7 and 57.

97 Adorno, letter to Benjamin, 29.2.1940, in: Adorno / Benjamin: "Briefwechsel", p. 418.

98 Adorno: "Noten zur Litcratur", Gesammelte Schriften 11, pp. 10 and 19.

\section{CHAPTER 12 THE GESAMTKUNSTWERK AS LABORATORY}

1 Latour" "We Have Never Been Modern", p. 100-3.

2 Latour and Woolgar: "Laboratoty Life: The Construction of Scientific Facts", p. 70; cf. p. 273-4 for the story behind I.atour's oblique turn.

3 Latour: "We Have Never Been Modern", p. 119.

4 CE. ibid, p. $411-2$.

5 Ibid, p. 102.

6 Tbid., p. 85.

7 Ibid., p. 21.

8 Ibid., p. 137. Instead of just anthropomorphism, Latour proposes technomorphism, zoönorphism, phusimorphism, ideomorphism, theomorphism, sociomorphism and psychomotphism.

9 Latour: "Pandora's Hope", p. 273n4.

10 Latour: "We Have Never Bcen Modern", p. 126.

11 Benjamin, Selected Writings 1, pp. 143-8 (The Early Romantic Theoty of the Knowledge of Nature).

12 Ibid., p. 144.

13 Ibid., p. 145 .

14 Ibid.

15 Ibid., p. 146.

16 Ibid. P. 148.

17 lbid. 
18 Benjamin: Selected Writings, Vol. 1, p. 487. (From "To the Planetarium", the concluding statement of "One-Way Street".) CE. Taussig: "Mimesis and Alterity" p. 38.

19. This does not mean that to the romantics, nature is simply incomprehensible, as Dilthey (and later, Heidegger) have concluded. Cf. Behler: "Friedrich Schlegell, p. 79. After all, Nowalis was trained as a mining engineer. It is more correct to conchude that the romantic epistemology is drastically ironic, in its conviction that every expetiment with nature is simaltaneously a historical experiment, that is: an experiment of mankind with itself.

20 On the surface, this identification of Latour's work with the reflexivity of Berijamin and the early Romantics is belied by a scathing article on Benjamin"s Attwork-essy, written by Hennion and Latour, "L'art, l'aura et la technique selon Benjamin". This article gravely underestimates Benjamin's own philosophical and literary technique: Hennion and Latour write that Benjamin was a prisoner of the romantic vision (p. 239), but neglect the critical, treflexive epistemology that was central to his work.

21 Latour: "Pandora's Hope: Essays on the IReality of Science Studies", p. 39.

22 Adorno/Horkheimer: "Dialectic of Enlightenment", p. 187.

23 Ibicl., p. 188.

24 Ibid., p. 189.

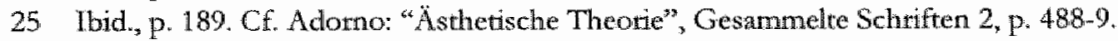

26 Latour: "Pandora's Hope", p. 287.

27 Ibid., p. 286.

28 Ibid., p. 287.

29 Cf. Bourdieu: "On Telerision", p. 34.

30 Ibid., p. 22.

31 Tbid, p. 18.

32 Ibid., p. 35-6.

33 Ibid, p. 23-4.

34 Ibid., p. 44-5.

35 Ibid.

36 Ibid., p. 18.

37 Ibid., p. 66.

38 Ibid., p. 21.

39 Appadurai: "Modetnity at Large", p. 33.

40 Ibic., p. 4.

41 Tbicl., p. 31.

42 Ibid., p. 43.

43 llibid, p. 34.

44 Ibid., p. 45 .

45 Ibid., p. 6. In this context, Appadurai writes that "There is a large and tespectalylie body of writing, notably by the critics of mass culture of the Frankfurt School and anticipated in the work of Max Weber, that views the modern world as growing into an iron cage and predicts that the imagination will be stunted by the forces of commoditization, industrial capitalism, and the generalized regimentation and secularization of the modern world." I have shown in the prew ceding chapter that, at least for Benjamin and Adomo, this representation of the Frankfurt School is a distortion.

46 Appadurai: "Modernity at Llarge", p. 7.

47 Sklar: "Movie-Made America" A Cultural History of American Movies", p. 86-7. 
48 bid., p. $81-2$

49 Appadurai: "Modemity at Large", p. 174.

50 lbid.

51 As printed in the booklet that accompanies the CD version of "The Forest". Cf chapter 3, section 7.

52 See chapter 6 section 4 .

53 Byme: "True Stories" p. $42-4$.

54 Tbid, p. 68 .

55 Wid., p. 36 and 38.9. Cr. the booklet that accompanies Talking Heads" "Stop Making Sense" album: The Space People think factories are musical instruments. They sing along with thetn. Each song lasts from 8 a.m. to 5 p.m. No music on weekends." See chapter 2 , section 1.

56 See chapter 4 , seetion 8 .

57 Ibid., p. 127 .

58 Byme, personal interview, February 22, 1999.

59 It is this reflexive character that distinguishes Byrne's work from that of director George Lucas, maket of the Star Wars-films. Lucas is, like Byrne, influenced by Joseph Campbell and his theory of archetypes. (See Campbel, "The Hero"s Joumey", p. 180.) Lucas has been very successful at creating a mythical film series by applying Jungian archetypes, but never attempts to use artistic means to reflect on actual performances and the archetypical enexgies implied in them.

60 Byme, interview with R.F. Thompson, Rolling Stone Magazine, April 21, 1988, p. 52.

61 Taussig: "Mimesis and Alterity", p. xiii.

62 lbid, p. xvi.

63 Ibid, p xwiit.

64. CE. Gibson and Rubin (eds.): "Adomo: A critical reader", p. 57.

65 See Henry W. Pickford, in:Gibson and Rubin (eds): "Adorno: A critical reader", p. 328.

66 Benjamin: Selected Writings 1, p. 444.

67 Schechner: "Between Theater \& Anthropology", p. 260.

68 Schechner: "The End of Humanism", p. 52

69 Three examples are "What A Day "That Was" from Byrne's album "The Catherine Wheel"; "City of Dreams" from "True Stories", and the cityscape Byme included in his 1996 exhibition in the Massachusetts Museum of Contemporary Art.

70 Schechner: "Between Theater and Anthropology", p. 93, describing a BBC documentary reconstructing the life of Iron Age Celts.

71 Byme, interview by Elisabetta d'Eme, in: Alias, weekly insert with II Manifesto, Trieste, Italy, September 12,1998, p. 1.

72 Bytne, "End Notes", in "Strange Ritual".

73 Byrne, interviewed by Elisabetta d'Ene, 11 Manifesto, September 12, 1998 ,

74. Byrne, interviewed by Marco Puntin, 11 Progetto 4, May 1998.

75 All lines taken from the Thalking Heads" albums "Little Creatures" and "True Stories". See Part 1 for many other examples.

76 Cuge: "Sillence", p. 3.

77 Ibid., p. 6.

78 lbid, p. 166.

79 Bytne, from "Crossed Wires" in: "Strange Ritual"(pages not numbered).

80 Byme, from "My Malaysian Childhood" in: "Strange Ritual"(pages not numbered). 
81. Bytne, interview by Elisabetta d'Erme, in: Alias, weekly insert with Il Manifesto, Trueste, Italy, September 12, 1998, p. 1 .

82 Geulen: "Zeit zur Darstellung", p. 583 "...der Text beschteibe keine Kunsthrise, sondern inszeniere sie..." As Rodolphe Gasché has noted, in her essay Geulen determines the epistemological point of view from which Benjamin writes his essay as that of a yet undecided future in whose perspective the present appears as past. This accounts for the double nature of the loss of the aura which so many interpreters have pointed at on the basis of what she analyses as the simultaneity of method and object, that is, in terms of the pexformative dimension of Benjamin's criticism. Cf. Benjamin and Osborne (ed.): "Walter Benjamin's Philosophy", p. 202, note 3.

83 Geulen: "Zeit zur Darstellung", p. 598.

84 Benjamin, "Illuminations", p. 221. CF. Geulen, "Zeit zur Darstellurgg", p. 602-3.

85 Frith: "Sound Effects", p. 11.

86 Ibid., p. 268.

87 Byrne, Parthet 23, pp. 120 and 126.

88 Byrne, interviewed by Matco Puntin, Il Progetto 4, May 1998.

89 Byrne, quoted on a leaflet published by Aktionsforum Praterinsel, Munich, Germany, accompanying his show "Glory! Success! Ecstasy! 3 Animations", from 26 September to 15 November 1998. 


\section{Bibliography}

Abrams, M.H. The Mirror and the Lamp: Romantic Theory and the Critical Tradition. Oxford: Oxford University Ptess, 1971.

Adorno, Theodor W. Gesammelfe Schriften 1-20. Frankfurt an Main: Suhrkamp, 1970-86. "Zur gesellschaftichen Lage der Musik," in Zeikscbrift fïr Sozialforschung Heft $1 / 2$ and 3 , Jahrgang 1, 1932, pp. 103-24 and 356-78: reprint, München, Deutscher Taschenbuch Verlag, 1980.

Minima Moralia: Reflexionen aus dem beschadighen Leben. Frankfurt am Main: Suhrkamp, 1951.

- Obne Leifbild: Parva Aestbotica. Frankfurt ann Main: Sulurkamp, 1967.

- Pbilosophiscbe Terminologie I/ II. Frankfurt am Main: Sulurkamp, 1973.

- Der Schatz des Indianer-Joe: Singspiel mach Mark Twain. Frankfurt am Main: Sulluxkarmp, 1979.

Adorno, Theodor W. et al., Der Pastivinmusstreit in der demtschen Sockiologie. Darmstadt: Luchterband, 1989 (1972).

Adomo, Theodor W., and Alfred Sohn-Rethel. Briefwethsed 1936-1969. Munich: Text + Kritik, 1991.

Adomo, Theodor W., and Walter Benjamin. Briffwectsel 1928-1940. ed H. Lonitz. Frankfurt am Main: Suhrkamp, 1994.

English translations of works by Theodor W. Adorno:

Adomo, Theodor. W. The Jargon of Asthenticity. Trans. Knut Tarkowski and Frederic Will. London: Routledge and Kegan Paul, 1973.

- Prisms. Trans. by Samuel and Shietry Weber. Cambridge, Mass.: MIT Press, 1982.

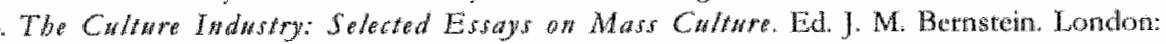
Routledge, 1991.

Diatectic of Enlightem wenf. Trans. John Cumning. London: Verso, 1995.

Negatite Dialectics. Translation E.B. Ashton. New York: Continunm Press, 1995.

- Minina Moralia: Reflecions from Damaged Life. "Trans. E.F.N Jephoott. London: Verso, 1996.

Beetbovn: The Philosopby of Music. Fragments and texts ed. by R. Tiedemann. Trams, E. Jephcott. Cambridge: Polity Press, 1998.

Akademie der Künste (ed.) SoHo - Downjown Manbattan. Berlin: Betiner Festwochen, 1976.

Abertazzi, Silvia. Dawid Byrne's Lyris. On Francey's David Byrne website fhetp: //www.bart.nl/-francey/th_db.html], 1996.

Alexander, Christopher. The Timeless Way of Bridding. New York: Oxford University Press, 1979.

Alexander, Christopher, et al., The Organ Experiment. New York: Oxford University Press, 1975.

-A Pattern Language: Towns, Builings, Consuruction. New York: Oxford University Press, 1977. 
Anderson, Benedict. Imaghed Compranities. Reflewions on the Origin and Spreat of Nationalism. Revised edition. London and New York: Verso, 1991.

Anderson, Laurie. Uniled States. New Yorlk: Harper and Row, 1984.

Stories frots the Nerve Bible: A Retrospective, 1972-1992. New York: Harper, 1994.

Antin, David. "Modernism and Postmodetnism: Approaching the Present in American Poetry," in Kostelanetz, Richard (ed.) The Atame-Garde Traditon in Literatwri, Buffalo, N.Y.: Prometheus Books, 1982, 216447.

Appadurai, Arjun. Modermity at Large: Cniturat Dimensions of Globaliqation. Minneapolis: Unwersity of Minnesota. Press, 1996.

Aragon, Louis. "Lettre ouverte à André Breton sur Le Regard du Sourd, l'art, la science et la liberté [Louis Aragon on the Patis production of "Deafman Glance ]," in Brecht, Stefan. The Theat of Visions: Robert Wrilson. Frankfurt am Main: Sulvtkamp, 1978.

Arpots, Joy. "Popteksten mogen zo op de leeslijst" in De Gids, 1991, 1, 70-5.

Art Lathyage. Eindhoven: Van Abbemuseum, 1980.

Art \& Language. De Scbilderifest. Brussel; Vereniging voor Tentoonstellingen wan het Paleis voor Schone Kunsten, 1987.

Artaud, Antonin. Het tbeater van de wredbeid. Trans. Simon Vinkenoogr. Amsterdam: Meulenhoff, 1982.

Asad, Talal, "The Concept of Cultural "Ttanslation," in Clifford, James, and Marcus, George E. (ed.) Writing Calture: The Poetics and Politics of Ethnograpby. Berkeley, University of California Press, 1986.

Ashley, Robert. Perfort Liwes: Aw Opera. New York: Archer Fields Press and Burning Books, 1991.

Barthes, Roland. Mythologieën. Amsterdam: De Arbeiderspers, 1975.

- Het plezier taln de tekst. Nijmegen: SUN, 1986.

Roland Barthes door Roland Baribes. Nijmegen: SUN, 1991.

. Empire of Signs. Trans. Richard Howard. New York: Hill and Wang, 1997.

- Image - Music - Text. Essays selected and trans. Stephen Heath. New York: Hill and Wang, 1998.

Baudrillatd, Jean. America. Translated from the French by Chris Tutner. London: Verso, 1988. - Simulaca and Simulation. Translated from the French by Sheila Faria Glaser. Ann Arbor: University of Michigan Press, 1994.

- The System of Objeas. Translated from the French by James Benedict. London: Verso, 1996.

Becren, Wim, et al., Energieën. Amsterdam: Stedelijk Museum, 1990.

Behler, Finst. Friedrich S 6 b/ege/ Reinbek bei Hambutg: Rowohlt, 1966.

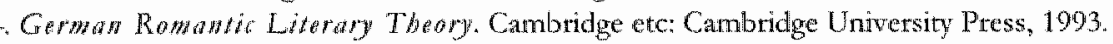

Behler, Enst, and Jochen Hörisch (ed.) Dir Akthalität der Fräbramantik. Paderborn: Schöningh, 1987.

Behrens, Roger. Pop Kultur Industrie: Zur Pbilosophie der popularen Musid. Würaburg: Königshausen und Neumann, 1996.

Benjamin, Andrew, and Peter Osborne (ed) Walter Benjamin's Pbitaropby: Destraction and Experimen. London and New York: Routledge, 1994.

Benjamin, Walter. Grsammelte Schroften I-VM. Frankfurt am Main: Suhrkamp, 1972-89. 
Briefe. Frankfurt am Main: Suhrkamp, 1978.

Minumations: Essayr and Reflections. Edited by Hannah Arendt, trans. Harry Zoha. New York: Shocken, 1988.

Reflectiont: Essayn, Apborisms, Azrobrograpbial Writings. Edited by Peter Demeti, trans. Edmund Jephcott. New York: Shocken, 1986.

One-Way Stret and Otber IV rifings. Trans. Edmund Jephoott and Kingsley Shorter. London: Verso, 1997.

Selected Writings, Volume 1: 1913-1926. Ed. Bullock and Jennings. Cambridge: The Belknap Press of Harvard University Press, 1996.

Selected Writings, Voltwe 2: 1927-1934. Ed. Jennings, Eilland, and Smith. Cambridge: The Belknap Ptess of Harvatd Univertity Press, 1999.

Th. Ariades Project. Trans. F. Elhand and K. McLaughlin. Cambridge: The Belknap Press of Harvard University Press, 1999.

Bennion, Jackie. "The Power of Advertising: David Byrme"s tribute to marketing muscle," Wired, Vol. 6 (Issue 2), 1998, 136-7.

Berman, Marshall. All That Is Solid Melts dnto Air. The Experience Of Modernity. New York etc.: Penguin, 1988.

Berman, Russell A. "Modern Art and Desublimation,"Telos 62 (1984-84), 31-57.

Best, Steven, and Douglas Kellner. The Postmodery Turn. New York: Guilford Press, 1997.

Birringer, Johannes. Tbeatre, Theory, Postmodermism. Bloomington and Indianapolis: Indiatnat University Press, 1993.

Blackwell, Lewis. The End of Print: The Graphic Design of Dasid Carsen. Introduction by Dawid Bytme. London: Lawrence King Publishing, 1995.

Blankopf, Kurt. Musik im Wandel der Gesellschaft: Grandqüge der Musiknoziologie. München: Pipet, 1982.

Boas, Franz. "The History of Anthropology" in: Stocking, Geotge W. Jr. A Framz Boas Reader": The Shaping of American Antbropology 1883-1911. Chicago and London: University of Chicago Press, 1974, pp. 23-36.

Bódy, Veruschka, and Weibel, Peter (eds.) Clip, Klapp, Bumr: Von der wismellen Musik zum Mussikvideo. Cologne: DuMont, 1987.

Boomkens, René. Kritiscbe massa: Ower massa, modorne erwaring en popowltwur. Amsterdam: Wan. Gennep, 1994

Bosma, Peter (ed). Finmkunde: Een inlexiding. Nijmegen: SUN/Ou, 1991.

Bourdiew, Pierre. On Telewision. Tr. P. Ferguson. New Youk: The New Press, 1998.

- Homa Academicas. Tr. P. Collier. Cambridge: Polity Press, 1988.

Distinction. A Social Critigue of the Judgement of Tasle. Tr. R. Nice. London: Routledge, 1992.

Bourdieu, Pierre, et al. The Weight of the World: Social Suffering in Combenporary Saciety. Tr. P. Ferguson, et al Cambridge: Polity Press, 1999.

Bowman, David. Fa fa fa fa fa fa: The Adventwres of Talkitg Heads in the 20th Centsiry. London: Bloomsbury, 2001.

Boxer, Sarah. "Slogans and Images, With Talking Heads Bending Your Ears," Nen York Times, Sunday, Angust 18, 1996, 35-7.

Boyden, David D. An Introduction to Maric. London and Bostom: Fabet and Fabet, 1978. 


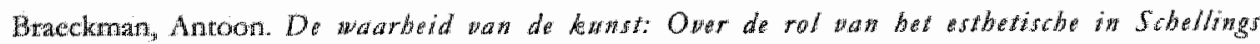
romatistiso modernistentskerifek. Leuwen: Peeters, 1996.

Brecht, Stefan. The Theatere of Visions: Roberi Wilsow. The Original Theatre of the City of New Yotk from the mid-60s to the mid-70s. Ftankfurt am Main: Suhrkamp, 1978.

Breuct Lee. "The Theatre and Its Trouble: An Essay," in Brever, Lee. Sister Smige Cinewa: The Callected Poems and Performanies, 1976-1986. New York: Theatre Communications Group, 1987

Brock Bazon. "Det Hang zum Giesamtkunstwerk: Pathosformeln und Energiesymbole zur Einheit won Denken, Wollen und Können," in Szemann, Der Hang zun Grsamkwnstwerk, 2239.

Bronson, A.A and Gale, Peggy. Performance by Artists. Toronto: Art Metropole, 1979.

Brown, Asby: "Reproduced Authentic: Galerie Via Eight," Artfortm, February 1991, p. 141.

Buck-Morss, Susan. The Origin of Negative Dialeatics: Theodor WW. Adorno, Walter Benjamin and the Frankfart Institste. New York: The Free Press, 1979 .

The Dialectics of Seeng: Walter Benjamin and the Arcades Project Cambridge, Mass. I London: MIT Press, 1989.

"Aesthetics and Anaesthetics: Walter Benjamin's Artwork Essay Reconsidered," Ortober $62,1992,3-41$.

Dreamuarld and Catastropbe: Tho passing of mass antopia in East and West. Cambridge, Mass. and London: MTT Press, 2000.

Bürget, Peter. Theorie der Apangarde. Frankfurt an Main: Suhrkamp, 1974.

Burwick, F. The Damnation of Newtan: Gaethe's Color Theary and Rannantic Perception. Betlia / New York: De Gruyter, 1986.

Bytne, David. Trw Stories. London/Boston: Fabes. and Faber, 1986.

"We Eart We Are Eaten," Artforwn, December 1989.

"Tnsert," Parkett 23, 1990, 119-29.

"Artist in Dialogue" in Howell: David Byrme, New York, 1992, 37-89.

"The Rei Momo Tour Diary," in Howell: Damid Byrne, New York, 1992, 107-38.

- Strange Ritual: Pictures and Words. London: Faber and Faber, 1995.

- Your Arion World: Winners Aro Loserx With A New Atrizade. Milan: Gotham, 1998.

" "The Holy Grail of No Style," in. Hall and Bictut (ed.) Tibor Kalmaw: Perperse Optimist.

New York: Princeton Architectural Press, 1998.

"Crossing Music's Borders: "I Hate World Music", New York Times, Sunday October 3, 1999.

The Dance of Politics. Curatorial statement for "Gesture, Posture and Bad Attitude in Contemporary News Photography", curated by David Byrne. New York: Apex Art, AprilMay 2001.

The New Sins. New York: MeSweeney's Books, and London: Faber and Fober, 2001.

Cage, John. Sithere: Lectwres and Writings. London: Boyars, 1995 [1963].

Campbell, Joseph. The Masks of God I: Priswitive Mylbology. New York: Atkana/Viking Penguin, $1991 \llbracket 1959]$.

The Masks of God II: Oriental Myrbology. New York: Viking, 1962.

The Heros 's Journey: Jaseph Campbell on bis Life and Work. Edited and with an introduction by Phil Cousinean. San Francisco etc: Harper \& Row, 1990.

Carroll, Noel. A Philosopby of Mass An. Oxford: Clarendon Press, 1998. 



African Musical Idions. Chicago/London: The University of Chicago Press, 1979.

"Naked Heads: The Talking Heads explain their world to John Miller Chernoff, author of "African Rhythm and African Sensibility" Sphin, April 1988, 48-52, 76-8.

"Thoroughly Modern Music: The Exolution of Talking Heads" in Musir es Somd Output, May 1988, 40-8, 78 .

Clifford, James. The Predicament of Culture: Twentitb. Century Etbnograpby, Literature, and Art. Cambridge, Mass., and London: Harvard University Press, 1988.

Clifford, James, and Marcus, George E. (ed) Writing Culture: The Poetits and Polition of Eubrograbby. Berkeley: University of Califorma Press, 1986.

Cole, Susan Letzlet. Diretors in Rebearsal: A Hidden World. New Yorls / London: Routiedge, 1992.

Corliss, Richard. "Our Town: George Bailey meets "True," Bhwe," and Peggy Sue"," in Fi/m Comment XXII / 6, Now Dec. 1986, 9-13, 16-7.

Coser, Lewis A. Masters of Saciological Thought: Idoas in Historical and Social Context. 2nd edition. New York etc: Harcourt, Brace, Jowanovich, 1977.

Coupland, Ken. "All Ower the Map with David Bytne" Graphis, international journal of graphis art and applied art, 313, 1998, 92-100.

Ctanston, Maurice. The Romantic Movenent. Oxford and Cambridge, Mass.: Blackwell, 1994.

Crawford, Peter Tan, and Turton, Dawid (ed.) Film as Elbnograpty. Manchester and New York: Manchester Uniwersity Press, 1992.

Crimp, Douglas. "The Photographic Activity of Postmodernism," in Thomas Docherty (ed.) Postmodermism: A Reader. New York: Harvester Wheatsheaf, 1993.

Critchlley, Macdonald, and Henson, R.A. (eds.) Music and tho Brain: Studies in the Neuralogy of Masic. London: Heinemann Medical Books, 1977.

Crowther, Paul. Critical Aestbetics and Pastmadermism. Oxford: Clarendon Press, 1993.

Csikszentmihalyi, Mihaly. Creativity. Flow and the Psychology of Discotery and Invention. New York: HarperCollins, 1997.

Dalton, Jody. "Robert Wilson: Seeing the Forest for the Trees" Ear Magazine 11, 1988.

Davis, Douglas. "Post-Performancism," Artfortm, October 1981 (Volume XX, no. 2), 31-9.

Davis, Jerome. Talking Heads: A Brograpby. London: Omnibus Press, 1987.

Deren, Maya "Art and Anthropology: "The Crossroads / From the Notebook of 1947", introduced by Catrina Neiman, in October 14, Fall 1980, 3-46.

The Voodoo Gods (original title: Divine Horsemen, 1953). Frogmore, St Albans: Granada/ Paladin, 1975.

Derrida, Jacques. Of Grammatology. Trans. G. C. Spivak. Baltimore and London: Johns Hopkins University Press, 1976.

Dews, Peter. Logics of Disintagration: Post-straturalist thought and the claims of critical thropy. London/New York: Verso, 1987.

Diamond, Elin (ed) Performance and Cuttural Politirs. London and New York: Routledige, 1996.

Dilthey, Wilhelm. Das Erlebsis und die Disbung. Leipzig: Reclam, 1991.

Disselkoen, Dick (ed.) Opera: Twaalf apera's als spuegels wan bwe tijd. Tekstboek en werkbock. Nijmegen and Heerlen: SUN/Ou, 1993. 


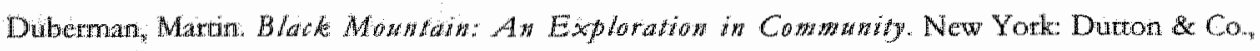
1972

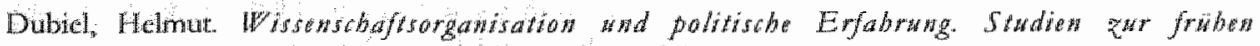
Krivishen Theorte. Frankfurt Suhrkamp, 1978.

During simon (ed) The Cutwra/Swdies Reader. Second edition. London: Routledge, 1993.

Eggleston, Wiliam. The Demacratit Forest. Introduction. Eudora Welty. London: Secker \& Watbung, 1989

Eno, Brian. "My own work in video..., in The Latwinows Image, 112-3.

- A Year with swollen Appondices: Brian Eno's Diary. London: Faber and Faber, 1996.

Eno, Brian, and Peter Schmidt. Oblique Strategies. Orig. 1975. http//music hyperreal.org/artists/brian_eno/oblique/oblique huml

Ero, Brian, and Russell Mills. Mar Dark Than Shark. Commentaries by Rick Poynot. London: Faber and Faber, 1986.

Fabian, Johannes. Tinn and the Otber: How Antbropology Makes its Object. New York: Columbia University Press, 1983.

Farelly, Liz. Tibor Kalmat: Design and Undesigu. London: Thames and Hudson, 1998.

Fichte, Johann Gotelieb. Ober dex Begriff der Wissenscbaftslebre, oder der sogewanuten Pbilosophie. Stutgart: Reclam, 1991 [1794].

Fishorr, Gerhard (ed). "With the Sharpened Axe of Reason": Approacbes to Walter Benjamin. Oxford and Washington, DC: Berg, 1996.

Fisher, Jean (ed). Global Vistons: Towards a New Imtermationalism in the Viswat Arts. London: Kala Press, 1994.

- Reverberations: Tactics of Resistance. Forsws of Agengy in Trans/cultural Practices. Maastricht: Jan van Eyck Editions, 2000.

Foster, Hal (cd). The Antia,Aesthetion Essays on Postwodern Cuhurr. Seatle: Bay Press, 1983.

The Return of the Reat: The Avani-Garde at the End of the Cantury. Cambridge, Mass., and London: MIT Press, 1996.

Frank, Manfted and Kurz, Gerhard (eds.) Materialien zu Sibellings pbilosopbistben Anfängen. Frankfurt an Main: Suhrkamp, 1.975.

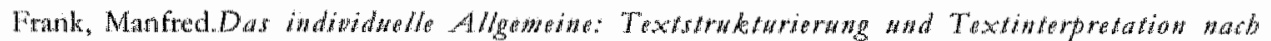
Scblexermacber Frankfurt am Main: Sulatkamp, 1985.

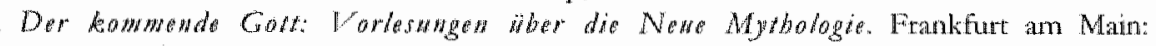
Suhrkamp, 1982.

- Gott in Exil: Forlestngen wber dio Newe Mythologie II. Frankfurt am Main: Suhrkamp, 1988.

- Bine Einforbrong in Sobellings Pblosopbie. Frankfurt am Main: Suhrkamp, 1985.

" "Intellektuale Anschnung": Drei Stellungnahmen zu einem Deutungsversuch von Sellystbewußtsein: Kant, Fichte, Hölderlin/Novalis," in: Behler and Hörisch (eds,) Die Aktualitat der Frabrowatute. Paderborn: Schöningh, 1987.

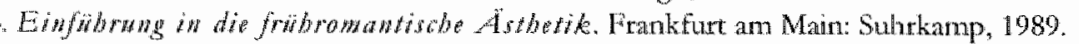

Frith, Simon. Somd Effects: Youth, Wistre, and the politics of rock "n" poll. New York Pantheon Books, 1981.

- Perforwing Rites: On the Value of Popular Masso. Cambridge, Mass.: Harvard University Press, 1998. 


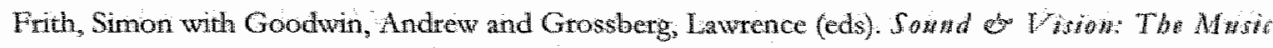
Video Reader. London / New York: Rourledge; 1993.

Fizot, Michel (ed). A Noas Histayy of Photography. Collogne: Konemann, 1998.

Gauss, Ulike (ed). Photo-Kunst: Arbenten aws 150 Jabren. Stuttgart: Cante, 1989.

Geertz, Clifford. The Interpretation of Cwltwres: Selected Essays. London: Fontana, 1993. "The Uses of Diversity", in: Sterling M. Mc Murrin (ed.) The Tanner Leatures on Haman Vakikes. London, 1986: pp. 252-275.

Geulen, Eva. "Zeit zur Darstellung: Walter Benjamins Das Kunstwerk im Zeitalter seiner technischen Reproduzierbarkeit,", in Modern Langsage Notes, 107 (1992): 580-605.

Gevers, Ine and Heeswijle, Jeanne van. Bepond Ethics aird Aestherics. Nigmegen: SUN, 1997.

Gibson, Nigel and Rubin, Andrew. Adomo. A Critica/ Reader. Ox ford: Blackwell, 2002.

Goldberg, Roselee. Performane Art: From Futurism to the Present, revised and enlarged edition. London: Thames and Hudson, 1988.

Gracyk, Theodore. Rbythm and Noise: An Aestbetics of Rock. London / New York: Tauris \& $\mathrm{Co}, 1996$.

Graham, Dan. Rack My Religion: Writings and art projects, 1965-1990. Ed. Brian Wallis. Cambridge, Mass... MIT Press, 1993.

Gray, Spalding. Sminming to Cambodia: The collected works of Spalding Gray. London: Pan Books, 1987.

Grcen, Renée. "Der Künstler als Ethnogtat? Zu Hal Foster, 'Return of the Real","in Texte zur Kunst, September 1997.

Haacke, Hans. Boderios. (Venice Biennale 1993: Geman Pavillion) ed. by BußMmann, Klaus and Matznet, Florian. Stutgarc Cantz, 1993.

Habetmas, Jürgen. Der pbilosopbische Diskurs der Moderne. Frankfurt am Main: Suhrkamp, 1985. . Moral Conscionsmess and Communicative Action. Trans. Chtiscian Lenhardt and Shierry Weber Nicholsen. Cambridge; Mass.: MIT Ptess, 1990.

Hall, Peter, and Bienut, Michael (eds). Tibor Kalman: Perperse Optimist. New York: Princeton Architectural Press, 1998.

Halliwell, Martin. Romantio Science asd the Experience of Self: Transathantio Crossurents from Welliam James to Oliver Sacks. Adershot: Ashgate Publishing, 1999.

Handelman, David. "Are four heads betrer than one? The world's smartest trock group talks about confronting the Daxid Byrne media blit" in Rolling Srone, January 15 th, 1987, 34-6,54-8.

Harris, Mary Emma. The Arts at Black Mountait College. Cambridge, Mass, and London: MlT Press, 1988.

Harrison, Charles. "Art \& Language: Enkele condities en interesses van de cerste tien jaar," in Ant br Language: De Sibilderijen. Brassel: 1987.

Hassan, Thab. The Dismewberment of Orphens: Touard a Postmoderm Cwhare. Second edinon. Madison: The University of Wisconsin Press, 1982.

Hebdidge, Dick. Hiding in the Light: On Images and Tbings. London and New York: Routledge, 1988.

Hennion, Antoine, and Bruno Latour. "L'art, l'aura et la technique selon Benjamin, ou comment devenir célèbre en faisant tant d'errenuss à lat fois..." in Cabiers de médiologio 1. Paris: Gallimard, 1996. 
Herman, Edwate S, and Noam Chomsky. Manufacturing Consent: The Political Ecomony of the Mass Media. New York: Pantheon, 1988.

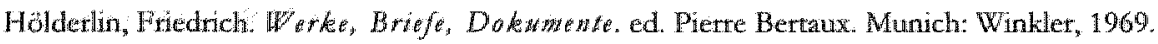

Holmberg, Arthur. The Theatre of Rabert W' ilsom. Cambridge: Cambridge University Press, 1996.

Horkheinet; Max Kants Krituk der Urteilsteraft als Bindeglied zwischen theoretiscber wnd praktisido Philosophit. Sturtgart Kohlhammer, 1925.

Howell, John." "Robert Wilson and David Byrne, "The Knee Plays", in Alice Tully Hall," in Artforwm, March 1987, p. 131.

Dـ Dawd Byrme. New York: Thuinder's Mouth Ptess, 1992.

-.. Laturie Anderson. New Youk: Thunder's Mouth Press, 1992.

Hurston, Zota Neale The Sanctified Church. Berkeley: Turtle Island, 1981.

Sporen op pad. Afterword by Alice Walker. Beda: De Geus, 1993.

Hutnyk, John. Crithiqu of Exotica: Masic, Politics and the Cultwre Indastry. London and Sterling, VA: Pluto Press, 2000.

Huyssen, Andreas, and Scherpe, Klaus R. (eds.) Postmoderne: Zeichen wines kulturellen Wandels. Reinbek bei Hamburg: Rowohlt, 1986.

Isler, Scott. "Going, Going, Ghana! David Byrne and Brian Eno bring Africa to Soho", in Trousers Press 61 , May 1981.

Jagt, Marijn van der. "Op het kruispunt van mythe en industriallsatie: The Forest van Bob Wilson en David Byme," in Tomal Theatraal, November 1988.

Jameson, Fredric. The Cultural Turn: Selected Writings on the Postmodern, 1983-1998. London: Verso, 1998.

Jay, Marin. The Dialectical Togination: A History of the Frankfurt Sibool and the Institute of Soridal Reseatcb 1923-1950. Boston/Toronto: Little, Brown and Company, 1973.

Jencks, Charles. The Language of Postmodern Arcbitectare. London: Academy Editions, 1991.

Jennings, Humphrey. Pawdatmoniwm. 1660-1886: TbB Coming of the Machine as Seen by Contenporary Obnervers. Ed. by M.L. Jennings and C. Madge. New York: The Free Press, 1985.

Jennings, Michael W. Dialential Inager: Walter Benjamin's Theary of Literary Criticism. Ithaca/London: Cornell University Press, 1987.

Johnson, Ken. "Report from North Adams: Back to the Future Again. After years of delays, MASS MoCA is now moving toward a 1988 opening date-with a radically revamped sense of audience and mission," includes: "David Bytne at MASS MoCA," in Art in Amerior, October $1996,51-5$.

Jowitt, Deborah (ed.) Meredith Monk. Baltimore and London: The Johns Hopkins University Press, Art + Performance Series, 1997.

Jung, Carl G. (ed) Man and bis Symbo/r. London: Aldus Books, 1964.

Jung, Carl G.Symbots of Transformation (second edition). Volume 5 of the Collected Works. Princeton NJ: Princeton University Press, 1990.

Cintigation in Transition (second edition). Volume 10 of the Collected Works. London and Henley: Routledge \& Kegan Paul, 1970.

- Psychology and Alcbemy (second edition). Volume 12 of the Collected Works. London and Henlley: Routledge \& Kegan Paul 1968.

- The Spirit in Man, Art and Literature. Volume 15 of the Collected Works. London and 
Henley: Routledge \& Kegan Paull, 1978.

Kalman, Tibor, with J. Abbott Miller, and Karrie Jacobs. "Good History / Bad History," in Looking Closer: Critugal Writugs on Graphie Design, ed. M. Bienut et al. New York: Allworth Press, 1994, 25 33.

Kamper, Dietmar, and Willem wan Rejen (eds.) Die Unwollendete Wrinnft: Moderne persus Postmoderne: Frankfutt am Main: Suhrkamp, 1987.

Kant, Immanuel. Grondlegugng zir Metaphysik der Sitwen. Ed. by Wilhelm Weischedel. Werkausgabe, vil. VII. Frankfurt am Main: Suhrkamp, 1974.

The Crisuque of Jadgement. Translated with analytical indexes by James Creed Matedith. Oxford: Clarendon Press, 1992.

Kardon, Janet: "Language and Image, Theme and Motif, in: Howell, J. Lawrie Anderson, 127-38.

Keesing, Roger M. Caltaral Anthropology: A Contemporary Perspedive. New York: Holt, Rinehart and Winston, 1976.

Keil, Charles, and Steven Feld. Musio Grooves: Exagy and dialogan. Chicago and London: University of Chicago Press, 1994.

Kellner, Douglas. "Critical Theory and the Culture Industries: A Reassesment", in Telos 62 (198485), 196-206.

Kertess, Klaus. "In Robert Wilson's Forest," Parkatt 16, 1988, pp. 56-59.

Kirby, Michael, and Victoria Nes Kirby. Futurist Performance. New York: Performing Arts Journal Publications, 1986.

Koenig, Gerson. Talking Heads Bibliograpby; first revision January 1997. WWW: gmkoenig @ acsu. buffalo.edu

Kosuth, Joseph. Reprodaced Aubentic. Galerie Via Eight, Tokyo, 1990.

- Art after Pbilosopby and after: Callected Writings, 1966-1990. Edited with an introduction by Gabriele Guercio, foreword by Jean-François Lyotard. Cambridge, Mass. and London: MIT Press, 1991.

Kostelanetz, Richard (ed) The Avamt-Garde Tradition in Literature. Buffalo, NY: Prometheus Books, 1982.

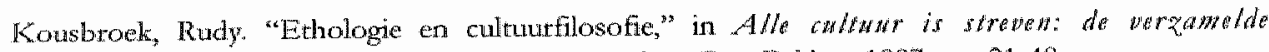



Kruger, Barbara. Retnote Control: Power, Cuttares, and the World of Appoaratios. Cambridge, Massi and London: MIT Press, 1993.

Kunneman, Harry, and Hent de Vties (eds.) Die Aktwalizät der Dialeklik der Aufklärmg": Zwischea Moderne und Postmoderne. Frankfurt am Main: Campus Verlag, 1989.

Lacoue-Labarthe, Philippe, and Jean Luc Nancy. The Literary Absolute: The Theory of Literatwre in Gerysan Romanticism. Allsany. NY: State University of New York Press, 1988:

Latour, Bruno, and Steve Woolgar. Laboratory Life. The Constration of Scientific Facts. Introduction by Jonas Salk. With a new postscript by the authors. Princeton, NJ: Princeton University Press, 1986 .

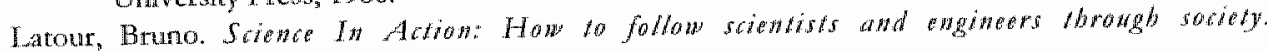
Cambridge, Ma.: Harvard Uniwersity Press, 1987. We Have Never Been Modern. Translated by Catherine Porter. Now York: Harvester Wheatsheaf, 1993. 
"Een (filasofisch) programma voor een linkse (Europese) parbij," Krisis, Tsjdscrifft voor Filosofit, 77, 1999, pp. 52-63.

Pandorats Hope: Essays on the Realiy of Science Studier. Cambridge, Mass.: Harrard University Press, 1999.

LeWitt, Sol Sol LeWitt. New York. The Museum of Modem Art, 1978.

Lingner, Michael. "Der Ursprung des Gesamtkunstwerkes aus der Unmöglichkear "Absoluter Kunst". Zut rezeptionsästhetischen Typologisierung won Philipp Otto Runges Unversalkunstwerk und Richard Wagners Totalkunstwerk," in: Szeemann, Der Hang zams Gesomthunsturerk, $1983,52-69$.

Verbal Ait Comananicanion: Thearetical and Practical Models. Art's Future Requiremonts. Maastricht: Jan van Eyck Academie, 1995.

Lippard, Lucy R. Six Years: The dematerialization of the art abjeat from 1966 to 1972. Berkeley. University of California Press, 1997 [1973].

Löbig, Michael, and Gerhard Schweppenhäuser (eds.) Hamburger Adorrou Sympostast. Lüneburg: Dietrich zu Klampen Verlag, 1984.

Lotringer, Sylvère: New Yorker Gespräbbe. Berlin: Merve, 1983.

Luria, A. R. Tho Mind of a Mmemonist: A little book about a wast memory. Cambridge, Mass. and London: Harvard University Press, 1987.

Lyotard, Jean-François: Das Patchuork der Minderbeiten. Berlin: Merve, 1977.

- La condition postmoderty: Rapport sur le savoit. Paris: Editions de Mimuit, 1979.

Het postmoderne uitgelegd ala onze kewderen. Kampen: Kok Agota, 1987. Original title: Le Postwoderve explique anx enfants: correspondance 1982-1985.

Het onzzenselijke: Causeriën over de kijd. Kampen:" Kok Agora, 1992.

Macdonald, Scott. "Interview with Bruce Conner," in Macdonald, Scott: A Critrical Cinema: Interviens with Imdependent Filmmakers. Berkeley and Los Angeles: University of California Press, 1988, 244-56.

Maenz, Paul, and Gerd de Vxies, (eds.) Art de Language: Texte zwon Phänomen Kanst und Spraibe. Terry Atkinson, David Bainbridge, Michael Baldwin, Harold Hurrell, Joseph Kosuth. Cologne; Du Mont Schauberg, 1972.

Mallick, Hearher. "Strange Ritual' by David Byrne: That's pretty strange - Only the very peculiar David Byme could have found a philosophy in his holiday snaps." Torouto 5 an, 19 November 1995 .

Marcus, Greil. Mystovy Train: Images of Ameriwa in Rock'n'Roll Mastic. Fouth revised edition. New York: Plume, 1997.

Marcuse, Hetbert. Tbe Aesthetis. Dimension: Toward a Critique of Marxist Aesthetics. Boston: Beacon Press, 1978.

Matcquard, Odo. "Gesamtkunstwerk und Identitätssystem: Oberlegungen im Anschluß an Hegels.

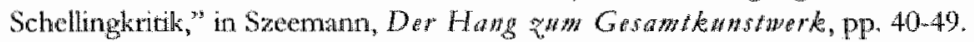

Maranca Bonnie (ed.) The Thedre of Images" Contains: Robert Wilson: "A Letter for Queen Victoria'. Richard Foreman: 'Pandering to the Masses: A Mistepresentation'. Lee Breuer: "The Red Horse Animation". Edited with introductory essays by Bonnie Marranca. New York: Drama Book Specialists, 1977.

"The Forest as Archive: Wilson and Interculturalism," in Performing Arts Journa/33/34, 1989.

Erologien of Theater: Essags at the Century THerning. Baltimore and London: John Hop- 
kins University Press 1996.

Martin, Jean-Hubert et al. (eds) Magicients de ha Terre. Paris: Centre Georges Pompidon, Musée National d'art moderne, 1989.

Marx, Karl, and Frederick Engels. The Comwanint Masnifesto. A modern edition, with an introduction by Eric Hobsbawm. London: Verso, 1998.

Marx, Karl. Das Kapital: Kritik der politisuben Okonons I (MEW 23). Berlin: Dieta, 1977.

McDonough, Tom. "Making Sense of David Byme: Talking Head analyzed on the occasion of his directing debut," in American Film 12/1, Oct. 1986, $31-8$

McKim, Richard. "True Stories," Cineaste 15/3, 1987: 44-6.

Menninghaus, Winfried. Walter Benjamins Theorie der Spracomagie. Frankfurt am Main: Suhrkamp, 1980.

Schwellentende: Walter Benjamins Passage des Mythos. Frankfurt am Main: Suhrkamp, 1986.

- Unendiche Verdopplang: Die frabromantiscbe Grindlegung der Kunstheorie ing Begriff absoluter Selbstreflexion. Frankfurt am Main: Suhrkamp, 1987.

Miles. Talking Heads: An illwstrated biograpby. London etc.: Omnibus Press, 1981.

Missac, Pierte. Wralter Benjatyin's Passages. Trans. S. W. Nicholsen. Cambridge: MIT Press, 1995.

Mul, Jos de. Romantio Desire in (Pont)modern Am and Pbilosopby. New York: State University of New York Press, 1999.

Nicholsen, Shierry Weber. Exact Imagination, Lats Wort: On Adono's Aeshotics. Cambridge: MIT Press, 1997.

Nietzsche, Friedrich. Werke. Ed. K. Schlechta. Frankfurt am Main: Ullstein, 1980.

Novalis. Werke. Study edition, ed. Gerhard Schulz.. Munich: C.H. Beck, 1987.

O'Doherty, Brian. American Masters: The Voice and the Myth. New York: Universe Books, 1988.

Olson, Charles. Propriactption. San Francisco: Four Seasons Foundation, 1965.

. Human Universe and other essays. Ed. Donald M. Allen. New York: Grove Press, 1967.

Ott, Ulrich (ed.) "Walter Benjamin," Marbacber Magaqin 55/1990.

Paetzold, Heinz (ed.) City Life: Essays on urbon cwiture. Maastricht / Amsterdam: Jan van Eyck Academy Editions / De Balie, 1997.

Panicelli, Ida. "Listen carefully: The Mahabharata on Film," Ar/form, Novenober 1989, 122 4.

Robert Wilson. Parkett 16, 1988.

Piper, Adrian. Ont of Order, Ont of Sight. Volwne I: Selected Writings in Metar Art 1968 1992; Volume II: Selected Writings in Art.Criticism 1967.1992. Cambridge: MIT Press, 1996.

Plato. Republic. Vol. V and VT in the lloeb Classical library. Thans. Paull Shorey. Cambridge, Mass. and London: 1982 and 1987 .

Puntin, Marco. "Intervista a Dawid Byme," in I/ Progefto 4, May 1998.

Rabkin, Gerald (ed.) Ribhard Foreman. Balcimone: Johns Hopkins University Press, 1999.

Ratcliff, Carter. "David Byrne and the Modern Self: How Do I Work This?", Aryforum 23, May 1985.

Richter, Hans. DADA: Kanst und Antiksmst. Der Berirag Dadar zor Kunst des 20. Jabrbunderts. Cologne: DuMont, 1964. 
Roberts, Julian. The Logit of Reflectom: German Pbilasopby in the Twenueth Century. New Hawen and London: Yale University Press, 1992.

Rockwell, John. "An Epic grows in Brooklym," Now York Times Magaqine, November 9, 1988, 50 , $51,84,86$

- All American Musro Composition in the late twentiath century. Reprinted with a new preface. New York: Da Capo Press, 1997.

Rulay, Jay. Parturing Cultwre: Explarations of Filno and Anthropology. Chicago: University of Chicago Press, 2000.

Rüter, Christoph, and Guntram Weber(eds.) The Forest (theater programowe). Berlin: Theater der Freien Volksbühne, 1988.

Sacks, Oliver. The Man Who Mistoate bis Wife for a Hat. London: Picador, 1986.

Sawtan, Dawid. Breateing The Rules: The Wrooster Group. New Yotk: Theatre Communications Group, 1988.

In Their Own Wards: Contemporary American Playurights. New York: Theatre Communications Group, 1989 [2nd printing].

Sayte, Henry M. The Object of Performance: The American Avant-Garde since 1970. Chicago: University of Chicago Press, 1989.

Schechner, Richatd. Exsays on Performance Theory 1970-1976. New York: Drama Book Specialists, 1977.

The End of Hunanism: Wrytings an Performance. New York: Performing Arts Journal Publications, 1982.

—_Brtween Theater Anthropology. Philadelphia: University of Pennsylvania Press, 1987.

- The Future of Ritual: Writings on culture and performance. London: Routledge, 1993.

Schecteri, Martin. "Beyond the Text: S(h)ifting through Postmodernisn (Nick at Nite, David Bytne, and Kathy Acker)," American Journal of Semiotics, Vol. 8, No. 4 (1991), 173-86.

Scheible, Hartmut. Theodor W. Adarmo. Reinbek bei Hamburg: Rowohlt, 1989.

Schelling, F. W. J. Texte zur Pbilosopbie der Kanst. Stuttgart: Reclam, 1991.

Schiller, Finedrich. Uber die ästbetisebo Erwabung des Menscben, in einer Reibe pon Briefen. Sturtgart: Reclam, 1995 [1795].

Schlegel, Finedrich. Kritisco whd theorefisibe Sihriften. Comp. A. Huyssen. Stutgart: Reclan, 1990.

-. Lascinde. Feankfurt atm Main: Insed, 1985.

Schleicrmacher, Friedrich. Hermenewtik wnd Kritik. Edited and introduced by Manfred Frank. Funkfurt am Main: Suhrkamp, 1977.

Schulte-Sasse, Jochen, et al. Theory as Pratice: A riticat antbology of early German Romantic wrivinger. Minneapolis: University of Minneapolis Press, 1997.

Sellars, Peter." "Exits and Entrances: Peter Sellars on Opera," Artforth, December 1989, 23-4.

Semetr, Richard. The Corronon of Cbarader: The personal consequestes of work in the new rapitalism. New York and London: Norton \& Co., 1998.

Sennetr, Richard, and Jonathan Cobb. The Hidden Lnjories of Class. New York: Vintage Books, 1973.

Shank, Theodore. Amerian Alterwative Tbeatre London: Macmillan, 1982.

Shatuck, Roger. The Bandwet Years: The origins of the anakitgarde in France, 1885 to World 


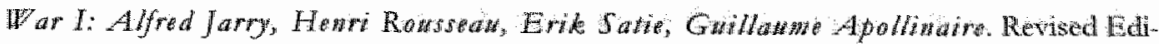
tion. New York: Vintage Press, 1968.

Sheppard. Anne. Aestbetics: An introdution to the philosopby of ant. Oxford: Oxford University Press, 1987.

Shyer, Laurence. "The Forest: A preview of the next Wilson-Byme collaboration," in Tbeater, Summer/Fall 1988.

. Rabert Wrilson and bis Collaboratorn. New York: Theatre Communications Group, 1989.

Silverman, Hugh J. (cd.) Postmodernism. Pbilosopby asd the Arts. New Yotk and London: Routledge, 1990.

Sklar, Robert. Movie-Made Amperica: A Cultural Histoyy of American Mowies. New Yonk: Vintage, 1976.

Sklarew, B.H., et al. (eds.) Bertolack "s The Last Emperor: Multiple Takers. Detroit: Wayne State University Press, 1998.

Sontag, Susan. Against Tuterpretation. New York: Dell, 1969.

- Under the Sign of Saturn. New York: Vintage, 1981

Spector, Nancy. "The Anti-Narrative: Metedith Monk's Theater," in Parkett 23, 1990, 110-13.

Sragow, Michael. "Heads. Will Roll," in Film Comment XX/3, Mayd une 1984, 19-21.

Steenstra, Sytze. "Noisy Concepts: Music as Anti-Essentialism," in: Issues in Convemporary Culture" and Aesthetics 10/11, April 2000, pp. 199-220.

. "Neutralizing... Now!!" in Fisher, Jean: Reverberations. Jan van Eyck Editions, Maastricht, 2000 , pp. 126-9.

"David Byrne: Getting the "T' out of Design," in: Dot dot dat 4, Winter 2001/2002, pp. 639.

Stein, Gertrude. Lectures in A Awerica. London: Virago, 1988.

Steiner, Uwe. Die Geburt der Kritike aus dem Geiste der Kunst: Untersalsungen zum Begriff dum Kritik in den früben Sibriften Walker Benjawins. Würzburg: Königshausen und Neumann, 1989.

Steinert, Heinz. Adorno in Wien: Uber die (Un-)Moglichkeit wan Kunst, Kulur and Befreingh. Frankfurt am Main: Fischer, 1993.

Steinhagen, Harald. "Zu Walter Benjamins Begriff der Allegorie," in Walter Hing (col.): Forwan and Funketionen der Allegorie. Stuttgart, 1979

Steinman, Louise. The Knowing Body: Elements of comtemporary performance and dane. Boston \& London: Shambhala, 1986.

Stoessel, Marleen. Aura, das vergesseme Messoblicbe: za Sprache whd Erfabrung ber Walter Benjam in. Munich: Hanser, 1983.

Szeemann, Harald. Der Hang zunt Gesamtemstwerk. Aarau / Trankfurt am Main: Saucrländer, 1983.

Talking Heads and Frank Olinsky. What The Sangs Look Like: Contemporary artists interpret Talking Heads songs. Introduction by David Bytne. New York: Harper and Row, 1987.

Tamm, Eric. Brian Eno. His Masir and the Verrical Color of Sound. Boston and London: Faber and Faber, 1989.

Taussig, Michael. The Nernous System. New York: Routledge, 1992. Minsesis and Alterity: A pattitular bistory of the senses. New York: Routledge, 1993. 
Taylor, Rogan P. The Death and Resurretion Sbow: From Shaman to Superstar. London: Anthony Blond, 1985.

Teubner, Ernist (ed) Hugo Ball (1886-1986) Loben ast Werk. Berlin: Publica, 1986.

The Expic of Gilgasnesh. An English version with an incroduction by N. K. Sandars. Revised edition containing new material london: Penguin, 1987.

The Luminoms Image. Amsterdam: Gary Schwartz in cooperation with the Stedelijk Murseum, 1984.

Thompson, Robert Farris. "An Aesthetic of the Cool," in African Arts 7, no. 1 (fall 1973), 40-3, $64-7,89-92$

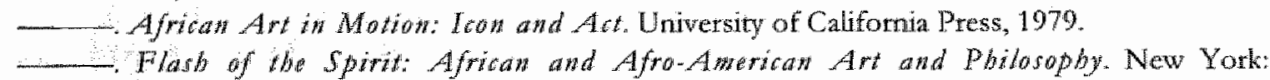
Vintage Books, 1984.

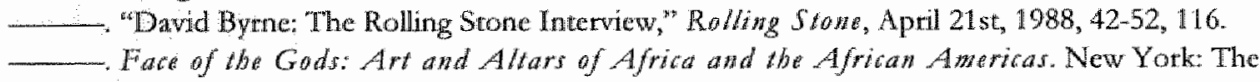
Museum for African Art and Prestel Verlag, 1993.

"The Medicine In The Imagining: Notes On Mambo," in First of Tbe Month, 1, 1998, 1011.

"Mambo: Microcosm of Black New York Creativity," in Jean Fisher: Reverberations; Maastricht: Jan van Eyck Editions, 2000, 164-73.

Tiedemann, Rolf. Studien zur Plilosopbre Walter Benjamins. Frankfurt am Main: Suhrkamp, 1973.

- Dialektik im Stillstand: Fersache sum Spätwerte Walter Bemjanins. Frankfurt am Main: Suhrkamp, 1983.

Tiger, Lionel, and Robin Fox. The Imperial Amimal. Foreword by Konrad Lorenz. New York: Henry Holt and Company, 1989 [1971].

Tomkins, Calvin. The Bride and the Batgelors: The heretical courtship in syodern art. London: Weidenfeld and Nicholson, 1965.

Tumer, J. F. Howard Finster, Man of Visions: The dife and work of a self-tanght artist. New Yotk: Knopf̈, 1989.

Tutuola, Amos. My Life in the Bush of Ghosts. London/Boston: Faber and Faber, 1981.

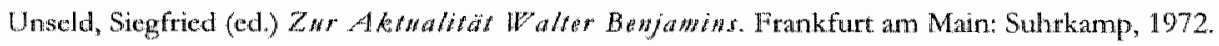

Vandermeersch, Patrick. Unresolwed Questions in the Frestl/Jnng Debate: On Pyythosis, Sexual Identry and Religion. Lewen: Lewen University Press, 1991.

Wallis, Briwn (ed,) Blasted Allegoriss. An Anthology of Writing by Contenporary Artists. New York: The New Museum of Contemporary Art. Cambridge: MIT Press, 1987.

Waters, Lindsay. "The Age of Incommensurability", in: Bosnday 2 28:2, Summer 2001, pp. 133 72.

Weber, Max. Dio protestantiscbe Etbik I: Eine Aufsatosantwing. Ed. Johannes Winckelmann. Gütetsloh: Verlagshaus Mohn, 1981.

Weht, Gerhard. Jang en qij" werk. Rotterdam: Lemniscaat, 1981.

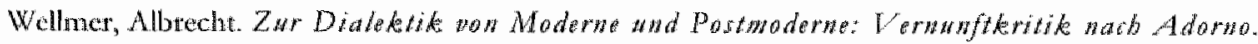
Frankfurt am Main: Suhrkamp, 1985.

Welsch, Wolfigang. Unsere poutmoderme Moderne. Third corrected edition. Weinheim: VCH Acta humaniosa, 1991.

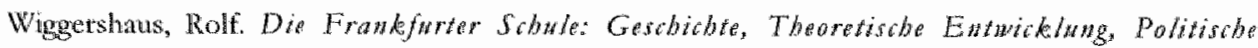
Bedeatung, Munich: Hanser, 1986. 
Wilson, Edward O. On Human Natrre. Cambridge: Harvatd University Press, 1995 [1978].

Wilson, Robert. Der deutsibe Teil won tbe CIVIL warli: a tree is best weasured when it is down, im Schatspiel Köln. Frankfurt am Main: Suhtkamp, 1984.

Portrait, Still Life, Laxdscape. Rotterdam: Museum Boymans-xan Beuningen, 1993.

Witte, Bend. Walter Benjamin. Reinbek bei Hamburg: Rowohlt, 1985.

Woods, Tim. Beginning Postmodermign. Manchester: Manchester University Press, 1999.

Wolfe, Tom. The Electric Kool Aid Acid Test. New York: Bantam Books, 1989.

Wyman, Bill. "Byrne's Town," in Film Comment $22 / 5$, Sept.-Oct. 1986, 62-4.

II sseling, Samuel. Mimesis: On Appearing at Being. Translated by H. IJsseling and J. Bloechl. Kampen: Kok Pharos Publishing House, 1997.

websites:

www talking-heads net

www.luakabop.com 


\section{Index}

Acconci, Viro, 5

Adorno, Theodor Wiesengrund, 14; 15; 20 -

$22 ; 241 ; 243 ; 268-274 ; 284 ; 288 ; 290-295$; $302-303 ; 313$

adwertising, $33 ; 38 ; 80 ; 105 ; 150-151 ; 157-159$; $209 ; 280 ; 283 ; 286 ; 294 ; 304 ; 311$

aesthetics, $1-3 ; 14 ; 17 ; 19-22 ; 30 ; 38 ; 46 ; 49-$ $53 ; 56-57 ; 95 ; 136 ; 156 ; 163-164 ; 184 ; 196$ $197 ; 200 ; 215 ; 218 ; 221-222 ; 234 ; 236$; $242-298 ; 302-304 ; 310 ; 313 ; 3117 ; 319 ; 321$ African music and art, 47; 49-57; 60-64; 71; $89-90 ; 125-130 ; 133-134 ; 137 ; 141-142$;

$145 ; 187 ; 217-220 ; 225-226 ; 266$

agency, $151 ; 306-307 ; 310-311$

Akalaitis, JoAnne, $3 ; 7 ; 17 ; 85 ; 113-116 ; 193$; 197

Nexander, Christopher, $50-51 ; 146 ; 185-187$; 219

allienation, 99; $225 ; 257 ; 276$

aljeration effect (Brechr), 114; 117; 197; 201

allegory, $23 ; 75 ; 183 ; 204 ; 211 ; 238 ; 248 ; 263$; $264 ; 279$

Allen, Terry, 143; 145; 204

ambivalence, $19 ; 194 ; 197 ; 199 ; 206 ; 209 ; 211$;

$213 ; 223 ; 227 ; 239 ; 314$

Anand, Vijaya, 142

Anderson, Laurie, $8 ; 18 ; 21 ; 113 ; 144-145$; $190 ; 197 ; 206-211 ; 224 ; 235 ; 319$

Andrews, Raymond, 92; 200

animism, $131 ; 171 ; 185-186 ; 225 ; 309 ; 313$;

$316 ; 318$ anthropology, $3 ; 7 ; 8 ; 15 ; 18 ; 19 ; 22 ; 50 ; 61 ;$ $64 ; 65 ; 69 ; 88 ; 113 ; 125-127 ; 139 ; 169-170$; $174-177 ; 202 ; 213-224 ; 228 ; 297-314 ;$. . als reflexive anthropology, ethnography anthropology of science, $22 ; 298-302$ anthropomorphism, 31; 65; 70;162;300; 310 Antin, David, 67

Appadurai, Arjun, 14; 22; 126; 305-311

appropriation, 225-226

archetype; $6 ; 64 ; 68 ; 71-72 ; 78 ; 81 ; 86 ; 102$; $107 ; 172-177 ; 180 ; 182-184 ; 202 ; 23 \% ; 283$; $285 ; 287 ; 304-305 ; 309 ; 317$

architecture, $39 ; 50 ; 55 ; 102 ; 105 ; 184 ; 186-$ $188 ; 190 ; 198 ; 203 ; 219 ; 231 ; 287$

Aristotle, 176

Art \& Language, $14-15 ; 35 ; 125$

Artaud, Antonin, 114; 139; 189; 191

Asad, Talal, 224

Attali, Jacques, 226

aura, 31; 161-163; 271; 275-278; 281; 284; $291 ; 294 ; 315-320$

authenticity, $27 ; 46 ; 62 ; 86 ; 109 ; 113 ; 122$; $137 ; 140 ; 142 ; 153 ; 226 ; 233 ; 239-240 ; 248$; $265 ; 267-268 ; 270 ; 276 ; 292 ; 307,314-315$; $318-321$

autism, 92; 200

axant-gatde, $17 ; 49 ; 85 ; 91 ; 93 ; 141 ; 151 ; 195$; $198 ; 222 ; 241 ; 243 ; 264-265 ; 282 ; 289$

Ayerofit, Jeff, 87

Balanescu, Alexander, 145.146

Ball, Hugo, 48-49

ballet, $71 ; 74 ; 146 ; 193$

Balzac, Honoté de, 282 
Barthes, Roland, $12 ; 31 ; 233 ; 238$

Basil, Toni, $3 ; 61$

Bascuiat, Jean-Michel, $9 ; 151$

Bastian, Adolf, 172

Bastos, Waldemar, 142

Bateson, Gregory, 220-221

Baudelairc, Charles, 272-273; 282

Baudrillard, Jean, $12 ; 237$

Baxter, Glen, 151

Beach Boys, The, 71

Beatles, The, 11;32;210

Beefheart, Captain (Don Van Vliet), 138

Beethoven, Ludwig van, $21 ; 28 ; 258 ; 272$; $289 ; 293$

Behler, Ernst, 251

Belew, Adrian, 63; 210

Benjamin, Watter, 9; 14-15; 20-22; 33; 153; $210-211 ; 222 ; 224 ; 228 ; 241 ; 243 ; 247$; $254-256 ; 268-295 ; 301 ; 306 ; 312 ; 314 ; 318-$ 320

Benz, Obic, 145

Bertolucci, Bernardo, 3; 144

Between The Teeth, 138

Bible, $142 ; 160 ; 260-261$

biogrammar, 65-66; $177-182$

biology, 64-67; 70; 105; 141; 170-177; 180; $240 ; 299$

Black Mountain College, 68; 80; 195

Blake, William, 127

Bloch, Emst, 287

Boas, Franz, 213; 218

Bongiovi, Tony, 44

Boundieu, Pierre, 164:304-311;313;316

Bowie, David, 17;63

Branca, Glenn, 140

Brechi, Bertolt, 22; 114; 117; 189; 191; 197; 265; 273

Breuer, Lee, 7; 113; 197

Brook, Peter 216

Brown, James, 224; 226

Btuckner, Anton, 120
Buñuel Luis, 238

Burroughs, William, 145; 204-205; 210

Byrne, David,

- as anthropologist, 8; 19; 61; 125-126;

$128-133 ; 139-140 ; 216-218 ; 226-227 ; 309$ $311 ; 313-316$

- as composer, $12 ; 32 ; 47 ; 49 ; 54-55 ; 59$; $71-72 ; 92-93 ; 120 ; 145$

- as conceptual artist, 4-5; 9-10;14-18; 34 $38 ; 39 ; 70-71 ; 145-146 ; 152-153 ; 163-164$; 295

- as dancer, $61 ; 83-84 ; 86 ; 90 ; 216 ; 312$

- as film- and videomaker, 61-62; 96; 98 -

$113 ; 122-124 ; 128-133 ; 138-139$; $145 ; 183$;

$184-185 ; 222 ; 227-228 ; 233-239 ; 309-310$; 320

- as musician, 40; 47; 55-56:71; 127; 134; $140 ; 145$

- as photographer, 9-10;44;80;149-163; $315-316 ; 321$

- as singer, $39 ; 40 ; 47 ; 59 ; 72 ; 75 ; 78 ; 84$; $134: 143$

- as songwriter, $9,41-44 ; 46-49 ; 59-61 ; 72$ -

$79 ; 93-97 ; 106-107 ; 111-112 ; 121 ; 127$; $134-136 ; 143-144 ; 147$

- as writer and essayist, 141;142;151-152; $154-156 ; 159-161 ; 164 ; 184 ; 217 ; 310-311$; $315-316 ; 3118 ; 321$

- as TV-presenter, 146

Cange, John, 1-2; 22; 68; 71, 80; 144; 145; 195; $201 ; 232 ; 264-265 ; 314 ; 316-317$

call-and-response, $52 ; 54 ; 60 ; 75 ; 133 ; 139$

camera, 86; 89; 99; 102; 105; 123; 149; 156; $221 ; 234 ; 277-289 ; 31.5 ; 320 ; 321$

Campbell, Joseph, 6; 18; 170-177; 182; 185; $189 ; 221 ; 314$

Candomble, $8 ; 19 ; 128-132 ; 141 ; 155 ; 183$; $218 ; 227$

canon, $21 ; 28 ; 51 ; 109 ; 223 ; 231 ; 270-274$; $293-294 ; 317$ 
capitalism, 9,$51 ; 70 ; 119 ; 164 ; 185,226,236$; $280-286 ; 288 ; 290 ; 294$

Cardona, Milton, $134 ; 218$

Cartesianism, 187; 246

Casebere, James, 9

chaos, $8 ; 123 ; 127 ; 146 ; 159-161 ; 184 ; 201$; $205 ; 209 ; 249 ; 250 ; 254 ; 264 ; 265 ; 281$; $283 ; 300 ; 321$

Chaplin, Chatlie, 291-292

Chemoff, John Miller, 50-59; 64; 71; 75; 125; $127-128 ; 133 ; 187 ; 218-219 ; 222$

Childs, Lucinda, 201

Chomsky, Noam, 146

choreography, $71 ; 110 ; 120 ; 146 ; 163-164$; $198 ; 203 ; 204 ; 206$

Coe, Sue, 151

Coleman, Ornette, 32

collage, $56 ; 59 ; 80 ; 99 ; 105 ; 110 ; 123 ; 151$; $197 ; 203 ; 213 ; 228 ; 305$

collective unconscious, $70 ; 170-175 ; 182-184$; $283-284 ; 287 ; 290 ; 304$

commodification, $37 ; 55 ; 185 ; 224 ; 227 ; 236$; $239 ; 274 ; 285 ; 290 ; 293$

communism, $69 ; 204 ; 285$

conceptual art, $1 ; 3-5 ; 7 ; 10 ; 14-15 ; 20 ; 34-39$;

$71 ; 152 ; 295$

Conner, Bruce, $3 ; 58 ; 222$

coolness, $50 ; 51 ; 53 ; 57 ; 76 ; 78 ; 192 ; 219 ; 311$; 316

Cooper, Alice, 41

Copernican tutn, 280;297,299;303

Cruz, Celia, 3; 134

culbism, 44; 60

cultural studies, $11 ; 13 ; 232$

Cunningham, Merce, $1 ; 68 ; 80 ; 195$

Dada, 35

Dali, Salvador, 238

Dante Alighieri, 160

Darwin, Charles, 65;119; 177; 185

deconstruction, $12 ; 55 ; 233 ; 236 ; 237$ delusion, $2 ; 36,42,61 ; 64 ; 86 ; 174 ; 239 ; 275$ $303 ; 313 ; 318$

Demine, Jonathan, $3 ; 7 ; 84 ; 100 ; 134 ; 143$; 145

Deren, Maya, $218 ; 220-222$

Derrida, Jacques, $233 ; 234 ; 237 ; 240$

Descattes, Rente, 246

dialectical image, 279

dislectics, $18 ; 187 ; 191 ; 192 ; 194 ; 197 ; 248$; $270 ; 271 ; 279 ; 284 ; 286 ; 289$

didacticism, $1 ; 2 ; 10 ; 62$

Dilthey, Wilhelm, 215

Dirty Dozen Brass Band, 92.93

Djur Djura, 142

documentary, $87-90 ; 102 ; 103 ; 126 ; 128133$; $139-140 ; 145 ; 155 ; 223 ; 227$

drugs, $145 ; 158 ; 159 ; 204 ; 206 ; 302$

Duchamp, Marcel 238

Dunbar, Sly, 49

Dunlop, Geoff, 8; 87-88

Durkheim, Emile, 299

Dylan, Bob, 143

Eagleton, Terry, 236

eatly Romanticism, 20-22; 163;241-243; 245 $268 ; 270 ; 272 ; 273 ; 277-278 ; 280-281 ; 291$; $294 ; 297 ; 3011-303 ; 318-319$

ecstasy, $29 ; 62 ; 64 ; 68 ; 78 ; 81 ; 87 ; 89-90 ; 119$; $193 ; 220 ; 288 ; 309 ; 311$

Eggleston, William, 108: 151

Eichendorff, Joseph von, 119

Eimstrin bu Whe Berots, 84; $91 ; 110 ; 117 ; 198 ; 207$

Ekman, Paul, 29

Eno, Brian, 40; 45;46; 48;49-51; 54 60; 64 $65 ; 71 ; 75 ; 76 ; 177$

enthusiasm, $2 ; 6 ; 86 ; 90 ; 112 ; 175 ; 176 ; 177$; $203 ; 219 ; 228 ; 239-240 ; 259 ; 284 ; 318 ; 321$

essentialism, $20 ; 27 ; 28 ; 30 ; 39 ; 52 ; 66 ; 67 ; 75$; $176 ; 179 ; 211 ; 225 ; 226 ; 248 ; 253 ; 255$ $263 ; 286$

ethics, $30 ; 51,53 ; 66 ; 180 ; 219 ; 246 ; 247 ; 249$. 250 
ethroggaphy, $88-89 ; 128-129 ; 133 ; 170 ; 213$;

$21.9,222-224$; see atso anthropology

ethomusicology; $27 ; 28 ; 49 ; 125 ; 127 ; 169$; $224 ; 227$

ethology; $65 ; 177 ; 183 ; 194 ; 240 ; 266$

Evelew, Yale, 141-142

evolution, $65 ; 105 ; 170 ; 177-178 ; 182 ; 209$; $213 ; 317$

Fasism; $101 ; 201 ; 225 ; 274 ; 275 ; 279 ; 287$; $311 ; 319$

Feld, Steven, 224-227

Ferratindez, Angel, 134; 136; 137; 143

fetish, 161; 163; 180;285; 300; 303; 307; 318

Fichte, Johann Gottieb, 245-247; 255

fielldwork, $18 ; 190 ; 219$

film, wee also: Bytne as filmmaker,

- Robert Wilson and film, 199-200

- fillm and anthropology, 220-224; 227-228

- film and poststructuralism, 233-239

- Benjamin and Adomo on film, 288-292

- film and histotical change, 306-309

Finster, Howard, 98

Foreman, Richard, 197

formalism, $28 ; 80 ; 92 ; 184 ; 231 ; 255-256 ; 264$

format, $5 ; 33 ; 34 ; 47 ; 49 ; 56 ; 71 ; 75 ; 84 ; 96$;

$196 ; 308 ; 318$

Foster, $\mathrm{Hal}, 222$

Foucault, Michel, 206; 233

found footage, 58,$88 ; 89$

found vocal: 76

Fourier, Chatles, 282

Fox, Robin, 65-66; 170; 177.180; 182; 240

rankfurt School, $15 ; 243 ; 270 ; 272$

Frant, Chris, $4 ; 39-40 ; 42 ; 49 ; 71 ; 98 ; 151$

Freud, Sigmund, $67 ; 172 ; 199 ; 270 ; 283 ; 287$

Friedtich, Caspat David, 119; 123

Frith, Simon, 29-31; 234

funk music, $54 ; 56 ; 60 ; 63 ; 76 ; 78 ; 83 ; 134$;

$138 ; 142 ; 146 ; 226 ; 266$

Fusco, Coco, 224

Gabriel, Peter, $137 ; 210 ; 226$
Galleano, Eduardo, 188

Gandhi, Mahatma, 131

Geentz, Clifford, 213; 224

genius, $51 ; 186 ; 249 ; 250 ; 258 ; 320$

Gesamtkunstwetk, $28 ; 91 ; 96 ; 100 ; 183 ; 197$. $198 ; 228 ; 243-244 ; 252 ; 256-258 ; 265 ; 268$; $270 ; 273-274 ; 279 ; 281 ; 295 ; 297 ; 303-304$; 317

Geulen, Eva, 319

Gil, Gilberto, 9; 141

Gilgamesh, $8 ; 117 ; 120 ; 123 ; 184 ; 309$

Ginsberg, Allen, 145; 204

Glass, Philip, 2; 3; 91; 92; 103; 110; 114; 117; $144 ; 207$

globalization, $22 ; 126 ; 142 ; 222 ; 223 ; 305$

glossolalia, 69; 77-78

Godard, Jean-Luc, 238

Goethe, Johann Wolfgang von, $21 ; 114 ; 271$; $272 ; 276-279 ; 289 ; 293$

Goldberg, RoseLee, 206; 209

Gomez-Pena, Guillermo, 224

Goodman, Felicitas D., 69

Gray, Spalding, 3; 8; 108 109; 189; 197; 203; 224

Green, $A 1,45 ; 159$

Grotowski, Jerzy, 68; 69; 193; 197; 216

Haas, Philip, $3 ; 8 ; 139 ; 140$

habitus, 306

Hanayagi, Suzushi, 3; 120

harmony, $52 ; 121 ; 133 ; 139 ; 184 ; 249 ; 277$; see also universal harmony

Harper, Peggy, 62

Harrison, Jerry, $4 ; 39 ; 47 ; 49 ; 71 ; 98 ; 151$

Hart, Mickey, 226-227

Haskell, Jimmic, 120

Hebdidge, Dick, 12; 79;99; 183; 232; 237-238

Hegel, Georg Wilhelm Friedrich, 255; 272

Hell, Richard, 46

Hendrix $x_{y}$ Jimi, 140

Hendryx, Nona, 49; 63

Henley, Beth, 101 
hermeneutics, $13-15 ; 125 ; 277 ; 281 ; 288$

heterogeneity, $1-3 ; 12 ; 18 ; 19 ; 22 ; 151 ; 170$; $182 ; 233 ; 242244 ; 250 ; 252 ; 262 ; 280 ; 288$; $291 ; 292 ; 300 ; 314 ; 318$

Hirst, Michael, 122-123

Hodgson, Michael, 87

Hoffman, Abbie, 145; 199

Holderlin, Friedrich, 221;247;257; 271; 272

Holmberg, Arthur, 201; 202

Holt, Edna, 63

Holzer Jenny, 9; 151; 159; 337

Horkheimer, Max, 241; 272; 302; 303

Howell, John, 12;13; 70; 337

Hurston, Zora Neale, $218 ; 219 ; 222$

Idol, Billy, 108

Ith Ayye, 128-132;140;155;183;227;315

illusion, $20 ; 85 ; 86 ; 172 ; 189 ; 232 ; 250 ; 275$; $286 ; 297 ; 313$

imagination, $9 ; 126 ; 127 ; 184 ; 194 ; 220 ; 242$; $250 ; 262 ; 278 ; 280 ; 295 ; 297 ; 304 ; 305$; $306 ; 308 ; 310 ; 311 ; 316$

immediacy, 22; 33; 40; 69; 99; 182; 196; 226;

$246 ; 247 ; 274 ; 294 ; 297 ; 306$

imperialism, $136 ; 180 ; 221$

incommensurability, $170 ; 232 ; 274 ; 318$

initiation, $42 ; 128 ; 130 ; 183 ; 193 ; 219$

intellectual intuition, $202 ; 246 ; 247 ; 279$

Hony, $23 ; 58 ; 64 ; 90 ; 105 ; 109 ; 112-113 ; 129$;

$132-133 ; 135 ; 144 ; 160 ; 217 ; 234 ; 236 ; 239$;

$240 ; 242 ; 248 ; 252 ; 259 ; 261 ; 263 ; 264-266$;

$301 ; 306 ; 307 ; 318$

Jagger, Mick, 225

Janacek, Leos, 120

Jarmusch, Jim, 3; 98; 113

Jarque, Finta, 142

Jarry, Alfted, 33; 183;238

Jay, Marnin, 15; 223; 227

jazz, 31; $92 ; 137 ; 146 ; 218 ; 293$

Jennings, Hurnphrey, 184-185

Jenshel, Len, 108; 151

Jerez, Ite, 139
Johnson, Philip, 187

Johnson, Steven R., 98

Joyce, Jumes, 265

Judson Dance Theater, 110

Jung, Carl G., 64; 70; 79; 81; 107; 114; 150; $161 ; 170-177 ; 180 ; 182-185 ; 189 ; 202 ; 214$; $236 ; 240 ; 268 ; 270 ; 283-285 ; 287 ; 294 ; 314$

juxtaposition, $18 ; 44 ; 100 ; 123 ; 126 ; 127 ; 161$; $211 ; 283 ; 292 ; 306 ; 319$

Kant Imnanuel, 202; 245-251; 254; 271; 272; $276 ; 280 ; 297 ; 299 ; 303$

Kaplan, E. Ann, 234-235

Kapucinski, Richard, 188

Kardon, Janet, 208

Kehoe, Mark, 35

Keil, Charles, 224-225

Kiverkegard, Soren, 291

Kina, Shoukichi, 142

kitsch, 289; 293-294.

Klee, Paul, 210

Klipper, Stuart, 108; 151

Knowles, Christopher, $92 ; 200$

Koons, Jeff, 159

Kosuth, Joseph, $5 ; 10 ; 15 ; 18-19 ; 21 ; 125 ; 152$

Kruger, Barbara, 9; 112;152; 159; 337

Kuhn, Hans Peter, 91

Kuti, Fela Anikulapo, 226

Lacan, Jacques, $234 ; 236$

Latour, Bruto, 14; 22; 298-304; 308-311.

LeCompte, Elizabeth, 109; 189; 197; 203.206

Leone, Sergio, 122

Lévi-Strauss, Claude, 191

LeWitt, Sol, 152

lifestyle, $23 ; 38 ; 86 ; 100 ; 145 ; 155 ; 314-315$

liminal zone in perfotmance, 191-192; 200; $206,273,314$

Lindsay, Arto, 141

Luaka Bop, 126; 134;140-143; 145; 155; 310

Luria, A.R., 67

Lutz, Adella, 161

Lyotard, Jean-François, 233 
Mabou Mines, 64; 78, 85; 113-116; 190; 193 ; $197 ; 314$

Mabsy, Lynn, 63

Madonina, 2; 108; 137

Magritce; Rene, 238

Mahler, Gustaw, $120 ; 272$

Malina, Judith, 145

Malliaumé, Stcphane, 272

mambo, 75; 134-136; 138; 139; 141; 218

mandala, $81 ; 183$

Marcuse, Herbert, 15

Marranca; Bonnie, 122; 202

Marx, Karl, 270; 273; 283.287; 294; 314

Marxism, $15 ; 36-37 ; 160 ; 224 ; 226 ; 268 ; 270$; $272-274: 283-286$

materialism, 161; 185;272-273; 286.287

Mauss, Marcel, 299

McDonald, Dolette, 63; 217

Mead, Margatet, 220

Menezes, Margareth, 137

Michelson, Annette, 221

Mies wan der Rohe, Ludwig, 187

mime, mimicry, $57 ; 99 ; 108 ; 136 ; 234 ; 251$

mimesis, - artistic rejection of mimesis, 34-38

- and early Romanticism, 252-275

- and media, 58; 86; 100, 113; 239-241;

243

and modernization, 279; 282; 290-295;

$298 ; 300-303 ; 310 k 314 ; 321$

- and music, 27-32; 75-80

- and photography, 149-150; 161; 224

- and post-stncturalism, 231-233; 236-237

minimalism, $2 ; 144 ; 152$

Monk, Meredith, 3; 8; 102; 110

montage, $9 ; 62 ; 81 ; 88 ; 89 ; 103 ; 132 ; 158 ; 220$;

$279 ; 280 ; 288 ; 312 ; 320$

Mülller, Heiner, 91; 117; 119; 121; 201; 202

music, see table of contents, also African

music, ethnomusicology, funk music, mambo, musicology, thythm, rock music musicology, $28 ; 31-32 ; 64 ; 271$
Muybridge, Eadweand, 238

mythology, 38;42; $56 ; 70 ; 77 ; 86 ; 91 ; 101$; $117-123 ; 161 ; 171-176 ; 182-185 ; 187-188$; $189 ; 191 ; 199 ; 214 ; 231 ; 242-243 ; 252$; $257-258 ; 261-262 ; 264 ; 266-268 ; 273 ; 276$; $279-293 ; 298-299 ; 302 ; 306 ; 309 ; 314$

nartative, $66-67 ; 99 ; 101 ; 112-113 ; 117 ; 145$; $146 ; 160 ; 190 ; 194-195 ; 201 ; 203 ; 209 ; 219$; $224 ; 227 ; 233 ; 236-237 ; 266 ;$ ff plot

Nascimento, Milton, 140

natural history, $105 ; 209-210 ; 243 ; 263$

naturalism, $56 ; 114 ; 232 ; 269 ; 270 ; 271 ; 272$; $273 ; 274 ; 275 ; 276 ; 278 ; 281 ; 286 ; 291$; $293 ; 294$

neutology, neuropsychology, 29;64:66

Newman, Randy, 41

Newton, Isaac, 276

Nietzsche, Friedrich, 176, 257-258; 271

Noh, 3; 92; 195

non-sequitur, 68 ; 160

Norman, Jessye, 117

Novalis (Friedrich von Hardenberg), 119; $163 ; 242 ; 245-266 ; 270-273 ; 277-279 ; 281$; $288 ; 297 ; 300-301 ; 320$

Olinsky, Frank, 151

Olson, Charles, 67-68; 80

opera, $28 ; 66 ; 91 ; 92 ; 96 ; 110 ; 117 ; 119 ; 138$; $196 ; 198 ; 257 ; 308$

Owens, Craig, 209

Paik, Nam June, 9; 151

painting, $8 ; 135 ; 39 ; 60 ; 81 ; 98 ; 140 ; 231 ; 232$

pantheism, 142; 251; 259; 261;266; sec also religion

parataxis, 68

parody, $116 ; 236$

participation, $2 ; 52 ; 55 ; 187 ; 191 ; 196 ; 208$; $219 ; 224-225 ; 228 ; 233 ; 236 ; 239 ; 252 ; 266$ performance, see table of contents, see also performance braid, persona, rehearsal, ritual

performance braid, $7 ; 191 ; 211 ; 300$ 
persona, $34 ; 37 ; 39-41 ; 44 ; 46-47 ; 56-57 ; 60$; $63 ; 72 ; 74 ; 76 ; 85 ; 86 ; 102 ; 127 ; 135-136$; $138 ; 198 ; 203 ; 209$

photography, 44; 80; 108; 149-1164; 209; 270; $275-279 ; 315-316 ; 321$

Picasso, Pablo, 60

Pinckney, Darryl, 119; 121

Plato, 14; 253-254

plot $84 ; 101: 118 ; 211$

poetics, $68 ; 185-188 ; 242-243 ; 248 ; 250-263$;

$267-268 ; 269-282 ; 294 ; 300 ; 317-318$

poetry, $48-49 ; 67 ; 77 ; 117 ; 130 ; 131 ; 142 ; 185$;

204:220; 291

polyattentiveness, $2 ; 19 ; 101$

polymetric music, $52.53 ; 57 ; 71$

pop art, 137

Porter, Cole, 1.35

posidivism, $269 ; 285 ; 301$

postmodernism, $110 ; 164 ; 195-197 ; 227 ; 231$.

$238 ; 240-241 ; 242 ; 321$

post-structuralism, 232-237;240;263; 270

Prado, Perez, 75

Presley, Elvis, 293

primal phenomenon, 276;279

Prince, 103; 108

projection, 61; 63-64; 79; 85; 93; 103; 150

$161 ; 197 ; 198 ; 199 ; 209 ; 223 ; 234 ; 288$;

$291 ; 300 ; 302-305 ; 313$

proprioception, $33 ; 67-68 ; 72 ; 74 ; 95 ; 176$;

$177 ; 193 ; 210 ; 233 ; 313 ; 316 ; 319$

psychoanalysis, $107 ; 170-172 ; 274 ; 287 ; 289$.

290

psychosis, $42 ; 86 ; 174 ; 178 ; 183$

punk, 5; 195; 314

Radcliffe-Brown, A.R., 174-175, 214

radio, $1 ; 31 ; 55-56 ; 59 ; 76 ; 94-95 ; 96 ; 107$;

$136 ; 137 ; 200 ; 313 ; 316 ; 319$

randomness, $16 ; 34 ; 37 ; 80 ; 93 ; 144 ; 204 ; 265$;

266

Ratcliff, Carter, 86
Rauscivenberg; Robert, 1; 9; 68;79-80; 112; 151,232

Reagan, Ronald, 142; 210

tealism, $42,163,172 ; 203,224,250 ; 269 ; 275$

reciprocity, $251 ; 262-263,266 ; 271 ; 273-274$; $275 ; 278 ; 281-283 ; 287 ; 290 ; 292 ; 303 ; 305$; 318

recording, $5-7 ; 16-17 ; 31 ; 44-47 ; 59 ; 60 ; 93$; $140 ; 226-227$

Redding, Otis, 42

retlexivity, in anthropology, $14 ; 20 ; 22 ; 125$ -

$126 ; 180 ; 213 ; 223-224 ; 310 ; 311$

- in Byrne's work, 43; 61; 155; 160-161; $184 ; 313-316 ; 318-321$

- in performance theatre, $92 ; 197 ; 200$; 202 ; 203 ;

- in philosophy, 19-22; 241-243; 247.249; $252-268 ; 273-275 ; 278-281 ; 293-295 ; 297-$ $304 ; 310$

rehearsal, 42; 59; 61; 71;76;85; 91;93;192; $199 ; 201 ; 204 ; 302 ;$ ser also restored behavior

religion, $50-51 ; 68-69 ; 76 ; 88-89 ; 1104112$; $128-132 ; 154 ; 159-163 ; 172-176 ; 185 ; 193$; $195 ; 218 ; 242 ; 251 ; 252 ; 257-266 ; 283 ; 316 ;$ 321 ; see also mythology, pantheism, spirituality

representation, critique of, $15 ; 36$

- in music, 31

- in performance, $121 ; 124$; sef also reciprocity

reproduction, $149-150 ; 153 ; 224-225 ; 239$; $241 ; 274.279 ; 294 ; 306 ; 312 ; 315 ; 318.321$ restored behaviour, 191; 192; 193; 216; 311; 320, see also rehearsal

rhythm, $30 ; 40 ; 47 ; 57 ; 59 ; 75 ; 112 ; 133 \ldots 134$; $139 ; 194$

- in African music, 52-54; $71 ; 141 ; 187$; 220

Richardson, Jack, 196

Richman, Jonathan, 4, 30 
ritual, and anthropology $219-222,224-225$

- in modernity, 275; 289; 300; 318-321

- and music, $28 ; 31 ; 128-132 ; 179-180$

- and proproception, 66m67;69-70

- and theatre, 190196

in Byme's work, 74,86;89-90; 101; 107;

$111-112 ; 128-132 ; 154-164 ; 318-321$

rock music, $30-34 ; 39-41 ; 46 ; 63 ; 131 ; 133$;

$137 ; 138-139 ; 145 ; 177 ; 182 ; 303$

- Byne's eritique of, $51 ; 54 ; 101 ; 121 ; 141$; 311,320

- and performance art, 195

Rockwell, John, 12-13; 31-32; 40; 46; 123

Rodgets, Nile, 210

Rodriguex, Sillvio, 141

Romanticism - and pop, $38 ; 46 ; 67 ; 158 ; 227$; $311 ; 321$

- in Jung, 173; 175; 1184

- in W/ilson's theatre, 118-120; 123; 202

- early Romanticism, 241-243; 245-268;

- in Benjamin and Aclorno, 272; 276-279; 292

- compared to Latour, 300-303

Rosenquist, James, 238

Rouch, Jean, 224

Ruby, Jay, 127; 223-224; 227

Ruscha, Edward, 9

Sacks, Oliwer, 60-67

sacrilisation, $156 ; 261$

Sagmeister, Stephan, 3; 158-159

Sakamoto, Ruichi, 145

Salas, Oscar, 138

Salgado, Sebastiāo, 127

salsa, $134 ; 136 ; 141 ; 146$

samba, $133 ; 136 ; 137 ; 138 ; 141 ; 227$

Sayte, Henty M., 12; 13; 209

Scales, Stewen, 63

Schechner, Richard, 8; 17-19; 68-69; 116; $189-197 ; 206 ; 213-217 ; 222 ; 223 ; 240 ; 265$; $302 ; 310 ; 314 ; 320$

Schecter, Martin, 113; 232; 236-237
Sehelling, Friedrich, 202; 247; 257; 262

Schiller, Friedrich, 257

Schleiermacher, Eriedrich, 246; 259; 260; 261

Schmidt, Peter, 16:45

Scholte, Bob, $15 ; 19$

Schönberg, Arnold, 21; 22:271;293

sculpture, $6 ; 15 ; 35 ; 50 ; 207 ; 219 ; 257$

Sellars, Peter, 205

shaman, 64; $175 ; 177$

Shank, Theodore, 199

Sherrington, C.S, 67

Sibelius, Jean, 120

Simon, Paul, 9; 128; 137; 144; 225

Sklar, Robert, $307-308$

Smith, Patri, 46

sociobiology, $170 ; 180 ; 182$

sociology - of music, $51 ; 55 ; 137 ; 314$

- and media, 164; 274; 279; 304-308

Socrates, 122

Sonkag, Susan, 13-14; 19-20

soundscape, $146 ; 154$

soundracks, 31; 89; 102-103;116;120; 130; $132 ; 139-140 ; 158 ; 227$

spirituality, 32; 50-51; 54; 63-64; 69; 114-115; $130-131 ; 174 ; 183 ; 277 ; 287 ; 300 ; 303$; see also teligion

Stanislavski, Konstantin, 114

Steinbach, Haim, 152

Stem, Daniel, 199

Sternfeld, Joel, 108; 151

Sting, 137

Strauss, Richard, 120

structuralism, see post-structuralism

Su, Cong, 145

surrealism, 99; 142; 270

Swarte, Joost, 151

symbolism, 51; 79; 150; 174; 263; 269-272; $275 ; 281 ; 293 ; 294$

symphony, 27-29; 120;266

Szarkowsky, John, 155 
Talking Heads, 4-9; 11-12; 32; 39-50; 59-60; $63-64 ; 75 ; 83-84 ; 87-90 ; 96 ; 126-128 ; 145$; $147 ; 150-151 ; 226$;

Taussig, Michael, 240-241; 312

television, $35 ; 37 ; 61-62 ; 87-90 ; 97 ; 114 ; 129$; $132-133 ; 136 ; 146 ; 155 ; 158 ; 196 ; 201$; 315-316; 319

- and social sciences, $164 ; 223 ; 288 ; 290$; $298 ; 303 ; 304-308 ; 313 m 314$

Tharp, Twyla, 3; 71

theatre, set table of contents

Thompson, Robert Farris, 50-51; 53; 57; 59; $75 ; 128-129 ; 133 ; 182-183 ; 216 ; 218-219$; 222

Tieck, Ludwig, 246; 260

Tiger, Lionel, 65-66; 152; 170; 177-182; 240

Tom Tom Club, 71; 83

trance, $55 ; 57 ; 61 ; 68 ; 78 ; 89 ; 112 ; 130 ; 183-$

$184 ; 192 ; 193 ; 195 ; 200 ; 220 ; 224 ; 225$

translation, $19 ; 29 ; 32 ; 47 ; 55 ; 113 ; 114 ; 170$;

$171 ; 220 ; 222 ; 224 ; 234 ; 317$

Tropicalismo, $9 ; 141 ; 143$

Turner, Victor, 214; 223

Tutuola, Amos, 56

Tzara, "Triston, 183; 238

unconscious, $29 ; 33 ; 64 ; 67 ; 70 ; 80 ; 107 ; 172$

$175 ; 182-184 ; 214 ; 265 ; 287 ; 289 ; 290 ; 293$;

$303-305 ; 308$

universal harmony, $250 ; 258 ; 262$

Valk, Kate, 205

Vandekeybus, Wim, 3; 146

Varderbeek, Stan, 222

Vawter, Ron, 206

Vega, Suzanne, 144

Veloso, Cactano, $9 ; 140 ; 143$

Velvet Underground, 205

wernacular, $12 ; 32 ; 72 ; 80 ; 100 ; 105 ; 110 ; 115$;

$244 ; 317$

video clip, $3 ; 58 ; 88 ; 96 ; 98 ; 110 ; 234 ; 236$

vodun (voodoo), 49; 102; 111-112; 128-129;

$162 ; 218 ; 220$ poice - and body, proprioception, persona, $29 ; 33 ; 67 ; 107 ; 135 ; 202 ; 209 ; 234 ; 276$

- Byrne's use of voice, $40 ; 47 ; 55-57 ; 59$ $60 ; 72 ; 74 ; 75-78 ; 84 ; 134 ; 139 ; 143$

- universal voice, $249 ; 258 ; 321$

voice-over, 129-130; 158

Wackenroder, Wilhelm, 246

Wagner, Richard, 120; 197; 257-258; 265;272

Wall, Jeff, 152

Wang, Wayne, 1.45

Warhol, Andy, 5; 222, 238

Waters, Muddy, 225

Weber, Max, 20; 51;270; 314

Wegman, William, 9; 151

Weir, Alex, 63

Wenders, Wim, 122; 143; 145; 308

Weymouth, Tina, $4 ; 11 ; 17 ; 39 ; 40 ; 42 ; 49 ; 63$; $71 ; 97 ; 98 ; 151$

White, Jim, 142

Wild, David, 145

Wittgenstein, Ludwig, 15; 36

Wodiczko, Krysztof, 151

Wooster Group, 64; 108; 189; 197; 203-206; 314

world music, $126 ; 137 ; 142-143 ; 226 ; 310$

Worrell, Bernie, 3; 63

Young, Neil, 32; 143

Zappa, Frank, 63

Ze, Tom, 9; 138; 142; 143

Zieve, Wayne, 39 



\title{
Samenvatting
}

\section{$<<$ Wij zijn het gedruis tussen zenders $>>$}

\author{
Een filosofische verkenning van het werk van David Byrne, \\ op het kruispunt van de massamedia, conceptuele kunst \\ en performance-theater
}

In 1952 schreef John Cage zijn Imaginaty Landscape No. 4, een compositie voor twaalf radio's. Tijdens dit muziekstuk van vier minuten werd elke radio bespeeld door twee musici die de tot in detail uitgewerkte compositie uitvoerden: één om de afstemknop te bedienen, en één voor volume- en toonregeling. Deze musici waren, in de woorden van Cage, "vissers op geluidsvangst". Ieder geluid dat zij opvingen was welkom, muziekprogramma's en andere uitzendingen evenzeer als storingen, tuis en stilte.

Zulke uitvoeringen nodigden het publiek uit om op een andere manier te gaan luisteren, met een open oor voor de diversiteit en de complexiteit die ons omringt. Zijn artistieke en didactische pleidooi voor "polyattentiveness", een veelzijdige oplettendheid die zichzelf niet bij voorbaat stilistische grenzen stelt, heeft grote invloed uitgeoefend op ieder artistiek gebied. Zijn werk en ideeën vormen daarom een goede leidraad voor dit onderzoek naar het werk wan David Byme.

"We Are The Noise Between Siations" is een overzicht van het uitgebteide en heel diverse werk van de New Yorkse kunstenaar David Byrne (1952), met nadruk op de conceptuele en theoretische achtergrond van dat werk. Byrne heeft een uitgebreid en zeer heterogeen oeuvre gemaakt. In de jaren "70 en " 80 werd Byme wereldberoemd als zanger en artistiek leider van de popgroep Talking Heads; daamaast werkte hij samen met vooraanstaande kunstenaats als theatermaker Robert Wilson, beeldend kunstenaar Joseph Kosuth, theatergroepen Mabou Mines en de Wooster Group, componist Brian Eno en vele anderen. Byrne regisseerde films en een antropologische documentaire, werkte mee aan theaterprojec- 
ten, hij exposeett fotowerk, maakt kunstboeken, werkt als curator van exposities en beheert een eigen muzieklabel, Luaka Bop, dat de wereldwijde diversiteit van de hedendaagse popmuzick wil laten horen.

Bytne gebruikt geen van deze kunstwormen als middel voor individuele expressie, maar maakt steeds een 'Gesamtkunstwerk', een ontmoetingsplaats van uiteenlopende vormen van artistieke representatie. En hoewel zijn werk functioneert in de populaire massamedia, waar ieder product, of het nu een filmscript is, een videoclip of een top 40 -liedje, moet voldoen aan strenge formele eisen van eenheid en herkenbaarheid, slaagt Byme er waak in om toch methoden toe te passen die zijn ontwikkeld in de conceptuele kunst en in het perfotmancetheater. Juist in de vermaaksindustrie, waar aan conventies angstvallig wordt vastgehouden, is hij erin geslaagd te experimenteren met de geldende mimetische conventies. Hij heeft bovendien gebruik gemaakt van een breed scala van artisteke methodes en wetenschappelijke inzichten om een reflexief perspectief te ontwikkelen op kunst en representatie in de breedste zin van het woord.

In het eerste deel wan het boek, "Conceptual work in the mass media", is Byrne's werk gedetailleerd beschreven. Het openingshoofdstuk, "Music as a mimetic arena", begint met een paragraaf over de verschillende theoretische benaderingen van muziek, van musicologie en psychologie van de muziek tot muzieksociologie, culturele antropologie en etnomusicologie. De begrippen van muziek die hieruit naar voren komen worden gebruikt om de ontwikkeling te beschrijven van Byrne's band, de Talking Heads, van een viettal kunstacademie-studenten die rock en roll als performance-act presenteerden, tot een gemengd blank/zwart funkorkest dat tijdens concerten extatisch enthousiasme losmaakte. Terwijl de Talking Heads in het begin van hun loopbaan de rituelen van rockmuziek (gitaar- en drumsolo's, overdreven poses, flitsende belichting) angstvallig vermeden, citeerde Byrne later in toenemende mate muzikale rituelen uit verschillende culturen, zowel uit de V.S. (met name de evangelische televisiedominees) als met name uit West- $A$ frika. Om de Afrikaanse polymetrische muziek te kunnen nabootsen werkte hij ook samen met etnomusicoloog John Chernoff, die in Nigeria was opgeleid tot traditioneel drummer. Byrne en Chernoff schreven samen songs en muziek voot een ballet.

Hoofdstuk 3, "Film and performance theatre", behandelt de invloed van het experimentele New Yorkse petformance theater uit de jaren '70 op Byme's werk, alan de hand van zijn samenwerking met vootaanstaande vertegenwootdigers van dit theater. Verworvenheden van dit theater zijn aan te wijzen in de Talking Heads-concertfilm "Stop Making Sense" en in de televisiedocumentaire "Talking Heads versus The Television". Bovendien schreef Byrne muziek voor de theaterproductie "The Knee Plays", een onderdeel van Robert Wilson's internationale theaterproject "the CIVIL warS". Ook verzorgde hij de muziek bij de verfilming van Mabou Mines" toneelstuk "Dead End Kids - A story of nuclear power". In 
1988 makkte Byrne met Robert Wilson en auteur Heiner Müllex "The Forest", een grote theaterproductie ter gelegenheid van het 750 -jarig bestaan van Berlijn. Bytne's belangtijkste film is "True Stories" uit 1986, een speelfilm watin hij werk van de artistieke avantgarde combineert met voorbeelden van performance uit het dagelijks leven. Aan de film werd meegewerkt door Meredith Monk en Spalding Grey (van de Wooster Group), Byrne citeert bovendien uit werk van Robert Wilson en het Judson Dance Theater. Als alledaagse vormen van performance toont de film onder andere een modeshow in een winkelcentrum, televisie-soaps, karaoke in een disco, een parade. "True Stories" is een informeel, collectief Gesamtkunstwerk, een film over de plaats van nabootsing en theater in het dagelinks leven.

Een rode draad door Bytne's werk is zijn belangstelling voor rituelen en theatervormen uit andere culturen, een belangstelling die hij deelt met andete makers van performance-theater. Hoofdstuk 4, "Anthropology and music", openr met "Ilé Aiyé", Byrne's tv-documentaite over Candomblé, een Afro-Amerikaanse religie in Noord-Brazilië. "Ilé Aiyé" combincert interviews en gefilmde ceremonieën met filmmateriaal uit atchieven, en gebruikt video-montagetechnieken om aan het beeld visuele "voetnoten" toe te voegen, om de toeschouwer tegelijk te informeren en onder te dompelen in deze cultuur, een mengsel van Afrikaanse en katholieke elementen. Andere voorbeelden van culturele uitwisseling zijn Byrne's samenwerking met een Latin orkest, soundracks die hij maakte voor een aantal documentaires over niet-Westerse kunstenaars, en. zijn muzieklabel Luaka Bop. Dit label btengt popmuziek uit onder andete Brazilië, Cuba, Angola, Algerije; India en Japan onder de aandacht van een Westers publiek. Byrne zoekt daarbij niet naar 'authentieke' muziek die niet door Westerse pop is beinvloed, maar juist naar muzikanten die contrasterende invloeden uit verschillende tradities verwerken, en zodoende afsteken tegen de eentonige hoofdstroom van de popmuziek.

In hoofdstuk 5, "Photography and books", wordt Bytne's werk als beeldend kunstenaar besproken. Het fotobock "Strange Ritual" toont uiteenlopende heiligdommen van over de hele wereld samen met quasi-religieuze winkelinrichtingen, persoonlijke ontboezemingen, boekomslagen et cetera. In mini-essays belicht Byrne de alomtegenwoordige behoefte om iets te sacraliseten. "Your Action World" is hiervan de tegenhanger. Door jaarverslagen van grote ondernemingen, reisfolders, en management- en self-improvement-goeroes te imiteren en uit te vergroten, toont Byme de pogingen om zelfs de meest routineuze commercie in een transcendent en inspirerend licht te plaatsen. "The New Sins", Byme's bijdtage aan de Biënnale van Valencia in 2001, lijkt qua tekst en vormgeving op een catechismus. In foto's en tekst speelt Bytne hier met het idee dat godsdienstige symbolen en mythen de chaotische wetkelijkheid vervalsen, en desondanks on- 
misbaar blijken. Ook Byrne's werk als tentoonstellingsmaker komt in dit hoofdstuk aan bod.

Om Byrne's werk adequaat te kunnen beschrijven, wordt in deel I regelmatig ingegaan op de theoretische achtergronden van bepaalde artistieke werkwijzes, en van kunstenaars met wie Byrne heeft samengewerkt. Deel II, "Theories of performance", is hellemaal gewijd aan de theoretische achtergronden van Byme"s werk. Byrne's eigen theoretische voorkeuren zijn daarbij het uitgangspunt. Hoofdstuk 6, "Exploring the foundations of performance", bespreekt enkele pogingen om een algemeen menselijke grondslag voor rituelen en religieuze symbolen aan te wijzen. De voornaamste is de psychologie van het onbewuste van C.G. Jung en de daarop geënte vergelijkende mythologie van Joseph Campbell. Deze gaan ervan uit dat een mythologiserende fantasie eigen is aan de menselijke geest, en stellen dat iedere samenleving ruimte moet bieden aan universele archetypische impulsen. Daar is wel iets op af te dingen: cultureel antropologen hebben Jung en de zijnen verweten dat zij de cruciale maatschappelijke functie van mythen en rituelen verwaarlozen. Byrne gebruikt het werk van Jung als een hypothese die de vergelijkingen tussen vormen van enthousiasme en rituele bezetenheid in diverse culturen aanmoedigt en structureert. Als aanvulling hierop heeft Byrne uit socio-biologisch onderzoek geciteerd, waarin door onderzoekers R. Fox en L. 'Tiger het bestaan wan een menselijke "biologische grammatica" wordt gepostuleerd. Zo'n bio-grammatica zou ten grondslag liggen aan alle menselijke culturen, wat helpt te verklaren dat mensen zich betrekkelijk gemakkelijk kunnen verplaatsen in andere culturen; er zouden biologische mechanismen tot uitdrukking kunnen komen in allerlei vormen van cultureel gedrag. Hoe verschillend de benaderingen van Jung en die van de sociobiologie ook zijn, ze hebben met elkaar gemeen dat ze de benaderingen uitsluiten die culturen als onderling onverenigbaar beschouwen. Zowel Jung als Fox en Tiger stellen de vraag of er aanpassingen nodig zijn om in modeme, hoog-technologische matschappijen rekening te houden met de menselijke behoefte aan rituelen en symbolen, zonder echter een bevredigend antwoord te formuleren.

In hoofdstuk 7, "Performance theory in the theatre", wordt deze vraag opnjeuw geformuleerd, maar nu in termen die op theater en ritueel zijn toegesneden, middels de ideeën van theatermaker en performance-theoreticus Richard Schechner. Schechner analyseert uiteenlopende performances en rituelen als een vlechtwerk van verschillende theatrale 'talen' zoals tekst, muziek, dans, scenografie en architectuur. Daarbij betrekt hij de verhouding tussen spelers en publiek, een onderscheid dat tijdens rituelen vaak geheel of gedeeltelijk verloren gaat, wanneer alle betrokken zich bevinden in de "drempelzone" van het spel, een tussengebied waarin het onderscheid tussen spel en realiteit tijdelijk ontkracht wordt. Tijdens theatervoorstellingen kunnen de deelnemets zich tijdelijk verplaatsen in een andere wereld, maar ze kunnen ook een blijvende transformatie doormaken, wanneer 
het ritueel hen woorgoed inwijdt in een nieuwe culturele tol. Schechner heeft een uitgebreide indeling ontwikkeld om de meest uiteenlopende vormen van ritueel en theater in detail te kunnen analyseren. Tegen deze achtergrond heb ik werk besproken van drie theatermakers die grote invloed op Byme hebben gehad, of met hem te vergelijken zijn. Ten eerste Robert Wilson, Amerika's leidende avant-garde regisseur, die in zijn werk de nadruk legt op de discontinuiteiten in de waarneming, bijvoorbeeld tussen zien en horen bij de toeschouwer, of tussen tekst en beweging bij de acteur. Door gebeurtenissen op het toneel te isoleren en uit te lichten, en middels een geformaliseerde, vaak sterk vertraagde bewegingsregie, maakt Wilson zijn voorstellingen tot een laboratorium waarin de toeschouwer zijn aandacht kan richten op zijn eigen waarnemingsprocessen, door na te gaan op basis van welke psychische behoeften hij de door Wilson gescheiden warmemingsdomeinen zelf weer combineert. De Wooster Group presenteert een door montage verdichte vorm van realisme, waarbij de ingrijpende stilering van de waargenomen werkelijkheid door de massamedia wordt benadrukt. In het werk. van de Wooster Group wordt met alle mogelijke theatrale middelen onderzocht hoe zulke hallucinerende stileringen deel uitmaken van de historische werkelijkheid. De loopbaan van Laurie Anderson, tenslotte, vertoont velerlei raakvlakken met die van Byrne. Anderson's werk, met name haar voorstelling "United States", laat zien hoe de mogelijkheid om het bestaan in een coherent levensverhaal vorm te geven wordt ondermijnd in een samenleving die zichzelf voortdurend herdefinieert aan de hand van de laatste technologische ontwikkelingen. Tegelijkertijd bieden de electronische media ongekende mogelijkheden om verhalen en tituelen uit te wisselen en opnieuw te monteren.

Twee voorbeelden kunnen het bovenstaande verduidelijken. In een liedtekst die hij schreef voor Robert Wilson's "The Knee Plays", getiteld "The Sound of Business", (zie blz. 94-95) beschrijft Byrne een alledaagse autorit.

"Ze reden in zuidelijke richting op de snelweg. Voor zaken naar cen sndere stad, groter dan de stad die achter hen lag. Zaken werden gedann tijdens kantooruten, in beide steden. Deze rit gold ook alls zakelijk. Het gevol andere auto"s in te halen was ook zakelijk: het gevoel van zakendoen, her gevoel langzaam te drijven door een veld wan bewegende voettugen. Dit was de ware snetheid: de snelheid van zaken. Let op de cijfers op de snelheidsmeter!

Eeri van de twee speelde met de radio, langzaam wisselend van de ene zender naar de ander, soms luisterde hij nanir twee zenders tegelijk. Op een zender paatte cen man mew een andere man aan de telefoon. De andere zender speelde oude hits, voorgoed verdwenen..."

Deze doodgewone situatie is in alle opzichten bepaald door technologische media. Steden, auto's, snelwegen, radiozenders, telefoon, radiogesprekken, popmuziek: het zijn in deze tekst allemaal overlappende media, die samen een ongrijpbaar, drijvend gevoel opleveren: de mensen in de auto zitten stil en bewegen, doen niets 
en werken, zijn geisoleerd en tegelijk door en door verbonden met de maatschappij waarin ze leven.

In "United States, Part I" beschrijft Laurie Anderson een andere doodgewone situatie, in "So Happy Birthdlay" (zie blz. 319):

we zei dat het het moelijkste was om har kind vam drie bij te brengen wat leeft en wat niet. De trlefoon gaat en we houdt hem bij haar kind en zegt, "Het is je grootmoeder. Zeg eens wat tegen grootmoeder." Maar ze heeft een stuk plastic vast. En het kind zegt bij zichzelf, "Wacht eens even. Leeft de teletoon? Leeft de televiste? En die radio dan? Wat leeft er in deze kamer, en wat niet? Helaas kan ze deze vagea niet onder wootden brengen."

Hoofdstuk 8, "Anthropology and performance", gaat nader in op de verhouding van culturele antropologie met het onderzoek naar theatrale representatie. Het uitgangspunt daarbij is de vraag of het mogelijk is inzicht te geven in andere culturen, de ene cultuur te vertalen in de andere, zonder daarbij gebruik te maken van artistieke middelen. De samenwerking tussen Richard Schechner en antropoloog Victor Turner leidt naar een bespreking van de antropologen waardoor Byme zich heeft laten beinvloeden: Z. N. Hurston, M. Deren, J. M. Chenoff, en R. F. 'Thompson. Z Zij hebben onderzoek gedaan naar de performatieve elementen van antropologisch onderzoek, en naar de mogelijkheden om met artistieke middelen adequater verslag te doen van etnografisch veldwerk. De uiteenlopende belangen die hierbij betrokken zijn, van pure wetenschapsbeoefening, kunstenaars, en commerciële massamedia, en de problemen die in deze combinatie schuilen, komen ook aan bod. Drie kritische benaderingen van de 'antropologische kunstbeoefening', door kunsthistoricus $\mathrm{Hal}$ Foster, filmetnograaf Jay Ruby, en etnomusicologen Keil en Feld worden voorgesteld en vergeleken. De voorlopige conclusie is, dat de spanningen en tegenstellingen die hie: ontstaan vanuit geen enkel standpunt kunnen worden opgelost, maar wel reflexief kunnen worden blootgelegd, juist door ze expliciet aan de orde te stellen. Daardoor kan, of het nu gaat om een antropologische monografie, een kunstwerk, een televisieprogramma of een popsong, een opener en meer veelzijdig beeld van de werkelijkheid worden geschapen.

In deel III, "A poetics of reflexivity", is deze stelling uitgewerkt door een filosofische traditie te beschrijven waarin reflectie het uitgangspunt is. Maar dit is niet de eerste interpretatie van Bytne's werk tegen een theoretische of filosofische achtergrond, en daarom worden eerst die voorgaande interpretaties doorgenomen. Daarin is Byrne's werk steevast beschreven vanuit een post-structuralistisch gezichtspunt; één auteur heeft Byme zelfs de ultieme deconstructivist genoemd, wiens beeld van Amerika in "True Stories"dat van Jean Baudrillard nog overtreft. Maar deze benadering schiet tekort in het verklaren van Byrne's belangstelling voor sacralisering, en kan geen recht doen aan het inzicht dat betekenissen meer 
zijin dan louter codes, omdat zij gedragen worden door een collectief. Terwil het poststructuralisme de mimetische mogelijkheden van de tatal principieel uitshir, staat de alomtegenwoordigheid van mimetisch handelen central in Byrne's werk. Om dit te behandelen, biedt de Duitse vroegromantiek, het werk wan Novalis en Friedrich Schlegel, een goed uitgangspunt, Zij ontwikkelden als eersten een begrip van mimesis dat de slaafse nabootsing overstijgt, door de grote poëtische en scheppende mogelijkheden van mimetisch handelen op velerlei terrein, van kunst, fillosofie en mythologie tot de kern van hun filosofische inspanningen te maken. De kem van hun filosofische methode is de mogelijkheid om nieuwe vormen van zelfreflectie te creëren door middel van formele itonie.

In hoofdstuk 10, "The model of early Romanticism"; is dit uitgewerkt. De achtergrond van de vroeg-romantische overtuiging dat subjectiviteit inherent reflexief, artistiek en mimetisch van aard is, is gevormd door de benadering van subjectiviteit in het werk van Kant en Fichte. Zij probeerden een absoluut fundament voor subjectiviteit uit te werken; maar Novalis en Schlegel concludeerden dat zulk absolutisme plaats moest maken voor het inzicht dat iedere poging daartoe voorlopig blijft, en gekenmerkt wordt door stilistische en culturele beperkingen. Dit impliceert dat kunst en filosofie in laatste instantie niet van elkaar te onderscheiden zijn. Dit blijkt ook uit de lievelingthema's van de vroeg-romantiek: het idee dat verschillende kunstvormen zouden kunnen samengaan (tot een 'Gesamtkunstwerk') om culturele vernieuwing te bewerkstelligen; het verlangen naar een nieuwe mythologie, waarin zulke ideeën voor iedereen begrijpelijk zonden worden; en het mystieke idee dat in het hoogste kunstwerk uiteindelijk de hele werkelijkheid zou kunnen worden gesymboliseerd, omdat in een universele wederkerige representatie uiteindelijk ieder object, teken of interpretatie kan worden gebruikt als teken voor al het andere, wat tot universele harmonie zou leiden. De ironie die de vroegromantiek kenmerkt, komt voort uit het besef dat dit ideale kunstwerk onbestaanbaar is, evenals trouwens de ideale samenleving die op dit kunstwerk gebaseerd zou zijn.

In Byme's werk zijn vele parallellen met dit ironische ideaal aan te wijzen, van zijn "catachismus van de chaos" tot zijn mimetische uitwisselingen met nietWesterse kunstvormen. Dat neemt nitet weg dat de historische afstand tussen de laat-achttiende-eeuwse speculatieve tomantiek en het huidige New York niet te bagatelliseren valt. Inzicht in die veelomvattende historische en artistieke modernisering is te ontlenen aan het werk wan Walter Benjamin en Theodor W. Adomo, waarschijnlijk de belangrijkste kunstfilosofen van de 20 ste eeuw. Hun werk vormt in wezenlijke opzichten een modernisering van de vroeg-romantische esthetica.

Hoofdstuk 11, "Benjamin and Adomo on the myths in modernity", introduceert het werk van Benjamin en Adorno aan de hand van de tegenstelling tussen symbolisme en naturalisme, tussen de realistische weetgave van de werkelijkheid 
en de poêtische en symbolische verwerking daarvan. In het middelpunt van hun essays over filosofie, kunst en geschiedenis staat de vraag naar de invloed die nieuwe technieken als fotografie, film en geluidsreproductie hebben gehad op de mimetische ervaring van de werkelijkheid. In zijn beroemde opstel over "Het kunstwerk in het tijdperk van zijn technische reproduccerbaarheid" heeft Benjamin de romantische ervaring van de werkelijkheid als auratisch (dat wil zeggen, doordrenkt met archetypische motieven en energieën) uitgewerkt tot de stelling dat de nieuwe technologieër gebruikt zouden moeten worden om die motieven politiek te verwerkelijken, en niet om mieuwe vormen van oude rituelen te ontwikkelen. En in zijn onvoltooid gebleven hoofdwerk, het "Passagen-Werk", heeft Benjamin inzichten van Marx en van Jung met elkaar gecombineerd om te kunnen beschrijven hoe in een moderne wereldstad als het negentiende-eeuws Parijs nieuwe modellen van collectieve mythologische ervaring zijn ontwikkeld. Volgens Benjamin biedt de modernisering van de mimetische ervaring unieke mogelijkheden om de dromen van de mensheid te verwerkelijken, indien het hele reservoir aan mimetische mogelijkheden vrijelijk zou kunnen worden benut. De ontwikkeling van nieuwe vormen van zelfreflectie zou dan niet door politieke of industriële belangen belemmerd mogen worden.

Het slothoofdstuk, "The Gesamtkunstwerk as laboratory", vormt een poging om de lijn van die van de vroegromantiek naar Benjamin en Adorno loopt, door te trekken naar het heden. Het uitgangspunt hiervoor is de wetenschapsantropologie van Bruno Latour, die de scheidslijn tussen primitieve en mythische niet-westerse samenlevingen en een rationeel, wetenschappelijk en modern Westen niet accepteert. Latour wijst erop dat wij in gemeenschappen leven waarin de samenhang in hoge mate afkomstig is van objecten die in laboratoria ontwikkeld zijn: om de technologische ontwikkelingen te kunnen volgens, hebben Westerse samenlevingen zelf kenmerken van een laboratorium overgenomen. Inwoners van die samenlevingen onderhouden volgens Latour een mimetische, en vaak fetisjistische relatie tot wetenschap en technologie. De moderniteit kan daarom niet alleen vergeleken worden met een enorm technologisch laboratorium, maar ook met een collectief Gesamtkunstwerk, dat zowel de massamedia en prenatale diagnostiek als intelligente bommen en voortdurend scherper gestelde wereldrecords omvat. De analyse die socioloog Pietre Bourdieu heeft gemaakt van de televisiejournalistiek laat zien hoe een machtig medium als televisie, door de druk die uitgat van de concurrentie tussen zenders, journaals en journalisten, ondanks de ver ontwikkelde techniek vaak maar weinig ruimte overlat voor reflectie op het vertoonde. Onbewust wordt de complexiteit en heterogeniteit van de modeme samenleving zodoende al snel gereduceerd tot een paar overzichtelijke collectieve vooroordelen.

Tegelijkertijd scheppen de elektronische media, zoals antropoloog Arjun Appadurai heeft beschreven, een nieuwe wereldwijde culturele instabiliteit, nu individuen 
en groepen hun overtuigingen vrijelijk kunnen samenstellen uit materiaal dat zij aan verschillende culturen ontlenen. Hierdoor ontstaan nieuwe gemeenschappen met geimproviseerde en hybride identiteiten, die een veelheid aan nieuwe, onderling tegenstrijdige sociale bewegingen mogelijk maken.

Tegen deze achtergrond verschijnt het werk van David Byrne als exemplarisch, omdat het dergelijke ontwikkelingen bewust en consequent heeft verwerkt. Het vormt een voorbeeld van mimetische reflexiviteir, door steeds te laten zien hoe de hedendaagse authentieke ervaring doordrenkt is van modellen die worden aangereikt door de massamedia. Dat maakt de ervaring niet inauthentiek, maar stelt wel hogere eisen aan de reflexiviteit. Byrne's oeuvre bevat een poëtica van de populaire massamedia. De massamedia, die in belangrijke mate moderne culturen vormgeven, kunnen volgens deze poëtica in principe een vermogen tot reflectie en zelfkritiek ontwikkelen, en daardoor een 'polyattentiveness' ontwikkelen, een veelzijdige gevoeligheid voor de veelvormige werkelijkheid. Byrne's positie op het kruispunt van de massamedia, conceptuele kunst en performance-theater biedt bijzondere mogelijkheden om de ervaring van een steeds meer gemediatiseerde werkelijkheid te begrijpen. 


\section{Acknowledgments}

In writing this book, I have had help from many directions. I thank Guy Widdershoven and Jos de Mul for supervising my dissertation. David Byrne always answered my queties about his work, and helped by providing me with rare videos and other material. The Faculty of Arts and Culture of Maastricht University let me teach courses that not only provided me with an income, but also with an environment full of critical and stimulating theories. And looking back I gratefully acknowledge the help of my parents, who supported me as a student.

This book was subsequently written in three places in Maastricht: in my studio at the Jan van Eyck Academy; in the attic of friends; and in a rented studio. I thank Heinz Paetzold for inviting me to work at the Jan van Eyck Academy after reading the short outline I had prepared for this project. I used my two years at the Jan van Eyck to develop my outline into a hundred-page sketch, benefiting all the while from the heady atmosphere there, an atmosphere that resulted from much dedicated individual research into the workings of art and theory. For that inspiring atmosphere, I am grateful to everyone present in the academy in those years, especially in the Theory Department and in Jean Fisher's 'Transcultural Studies-programme. Thank you, Antoon, Berto, Frank, Gabriele, Gregory, Heinz, Herma, Hortense, Jean, Jo, John, Jon, Marjan, Mirela, Nadežda, Nastin, Octavian, Peter, Polly, Ron, Sue, Tuur, Zeina, Zladko, and others.

When those two years had gone by, Hildegard Schneider and René de Groot invited me to write in their attic. Opposing the romantic cliché of a writer's dire circumstances, their attic is roomy, well furnished and centrally heated: the very image of hospitality.

Finally, my own studio was the scene of much writing and rewriting. I thank Josh for her support during the long trajectory from idea to completion, for her stubborn patience with my stubborn insistence to rewrite, as well as for her work on the book design. I hope Olaf and Alma will some day want to read this book, my home away from home for several years. 



\section{Curriculum vitae}

Sytze Steenstra was born in Leeuwarden, The Netherlands, on July 26, 1960 . He completed his secondary school (gymnasium B) at the Corderius College in Amersfoort in 1978. He studied sociology and philosophy in Utrecht and Amsterdam. In 1984, he studied philosophy at the Free University in West-Berlin. He then returned to Amsterdam, where he completed his MA in 1987, with a thesis on the philosophy of language of Walter Benjamin and Theodor W. Adomo.

He worked for one year as assistant professor at the department of Social Philosophy of the University of Amsterdam, and from 1990 to 1994 worked at the Open University of the Netherlands, heading the team that wrote the course Introduction to Philosopby - the true, the good and the beautiful. He translated Walter Benjamin's Einbahnstraße (One-IWay Street) into Dutch. After a stint as a high school philosophy teacher, teaching courses at art school and at HOVO (Open Higher Education), in the years 1997-1999 he worked as researcher in the Theory Department of the Jan van Eyck Academy in Maastricht, where he started work on this dissertation.

Sytze Steenstra now teaches at the Faculty of Atts and Culture of Maastricht University. 